
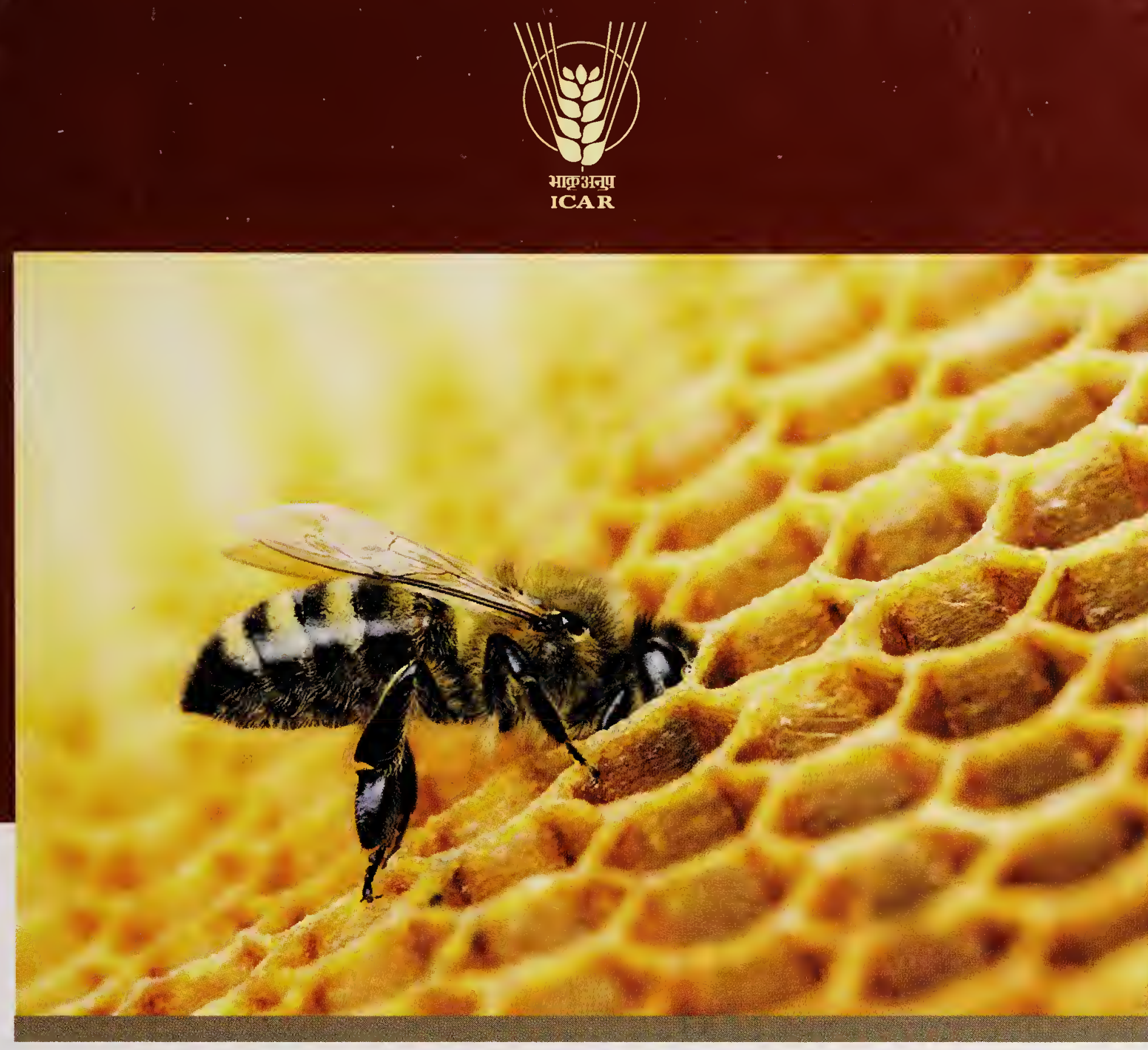

APICULTURE

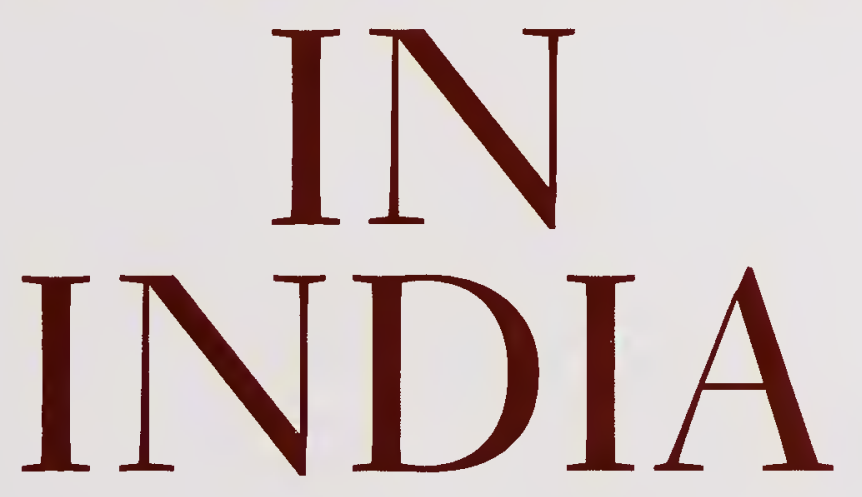

ATUAR RAHMAN

Indian Council of Agricultural Research 
Digitized by the Internet Archive in 2018 
APICULTURE IN INDIA 


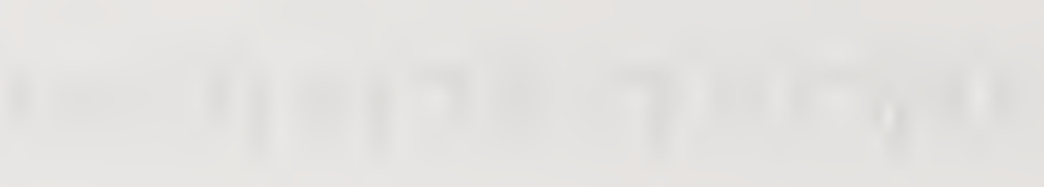




\title{
APICULTURE IN INDIA
}

\author{
Atuar Rahman \\ Principal Scientist \\ AICRP on Honeybees and Pollinators \\ Assam Agricultural University \\ Jorhat (Asom) 785013
}

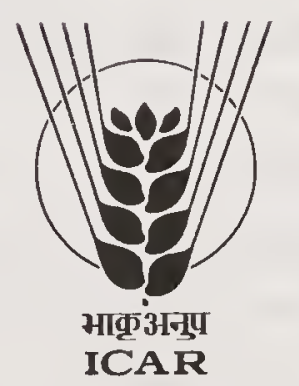

Published by

Directorate of Knowledge Management in Agriculture Indian Council of Agricultural Research

Krishi Anusandhan Bhavan, Pusa, New Delhi 110012 
Printed : February 2017

\author{
Project Director (DKMA) : Dr Rameshwar Singh \\ Incharge, English Editorial Unit : Dr Aruna T. Kumar \\ Editing : Dr Sudhir Pradhan \\ Chief Production Officer : Dr V.K. Bharti \\ Assistant Chief Technical Officer : Ashok Shastri
}

All Rights Reserved

(C) 2017, Indian Council of Agricultural Reserved

New Delhi

ISBN: 978-81-7164-165-9

Price: Rs. 1000/-

Published by Dr Rameshwar Singh, Project Director, Directorate of Knowledge Management in Agriculture, Indian Council of Agricultural Research, New Delhi 110 012; laser typeset by Xpedite Computer Systems, 201 Patel House B-11, Ranjit Nagar Commercial Complex, New Delhi 110008 and printed at Chandu Press, New Delhi. 


\section{Foreword}

$\mathrm{T}$

HE practice of beekeeping is as old as human civilization. In the past, honey bees were reared in log-hive, pot-hive and skep etc. for extracting honey only. But the discovery of movable frame beehives, honey extractor, smoker during $19^{\text {th }}$ century and the development of knowledge on biology, behavior and management of honey bee gave a scientific basis to the beekeeping. With the successful introduction of exotic honey bee, Apis mellifera and coupled with indigenous species, Apis cerana, apiculture is emerging as a profitable venture and is considered as a subsidiary occupation for the farm families. The term beekeeping was popularly used for rearing of two domesticated honey bee species whereas apiculture is a broad term derived from the generic name Apis and includes all the species of honey bees, their scientific culture and management.

Traditionally, in India apiculture was mainly practised by indigenous Apis cerana species only. But with the successful establishment of Apis mellifera, an exotic honey bee species in India has revolutionized the apiculture in the country. Both conservation of indigenous Apis cerana species coupled with introduction and augmentation of Apis mellifera will surely contribute to the sweet revolution and help enhancing crop productivity. The Indian Council of Agricultural Research has been engaged in research and developmental activities in various disciplines of agriculture including apiculture. At present, the information generated through various research works on bee pollination, toxicity to honeybees, diseases, enemies and hive products under the aegis of All India Co-ordinated Project on Honey bees and Pollinators and through other agencies help developing technology on apiculture.

Modern agriculture has come a long way from subsistence to exploited and recently entered into integrated phase. The pest problems have been aggravated by the advancement of technology. Though the agriculture production system has entered into integrated phase but the use of pesticides in the system has been unabatedly continuing. Honey bees as a pollinator catalyst have been recognized for millennia. However, declining of honey bee population is being observed due to changing environmental conditions worldwide resulting in pollination crisis thus raising a serious concern to agricultural production, conservation and maintenance of biodiversity. Pesticide poisoning coupled with diseases has been overshadowing the other problems in apiculture. Possible drivers for decline of honey bee population include habitat loss, intensive land use and pollution of pesticide, loss of genetic diversity, detrimental apiculture practices and climate change. Honey bee genetics and breeding process in India is yet at takeoff stage 
and artificial queen bee insemination technique could not be exploited to maintain the germplasm and also for the improvement of stock.

There are lot of books on bees and beekeeping in India but the books Beekeeping in India by Dr Sardar Singh (1962) and Honey bees and their Management in India by Dr R.C. Mishra (1995) were published under the aegis of Indian Council of Agricultural Research, New Delhi and were a pioneering literature in apiculture. Apiculture in India is a third book of its series contributed by Dr A. Rahman, (Principal Scientist, AICRP on Honey bees and Pollinators), Assam Agricultural University, Jorhat, India to be published by the Directorate of Knowledge Management in Agriculture, ICAR, New Delhi. I appreciate the task of Dr Rahman, who has attempted to encompass sample information and update the knowledge on apiculture not only of India but also other countries of the world. It is a comprehensive account on different aspects of apiculture as reflected in the content of the book and hope our beekeepers, students, academicians and professionals will be benefited by the book.

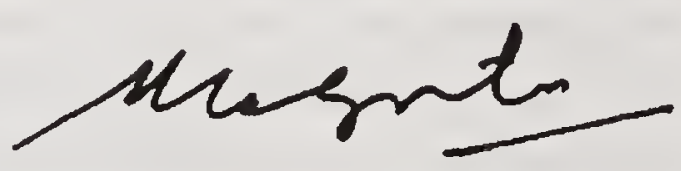

(T. Mohapatra)

Secretary (DARE) and

Director General

Indian Council of Agricultural Research

New Delhi 110001 


\section{Prologue}

$\mathrm{H}_{\mathrm{i}}^{\mathrm{o}}$ ONEYBEE has been familiar for providing honey to mankind since time immemorial. But the discovery of movable frame beehives, honey extractor, smoker and the development of knowledge on biology, behaviour and management of honey-bees has given a scientific basis of the beekeeping. The term beekeeping is popularly used for rearing of two domesticated honeybee species whereas apiculture is a broad-term, which includes the study of all Apis species and their management. The broad areas of apiculture are: bee pollination studies with the objective of effective management of honeybee colonies in respect to crop pollination, management of bee diseases and enemies, bee toxicity, evaluation of selectivity of insecticides to honeybees as well as their efficacy against target pests and bee products in which different bee hive products are included. With the establishment of exotic honeybee, Apis mellifera coupled with indigenous species Apis cerana, apiculture is emerging as a profitable venture and is being considered as livelihood by farm families. Besides, honey and hive products, the benefit derived from bee pollination in increasing crop yield of many cross pollinated crops has recently been greatly acknowledged. Pollination is an essential ecosystem service and in the wake of food security demand in the country, pollination mediated enhancement of crop productivity is of paramount importance more particularly in organic agriculture. National Commission on Agriculture (NCA, 1976) while emphasizing on apiculture recommended that apiculture to be extended to every village in India. In the line of NCA recommendation, Indian Council of Agricultural Research (ICAR) conceived a project entitled, 'All India Co-ordinated Project on Honey bee Research and Training' during 1980-81 and in 2007, the project has been designated as All India Co-ordinated Research Project on Honey Bees and Pollinators under which various apicultural aspects have been studied. Dr A. Rahman (Principal Scientist), AICRP on Honey bees and pollinators has long been associated with the project at Assam Agricultural University, Jorhat, and has acquired ample of knowledge in apiculture which help in contributing the book on apiculture. There is a series of book on bees and beekeeping in India published from India as well as abroad. Dr Rahman has also made an attempt to contribute the book 'Apiculture in India' after 'Beekeeping in India' by Dr Sardar Singh (1962) and 'Honey bees and their Management in India' by Dr R.C. Mishra (1995) under the aegis of ICAR, New Delhi.

The Directorate of Knowledge Management in Agriculture, Indian Council of Agricultural Research, New Delhi encourages the agricultural professionals to contribute to books on different subjects in Agriculture. Apiculture is also one of 
the vital fields of agriculture in which book on 'Apiculture in India' by Dr Rahman is timely and the effort made by the DKMA for publication of the book is praiseworthy. This is a commendable endeavour by Dr A. Rahman and the book is comprehensive in nature, which is aimed at different stakeholders right from field functionaries to the students and professionals.

Hope, the readers will be benefited by this book.

K.M. Bujarbaruah Vice-Chancellor Assam Agricultural University Jorhat (Asom) 785013 


\title{
Preface
}

\begin{abstract}
A PICULTURE is the science and culture of honey bees and their management. Most of the people are attracted to fascinating world of honeybees for their wonderful behaviour and contribution to mankind in the form of hive products and crop production. Modern beekeeping has come a long way from the traditional clay-pots, log-hives, bamboo-baskets and wooden-boxes to movable frame, beehive based on the principle of bee space (Rev. L.L. Langsthroth, 1851), honey extractor (Major Hruschka, 1865) and smoker (Moses Quinby, 1870), the base of apiculture has been established. Attempts have been made to introduce these innovations in our country. First attempts to keep bees in movable frame-hives were made during 1882 in Bengal, and during 1883-84 in Punjab but were of little success. In south India, Rev. Newton devised a hive for Indian honeybees during 1911 which was known as Newton bee-hive. The recommendations of the Royal Commission on Agriculture (1928) for developing cottage industries gave a fillip to beekeeping. Beekeepers of India organized themselves and formed an All India Beekeepers' Association in 1938-39 and published the Indian Bee Journal. The Indian Council of Agricultural Research (ICAR) coordinated the activities of apicultural research. The Council established Beekeeping Research Station in Punjab in 1945 and at Coimbatore in Tamil Nadu 1951. From 1980 onwards, ICAR conceived and formulated an All India Coordinated Project on Honeybee Research and Training. Since then the beekeeping has got the momentum for its scientific venture as well as for developmental activities. The research and developmental activities of honeybees has broadened its field to apiculture, which includes crop productivity through pollination, toils of honey bees, i.e. honey and other bee-hive products such as beeswax, royal jelly, bee venom etc. In this book, "bee" mainly refers to honey bees only. Honey bees play the multiple roles of pollinating crop and producing honey, wax, bee venom, royal jelly, propolis etc. Honey is a balanced nutritious food having high medicinal value. Beeswax is even more valuable and is used for manufacturing more than 300 items such as candles, ointments, lotions, lipsticks, polishes, pharmaceuticals, paints and varnishes etc. Bee venom is a pain healer and royal jelly provides vigour and vitality to the human health.

Apiculture may be taken up as rural livelihood and is an additional source of income for farm-families. It is non-land based and requires low investments (although initially high) and so can be taken up by small-, marginal- and landless-farmers and educated unemployed youth. It can thus serve as an additional income generating activity and provide round-the-year employment in the
\end{abstract}


activities of managing hives, migrating honey bee colonies in different crop fields, harnessing honey and other bee-hive products. In the present day, organic farming concept, bees are considered as an input for crop production. Many developments in apiculture have taken place both in national as well as world scene in recent years and some knowledge has been accumulated with reference to Indian conditions. Humble efforts have been made to update the information on different aspects of apiculture and tried to encompass this knowledge on apiculture both from India and abroad in 'Apiculture in India'. The book deals with both basics and applied aspects of apiculture and designed to address the needs of beekeepers, entrepreneurs, students, academicians and others related to this field. Some of the new areas that are included are value-added products from apiculture and commercialization of apiculture.

The author expresses his indebtedness to the various writers and research workers in apiculture whose literature and work have been consulted for preparing this manuscript. Acknowledgements are due to Longstroth (1878), Snodgrass, Grimaldi \& Engel (2005) — being added in correct copy. The author is also grateful to the authority of Assam Agricultural University, Jorhat, ICAR, New Delhi for funding the All India Co-ordinated Project on Honey bees and Pollinators under which much of the information has been generated and help in preparing this book, The Directorate of Knowledge Management in Agriculture, ICAR for encouraging me to contribute to the book in Apiculture, especially Drs R.P. Sharma, (Former Incharge, EEU) and Aruna T. Kumar, (Present, Incharge, EEU) who inspired me to write the book after contribution of 'Apiculture' chapter in the Handbook of Agriculture published by the ICAR. Dr R. Singh, (Project Director, DKMA) for immediately approving the synopsis of the book 'Apiculture in India' and Dr S. Pradhan for his pursuance. Thankfully acknowledge the service from the staff of AICRP on Honey bees and Pollinators, AAU, Jorhat both old and new more particularly Mr R.R. Taye, Ms P. Rajkumari and others for preparing the manuscript and $\mathrm{Mr}$ J. Saikia for designing the cover page and diagram of 'Apiculture in India'.

Author 


\section{Contents}

Chapter No. Chapter

Page No.

Foreword

iii

Prologue v

Preface vii

1 History and Development 1

2 Evolution and Diversity 10

3 Morphology and Physiology 25

4 Developmental Biology 43

5 Bee Behaviour 52

$6 \quad$ Genetics and Breeding $\quad 73$

7 Queen Rearing and Multiplication 84

8 Apiculture Equipments 98

9 Bee Management 109

10 Bee Diseases and their Management 122

11 Bee Enemies and their Management 137

12 Bee Pasturage 152

13 Bee Pollination 176

14 Toxicity to Honey Bees 193

15 Migratory Apiculture 207

16 Bee Hive Products 219

17 Value Added Beehive Products 235

18 Commercialization of Apiculture 242

19 Perspective in Apiculture 249

Glossary 254

Subject Index 266 



\section{1 \\ History and Development}

$\mathrm{T}$ HE history of apiculture is as old as human civilization. With the emergence of civilization, the art of writing developed inscriptions found in the earliest Egyptian pyramids indicates that the Egyptians were well acquainted with bee keeping 4,000 years ago. More than 200 million years ago, the continents like Africa, Australia, South America, and the Indian subcontinent were joined in a vast landmass known as Gondwana (Hallam, 1994). The first visible proof of the association of man and bees is found to be in rock paintings attributed to neolithic period. Obermaier (1924) included a copy of painting which depicts the removal of combs from a nest of bees. The sign of bee paintings appeared to have been associated with the royalty from the first dynasty of Pharaoh. According to Fraser (1942), the symbols indicated a reed which preceded the name of the king. The reed indicated upper Egypt whereas bee symbolized lower Egypt. The Egyptian practised migratory bee keeping and the colonies of bees were placed on Burges in the bank of Nile and the Burges were moved up or down stream to allow the bees to take advantage of different honey flows.

Greek mythology supported the belief that the association of bees and men is of time immemorial. One of the fables of ancient mythology involved the bee as the provider of food for the infant Zeus. According to legend, Zeus was entrusted by his mother of two Cretan nymphs, Amalthea and Melissa to avoid his death at the hands of Saturn. The two nymphs raised Zeus on a diet of milk and honey. Aristotle (384-322 BC) mentioned that Greeks were bee masters which were included in his book 'Historia annimalium'. Aristotle was the first to record division of labour among the bee workers. Greek colonists carried bees with them and it was possible that bee keeping was introduced to Cyprus, Greece and Palestine. In pre-historic Greece, there existed a system of high status apiculture as is evidenced from the hives, smoking pots, honey extractors and other beekeeping equipments. Beekeeping was considered a highly valued industry controlled by beekeeping overseers (Evan, 1876).

Romans were also apt in bee keeping. Of the Romans, the works of Varrow and Columella are noteworthy. They recorded that one apiarist could produce 5,000 pounds $(2,270 \mathrm{~kg})$ of honey annually from his sizable bee colonies. Varrow discussed the qualification of a good apiary site, how to make hives and other essential items required for bee keeping. Columella was specially methodical and thorough in his observations and writings. His observations included that hives should be cleaned about the end of March as swarming season started between May and June, hives should be prepared for winter. Roman writer Virgil kept 
bees and apparently was very fond of them. During the reign of the Emperor Constantine (950 AD), a set of books on agriculture was compiled. The compilation is known as Geoponica which included material on bee husbandry. After the Geoponica, no writings of great significance concerning bees were found until 1609. Charles Butler published 'The Feminine Monarchie' in 1609. In the preface of the book, he stated that "We must not call the Queen "Rex", the bee state is an Amazonian or feminine kingdom". Reverend John Thorley of Oxfordshire, England published a book 'Mellisselogia- The Female Monarchy' in 1744. Thorley mentioned the virtues of bee, stating "In that innumerable multitude and surprising variety of insects in the World made for the service of man, bees are most to be admired; there are none that can equal, much less excel them". While comparing the silk worm and bee, Thorley indicated that the former provides adornment for our bodies whereas the bee contributes to our health and necessity. One of the notable figures in bee keeping is Francois Huber, a Swiss who lived from 1750 to 1831. The Encyclopadia Britannica is the authority for the following statement on Huber "He was able to carry out investigations that laid the foundation of our scientific knowledge of the life-history of the honey bee". His Nouvelles Observations sur les Abeilles was published at Geneva in 1792.

The nineteen century has been considered as the golden period in apiculture. During this century, some of the greatest contributions on bee keeping were made. Much of the credit goes to American and European investigators whose toil has made the base of modern and commercial apiculture. Edward Bevan made valuable contributions to apiculture by compiling literatures on honey bees. Second contribution was made by Johannes Mehring of Germany, who in 1857 invented a press to make wax sheets having the indentations of the bottoms of the cell. This led ultimately to the perfecting commercial methods of making comb foundation. The third man to be considered was the Austrian Franz von Hruschka, who is credited with the invention of the honey slinger in 1865 . This discovery led to the manufacture of the honey extractor, both in Europe and in the United States. During nineteen century, the contributions of American investigators were of immense. In 1851, Reverend Lorenzo Langstroth designed the movable frame bee hive and considered him to be the father of apiculture, Moses Quinby, the father of commercial apiculture; C. C. Miller, the Nestor of American bee keeping; and A. I. Root, the first commercial manufacturer of bee equipments in the world. Rev. L. L. Langstroth, who lived from 1810 to 1895, was born in Philadelphia, he was educated at Yale and taught mathematics there for a short time and ecoming deeply interested in theology, he studied for the ministry and was ordained as pastor of a church in Andover, Massachusetts, in 1836. Moses Quinby was considered by Dr E. F. Phillips to be the father of commercial bee keeping in the country. Quinby lived from 1810 to 1875 in new work state. His contributions were largely practical. He discarded the practice of killing his bees with sulfur in order to obtain the honey, and placed boxes on his hives in which the surplus honey was stored. Dr C. C. Miller (1911) was born in Pennsylvania and was educated at Union College, received his B.A. in 1853. Dr Miller's interest in bees began in 1861, when his wife captured a stray swarm. He gradually increased his holdings and in 1878 gave up other work to concentrate on bees. Dr Miller 
contributed many articles to bee journals and served as technical editor for the American Bee Journal. Rev. L. L. Langstroth patented the movable frame bee hive in 1852 which is still holds good. The design of bee hive was based on principles of bee space.

It some persists fom begins on the wall of lin puple, Nyuserre in from the Fifth Dynasty (before 2,422 BC), workers were depicted blowing smoke into hives as they move honeycombs. Inscriptions detailing the production of honey were found on the tomb of Pabasa from the Twenty-sixth Dynasty (650 BC E), depicting pouring honey in jars and cylindrical hives. Sealed pots of honey were found in the grave goods of pharaohs such as Tutankhamun.

Archaeological findings relating to beekeeping have been discovered at Rehov, a Bronze and Iron Age archaeological site in the Jordan Valley, Israel. Thirty intact hives, made of straw and unbaked clay, were discovered by archaeologist, Amihai Mazar of the Hebrew University of Jerusalem in the ruins of the city dating from about $900 \mathrm{BCE}$. The hives were found in orderly rows, three high, in a manner that could have accommodated around 100 hives, held more than 1 million bees and had a potential annual yield of $500 \mathrm{~kg}$ of honey and $70 \mathrm{~kg}$ of beeswax, according to Mazar et al., (2008), that there were an advanced honey industry existed in ancient Israel 3,000 years ago. Ezra Marcus, an expert from the University of Haifa, said the finding was a glimpse of ancient beekeeping seen in texts and ancient art from the near East. In ancient Greece, aspects of the lives of bees and beekeeping were discussed at length by Aristotle. Beekeeping was also documented by the Roman writers Virgil, Gaius Julius Hyginus, Varro, and Columella. The art of beekeeping appeared in ancient China for a long time and is hardly traceable to its origin. In the book, 'Golden Rules of Business Success' written by Fan Li and Tao Zhu Gong during the Spring and Autumn period, there were some parts mentioning the art of beekeeping and the importance of the quality of the wooden box for bee keeping that can affect the quality of its honey. The ancient people of Maya civilization domesticated a separate species of stingless bee. Michener (2000) in his book 'The Bees of the World' revealed a diverse fauna that numbers more than 17,000 species and ranges from the common honeybee to rare bees that feed on the pollen of a single type of plant. Moreover new facts, reclassifications, and revisions provide the most comprehensive treatment of the 1,200 genera and subgenera of the Apiformee. Oldroyd and Wongsiri (2006) gave a detail account of Asian honey bees with their evolution, speciation, reproductive and nesting habit of different honeybee species. Further, they mentioned the various factors affecting both domesticated and wild honey bee population with their conservation strategy. Breadbear (2009) prepared a guide to the services provided by bees and the sustainable harvesting, processing and marketing of their products and included in the publication of the Food and Agriculture Organization as 'Bees and Their role in Forest Livelihoods'. Abrol (2013) also provided the profile of Asiatic honey bee, Apis species, their biodiversity, conservation and utilization for agricultural production.

\section{Development of hive designs}

Langstroth's design for movable frame hives was seized upon by apiarists and 
inventors on both sides of the Atlantic and a wide range of moveable frame hives were designed and perfected in England, France, Germany and the United States. Classic designs evolved in each country: Dadant hives and Langstroth hives are still dominant in the USA; in France, the De-Layens trough-hive became popular and in the United Kingdom, a British National Hive became standard as late as the 1930s although in Scotland, the smaller Smith hive is still popular. In some Scandinavian countries and in Russia, the traditional trough hive persisted until late in the $20^{\text {th }}$ century and is still kept in some areas. However, the Langstroth and Dadant designs remain ubiquitous in the USA and also in many parts of Europe, though Sweden, Denmark, Germany, France and Italy all have their own national hive designs. Regional variations of hive evolved to reflect the climate, floral productivity and the reproductive characteristics of the various subspecies of native honey bee in each bio-region. The evolution of bee hives from traditional basket and log hive to modern bee hives is shown in Fig. la-c.

The differences in hive dimensions are insignificant in comparison to the common factors in all these hives: they are all square or rectangular; they all use movable wooden frames; they all consist of a floor, brood-box, honey super, crownboard and roof. Beekeepers also use queen excluders between the brood-box and honey supers to keep the queen from laying eggs in cells next to those containing honey intended for consumption. Also, with the advent in the $20^{\text {th }}$ century of mite pests, hive floors are often replaced for part of (or the whole) year with a wire mesh and removable tray.

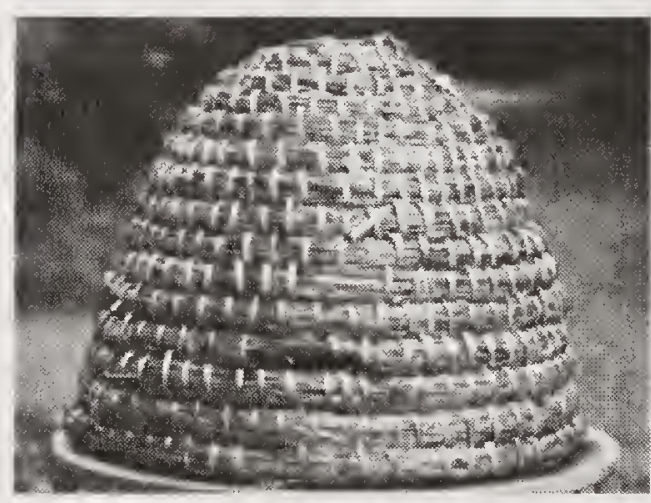

(a) Skeps (bee boles)

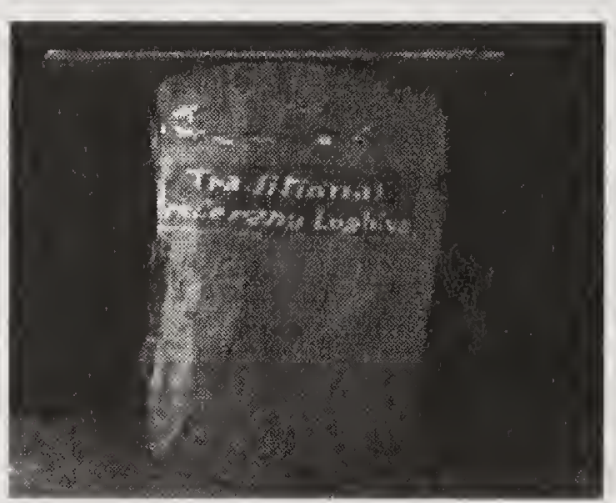

(b) Log hive

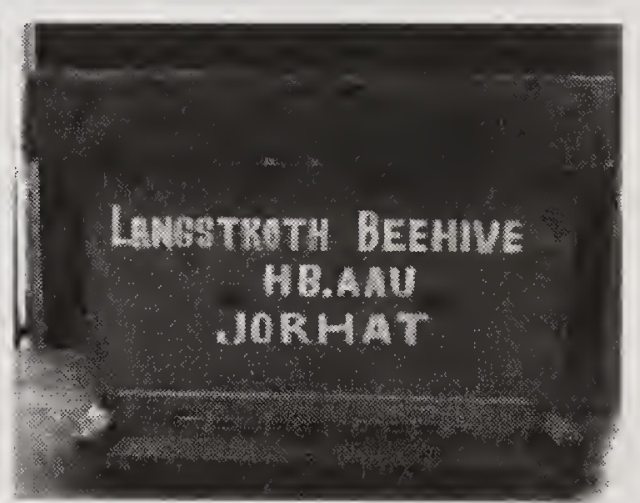

(c) Langstroth hive

Source: Fig.1 [(1a)Adopted from IBRA, 2014 and (1b and c) AICRP on Honey bee and Pollinators, AAU, Jorhat)].

\section{History in India}

Apiculture in India is as old as Indus valley and Harrappan civilization. The winged creatures find its place almost all religious epics such as the Vedas, Ramayana, Mahabharata, Quran, Bible etc. The knowledge based on bees, honey and honey harvesting had been in operation through the ages. During the Vedic period, large information was available on different species of honey bees, their habits, different flora that offered nectar and pollen to bees. Honey had been included as a panchamrit in the diet of devatas. It had been variously praised as a nutritious food and valuable medicine in Rig Veda and other works. In Ayurveda, honey found a place of honour as a valuable gift of nature to man. Besides honey, other bee hive products such as bee venom through stinging by bees was found post-vedic literature like the Upanishads and the Qurans. Honey was the first 
sweet food tasted by the ancient Indian inhabiting in rock shelters and forests. Food hunters and gatherers hunted bee hives for honey. With the development of civilization, honey acquired a unique status in the life of the ancient Indians. They considered honey as a heavenly substance that cured many diseases and contributed in vigour and vitality of human beings.

Although, honey and honey bees were known to Indian people from time inmemorial but bee keeping remains traditional. Collection of honey from wild bee colonies by the use of smoke and squeezing honey was a common practice. The modern bee keeping has come a long way with the discovery of principle of bee space by L.L. Langstroth and its refinements and introduction in India. First attempt to keep bees in movable frame hive were made in 1882 in Bengal and in 1883-84 in Punjab but with little success. In 1883, government of India published the information on beekeeping, collected from the provinces, under the title " $a$ collection of papers on beekeeping in India". A year later, John Doughlas, an employee of the Telegraph Department, published A Handbook on Beekeeping in India.

The recommendation of the Royal Commission on Agriculture (1928) for developing cottage industries gave a fillip to beekeeping. Work on this subject in right earnest was taken up in Madras in 1931, Punjab in 1933, Coorg in 1934 and Uttar Pradesh in 1938. Other states and provinces followed suit but no important landmark was made. Beekeepers of India organized themselves and formed an All India Beekeepers' Association during 1938-39. Since then the Association has been publishing the Indian Bee Journal. The Indian Council of Agricultural Research co-ordinates the activities of research work in beekeeping. The Council established a beekeeping research station in the Punjab in 1945 and six years later at Coimbatore in Tamil Nadu. From 1950, the ICAR has been funding various research projects on honey bees in the universities and other organizations. Besides, since 1980 it has started an All India Co-ordinated Research Project on Honeybees Research and Training. During, the past three decades' State Universities, Khadi and Village Industries Commission (KVIC) have also contributed to the development of apiculture. The Central Bee Research and Training Institute was established in 1962 in Pune under aegis of KVIC.

Honeybees were present in old world countries since ages but to new world countries, Apis species was introduced only 300-400 years ago. There are four Apis species viz. Rock bee Apis dorsata F., little honeybee Apis florea F., Indian honeybee Apis cerana F. and European honeybee Apis mellifera L. The former two species are wild and latter two are domesticated and used for commercial beekeeping. First three species were present in India but Apis mellifera was introduced from European countries. Before sixties, many unsuccessful attempts were made by the workers to introduce and establish $A$. mellifera bees. First attempt, as per record, is of Ghosh (1920), who imported three colonies from Italy and maintained a small apiary up to 1931. Failure of queen mating because of various reasons led to loss of colonies. Thomson (1940) had also mentioned about some unsuccessful attempts in various parts of India to introduce $A$. mellifera bees. Baldry attempted to introduce $A$. mellifera in Mahabaleshwar, the colonies were later migrated to Coimbatore which got perished. Exotic bees brought to 
Kerala by Thomson, in thirties, could not be succeeded. He attributed it to unfavourable climatic conditions of the area to A. mellifera bees. Beadnell (1939) brought many consignments of $A$. mellifera and maintained an apiary in Nilgiri Hills. Rehman and Singh $(1940,1945)$ received two consignments of two and three colonies and attempted to interbreed with $A$. cerena but it also failed. Both Apis cerana and $A$. mellifera did not accept each others brood, workers or queen. Apis mellifera colonies were imported to Kashmir in 1951 (Vats, 1953). The queens were introduced to $A$. cerana colonies and were reported to be doing well until 1959. After that there was no report on the progress of these bees, and it is presumed that they have perished. Successful introduction and establishment of $A$. mellifera was made possible in sixties. Apis mellifera and its hybrids were obtained from U.S.A. and Italy between 1962-1964 and were introduced in Nagrota, Himachal Pradesh (Atwal and Sharma, 1967;1970a;1970b). The queens were successfully introduced in $A$. cerana indica nuclei with young workers. Performance of five strains of $A$. mellifera was studied. 'Californian yellow' and 'Starline' strains were superior to others in colony strength, brood rearing and food storage capacity. The 'Italian' strain was similar to 'Californian' strain in general behavior and brood rearing activity but was poorer in honey production. In all strains, honey production was much better than that of $A$. cerana.

The National Commission on Agriculture (Anon. 1976) while emphasizing on apiculture recommended apiculture to be extended to every village. Six million bee colonies are to be developed in modern apiaries at an average rate of 10 colonies per village. Present annual yield of honey of about $5 \mathrm{~kg} /$ colony is to be doubled by developing and harnessing bee fauna both for honey and crop production. In the line of NCA recommendation, Indian Council of Agricultural Research (ICAR) conceived a project entitled 'All India Coordinated Project on Honeybee Research and Training' in 1980-81. At first, the Project started functioning with the Project Coordinating Unit at Central Bee Research and Training Institute, Pune with six centres including one in an ICAR institute. Five more centres, four State Agricultural Universities (SAU) and one in an ICAR Institute were sanctioned in 1983. Project Coordinating Unit was shifted to Haryana Agricultural University, Hisar in 1987. There were nine University-based coordinating centres during the X Five- Year Plan at Solan (Himachal Pradesh), Ludhiana (Punjab), Vijayarai (Andhra Pradesh), Jorhat (Asom), Pusa-Samastipur (Bihar), Vellayni (Kerela), Hisar (Haryana), Pantnagar (Uttrakhand) and Bhubaneshwar (Odisha). The objectives were redefined and the title of the project was redesignated as All India Coordinated Research Project on Honey Bees and Pollinators in July, 2007. During XI Five-Year Plan, five more SAU based regular centres and two SAU based voluntary centres were added at Bengaluru (Karnataka), Kanke-Ranchi (Jarkhand), Kumarganj-Faizabad (Uttar Pradesh), Medziphema (Nagaland), Raipur (Chattisgarh), Jammu (Jammu \& Kashmir), and Kota (Rajasthan) (Thakur et al., 2013). During 1993-94, Department of Agriculture and Co-operation, Ministry of Agriculture, Government of India launched a programme 'Development of Beekeeping for Crop Productivity' in which different organizations such as ICAR, Central Scientific Industrial Research Institute (CSIR), SAUs and NGOs were involved. 
The exotic bee, Apis mellifera made a breakthrough and is now being used for commercial apiculture in almost all the zones viz. northern, western, southern and eastern parts of India. Earlier, attempts were made to establish A. mellifera species but have probably failed due to lack of knowledge rather than unsuitability of the area for the species. At present, the species is fast spreading covering almost all the regions of India. From the later part of twentieth century, some organizations have keenly taken up beekeeping research and development and their efforts have resulted into standardization of management practices. Most management practices for hive-bees in India were adopted from Europes/U.S.A. suiting to the Indian conditions and the climate. Despite the unabated efforts, the growth of beekeeping in India is not encouraging and the number of hive-bee colonies and also the honey production remains low. However, there is a ray of hope in apiculture with the successful introduction of Apis mellifera and its augmentation and also through conservation of Apis cerana. The breakthrough is evident in crop pollination and honey production. India finds place in the honey exporting map of the world. But, there are certain problems for Indian apiculture as there is rapid deforestation for which natural source has been declining during past few decades. It is estimated that less than one-fourths of the present day flora is being availed by bees. Besides the flora, the strategies for apiculture development have to be reoriented to achieve fast progress. Beekeeping with Indian honeybees was virtually unknown in the states of Punjab and Haryana. Beekeeping with Apis mellifera was taken up in Punjab by the beekeepers in 1977. The apiculture has also received boost in Himachal Pradesh, Jammu and Kashmir and Haryana where Apis mellifera is now used in commercial apiculture. Bihar, West Bengal, North-East and Peninsular India have taken up massive effort in apiculture and the prospect is evident throughout the Country.

During the course of time, several apiculture literatures have come up both in popular and scientific series in India. Some of the salient literatures are: Singh (1962) contributed a book on Indian beekeeping which included beekeeping practices; management of honeybee species, bee pasturage, disease and enemy management of honey bees in India. Verma (1990) wrote a book on Beekeeping in integrated mountain development: economics and scientific perspectives which is a testimony of integrated programme on mountain development in which apiculture was included as component. Later on Mishra (1995) gave a comprehensive knowledge on honey bees and their management in India and published under the aegis of Indian Council of Agricultural Research in which he has highlighted research and management activities on different honey bee species. Joshi (1996) in her bibliography of Doctoral dessertations on bees, beekeeping and related aspects highlighted different areas of apicultural research such as mellitopalynology, bee botany and pollination, bee management, bee pathology and bee systematics etc. Atwal (2000) contributed a book on 'Essentials of Beekeeping and Pollination' which highlighted beekeeping as essential ingredient in agricultural production system. Dr Rahman (2006) contributed the chapter on 'Apiculture' in the Handbook of Agriculture published by the Indian Council of Agricultural Research, New Delhi which was revised in 2009 and 2012, gave a comprehensive account on Indian Apiculture. Dr. Abrol (2009) in his book 'Bees 
and Beekeeping in India' gave an elaborative scenario of both domesticated and wild bees in India. Thakur et al. (2013) compiled the research activities on apiculture in India under Apiculture Research and published as Abstract of Research Publication, 2000-2012 under the aegis of Indian Council of Agricultural Research, New Delhi. The publication encompassed recent information on various aspects of apiculture, viz. bee forage and foraging behaviour, pollination, ecology, bee biology and morphmetrices, bee products and technology, bee diseases and enemies, pesticide toxicity, bee keeping equipments etc. Abrol (2013) contributed the book on Asiatic honeybee, Apis cerana: Biodiversity Conservation and Agricultural Production. A detail Monograph on Morphometry and Phylogeny of Honeybees and Stingless bees of India' was published under the aegis of Department of Biotechnology, Government of India, New Delhi (Viraktamath et al., 2013). The monograph depicted a comprehensive morphometry and phylogeography of Indian honeybees and stingless bees.

\section{REFERENCES}

Abrol, D.P. 2013. Asiatic Honeybee, Apis cerana: Biodiversity Conservation and Agricultural Production. Springer Science and Business Media. United Kingdom, 1053 $\mathrm{pp}$.

Abrol, D.P. 2009. Bees and Beekeeping in India. Kalyani Publisher, Ludhiana.719 pp.

Anonymous. 1976, Report on National Commission on 'Agriculture'. Controller of Publications, Government of India, New Delhi.481-501.

Atwal, A.S. 2000. Essentials of Beekeeping and Pollination. Kalyani Publishers. Ludhiana. $394 \mathrm{pp}$.

Atwal, A.S. and Sharma, O.P. 1967. The introduction of Apis mellifera queen into Apis indica colonies and the associated behaviour of the two species. XXI International Beekeeping Congress Preliminary Science Meet Summct. 77 pp.

Atwal, A.S. and Sharma, O.P. 1970a. Brood rearing activity of the Italian honeybee, Apis mellifera L. in Punjab plains at Ludhiana. Indian Bee Journal 32: 62-67.

Atwal, A.S. and Sharma, O.P. 1970b. Studies on the performance of five strains of Apis mellifera L. as compared with Apis indica F. under Nagrota conditions. J. Res. Ludhiana 7(4): 477-86.

Atwal, A.S. and Goyal, N.P. 1973. Introduction of Apis mellifera in Punjab plains. Indian Bee Journal 35(1-4): 1-9.

Beadnell, C.B. 1959. Transporting bees abroad. British Bee Journal 67: 190.

Breadbear, N. 2009. Bees and their Role in Forest Livelihood. Food and Agriculture Organization of United Nations, Rome. $194 \mathrm{pp}$.

Evans, A. J. 1876. Through Bosnia and the Herzegóvina on foot during the insurrection, August and September 1875; with an historical review of Bosnia and a glimpse at the Croats, Slavonians, and the ancient republic of Ragusa. Longmans, Greens and Co. London.

Fraser, H.M. 1942. Early English methods of beekeeping before 1800. Bee world. 31(5): 33-38.

Ghosh, C.C. 1920. Bekeeping in India. Proceedings III. Entomology Meeting. Pusa. 77082.

Hallam, A. 1994. An Outline of Phanerozoic Biogeography. Oxford University Press, New York.246 pp.

Joshi, M.A. 1996. Trends in Doctoral research on bees in India. Indian Bee Journal 58(3): 143-149. 
Mazar, A. Panitz-Cohen N. and Namdar, D. 2008. An Iron Age Apiary at Tel Rehov: the Find and its Significance. Qadmoniot 136: 83-92.

Michener, C.D. 2000. The Bees of the World. Johns Hopkins University Press, Baltimore, Maryland.

Miller, C .C. 1911. Fifty-years Among the Bees. The A.I. Root company medina, Ohio. $457 \mathrm{pp}$.

Mishra R.C. 1995. Honeybees and Their Management in India. ICAR New Delhi. 168pp

Oldroyd, B.P. and Wongsiri, S. 2006. Asian Honey Bees: Biology, Conservation and Human Interactions. Harvard University Press

Pellett, F. C. 1938. History of American Beekeeping. 393 p. Collegiate press, Ames, Iowa

Rahman, A. 2006. Apiculture. Handbook of Agriculture, ICAR New Delhi.

Rahman, A. 2009. Apiculture in Handbook of Agriculture, ICAR New Delhi

Rahman, A. 2012. Apiculture in Hand book of Agriculture, ICAR New Delhi

Rehman, K.A. and Singh, S. 1940. Italian versus Indian bees. Indian Bee Journal 2: 1-2.

Rehman, K.A. and Singh, S. 1945. American bees by air. Indian Bee Journal 7: 5-6.

Singh, S. 1962. Beekeeping in India, ICAR, New Delhi. 214pp.

Thakur, R.K., Kaushik, H.D. and Yadav, S. 2013. Apicultural Research, Abstract on research publications 2000-2012, ICAR, New Delhi.

Thompson, C.R. 1940. Presidential address to First Annual General Meeting of the All India Beekeepers Association. Indian Bee Journal 2 (1/2): 10-13.

Vats, B.R. 1953. Breeding Italian bees in Kashmir. Kashmir 3(2): 23-24.

Verma, L.R. 1990. Beekeeping in integrated mountain development: economics and scientific perspective. Oxford and IBH Publishing Co. Ltd, New Delhi.

Viraktamath, S., Fakruddin, B., Vastrad, A.S. and Mohankumar, S. 2013. Monograph on morphometry and Phylogeography of Honeybees and Stingless bees in India (Eds.) Department of Biotechnology, Government of India, New Delhi, 259 pp. 


\section{2 \\ Evolution and Diversity}

$\mathrm{T}$

HE evolutionary history of honey bees revealed that they evolved 120-130 million years ago (Engel, 2001). The Spheciformes are morphologically diversified to such an extent that various authors have commented on the consistency for the custom of dividing the bees into several families while regarding their closest relatives as constituting a single family, the Sphecidae. Lomholdt (1982) addressed the problem in a cladistic study in which he divided the Spheciformes into the Sphecidae. (for Sphecinae and Ampulicinae) and the Larridae, which should be called Crabronidae. The Crabronidae are held together by one strong synapomorphy, the double salivary opening of the larva, which is shared neither with the bees nor with the Sphecidae. In the crabronid subfamily Astatinae, the larval salivary opening has been described as single. This appears to have been an observational error; whatever the explanation, the Astatinae do have a double opening like that of other Crabronidae (Evans, 1958). It is thus quite likely that Lomholdt was right in considering this family as monophyletic
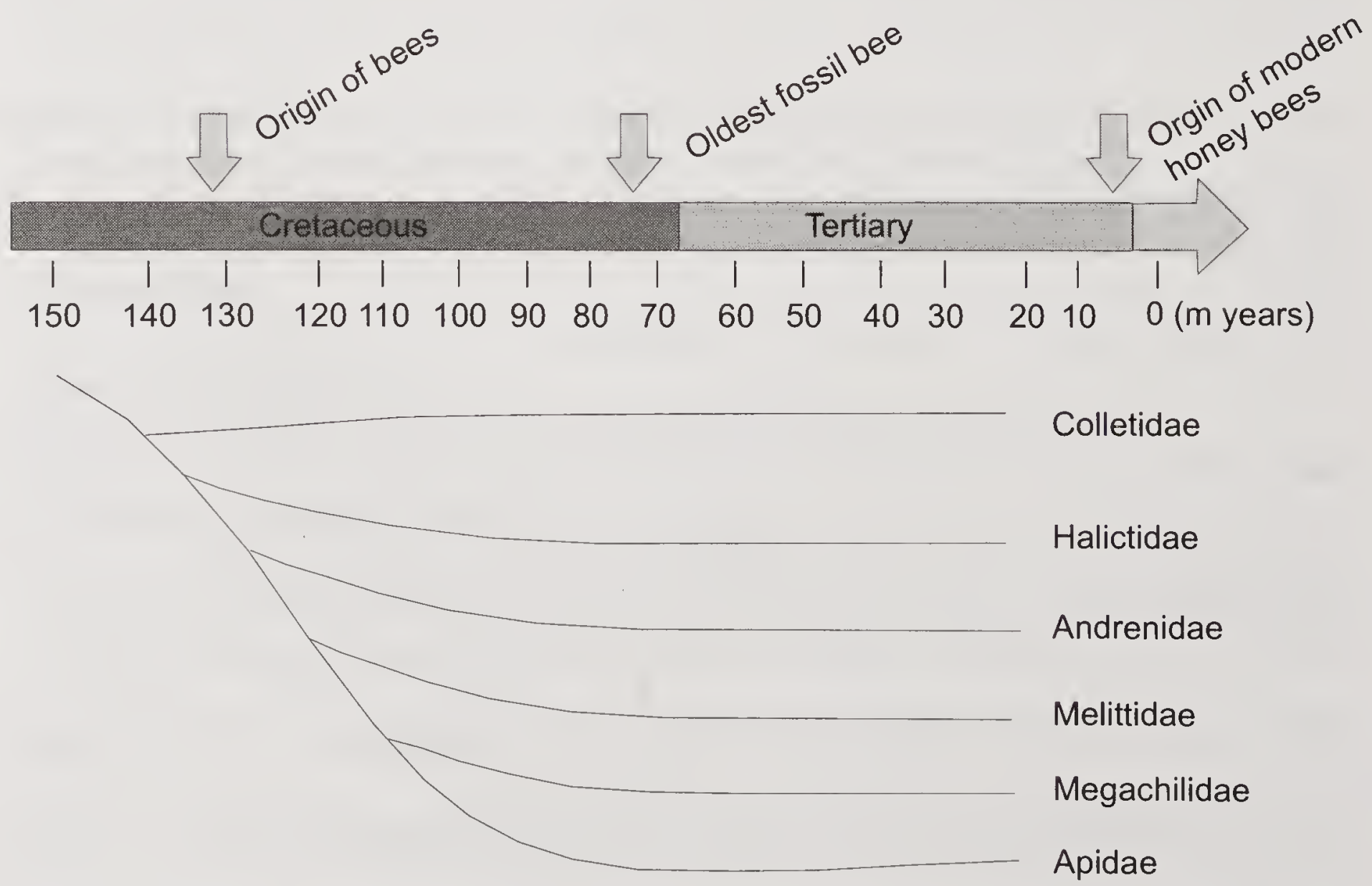

Colletidae

Halictidae

Andrenidae

Melittidae

Megachilidae

Apidae

Corbiculate

Apidae

Fig. 2.1. Geological era of bee evolution (Grimaldi and Engel, 2005). 
and the sister group to the bees. Malyshev (1966) and others have conceived that, it is in the Pemphredoninae that one finds the closest sphecid relatives of the honey bees. Bees as we know them are dependent on products of angiosperms (nectar, pollen, sometimes oil) for food. The group therefore is usually believed to have arisen at the same time as the angiosperms. Bee-pollinated plants tend to produce limited quantities of sticky pollen that does not blow extensively in the wind. It may be, therefore, that bee-pollinated plants became abundant, especially in dry areas, well before their pollens appeared abundantly in the fossil record. For these reasons, one can postulate that bees arose before the middle Cretaceous, a Geological era of bee evolution was given by Grimaldi and Engel (2005) Fig. 2.1.

Honey bees are distantly related to the stingless bees. The common ancestor of the corbiculate bees was eusocial, and there has been a reversal to "primitive" eusociality in the bumble bees and solitary life history in the orchid bees. Eusociality has evolved independently in termites, wasps, bees, ants, beetles, thrips, aphids, spiders, scorpions, and naked mole rats (Crespi and Choe, 1997), so two origins of eusociality is being particularly unlikely in the corbiculate bees. It is concluded therefore that under the phylogeny supported by $c y t b$, the honey bees arose from a solitary ancestor related to the orchid bees. The time and place of this divergence is unclear.The study of morphology, behaviour, and biogeography, suggested that the two highly eusocial tribes, the stingless bees and the honey bees, are sister taxa. This suggested that the ancestor of the honey bees was eusocial, and shared many morphological and behavioral features with extant honey bees and stingless bees. The common ancestor of the bumble bees, stingless bees, and honey bees would have been "primitively" eusocial (Michener, 1974), with the nest founder dominating reproduction, but lacking the strongly divergent queen and worker castes.

Europe was subtropical during Oligocene and the biota resembled to the IndoMalayan. Global cooling at the middle of the Miocene saw extinction of the ancient honey bee and stingless bee species in temperate regions; they persisted only in tropical Asia. The extinction of the ancient European honey bees indicates that they were open-nesting, single combed species, for if they had developed cavity nesting and multiple combs, they should have survived the Miocene cooling in Mediterranean refugia (Ruttner, 1988). Engel (1999) suggested that the modern open-nesting species first appeared in south-east Asia 6-10 million years ago, presumably a remnant of a more broadly distributed Eurasian species, possibly Apis armbrusteri. Cavity nesting emerged slightly later, possibly in the Himalayan region, where there was a diversity of biotypes and climates, which may have facilitated evolutionary change (Ruttner, 1988). Cavity nesting and multiple combs allow for precise thermoregulation with less energetic cost, so the new cavitynesting species could colonize temperate as well as tropical regions. This ancestral cavity-nesting species spread throughout tropical and temperate areas of Asia.This cavity-nesting species eventully radiated into temperate regions of Europe and Asia. The European lineage became isolated from the Asian lineage by the expansion of desert areas of the Middle East. In isolation it evolved into modern Apis mellifera, which is now distributed throughout most of Europe, Scandinavia, and Africa. The Asian lineage gave rise to Apis cerana and its related species. The 
time of divergence of $A$. cerana and A.mellifera is unclear, but it may have been soon after the emergence of cavity nesting. The $\mathrm{ND}_{2}$ gene of the mitochondria shows $17-19 \%$ divergence between $A$. cerana and $A$. mellifera, which suggests (based on $2 \%$ divergence per million years) a divergence time of 3 million years ago (Arias and Sheppard, 1996).

\section{Diversity of honey bees}

Bees are aculeate Hymenoptera and belong to the superfamily Apoidea. The super family includes 9 families, 250 genera and almost 25, 000 species. These bees are either solitary or lead a social life but all individuals share some common characteristics. Body of all the bees is covered with branched hairs. Nearly all bees feed on pollens and nectar and provide the young ones in the cells with food for the developing individuals. They make nests with wax secreted from their bodies, resins, mud, sand, pieces of leaves, hairs and fibers or from secrétions of sting gland and silk produced by adults. Batra (1977), classified the Indian bees in her article on Bees of India (Apoidae), their behaviour management and key to the genera and the family (Table 2.1), and also Michner (1974) classified the bees of the world.

The family Apidae includes bumble bees, stingless bees and true honeybees. Bumble bees collect food for larvae and have social organization. Fecundated females come out of hibernation in the spring, make wax cells, provide them with pollen and nectar before depositing an egg. Full-grown larvae spin cocoon and newly emerged females, having underdeveloped gonads assist the mother female to expand the nest. In autumn, both males and females are produced and females after mating go for winter hibernation. Bumble bees have thick insulating hairs and are very efficient in thermo-regulation. These are found in the Himalayas (Mani, 1962) 4,000 m above sea-level. True honeybees have adapted to varied climates. The origin of Apis is believed to be from South Asia since many forms of Apis spp. are present between Mediterranean and Caucasus (Deodikar and Thakar, 1966). Apis species were present in old world countries since ages but to new world countries the honeybees were introduced only 300 to 400 years ago. There are four Apis species viz. Rock bee, Apis dorsata F.; the little bee, Apis florea F.; Asian honeybee, Apis cerana F. and European honeybee, Apis mellifera L. Apis cerana is the race of Apis cerana present in India. The former two species are wild and latter two are domesticated and serve the commercial beekeeping. First three species were present in India but Apis mellifera was introduced from European countries. They prefer hilly areas up to $1,600 \mathrm{~m}$ above sea-level. Geographical distribution extends from temperate to tropical India, Sri Lanka, Malaysia, and Indo-China region, Philippines, China and Indonesia. During summer, the colonies migrate to mountains up to the elevation of about $2,100 \mathrm{~m}$ to avoid extreme heat or in search of flora. The colonies arrive in the plains during October- March-November and return to hills in June/July before the monsoons. During migration the swarms are known to make short halts en route. During winters they are abundantly found in plains. The migration improves colony survival and provides several crops for honey in the areas en route during the year. 
Table 2.1 Family, sub-family and genus of Apoidea (Michner, 1974 and Batra, 1977)

\begin{tabular}{|c|c|c|}
\hline Family & Sub-family & Genera \\
\hline \multirow[t]{2}{*}{ Colletidae } & Colletinae & Colletus \\
\hline & Hylaenae & Hylaeus \\
\hline \multirow[t]{6}{*}{ Halictidae } & Halictinae & Halictus \\
\hline & & Lasioglossum \\
\hline & & Nomioides \\
\hline & & Sphecodes \\
\hline & Nomiinae & \\
\hline & Andraninae & Andrena \\
\hline Melittidae & Ctenoplectrinae & Ctenoplectra \\
\hline \multirow[t]{10}{*}{ Megachiliade } & Megachiliane & Chalicodoma \\
\hline & & Hariades \\
\hline & & Coelioxys \\
\hline & & Anthecopa \\
\hline & & Osmia \\
\hline & Anthidinae & Anthidium \\
\hline & & Anthidiellum \\
\hline & & Parevaspis \\
\hline & & Stelis \\
\hline & Lithurgiane & Lithurgus \\
\hline \multirow[t]{18}{*}{ Anthophoridae } & Anthophoriane & Parahophites \\
\hline & & Tetralonia \\
\hline & & Tetraloniella \\
\hline & & Anthophora \\
\hline & & Protemelissa \\
\hline & & Amegilla \\
\hline & & Habropoda \\
\hline & & Elaphropoda \\
\hline & & $\begin{array}{l}\text { Tyreus } \\
\text { Melecta }\end{array}$ \\
\hline & Nomadinae & Nomada \\
\hline & & Ammobates \\
\hline & & Morgania \\
\hline & & Epeolus \\
\hline & Xylocopiane & Xylocopa \\
\hline & & Proxylocopa \\
\hline & & Ceratina \\
\hline & & Pithitis \\
\hline & & Braunsapis \\
\hline \multirow{4}{*}{ Apidae } & Meliponinae & Trigona \\
\hline & Bombinae & Bombus \\
\hline & & Psithyrus \\
\hline & Apinae & Apis \\
\hline Fidelidae & Fidelinae & Fidelia \\
\hline \multirow[t]{2}{*}{ Oxaeidae } & Oxaeinae & Oxaea, \\
\hline & & Protoxaea \\
\hline
\end{tabular}




\section{Rock bees}

The Apis dorsata F. known as rock bee builds single-comb nest attached to a branch of tree, rocks and ceilings of neglected and uninhabiated house etc. (Fig. 2.2), protecting it from direct sun rays and rain. Concentration of colonies on one tree is common and there can be 50 to 100 colonies on a tree where the forage sources are plenty. Colonies return to the same tree year after year. Either some odour is left by the swarm at the nesting site or suitability of the site may be the reason for this phenomena. The comb area can be up to $1 \mathrm{~m}^{2}$. Worker and drone cells are equal in size. There are $4.50-4.75$ cells per linear $25 \mathrm{~mm}$ with a mean depth of $16 \mathrm{~mm}$. Drone cells are differentiated by height alone (Reddy and Reddy, 1987). About 7,000

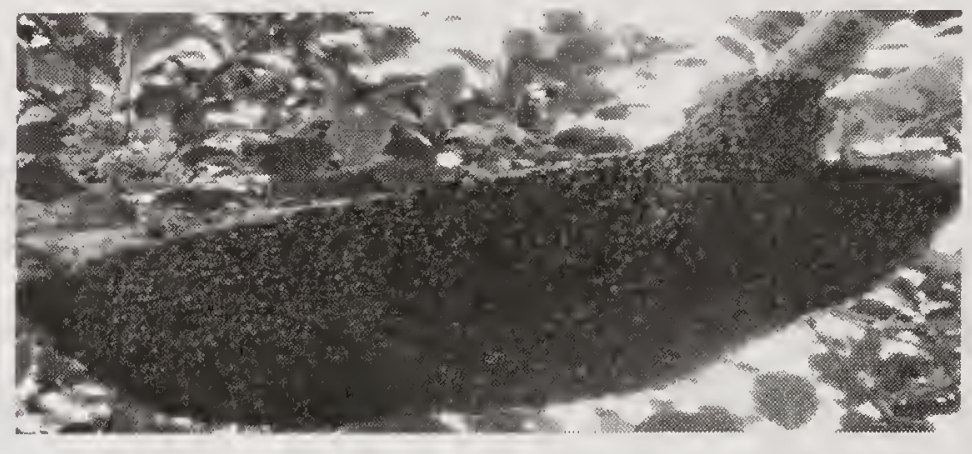

Fig.2.2 Apis dorsata colony. bees would weight $1 \mathrm{~kg}$. Average tongue length is $6.684 \mathrm{~mm}$. The queen is darker in colour than the workers, about $20 \%$ longer than the workers and about $2 \mathrm{~mm}$ broader.

Rock bee has a ferocious temperament and is provoked by slight disturbance. Worker bees attack enmasse and follow the victim over long distances. Worker bees cover the comb like a curtain and orient upwards for insulation and protection. They are sensitive to smoke which is normally used by honey hunters.

The species is a good honey gatherer. Honey is stored in the top half portion of the comb. It can, therefore, be harvested without destroying the colony by cutting the honey storing portion of the comb. As high as 50 to $80 \mathrm{~kg}$ honey per colony can be obtained. A sizable portion of honey produced in India comes from $A$. dorsata species. There appears to be some possibilities of semi-domestication of the wild species. Fletcher (1952) reported that the attempts to keep A. dorsata in hives met with no success. Muttoo (1952), on the other hand, reported the rock bee swarms could be made to settle on two story frames. These were fixed to strong branches of known bee tree just before the swarms were due to return. The frames with bees could be lowered to the ground with ropes and could be manipulated. Similar method of attracting $A$. dorsata colonies to wooden planks was given by Muthappa (1979) in which he used the juice of Cinnamomum incus as an attractant. In an experiment, few of $A$. dorsata larvae placed in queen cell cups reared by $A$. cerana workers and then queen cells were capped. However, no adult queens emerged. Introduction of mated queens (obtained from colonies) in nuclei of young workers of $A$. cerana indica or $A$. mellifera as a method to domesticate the wild bee, was attempted (Mishra et al., 1977) but the queens were not accepted. Observations on the biology of the species, in general, show their behavior to be similar to domesticated Apis species. The egg placement in the cells, the concentric arrangement of brood, the raising of queen cells, issue of swarms, communication dances etc. are broadly similar to $A$. mellifera and $A$. cerana. But in contrast to theses $A$. dorsata bees have been reported to forage during night also. Concerted efforts in systematic way are needed to get more of the species. This species is very hard working and very efficient pollinator of 
crops in India. Apis laboriosa, is also found in the mountaineous and hill region that is in terai region between Nepal and India, but its proper species status is yet to be accorded. Muthuraman et al. (2013) provided the detailed morphometric analysis of Apis dorsata from India. Analysis of variance of morphometrics showed that 14 out of 16 morphometric variables displayed statistically significant difference in Apis dorsata population in India.

Dwarf or Little bee: There are two species of dwarf honey bee, Apis florea Fab. and $A$. andreniformis Smith. Apis andreformis has been recently separated from $A$. florea on taxonomic basis. This species is found in plains of India up to 300 masl. This is a wild bee but attempts to keep it in specially designed hives have met with partial success in India. White comb (1982) has however, described the successful method of keeping the colonies in hives in Oman. Apis florea is highly migratory but long distance migrations are unknown. Disturbances cause them to desert the comb, leaving behind honey, brood and

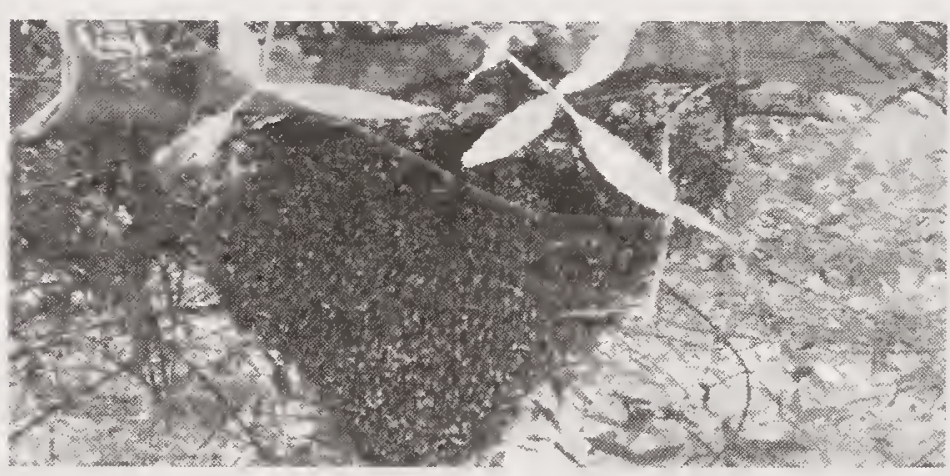

Fig. 2.3 Apis florea colony pollen stores. But the bees continue to return to old comb to take away comb wax, honey and pollen (Fig 2.3). Mean tongue length of A. florea is $3.27 \mathrm{~mm}$. A comb has 13.2 cells $/ \mathrm{cm}^{2}$ (Narayanan et al., 1960) and number of cells per linear $\mathrm{cm}$ are 3.50 (Mutto 1957, Thakar and Tonapi 1962).

The little bee builds a single comb nest and the comb is fixed to branches of bushes, hedges, trees, etc in the shaded places. In the autumn, the colony move short distances to unshaded nesting sites. The comb is broad at the top and it serves as a landing place for the foragers. The comb is always covered by curtain of bees. Drone cells are 1.55-fold larger in diameter than worker cells. Queen cells are raised in spring and autumn at the bottom edge of the comb. These bees are very prone to swarming. They are gentle in temperament; however they do sting when irritated. Colonies can be shifted to crops at blooming time for pollination. The species is distributed in India, Sri Lanka, Pakistan, Indo-China region, Malaysia, Philippines, and Indonesia and up to Iran and Oman in the west.

Apis florea is a poor honey yielder and a comb yields 200 to $500 \mathrm{~g}$ of honey on an average. This honey is thin in consistency. Honey hunters take away the whole comb and thus destroy large number of colonies. The honey produced by this species is believed to have special medicinal values but there are no scientific studies to support this belief. The medicinal value, if any, must be attributed to the nectar of the plants in the locality which are available to other bee species also. Apis florea honey fetches higher price in countries like Middle East. Viraktamath et al. (2013) reported the distribution of Apis florea in India. According to them, A. florea is predominant in peninsular India followed by Maharashtra, Asom, and Jammu and Kashmir. Little bees from Asom, and Jammu and Kashmir were distinctly bigger than peninsular India. 


\section{Apis andreniformis Smith}

Apis andreniformis Smith is a species of honeybee whose native habitat is the tropical and subtropical regions of Asia. Apis andreniformis (Fig. 2.4) is the second honeybee species to be recognized, and its biology, geographic distribution, and its specific status was recognized by many authors. However, it must be mentioned that the species was only recently separated from Apis florea since there are sites where both $A$. andreniformis and $A$. florea live conspecifically. Both species are distributed throughout tropical and sub-tropical Asia, including South-East China, India, Burma, Laos, Vietnam, Malaysia, Indonesia (Java and Borneo), and the Philippines. The most significant morphological characteristics of the species is the black stripes in legs, especially on the tibia and on the dorsolateral (back and side) surface of the basitarsus. Additionally, the pigmentation of the $A$. andreniformis is blackish, while that of $A$.florea is yellowish. Other distinguishing characteristics include a difference respective cubital indexes: $A$. andreniformis has an index of 6.37 , and that $A$. florea of 2.86. Also, the proboscis of $A$. andreformis has a length of $2.80 \mathrm{~mm}$, while that of $A$. florea is $3.27 \mathrm{~mm}$. This physical difference contributes to a division in the distribution of naturally occurring between the two species. Finally, there are differences in the

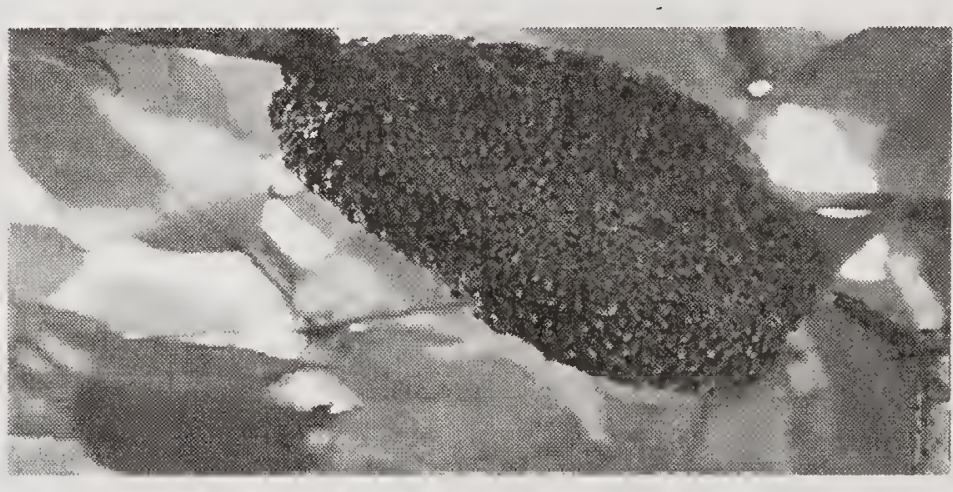

Fig. 2.4 Apis andreniformis colony. barbs of the stinger, and in the basitarsus of the drones.

Indian honey bee, Apis cerana F. Apis cerama species has been the base of Indian beekeeping and is found throughout India. The species is also distributed in Pakistan, Sri Lanka, Malaysia, Indo- China, Philippines, China, erstwhile USSR, Japan and Indonesia. It thrives up to 2,500 $\mathrm{m}$ asl. In China and Japan, the indigenous domesticated $A$. cerana has now mostly been replaced by $A$. mellifera which was introduced some decades ago. In Japan, Apis cerana is now present in small numbers in the hills. In India and Indonesia, this species provides the conventional beekeeping. In India, there was hardly any beekeeping with $A$. cerana in Punjab, Haryana and plains of Uttar Pradesh but $A$. mellifera is doing very well in those areas.

The Indian race of the species is $A$. cerana (Fig.2.5) and there are many distinct strains present in different geographical regions. Kshirsagar (1980) described the importance of biometrical characteristics for characterization of Apis cerana indica at species ecotypes or strains level. Tongue length of Apis indica is $5.25 \mathrm{~mm}$ in bees of Kulu, Himachal Pradesh. Kapil (1956) compared the biometrical characteristics of workers of plains (Allahabad, $26^{\circ} \mathrm{N}$ latitude) races of the species. The differences between the two races were significant for each characteristics except for the number of hooks on the hammuli and cubital index. Narayanan et al. (1960) reported the tongue length was $4.84 \pm 0.05 \mathrm{~mm}$ for leather colored plain race, $5.16 \pm 0.01 \mathrm{~mm}$ for leather grey hill race and $4.9629 \pm 0.0041 \mathrm{~mm}$ for bees from Pusa (Bihar). Numbers of wing hooks were $16.91 \pm 0.09$ and $18.26 \pm$ 0.06 for the plains and hill races, respectively. The studies led the author to conclude that three races (biological varieties) of Apis cerana i.e The Himalayan, Gangetic 

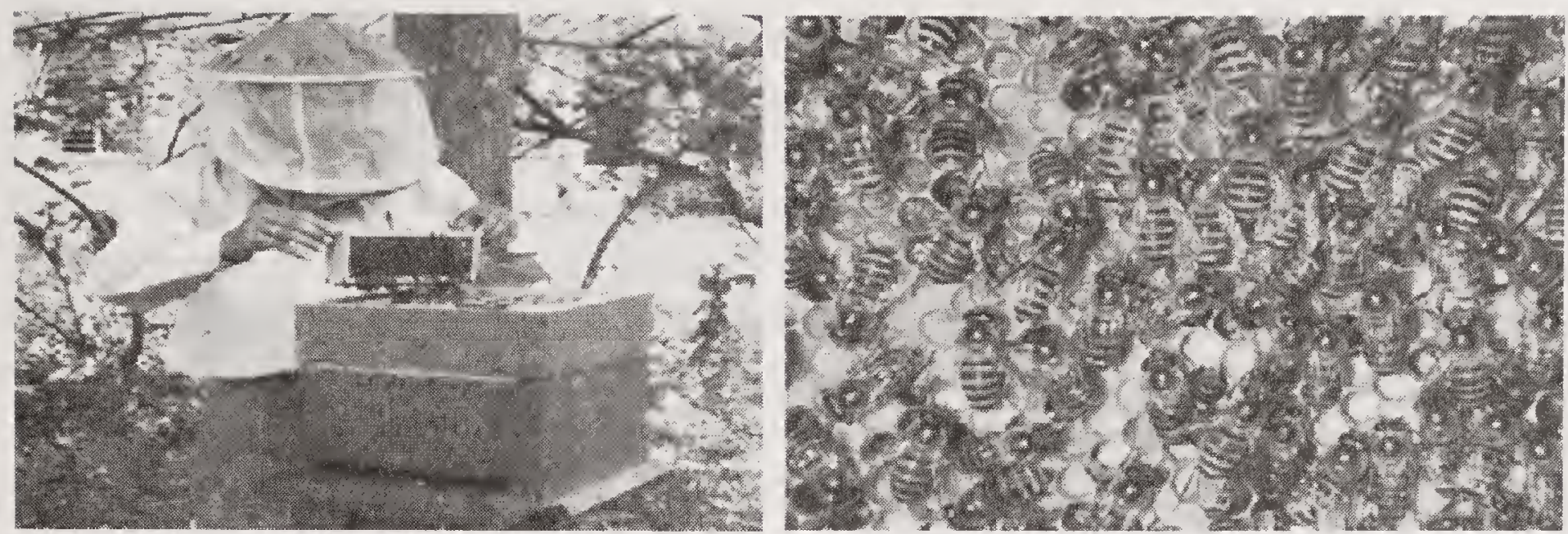

Fig. 2.5. Apis cerana bee hive and comb with worker bee.

plains and South Indian could be distinguished. Information on morphometric characters of bees from different regions is now available (Mattu and Verma, 1983, 1984a, 1984b; Kshirsagar and Ranade, 1981; Singh, 1984).

The bee lives in the cavities of the tree trunks, hollows of rocks, poles and other covered places. It can be domesticated in all kinds of hollows and recesses. Hollowed out logs, wooden boxes, packing cases, kerosene tins, mud receptacles, earthen pitchers, wall recesses and unused almirahs are the common. Worker comb cell is 4.3-5.0 mm in diameter. Drone cells are 1.2 times larger in diameter than worker cells. Smaller hives are used for Apis cerana in most part of India. The build-up capacity is low but in Kashmir, 'Langstorth' type of hives are used. Brood-rearing in a bee colony determines the colony strength. Sharma (1948) recorded the egg laying of 500-600/day. Kapil (1957) observed 6,178 and 8,178 sealed cells and the egg laying rate was worked out to be 500 to 700 eggs per day. Sharma (1948) compared the egg laying capacity of plains and hills races of Apis cerana. The maximum egg laying in hill races was about 1,000 eggs per 24 hours compared with 600 for golden variety of plains. But Kashmir bees are very fertile and Shah et al. (1981) found the egg laying between January and October to be 1, 603 eggs/day. This egg laying rate is comparable to Apis mellifera.

Apis cerana, a bee with high swarming instinct and responds to smoking, it is frugal in habits but lack of flora is quickly compeled to absconding. It also has a strong tendency for swarming; a colony may issue up to 5-6 swarms in a year. Management and manipulation practices to prevent and control swarming also do not always work. Due to incessant swarming, ravages of bee enemies, lack of bee flora and resultant absconding, one comes across a large number of weak colonies. It is poor propolizer and practically no propolis is brought to the nest for reinforcing the combs or sealing the cracks and crevices etc., therefore, wax moth does considerable damage, swarming etc. this species is a low honey-yielder. On an average a colony yields $3-5 \mathrm{~kg}$ of honey per year in plains but the yields are as high as 20-25 kg in Kashmir. The selective breeding does help in improving the desirable traits but of little practical value because of no control on parentage.

Devanesan et al. (2007) studied ecotypes of Asian honey bee, Apis cerana indica in different ecological niche in Kerela, India. Univariate analysis showed significant variation in all the fifty characters indicating the desirability of a multivariate anaylsis for identifying sub groups of $A$. cerana indica available in the state. Comparison of the honey bee population of different topographic division 
of the state revealed the bees from high land were distinct from those of the midland. The highland bees possessed longer proboscis, antennae, wings and legs. The abdominal size also showed increasing trend in highland from midland bees. Eleven morphometris characters were positively correlated with altitude, while seven characters showed negative correlation. Multivariate analysis revealed the existence of four different cluster/ecotypes of Apis cerena indica population in Kerela. Cluster I included bees from all the six locations of midland and four from highland. Cluster II included two locations of highland only. Cluster III included bees from five locations of varying altitude Contribution of each morphometric character towards divergence of the clusters showed that 17 characters contributed 2.5 to $6.4 \%$ of divergence.

Pal et al. (2008) explored Apis cerana indica worker from different locations of Odisha for determining morphometric diversity in A.c.indica in the state. Samples of worker honeybees, A. c. indica collected from 17 locations of 12 districts in Odisha showed distinct variation in respect of various morphological features. The maximum length $(8.05-8.20 \mathrm{~mm})$ and width $(2.89-3.00 \mathrm{~mm})$ of forewing was noticed in bees of certain locations in Puri, Nawarangpur, Kandhal and Koraput districts. The hind wings dimensions also varied with locations. The number of wing hooks was found to be distinctly more $(19.10-19.70 \mathrm{~mm})$ in bees of coastal districts like Puri and Balasore as compared to other districts $(16.60-17.50 \mathrm{~mm})$. Large-sized bees were seen in samples of Bhadrak, G. Udaigiri and Jhardeda, while the smallest sized bees $(10.15-10.20 \mathrm{~mm}$ ) were noticed in sample collected from Kendupali and Nayagarh. On the basis of body weight of 10 worker bees of Jharbeda, G. Udaigiri and Balighai were found to be stoutly built weighing more than $0.63 \mathrm{~g}$. Viraktamath et al. (2013), in their study on morphometry and phylogeography of Indian honey bee, Apis cerana recorded the variation in size of the races that showed a decreasing trend from North to South and West to East India.

\section{Races of Apis cerana}

There are almost 9 different races of Apis cerana (Table 2.2) on the basis of habitats and distribution. However, Apis cerana varies in size throughout its range, and tropical races are much smaller than the temperate and the races are mentioned as per Engel (1999).

Table 2.2. Apis cerana races with their distribution (partly adopted from Engel, 1999)

\begin{tabular}{ll}
\hline Races & Distribution \\
\hline Apis cerana cerana & Afghanistan, Pakistan, North India, China and North \\
& Vietnam \\
Apis cerana heimifeng & Central China \\
Apis cerana indica & South India, Sri Lanka, Bangladesh, Burma, Malaysia, \\
& Indonesia and the Philippines \\
Apis cerana japonica & Japan \\
Apis cerana javana & Java and East Timor \\
Apis cerana johni & Island of Sumatra \\
Apis cerana nuelensis & Malayasia \\
Apis cerana skorikovi & Central and East Himalayan mountains \\
\hline
\end{tabular}




\section{Western honeybee, Apis mellifera L.}

The species is found all over Europe and has spread to other continents also during the last five centuries. Now, it is found almost in every country. There are many well recognized races and strains of mellifera. Proboscis length varies from 5.5 to $7.2 \mathrm{~mm}$. The bee is similar in habits to the Indian honeybee in that it builds parallel combs in hollows of trees, walls or in shady places. Geographical races greatly differ in appearance. Four European races, viz., Apis mellifera, Apis mellifera ligustica, Apis mellifera carnica and Apis mellifera caucasica are most important for beekeeping. Apis mellifera ligustica is considered to be the best and has been introduced in many countries. It has many desirable traits. It maintains a prolific queen, swarm less, has gentle temperament and is good honey-gatherer. This race has achicved a great success in some states of India where this has proved to be superior performer than Apis cerana and commercial apiculture in the country is mainly based on this species. Some distinct traits of different $A$. mellifera races are given in Table 2.3. Out of the listed species, Apis mellifera liguistica and A. m. carnica are mostly available in India and are termed as western honeybee (Fig. 2.6).
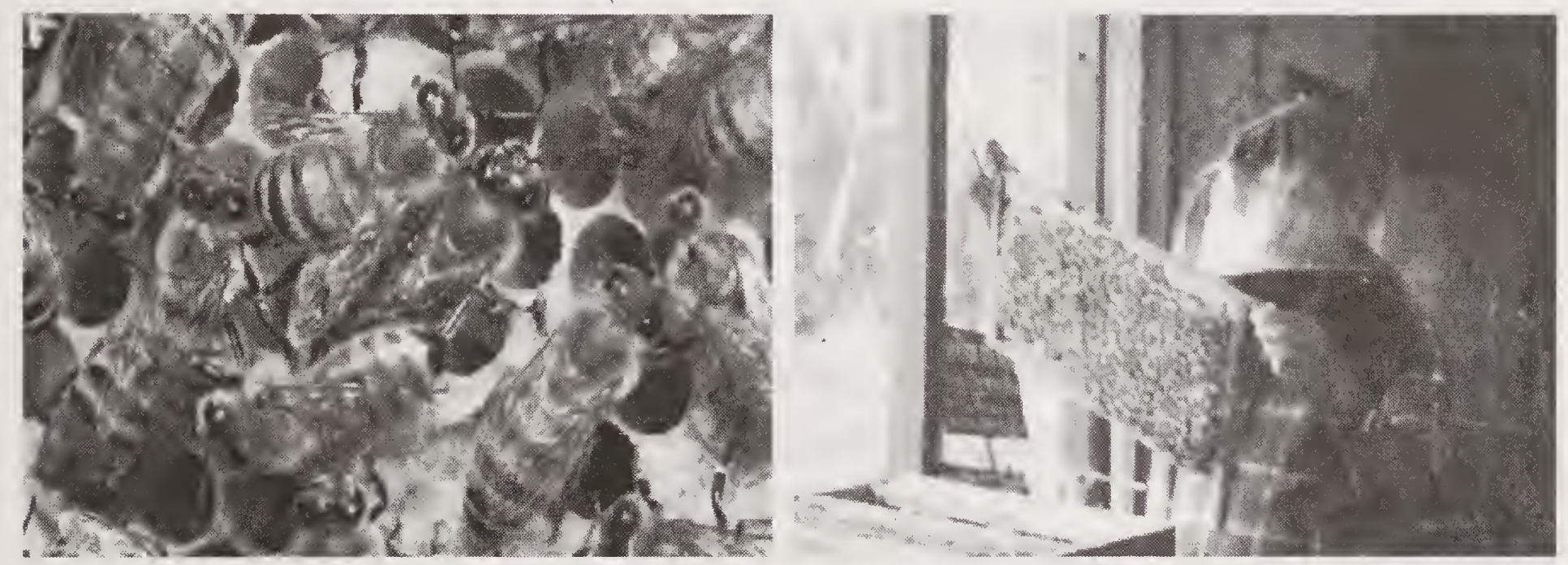

Fig. 2.6. Worker bees in Apis mellifera colony

\section{Phylogeny and classification}

Bee classification is primarily based on phylogeny (Fig. 2.1). Some specialists (cladists) base classification entirely on phylogeny; others consider information also from diverse sources in developing a classification. No one, however, should presume to make a classification without having all available phylogenetic information. For practical purposes, it was presented on bee classification, prior to the section on phylogeny, because use of the family-group names makes explanation and understanding easier. Recent phylogenetic studies have not overturned this classification in a major way; it is therefore possible to discuss phylogeny using for the most part, the taxa that have been accepted in the past by many specialists. In dealing with a large group such as the bees, it is inevitable that the classification will be unsatisfactory in some areas even though quite satisfying in others. This situation arises partly because of intrinsic differences among living bees. Another reason for differences in the usefulness of taxonomic constructs is the amount and kind of study to which each group has been subjected. Some taxa have been analyzed phylogenetically, others have not, and some such 
Table 2.3. Races of Apis mellifera

\begin{tabular}{cccccc}
\hline Race & $\begin{array}{c}\text { Geographical } \\
\text { distribution }\end{array}$ & $\begin{array}{c}\text { Body } \\
\text { size }\end{array}$ & $\begin{array}{c}\text { Body } \\
\text { shape }\end{array}$ & $\begin{array}{c}\text { Proboscis } \\
\text { length }(\mathrm{mm})\end{array}$ & $\begin{array}{c}\text { Body } \\
\text { colour }\end{array}$ \\
\hline
\end{tabular}

(4)

(5)

(6)

A. Eastern races Apis. mellifera Armenia, east remipes Antolia, Iran

A. mellifera Syria, Israel, syriaca Lebanon

B. European races

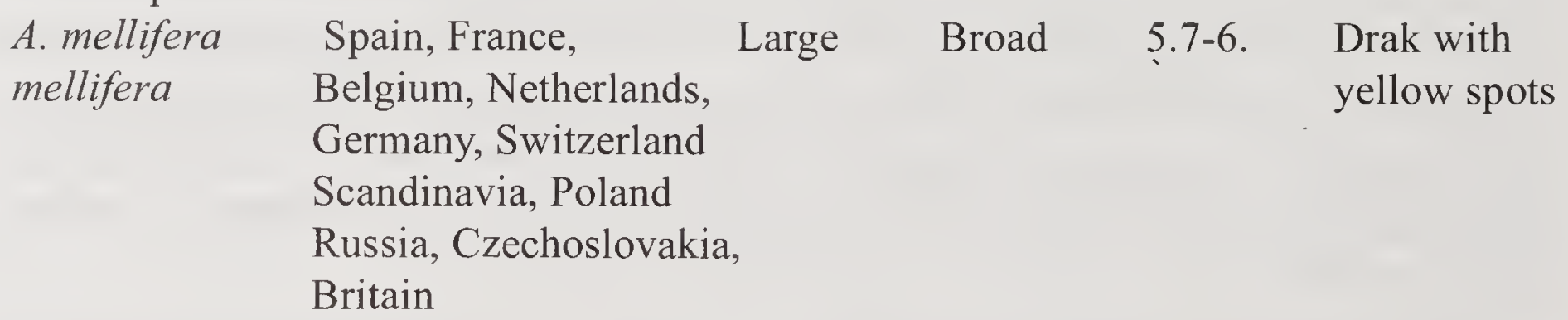

$\begin{array}{ll}\text { A. mellifera } & \text { Italy, now spread } \\ & \text { ligustica } \\ & \text { golden, } \\ & \text { including India }\end{array}$

$\begin{array}{ll}\begin{array}{l}\text { A. mellifera } \\ \text { cernica region }\end{array} & \begin{array}{l}\text { Austria, Balkan } \\ \text { (Yugo-slavia) }\end{array} \\ \begin{array}{l}\text { A.mellifera } \\ \text { Caucasiaca }\end{array} & \text { Caucasus (USSR) } \\ \begin{array}{ll}\text { C. African races } \\ \text { Apis mellifera } \\ \text { intermissa }\end{array} & \begin{array}{l}\text { North Africa } \\ \text { from Libya to }\end{array} \\ & \text { Morocco } \\ \text { Apis m. major } & \text { Small pocket } \\ & \text { In Rif Mountain } \\ & \text { (Morocco) }\end{array}$

$\begin{array}{ll}\text { Apis } m . & \text { Nile valley in } \\ \text { lamarckii } & \text { Egypt }\end{array}$

Apis m. Sudan

nubica

Apis m. In oases near sahariensis northern edge of Sahara

\begin{tabular}{|c|c|c|c|}
\hline $\begin{array}{l}\text { Smaller } \\
\text { in other co }\end{array}$ & $\begin{array}{l}\text { Broader } \\
\text { untries }\end{array}$ & $6.3-6.6$ & $\begin{array}{l}\text { yellow, } \\
\text { than }\end{array}$ \\
\hline & \multicolumn{2}{|c|}{ Mellifera } & $\begin{array}{l}\text { yellow brown } \\
\text { markings }\end{array}$ \\
\hline $\begin{array}{l}\text { As in } \\
\text { ligustic }\end{array}$ & Slender & $6.4-6.8$ & $\begin{array}{l}\text { Dark, grey } \\
\text { haired }\end{array}$ \\
\hline $\begin{array}{l}\text { Similar } \\
\text { to carnica }\end{array}$ & Slender & $\begin{array}{l}\text { Up to } \\
7.2\end{array}$ & $\begin{array}{l}\text { Dark brown } \\
\text { with spots }\end{array}$ \\
\hline Long & Broad & $6.4 \mathrm{~mm}$ & $\begin{array}{l}\text { Dark } \\
\text { pigment, } \\
\text { spares hairs }\end{array}$ \\
\hline Long & Broad & $7.0 \mathrm{~mm}$ & $\begin{array}{l}\text { Dark with } \\
\text { yellow } \\
\text { markings }\end{array}$ \\
\hline $\begin{array}{l}\text { Medium/ } \\
\text { long }\end{array}$ & $\begin{array}{l}\text { Slender } \\
\text { colour, } \\
\text { broad }\end{array}$ & $5.7 \mathrm{~mm}$ & $\begin{array}{l}\text { Intense } \\
\text { yellow }\end{array}$ \\
\hline Small & Slender & $5.4 \mathrm{~mm}$ & $\begin{array}{l}\text { Intense } \\
\text { yellow } \\
\text { colour }\end{array}$ \\
\hline Medium & Slender & $6.3 \mathrm{~mm}$ & $\begin{array}{l}\text { Yellow } \\
\text { markings }\end{array}$ \\
\hline
\end{tabular}


(Contd. from p.20)

\begin{tabular}{|c|c|c|c|c|c|}
\hline Race & $\begin{array}{l}\text { Geographical } \\
\text { distribution }\end{array}$ & $\begin{array}{l}\text { Body } \\
\text { size }\end{array}$ & $\begin{array}{l}\text { Body } \\
\text { shape }\end{array}$ & $\begin{array}{c}\text { Proboscis } \\
\text { length }(\mathrm{mm})\end{array}$ & $\begin{array}{l}\text { Body } \\
\text { colour }\end{array}$ \\
\hline $\begin{array}{l}\text { Apis } m . \\
\text { jemenitica }\end{array}$ & Yemen & Small & Broad & $5.4 \mathrm{~mm}$ & $\begin{array}{l}\text { Intense } \\
\text { yellow colour }\end{array}$ \\
\hline $\begin{array}{l}\text { Apis } m . \\
\text { littorea }\end{array}$ & $\begin{array}{l}\text { Coastal area } \\
\text { of Tanzania }\end{array}$ & Small & $\begin{array}{l}\text { Relativel } \\
\text { slender }\end{array}$ & ely $5.7 \mathrm{~mm}$ & $\begin{array}{l}\text { Yellow } \\
\text { tergites }\end{array}$ \\
\hline Apis mellifera & Ethiopia, Kenya & Small & Slender & . $5.9 \mathrm{~mm}$ & $\begin{array}{l}\text { Intense } \\
\text { yellow }\end{array}$ \\
\hline $\begin{array}{l}\text { Apis } m . \\
\text { monticola }\end{array}$ & $\begin{array}{l}\text { Mountain regions } \\
\text { of Tanzania, } \\
\text { Kenya, Ethiopia }\end{array}$ & Long & Broad & $6.2 \mathrm{~mm}$ & Dark \\
\hline $\begin{array}{l}\text { Apis } m . \\
\text { adansonii }\end{array}$ & $\begin{array}{l}\text { West Africa, south } \\
\text { of the Sahara }\end{array}$ & Small & Broad & $6.2 \mathrm{~mm}$ & $\begin{array}{l}\text { Yellow } \\
\text { marking }\end{array}$ \\
\hline $\begin{array}{l}\text { Apis } m . \\
\text { capansis }\end{array}$ & $\begin{array}{l}\text { Southern tip of } \\
\text { South Africa }\end{array}$ & Medium & Broad & $5.9 \mathrm{~mm}$ & $\begin{array}{l}\text { Inconspicuous } \\
\text { yellow Mark }\end{array}$ \\
\hline $\begin{array}{l}\text { Apis m. } \\
\text { unicolour }\end{array}$ & Madagascar & Small & Slender & er $5.6 \mathrm{~mm}$ & $\begin{array}{l}\text { Relatively } \\
\text { dark }\end{array}$ \\
\hline
\end{tabular}

The Table is partly adopted from Drescher and Crane, 1982.

analyses are convincing while others are not. Thus, the parts of the classification differ in their usefulness. The tradition has been to recognize large genera of bees, like Andrena, Lasioglossum that and Megachile. It is believed that this is desirable, for it allows many biologists to recognize the genera and know what is meant by the names. A frequent result of maintaining large genera is the development of multiple subgenera. Melittologists are sometimes criticized for extensive use of subgenera. Species-groups, named informally with specific names, could be used instead of subgenera; such a procedure would avoid burdening the literature with numerous subgeneric names and their associated formalities such as type species and problems of homony. For large genera, however, with hundreds or thousands of species, the choice is not between recognizing a genus with subgenera vs. a genus with species groups. It is between recognizing a genus with subgenera vs. several or many genera, because many of the current subgenera are quite different from one another.

The phylogeny of the honey bees has been controversial with considerable divergence of the topologies derived from molecular data sets (Willis et al. 1992) and those inferred from behavioral and morphological data (Alexander 1992). Recently, however, trees derived from molecular, behavioral, and morphological data have been brought into agreement, and a phylogeny similar is broadly accepted (Arias and Sheppared 2005). The phylogeny clusters the closely related Asian cavity-nesting species (A.cerana, A.nigrocincta, and $A$. nuluensis) in a shrubby tip. Outside of this clade are A. koschevnikovi and the European A.mellifera. 
Outside of these are two giant species Apis dorsata and Apis laboriosa. The most basal clade comprises the dwarf open-nesting species $A$. florea and $A$. andreniformis.

The ancestor of the honey bees probably emerged about 35-40 million years ago in the Indo-European region. Oligocene-Miocene cooling caused honey bees to go extinct in Europe, but they persisted and speciated in tropical Asia. The ancestor of modern open-nesting Apis probably emerged about 10 million years ago. Slightly later, possibly 6 million years ago, an $A$. cerana-like bee that could efficiently thermoregulate owing to cavity nesting and multiple combs emerged, possibly in the Himalayan region. It spread east and north, becoming ubiquitous throughout Asia. About 2-3 million years ago, during a Pleistocene warming, this bee expanded west into Europe and than into Africa to become A.mellifera. Phylogenetic tree of bees has been produced in Fig. 2.7.

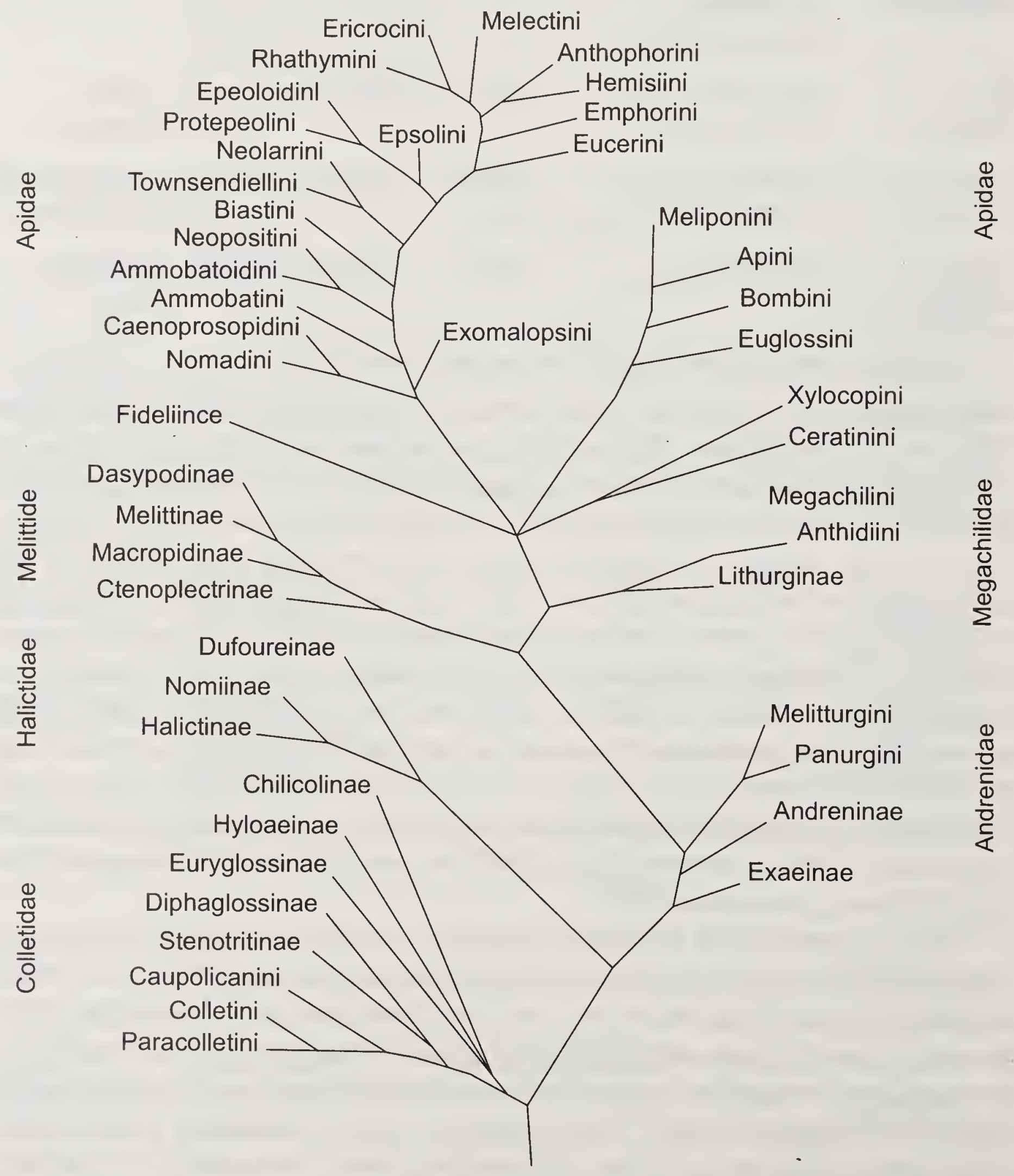

Fig. 2.7 Phylogenetic tree of bees (C.D. Michener, 1944). 


\section{REFERENCES}

Alexander, B. 1992. Phylogenetic analysis of the genus Apis (Hymenoptera: Apidae). Entomologist Society of America. 84: 137-48.

Arias, M.C. and Sheppard, W.S. 1996. Molecular Phylogenetics of honey bee subspecies (Apis millefera L.) inferred from mitochondrial DNA sequence. Molecular Phylogenetics and Evolution 5: 557-66.

Arias, M.C. Sheppard, W.S. 2005. Phylogenetic relationships of honey bees (Hymenoptera: Apinae: Apini) inferred from nuclear and mitochondrial DNA sequence data, Molecular phylogenetics and evolution. 37 (1): 25-35, 2005.

Batra, S.W.T. 1977. Bees of India (Apoidea), their behaviour, management and key to the genera. Oriental Insects. 11(3) : 289-324.

Crespi, B. J. and J. C. Choe. 1997. Evolution and Explanation of Social Systems. pp. 499524 (In) J. Choe and B. J. Crespi, editors. The Evolution of Social Behavior in Insects and Arachnids. Cambridge University Press, Cambridge, United Kingdom.

Deodikar, G. B. and Thakar, C.V. 1966. Utilization and Improvement of the local floras as bee pasturage. Proceedings of Autumn School Bot. Poona University, India. 122-28.

Devanesan, S, Shailaja, K.K. and Premila, K.K. 2007. Ecotypes of the Asian Honeybee, Apis cerana indica Fab. In different ecological niche in Kerela, India. Proceedigs $40^{\text {th }}$ Apimondia 2007 International Apicultural Congress, Melbourne, Australia p 125.

Drescher, W. and Crane, E. 1982. Technical co-operation activities. Beekeeping: A Directory and Guide. German Agency for technical co-operation. Eschborn. pp 166.

Engel, M.S. 1999. The Taxonomy of recent and fossil honey bee (Hymenoptera: Apidae : Apis) Journal Hymenopt Research 165-176.

Engel, M. S. 1999. A monograph of the Blatic amber bee and evolution Apoidea. American Museum Noviates 3296: 4-11.

Engel, M.S. 2001. A monograph of the Baltic amber bees and evolution of the Apoidea (Hymenoptera). Bulletin of the Amer. Muse. Nat. Hist. 259: 1-192.

Evans. H. E. 1958. Studies on the larvae of digger wasps. Part IV: Astatinae, Larrinae, Pemphredoninae. Trans. Amer. Entomol. Soc. 84: 109-39.

Fletcher. L. 1952. Apis dorsata, the bambara or giant bee of India and Ceylon. Bee Craft 34 (9): 139-40.

Grimaldi, D. and Engel, M.S. 2005. Evolution of the Insects. Cambridge University Press, $755 \mathrm{pp}$.

Kapil, R.P 1956. Variation in biometrical characters of Indian honey bee (Apis indica F.) Indian Journal Entomology 18(4): 440-57.

Kapil, R.P. 1957. The length of life and the brood-rearing cycle of the Indian bee. Bee World 8(10) : 258-63.

Kshirsagar, K.K. and Ranade, D.R. 1981. Morphometric characterization of Indian hive bee, Apis cerana indica F. (Apidae. Hymenoptera) worker. Journal Ulliv. Poona Sci. Tech. Soc. 4 ; 101-20.

Kshirsagar. K.K 1980. Morphometric studies on the Indian hive bee, Apis cerana indica F. Morphometric characters useful in identification of intraspecific taxa. Proc. 2nd International Conf Apic. Trop. climates, New Delhi. .254-61.

Lomholdt, 1982. On the origin of the bees. Entomological Scandinavica 13: 185-90.

Malyshev, S.I. 1966: Genesis of the Hymenoptera and the phases of their evolution. London, $319 \mathrm{pp}$.

Mani, M. S. 1962. Introduction of High Altitude Entomology, Methuen \& Co. London.

Mattu, V. K. and Verma, L. R. 1983. Comparative morphometric studies on the Indian honeybee of the north-western Himalayas. 1. Tongue and antenna. Journal of Apiculture Research 22(2): 79-85. 
Mattu, V. K. and Verma, L. R. 1984a. Comparative morphometric studies on Indian honeybee of the north-western Himalayas. 2. wings. Journal of Apiculture Reserach 23(1) : 3-10.

Mattu, V. K. and Verma, L. R. 1984b. Comparative morphometric studies on the Indian honeybee of north-western Himalayas.3. Hind leg, tergites and sternites. Journal of Apiculture Research 23(3): 117-22.

Michener C. D. 1974. The social behavior of the bees: A Comparative Study. Cambridge, MA. Harvard Univ. Press. 404 pp.

Mishra, R. C., Dogra, G. S. and Gupta P. R. 1977. An attempt to domesticate Rock'bee, Apis dorsata F. Indian Bee Journal 38(1/4) : 20-22.

Muthappa, B.M. 1979. Rock bee culture in forests. Myforest 15(3): 189-99.

Muthuraman, M., Raju, A.J.S, Vijaykumar, K. Devanesan, S., Abrol. D.P. and Viraktamath, S. 2013. Morphometry of rock bee, Apis dorsata F in Monograph on Morphometry and Phylogeography of honeybees and stingless bees in India. Department of Biotechnology, Government of India, New Delhi. 5-13 pp.

Muttoo, R.N. 1952. Tree apiaries. Indian Bee Journal 14: 87-89.

Muttoo, R.N. 1957. Some so called peculiarities of behaviour of Indian honey bees as compared to the European bees. Indian Bee Journal 19(3/4) : 62-64.

Narayanan, E.S., Sharma, P.L. and Phadke, K.G. 1960. Studies on biometry of the Indian bees. I.Tongue length and number of hooks on the hind-wing of Apis indica. Indian Bee Journal 22: 58-63.

Pal, S. Patnaik, H. P. and Satapathy, C.R. 2008. Morphometric diversity in Apis cerana indica F. worker bees of Orissa. Journal of Plant Protection and Environment 5(2): 42-51.

Reddy, M.S. and Reddy C.C. 1987. Rates of colonization and de-colonization of rock bees, Apis dorsata F. Indian Bee Journal 49: 1-4.

Ruttner F. 1988. Biogeography and taxonomy of honeybees. Springer, Berlin, xii 284 pp. Shah, F.A. and Shah, T.A. 1981. Egg-laying capacity of Kashmir bee. Apis cerana. Bee World. 62(3): 114-15

Sharma, P.L. 1948. Studies on seasonal activities of Apis indica F. at Lyallpur. Indian Bee Journal 10: 20-23.

Singh, M.P. 1984. Morphometric Studies on Indian Honeybee, Apis cerana indica F. of North-Eastern Himalayas. M.Phil. Dissertation, H.P. University, Shimla, India, 129 pp.

Thakar, C.V. and Tonapi, K.V. 1962. Nesting behaviour of Indian honeybees. II. Nesting habits and comb cell differentiation in Apis florea Fab. Indian Bee Journal 24(1/3): 27 -31 .

Viraktamath, S., Abrol, D.P., Vastrad, A.S., Mathuraman, M., Rajankar, B., Muthuraman, M., Devanesan, S. and Raju, A.J.S. 2013. Morphometry of Indian honey bee, Apis cerana F. in Monograph on Morphometry and Phylogeography of Honeybees and Stingless bees in India (Ed). Department of Biotechnology, Government of India, New Delhi, 26-46 pp.

Viraktamath, S., Rajankar, B., Lazar, K.V., Devanesan, S., Vastrad, A.S., Mathuraman, M., Raju, A.J.S and Abrol, D.P. 2013. Morphometry of little bee, Apis florea F. in monograph on Morphometry and Phylogeography of Honeybees and Stingless bees in India (Edt). Department of Biotechnology, Government of India, New Delhi, 14-25 pp.

Whitecombe, R.P. 1982. Experiments with a hive for little bee: some observations on manipulating colonies of Apis florea in Oman (pari I). Indian Bee Journal 44(3): 57 63.

Willis, L.G., Winston, M.L. and Honda, B.M. 1992. Phylogenetic relationships in the honeybee (Genus Apis) as determined by the sequence of the cytochrome oxidase II region of mitochondrial DNA. Molecular Phylogenetics and Evolution. 1: 169-78. 


\section{3 \\ Morphology and Physiology}

$\mathrm{T}$

HE study of bee morphology gives an understanding of not only the external morphology but also the anatomy and physiology of the bees. Coupled with external and internal morphology of bees would offer economic relationship of this insects to agricultural and other economic products. Like insects, the honeybee (Fig. 3.1) has three principal body divisions. Some insect morphologists denote thorax as mesosoma and abdomen as metasoma for hymenopteran insects. The head bears the mouth parts, the eyes and the antennae. It is attached to the mesosoma by means of a membrane which allows great flexibility of movement. The movements of the head are activated by five pairs of muscles which extend from the thorax to the posterior region of the head. The thorax of the bee, unlike that of most insects, is composed of four segments consisting of the pro-, mesoand meta-thorax and the first abdominal segment's, the propodeum. Some authors call this body division, the mesosoma. Each of the true thoracic divisions bears a pair of legs. The meso- and meta-thoraces each bear a pair of wings. The wingbearing portions of the thorax and the propodeum are collectively termed the alitrunk. The abdomen is attached to the alitrunk by a short peduncle. The abdomen appears to be composed of 6 segments, but actually contains nine, excluding the propodeum.

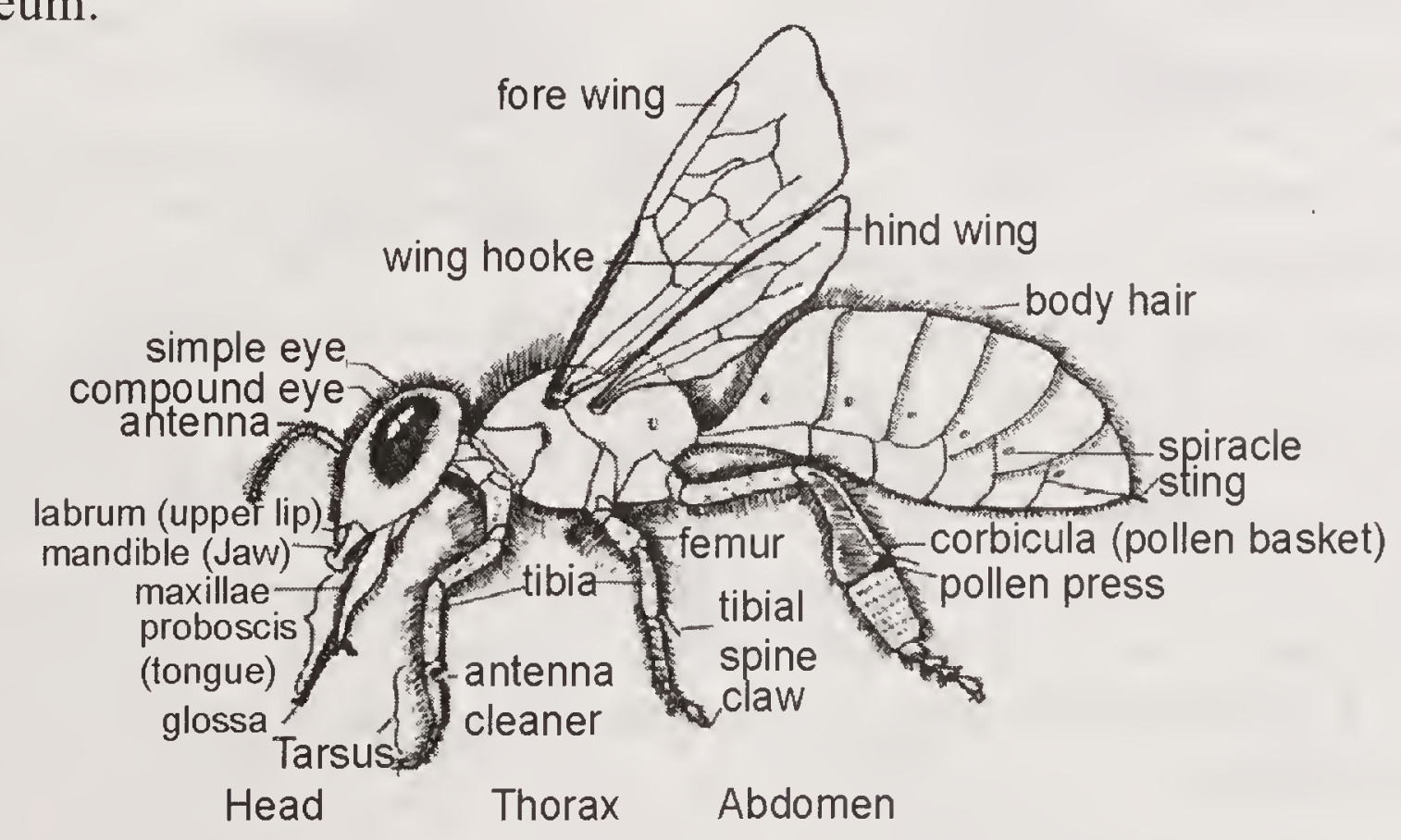

Fig. 3.1 General view of honeybee (From Snodgrass, 1956).

\section{External morphology}

\section{The head}

The head (Fig. 3.2) of the worker is subtraingular when viewed anteriorly, being broad dorsally. The compound eyes are located on the lateral surface of the 
head of the worker and queen, but found on the top of the head of the drone. The three ocelli are located in a triangle near the mid-point of the front of the head of the worker and queen and on the front of the drone. The mouthparts are located on the lower part of the head. When removed from the body, the head is seen to be concave posteriorly. The prominent features of the back of the head are (1) occipital foramen through which pass the muscles, the oesohagus, aorta, nerves, salivary ducts, and the tracheae or air tubes, the fossa of the proboscis, a horse-shoeshaped notch which receives the base of the maxillae and labium. The honeybee possesses two types of eyes. The large, lateral, compound eyes are composed of many ommatidia. Snodgrass (1956) indicated that there are 4,000-5,000 of these elements in the eye of the worker, 3,000 to 4,000 in the eye of the queen, and 8,000 or more in the eye of the drone. Each ommatidium consists of an external cornea or crystal-line lens, a crystalline cone, and a rhabdom which is surrounded by eight retinacular cells. Surrounding the back of the crystalline cone are the corneal pigment cells, and the outer pigment cells invest each ommatidium except for the cornea. The function of the pigment has been considered by some morphologists to prevent rays of light passing from one ommatidium to another. Others consider that the pigment regulates the amount of light that impinges on the retina. Wolf and Zerrahn-wolf (1935) investigated the adaptability of the eyes of the honey bee to light intensity and concluded that the intensity range of the eye of the bee is nearly identical with that of the human eye.

The chief function of the compound eye is perception of objects, but von Frisch (1950) and Autrum and Stumpf (1950) had demonstrated that the compound eyes can analyze polarized light, thus permitting the bee to use the sun's position as a compass during

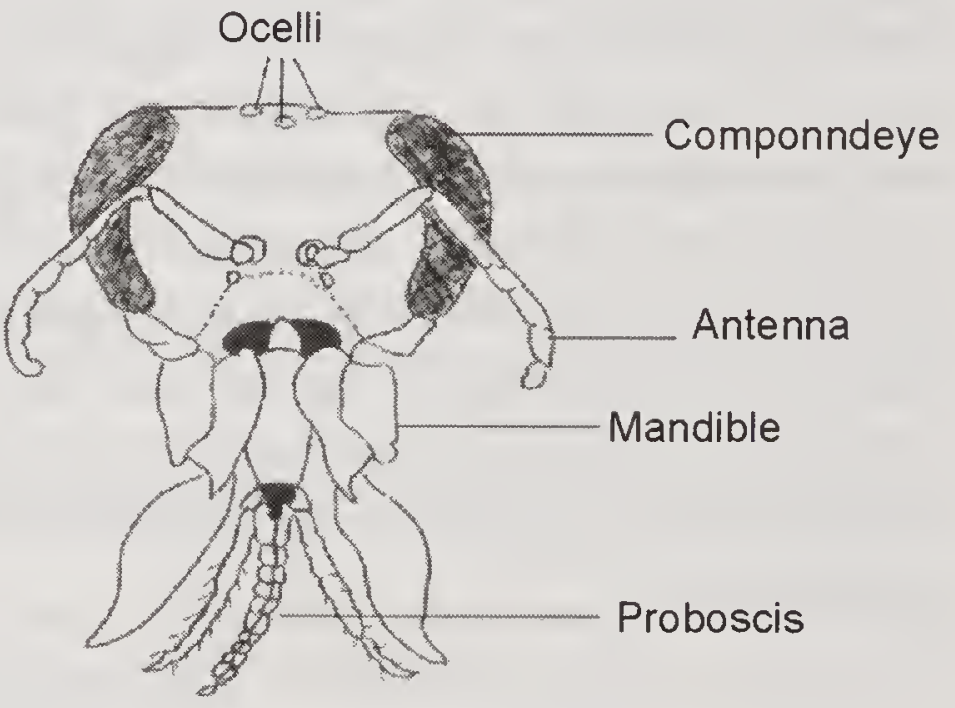

Fig. 3.2 Head along with different parts of honeybee (Snodgrass, 1956) flight. According to Wolf and Zerrahn-Wolf (1935), the eye of the bee is inferior to that of man as far as visual accuracy is concerned but equal to that of man in recognizing flicker. They believe that this ability is of importance as far as detection of form and recognition of flowers is concerned. The ocelli of adult insects are not believed to be capable of forming perception images, since according to Parry (1947) the image would fall behind the retina. Dethier (1943), concluded that the ocellus is a light-sensitive organ which upon stimulation augments the general excitatory response.

\section{The antennae}

Each antenna is composed of a long basal segment, the scape, and the flagellum which is formed of 11 segments in the worker and queen, but 12 in the drone. The antenna is attached by a membrane to the antennal socket. Four muscles which arise from the tentorium are attached to the bulb of the scape and control the 
major antennal movements. The function of the antenna has been a matter of dispute, but Snodgrass and von Frisch have indicated that the principal functions are touch and odour.

\section{The mouth parts}

The mouth parts are composed of the subrectangular upper lip or labrum, the epiphaynx which is concealed by the upper lip, paired mandibles, paired maxillae, and the lower lip or labium. The sucking tube or proboscis is not a single organ as it is in the bugs or mosquitoes, but is formed by the association of the maxillae and labium (Fig. 3.3).

The mandible of the worker is broad at each end but narrowed in the middle. The tip of the mandible has a pronounced channel on its inner surface. From this, a slight groove extends to the base. The worker bee uses its mandibles in collecting and eating pollen, in comb- building, in cleaning the hive, in fighting, in gathering and working propolis, and various other ways. Owing to their shape, the mandibles of the worker are incapable of penetrating the flesh of sound fruits, contrary to the claims of many uniformed "observers".

The maxilla is composed of several segments. The basal one, the cardo, is a slender rod-like structure. The basal segment of each maxilla is united to the base of the labium by the lorum. Attached to the cardo are the broad stipes, which bear a membranous lobe, the lacinia, which functions in the formation of the food canal when the bee is sipping liquids, and a small subtriangular plate, the subgalea. Beyond the sub-galea and continuous with it is the large flattened galea and two-segmented maxillary palpus. The labium is likewise composed of several

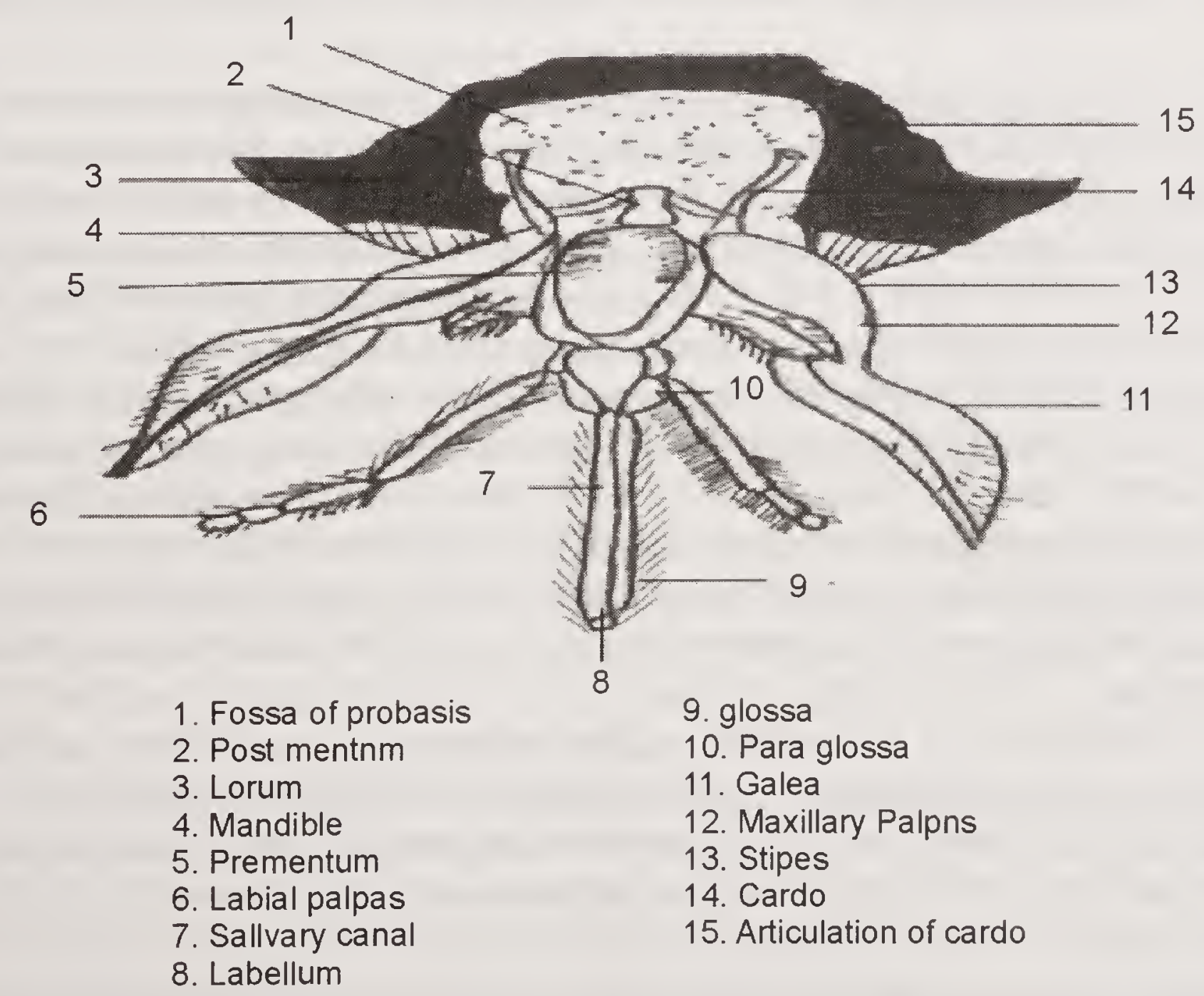

Fig. 3.3 Mouth parts of worker honeybee (Snodgrass, 1956). 
segments. The basal one, the postmentum, is triangular and is attached to the centre of the labrum. Attached to it is the broad, subrectangular prementum. Attached to the prementum is the median tongue, comprised of the combined glossae and the paraglossae which enclose the base of the glossae. The long, paired, four- segmented labial palpi are also attached at the base of the prementum.

Snodgrass (1956) has described in great details the action of the mouthparts in sucking liquids. Briefly, the tongue is enclosed in a tube formed by the galeae of the maxillae and the labial palpi. The tongue begins a rapid back-and-forth movement and apparently draws liquids into the proboscis. The cibarial pump then draws the liquid from the proboscis into the mouth opening.

\section{The mesosoma}

As previously noted, the apparent thorax of the bee also contains the first abdominal segments, called the propodeum, while the thorax proper is composed of the pro-, meso-, and meta- thoraces. As in other insects, the terms notum, sternum and pleuron refer to the dorsal, ventral and lateral protions of the body. The mesosoma bears three pairs of spiracles of which two are thoracic and the third occurs on the propodeum.

The prothorax is the smallest of the thoracic regions. The pronotum is a collarlike structure extending posteriorly over the mesopleuron. The propleuron and the sternum are reduced in size. The propleuron is produced anteriorly into a point which supports the head. The prosternum is a small triangular plate to which the prothoracic legs are attached. The prothoracic spiracles are the second largest of the ten pairs of spiracles and occur just below the fromt of the attachment of the fore wings. Each is covered by a flap-like lobe, fringed with branched hairs.

The mesothorax is the largest of the thoracic divisions. Its size is apparently correlated with the development of the indirect wing muscles. The mesonotum is the largest of the thoracic sclerites. It is comprised of a scutum and a scutellum. The mesothoracic wings arise from the area between the notum and the mesopleuron. The tegula is a shield-like structure in front of the base of the fore wing.' In the honeybee, the pleural and sternal areas are not well differentiated, but form a bowl-like structure, enclosing the sides and ventral surface of the mesothorax. Ferris (1940) considered that the pterothoracic sterna are rare except as secondary sclerotizations. He advanced the theory that the ventral and lateral sclerites of the pterothorax are subcoxal in origin. Michener (1944), in his excellent monograph of the bees, seemed to agree with Ferris. A small spiracle occurs on each side of the mesothorax between the upper end of the mesepimeron and the metapleura.

The metathorax is a band-like region between the mesothorax and the propodeum. The metanotum is made up of a narrow band-like median portion which broadens laterally and bears the anterior and posterior notal wing processes. The metathoracic wings arise between the notum and the pleuron. The pleural and the sternal areas are reduced in comparison with those of the mesothorax. Apparently the same condition found in the mesothoracic sterna area is present in the metathoracic region. 
The propodeum closes the mesosoma posteriorly. It is comprised of a large notum and a greatly reduced sternum which lies behind the third pair of legs. The propodeum bears the first pair of abdominal spiracles.

\section{Mesosomal appendages}

The thoracic appendages consist of three pairs of legs and two pairs of wings. By means of these, the bee is able to move about. The legs are also modified so as to aid in the collection and carrying of pollen and in cleaning the body of the bee.

Each leg is made up of 6 principal segments (Fig. 3.4). The coxa articulates with the coxal process of the pleuron or the subcoxal process. Next is a small sclerite, the trochanter. The femur is the most robust sclerite of the leg. It is followed by the tibia, which is flattened and covered densely with hair. The meta-thoracic tibia is concave on its outer surface and fringed with long, unbranced hairs. The concavity is known as the corbiculum or pollen basket, and serves to carry pollen and propolis to the hive. The tarsus is composed of five segments or tarsomeres. The prothoracic basitarsus has a basal groove, the antenna cleaner. The basal segments of each toxsys bears rows of heavy spines, the pollen brushes, which combs pollen from the body. Those of the hind tarsus are scraped against the row of spines on the tibia of the opposite leg. The pollen is then forced up into the pollen basket by a lobe, the

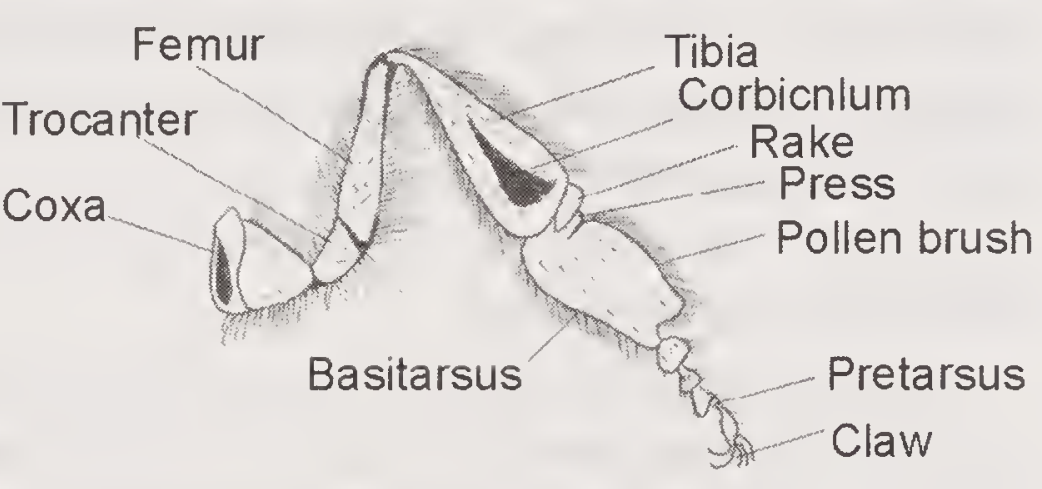

Fig. 3.4 Hind leg of worker bee (Snodgrass, 1956). auricle. The ultimate segment is pretersus which bears the claws and the fleshy, median lobe known as the arolium. The claws are used in walking over rough surfaces. The arolium is used when the bee must walk on a smooth or slippery surface. It presses against the surface and the tender hairs on the lower surface emit a sticky fluid. The bee is able to release the arolium by relaxing the tension on it.

The wings consist of membranous, two-layered fused extensions of the body surface. Throughout the membranes are thickened sclerotized supporting structures known as veins. They are articulated to the wings processes by several small axillary sclerites.

The fore-wing is the larger of the two wings. It is subtriangular in outline. Michener (1944) had presented a good discussion of the terminology of the wing veins and the cells. The student is urged to consult this reference for detailed information on these subjects. On the posterior edge of the fore wing is a fold: this is a part of the wing-coupling device.

The hind wing is smaller and has fewer veins. On the outer half of the front of the hind wing are hooks or hamuli which fit into the fold of the fore wing to form a very efficient wing- coupling mechanism.

\section{Metasoma}

The abdomen of the worker appears to consist of 6 segments. However, it 
must be remembered that the first true abdominal segment is closely associated with the thorax. The segments of the abdomen readily are visible in the worker or queen which number II to VII. Segments VIII-X are concealed within segments VII. They are highly modified and are difficult to recognize as entities. The drone appears to have an additional segments which is composed of the $8^{\text {th }}$ tergite and the $9^{\text {th }}$ sternite. In both sexes, the $x^{\text {th }}$ segment is reduced to a small lobe which bears the anus.

The abdomen bears 7 pairs of spiracles apart of those on the propodeum. It also bears 4 pairs of wax glands, a dorsal scent gland, and in the worker and queen, the sting and its associated structures. It contains most of the visceral organs.

\section{The wax glands}

The wax glands are located on the ventral surface of abdominal sternites IV to VII. The anterior portion of each of these sternites bears two transparent, polished surfaces known as mirrors. The wax glands are located inside the abdomen over the mirrors. The wax is secreted as a liquid and forms a thin flake in each wax pocket between the mirrors and the posterior, under lapping portion of the preceeding sternite.

\section{The dorsal scent gland}

Located under the base of the VII ${ }^{\text {th }}$ abdominal tergite is the dorsal scent gland, or gland of Nassenoff. Mclndoo (1914b) has described the structure as being composed of unicellular epidermal gland cells. It is believed that the secretion of the scent gland passes through the epidermis by tiny ducts opening to the exterior. According to Mclndoo, the scent gland of the queen is larger than that of the worker. This has been disputed by Jacobs (1924), who stated that the scent gland is lacking in the queen and in the drone. The scent is used as a means of communication between the individual bees.

\section{The sting}

The sting of the worker and queen bees is a modified ovipositor. Instead of being used to prepare a suitable site for eggs, as it does in many other insects, the sting is used to inject poison (Fig. 3.5). The sting and most of its associated organs are contained in a special cavity or sting chamber. The sting consists of a dorsal style or sheath and two ventral lancets. The stylet is enlarged baselly. It has a pair of projecting condyles and each lancet possesses a dorsal groove. The lancets can slide freely along the condyles but are held closely together. The stylet and lancets form a cavity, the poison cannel, through which poison is injected when the bee stings. The lancets possess strong recurved teeth in the worker. While the sting of the queen possess barbs, they are not so well developed and the sting is more strongly attached. Hence, the queen does not lose her sting, where as the sting and associated organs of the worker are torn from the body in the process of stinging.

Associated with the sting are three pairs of plate, the quadrate which is the largest, the triangular which is the smallest, and the along which is intermediate 
in size, a pair of fresh lobes formerly known as the sting palpi, but now referred to as the sting sheath, and the poison sac, poison gland, and alkaline gland. All these structures function in the process of stinging. It should be noted that the sting is capable of independent motion once it has been inserted in an enemy. By muscular action, the sting and poison are driven

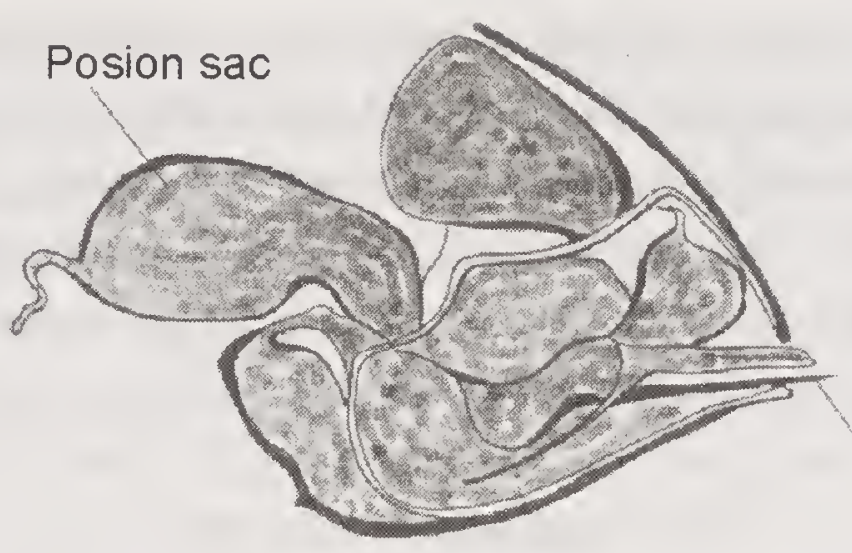

Fig. 3.5 Poison gland with sting (Snodgrass, 1956). deeply into the wound.

In the process of stinging, the bee curves the abdomen ventrally, extrudes the sting, and thrusts it into the victim. The barbs on the lancet hold the sting in the wound. By muscular action, first one and then the other lancet is 50 driven deeper into the wounded. Unless the sting is removed, it is soon embedded for its entire length. The poison, in the meantime flows.

To remove a sting, the fingernail or a knife blade should be used to scrape this organ from the flesh. If the sting is grasped by the fingers or by tweezers, usually more poison is squeezed into the wound. Beekeepers generally scrape out the sting by rubbing their hands or arms against their clothing or by scathing the area stung.

\section{Morphometrics of Indian honey bee}

Honeybee morphology has not been worked at length in India but few of the relevant morphological studies have been included in this chapter. Kapil (1956) compared the biometrical characteristics of workers of plains (Allahabad, $26 \mathrm{p} \mathrm{N}$ latitude) races of the species. The difference between the two races were significant for each characteristics except for the number of hooks on the hammuli and cubital index. Narayanan et al. (1960) reported tongue length asl. $4.84 \pm 0.05 \mathrm{~mm}$ for leather colored plain race, $5.16 \pm 0.01 \mathrm{~mm}$ for leather grey hill race and $5.9629 \pm 0.0041 \mathrm{~mm}$ for bees of Pusa (Bihar). Number of wing hooks were $16.91 \pm 0.09$ and $18.26 \pm 0.06$ for the plains and hill races, respectively. The biometrical studies for characterization of Apis cerana indica at species level, Kshirsager (1980) revealed that tongue length of Apis indica is $5.25 \mathrm{~mm}$ in bees of Kulu, Himachal Pradesh. Das and Rahman (1999) in their study on biometrical changes during post embryonic development of Apis cerana, worker showed a considerable variation in different seasons of the year, viz. spring, summer, autumn and winter. Trunk length and width were $2.52-2.59 \mathrm{~mm}$ and $1.08-1.14 \mathrm{~mm}$ at $16 \mathrm{~h}$ larval age and they increased to 12.14 to 12.68 and 5.23 to $5.47 \mathrm{~mm}$ at $112 \mathrm{~h}$ larval age respectively. However, the measurement of head size showed variation in different seasons but they were not significantly different. The increase of trunk length and width significantly differed at latter stage of growth (i.e $64^{\text {th }}, 88^{\text {th }}$ and $112 \mathrm{~h}$ ). The growth index was higher in autumn (16.77) followed by spring (16.51) and winter (15.28) and the lowest was in summer (13.06).

Pal et al. (2008) on morphometric analysis of Apis cerana indica worker bees of Odisha reported that the maximum length $(8.05-8.20 \mathrm{~mm})$ and width $(2.89$ - 
$3.00 \mathrm{~mm}$ ) of fore wings was noticed in bees of certain locations in Puri, Nawarnagpur, Kandhamal and Koraput districts. The hind wing dimensions also varied with locations. The number of wing hooks was found to be distinctly more (19.10-17.70 $\mathrm{mm}$ ) in bees of costal districts like Puri and Balasore as compared to other districts (16.60-17.50). Large-sized bees were seen in samples of Bhadrak, Udaigiri, Baulachauka and Jharbeda, while the small-sized bees (10.15 to 10.20 $\mathrm{mm}$ ) were noticed in sample collected from Kendupalli and Nayagarh. On the basis of body weight of 10 worker bees of Jharbeda (Keonjhar), Udaigiri (Kandhamal) and Balighai (Puri) were found to be stoutly built weighing more than $0.63 \mathrm{~g}$. Similarly while comparing the dimensions of other morphological features in bees of different locations, it was evident that in potential beekeeping areas like Sakhigopal, Baulachauka, Bhadrak and Nayagarh, the proboscis length was invariably found to be maximum $(2.80-300 \mathrm{~mm})$ as compared with other locations (1.99 to $2.76 \mathrm{~mm}$ ). The factor and cluster analysis based upon 15 morphological character in $A$. cerana indica revealed that features like body length, proboscis length and antenna length showed maximum contribution (10.61 to $16.89 \%$ ) towards the divergence in bee population across locations in Odisha.

Muthuraman et al. (2013) while studying the population variations of Apis dorsata in seven states of India recorded the mean values and standard deviations of the 16 morphometric characters. The mean number of hamuli was ranging from 24 to 26 . The mean tongue length varied from 5.06 to $5.70 \mathrm{~mm}$. The bees from Jammu and Kashmir showed the highest mean ratio between length and width of head, metatarsus and wax plates.

Viratamath et al. (2013) studied the morphometry of Apis florea from India in which 15 morphimetric characters were taken. The head width was found to be greater in the bees from Asom $(2.70 \mathrm{~mm})$ and Jammu and Kashmir $(2.68 \mathrm{~mm}$ ). However, in peninsular India, the head width was more in the bees from Karnataka $(2.53 \mathrm{~mm})$, Maharashtra $(2.52 \mathrm{~mm})$ while it varied from 2.45 to $2.47 \mathrm{~mm}$ in other states. The bees from Asom also had longer proboscis $(3.02 \mathrm{~mm})$ followed by the bees from Karnataka $(2.91 \mathrm{~mm})$ while in bees from remaining states, it varied from 2.74 to $2.88 \mathrm{~mm}$. The distance between the lateral ocelli was more in the bees from Andhra Pradesh $(0.42 \mathrm{~mm})$ and Tamil Nadu $(0.41 \mathrm{~mm})$ while it ranges from 0.35 to $0.38 \mathrm{~mm}$ in the bees from other states. Distance between lateral ocellus and compound eye in the bees from different states varied from 0.26 to $0.30 \mathrm{~mm}$. Longer antennae were observed in the bees from Asom (2.96 mm), and Jammu and Kashmir (2.97) followed by Tamil Nadu (2.92 mm). Length of antennae varied from 2.66 to $2.84 \mathrm{~mm}$ in the bees from other states. Bees from lower latitudes characterized by hot and dry weather were reported to be small in size (Narayanan et al., 1960; Bhandari, 1983).Viratamath et al. (2013) further in their comparative morphometric analysis of Apis cerana worker of different states in India reported that there are different morphoclusters obtained from North and South India showed distinct geographical affinities. The bees from Jammu and Kashmir were the largest with highest head width of $3.67 \mathrm{~mm}$ followed by bees from Asom $(3.51 \mathrm{~mm})$. The bees from Karnataka, Kerala and Maharashtra were of moderate size with head width ranging from 3.34 to $3.36 \mathrm{~mm}$ while bees from Tamil Nadu and Andra Pradesh were smaller (2.91 to $2.97 \mathrm{~mm}$ ). The proboscis was the longest 
$(4.59 \mathrm{~mm})$ in the bees from Jammu and Kashmir followed by the bees from Maharashtra $(4.48 \mathrm{~mm})$ and Kerala $(4.46 \mathrm{~mm})$. However, the length varied from 3.97 to $4.01 \mathrm{~mm}$ in other states. The distance between two lateral ocelli and ocularocellar distance was highest in the bees from Jammu \& Kashmir (0.34 and $0.44 \mathrm{~mm}$, respectively. Shah and Shah (1980) recorded that the bees collected from Jammu \& Kashmir were larger than bees collected from South India

\section{INTERNAL MORPHOLOGY AND PHYSIOLOGY}

The internal morphology deals with different organs or structural parts that assemble to facilitate proper metabolism in the honey bee system. There are various systems are: Digestive system, excretory system, nervous system, circulatory system, respiratory system, reproductive system and special organs.

\section{The digestive system}

As in most insects, the alimenetary canal of honeybee can be divided into three regions, the foregut, the midgut or ventriculus and the hindgut (Fig. 3.6). The foregut is composed of the portion of the alimentary canal that extends from the mouth opening to the pro-ventriculus. Behind the mouth opening is the cibarium which is an enlarged muscular chamber. Attached to the anterior portion of the cibarium are muscles which can make this region expand and contract to act as a pump for drawing liquids into the mouth opening. Posterior to the cibarium is the pharynx, which is also equipped with strong muscles and functions probably to force the food into the oesophagus. The latter extends through the neck and thorax to the abdomen, where it expands to form the thin-walled crop, nectar sac or honey stomach, which is capable of great expansion. Posterior to the Crop is the proventiculus which controls the passage of food into the mid-intestine or ventriculus and also causes the nectar to be retained in the crop. This is accomplished by the proventricular valve, composed of four triangular flaps which can be folded together to form a very efficient valve. It is a one-way valve, opening backward only, and thus prevents any substance from entering the honey stomach from the midgut. This ensures the continued purity of the nectar.

The midgut or ventriculus is a relatively thick tubular organ. Its epithelium is composed of many folds which increase both the digestive surface and the capacity

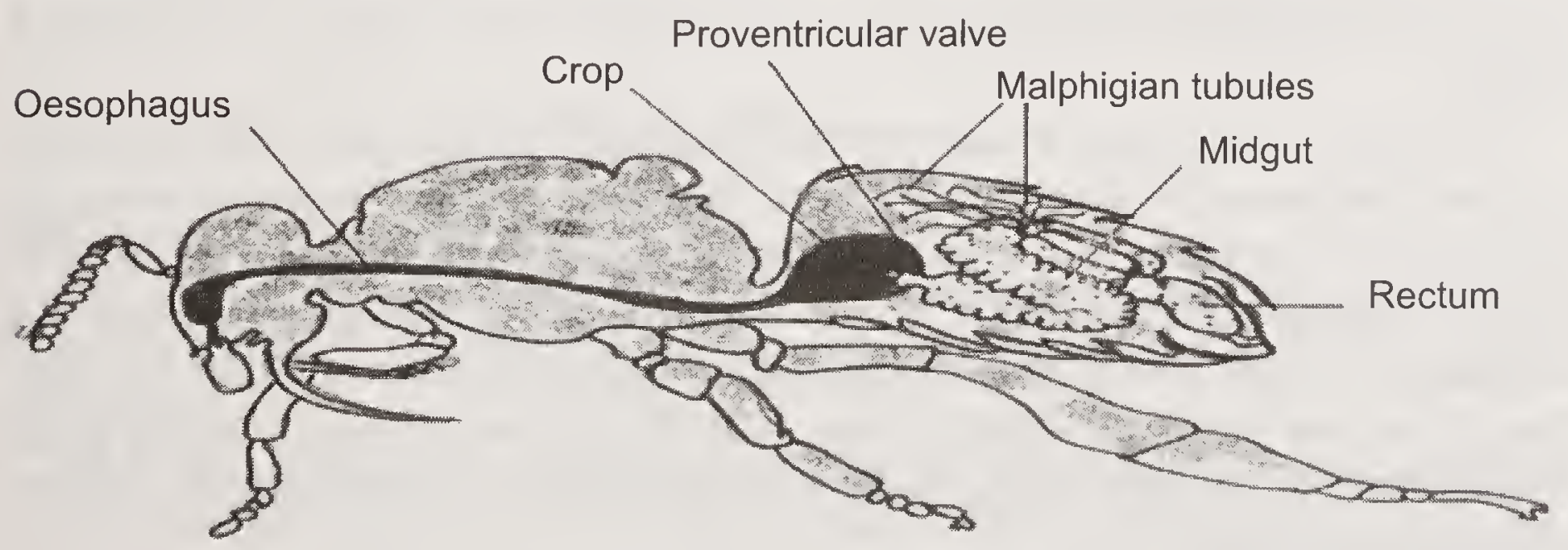

Fig. 3.6 Digestive and excretory system of worker bee (Snodgrass, 1956). 
of the organ. The ventriculus is composed of several layers, beginning externally with a sheath of longitudinal muscles under which lie the circular muscles. Interior to the circular muscles is the thick epithelial layer and a thin, non-cellular membranous structure, the peritrophic membrane. In the digestion of food, the epithelium secretes the digestive fluids and enzymes. After digestion, the digested substances pass through the peritrophic membrane and the walls of the ventriculus to the blood, which circulates in the body cavity.

The hindgut is made up of a tubular small intestine and a large rectal sac or rectum. Wastes are discharged through the anal opening. This portion of the alimentary canal, while functioning mainly to discharge wastes, does absorb excess water, some salts, and probably other material of nutritive value. In addition, the rectum serves to retain the feaces during periods of the winter when bees cannot fly to eliminate their wastes outside the hive.

\section{The excretory system}

The waste products of metabolism of the bee are removed principally by the Malpighian tubes. However, both $\mathrm{CO}_{2}$ and some water pass off through the tracheae. Some investigators also have claimed that nitrogenous wastes are accumulated in the urate cells which are associated with the fat body. Uric acid deposits, together with certain pigments, are also found in the cuticle of some insects. The pericardial nephrocytes are also believed to act in excretion.

The Malpighian tubes are small, tubular structures which extend throughout the abdominal cavity. They number about 100 in the adult. The wall of each is one cell in thickness. The tubes remove wastes from the blood and these are discharged into the alimentary canal at the junction of the midgut and the hindgut.

\section{The nervous system}

Insects in general have three types of nervous systems: (i) the central nervous system, (ii) the stomogastric or sympathetic nervous system, and (iii) the peripheral nervous system. We have more detailed information on the central nervous system of the honeybee than we have on the other systems.

The central nervous system (Fig. 3.7) consists of a dorsal brain and a row of ventral ganglia joined by paired longitudinal connectives. There are two large nerve masses in the head, the brain and the sub-oesophageal ganglion. The oesophagus passes between these two masses, which are joined by circumoesophageal connectives. Both nerve masses of the head are compound ganglia.

The brain is composed of three more or less clearly defined parts. These include the protocerebrum, the deutocerebrum, and the tritocerebrum. These nerve masses innervate the antennae, the compound and simple eyes and the labrum. By the frontal commissures, the brain is connected to the frontal ganglion and the stomogastric nerve which extends posteriorly along the dorsal wall of the pharynx. The drone possesses the largest brain, but this is due primarily to the great development of the optic lobes. As far as the true brain is concerned, the worker possesses the largest.

The sub-oesophageal ganglion innervates the mandibles, the maxillae and the 


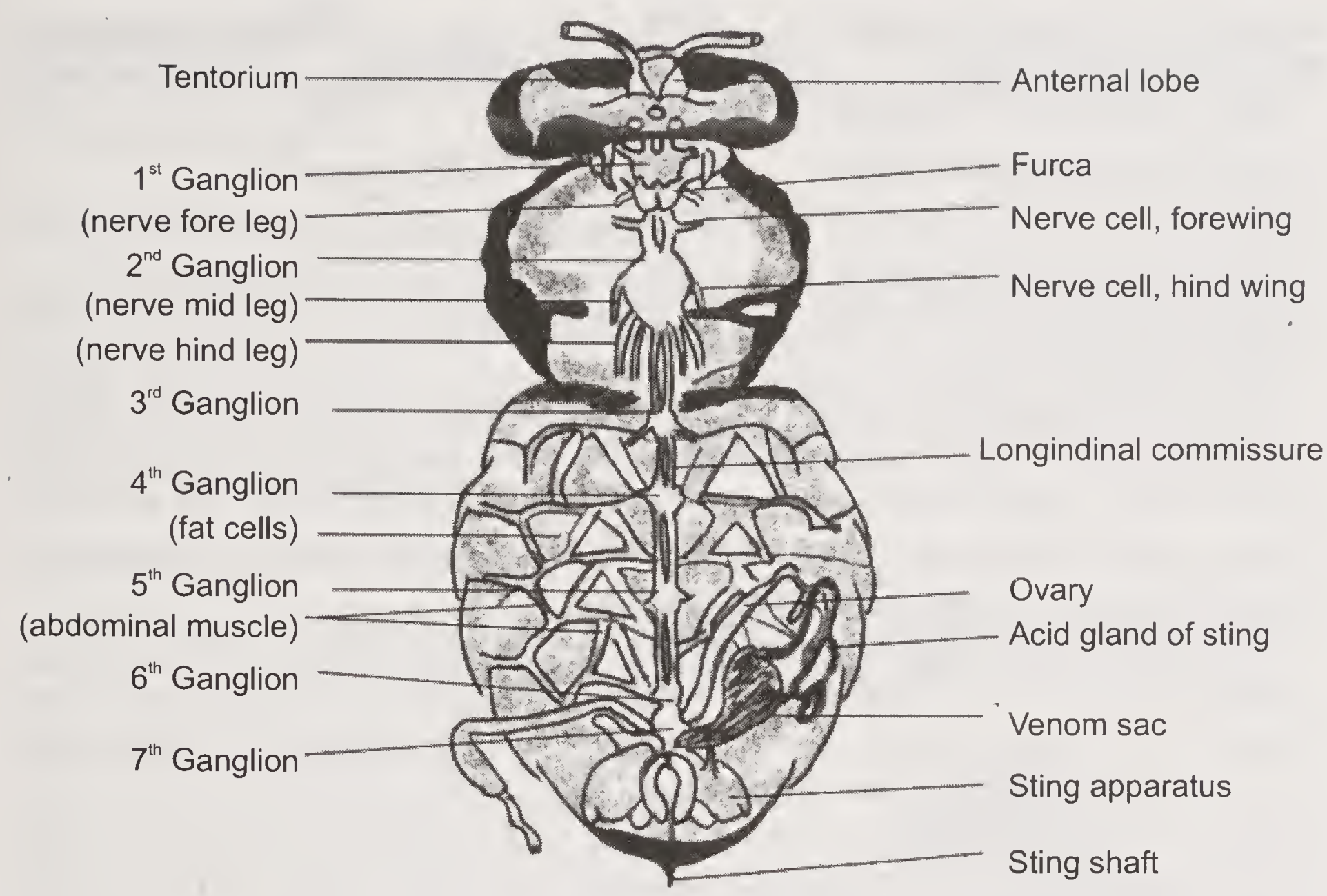

Fig. 3.7 Nervous system (Snodgrass, 1956).

labium. Posteriorly, the suboesophageal ganglion is united to the first thoracic ganglion by long paired connectives.

The stomogastric nervous system is concerned with the innervations of the digestive, circulatory and reproductive systems. The peripheral nervous system is concerned primarily with the innervations of sensory cells in the integument.

The ventral nerve trunk consists of seven nerve masses or ganglia. The first is located in the prothorax and its principal function is the innervations of the first pair of legs. The second ganglion of the ventral nerve trunk lies approximately at the juncture of the meso-and meta-thoraces. This is a compound ganglion and innervates the meso- and meta-thoraces, the propodeum and the second true abdominal segment. In the abdomen, there are five ganglia which innervate abdominal segments III-VII. Since, the posterior ganglion innervates all the segments posterior to it must be a compound ganglion composed of ganglia representing segments $7-10$.

As in other insects, the coordination of the muscles does not depend on the brain. Each ganglionic mass appear to have more or less independent control over the portion of the body it innervates.

\section{The circulatory system}

The circulatory system (Fig. 3.8) consists of a single pulsatile organ, the heart aorta. In addition, the flow of blood is also regulated by dorsal and ventral diapharagms.

The 5-chambered heart is found in the dorsal part of the abdomen. Each chamber of the heart possesses a pair of ostia or slits which permit blood to enter the chambers. The lips of the ostia project anteriorly into the chamber ahead and act 
as valves to prevent the blood from flowing backward.

The aorta is a tubular continuation of the heart. It has no chambers of ostia. The aorta extends through the thorax into the head where it divides and

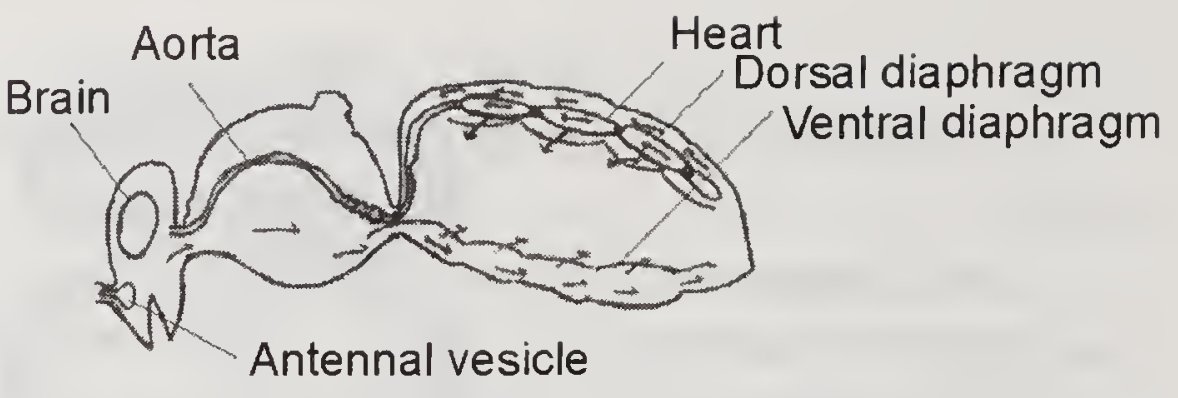
opens below the brain.

The blood is pumped anteriorly from one chamber to another by the rhythmic contraction of the heart. It passes through the aorta and pours out into the head near the brain. It then flows back through the thorax to the abdomen. The pulsation of the ventral diapharagm force, the blood backward and probably upward. The dorsal diaphragm forces the blood anteriorly.

The blood of the bee is a pale yellowish or somewhat amber-colored liquid. It consists of a fluid in which various form of blood cells or haemocytes occur. These cells are more closely comparable with the white blood cells or leucocytes of the vertebrates than with the red blood cells. The principal functions of the blood are the transportation of digested food products and the removal of waste from the cells in all parts of the body. These wastes are then eliminated principally by the Malpighian tubes. In the bee, oxygen is not carried by the blood cells, as it is in the vertebrates.

\section{The respiratory system}

The respiratory system (Fig. 3.9) consists of long, tubular, branched investigation of the ectoderm known as tracheae. The arborescent ending of the tracheae, the tracheoles, come into contact with practically all the body cells. Hence, the exchange of oxygen and $\mathrm{CO}_{2}$ occures without any necessity for blood as a carrying medium.

Air is taken into the body through the spiracles. It soon enters the air sacs, which are thin-walled expansions of the longitudinal tracheae. From the air sacs, transverse tracheae extend dorsally and ventrally. The tracheae is subdivided to form tracheoles which are closely attached to the various organs and which end blindly. In some insects, the ends of the tracheoles are filled with liquid, which is believed to facilitate the exchange of oxygen and $\mathrm{CO}_{2}$.

Bailey (1954) has indicated that gaseous exchange is modified by the activity of the bee. He found that inactive bees inhale and exhale

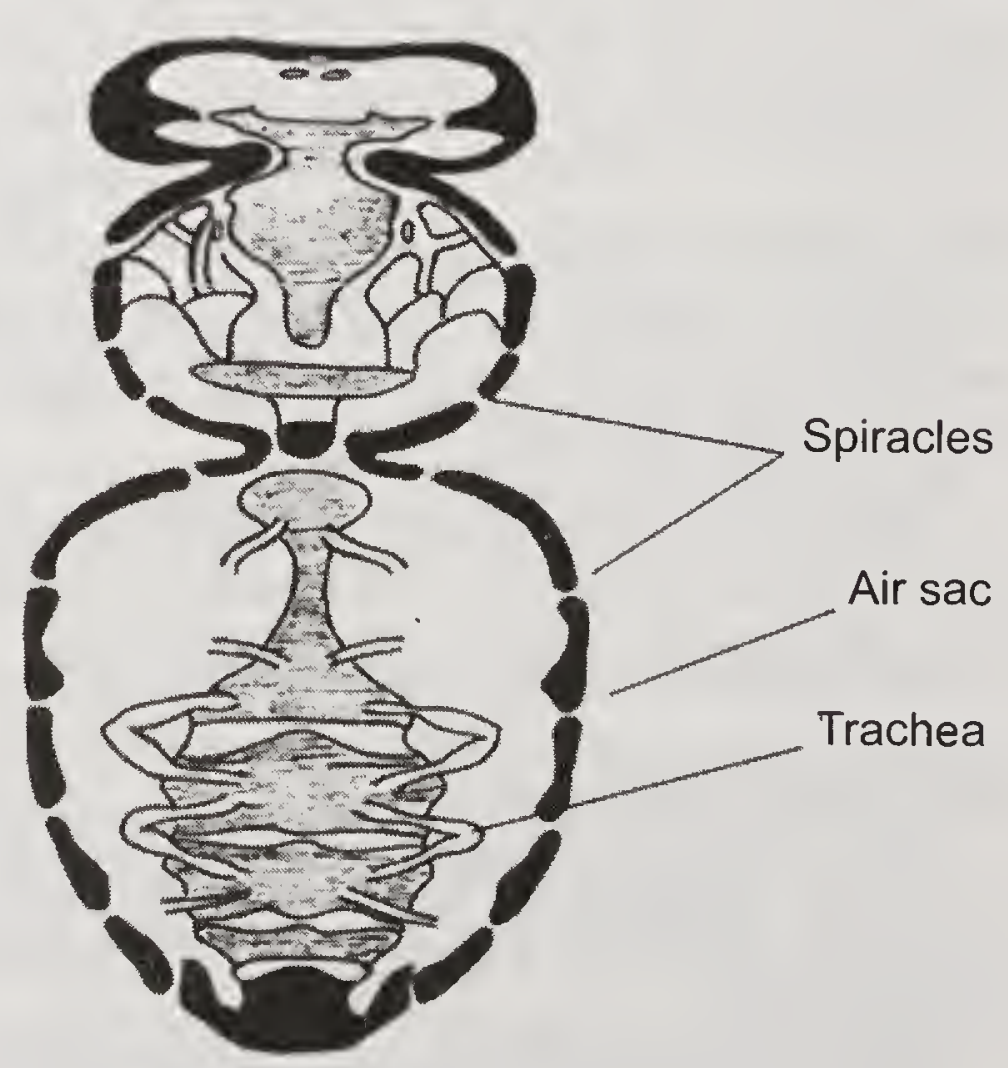

Fig.3.9 Respiratory system of worker bee (Snodgrass, 1956). 
through the first thoracic spiracles, but that active bees producing a high $\mathrm{CO}_{2}$ tension inhale through the prothoracic and abdominal spiracles and exhale through the propodeal ones.

\section{The reproductive system}

The reproductive organs produce sperms or ova from which succeeding generations develop. In many animals, these are comprised of external and internal organs, but in the bee they are practically all internal. Since the structures of the two sexes are markedly different, the discussion of these systems must be considered independently.

\section{The female reproductive organs}

The female reproductive organs are composed of a number of structures. The ovaries in a laying queen are more or less pear-shaped. Each ovary is made up of many tubular ovarioles $(160-180)$ in which the ova develop. At the posterior end of each ovary is an oviduct. The two lateral oviducts fuse to form a single median common oviduct, which merges into the vagina. This in turn leads into the bursa copulatrix, which opens to the exterior near the base of the sting. From the dorsal wall of the vagina, a tubular spermathecal duct leads to the

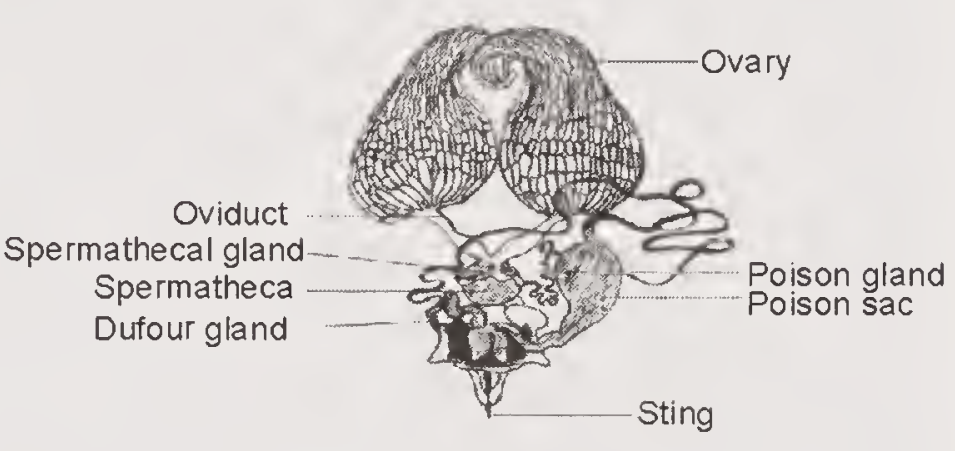

Fig 3.10 Female reproductive system (Snodgrass, 1956). spermatheca, a round organ in which the spermatozoa of the drone are stored at the time of insemination. Paired spermathecal glands branch from the terminal portion of the spermathecal duct (Fig. 3.10).

The ova originate from primary reproductive cells in the tips of the ovarioles. The developing ova pass down to an ovariole. Each ovum is accompanied by nutritive cells, the so-called nurse cells, which serve to nourish them. When the eggs are fully grown, the follicle cells of the ovariole secret a thin shell, the chorion, which protects the egg. The shell covers the egg completely except for a tiny pore, the micropyle, located at the anterior end of the egg. This permits the entrance of the spermatozoa which fertilize the egg. Kapil (1962) in his investigation on anatomy and histology of the female reproductive system of Apis indica F. reported that each ovary of the queen bee consists of 73 polytrophic ovarioles. The ovary of the newly emerged queen bee is small in size and does not show mature stages of the oocyte. The old ovary is found exhausted with nurse cells, showing black granules. The ovary of the worker bee has 1-12 ovarioles. The calyx of the reproductive organs of the worker bee is anteriorly a solid structure with opening lined with an irregular intima. Bordering its epithelium is a circular muscle layer. An irregular egg-laying behaviour of the worker bees has been attributed to the synchronous ovulation of the ovaries. The glandular epithelium of the spermathecal gland contains two types of nuclei-the large and endothelial. Each cell has a duct terminating into the lumen of the gland. The evolutionary trends and affinities between the two domesticated species of Apis have been discussed. Mariselvam 
et al. (2014) in their study on reproductive behaviour of workers and ovary difference in normal workers in egg laying workers of honey bees in Apis cerana recorded that there were physiological and structural differences among the ovaries tissue of the Apis cerana indica normal worker honey bees and egg laying worker honey bees. To determine the influence of queen on the ovary development of the worker bees, the queen was manually removed from a colony and the development of the ovaries of the worker bees in normal and queen removed colonies were examined by histological studies. The worker honey bee ovary was incompletely developed in the queen right colony. In queenless colony, the worker bees have developed functional ovaries and laid unfertilized eggs.

\section{The male reproductive organs}

The male reproductive organs (Fig. 3.11) consist of many complicated structures. The testes are flattened and somewhat kidney shaped. In the testes, there are many tubules, the testicular follicles, in which the male sex cell developed. The follicles open into the vas deferens which leads to a large, tubular, seminal vesicle. The mature spermatozoa are retained temporarily in the vesicle but eventually pass down into the bulb of the penis. Associated with the seminal vesicles are a pair of large mucous glands into which the vesicles empty. From the mucous glands a single tubular ejaculatory duct leads to the bulb of the penis. The penis is composed of a number of structures, including a dorsal fimbriated lobe, a ventral ridged cervix, and a terminal bursa. On the dorsal wall of the bursa there is a pair of dorsal horns. The external opening of the male reproductive system lies below the anus and above the $9^{\text {th }}$ sternite.

In the process of mating, the penis is everted into the vagina of the female and the spermatozoa migrate through the spermathecal duct to the spermatheca. After the union of the sexes, the penis of the male is torn from the body and the bulb of the penis remains temporarily in the genital tract of the queen. The drone dies after the act of mating.

The manner in which the spermatozoa are nourished and kept alive in the spermatheca of the queen for several years is one of the marvels of bee physiology.

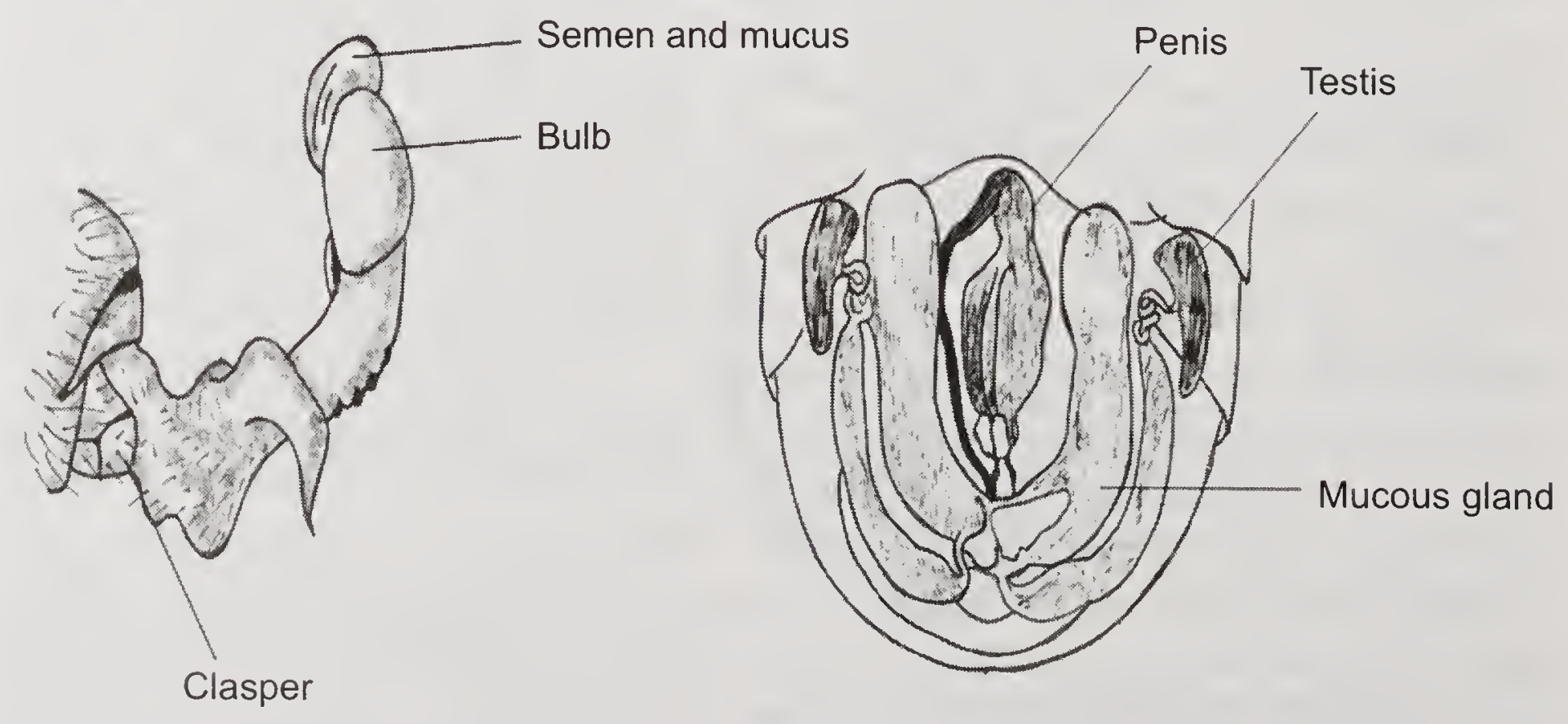

Fig. 3.11 Male reproductive system (Adopted from Winston, 1887). 
The spermatheca is well supplied with trachea which furnishes the cells with oxygen and carries off gases and water vapors. It is also equipped with two spermathecal glands and a pump. These glands and the lumen of the spermatheca and the duct which connects the spermatheca with the common oviduct. The pumps and the glands apparently function in keeping the spermatheca turgid and in controlling the entrance and release of the spermatozoa. If the duct leading from the spermatheca is cut between the pump and the oviduct, the spermatheca will remain hard, but it will collapse if the duct is severed between the pump and the union of the two glands.

The supermatheca holds between 4 to 7 million spermatozoa. These are released in small numbers for the fertilization of the eggs that are to produce worker larvae. How the queen controls their release is not known. A normal mated queen seldom makes the mistake of laying fertilized eggs in a worker cell. It can be proven rather easily that the size of the cell does not determine the type of egg that is laid. If a newly mated queen is supplied only with combs composed entirely of drone cells, she will frequently lay in each cell an egg that will produce a worker bee. Immediately beneath the opening of the spermathecal duct into the vagina of the queen, there is a valve fold in the floor of the vagina which, when raised, would cause the egg to pass immediately in front of this opening. The egg is slightly curved and is laid with the smaller end first. This curvature and the valve fold would bring the micropyle or opening in the egg against the duct opening in the roof of the vagina and would permit the spermatozoa to come into contact with the egg at this point. If the valve fold is not raised, the egg would not be brought into contact with the duct opening. It seems highly probable that the actions of the valve fold and the spermathecal pump are directly correlated with each other by some stimulus that enables the queen to lay a drone or worker egg at will. Laidlaw (1944) and other have demonstrated the necessity of manipulating this valve fold in the successful artificial insemination of the queen. Kapil (1962) studied the anatomy and histology of the male reproductive system of Apis indica $\mathrm{F}$. in India.

\section{Special organs}

The special organs not already discussed include various glands, oenocytes, rectal pads, Johnston's organ, scolopophorous organs and endocrine organs.

Glands: Hypopharyngeal or brood-food glands are located in the head. They consist of a pair of long ducts to which are attached many, 500 or more, sac-like secreting bodies. It is generally accepted that the royal jelly or brood food is secreted by these glands. However, some investigators have suggested that the labial glands may also contribute to the formation of this materials.

Labial or salivary glands exist in two sets, one of which occurs in the head, the "post-cerebral glands" and the second in the thorax. It is commonly believed that the primary function of this organs is the production of enzymes such as diastase, invertase, lipase and a proteinase. More information is needed before we can definitely indicate their exact function. Mandibular glands are located in the head just above the bases of the mandibles. Their function is somewhat obscure. The most common theory is that they emit a substance which modifies the properties 
of wax in preparation for comb building. Another theory is that they may soften the pupal cocoon.

Rectal pads are located on the anterior surface of the rectum. They are 6 in number and extend longitudinally. They were known as rectal glands. Their function is not definitely known but they may serve to maintain the water balance of the bee.

Oenocytes: The oenocytes are large cells which have a densely staining nucleous. They are usually associated with the fat cells. Their exact function is not known. Snodgrass (1956) indicated that there may be a relationship between them and wax secretion. Others have suggested that the cells secret enzymes necessary for the physiology of the bee.

Johnston's organ: This structure is located in the antennal pedicel. Snodgrass indicated that its structure suggest that it registers flagellar movement.

Scolopophorous organs: These are complex structures which occur in the head and legs of the honeybee. At one time, they were considered to be chordotonal in function but recent workers have discounted this view. Snodgrass suggested that they may register the effects of muscles tension on the body wall.

Endocrine organs: In the honeybee, as in most other insects, growth, moulting and other developmental changes are regulated by chemical substances known as hormones. These are produced by various organs which are collectively termed endocrine glands. In addition, such substances are secreted by a group of neurosecretory cells located in the pairs intercerebralis of the brain.

The endocrine glands of the bee include the corpora cardiaca, the corpora allata, and probably the thoracic glands. The latter are found in the preinnago stage and disappear during pupation. They are found in the thoracic region at the sides of the alimentary canal between the first and second ganglia of the ventral nerve cord.

The corpora cardiaca of the adult bee are small organs located above the region where the oesophagus and pharynx join. They are connected to the brain by nerves which extends also to the corpora allata. It is indicated that neurosecretory materials from the corpora cardiaca may ooze into the aorta. The corpora allata are globular and are located against the sides of the oesophagus. They are closely associated with the corpora cardiaca.

There is a lacking in detail knowledge of the function of each of the endocrine glands in the honeybee. In other insects that have been studied, the corpora allata secretes a juvenile hormone which inhibits growth of the immature stages between mouths. However, in adult honey bees the corpora allata are known to change in size depending on the age of the bees and their activity. This has led to the theory that the secretion of the corpora allata regulates the general metabolism of the honeybee. It is believed that the hormone that regulates growth and development is provided from the neurosecretory cells of the brain and possibly from the corpora cardiaca. Some evidences indicated that the secretion of the neuro-secretory cells of the brain may act on the thoracic glands, which ultimately produces the hormone that regulates growth and development.

Nagaraja (2014) conducted an experiment on the olfactory learning and memory recall in the drones of Apis cerana and Apis florea through olfactory conditioning. 
The results showed that, the drones of Apis cerana and Apis florea learn and recall olfactory memory of queen mandibular odorants, the (2E)-9-oxodecenoic acid, (9-ODA), (2E)-10-hydroxydecenoic acid (10-HDA) and (2E)-9hydroxydecenoic acid (9-HDA). Drones of Apis cerana showed greater response towards 9-ODA in contrast to Apis florea drones, towards 10-HDA. However, the drones of both species responded to 9-HDA but, Apis florea drones in greater numbers. Results of the study conclude that, 9-ODA is a major sex pheromone component in Apis cerana in contrast to 10-HDA in Apis florea queens.

\section{REFERENCES}

Autrum, H. and Stumpf, H. 1950. Das bienenaugealsanalysator fur polarisierteslicht. Zeetschrift Naturf. 56: 116-22.

Bailey, L. 1954. The respiratory currents in the tracheal system of the adult honeybee. Journal of Experimental Biology 31: 589-93

Bhandari, V. C. 1983. Biometrical studies on Apis florea $\mathrm{F}$ and Apis cerana $\mathrm{F}$ and Apis dorsata F. of north-western India. Ph.D. Thesis, Himachal Pradesh University, Shimla.

Dade, H. A. 1962. Anatomy and Dissection of the Honeybee. Bee Research Association London.

Das, P. K. and Rahman A. 1999. Biometrical changes during post-embryonic development of Apis cerana Fab. workers in Assam. Indian Bee Journal 61(s1-4): 31-36

Detheir V.G. 1943.The dioptric apparatus of lateral ocelli II. Visual capacities of the ocellus. J. Cell. Comp. Physiol. 22: 115-26.

Ferris, G. F. 1940. The myth of the thoracic sternites of insects. Micro entomology 5: 8790

Frisch, K. V. 1950. Bees, their vision, chemical senses and language. New York, Cornell.

Jacobs, W. 1924. Das Duftorgan von Apis mellifra up diihnliche Hautdriisenorganesozialer und solitarer Apiden. Zeetschriffim Morph. Okol. Tiere 3: 1-80.

Kapil, R. P. 1956. Variation in biometrical characters of Indian honey bee (Apisindica F.) Indian Journal Entomology 18 (4): 440-57.

Kapil, R. P. 1962. Anatomy and histology of the female reproductive system of Apis indica F. (Hymenoptera, Apidae). Insectes Sociaux. 9(2): 145-63

Kapil, R. P. 1962. Anatomy and histology of the male reproductive system of Apis indica Fab. (Hymenoptera, Apidae). Insectes Sociaux. 9(1): 73-90

Kshirsagar, K.K. 1980. Morphometric studies on the Indian hive bee, Apis cerana indica F.l. Morphometric characters useful in identification of intraspecific taxa. Proceedings of Second International Conference of Apiculture in Tropical Climates. New Delhi.254$61 \mathrm{pp}$.

Laidlaw H. H. Jr. 1944. Artificial insemination of the queen bee (Apis mellifera L.). Morphological basis and results. Journal of Morphology 74(3): 429-65

Mariselvam, R., Sridhar H., Uma Maheswar, S. and Ranit singh, A. J. A. 2014. Workers reproductive and ovary difference in normal workers and egg laying worker honey bees in Apis cerana indica (F.) honey bee colony. International Journal of Advance Science \& Technology 4(4): 780-86.

McIndoo, N. E. 1914. The olfactory sense of the honeybee. Journal of Experimental Zoology 16: 265-346.

Michener, C. D. 1944. Comparative external morphology, phylogeny, and a classification of the bees (Hymenoptera.). Bulletin of American Museum of Natural History 82: 151326.

Mutharaman, M., Raju, A.J.S., Vijaykumar, K., Devanesan, S., Abrol. D.P. and Viraktamath, 
S. 2013. Morphometry of rock bee, Apis dorsata F in Monograph on Morphometry and Phylogeography of honeybees and Stingless bees in India. Department of Biotechnology, Government of India, New Delhi. 5-13 pp.

Nagaraja, N. 2014. Olfactory learning and memory in drones of Apis cerana Fab. and Apis florea Fab. towards queen mandibular pheromone odorants. Journal of Entomological Research 38 (3): 165-68.

Narayanan, E.S., Sharma, P.L. and Phadke, K.G. 1960. Studies on biometry of Indian bee, Tongue length, wing hooks, worker brood cell size and thickness of comb of Apis florea $\mathrm{F}$. at Pusa (Bihar). Indian bee Journal 22: 81-88.

Pal, S., Patnaik, H. P. and Satapathy, C.R. 2008. Morphometric diversity in Apis cerana indica F. worker bees of Orissa. Journal of Plant Protection Environment 5(2): 42-51.

Parry, D. A. 1947. The function of the insect ocellus. Journal of experimental Biology 24: 211-19.

Shah, F.A. and Shah, T.A. 1980. Flight range of Apis cerana from Kashmir. Indian Bee Journal 42: 48.

Snodgrass, R .E.1956. Anatomy of the Honey bee: Comstock Publishing Associates, New York.

Snodgrass, R.E. 1956. Anatomy of the Honey Bee. Ithaca, New York: Cornell University Press. XIV: 334.

Viraktamath, S, Abrol, D.P., Vastrad, A.S., Muthuraman, M., Rajankar, B., Devanesan, S. and Raju, A.J.S,. 2013. Morphometry of Indian honey bee, Apis cerana F. in monograph on Morphometry and Phylogeography of Honeybees and Stingless bees in India. Department of Biotechnology, Goverment of India, New Delhi, 26-46 pp.

Viraktamath, S., Rajankar, B., Lazar, K.V., Devanesan, S., Vastrad, A.S., Mathuraman, M., Raju, A.J.S. and Abrol, D.P. 2013. Morphometry of little bee, Apis florea F. in monograph on Morphometry and phylogeography of honeybees and Stingless bees in India (Edt). Department of Biotechnology, Government of India, New Delhi, 14-25 pp.

Winston, M. L. 1887. The Biology of the Honey bee. Harvard University Press, Cambridge, MA., United Kingdom.

Wolf, E. and Zerrahn-Wolf, Gertrude 1935. The effect of light intensity, area and flicker frequency on the visual reactions of the honeybee. Journal of General Physiology 18: $853-63 \mathrm{pp}$. 


\section{4 \\ Developmental Biology}

$\mathrm{B}$ EES undergo complete metamorphosis, and pass through egg, larval, pupal and adult stages. The haplodiploid system of sex determination has had a major influence on the evolution of the Hymenoptera. As in most Hymenoptera, eggs of bees that have been fertilized and develop into females; those that are unfertilized develop into males. Sex is controlled by alleles at one or a few loci; heterozygosity at the sex-determining locus (or loci) produces females. Development without fertilization, i.e., with the haploid number of chromosomes, produces males, since heterozygosity is impossible. Inbreeding results in some diploid eggs that are homozygous at the sex-determining loci; diploid males are thus produced. Such males are ordinarily reproductively useless, for they tend to be short-lived (larval mortality of Apis) and to have few sperm cells; moreover, they may produce triploid offspring that have no reproductive potential. Thus for practical purposes the sex-determining mechanism is haplodiploid. When queen mates, a female stores sperm cells in her spermatheca; she usually receives a lifetime supply. She can then control the sex of each egg by liberating or not liberating sperm cells from the spermatheca as the egg passes through the oviduct. Because of this arrangement, the female (of species whose females are larger than males) is able to place female - producing eggs in large cells with more provisions, male-producing eggs in small cells. In Apis, the males of which are larger than the workers, male-producing cells are larger than worker-producing cells and it is the cell size that stimulates the queen to fertilize or not to fertilize each egg. Moreover, among bees that construct cells in series in burrows, the female can place male-producing eggs in cells near the entrance, from which the resultant adults can escape without disturbing the slower developing females. The number of eggs laid during her lifetime by a female bee varies from eight or fewer for some solitary species to more than a million for queens of some highly social species. Females of solitary bees give care and attention to their few offspring by nest-site selection, nest construction, brood-cell construction and provisioning, and determination of the appropriate sex of the individual offspring. Hence, it is such attention to the well-being of offspring that makes possible the low reproductive potential of many solitary bees. The eggs of nearly all bees are elongate and gently curved, whitish with a soft, membranous chorion ("shell") usually laid on (or rarely, as in Lithurgus, within) the food mass provided for larval consumption. In bees that feed the larvae progressively (Apis Bombus, and most Allodapini), however, the eggs are laid with little or no associated food. Eggs are commonly of moderate size, but are much smaller in highly social bees, 
which lay many eggs per unit time, and in Allodapula (Allodapini), which lays eggs in batches, thus several eggs at about the same time. Eggs are also small in many cleptoparasitic bees that hide their eggs in the brood cells of their hosts, often inserted into the walls of the cells; such eggs are often quite specialized in shape and may have an operculum through which the larva emerges. Mature larvae of many bees spin cocoons usually at the time of larval defecation. Most short tongued bees have lost cocoon spinning behaviour and often are protected by the cell line secreted by the mother bee.

The honeybees are holometabolus insect undergo and complete metamorphosis. All the four stages of development are there viz. egg, larva, pupa and adult. Duration of life cycle of Indian bee, Apis cerana and western bee, Apis mellifera is given in the tables. After nuptial flight, the queen returns to her hive and start laying eggs. The mother queen glues or sticks a short delicate white tubular egg, slightly curved on one side at the bottom of the cell of a comb. From this egg, a tiny white larva hatches out and feeds voraciously on the food supplied by the nurse bees. When fully fed, it weighs several times of its original weight. The cell is capped by the worker bees with waxen cover. The fully fed larva spins a cocoon in the cell and enters a period of rest during which it transforms itself into pupa. The major changes in the structure of the body occur at the cost of the fat stored in the body by the larva. The pupa is similar in appearance to the adult bee, having developed mouth parts, legs, wings and other appendages of the body. The adult bee emerges after cutting cocoon and the waxen capping of the cell. The post embryonic development of Apis cerana was studied by Mishra and Dogra (1983) in Himachal Pradesh, Das and Rahman (1999) in Asom and Apis mellifera was made by Gayan and Rahman (2005) in Asom which is reproduced below Tables 4.1 and 4.2. Haplodiploid system of sex determination is there in honey bees. Eggs that have been fertilized give rise to female and unfertilized or parthenogenicity produces male or drone.

Table 4.1 (a): Lifecycle of different caste of Apis cerana (Das and Rahman, 1999)

\begin{tabular}{lcccc}
\hline Categories caste & \multicolumn{4}{c}{ Duration of stages (days) } \\
\cline { 2 - 5 } & Egg & Larva & Pupa & Total \\
\hline Queen & 3 & 5 & 7 & 15 \\
Worker & 3 & 5 & 10 & 18 \\
Drone & 3 & 7 & 14 & 24 \\
\hline
\end{tabular}

Table 4.1 (b): Life-cycle of Apis cerana worker during different seasons (in days)

\begin{tabular}{lcccc}
\hline Seasons & Egg & Larva & Pupa & Total \\
\hline Spring (March-May) & 3 & 6 & 10 & 19 \\
Summer (June-August) & 3 & 6 & 12 & 19 \\
Autumn (September-November) & 3 & 6 & 10 & 19 \\
Winter (December-February) & 3 & 6 & 12 & 20 \\
\hline
\end{tabular}


Table 4.2 (a): Life-cycle of different castes of Apis mellifera (in days) (Gayan and Rahman, 2005)

\begin{tabular}{lcccc}
\hline Categories caste & \multicolumn{4}{c}{ Duration of stages (days) } \\
\cline { 2 - 5 } & Egg & Larva & Pupa & Total \\
\hline Queen & 3 & 5 & 8 & 16 \\
Worker & 3 & 6 & 12 & \\
\hline
\end{tabular}

Table 4.2 (b): Life-cycle of Apis mellifera workers during different seasons (in days)

\begin{tabular}{lcccc}
\hline Seasons & Egg & Larva & Pupa & Total \\
\hline Spring (March-May) & 3 & 5 & 11 & 19 \\
Summer (June-July) & 3 & 6 & 12 & 21 \\
Autumn (September-November) & 3 & 5 & 11 & 19 \\
Winter (December-February) & 3 & 6 & 11 & 20 \\
\hline
\end{tabular}

\section{The egg}

The egg of the honey bee is white and sub-cylindrical, with one end slightly enlarged. It is about $1.56 \mathrm{~mm}$ long and weighs about $0.1 \mathrm{mg}$. In a normal colony, all the eggs are laid by the queen. Before deposition of the egg, the queen examines the cell of the comb, which must be clean and polished. If the cell appears to be satisfactory, the queen thrusts her abdomen into the cell and deposits an egg, which adheres to the bottom of the cell by its smaller end.

The egg is covered by a thin protective shell, the chorion, which bears the impression of the follicle cells of the ovary. Under the microscope, the egg surface appears to be divided into pentagonal cells. Within the chorion is the vitelline membrane, a thin non-cellular structure which is the true egg wall. Within the vitelline membrane is found the cytoplasm, the nucleus, and the yolk. The nucleus is near the anterior, or larger, end of the egg in a small mass of cytoplasm. The remainder of the cytoplasm forms a network in the yolk and, in addition, a somewhat denser layer, the so called cortical layer, outside the yolk in contact with the vitelline membrane.

\section{Number of eggs laid by a queen}

Egg production in the queen is closely correlated with many environmental factors, among which are the temperature of the hive, the quality and quantity of food fed to the queen, the number of nurse bees present in the colony, the availability of fresh pollen and nectar and the stores of pollen and honey in the hive. The individual egg cells start developing in the trips of the ovarioles and reach the oviduct in two to three days, at which time they are ready to be laid. The number produced will depend on the number of ovarioles in each ovary and the quantity and quality of royal jelly fed to the queen by the nurse bees. A normal queen generally starts laying a few eggs in early spring before fresh nectar or pollen is available and increases the daily number as temperature and food become more favourable, until she may lay from 1,500 to 2,000 eggs a day at the height of 
her egg laying ability. During this period of high rate of egg-laying, it is evident that the queen must consume more than her weight in royal jelly for the weight of the eggs laid sometimes exceeds that of her body.

\section{Deposition of the egg}

The sting of the bee is frequently referred to as a modified ovipositor. Its primary function is that of a weapon, a means of injecting poison into an enemy. The sting of the queen is decurved and the curvature rather closely approximates the curvature of the egg. In the process of laying an egg, the sting of the queen and the sting palpi from a groove, the curvature of the sting forming the upper portion of the groove between the two palpi. The egg passes down this groove, small end first, and is thus held in position momentarily against the bottom of the cell. A glue-like substance has been deposited on the small end of the egg which affixes it to the cell bottom in an upright position. Laying workers usually drop their eggs into the cells, probably because they have difficulty in reaching the bottom of the cells with the abdomen. The fact that the sting of the worker is straight might add to this difficulty in depositing eggs in an upright manner in the bottom of the cell.

\section{General development of the egg}

Since the drone egg develops parthenogentically and hence is somewhat specialized. As the worker egg passes the opening of the duct of the spermatheca before deposition, sperms are discharged from the spermatheca. One or more penetrate the egg through the micropyle. The nucleus has already undergone changes in preparation for union with the sperm. After fertilization, the segmentation nucleus (formed by union of male and female pronuclei) begins to divide. Each of the cells (the so-called cleavage cells) that results from the division of the segmentation nucleus is surrounded by a small amount of cytoplasm. These cleavage cells are seattered through the yolk. Most of them migrate to the periphery of the egg to form a continuous cellular layer, the blastoderm. A few cells remain in the yolk and help to assimilate it.

The blastoderm is at first nearly uniform in thickness. The cells of the lateral and ventral regions of the blastoderm soon elongate. Shortly thereafter two folds appear in the blastoderm on the ventral surface. The mid-ventral region of the blastoderm thus set off sinks into the yolk and is overgrown by the lateral regions. As a result, an apparently two-layered embryo is formed. The lateral and ventral portions of the outer layer form the future ectodermal organs. The dorso-lateral region forms a protective envelope, the serosa. In addition, a few cells in the dorsal region coalesec to form the so-called dorsal organ, whose function is not well understood and which eventually degenerates in the yolk. The portion of the blastoderm, the "mesoderm," that sank into the yolk will give rise to the organs of mesodermal origin. Soon after its formation, the mesoderm divides to form inner and outer layers lateally but remains as a single layer along the midline.

The question of the presence or absence of a true endoderm in insect embryo is somewhat debatable. Johannsen and Butt (1941) consider that in the honey bee different layers that would correspond to endoderm in higher forms develops as 
follows: "The rudiments of the mid-gut epithelium are formed by the inward migration of blastoderm cells, a discoid swelling being thus produced at each of the two ends of the middle plate but outside its limits. These rudiments later are covered by the ectoderm excepting that in the case of the anterior rudiment, a small circular area remains uncovered which later forms the floor of the stomodaeal invagination."

After the division of the blastoderm into ectodermal, mesodermal, and endodermal portions, and the growth of the serosa, segmentation of the embryo is evident. A total of 21 segments can be distinguished. Appendages are evident on the antennal, mandibular, and three thoracic divisions but are lacking on the abdomen.

\section{The larva}

The larva of honey bee varies considerably in colour, shape, and size (Fig. 4.1). When newly emerged, it is $1.6 \mathrm{~mm}$ long, weighs about $0.1 \mathrm{mg}$. It is subcylindrical and legless, the head is not heavily sclerotized, and the appendages of the head are not so evident as they are in many insect larvae. The body appears to be composed of the head plus 13 ring-like divisions of segments. The color of the newly emerged larva is white with a slight yellowish cast. As the larva approaches maturity, it becomes fusiform in shape, the posterior end being larger. The color becomes an ivory white, althoughmany beekeepers describe the larvae as being milky white. The divisions of the body become more apparent with the growth of the larva.

The head of the larva is subconical and is retracted into the prothoracic segment. The head, from the frontal aspect, appears to be divided vertically by a mediam cleft into two subequal lobes. A horizontal cleft divides the head into regions, the upper composing about two-thirds of the head and the lower, one-third.

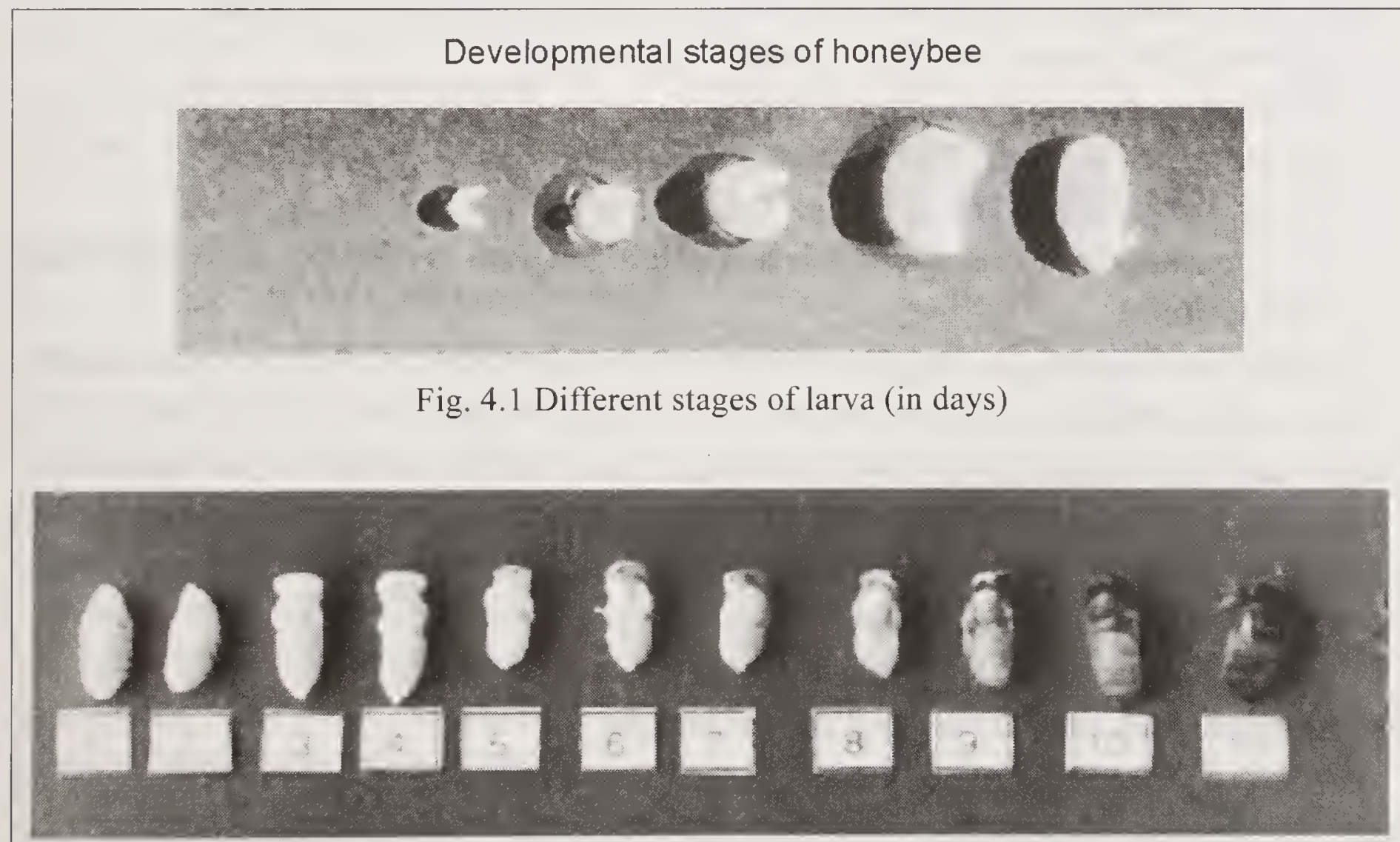

Fig. 4.2 Different stages of pupa (in days)

(Source: AICRP on Honey bees and Pollinators, AAU, Jorhat). 
The upper region bears two disc-like swellings, the antennal rudiments, a median flap-like structure, the combined clypeus and labrum, and the mandibles. The lower third of the head bears the maxillae and the labium. The spine-like structures observed on the maxillae and labium are probably comparable with the palpi on the adult insect. In addition, the labium bears the common opening of the silk glands.

The thoracic segments are subequal in length but not in diameter. In the thoracic regions are located two pairs of spiracles, and on the ventro-lateral margins of segments two and three, indistinct wing rudiments are visible.

The abdominal segments are subequal in size except for the last two, which are reduced. The ultimate division bears a small lobe on which the anal opening is located. Spiracles are present on the first 8 abdominal segments. A deep groove extends from abdominal segments one through eight separating the lateral from the ventral region. Swollen areas, the epipleural lobes, arise from the lateral margins of these same segments. Stabe (1930) concluded that the maximum weight of the worker, $159 \mathrm{mg}$ is attained between 114 and $122 \mathrm{hr}$.

\section{The pupa}

Certain changes begin to appear during the last larval stage, the so-called prepupal stage (Fig. 4.1). After the spinning of its cocoon, the larva becomes quiescent. The head contracts within the larval head capsule and the mouthparts lengthen. The compound eyes and antennae begin their development. The thoracic and abdominal appendages become evident. Growth proceeds rapidly and just before the last larval moult, if the insect is removed from the larval skin it closely resembles an adult.

After the fifth moult, the pupa appears to be fully formed (Fig. 4.2). The significant changes undergone since the larval stage are as following:

1. The head and appendages are well developed.

2. The head is now directed ventrally.

3. The mesothorax has greatly increased in size.

4. The first abdominal segment has fused with the thorax.

5. The remainder of the abdomen is separated from the rest of the body by a deep constriction.

As the pupa matures, changes in pigmentation take place. These are most evident in the compound eye, which become pink, later purple, and finally black. The thorax and abdomen brown and gradually take on the colour of the adult bee. Other changes include the growth of branched hairs and other processes of the integument. The pupal period is from eight to nine days for the worker and drone bees, but only five for the queen.

\section{Development of the larval and pupal stages}

Shortly before the egg hatches, a worker bee deposits a small amount of larval food, royal jelly, in the cell. It is believed that the moisture from the royal jelly is essential to the hatching of the egg. Immediately after hatching, the nurse bees provide such a lavish amount of royal jelly to the larva that it is literally floating in the fluid, as a result of "mass feeding." On the third day, a different food is 
supplied, one containing pollen. Moreover, the method of feeding keeps on changing. No longer do the larvae have an excess of food at all times, but are fed supposedly as they need food. It has been accepted the statement that the type of food determines whether a given larva will develop into a queen or a worker. It has been stated that larvae which will become queens are fed royal jelly throughout the entire feeding period. However, Haydak (1949) is of the opinion that the production of either the queen or the worker is due primarily to the different amounts of essential nutrients consumed by the queen and the worker larvae. He considers that workers are undernourished females. Haydak, in correspondence, modified his opinion of 1949 by adding that not only is the quantity less than but also quality received by worker larvae is inferior to that supplied to queen larvae. Apparently, such qualitative differences can be noted in the decrease of certain vitamins as the worker larvae mature. Weaver (1955) is of the opinion that royal jelly contains a highly labile factor essential for queen differentitation.

With the growth of the larvae, there is an increase in the amount of time spent by the nurse in feeding individual larvae. Lineburg (1924) estimated that each larva requires a total of 10,000 visits during its feeding period. This averages $1,300 /$ day and represents a total expenditure of about 43 $44 \mathrm{hr} /$ larva.

After the feeding period, the larvae are sealed in the cells. They use the remainder of food in their intestines, then spin a thin cocoon and become fully extended in the cell. At this time, they are said to be in prepupalstage. After the final larval moult, the pupal stage is reached. During this period, all the larval tissues are replaced by those of the adult. The nervous system undergoes fusion of some of the ganglia. The eyes and the appendages (mouthparts, antennae, wings,

Table 4.3. Time sequence of instars and moults in the worker honeybee, Apis cerara indica (Mishra and Dogra, 1983)

\begin{tabular}{|c|c|c|c|}
\hline Days & Hours & Instars & Ecdyses \\
\hline \multicolumn{4}{|l|}{1} \\
\hline 2 & & Egg & \\
\hline 3 & 0 & & Hatching \\
\hline 4 & $18-24$ & $1^{\text {st }}$ & $1^{\text {st }}$ \\
\hline 5 & $42-48$ & $2^{\text {nd }}$ & $2^{\text {nd }}$ \\
\hline 6 & $60-66$ & $3^{\text {rd }}$ & $3^{\text {rd }}$ \\
\hline 7 & $84-90$ & $4^{\text {th }}$ & $4^{\text {th }}$ \\
\hline 8 & & Sealing & \\
\hline 9 & & $5^{\text {th }}$ Andpharate pupa & \\
\hline \multicolumn{4}{|l|}{10} \\
\hline 11 & & $5^{\text {th }}$ & \\
\hline 12 & & $\begin{array}{l}\text { Non-pigmented } \\
\text { white eyed pupa }\end{array}$ & \\
\hline 13 & & $\begin{array}{l}\text { Non-pigmented } \\
\text { pink eyed pupa }\end{array}$ & \\
\hline 14 & & $\begin{array}{l}\text { Non-pigmented } \\
\text { violet eyed pupa }\end{array}$ & \\
\hline \multicolumn{4}{|l|}{15} \\
\hline \multirow{2}{*}{\multicolumn{2}{|c|}{16}} & $\begin{array}{l}\text { Pale-yellow } \\
\text { brown eyed pupa }\end{array}$ & \\
\hline & & & \\
\hline \multirow{3}{*}{\multicolumn{2}{|c|}{18}} & $\begin{array}{l}\text { Light-brown } \\
\text { dark-brown eyed pupa }\end{array}$ & \\
\hline & & $6^{\text {th }}$ emerging & \\
\hline & & Imago & \\
\hline
\end{tabular}
legs etc.) develop from budlike rudiments present in the larva. The first abdominal segment becomes fused with the thorax. The color changes from white to brownish and finally to the colors of the adult. This smooth shiny body becomes covered with hairs (Table 4.3). 


\section{Biometrical study in India}

Das and Rahman ( 1999) in their study on the post embryonic development of Apis cerana worker showed a considerable variation in different seasons of the year viz. spring, summer, autumn and winter. Egg hatched in 2.79-3.65 days, larval stage ranged 5.71-6.43 days and pupation completed within 10.10-12.71 days depending upon seasons of the year. Length and width of head capsule were $0.75-0.79 \mathrm{~mm}$ and $0.7-0.73 \mathrm{~mm}$ at $16 \mathrm{~h}$ larval age which increased to 2.44-2.49 and $1.82-1.94 \mathrm{~mm}$ at $112 \mathrm{hr}$, respectively. Trunk length and width were 2.52-2.59 $\mathrm{mm} 1.08-1.14 \mathrm{~mm}$ at $16 \mathrm{hr}$ larval age and they increased to $12.14-12.68 \mathrm{~mm}$ and 5.23-5.47 $\mathrm{mm}$ at $112 \mathrm{~h}$ larval stage respectively. However, the measurement of head size showed variation in different seasons, they were not significantly different. The increase of trunk length and width significantly differed at later stage of growth (i.e $64^{\text {th }}, 88^{\text {th }}$, and $112^{\text {th }} \mathrm{hr}$ ). The growth index was higher in autumn (16.77) followed by spring (16.51) and winter (15.28) and the lowest was in summer (13.06)

Thakur et al. (2000) conducted experiment on production of quality queens of Apis mellifera L. under under mid-hill conditions of Himachal Pradesh, and revealed that queens can be reared efficiently in the months of March-May. These months are the nectar-flow periods and can be designated as breeding period under local condition. The loss of a queen during autum can be made good by rearing new queens in September and October and colonies can be given a new prolific queen in order to face effectively the coming winter season. However, March to May is the best period for breeding and replacement of old queens and multiplication of stock. The insemination of quality-queens produced during April was successful since spermatheca contained 0.29 to 1.13 million sperm/queen. However, lower weight queens were more difficult to inseminate and spermatheca of such queens did not show the presence of sperm.

Chand et al. (2002) conducted an experiment on the biological development of Apis mellifera L. and Apis cerena indica F. during different seasons under Bihar conditions. The experiment revealed that the total developmental periods of workers and drones of $A$. mellifera and $A$.cerana indica varied significantly between breeding (November-January) and dearth (Jully- September) seasons. The developmental periods were $20.002 \pm 0.223$ and $20.964 \pm 0.275$ days for workers and $23.534 \pm 0.342$ and $24.016 \pm 1.374$ days of $A$. mellifera, the total developmental periods of $A$. cerana indica were $19.110 \pm 0.120$ and $19.922 \pm 0.194$ days for workers, $22.690 \pm 0.361$ and $23.614 \pm 0.133$ days for drone during the breeding and dearth seasons, respectively and $15.134 \pm 0.302$ days for queen during the breeding season.

Gupta et al. (2003) studied the pattern of brood comb use in honey bee, Apis mellifera colonies with larvae of different survival rates. The colonies of $A$. mellifera were grouped into three categories viz. high (90-99\%), medium (80$89 \%$ ) and low (70-79\%) brood survival groups. Proportion of brood comb utilized by bees of different survival groups for eggs, larvae, sealed brood, pollen, nectar/ honey as well as empty comb area was determined at 21 day interval during different periods. The results are expressed in terms of per cent area utilized for each category. Honeybees belonging to high brood survival group utilized more comb area for brood as compared to low brood survival group colonies during 
June till beginning of September and later differences were non-significant. Again in October, high brood survival colonies had more proportion of eggs and larvae in the comb as compared to other two groups. However, during spring (February) the colonies of the three groups utilized almost similar proportion of brood comb for brood indicating that during this period colonies of low brood survival group are able to replace cannibalized larvae. There was no specific trend in the proportion of comb used for pollen and honey during different periods of the year by the colonies of three groups. However, in general June and July proportion of brood comb utilized for storing pollen and honey was less in all categories of bees indicative of dearth of bee flora during this period. The percentage of empty cells in the brood area was always high in the colonies of low brood survival group.

Mohapatra et al. (2009) studied the brood rearing trends and cause of absconding in Apis cerana indica F., The brood area in A. cerana indica colonies was found maximum (313.4-3.98.4 $\mathrm{cm}^{2}$ and 331.7-372.5 $\mathrm{cm}^{2}$ ) during April-May and November-December under coastal conditions of Odisha. Maximum pollen store $\left(54.6-73.1 \mathrm{~cm}^{2}\right)$ was also seen during the same time indicating the impact on pollen store on the brood development. Absconding of bee colonies is a common phenomenon during April-May when there is brood area and pollen and honey store is low after the last extraction of honey.

\section{REFERENCES}

Chand, H., Yaquin, E. and Singh R. 2002. Biological development of Apis mellifera L. and Apis cerana indica Fab.during different seasons under north Bihar conditions. Shashpa. 9(2):133-37.

Das, P.K. and Rahman A. 1999. Biometrical changes during post-embryonic development of Apiscerana Fab. workers in Assam. Indian bee Journal 61(1-4):31-36.

Gayan, J. and Rahman, A. 2005. 'Brood rearing and post embryonic development of Apis mellifera L. (Hymenoptera: Apidae)'. M.Sc. (Agri.) Thesis. Assam Agricultural University, Jorhat.

Gupta, J.K., Chaudhary, S., Rana, B.S. and Sharma, H.K. 2003. Pattern of brood comb used in honeybee Apis mellifera colonies with larvae of different survival rates. Asian Bee Journal 5(1-2): 34-38.

Haydak, M.K. 1949. Honey as food. Rep. Iowa St. Apiarist. 1948:42-52

Johannsen,O.A. and Butt, F.H. 1941. Embryology of insects and myriapods. McGrawHill, New York: 1-462pp.

Lineburg, B. 1924. The feeding of honeybee larvae. Bulletin U.S, Department Agriculture 1222: $25-37$.

Mishra R.C. and Dogra G.S. 1983.Post-embryonic development of Apis cerana indica F worker bee. International Conference on Apiculture on Tropical Climate.2: 278-88.

Mohapatra, L.N., Patnaik H.P and Satapathy, C.R. 2009. Studies on the brood rearing trends and cause of absconding in Apis cerana indica F. under costal Orissa condition. Indian Journal of Entomology 70(4):137-40.

Stabe, H.A. 1930. The rate of growth of worker, drone and queen larvae of the honeybee. Journal of Economics of Entomology 23: 447-53.

Thakur R.K., Gupta, J.K. and Dogra, G.S. 2000. Production of quality queens of Apis mellifera L. under mid-hill conditions of Himachal Pradesh for use in instrumental insemination. (In:) Progress of Research and Development, Asian Bees and Beekeping. Oxford \& IBH publishing Co. New Delhi pp. 116-19.

Weaver, N. 1955. Rearing of honeybee larvae on royal jelly in laboratory. Science. 121:50910. 


\section{Bee Behaviour}

$\mathrm{H}$ ONEYBEES are social insects and live in colonies with a highly organized system of division of labour. Honeybee colony is composed of different castes and number of workers in a colony is very large but a colony acts as a single unit. All individuals are highly organized. Each worker bee follows a sequence of activities and this depends upon its age. With the advancement of age, certain changes in structure take place and it is known that behavior and activities depend upon these changes. In other words, a bee behaves and performs the activity which she is capable of doing. Besides physiological development of worker bee, behavior is also believed to be genetically controlled because activities are not the result of learning. Even stimuli like sound, chemicals and mechanical influence bee behaviour.

\section{Colony organization and caste system}

There are three castes: Queen, Worker and Drone (Figs 5.1 and 5.2). In a normal Indian honeybee, Apis cerana colony, there is one queen, 10,000 to 30,000 workers and few hundred drones. In western bee colony, $A$. mellifera the number of workers may range between 30,000 and 50,000.

Queen: The queen is the only perfectly developed female and is the mother of the colony. In the peak of the season, she may lay sufficient eggs in a day, weight of which is almost twice the weight of her body. She mates with the drone in the air only once in her life time which is known as nuptial flight and settles down for egg laying in the hive. The stock of male sperms received during mating is preserved for her life in a pouch-like structure i.e. spermatheca in her body. She draws upon it for a long time (may be two or three years) to regulate the sex of the off-springs. Queen can lay fertilized or unfertilized eggs as is indicated to her by the worker bees. The fertilized eggs give rise to workers and sexual females or potential queens and from unfertilized drones are produced. The differentiation in the queen and workers is not due to the quality as previously believed but to the quantity and nutritive value of the food fed to the larvae. The limitation of food supply from the third day onward to the female that are reared in worker cells results in their differential growth and they become workers instead of queens.

The healthy larvae are selected for the queens and placed in the larger queen cells and have constant access to sufficient quantity of nutritious food. The queen in her round over the combs lays eggs in the worker, queen or drone cells. The eggs are laid generally in concentric circles. As the old queen exhausts in laying fertilized eggs or a colony is in swarming instinct, supersedural or emergency 
impulse, new queens are reared specially prepared queen cells. On emergence, the new queen roams over the comb, feed herself on honey and takes one or more orientation flight out of the hive within week.

On her nuptial flight, she is followed by drone and has multiple mating in one or more times. Her mate dies during the act of copulation and she returns to the hive and starts laying eggs in the cells of the combs. She lays egg slowly and increases the capacity of egg laying depending upon the amount and kind of food she receives from the workers. The queen however lacks the motherly instinct and the function of nursing the young one is performed by the worker bees. An Apis mellifera queen lays in

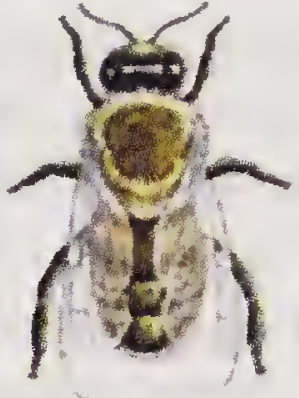

Drone

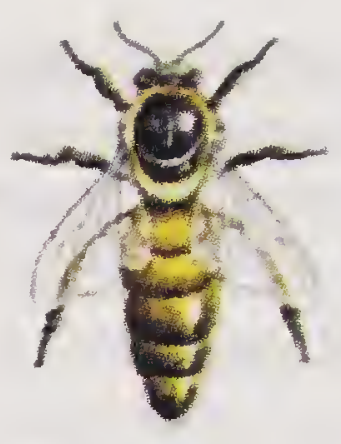

Queen

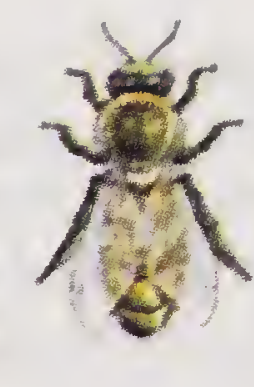

Worker

Fig. 5.1. Different caste of honeybee

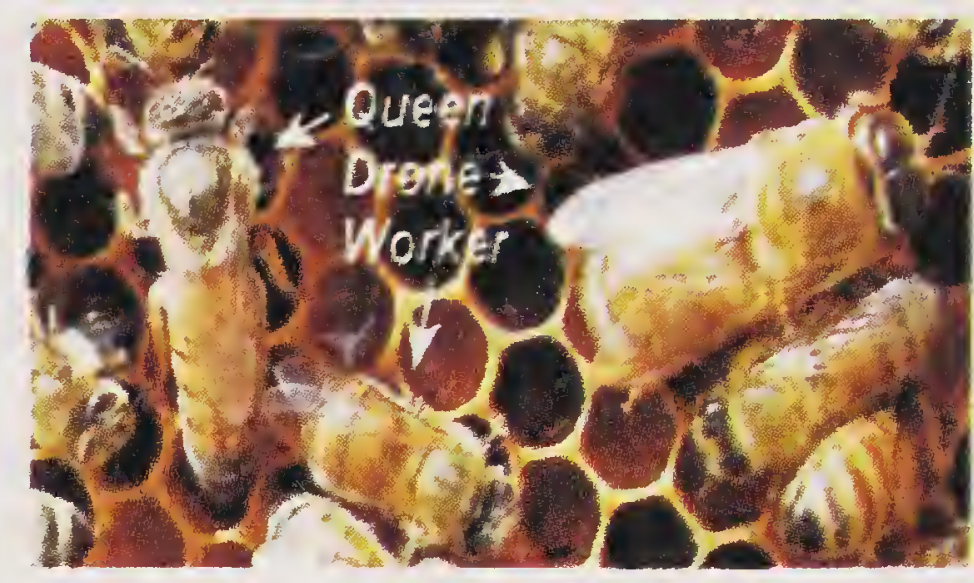

Fig. 5.2 Different caste of honeybee in comb between 1,500 and 1,800 eggs/day during active brood rearing season whereas Apis cerana queen lays 500 to 800 eggs/day. Egg laying rate diminishes with the advances in age.

Worker: The worker bees are imperfectly developed females unable to reproduce but posses all the maternal instinct. Workers are considered to be driving force of a colony and are responsible for all the work necessary for the maintenance and welfare of the colony. Division of labour among the workers is on a physiological basis. Each worker has to perform different types of work in her life time and becomes fitted for various duties in succession as her age advances. During the $1^{\text {st }}$ half of her life, she becomes nurse bee attending such indoor duties as secretion of royal jelly, feeding the brood, feeding the queen, secreting bees wax, building combs, cleaning and fanning and after that she becomes guard bee guarding the hive. In the second half of her life lasting for three weeks, she becomes searcher and gatherer bees searching and locating the source and collecting pollen, nectar, propolis and water. A worker bee's life span is about six weeks during active brood rearing season but live longer when foraging and brood rearing activity is low .

Drone: The only function of the male bee is to mate with queen. Drone has short proboscis but does not collect pollen and nectar from flowers. The proboscis is used to receive food from worker bees. Drone has no wax and scent glands. Generally, it takes 3-6 workers bees to feed a drone. Drones are reared in the active breeding season i.e. in spring when it serves the purpose of mating the new queen. They are driven out of the hive to die of starvation when not needed. The annual life span of an Indian species drone is almost two months.

Larval activities: The first visible evidence of the activities of the larval bee is the brushing of the shell of the egg. Most authorities agree that before it hatches the egg must be moistened. It is believed that royal jelly is the source of this 
moisture. After hatching, the larva assumes a semicircular shape, having the ventral surface as its inner circumference. As the larva grows, it assumes the form of the letter $\mathrm{C}$, reaching this stage at about three days of age. By the end of the fourth day, the end of the larva overlap, with the anterior always above the posterior. At the time that the larva is being sealed in its cells, it appears distorted, the body being flattened and some what telescoped. Soon after the cell is capped, the larva begins to straighten out on the floor of the cell. In order to carry out this process, heavy folds and ridges of the body are used somewhat as legs. Lineburg describes this movement by stating that the larva turns its head toward the cell cap and assumes the shapes of a short spiral coil. Before pupation, the larva spins a thin silk cocoon, accomplishing this in about $24 \mathrm{hr}$. In doing so, the larva has to move from end to end in its cell about 150 times during the spinning process. When the process is completed, the larva stretches out with the dorsal portion on the floor of the cell, the head toward the cap and the posterior portion of the body curled upward in the bottom of the cell.

A final point to consider is the elimination of body wastes. During its feeding stages, the larval bee cannot deposit wastes in the cell since there is no connection between the mid-and the hind-intestine. Bertholf (1925) state that the cast skin that results from the last larval moult is pushed back to the base of the cell, where it is mixed with the yellow feaces given off by the larva during or just after the spinning of the cocoon. Dobrovsky (1951) studied the sequence of events in the depositions of body wastes. According to hive, the larval malpighian tubes are emptied shortly before the larval midgut contents are evacuated.

Nursing: When the bee is 4 to 6 days old, it begins to function as a nurse (Fig. $5.3 \mathrm{a}$ ). At first it feeds the older larvae, a mixture of pollen and honey. It is believed that the pollen stimulates the functioning of the pharyngeal glands which supply royal jelly. At any rate, after two or three days, the nurse bee begins to feed the young larvae, by mass feeding, and continues this work until she is 10 to 13 days old. The amount of work involved in the feeding of larval bees is tremendous. Nelson, Sturtevant and Lineburg recorded that 10,000 visits are required for each developing larva until the cell is sealed. Besides, the time spent in the actual feeding, the bees must secure and elaborate the food and transport it to the cells.

At the age of 7 days, the bee begins orientation flights, the so called 'play flights'. Thorley (1944) observed such activities, noted that the young bee hovered near the hive, facing it, and gradually extended its range of flights are taken until the bee is familiar with the area within the radious of about $3.5 \mathrm{~km}$ at the time she begins her field duties

Toward the end of the nursing period the wax glands, located ventrally in the last four nursing visible segments of the abdomen, begin to develop. At about the same time, the house bees receive nectar from the field bees and store pollen in the cells.

A nectar carrying bee delivers her load to one or several bees on her return to the hive. These usually then manipulate the nectar between the mandibles and the partly extended proboscis, allowing the nectar to be exposed to the air. The process may continue for $20 \mathrm{~min}$. It is believed that during this manipulation enzymes are added to the nectar. The bee then enters a cell and deposits the nectar, or it may 
hold it in its honey stomach if sufficient cells for storage are available. After it has lost part of its moisture through evaporation, the nectar is then removed to storage cells. The pollen is packed in cells by the bees, which use their mandibles for this purpose.

Comb building: When the scales are developed, the worker bee builds comb. This is usually at the age of 12 to 18 days, and the bees secreting wax cling together in curtains in the area in which combs are to be built. The temperature at which wax secretion is carried on varies from $35^{\circ}-36^{\circ} \mathrm{C}$ and is the highest in the hive. The wax scales are removed by the spines on the basitarsus of the hind leg, pass forward to the mouth, and are chewed. In the process, apparently some substances are added, possibly from mandibular glands, and the wax becomes soft and easily molded. The bee applies the wax to the frame or to partially built comb and molds it in shape with her mandibles. The comb is usually built from the top downward. Often the bees begins comb building in more than one place in a frame. This is particularly noticeable when bees are allowed to build combs in frames lacking foundation. Such combs when completed exhibit many transition cells and are often irregular in shape.

Most combs are about $2.5 \mathrm{~cm}$ thick. They are made up of two principal types of cells, the worker cells averaging about five per linear inch, and the drone cells slightly over four per linear inch. In addition, transition cells are constructed where the two types of cells join or in damaged combs, the cells are not built horizontally but slope slightly upward. The opening of the normal worker or drone cell is hexagonal in outline. There has been much conjecture of the mathematical ability of the bee to determine the correct proportions of the cells, but we have no real information on why the honey bee constructs a hexagonal cell.

During the same period (12-18 days), the bee may carry on a variety of work in addition to her duties as a comb builder. Among these are cleaning and ventilating the hive. At the age of 18 to 20 days, the young bee serves as a guard.

Guarding and defense: Bees of 18 days old become guard (Fig 5.3 b). Number of guard bees varies from season to season and the number is low during honey flow season but high during dearth period. Robber bees, on approaching a colony, exhibit a characteristic behaviour. They hover in front of the hive and appear hesitant to enter. When they alight, they are seized by guard bees. The robber always attempts to escape, but if unable to do so, she grasps the guard and attempts to sting her. Often several guards attack an individual robber. A drifting bee not carrying pollen or nectar adopts a submissive attitude toward the guards. She does not attempt to run away and is not aggressive. The bee may offer food to the

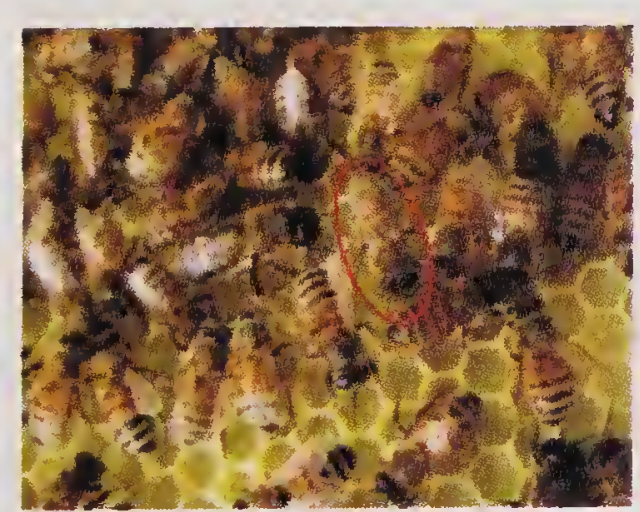

Fig. 5.3. (a) Nurse bee

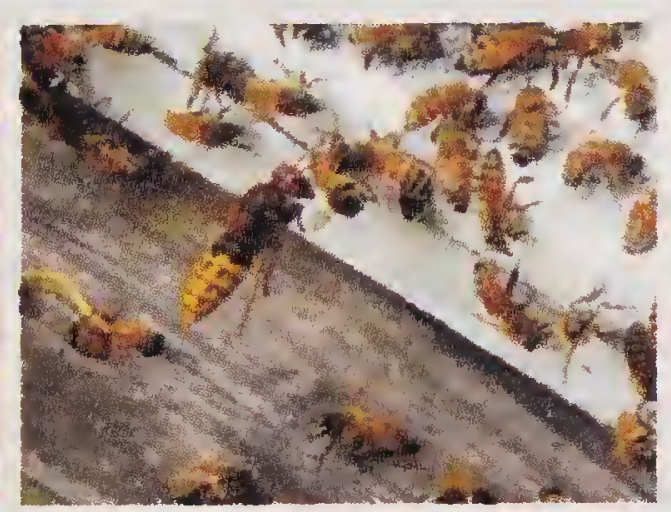

(b) Guard bee

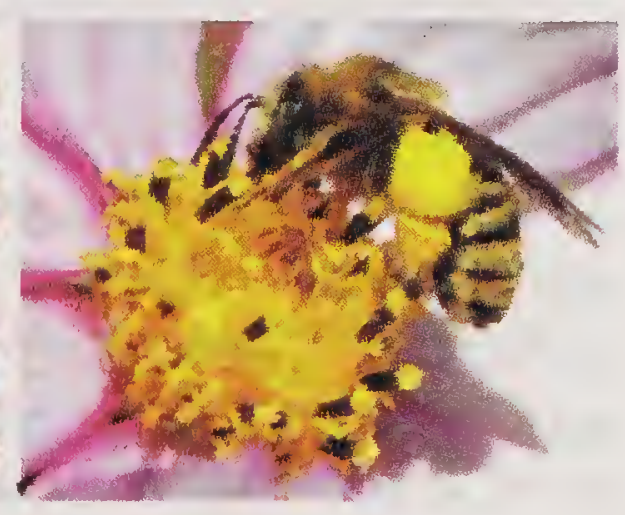

(c) Gatherer bee 
guards, but this is usually refused and the intruder may extend her tongue and strop it with her front legs. Eventually the submissive bee is mauled and driven away. Sometimes such a bee becomes entirely passive and is carried around by guards. When she is released she may proceed toward the entrance again. While it has been generally accepted that guard bees are in the 18-20 day age-group, recent work indicates that guards may be recruited from almost any age. They intercept and examine all bees entering the hive. The guard assumes a characteristic attitude near any hive opening. She raises her front legs and is obviously on the alert. She may approach to invader with open mandibles, seize her and attempt to sting. In addition, the guards attack and sting other forms of life which attempt to molest the hive. It is to disorganize the guards that the beekeeper employs smoke. The behaviour of colonies that have been alerted by robber bees or other intruders differs. Some remains alert for a few minutes, other for several days.

Swarming instinct: The first sign of swarming is the increase in drones. Next, queen cells are constructed. According to Haydak and Vivinoa (1950), the queen cells are made because of a discrepancy between the egg-laying activity of the queen and the amount of larval food produced. Apparently, there are more nurse bees than needed for the care of the brood. Butler (1945) advanced the theory that a "queen substance" secreted by the queen may function in the preparation for swarming. The activity of the field bees diminishes and they often form a cluster about the hive entrance. Swarming commonly occurs during the mid-part of the day. Under normal conditions, the first swarm, the so called 'prime swarm' issue about the time the queen cells are sealed. It is composed of the queen of the parent colony, some drones, and many thousand young or middle-aged worker bees. The bees pour from the hive and literally appear to fill the air. The whirling swarm may drift about over the apiary for some time or it may settle almost immediately on a branch or building in fact on almost anything. As the cluster forms, it can be noted that many of the bees expose their dorsal scent glands and fan their wings, thus undoubtedly assisting the circling bees to locate the cluster. Much has been written concerning the role of the queen in swarming. Some have claimed that she leads the bees. That this is not always the case can be shown by the issuing of a swarm colony that has a clipped queen. It is evident that such swarms can detect the absence of the queen, since they usually return to the hive. The swarm may remain where it clusters for $15 \mathrm{~min}$. to an hour or more or it may actually build combs and remain there during the warm season. Lindauer (1957) observed dancing bees on the surface of swarms and believes that the locations of the new homes is communicated the same way as are food sources.

When the swarm reaches its new home, some of the bees which face the entrance expose the dorsal scent gland and fan their wings. Others soon face in the same direction and exhibit the same behavior. Soon the entire mass moves into the hive. Some of the bees clean the interior others secrete wax and build comb. In a comparatively short time normal functions of a colony are resumed. They all 'forget' their former location.

If the parent colony sends out more than one swarm, the later ones are referred to as "after-swarms". The behaviour of after swarms is rather unpredictable. Sometimes such swarms may cluster without a queen. At other times, several 
after-swarms may cluster together. Under such conditions two or more virgin queens may be present. In some cases, small swarms may accompany a virgin queen when she takes the mating flight.

\section{Activities of the field bees}

The three-to-four week worker bee becomes field bee by taking field activities. As previously noted, the workers begin orientation flights at an age of about one week but only under abnormal conditions will she begin to collect provisions or other materials at such an early age.

As a field bee, the individual worker is probably directed to sources of pollen, nectar, propolis or water by other field bees. We have insufficient evidence on whether or not any definite sequence of gathering these materials is followed. Some authors have speculated that water is first collected, others state that pollen is the substance first sought whereas, Butler (1945), anaesthetized pollen collectors with $\mathrm{CO}_{2}$. After this treatment most of the bees gave up pollen collecting and gathered nectar instead. Similar results were obtained when nitrogen was used as anaesthetic, but treatment with chloroform did not result in such a change in behaviour. It would seem that availability of pollen or nectar, the colony needs and probably other factors, all may determine what the bee collects first.

According to Bonnier (1906), the field bees are divided into two groups, searcher and gatherer (Fig. 5.3c). The searcher goes out first and locates a good source of nectar or pollen. She then returns to the hive with her provisions. Other bees from the same hive soon visit the same source and collect pollen or nectar. Once the searcher has found a good source of nectar or pollen, she abandons her duty as a scout and becomes a collector. Bonnier concluded that, the number of bees visiting any particular source of food depends on the abundance of the flowers. From his observations, Bonnier stated, "they (the bees) thus accomplish, on the whole, the collection of the most in the least possible time of the substances necessary."

According to scientists, a scout bee discovers a source of supply. If the source is suitable, she collects a load and returns to the hive. By a series of characteristic dances, she indicates the source of supply in relation to the location of the hive and the position of the sun. The exact method of communication will be discussed later in this chapter "communication in bees.

The species of plant to be visited is probably indicated by odor. Nectar, pollen or possibly flower odour might function in this way. Some observers have indicated that collecting bees may have scent favourable flower sources. It is known that bees can distinguish colors, but we have no evidence that a searcher can designate the color of a plant to another bee.

Observations by Vansell (1947) indicated that bees concentrate their activities in the near vicinity of their hives for the first few days in a new location and then gradually extend their activities for $3 \mathrm{~km}$ or more a field. Some have assumed that the young bees work nearer their hives on their first trips as fielders and gradually extend their operations. Concrete data are lacking with which to prove this. 


\section{Foraging behaviour}

Plant-pollinator interaction is known since the angiosperms evolved. Coevolution is a natural phenomenon in which both plants and pollinators survive. Bees are good pollinators of many of our crops. Honeybees show a great degree of affinity towards flower as they get both pollen and nectar reward and other way helping in crop production. Bees restrict their foraging to small areas and they make it possible with the help of landmarks. The foraging area is determined by the intensity of flora and amount of nectar and pollen source. Bees have to increase the foraging area if there is stiff competition from the same species or different species. The foraging range for Apis cerana bee extended from 0.8 to 1 $\mathrm{km}$ and 2-3 km for Apis mellifera depending upon the intensity of flora. The foraging speed depends upon both biotic and abiotic factors such as nectar and pollen content, floral phenology, climatic conditions and competition. The factors controlling the activities of honeybees have been a source of speculation from the early days of beekeeping. Aristotle observed many of the different functions of the worker bees and interpreted some of them correctly. He noted a division of labour, starting that "they differentiate their work, some make wax, some make honey, some make bee bread, some shape and mould the comb, some bring water to the cells and mingle it with the honey, some engage in out-of-door work. He also noted that the bee, if well fed, begins its labour when only three days old. Subsequent observers have advanced many explanations of the forces that govern bee behaviour (Butler, 1945).

The explanation of the activities and behaviour of bees is not simple. The organization and interpretation of the available data are most difficult. In addition, we are really beginning our investigations of the subjects; hence there are many gaps in our store of information. The subject has been presented in many ways. Some authors have tried to correlate the relationship of environmental factors and bee behaviour. Other have considered the subject from the standpoint of the work done by the bee. Still others have treated the subject as a study of the individual, emphasizing the relationship of the age of the bee and the functions they perform. All these various methods have good and weak points. The interpretation of bee behaviour on the basis of the physiological condition of the bee is probably as sound as any. However, recent work indicates that the individual bee is capable of doing a rather wide variety of the work regardless of her age.

Floral fidelity: Floral fidelity of bees evokes much speculation as fidelity of individual bee varies according to food source. Bonnier (1906) concluded that once a bee began to collect pollen, nectar, propolis or water she could not readily be included to shift her activities. When honey was offered to pollen-collecting bees they refused to eat it. Many other investigators have substantiated the fidelity to occupation of bees. Some note that bees, collecting pollen or nectar from a plant which furnishes these materials only part of the day, will return to the hive when the food supply is exhausted. Such bees remain quietly within the hive and do not respond to the dances of other bees which may have found other good suppliers. Vansell (1942) indicated that there is a shifting of bees from one plant to another in search of rich nectar. He records that in the forenoon bees collected nectar from mustard, but as this supply became reduced later in the day, the bees 
shifted to orange blossoms. A similar observation was noted with reference to the collection of nectar from plum and manzanita. In this case, the bees almost deserted plum for manzanita by $10 \mathrm{AM}$ but returned to plum in mid-afternoon. It was not determined if the same bees worked both sources but it was assumed that they did. Singh (1950) stated, "The observed variability in numbers of individual bees on various species of plants during several parts of a day is then to be interpreted as due to the visits of entirely different individuals and not as an indication that individual bees shift from species to species during the same day. When the material that the individual bee has collecting ceases to be available at the accustomed place of collection she simply remains in the hive. He added, however, that individual bees may shift to another crop if the source of supply failed or if the hive was moved.

The bevaviour of the bee in collecting is of importance both on an economic and an academic basis. From the standpoint of the value of the bee in pollination, we should know what area will be worked by a bee. There has been much controversy on this matter. At present, the best data indicate that an individual bee may cover a relatively small area. Minderhoud (1931) reported that if a bee collected from a species with abundant blossoms her area of collection might not 10 meters square. They moved to other plants only if the branches interlaced or when the blossoms faded. In a later article, he indicated that the number of blossoms determined the area visited by the individual bee. Singh (1950) recorded that a bee working goldenrod concentrated her visits to an area $5.1 \mathrm{~m} \times 3 \mathrm{~m}$ for eight days. On dandelion, a bee worked over an area $9 \mathrm{~m} \times 5.1 \mathrm{~m}$ as long as abundant blooms were present. When the number of blossoms diminished, the bee increased her field of operations to $18.3 \times 7.5 \mathrm{~m}$. In studies of the behavior of bees on apple blossoms, Singh stated that some bees may be localized to one tree, others to borders of two trees. The later, together with the searcher bees are of chief benefit in effecting cross pollination. He concludes, "Thus the gathering bees, though given to resorting their field work to small areas, adapted themselves to the fluctuating conditions available in the field during part of a day or over several days. Their area of localization (over a number of days) is fairly elastic."

The relationship of distance flown to increase in colony weight is somewhat controversial. Eckert (1933) found that colonies at distances of 0.5 to 2.0 miles from nectar sources made greater gains than did those located within the area where the plants were grown. Beyond a distance of three miles decreases in weight were roughly proportional to increases in distance. Sturtevant and Farrar (1935) found that colonies within a nectar source averaged about 208 pounds, whereas those located 1.5 miles away averaged 153 pounds.

\section{Number of trips per day}

Environmental factors including temperature, moisture, wind, sunlight, source of pollen and nectar, distance and probably other factors, all limit the number of trips completed by bees. As regards to nectar gatherer, there are reports for 4 to 110 trips/day, Phillips concluded that 5 or 6 trips/day were reasonable, basing this on the relationship of increase of weight of the nectar to colony population. He believed that the higher figures reported to be represented an abnormal situation, 
such as robbing, Lundie (1925) concluded that bees would have average 15 trips per day. Park (1929) determined that under conditions favorable for flight, $41 \%$ of the field bees made 10 to 15 trips for nectar. Under unfavorable conditions only $8 \%$ of the field bees made 10 to 15 trips. Our information on the numbers of trips made by pollen collector is somewhat fragmentary. Park (1929) as a result of studies made of the collection of corn pollen by bees, states that bees averaged from 5 to 8 trips/day. Many other authors have stated that bees will collect a load of pollen in from 15 to 30 minutes. Since some plants furnish pollen only in the early morning, whereas others yield more or less pollen all day, the availability and sources of pollen should be considered in forming opinions of the number of trips made. The activities of bees in collecting water have received little attention in comparison with the study made of nectar gather. Park concludes that if a water supply is close at hand, a bee can collect a load and return to the hive in 5 minutes. He believes that the average number of trips per day will be about 50 with a maximum of about 100 . We have no authentic information on the time necessary for bees to collect propolis. There is record that propolis was most freely collected from 7 or $8 \mathrm{AM}$ until noon and that it required about 30 minutes for the house bees to remove the propolis from a field bee on her return to the hive.

\section{The speed of flight}

Park found a maximum speed of $40 \mathrm{~km} / \mathrm{hr}$ for both outgoing and incoming bees, but that they made little progress when flying into a wind having a velocity of $23 \mathrm{~km} / \mathrm{hr}$. Other observers are in substantial agreement with these findings. When the velocity of the wind is over $14 \mathrm{~km} / \mathrm{hr}$, bees fly closer to the ground and frequently take advantage of natural windbreaks in their line of flight.

\section{Behavior of bees in collecting}

Water: Bees use water to dilute honey for feeding the larvae, to reduce hive temperature under extreme heat and in their own diet. It has been noted that bees collect the greatest amount of water during the absence of a nectar flow. According to Butler (1949), bees have a water perception since, it is suggested that they detect the presence of water through the gradient of water vapor in the atmosphere surrounding such a source. Park (1943) described the behaviour of the water collecting bees. They may obtain this liquid from moist earth or from streams, ponds or other bodies of water. If a good source is visited, the bee can obtain a full load in 1 to 2 minutes. Then she returns to the hive and performs a dance. The bees which are attracted by her behaviour are given a sip of water and eventually she disposes of her load, sometimes 2 or 3 house bees and at other time to many bees. Park has also recorded the storage of water in "reservoir-bees" and suggests that such bees may provide water during weather unfavourable to flight.

Propolis: The investigation revealed that the bee tears a bit of the resinous exudates from its source. Because of its sticky nature, the propolis forms a thread, which is placed in the pollen basket by means of the claws of the second pair of legs. The propolis is next manipulated by the middle legs until it is moulded to fit the contours of the pollen basket. The process is then repeated until the pollen 
basket is loaded. On the return to the hive, the propolis gather usually goes to the part of the hive where propolis is being used and is divested of her load by house bees. Sometimes this is done inside the hive at other times on the alighting board. The house bees remove the propolis, carry it to where it is to be used and mould it, using the mandibles for these purpose. It is logical to believe that some secretion is added at this time, since the propolis becomes more fluid.

Pollen: Parker (1926) studied the pollen collection behaviour by honey bee and the following structures are used in the collection and manipulation of pollen.

Hairs: Both the branched and simple types, the former being the more important

Mouth parts: The mandibles scrape pollen from the anthers. In addition, considerable pollen adheres to the maxillae and labium.

Legs: Each leg has special structures for the manipulation of pollen. The basitarsus of each leg is thickly covered with hairs and is used a brush to remove pollen from the body. The fore leg bears the antenna cleaner. The hind tibia is modified to carry pollen on its outer surface. On its apex is a comb like structure, the pectin, which serves to remove pollen from the pollen combs of the basitarsus of the opposite leg. The basitarsus of the hind leg bears about 12 transverse rows of stiff spines, the pollen combs. Its proximal outer surface is lobe-like and functions in the loading of pollen in the pollen basket.

In collecting pollen, the behaviour of the bee differs with the type of blossom. With different flowers, such as the staminate flower of corn, the bee alights on the flower spike and crawls along it. It bites and licks the anthers, thus collecting pollen and moistens this with fluid which may be nectar or honey. A considerable amount of pollen falls from the anthers and is collected by the branched hairs. With larger, open flowers or flower-heads such as those found in dandelion and other composites, the bee may practically bury herself in her efforts to secure pollen. With flowers of the closed type, as those of white clover, Parker states that the bee alights on the wings of the flower and separates the keel from the wings with its fore legs. The anthers are thus exposed and the bee collects pollen on its mouthparts and forelegs. Pollen also adheres to the hairs on the ventral portion of the bee's body.

The number of flowers visited in order to collect a pollen load varies with the flower and the availability of the pollen. Scientist states that a pollen collector on the average will visit 72 apple blossoms per trip. Dunham (1939) states that a bee must visit about 346 individual red clover florets in order to secure a load of pollen.

Casteel (1912) described the role of the legs in collecting pollen as follows:

(a) The first pair of legs remove scattered pollen from the head and region of the neck and the pollen that has been moistened by fluids from the mouth.

(b) The second pair of legs, remove scattered pollen from the thorax more particularly from the ventral region and they receive the pollen that has been collected by the first pair of legs.

(c) The third pair of legs collect a little of the scattered pollen from the abdomen and they receive the pollen collected by the second pair. Nearly all of this pollen is collected by the pollen combs of the hind legs and is transferred from the combs to the pollen baskets or corbicul. 
The loading of the pollen baskets is somewhat complicated. During this process, the bee is either on the wing or may clasp the flower with one or both of her forelegs thus allowing the middle and hind legs to function in pollen loading. The pollen from the pollen combs of the hind leg is removed by drawing the basitarsus over the pectin of the opposite leg. The pollen is then forced up into the pollen basket by the movement of the auricle. Since at least a portion of the pollen is moistened with nectar, honey or other fluid from the mouth, it adheres to the concave surface of the pollen basket. As more pollen is accumulated, it is in turn scraped off on the pectin and forced into the pollen basket. The middle legs may add a little pollen during their molding of the pollen mass. On her return to the hive, the pollen collector may perform a dance indicating a sources of pollen to other bees, or may seek out an empty cell or one partly field with pollen, generally adjacent to brood. After looking into the cell, she walk across it, until she can extend her hind legs into it. She then alternately crosses her hind legs, rubbing the inner surface of the basitarsus of one against the outer surface of the pollen pellet on the other until the pollen pellets are dislodged. She then straightens up somewhat and with the brushes on the basitarsus of the middle legs brushes any remaining pollen from the pollen basket into the cell and then walk away.

Nectar: As in pollen collection, the behaviour of the nectar gatherer is modified by the type of blossom she is visiting. If the flower is of the open type found in apple, plum and other deciduous fruits, the bee may alight on a petal of the reproductive elements of the flower. She may thrust her proboscis into the blossom from its side or from its top. Often a bee will be seen to extend her proboscis into two or three blossoms before settling down to suck up the nectar or simply hover over them without alighting. With small flowers, such as found in blueberry, barberry and certain mints, the bee alights on whatever part of the plant is most convenient. Then she extends her proboscis searching the flower for nectar. According to Park (1949), a bee can detect probably through odor, flowers that have been worked recently and commonly does not try to collect nectar from such blossoms.

It has been estimated that, depending on the nectar availability, a bee may visit from 50 to 1,000 blossoms to secure a load of nectar. A few blossoms as tulip tree or citrus yield more than a load of nectar. Park states that a bee will return an average net load of $30 \mathrm{mg}$. of nectar per trip.

\section{Pollen load}

Ribbands (1953) summarized several reports of observations made to determine the weight of various loads carried by bees. Park observed the weights to vary with the species of plant from which the pollen is gathered, as well as the temperature, as he found loads of elm pollen weighted $11 \mathrm{mg}$. maize pollen 14 mg., apple pollen $25 \mathrm{mg}$. and hard maple pollen $29 \mathrm{mg}$. Parker (1926) added the weights of pollen from other sources such as $9 \mathrm{mg}$ from ragweed and $15 \mathrm{mg}$ for the average weight of 233 loads from seven species. Maurizio (1953) found the mean weights of loads from 35 different species of plants varied from $8.4 \mathrm{mg}$ to $22 \mathrm{mg}$ and reported that while bees could carry 111 to $120 \%$ of their own weight of honey or 70 to $85 \%$ of their weight in watery nectar. Yet an average weight of 
$30 \mathrm{mg}$ was good and $50 \mathrm{mg}$ was exceptional. The average weight of a bee is approximately $80 \mathrm{mg}$. Parker reported average loads of nectar to be $40 \mathrm{mg}$. with a maximum of $70 \mathrm{mg}$. Chaudhhary et al. (2000) in their investigation on foraging speed and rate of honey bees on litchi flowers revealed that the foraging speed (time spent in second/panicle) was observed to be 2.71, 3.40,5.06 and 1.70 seconds by Apis cerana indica, A. mellifera, A. dorsata and A. florea respectively but lesser speed was recorded in early morning and again in the evening. Foraging rate (No. of flowers visited/minute) on an average was recorded to be 19.25 , $18.80,16.53$ and 21.45 flower/minute by $A$. cerana indica, A. mellifera, A. dorsata and $A$. florea respectively. Mall and Rathore (2001) in their investigations on the foraging pattern of rockbee, Apis dorsata as influenced by seasonal variations reported that the maximum and optimum foraging range of $A$. dorsata during both the seasons were the same i.e $1,400 \mathrm{~m}$ and $600 \mathrm{~m}$, respectively. Rate of recruiting was more during summer than during winter. Sharma et al. (2001) in their study on foraging behaviour of Apis spp. in semi arid tropical climate on flowers of mustard, onion, carrot, berseem and sunflower reported that Apis florea spent maximum time per flower $(3.54,7.43,37.09$ and 15.24 sec.) and visited least number of flowers/umbels $(6.7,2.6,2.2$ and 3.6) per minute on mustard, onion, carrot and Egyptian clover, respectively. However, A. mellifera spent least time $(1.6,8.58$, and $128.47 \mathrm{sec})$ per flower/head and tripped highest number of flowers/head (15.2, 8.2 and 1.2) per minute on mustard, Egyptian clover and sunflower followed by $A$. dorsata which spent $2.18,2.48,11.46$ and $186.73 \mathrm{sec}$ per flower and visited 12.0,3.7 and 1.5 flowers/head per minute except sunflower where the observation time was $5 \mathrm{~min}$. All the foraged as top workers on all the crops except $A$. florea which forage as side worker on Brassica flowers. Kaushik et al. (2002) in their study on foraging behaviour of Apis spp. in semi arid and sub-tropical climate on flowers of phalsa observed that the total number of flowers visited per minute by Apis dorsata, A. mellifera and A. florea irrespective of plant type 5.2, 5.7 and 8.3 flowers/min, respectively. The average number of flowers visited by $A$. florea ( 8.3 flowers $/ \mathrm{min}$ ) was significantly higher than $A$. mellifera (5.7 flowers/min) and $A$. dorsata (5.2 flowers/min) which were comparable with each other. These differences were due to the fact that $A$. florea foraged almost all the flowers of the same clusster of the same branch throughout this foraging time, while other two Apis spp. took distant flight from one branch to another.

Chaudhary et al. (2002) in their study on the diurnal variation in foragers activity on litchi flower revealed that the time at which foraging flight commenced and ceased varied significantly in different foragers at different hours of the day. The honeybee species, Apis dorsata and A. cerana indica predominated over other foragers. Although the number of visitors was more during half of the day i.e., up to 11:00 h, their increase or decrease in number did not follow a definite trend. Chaudhary et al. (2002)in their investigation on the relative abundance of pollinators/insects visitors on litchi blooms revealed that Apis mellifera were predominated (34.97\%) over all the honeybee species and rates under study followed by $A$. cerana indica (18.62\%), A. dorsata (13.38\%) and A. florea (6.20\%), with a total of $614,327,235$, and 109 , respectively. The visits of foragers was not so badly affected by weather parameters, however, minimum temperature and 
relative humidity (14 hours) revealed negative correlation. The population of visitors was flower density-dependent rather than due to environmental parameters.

Kumar et al. (2002) studied on the foraging activity of Apis cerana indica and Apis mellifera visiting sunflower. The bees were recorded foraging for nectar, pollen or both at 5-day intervals from 18 December 1999 to 9 January 2000. The number of bees present were recorded on 5 capitula over the course of a minute, every $2 \mathrm{hr}$ between 10:00 and 16:00 hr. More bees visited the capitula during the early flowering stage of the crop, before maturity. The highest number of bees was recorded visiting capitula at $12.00 \mathrm{~h}$ (overall mean of both species on all dates of $10.85 \mathrm{bees} / \mathrm{min} / 5$ capitula) followed by $14: 00 \mathrm{~h}$, while the lowest $(6.19$ bees/min/5 capitula) was at 10:00 h, followed by 16:00 h. Honey bee numbers were affected by temperature and relative humidity, with higher numbers recorded under the highest mean temperature $\left(18.30^{\circ} \mathrm{C}\right)$ and at low humidity $(60 \%)$. Generally, A. mellifera was recorded in higher numbers than $A$. cerana indica throughout the flowering period. Singh et al. (2002) in their study on the foraging activity of honeybee on litchi flower in north Bihar revealed that the maximum number of bee foragers/minute/panicle was recorded in Apis mellifera (46.51\%), followed by $A$. cerana indica (40.28\%), A. dorsata (9.05\%) and A. florea (4.16\%). The foraging rate (the number of flowers visited by bees per minute) was maximum in A. mellifera (10.74), followed by A. cerana indica (9.30), A. dorsata (2.09) and A. florea (0.96). During the day, the maximum number of bee foragers/minute/ panicle was recorded at 10:30-11:30 h, followed by $11: 30-12: 30 \mathrm{~h}$, while the least number of bee foragers/ minute/panicle was recorded at 15:30-16:30 h. Kumar et al. (2003) in their study on the foraging rate and foraging speed of Apis cerana indica Fab. and Apis mellifera L. in sunflowers revealed that the foraging rate was maximum at 13:00 $\mathrm{h}$ and minimum at 10:00 $\mathrm{h}$ for both the species. The foraging speed (time in seconds spent by a bee per capitulum) revealed that $A$. mellifera spent more time (6.69 seconds/capitulum) compared to $A$. cerana indica (5.37 seconds/capitulum). The foraging speed of both the species was recorded highest at 14:00 h and lowest at 10:00 h. The weather factors (day temperature and relative humidity) influenced the foraging rate and foraging speed of both the species as also age of the flower. Gogoi et. al. (2006) in their study on foraging behaviour and effect of Apis cerana pollination on fruit set and yield of Asom lemon reported that bee (Apis cerana) visited the flowers right from 07:00 to 16:00 $\mathrm{h}$ although the peak of their foraging activity was in between 10:00-11:00 $\mathrm{h}$ with $9.42 \pm 0.53 /$ minute and frequency of flower visit was $13.26 \pm 0.62 /$ minute. The study showed that the maximum yield of Asom lemon was obtained in bee pollination treatment (48.88 tonnes/ha) against 32.89 tonnes/ha in without bee pollination and 44.00 tonnes/ha in open pollination treatment. There was $89.45 \%$ yield increase of Asom lemon in bee pollination treatment over without bee pollination. Abrol (2007) studied the foraging behaviour of Apis mellifera and Apis cerana $\mathrm{F}$. as determined by the energetic of nectar production in different cultivars of Brassica campestris var. toria. Twenty-four cultivars of Brassica campestris var. toria were examined for their nectar secretion characteristics, nectar sugar concentration, amount of sugar and energy per flower per day in relation to their attractiveness to honeybees, Apis mellifera L. and Apis cerana $\mathrm{F}$. 
The volume of nectar produced ranged from a minimum of 0.0521 to a maximum of 0.120 /flower/day. Nectar sugar concentration ranged between 36.0 and $43.8 \%$ and the amount of sugar ranged between 0.0198 and $0.0504 \mathrm{mg} /$ flower per day. The energy reward varied from a minimum of 0.330 joules to a maximum of 0.845 joules/flower/day. The number of bees/1 sq.m ranged between 4.0-12.0 and 2.6-10.2 in the case of $A$. mellifera and $A$. cerana, respectively in different cultivars of Brassica. These variations were found to be significantly and positively correlated with the foraging populations of honeybees, Apis mellifera L. and Apis cerana $\mathrm{F}$. The results suggested that cultivars with higher calorie rewards had a competitive edge over others in attracting foraging populations and, consequently, in pollination. Singh et al. (2008) in their study on spatial and temporal foraging by Apis mellifera Linn. bees on Brassica rapa Linn. var. toria revealed that the bee intensity, in terms of number of bees $/ \mathrm{m}^{2}$ of crop area/minute, decreased continuously with increase in distance from the source of hive and the intensity at any distance was significantly higher in later part of blooming when bloom density was higher and vice-versa. During the morning hours, the bee visitation was concentrated near the colony whereas during noon and afternoon hours, it was observed scattered on the crop. The bee intensity was the highest in late morning and it declined continuously with passage of day-time in the afternoon. The percentage of nectar foragers was more on early phase of crop blooming by more than $5 \%$ than when it was on full bloom. The mean proportion of nectar foragers continued to increase from late morning to evening hours. At the different distances up to $100 \mathrm{~m}$ from the hive too, the nectar collectors were significantly higher in the afternoon than in the morning hours. Thus, colonies migrated on the crop for honey production should be opened in the afternoon hours. However, those meant for achieving crop pollination should be opened in the morning time for maximum pollination. Brar et al. (2008) in their study on the foraging behaviour of Apis mellifera Linn. on radish revealed that Apis mellifera foragers, on an average, visited $9.17 \pm 0.17$ to $9.98 \pm 0.19$ flowers per minute on radish. The highest foraging rate was observed at noon $(1200 \mathrm{~h})$ and during peak blooming phase (Feb. 21) of the crop. All the foragers were the top workers. The foragers were the most active in collecting nectar $(24.2 \pm 4.27$ to $23.3 \pm 3.20 \%)$ between $12: 00$ and $14: 00 \mathrm{hr}$ and pollen (13.4 \pm 2.96 to $16.7 \pm 3.64 \%$ ) between 10:00 and 14:00 h. Diurnal foraging simultaneously for both nectar and pollen $(59.2 \pm 4.88$ to $74.2 \pm 5.43 \%)$ was higher in the morning at $10: 00 \mathrm{~h}(71.7 \pm 3.38 \%)$ and again in the evening at $16: 00 \mathrm{~h}$ $(74.2 \pm 5.43 \%)$. Throughout the flowering period of the crop, proportion of bees foraging simultaneously for both nectar and pollen was much higher than those foraging for nectar or pollen alone. Soni et al. (2010) in their study on the foraging activity of different pollinators on pepino (Solanum muricatum) revealed that the foraging rate (number of flower visited/min) of Apis cerana was higher during noon hours (6.12) as compared to morning and evening hours (4.64 and 5.33, respectively).

\section{COMMUNICATION IN BEES}

The methods of communication in bees have occasioned considerable study 
and much speculation. Lubbock, Forel, Wolf, Butler, Bertholf, Park, von Frisch and others have demonstrated the ability of bees to perceive shapes, odors, colors and detect distance and direction. Von Frisch has demonstrated the ability of bees to detect four different qualities of color i.e. yellow, blue-green, blue, and ultraviolet. Bees are red-blind. Von Frisch considers that bees can distinguish substances having sweet, sour, salty and bitter tastes. He concludes from the results of his experiments that odors that are similar for the human nose are also similar for bees. Mcindoo (1914) concluded that the olfactory organs are located mainly on the thorax, Von Frisch has data indicating that the last eight segments of the antennae are the most important in detecting odors. Butler (1949) advanced the theory that bees have the ability to detect distance travelled and also a sense of direction relative to the sun on their outward journeys to sources of food.

With the above, as a brief statement of the various senses of the bees, let us consider their use in communications. We will assume that a searcher bee has found good sources of pollen or nectar and has returned to the hive. Upon her entrance to the hiven, she performs characteristic behaviour patterns referred to as dances. It was early noted that these dances were of two types, the so-called round dance (Fig. 5.4a) and the wag-tail (Fig. 5.4 c). In his early work, Von Frisch believed that the round dance indicated a source of nectar whereas the presence of pollen was indicated by the wag tail dance. Park (1923) criticized the theory, stating that bees perform the wag-tail dance regardless of whether they carry nectar, water or pollen. Tschumi (1950) and Hein (1950) have indicated that bees perform other types of dance. These include the sickle dance (Fig. 5.4b) which are intermediate between the round and the wag-tail types. Hein also states that bees may indicate the direction of food sources at a distance not over six and half feet from the hive by means of the 'pull' dance. Subsequently, studies by Von Frisch indicate that such differences in behaviour may be due to inherent characteristics of different races.

In 1947, Von Frisch found that the type of dance performed by the incoming bees varied with the distance of the source of food. At distances up to $50 \mathrm{~m}$, the round dance was performed. Between 50 and 100 meters and beyond this distance only the wag-tail dance was performed. The exact distance is shown in the wagtail dance by the number of turns made in a given time. Von Frisch used 15 seconds as a given interval. At distance up to $100 \mathrm{~m}$, the bees made 9 to 10 turns in $15 \mathrm{sec}$,

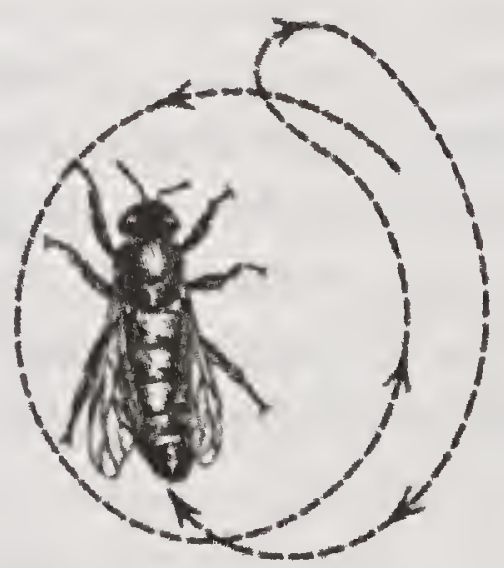

(a)

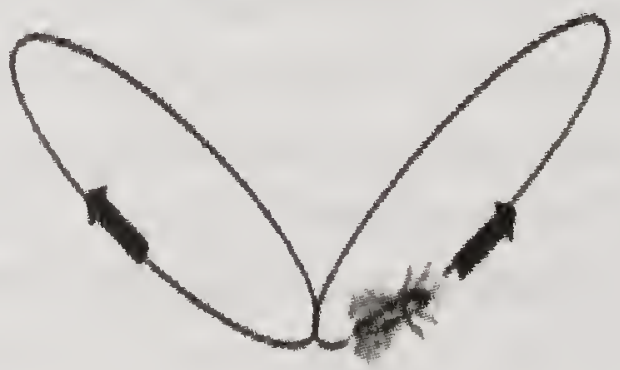

(b)

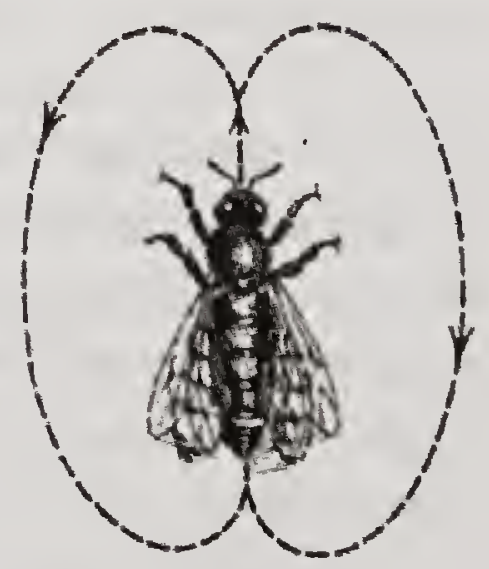

(c)

Fig.5.4. (a) Round dance; (b) Sickle dance; (c) Wag-tail dance (Source: Ribbands, 1953). 
at $200 \mathrm{~m}$ there were 7 at $1 \mathrm{~km}$ only 4.5 . Von Frisch indicates that there may be some variation due to wind direction and to the strength and characteristics of the individual bee, he concludes that the estimation of distance is related to the time or effort needed to reach the food source.

The problem of how bees may detect direction was first indicated from the work of Wolf, Santschi and others who investigated the behavior of bees and ants in a plain area devoid of striking landmarks. These workers conclude that inasmuch as the position of the sun did not shift markedly during a foraging trip, the insects could use the relative positions of the sun, the source of food and the colony location as reference points in determining position.

Von Frisch (1968) conducted experiments to test this theory. He noted that the direction in which a bee crossed the comb in the wag-tail dance varied during the day and concluded that in some way, the bee was using the position of the sun to detect direction (Fig. 5.5). The situation is complicated because of two factors: first that the bee performs her dance on a perpendicular rather than on a horizontal surface; and second that in the hive, the bee cannot perceive the position of the sun while she is dancing. In his own words, Frisch explains this situation as follows: we must recall that under normal circumstances, a bee dances on the perpendicular honeycomb inside a hive where it is quite dark. In the ordinary hive, bees cannot perceive the direction of the sun but apparently rely instead on the direction of gravity. They orient the straight portion of the dance at the same angle to the force of gravity as the angle flown with respect to the sun during the flight from hive to feeding place. If a dancer heads directly upward during the straight part of her dance on the honeycomb, this apparently means, the feeding place is in the same direction as the sun. Similarly, if during the straight part of the dance, the bee heads $60^{\circ}$ to the left of the vertical, then the feeding place is situated $60^{\circ}$ to the

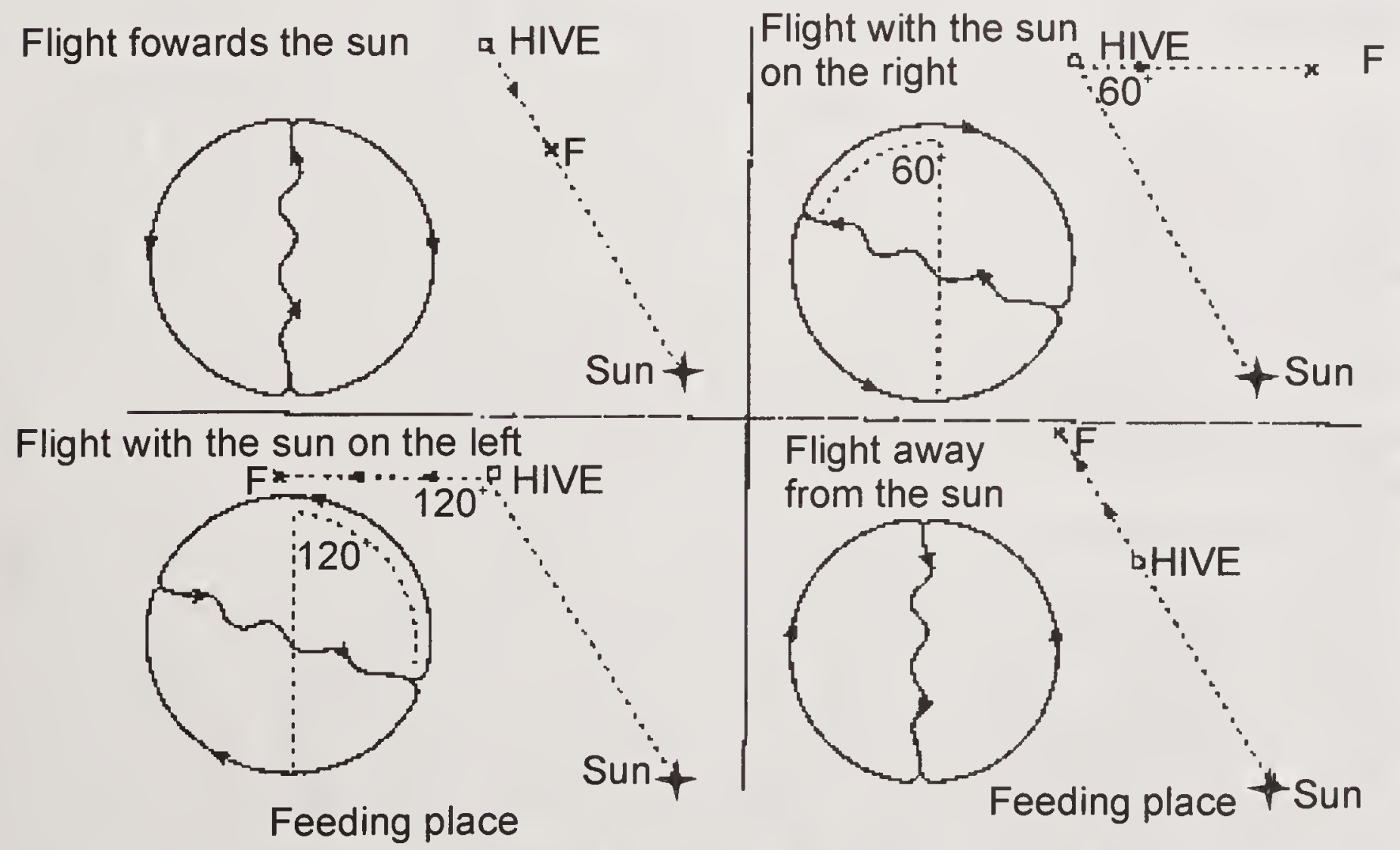

Fig. 5.5 Relationship showing angle of bee dance on the vertical comb with respect to sun and location of food (Frisch, 1968). 
left of the sun. Subsequent work by Von Frisch indicates that the bee actually makes use of polarized light for her orientation. He concludes that the single ommatidium functions as an analyzer of polarized light.

\section{PHEROMONE FOR NAVIGATION}

Pheromones are chemicals capable of acting outside the body of secreting individuals to impact the behavior of the receiving individuals. These chemicals are used for communication among members of a species. Honey bee pheromone has releaser effect through sex attraction, alarm and aggregation, trail production, clustering and mutual recognition and prime effect through inhibition of reproduction. Honey bees communicate in a variety of ways. However, like so many other species in the natural world, communication through the interchange of volatile chemical signaling is the most predominant and robust method used. Pheromones are very often extremely volatile compounds or cocktails that are excreted by one member of a particular species and affect the behavior ("release pheromone") or the physiology ("primer pheromone") of another member of the same species. In honey bees, there are many pheromones that govern and coordinate the activities of the hive. The most prominent pheromones are:

Queen pheromone: This first and foremost primer pheromone known in nature is a five chemical cocktail produced in the mandibular glands of the queen bee. The queen pheromone actively suppresses the egg maturation process in the nonreproductive worker caste. It also has a variety of releaser pheromone functions, such as preventing queen cell construction, enabling worker cohesion during swarming, promoting collection of food and guiding the males to the virgin queen in its mating flight.Trhlin and Rajchard (2011) in their study on chemical communication in the honeybee (Apis mellifera L.) revealed that queen retinue pheromone (QRP) is a blend of the nine compounds (9-oxo-(E)-2-decenoic acid, (R)- and (S)-9-hydroxy-(E)-2-decenoic acid, methyl p-hydroxybenzoate, 4hydroxy-3-methyl oxyphenylethanol, methyloleate, coniferyl alcohol, palmityl alcohol, and linolenic acid) and acts as a releaser pheromone by attracting worker bees to the queen. QRP also acts as a primer pheromone by physiologically inhibiting the ovary development of worker bees. An essential component of QRP, 9-oxo-(E)-2-decenoic acid, acts as a long-distance sex pheromone. Defensive behaviour of honeybees is induced and modulated by alarm pheromones. The essential alarm pheromone component is isopentyl acetate (IPA). The unsaturated derivative of IPA, 3-methyl-2-buten-1-yl acetate, was found in colonies of Africanized honeybees. The Nasanov gland of worker bees produces a pheromone (a blend of nerol, geraniol, (E)- and (Z)-citral, nerolic acid, geranic acid and (E, E)-farnesol) that acts as an attracting signal. This pheromone is used for aggregation (during swarming). Adult worker bees also produce a substance, ethylloleate, that has a priming effect. Ethyloleate is produced by adult forager bees and acts as a chemical inhibitory factor to delay age at onset of foraging (the presence of older worker bees causes a delayed onset of foraging in younger individuals). Chemical cues on the surface of larvae called a brood pheromone (ethyl and methyl esters of palmitic, linoleic, linolenic, stearic, and oleic acids, E- $\alpha$-ocimene) are 
important in the communication between brood and worker bees. This pheromone modulates the feeding behaviour of worker bees, inhibits the activation of the worker ovary, induces worker bees to cap brood cells, increases the activity of the hypopharyngeal glands of nurse bees and modulates the behavioural maturation of worker bees

Nasanov pheromone: Bees have an innate preference for sweet citrus-like smelling monoterpines. One of the reasons for this is the secreted components of the Nasanov gland located on the bee's posterior abdomen. When seeking a new nest, then signaling the new queen the way to home from a mating flight, or when signaling displaced bees the way back to the hive, the Nasanov gland is exposed and the bees fan their wings to create a scented airborne trail. This citrus-smelling trail is picked up in a homing manner and often elicits similar behavior in a nestreturning bee that has located the hive entrance.

Brood pheromone: Brood pheromone (BP) is responsible for feeding behaviour of nurse bees. Although bees cannot scream or hear, when larvae are in open cells, they excrete chemicals that elicit feeding behavior in nursing bees. Young larvae are fed the excretion of the nurse bees' feeding glands, whereas older larvae are fed bee-bread. Alaux et al. (2009) in their study on the regulation of brain gene expression in honey bees by brood pheromone revealed that brood pheromone (BP) caused changes in the expression of hundreds of genes in the bee brain in a manner consistent with its known effects on behavioral maturation. Brood pheromone exposure in young bees causes a delay in the transition from working in the hive to foraging, and we found that BP treatment tended to upregulated genes in the brain that are upregulated in bees specialized on brood care but down regulate genes that are upregulated in foragers. However, the effects of BP were age dependent; this pattern was reversed when older bees were tested, consistent with the stimulation of foraging by BP in older bees already competent to forage. These results support the idea that one way that pheromones influence behavior is by orchestrating large-scale changes in brain gene expression

Alarm pheromone: Most humans fear bees because of their stinging - the pain, the swelling, the itching and the dreaded consequences of anaphylactic shock for those who are hyper-allergic. Yet, for the honey bee, stinging is a suicidal action because of the dissociation of its digestion system. Such an action is hardly useful, if it does not lead to the fleeing of the person or animal that threatened the hive. Prior to stinging the guard will try to ward off the threat by typical "harass" flights. But often, the temptation of the honey is too much for the assailant to pass by, and the bees must coordinate an efficient attack. They do so by the unique blend of chemicals that is released from the dufour glands located in close proximity to the sting apparatus. This alarm pheromone elicits stinging behavior in other individuals of the hive in order to increase the attack's efficacy. Jianjun Li et al. (2014) in their investigation on effects of natural and synthetic alarm pheromone and individual pheromone components on foraging behavior of the giant Asian honey bee, Apis dorsata revealed that social pollinators such as honey bees face attacks from predators not only at the nest, but also during foraging. Pollinating honey bees can therefore release alarm pheromones that deter conspecifics from visiting dangerous inflorescences. However, the effect of alarm 
pheromone and its chemical components on bee avoidance of dangerous food sources remains unclear. It was tested for the responses of giant honey bee foragers, Apis dorsata, presented with alarm pheromone at a floral array. Foragers investigated the inflorescence with natural alarm pheromone, but 3.3 fold more foragers preferred to land on the "safe" inflorescence without alarm pheromone. The GC-MS analysis showed eight chemical components in the alarm pheromone, of which three components (1-octano, decanal, and gamma-octanoic lactone) have not previously been reported in this species. The bioassay analysis of each compound proved that gamma-octanoic lactone, isopentyl acetate, and (E)-2decengylacetate are active compounds that elicit significant alarm responses. Gamma-octanoic lactone elicited the strongest response to a single compound and has not been previously reported in honey bee alarm pheromone. Isopentyl acetate is widely found in the alarm pheromones of sympatric Asian honey bee species, and thus alarmed $A$. dorsata foragers may produce information useful for conspecifics and heterospecifics, thereby broadening the effects of alarm information on plant pollination.

\section{REFERENCES}

Abrol, D. P. 2007. Foraging behaviour of Apis mellifera and Apis cerana F. as determined by the energetic of nectar production in different cultivars of Brassica campestris var. toria. Journal of Agricultural Science 51(2): 9-23.

Alaux, C., Le Conte, Y. Adams, H. A., Rodriguez-Zas S., Grozinger, C.M., Sinha, S. and Robinson, G. E. 2009. Regulation of brain gene expression in honey bees by brood pheromone. Genes, Brain and Behavior 8: 309-19.

Bertholf, L. M. 1925. The moullts of the honey bee. Journal of Economics Entomology 18: 380 .

Bonnier, G. 1906. Sur la division du travail chez les abeilles. Academy of Science, Paris 143: $941-46$

Brar, P. K., Gatoria, G.S. and Chhuneja, P.K. 2008. Studies on the foraging behaviour of Apis mellifera L. on radish (Raphanus sativus L.). Indian Journal of Ecology 35(1): 52-58.

Butler, C. G. 1945. The behaviour of bees when foraging. J. R. Soc. Arts 93, 501-11.

Casteel, D.B. 1912. The behaviour of honeybees in pollen collecting. USDA. Bur. Ent. Bull. 121: 7-33.

Chaudhary, D. K., Singh, B., Singh, P. P. 2002. Relative abundance of pollinators/insect visitors on litchi blooms. Indian Journal of Entomology 64 (2): 170-74.

Chaudhary, D. K., Singh, B., Singh, P. P. 2002. Diurnal variations in foragers activity on litchi Journal of Applied Zoological Research 13(1): 97-99.

Dobrovsky, T. M. 1951. Postembryonic Changes in the digestive tract of the worker honeybee (Apis mellifera L.).Ithaca. New York. Cornell University.

Dunham, W. E. 1939b. Insect pollination of red clover in Western Ohio. Glean. Bee Culture 67: 486-88, 525.

Eckert, J. E. 1933. The flight range of the honeybee. Journal of Agricultural Reserach 47, 257-85.

Frisch, K. von. 1968. The role of dances in recruiting bees to familiar sites. Animal Behaviam 16, 531-35.

Gogoi, B., Rahman, A., Rahman, S. and Deka, M. K. 2006. Foraging behaviour and effect of Apis cerana pollination on fruit set and yield of Asom lemon (Citrus lemon). Indian Journal of Agricultural Sciences 77(2): 56-57. 
Haydak, M. H. and Vivino, A. E. 1950. The changes in the thiamine, riboflavine, niacin and pantothenic acid content in the food of female honey bees during growth with a note on the vitamin $\mathrm{K}$ activity of royal jelly and bee bread. Entomology Society of America, 43, 361-67.

Hein, G., 1950 - Uber richtungsweisende Bienentanze bei Futterplatzen in Stocknahe. Experiential 6: 142-44.

Jianjun, L., Zhengwei, W. Ken, T., Yufeng, Q. Nieh, J.C. 2014. Effects of natural and synthetic alarm pheromone and individual pheromone components on foraging behavior of the giant Asian honey bee, Apis dorsata. Journal of Experimental Biology 217: 3512-18

Kaushik, H.D., Sharma, S.K. and Gill, S.S. 2002. Foraging behaviour of Apis spp. in semi arid and sub-tropical climate on flowers of phalsa. Bangladesh Journal of Agricultural Research 27(1): 131-132.

Kumar M, Singh, R., Chand. H. 2003. Foraging rate and foraging speed of Apis cerana indica Fab. and Apis mellifera L. in sunflower (Helianthus annus L.). Shashpa 10 (1) : 27-32

Kumar M, Singh, R., Chand. H. 2002. Foraging activity of Apis cerana indica and Apis mellifera visiting sunflower (Helianthus annus L.). Shashpa 9 (1).31-34.

Kumar M., Singh, R., Chand. H. 2001. Effect of different modes of pollination on quantitative and qualitative characters in sunflower seeds (Helianthus annus L.). Shashpa. 8(2): 157-160.

Lindauer, M., 1957. Communication in swarm-bees searching for a new home. Nature 179: $63-6$

Lundie, A. E. 1925. The flight activities of the honeybee. Bulletin US Department Agricultural 1328.

Mall P and Rathore R.R.S. 2001 Investigations on the foraging pattern of rockbee, Apis dorsata as influenced by seasonal variations. Indian Journal of Applied Entomology 15(1): $1-6$.

Maurizio, A. 1953. Weitere Untersuchungen an Pollenhöschen. Beih zur Schweiz BienenZtg. 2: 486-556.

Mcindoo, N.E. 1914. The olfactory sense of the honey bee. Journal of Experimental Zoology 16: $265-346$.

Minderhoud, A. 1931. Untersuchungen uber das Betragen der Honigbiene als Blutenbestauberin. Gartenbauwissenschaft 4, $342 \mathrm{pp}$

Park, O. W., 1949. The hive and the honeybee. Datan \& Sons, Hamilton, Illinois.

Park, O. W. 1929. The influence of humidity upon sugar concentration in the nectar of various plants. Journal of Economic Entomology 22, 534-44.

Park.O.W. 1923. Flight studies of the honey bee. American Bee Journal 71: 71.

Parker, R. L. 1926. The collection and utilization of pollen by the honeybee. Memoirs Cornell agricutural Experimental Stations 98: I-55.

Ribbands, C. R. 1953. The Behaviour and Social Life of Honeybees. Bee Research Association, London.

Sharma, S.K., Singh, J.R., and Mehla, J.C. 2001. Foraging behaviour of Apis spp. in semi arid tropical climate on flowers of mustard, onion, carrot, berseem and sunflower. Crop Research 21(3): 332-42.

Singh, J., Chhuneja, P. K. and Gatoria, G. S. 2008. Spatial and temporal foraging by Apis mellifera Linnaeus bees on Brassica rapa L. var. toria. Journal of Insect Science 22(3): 266-71.

Singh, R., Kumar, M. and Chand, H. 2002. Foraging activity of honey bee on litchi (Litchi chinensis Sonn.) flowers in North Bihar. Journal of Entomological Research 26(4): 309-311. 
Singh, S. (1950). Behaviour studies of honeybees in gathering nectar and pollen. Mem. Cornell Agric. Exp. Stn. 288.

Soni, J., Thakur, R,K., Chauhan, A. and Sharma, M.K. 2010. Foraging activity of different pollinators on pepino (Solanum muricatum). Pest Management Economic Zoology 18(1/ 2): 266-70.

Sturtevant, A. P. and Farrar, C. L. 1935. Further observation on the flight range of the honey bees in relation to honey production. Journal of Economics Entomology 28(3): 585-589.

Thorley, J. 1944. Melisselogia or, the female monarchy: being an enquiry into the nature, order and government of bee, Thorley, London.

Trhlin, M. and Rajchard, J. 2011. Chemical communication in the honeybee (Apis mellifera L.): a review. Veterinarni Medicina, 56(6): 265-73.

Tschumi, P. 1950. Uber den Werbetanz der Bienen dei nahen. Trachtquellen. Schweiz. Bienenztg, 73 (3), 129-34

Vansell, G. H. 1947. Factors affecting the usefulness of honeybees in pollination. U.S. Department Agriculture Circular no. 650: 31pp. 


\section{6 \\ Genetics and Breeding}

$\mathrm{G}$

ENETICS is the study of genes, heredity and variation in living organisms.

Cytogenetics is a blend of cytology, genetics, and molecular biology. There is a large body of information which could be included in the honeybee cytology and cytogenetics. Honeybees have several advantages for cytogenetic research, including their large colony populations, their ability to take care of themselves, and their physiological, morphological, and genetic diversity. Honeybee cytology and cytogenetics, uptill now, have never been the exclusive subjects of a detailed review, although several have touched on these areas (Cale and Rothenbuhler, 1975). The cytogenetic study of honey bee reveals that there are uniform number of choromosomes in Apis species. The common number chromosomes $(n=16)$ of Apis cerana and $A$. mellifera is often considered a sign of their close relationship (Deodikar et al., 1959; Hoshiba et al., 1981). Since tetrads in male and octads in female meosis appear often, the number of $n=16$ is said to be the result of phylogenetic polyploidy formation, (Fig. 6.1). Deodikar and Thakar (1966) claimed that $A$. dorsata and $A$. florea should have a chromosomal set of $n=8$; however, Fahrenhorst (1977) showed that these two species also have $n=16$. The haploid chromosomal set of all three Asian species of Apis recorded to be $n=16$ (Fahrenhorst, 1977). All three complements include only one large mediocentric chromosome, so the chromosome number cannot result from somatic polyploidy. Thus, the karyotype of the four species of Apis cannot be used to show a phylogenetic relationship in the genus. Also, the DNA study of Jordan and Brosemer (1974) gave no clear separation among the species A. mellifera, A.cerana, and $A$. florea. They characterized the DNA of these species by distribution of the guanine-cytosine (GC) pairs. Though Apis mellifera and A.cerana DNA was rather similar, all three species had a broad GC distribution. Although Apis cerana and A.mellifera are closely related species, they are quite distinct and there have been no reports of vital hybrids. Ruttner (1969) and Maul (1969) obtained hybrid eggs by artificial insemination. These eggs only developed to the blastoderm stage and then died. Ruttner and Maul suggested that the material enzyme apparatus may cease functioning at that stage and that as the hybrid genome starts its own protein synthesis, the regulation of metabolism stops.Fahrenhorst (1977) and Hoshiba et al. (1981) showed that the haploid chromosomes number is 16 for each of the four species of Apis. Woyke et al. (1966) determined that laboratory-reared diploid drones have 32 chromosomes in spermatogenesis and in the blastoderm stages. Chaud-Netto and Kerr (1980) inseminated normal diploid queens with diploid semen from diploid drones. Worker ovarian tissue was cytogenetically triploid 
$(3 n=48)$. Winstock et al. (2006), while reporting on the genome sequence of the honeybee, Apis mellifera, a key model for social behaviour and essential to global ecology through pollination. Compared with other sequenced insect genomes, the A. mellifera genome has high $\mathrm{A}+\mathrm{T}$ and $\mathrm{C}+\mathrm{G}$ contents, lacks major transposon

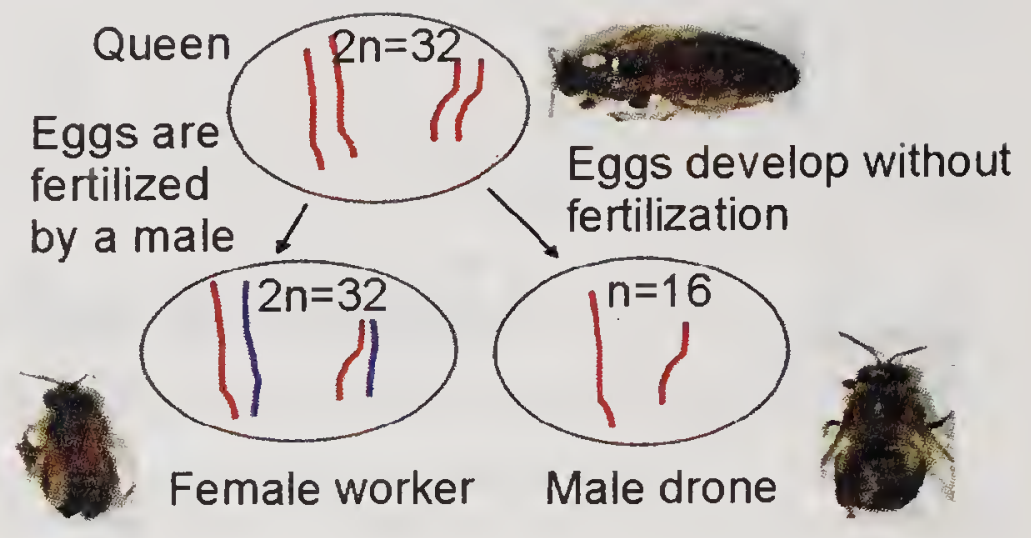

Fig. 6.1 Chromosomes showing in different caste of honeybee. families, evolves more slowly, and is more similar to vertebrates for circadian rhythm, RNA interference and DNA methylation genes, among others. Furthermore, A. mellifera has fewer genes for innate immunity, detoxification enzymes, cuticle-forming proteins and gustatory receptors, more genes for odorant receptors, and novel genes for nectar and pollen utilization, consistent with its ecology and social organization. Compared to Drosophila, genes in early developmental pathways differ in Apis, whereas similarities exist for functions that differ markedly, such as sex determination, brain function and behaviour. Population genetics suggests a novel African origin for the species A. mellifera and insights into whether Africanized bees spread throughout the new world via hybridization or displacement.

Mohankumar et al. (2013), in their study on genetic diversity and phylogeography on Apis dorsata F. in India reported the genotype analysis of 454 individuals worker bees of Apis dorsata from 36 populations collected from 7 states of India. The number of alleles per locus varied from 45 to 97 and average heterozygosity ranged from 0.41 to 0.81 . Govindaraju (1989) distinguished three levels of gene flow: high $\mathrm{Nm}>1$, intermediate $(0.25<\mathrm{Nm}<0.99)$ and low $\mathrm{Nm}<$ 0.25 . the mean number of migrants $(\mathrm{Nm})$ across the populations for all the loci screened was 1.023 indicating a high migration rate in populations. Lazar et al. (2013), while studying genetic diversity of Apis florea $\mathrm{F}$. from India recorded two species of dwarf honey bee viz. Apis andreformis Smith. and A. florea $\mathrm{F}$. the microsatellite analysis revealed significant observation and expected heterozygosity among the population, clearly indicating the presence of significant genetic diversity within the $A$. florea population . The molecular analysis revealed the presence of new haplo-groups and 49 new haplotypes have been identified.

Fakruddin et al. (2013), analysed the genetic diversity of Apis cerana $\mathrm{F}$. in the Asiatic honeybee in India. Number of alleles among the polymorphic microsatellite loci ranged between 68 and 111 across the population from eight states of India. The haplotype analysis revealed the presence of new haplogroups and 94 new halpotypes were identified involving the red and black Apis cerana races.

\section{Reproduction}

Honey bees are eusocial insects. As such, they have "a reproductive division of labour in the colony, that is, a worker caste cares for the young of the reproductive caste". Also, "there is agenerations so that offspring can assist parents" (Wilson, 1971). Thus, individuals in a honey bee colony are replaced in succession 
without dissolving the colony. Furthermore, the honey bee queen is not able to raise brood without workers. Honey-bee reproduction must be considered as two separate processes: (1) replacement and multiplication of the members in the colony when transmission of genes to a new reproductive generation only occurs through mating drones or when the old queen is replaced, and (2) multiplications of the colony through swarming when the old and young queens, each found new colonies with a part of the workers of the whole colony. The remaining workers stay with the last young queen at the old nesting site. In the second case, genes are transmitted to a new reproductive generation through both queens and drones.

Queens: Shortly after emergence, the queen can be observed moving about the brood area of the nest. She will destroy sealed queen cells she encounters if the colony is not preparing to swarm. Worker bees apparently do not show reactions to newly emerged queens during the first few hours. However, from noon of the first day, some workers start to follow her. They lick and touch her with their antennae and front legs, and three to four times a day they feed her. At the same time, the first antagonistic behavior is seen; the workers push and bite the virgin queen, pull her legs, or even "ball" her. "Balling" involves enough bees biting and holding a queen that only a ball of bees can be seen. The queen runs from these antagonistic activities, and when she is caught, she starts to produce a peculiar sound by vibration of the thoracic muscles- "she pipes". Piping results in a "stop reaction" of the workers. The aggressive treatment of the queen by the workers always has a peak in the early afternoon hours. Since, this is when queens normally take mating flights, one gets the impression that the workers, aggressive activities result in chasing the virgin queen out for a mating flight. There is experimental evidence for this hypothesis. A queen kept with worker not older than 3 days was not attacked but also did not leave the hive (Hammann, 1956).

Drones: For the first 3 days after emergence, drones are fed by workers. When they are only one day old, they get less food than older drones; probably they are still unable to beg for food effectively. Until they are 5 days old, they stay within the brood nest. They spend $70-80 \%$ of their time inactively, only occasionally cleaning themselves or wandering over the comb and soliciting food. Mainly, they are fed by nurse bees though the food originates from the honey sac rather than the pharyngeal glands (Free, 1987). As the drones grow old, they move from the brood nest to the honey combs and start to feed themselves from the cells. Workers take more care of young drones. More workers cluster on cages with drones 6-7 days old than on cages with drones when the older ones are already driven out of the colony in the fall.

The genetical aspects of spermetogenisis are completed by the time drones emerge from the cell. In adult drones 3-8 days old, spermatozoa migrate from the testis into the vesicular seminalis, where they undergo several days of final maturations. They are positioned in the vesicular with their heads against the glandular epithelial walls. These cells secrete by terminal constrictions. In this way, the epithelium shrinks while the cavity of the vesicular seminalis enlarges. Eventually, the contents of this origin consist of a small amount of lymph like fluid, with about $1110^{6}$ spermatozoa. Mucus production in accessory glands stay only after the emergence of the male and is finished at the age of 6-7 days. Sperm 
and mucus stay in the vesicular seminalis and in the mucous glands, respectively, until mating.

\section{Flight range}

The flight of queens and drones cannot be observed directly but can be inferred from certain experiments. Ruttner and Ruttner (1972) distributed 250 genetically marked virgin queens and three groups of genetically marked drones. The comparison of the worker progeny of these queens with the composition of the drone populations showed that only a few matings occurred with drones from the vicinity of the queen's colony. The average distance between apiary and mating place was more than $2 \mathrm{~km}$, and the maximum distance was $5 \mathrm{~km}$. These results are similar to those of Woyke (1960), who found that queens had better mating success when drones were placed $2.5 \mathrm{~km}$ away rather than in the same apiary. The flight range of drone is about $6 \mathrm{~km}$, with flights of 5 $\mathrm{km}$ being common (Fig. $6.2 \mathrm{a}$ ). Thus, flight range of drone spread over an area of roughly $78 \mathrm{~km}^{2}$ (Ruttner, 1972). In an area containing only experimental bees, the greatest mating distance was more than $16 \mathrm{~km}$ (Peer, 1957), but only three of 12 queens

(a)

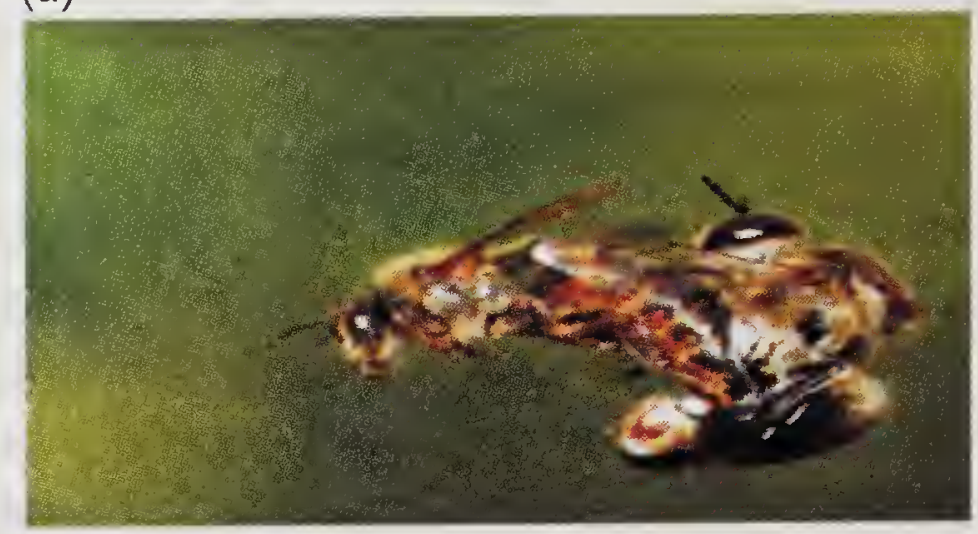

(b)

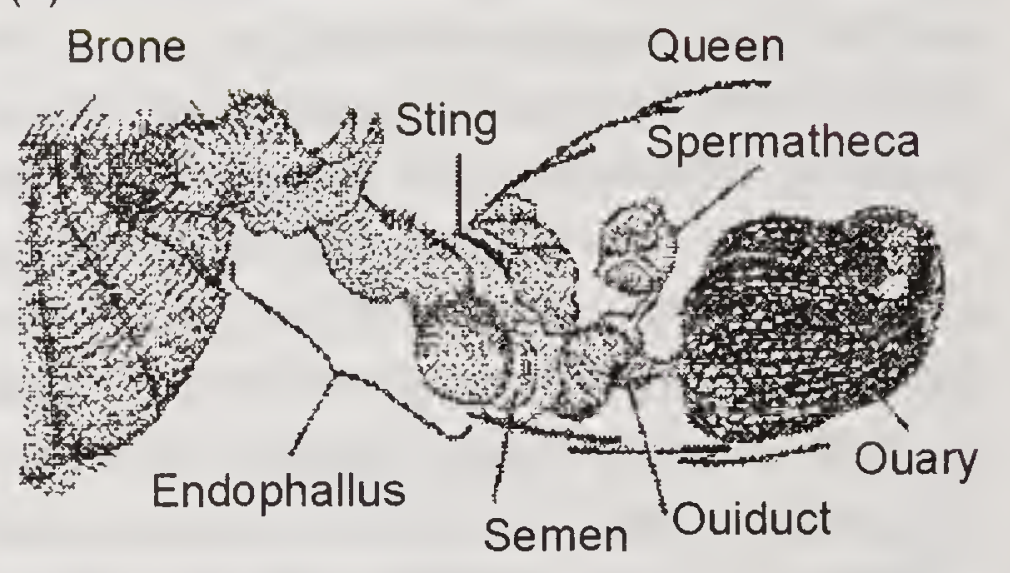

Fig. 6.2 (a) Mating flight; (b) Showing Mating and Copulation (Ruttner, 1988).

from droneless nuclei mated at this distance and only after 4 weeks. Distances of 5.7 and $12.8 \mathrm{~km}$ resulted in 89 and $67 \%$ mating success, respectively. Ruttner (1988) discussed the bee breeding techniques and selection of queen for effective breeding.

\section{Mating behavior}

Apis cerana is closely related to A. mellifera and has very similar mating behavior. Ruttner (1973) observed matings of $A$. cerana in the same drone congregation area used by $A$. mellifera in Germany. Drones of $A$. cerana have much less semen than those of $A$. mellifera and A.cerana queens mate with more males (30 males per queen). In their original habitat in India, Woyke (1975) showed that A.cerana queens mate with an average of 10 males during their first mating flight. Larger number of males per queen might be common since in most cases a second mating flight is taken (Shah and Shah, 1980). From the data of Woyke (1975), it was worked out that approximate flight time from hive to congregation area and the mean time per mating. Apis cerana has a shorter mating time per drone (0.79 $\mathrm{min}$ ) than Apis mellifera (2.04 min; Woyke, 1956). The duration of the flight between the hive and the congregation area is about $10 \mathrm{~min}$ for both 
species. Apis mellifera and A.cerana are not sympatric and have similar mating times. In the study, Ruttner (1972) found that Apis cerana queens did not successfully mate when Apis mellifera drones were abundant; however, when the Apis mellifera drones were excluded from the congregation area, Apis cerana queens mated successfully. Imported Apis mellifera queens did not successfully mate under natural conditions (Fig. 29b).

Little is known about the mating behavior of the other Asian species. However, all four species of Apis have many similarities in behavior and anatomy (Koeniger, 1976). The same sex pheromone attracts drones of all species (Shearer et al., 1970) as do queen extracts from the different species (Butler et al., 1967). The three Asian species occur sympatrically in many habitats and interspecific matings, or the interference of specific matings, might easily result from such similarities. However, Koeniger and Wijayagunasekera (1976) showed that this is prevented drone and presumably the queen flight times in Sri Lanka. Apis florea drones flew early in the afternoon; $A$. cerana made their mating flights late in the afternoon; $A$. dorsata drones had their main flight activity at dusk.

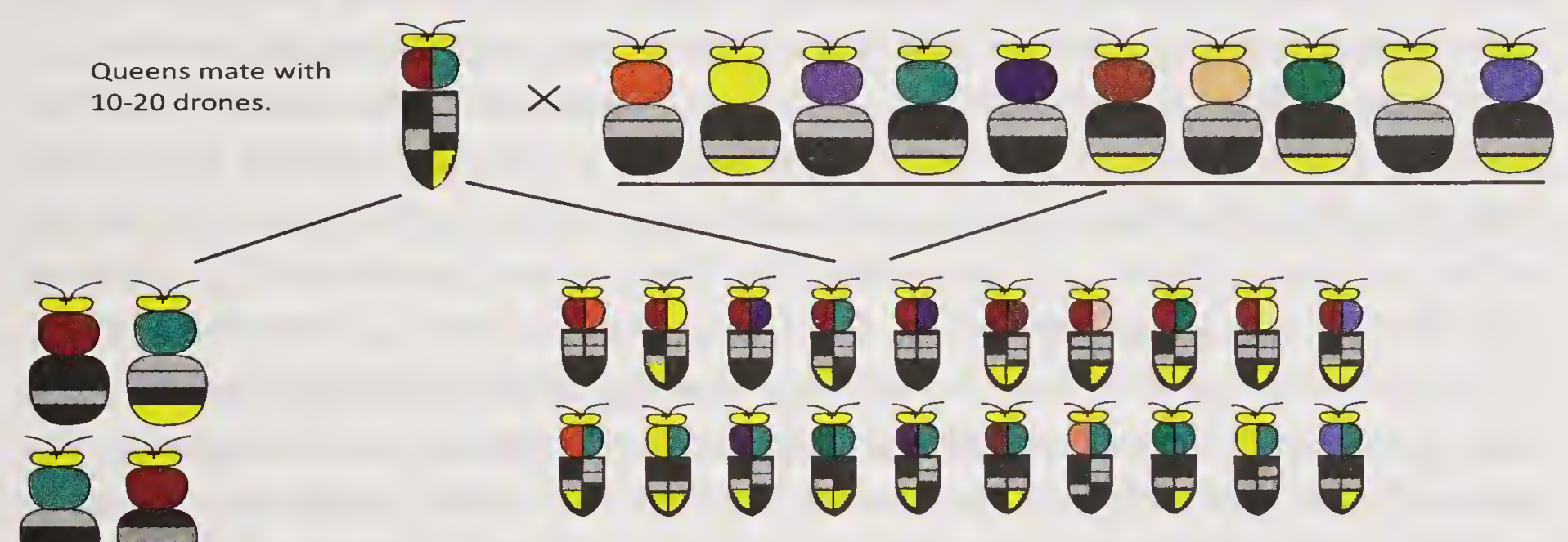

These are a few of the 1,000's of gene combinations possible.

Fig. 6.3 Mating behaviour showing gene combination (Glenn, 2002).

\section{Sex determination}

Sex determination in Apis cerana is nearly identical to that in A. mellifera. Using instrumental insemination, Woyke (1979), produced inbred lines of $A$. cerana. The drones of $A$. cerana only produced $0.2 \mathrm{~mm}^{3}$ of semen (one-sixth that of $A$.mellifera drones), and only those queens inseminated with the semen of more than 15 drones laid normal numbers of fertilized eggs. Examining 572 larvae of the offspring of inbred queens, Woyke detected that $27.4 \%$ were diploid drones. He suggested that, as in $A$. mellifera, there is only one sex locus with several alleles (Fig. 6.3). Homozygosity or hemizygosity at that locus results in males. Hoshiba et al. (1981) observed the same ratio of diploid drones in A. cerana japonica and confirmed Woyke's model. Diploid-drone larvae of $A$. cerana and not eaten by the workers just after hatching (as in $A$. mellifera), but mostly they are eaten at the age of one day. Some larvae were even reared for 4 days, and Woyke (1980) suggested that under favorable natural conditions, $A$. cerana diploid drones might even develop to the adult stage. Presumably, the diploid drone larvae of $A$. cerana produce much less cannibalism substance than those of $A$. mellifera 
(Dietz, 1975). However, Apis cerana diploid-drone larvae seem to produce this substance longer.

\section{Breeding}

Like animal and plant breeding, honey bee breeding is also a continuous processs to improve the future generations. Most breeding programs are designed so that the "best" parents are selected and used to produce the next generation. In general terms, the "best" parents should produce the "best" offspring and the average quality of the stock is improved. Such guidelines are deceptively simple, especially with honey bees. This chapter suggests ways to define and measure honey-bee characteristics so that the "best" parents for honey-bees stock improvement programs can be selected. Home computers make possible the application of fundamental selection theory to the selection programs of small family-owned bee-breeding enterprises.

The breeding of bees and hence their genetic improvement awaited the developments of movable-frame beekeeping equipment and methods to produce large numbers of queen bees (Doolittle, 1988). The addition of instrumental insemination techniques for honey bee and their later improvement have brought the mating of bees under complete control and "opened a wide door to both bee breeding and genetics" (Cale and Rothenbuhler, 1975). The eastern honey bee, Apis cerana is a hive bee and is commercially exploited with similar bee-husbandry techniques used with $A$. mellifera. Movable frame hives, queen-rearing, and even instrumental in-seminaton (Woyke, 1975) are usable techniques with this species. Currently the use of $A$. cerana is restricted to its naturally occurring range. This is because $A$. mellifera is considered a better honey producer. Considering the advantages of Apis mellifera, the species has been successfully introduced in India and augmentation effort is going on. However, as pests and diseases of this species become spread throughout the world including India, therefore a conservation effort is made to restore indigenous Apis cerana in our country.

Additionally, $A$. dorsata and $A$. florea are not "reared" but feral. Colonies are commercially exploited through intensive organized honey hunting. The migratory and absconding nature of these species is a major obstacle to their commercial management. However, a beginning has been made a managed "migartions" of $A$. florea (Dutton and Simpson, 1977). Further management developments may stimulate attempts to breed more commercially desirable stocks of these species.

\section{Stock improvement}

Using improved stocks of bees is an effective way to improve the productivity of a beekeeping operation. Regardless of the stock of bees used, basic operational expenses will remain mostly the same.

Success in improving bee stocks is a reachable goal. As we have seen, there are great variations in bee stocks available with the bee breeders. This variation is the raw material used by bee breeders. Working with the tool of selection, bee stocks can be molded to show high performance for desired characteristics. 


\section{Selection methods for the desired stocks}

The first task of a bee breeder is to describe in specific terms what characteristics are desired in the bee stock to be produced. Most certainly a number of characteristics will be listed. Generally, desired characteristics will relate to the production needs of a group of beekeepers who are in similar localities or have similar needs. Desirable characteristics might include fast spring buildup, intensive honey production, and strong overwintering ability, disease resistance, and good handling qualities, heat tolerance and pollination activity.

A knowledgeable bee breeder will be careful to be only as specific in his stock descriptions as good information permits. Unless scientific proof is developed to the contrary, physical characteristics such as colour, size of bees, and shape of wings are proof choices. Generally, if such characteristics are important, they will be selected and improved automatically along with more general characteristics such as honey production or diseases resistance.

Overall, there is need in the beekeeping industry for a number of bee stocks, each having a collection of characteristics economically important to different segments of the diverse beekeeping community. No one bee stock can possibly be universally acceptable, and attempts to produce such a stock would prove fruitless. Thus, communication between an individual bee breeder and the beekeepers using the breeder's stock is important. This communication will help the breeder decide which characteristics to emphasize on during the breeding program.

\section{Measuring superior breeding stock}

Once the breeding goal has been established by describing the desired stock, choices need to be made as to how the various characteristics will be measured. Although more precise ways to evaluate colonies may be devised in the future, at present the breeder must choose his stock from the on-site performance of colonies established in apiaries.

Test apiaries should be established with colonies arranged in an irregular pattern, with the colonies spaced as far apart as possible. Apiary sites that have trees, shrubs, or other such landmarks are valuable. These various precautions will tend to prevent the drifting of field bees. Other management producers also should be reasonably uniform so that all colonies have an equal opportunity to perform. Management producers should conform reasonably well to the management procedures used with production colonies.

Test colonies will be evaluated for the various characteristics to determine which colonies will be used as breeding stock. In all cases, beekeeping judgment will be brought to bear on the evaluation. The power to select more accurately the best breeders, however, will be enhanced if each colony is given a numerical score for each characteristic being evaluated. This will require the keeping of extensive records on colonies. Obviously, deficient colonies can be left out of the record keeping to ease the load. Such records are particularly important when different evaluations, such as honey production and over-wintering important when different evaluations, such as honey production and over-wintering ability, are made at different times. 
Once all the colonies have been evaluated, which will take 1 to 2 years, depending on the characteristics to be improved, breeder colonies can be chosen. The scores given to a single colony for all the various characteristics can be added to provide a single numerical score for the entire colony. Such scores can then be compared to select the best colonies available. More emphasis can be put on one or other characteristics by adjusting the scores given for that characteristic. For example, honey production may be scored on a scale of $0-20$, while temper may be scored on a scale of $0-10$. This arrangement would be used if honey production was considered twice as important as temper.

\section{Breeding methods}

The breeding methods as given by Rinderer (1977) have been discussed below.

Line-breeding: The common method of breeding practiced by queen breeder is known as line-breeding. It can be defined as breeding and selecting within a relatively small closed population. The bee breeders' colonies constitute such a population to the extent that mismatings with drones outside their stock do not take place.

The general procedure in line-breeding is to rear queens from the best colonies. These queens are both sold as production queens and used to requeen the bee breeders' test colonies. The queens are allowed to mate with the drones present in the bee breeders' outfit at the time the queens are reared.

In line-breeding, some inbreeding is inevitable. Its main effects are (1) fixation of characteristics so rapidly that effectiveness of selection for good qualities is reduced, (2) the stock looses vigor as a general consequence of inbreeding, and (3) the poor brood pattern from homozygous sex alleles. These effects can be reduced by using as many breeding individuals as possible for every generation.

To keep inbreeding at a minimum, one should rear queens from a large number of outstanding queens as possible and requeen all the field colonies with equal numbers of queens from all the breeders. Each group of queen progeny is then considered a queen line and each year, after testing, at least one queen in each line is used as a grafting mother.

Despite these several precautions against in breeding, stock may begin to show a spotty brood pattern and other symptoms of inbreeding. When this occurs, new stock must be brought in the operation. At least 10 virgin queens from each of several promising stock should be mated with drones of the declining stocks and established in apiaries outside the matting range of the bee keeper's queen-mating yards. They should be evaluated there to determine which stock(s) combine best with the deteriorating stock. Once this evaluation is made, the preferred stocks can be established as new queen lines.

Hybrid breeding: When inbred lines or races of bees are crossed, the hybrid progeny often are superior to either parent for one or many traits. This phenomenon is called hybrid vigor or heterosis. Hybrid bees have more heterozygosity in their genome than do inbred or line-bred bees. This heterozygosity is thought to be the basis for hybrid vigor.

Hybrid-breeding programs in bees are considerably more complicated than line-breeding programs. At the very least, three inbred lines must be combined so 
that both queens and their worker daughters are hybrids. An inbred queen mated to inbred drones will produce hybrid workers. However, the egg-laying qualities of the inbred queen probably would be inadequate. Therefore, there is a need to mate hybrid queens to inbred drones so that queens and workers in production colonies are hybrid.

Four-line hybrids also are possible and commercially available. Such a hybrid may involve lines 1, 2, 3, and 4 and could be combined in the following way: An inbred queen of line 3 artificially mated to drones of line 4 is used as a grafting queen to produce hybrid $(3 \times 4)$ queens. These are allowed to mate naturally and are used to produce drones. Queens of line 1 are then mated to drones of line 2 and hybrid virgin queens $(1 \times 2)$ are reared from the mating. Queens are produced from a cross of virgin queens (1/2) mated to the drone progeny from the $3 \times 4$ queens. Colonies produced by this cross will be headed by two-way hybrid queens, which will be uniform in appearance, whereas the worker bees will be four-way hybrids and variable in appearance, unless the colour markings of the parent lines are very similar.

Comparative tests of hybrids have shown their superiority. Increased productivity of 34 to $50 \%$ over average of line-bred strains has been reported. Segregation and random mating in the generations following hybridization are likely to result in queens that are no better than the average supersedure queen. Hybrids are an end product, and to make best use of them, it is necessary to requeen every year.

Whatever the specific choice of breeding scheme be, hybrid breeding requires the use of instrumental insemination and careful record keeping. As a consequence, few bee breeders have undertaken the entire operation of a hybrid program. However, many have become involved as producers of hybrid queens with the breeding stock supplied by an outside source.

\section{Germplasm storage}

Germplasm is the hereditary material that can produce new individuals. In honey bees, this includes eggs, sperm and tissue that can potentially produce eggs or sperm. Since, every breeding program needs to keep certain stock for current and future use, the problem becomes one of either storing it or continually propagating it.

At the present time, honey bee germplasm is kept primarily through propagation. Thus, germplasm is usually in the form of mated queens-their ovaries and the sperm in their spermatheca. Alleles are lost gradually through inbreeding, so each generation reduces the variability of the germplasm slightly.

To avoid this loss and the labour involved in propagation, attempts have been made to store honey bee germplasm. Among the possible candidates for storage (eggs, larvae, pupae, virgin queens, sperm), sperm storage has been the most successful. Sperm stored for less than 2 weeks at nonfreezing temperatures seems to be as viable as fresh sperm, but longer storage results in fewer sperm reaching the spermatheca. Although inferior inseminations result from sperm stored in liquid nitrogen $\left(-169^{\circ} \mathrm{C}\right)$, nitrogen shows great promise for long-term storage where survival of the germplasm is the major concern. 


\section{REFERENCES}

Butler, C.G. 1967. A sex attractant acting as an aphrodisiac in the honey bee (Apis mellifera L.) Proceedings of Royal Entomological Society London 42: 71-72.

Cale G.H., Rothenbuhler W.C. 1975 Genetics and breeding of the honey bee, (In) Dadant and Sons (Ed.), The hive and the honeybee, Dadant and Sons, Hamilton, Illinois, pp. $157-84$.

Chaud-Netto, J. and Kerr, W.E. 1980. Genetic mechanisms for the development of reproductive organs of Apis mellifera workers and diploid drones. A complementary hypothesis Braz J. Genet 3: 127-38.

Chaud-Netto J. 1975. Sex determination in Bees. II. Additivity of maleness genes in Apis mellifera. Genetics 79: 213-217.

Deodikar, G. B. and Thakar, C.V. 1966. Utilization and Improvement of the local floras as bee pasturage. Proceedings of Autumn School Bot.Mahabaleshwar. Dept. Bot, Poona University $122-28 \mathrm{pp}$.

Deodikar, G. B., Thakar, C. V. and Shah, P. N. 1959. Cytogenetic studies in Indian honeybees.Proceedings of the Indian Academy of Sciences - Section A Part 3, Mathematical sciences 49(3): 194-206.

Dietz, A. 1975. Nutrition of the adult honeybee. In: The hive and the honeybee. Dadant \& Sons, Hamilton, Illinois. pp. 125-56.

Doolittle, G. M. 1889. Scientific Queen Rearing. Thomas G. Newman. Chicago. III

Dutton, G. M. and Simpson, S.1977. Producing honey with Apis florea in Oman. Bee World. 56: 71-76.

Fahrenhorst, H. 1977. Chromosome number in the tropical honeybee species $A$. dorsata and A. florea. Journal of Apicultural Research 16: 56-58 pp.

Fahrenhorst, H. 1977. Uniform chromosome numbers (N 5 16) in 4 species of Apis. Apidologie. 8: 89-100.

Fakurddin, B., Babu, K. O., Yerimani, A. Mohankumar, S., Lazar, K.V., Chapalkar, S., Viraktamath, S. and Vastrad, A.S. 2013. Genetic diversity and phylogeography of Apis cerana Fab. in monograph on morphometry and phylogeography of honeybees and Stingless bees in India (Edited). Department of Biotechnology, Government of India, New. Delhi, 123-57 pp.

Free, J.B. 1987. Pheromones of social bees. Cornell Univ Press, Ithaca, NY

Glenn, T. 2002. Workshop on principles of honeybee genetics', Cornell University, USA.

Govindaraju D. R. 1989. Estimates of gene flow in forest trees. Biological Journal of Linneous Society 37: 345-58.

Hamman, E. 1956. Werhat die Initiative bei den Ausflùgen der Jungkonigen, die Konigin order die Arbeitsbienen? Institute Society 4: 91-106.

Hoshiba, H., Okada, I. and A. Kusanagi. 1981. The diploid drone of Apis cerana japonica and its chromosomes. Journal of Apicultural Research 20: 1432-47.

Hoshiba, H. and Kusanagi, A. 1978. Karyological study of honeybee, Journal of Apicultural Research 17, 105-09.

Hoshiba, H., Okada, I., and Kusanagi, A. 1981. The diploid drone of Apis ceranajaponica and its chromosome. Journal of Apicultural Research 20, 143-47.

Jordan, R.A., Brosemer, R.W. 1974. Characterization of DNA from three bee species. Journal of Insects Physiology 20: 2513-520.

Koeniger, N. 1976. Neue Aspekte der Phylogenie innerhalb der Gattung Apis. Apidologie 7: $257-66$

Koeniger, N. and Wijayagunasekera, H. N. P. 1976. Time of drone flight in the three Asian honeybee species (Apis cerana, Apis florea, Apis dorsata), Journal of Apicultural Research 15: 67-71. 
Kulincevic, J. and Rothenbuhler, W. C. 1975. Selection for resistance and susceptibility to hairless black syndrome in the honey bee. Journal of Invertebrate Pathology 25 : 289-295 pp.

Lazar, K.V., Fakurddin, B., Babu, K. O., Mohankumar, S., Parthiban, T. P., Chapalkar, S., Viraktamath, S. and Vastrad, A. S. 2013. Genetic diversity and phylogeography of Apis florea Fab. in monograph on Morphometry and phylogeography of honeybees and Stingless bees in India (Edited). Department of Biotechnology, Govt. of India, New Delhi, 101-123 pp.

Maul, V. 1969. Die Ursache der Kreuzungsbarriere zwischen Apis mellifera L. and Apis cerana Fab.2. Eibefruchtung und Embryonalentwicklung Proceedings International Apicultural Congress (Apimondia) 22: 515-516.

Mohankumar, S., Preetha, B., Fakurddin, B., Babu, K. O. Chapalkar, S., Lazar, K. V., Viraktamath, S and Vastrad, A.S. 2013. Genetic diversity and Phylogeography of Apis dorsata Fab. in monograph on Morphometry and phylogeography of honeybees and Stingless bees in India (Edited). Department of Biotechnology, Govt. of India, New Delhi, 66-100 pp.

Peer, D.F. 1957. Further studies on the mating range of the honey bee.Can. Entomol. 89: 108-10.

Rinderer, T. E. 1977. A new approach of honey bee breeding at the Baton Rouge USDA laboratory. American Bee Journal 117(3): 1146-47.

Ruttner, F. 1969. The cause of the hybridization barrier between Apis mellifera L. and Apis cerana F. 8. Experiment with natural and artificial insemination. Proceedings International Apicultural Congress (Apimonidia) 22: 561.

Ruttner, F.1988. Breeding techniques and selection for breeding of the honeybee. British Isles Bee Breeders Association. 152pp.

Ruttner, H. 1972 Technical recommendations for methods of evaluating performance of bee colonies. Apimondia. $87-92 \mathrm{pp}$

Shah, F. A. and Shah, T. A. 1980. Early life, mating and egg laying of Apis cerana queens in Kashmir. Bee World. 61: 137-40.

Shearer, D. A., Boch, R., Morse, R. A. and Laigo, F. M. 1970. Occurrence of 9-oxodectrans2-enoic acid in queens of Apis dorsata, Apis cerana and Apis mellifera. Journal of Institute Physiology 16: 1437-41.

Thakar, C. V. and Deodikar, G. B., 1966. Chromosorne nurnber in Apis florea Fab., Current Science, 7: $186 \mathrm{pp}$.

Weinstock, G. M., Robinson, G. M. and Gibbs, R. A. 2006.Insights into social insects from the genome of the honeybee Apis mellifera. Nature, London 443: 931-949.

Wilson, E.O. 1971. The Insect Society. Harvard University Press, Cambridge, MA. 548 PP

Wokye, J. 1979. Sex determination in Apis cerana indica. 18: 122-27.

Wokye, J. 1980. Evidence and action of cannibalism substances in Apis cerana indica. Journal of Apicultural Research 19: 6-16.

Woyke, J. 1975. Natural and artificial insemination of Apis cerana in India. Journal of Apicultural Research 14: 153-59.

Woyke, J. 1960. Natural and artificial insemination of queen honeybees. Bee world. 43: 21-25.

Woyke, J., Knytel, A. and Bergandy, K. 1966. The presence of spermatozoa in the eggs as proof that drones can develop from inseminated eggs of the honeybee. Journal of Apicultural Research 5: 71-78. 


\title{
7 \\ Queen Rearing and Multiplication
}

\begin{abstract}
$\mathrm{T}$ HE performance of a colony of bees depends largely on the inherited and physical qualities of its queen. The queen transmits to the colony through her inherited characters and those acquired through the fertilization of the egg, all of the characteristics pertaining to longevity, industriousness, disease resistance, temper, colour, swarming tendencies, degrees of excellence in building comb, robbing properties, and many other important values of individual and colony behavior. A young, vigorous, and prolific queen generally produces a larger number of bees than an old queen and colonies headed by young queens swarm less than those that have old queens. In order to secure the greatest gain from beekeeping, the beekeeper must maintain good, prolific queens in all of his colonies. This requires requeening all colonies every second year and in many sections of the country where brood rearing is longer and more intense, the change of queens every year is a distinct benefit. Besides such periodic changes of queens, there is a need to replace queens which fail, or are injured, or which disappear during the manipulation of the colonies or when hives are moved, as in pollination services or migratory beekeeping. To maintain the strength of colonies for continued production, queens should be readily available for all such replacements. When the beekeeper can give individual attention to each colony, occasional queens can be left to give satisfactory service for longer than one or two years.
\end{abstract}

Drones which are reared from the unfertilized eggs are haploid and carry the genomes of their mother. The males and queen contribute to the heredity of the offspring workers. Under natural conditions a beekeeper cannot exercise control on parentage and drones from the vicinity can take part in fertilizing a queen. But good queens can be reared from better performing colonies so that the hereditary characters contributed by the mother can be improved to a greater extent. In an apiary, many queens may require requeening and colony division. Mishra (1995) described the queen rearing and artificial queen bee insemination at length in India.

\section{Selection of mother stock}

Requeening of some or all the colonies in an apiary becomes a feature of annual management. With some additional efforts, an element of multiplying a better stock can be introduced. All the colonies in an apiary are not equally superior performers. Beekeepers are concerned with higher honey production but honey production is directly correlated with amount of brood rearing as also the queen's 
egg-laying capacity, industriousness of workers, swarming and absconding tendency, frugal behavior and disease resistance. Apiary records for these attributes are essential to select the best colonies for queen rearing. In the absence of records for all these attributes, only the honey yield records of colonies can serve an important criterion for selecting colonies for mass queen rearing. Superior colonies can also be induced to rear drones. Though the mating with these drones cannot be assured yet the chances can be increased by making these colonies to rear more drones.

\section{Biological basis of queen rearing}

Queen bee lays fertilized as well as unfertilized eggs. Both the workers and queen developed from fertilized egg. A larva from a fertilized egg can be reared into a worker or a queen. There seems to be no or very little genetic bias in caste determination. Worker and queen larvae are fed on glandular food for the first 2 or 3 days and there is hardly much difference in the quality of food of the 2 castes. Moreover, supply of food is more than the requirement. At about the age of three days, there is a shift in food to worker larva, whereas queen larva continues to get the nutritious glandular secretion food. Honey and pollen is mixed in the food of worker larva and also the feeding is progressive or in other words, the developing larva is starved to some extent.

Larvae from fertilized egg is flexible for caste determination up to the age of $72 \mathrm{hr}$ but the queens reared from larvae older than $72 \mathrm{hr}$ may develop into intercastes. Diet is the major caste determining factor. Though the better food is responsible for higher $\mathrm{JH}$ content in queen larvae which consequently affects the development of reproductive organs. Feeding of stored royal jelly is also not a perfect food for queens rearing which indicates that the royal jelly has some labile fraction. A colony rears queen, only when certain favourable conditions are available. The bee colony must be crowded so that bees feel the necessity of rearing queens under swarning impulse. This condition can be altered in case of queenlessness, where the influence of queen larvae, large number of young nurse bees are required because worker bees of the age of 6 to 13 days have well developed and active food glands. Food glands of worker bees remain actively secretory if they get a continuous supply of pollen. Therefore, continuous income of pollen and nectar also creates favourable conditions for queen rearing. The queen rearing is possible if these prerequisites are naturally available or are artificially created by manipulations.

\section{Selection of breeding stock}

In India, the concept of bee breeding is by and large lacking. To achieve this objective, the quality queens need to be produced in large numbers. Generally, the stock of the honeybees with the beekeepers is not of uniformly good quality from the production point of view. Individual colonies differ from one another in various attributes. Selecting best colonies for breeding is an art which depends upon experience and keen sense of observation on the part of the beekeeper. The past honey production if maintained by the beekeeper for individual's colonies are helpful in making the right selection of colonies. Besides this, such factors as 
fecundity, longevity, industriousness, disease resistance, lack of swarming instinct etc. are also important for consideration during selection. The whole stock needs to be restored and a few colonies are finally selected as breeder queens for queen cell production and stock multiplication (Laid law, 1979).

\section{Important attributes for selection of breeder queen}

Hamdan (2008) mentioned the following important traits for selecting queens.

1. Gentleness

2. High honey production

3. Early spring build up in population

4. Non or low level of swarming tendency

5. Disease and varroa mite resistance

6. Quite on the comb

7. Good comb builders

8. Ripens honey rapidly

9. Honey comb capping be white

10. Non or low propolis producers

11. Good wintering quality

12. Non or low followers (i.e. bees do not follow the beekeeper when leaving the apiary)

13. Economical brood rearing when nectar flow is low or stopped.

14. Bees that fly out at lower temperatures

\section{Conditions for queen cell construction}

Swarming impulse (Impulse for natural increase): If the population of a colony gets greatly increased, it leads to crowded conditions and insufficient availability of queen substance to the workers. Thus, swarming impulse gets dominated in the colony, and the workers start constructing the queen cells on the edges of the brood frames. The young larvae selected for queen rearing are considered to be well fed during this impulse and good quality/heavy weight queens are expected.

Supersedure impulse (Impulse for replacement of aged queen bee): This impulse is triggered off by the failure of old queen to produce sufficient quantity of queen substance. Under this impulse, a few queen cells are constructed, unusually on the edges of brood area. This impulse also can not be created at will by the beekeepers for utilization in the mass production of queen cells on commercial scale.

Emergency impulse (Queenlessness): Queenlessness impulse is characterized by the sudden absence of queen which deprives all the workers of the queen substance. The queen cells are, thus, constructed under emergency condition anywhere around the existing eggs/larvae of suitable age by removing the partition wall of adjacent worker cells, thereby enlarging the cell for rearing the queen. Queen cells constructed under this impulse are not necessarily on the lower edges of the brood area. This impulse can easily be aroused simply by dequeening the parent colony during breeding season and is utilized for commercial production of the quality queens from the selected stocks. 


\section{Pre-requisites for queen rearing methods}

For all the methods of mass queen rearing, important operations are management of breeder colony, starter colony and cell or finisher colony.

\section{Breeder colony}

To get larvae from selected colony for grafting, specific comb arrangement in the breeder colony is required. The hive body of the breeder colony is divided by inserting a piece of queen excluder vertically into two compartments so that one part contains six frames of honey and pollen and other part contains one frame of open brood and one frame of sealed brood. In between these two frames, one empty, slightly dark coloured empty comb with worker cells is placed for the queen to lay eggs. The mother queen bee is confined to this three frame compartment of breeder colony. The colony is supplemented with sugar solution feeding or enhancing brood rearing by the nurse bees. After 3 days of deposition of eggs in the empty dark comb, it is full of newly hatched larvae for grafting in the queen cell cups. Each time removing the larvae another empty comb is replaced for egg laying. After emergence of adult bees, that comb is replaced with another scaled brood comb to ensure the proper strength of nurse bees in the colony.

\section{Queen cell starter colony}

Usually this is a queenless colony with enough food stores (honey and pollen) and good number of nurse bees. This can also be prepared by uniting two colonies. This colony is regularly supplied with food, sealed and larval brood. Frame with grafted larvae is placed in between larval brood frame and pollen stores.

\section{Cell builder or finisher colony}

Cell builder is established four (4) days prior to larval grafting by dequeening a 10 frame strong colony. The dequeened colony will raise a few queen cells from which the royal jelly extracted to prime the artificial queen cell cups by discarding the larvae. Extra young bees or sealed brood frames are given to the colony to maintain a sufficient number of nurse bees.

Cell finisher colony can also be strong double chamber queen right colony in which the queen is confined to the lower chamber by using a queen excluder and queen rearing frame is placed in the upper queenless hive body having the bee frame arrangement as described for queenless cell builder colony.

\section{Methods for commercial queen rearing}

There are several methods of mass queen rearing discussed by various authors; Laidlaw, 1979; Ruttner, 1983; Graham, 1992 which are briefly described below;

Queen rearing: It is inhibited by pheromone secreted by the mandibular glands of the queen and spread over the queen's body to be licked by the workers. Certain level of this pheromone would be required to suppress the queen rearing urge. The level of the queen pheromone available to the workers may be reduced when the colony population is very high. Such overcrowded and populous colonies rear queen cells under swarming instinct. The reduced amount of queen pheromone is available to the workers in a colony when the queen is old and is exhausting. The 
bees feel the necessity of superseding the old, failing queen and queen cells are raised on the face of the comb but are fewer in number. The queen can be reared fom the eggs or the larve. Failing queen. herself lays eggs in the supersedual cells raised by the workers. In case of sudden loss of queen, the queen cells are built under emergency impulse and these queens are reared from worker cells with larvae of certain age. Therefore, they are built on the face of the comb and the queens vary in development stages. Queen rearing is triggered off when any of the above 3 conditions are available or artificially created. When few queens are required, a beekeeper can remove the queen from a colony and few emergency queens are raised by the bees. Modified swarm box method used for swarm control can be profitably used without removing the queen.

Darmee method of swarm prevention: The queen with a brood comb, honey and pollen comb and remaining frames with empty combs or comb foundation is restricted to the lower chamber. All other frames with sealed and unsealed brood are kept in upper chamber with a queen excluder in between the two. The second super if already there can be placed in between the 2 chambers. Few queen cells are built above the queen excluder and the sealed queen cells can be carefully removed from the base and the emerging queens can be used.

Miller method (1911): In this methods comb foundation is cut into deep vshaped sections and reaching about two-third way down the frame is used/fixed. The wires except the upper one from such frames should be removed. The frame is then inserted into the middle of brood nest of the selected strong queen-right colony. By feeding the colony with sugar syrup the bees are induced to work/ raise comb cells on $\mathrm{V}$-shaped comb foundation sheet for the queen to lay eggs in cells. When this has been achieved, the frame is removed from the mother colony and is inserted in the centre of a cell builder colony. Cell builder colony should be very strong and dequeened at least 24 hours before inserting the egg frame. All the eggs and young larvae should also be removed from the cell builder colony. The bees will build queen cells along the border of the given $\mathrm{v}$-cut comb and after about 10 days sealed queen cells would be ready for transplanting in the desirous dequeened colonies. With this method, even up to thirty queen cells are frequently produced on each comb under favorable conditions.

Alley method (1883): The breeder queen is induced to lay eggs in the newly drawn comb. After 3 days of laying, the eggs will hatch and the comb is cut into strips of one row cells wide. The cell walls of the comb containing the larvae are shaved down to about $6 \mathrm{~mm}$ from the cell base. The next step is to destroy two out every three cells along with their larvae (by putting a match stick in the cells) so as to provide sufficient space between the two royal cells. The strip of combs, containing young larvae, is then glued to the lower edge of a comb already trimmed in a semi-circle. This frame is then given to the cell builder colony and prepared as mentioned in Miller methods. The workers will remodel the cell containing newly hatched larvae and raise them into queen cells.

Smith method (1949): This method is a modification of the Alley method in which the stripes of cells containing eggs or very young larvae ( 1 to 2 days old) are glued by wax to the horizontal wooden bars and then the bars are fitted into frames parallel to the top bars. Such frames are then placed in the cell builder colonies. 
Hopkin method (1886): With this method, a large number of queen cells are obtained. A fresh comb is placed in the brood nest of mother colony until it is filled up with eggs. Then it is removed and brought into a warm room and placed flat on a table. Three out of every four rows of cells across the comb are destroyed upto the mid rib, leaving every fourth row intact. Two out of three eggs are destroyed in each row. This frame is then laid over the top bars of the frames in the brood chamber of cell builder colony with the prepared side facing downward. In order to provide space for bees to raise the queen cell properly, one empty wooden frame without wires is placed just beneath the laid over comb. The bees will start raising the queen cells. When the raised queen cells are sealed they are cut out with the sharp warm knife and grafted in to the dequeened colonies.

Karljenter Queen cell cup kit method: Karilenter (1986) developed "Queen Cell Cup Kit Apparatus" for grafting worker larvae without touching. The queen bee is made to lay fertilized eggs in a plastic comb where comb cells are extended beneath to a removable brown plastic cell cup. After egg hatching, these plastic cell cups along with young larvae are removed with cell cup cap and are fixed on to a cell bar of queen rearing frame with already fixed plug holder. The frame is then given to a queenless cell bulder colony nursing the gynes.

Doolittle or Grafting method (1889): Doolittle or grafting method is most commonly used for mass queen rearing. This method requires the grafting of young larvae in queen cell cups. The cups can be of plastic or made from pure bees wax with inside diameter of 8-12 mm for Apis mellifera and 6 to $9 \mathrm{~mm}$ for Apis cerana. Single forming stick can be used for preparing large queen cups when only few queens are to be raised. For preparing large number of cups, the single forming stick is not practicable and multiple forming sticks are useful. The multiple forming stick is a bar made by attaching 10-15 cell forming sticks of same length to a thick stripe of wood with spacing of about $2.5 \mathrm{~cm}$ from centre to centre. Wax is melted in a tray on thermostatically controlled hot plate or in water jacketed tray. The wax for attaching the cups to the bars is melted just above the melting point. The cell bar is laid over the pan of wax for attaching the cell cups to bars. Wax put over the upper surface and the sticks with the cell cups are rested on the bar and more wax is put along the sides and between the cups. The sticks are held in position till the wax has cooled. The forming sticks are then lifted off by putting an even pressure on the ends off the bar. A strong, well-fed and superiorperforming colony is selected for obtaining larvae for grafting. The bees are shaken off and the frame containing sufficient young larvae is taken to grafting room. A temperature and of $24^{\circ} \mathrm{C}$ and relative humidity of about $50 \%$ is suitable. Grafting in the open may lead to drying and desiccation of grafted larvae if the temperature and humidity conditions are not conducive larvae get chilled if the atmospheric temperature is low. A bright lamp is

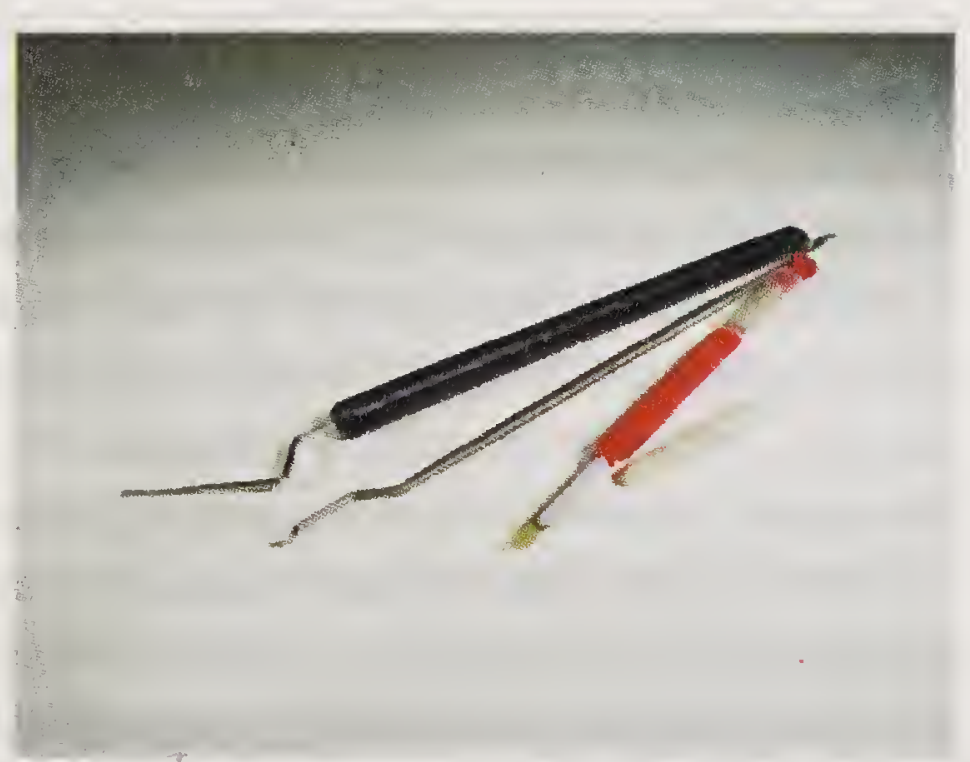

Fig. 7.1 Grafting needles 
placed so that shines directly on the bottom of the comb cells when the comb containing the larvae to be transferred is little titled towards the operator.

For grafting, a grafting needle with flat upward bent is used (Fig. 7.1). For more extensive queen rearing, the use of automatic grafting needle is advisable. Automatic grafting needle has retractable tongue which is extended about 1.5 $\mathrm{mm}$ before it is slipped sideways under the larvae. This grafting tool also transfers sufficient royal jelly along with the larvae and is very successful in dry grafting. While placing the larvae at the base of the queen cell cup, the lever of the grafting needle is released so that the tongue retracts back and larva is left on the base of the cup. Less experienced operator may need priming of cell cups with royal jelly to achieve better results.

Queen cell builders: There are several methods for starting the queen cells but swarm box is common method. Little before the newly grafted queen cells are given, the box is the stocked with $2.5 \mathrm{~kg}$ of bees taken from active brood nest (Fig. 7.2). Two pollen combs are given on either side of the frame with grafts. Combs with stored honey are given to the cell starter and continuous supply of sugar syrup is useful. A useful modification of this queenless swarm box is profitably used. The 'modified swarm box' is a cell starter in which the bees are confined above the two-storey colony for 24-36 hr while cells are being started. Queen is confined beneath the excluder in the bottom body with sealed brood and empty combs and combs with young brood are moved to the upper body. A full depth body is prepared by putting 2 pollen combs, 2 or 3 combs with honey stores and division feeder full of sugar syrup. The frame with grafted cell cups is placed in between the 2 combs with pollen stores. All the young bees from above the queen excluder, that is, second hive body, is shaken off in the prepared starter body below which a 8mesh hardware screen is fastened. The combs with young brood are returned

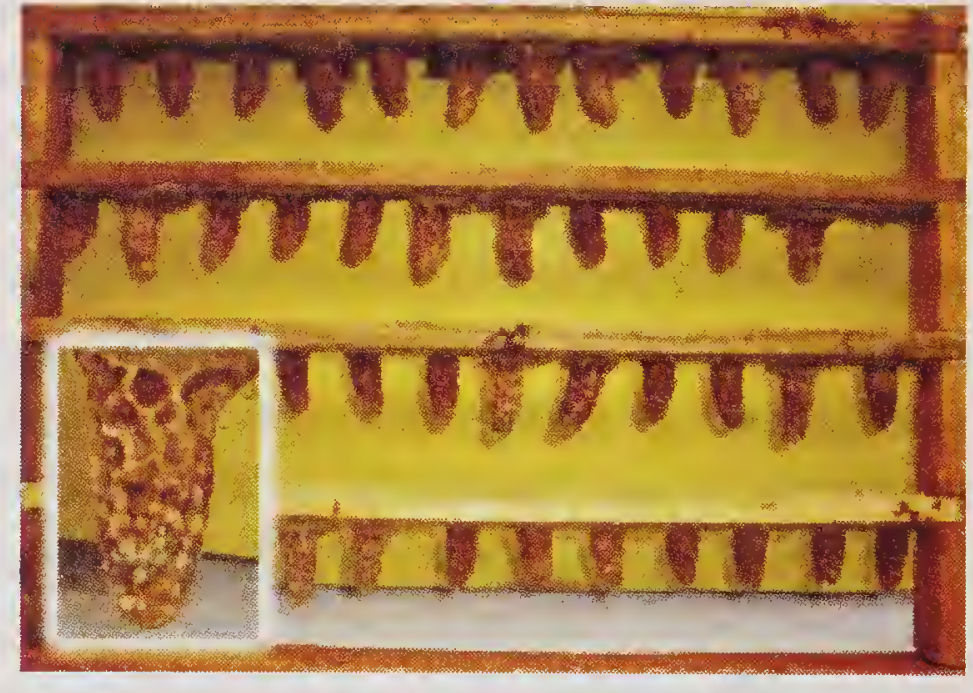

Fig. 7.2 Sealed queen cells obtained from mass queen rearing by grafting (Buchler et al., 2013) to the second hive body. The bees cannot move from the second to the third hive body and bees are confined there for $24-36 \mathrm{hr}$ by which time the cells are drawn and queen larvae are being reared. The screen is then removed and the hive is reduced to 2 bodies with and exclude in between the two. The cells are sealed and sealed and removed a day before emergence and put in incubator for emergence.

Cell builder colonies can be repeatedly used for starting the cells. The cells once started can be given to cell finisher colonies for completion. The cell finisher colony can be a strong 2-storey queen right colony. Queen is confined to the lower body by an excluder and cells are completed in the upper body.

Double grafting is also practiced to ensure good quality queens. In double grafting, the first grafts are removed after the cells have been started and second graft is given in the same cell cup. This is to avoid starving of the graft and the second graft will get food supply immediately. 
Transplanting queen cells: This is an important operation in queen rearing and the success lies in the accuracy and precision of this operation. Since a large number of queen cells are raised at a time, one should prepare in advance, an equal number of nucleus colonies to which these sealed queen cells are to be transplanted. Nucleus hives/nucleus should have sufficient number of worker bees of all ages, mature drones and sufficient quantity of food reserves so that the emerging young queen is attended well in the colony. Before actual transplantation of a queen cell, it must be ensured that the workers in the nucleus hives already have felt the absence of the queen atleast $24 \mathrm{hr}$ prior to the transplantation, otherwise, the chances of tearing off immature queen cells by the recipient colony workers cannot be ruled out. Removing the queen cell from the cell builder colony and transplantation into the nucleus hive is an operation, which needs a good amount of experience. Individual queen cells are scrapped off with a sharp edged knife. The cells removed in this way should be transplanted just near the brood area and it must be ensured that it is properly fixed on the raised comb in the recipient colony. The transplanted cells should be fixed in such a way and at a location on the frame that it is properly covered by the bees.

\section{Artificial queen bee insemination}

Artificial queen bee insemination technique is now available and mating in the open can be bypassed. There are distinct advantages of the technique. By artificial queen bee insemination method, the parentage can be controlled. The virgin queens can be inseminated with the semen from desired drones and hence the technique is the only method for bee breeding but for commercial beekeeping the artificially inseminated queens are less suitable. The queen insemination can be possible at any time of the day and even in bad weather. But the disadvantage is that the operator should be experienced to achieve high success. Success of instrumental insemination also depends on the simplicity and reliability of insemination apparatus. Mackensen and Roberts were the first to develop it in 1948 which met these requirements. During the same year. Laidlaw also developed an artificial insemination equipment. Mackensen and Robert's apparatus is more widely used because of its simple construction and easy handling. Several improvements have since been made in this apparatus. The two types of apparatus basically differ as follows:

With both the apparatus, the operation of insemination consists of the same steps but details of how these steps are accomplished differ. Glass in place of plastic syringe tips is now developed. Glass tips can be drawn with substantially smaller diameters than plastic tips. Because of smaller diameters, the tips should be more suitable for inseminating Apis cerana indica queens. Glass tips have smoother surface and, therefore, injure the queen less frequently. They are also easier to sterilize but are easily broken.

Insemination: There are some important considerations for the success in queen bee insemination. (i) Queens reared from different breeder colonies differ with respect to the case of insemination. (ii) Large-sized queens with long tapering abdomens are easy to inseminate than short, stubby queens. (iii) Virgin queens of the age of about one week are better as it is easy to locate their vaginal orifice but 
in older queens the operation becomes difficult.

Preparing the queen for artificial insemination is important. Queen is made to move into the tube similar to the queen holder. When she reaches the narrow opening end she backs up and queen holder is quickly placed with the open end of the tube. As she reaches the narrow end of the queen holder, the stopper through which $\mathrm{CO}_{2}$ is flowing is pushed in so that the last segments of the abdomen protrude. As soon as the queen is quiet, 2 hooks are put in position to open the abdominal end. Syringe is prepared by filling the syringe tip with solution to serve as a liquid plunger. Sodium chloride $(0.9 \%)$ is satisfactory but Ringer's solution is good. These avoid the mortality of the sperms. Air in the syringe is avoided because it nullifies the purpose of the liquid plunger.

Drones vary in the case with which they are induced to ejaculate and also in the amount of semen produced. All the drones caught at the hive entrance do not evert and deliver semen, some evert so violently that the semen is lost or sometimes even penis bursts. For quicker collection of semen the drones are caught from the entrance in the afternoon and caged in the cages. The drone holding cages are held in normal bee colonies. The cage has a queen excluder sheet on one side and hardware screen on the other and it allows nurse bees to feed the drones. These drones are used for semen collection after few days so that all are advantageously made to fly in drone flying cages, so that they get excited. Drone is held from the head and thorax between the thumb and index finger and with little ticking it everts. The operator needs experience to collect semen without mixing the mucus. The tip of the syringe is applied to the semen and is drawn by retracting plunger of the syringe. The semen should be quickly collected after eversion. The operator should avoid to collect every bit of the semen on the penis because in that case there are chances of drawing the mucus into the syringe. As soon as the syringe tip is filled, a small amount of physiological saline is drawn into the syringe tip. Washing technique for semen collection involves scrapping of semen and mucus in physiological diluent in a semen washing funnel and a collecting tube. The mixture of semen, mucus and diluent is centrifuged at 2, 500 rpm for $10 \mathrm{~min}$ to separate semen from mucus and diluent.

For the insemination of semen, the syringe tip is posed above the vaginal opening. It is inserted into the dorsal part of the vagina and the valve fold is pushed ventrally until the tip of syringe has passed beyond the valve fold. In natural mating, the queen herself lowers the valve fold. If the column of semen does not begin to move by moving the plunger, then the syringe is not in median oviduct and must be withdrawn for another attempt. Number of sperms injected. 8 microlitres of semen is adequate. Semen given in 2 inseminations with equal amount is better since more number of sperms are stored as compared to single insemination.

Inseminated queens are kept in cages and held in nursery colonies. They start laying eggs after 2-4 days but $\mathrm{CO}_{2}$ treatment reduces this period.

Woyke (1973) explored the possibility of instrumental insemination of Apis cerana queens. He found that semen was difficult to be separated from mucus and average semen was only $0.16 \mathrm{~mm}^{3} /$ drone as compared to $1 \mathrm{~mm}^{3}$ in Apis mellifera. Concentration and activity of spermatozoa is also lower in Apis cerana. 
Semen from 40-60 drones is necessary for effective insemination of Apis cerana queen. Crosses between the two species have also been attempted but could not be successful. Hardly any work has been conducted on Indian honeybee on the aspects discussed in this chapter.

\section{The insemination technique}

Requirements: Besides queen and drones, an insemination instrument (Fig. 7.3), complete with a syringe, hook accessories and a source of carbon dioxide $\left(\mathrm{CO}_{2}\right)$ for anaesthetization are required. A stereo microscope with a suitable cold-light source is also essential (Table. 7.1).

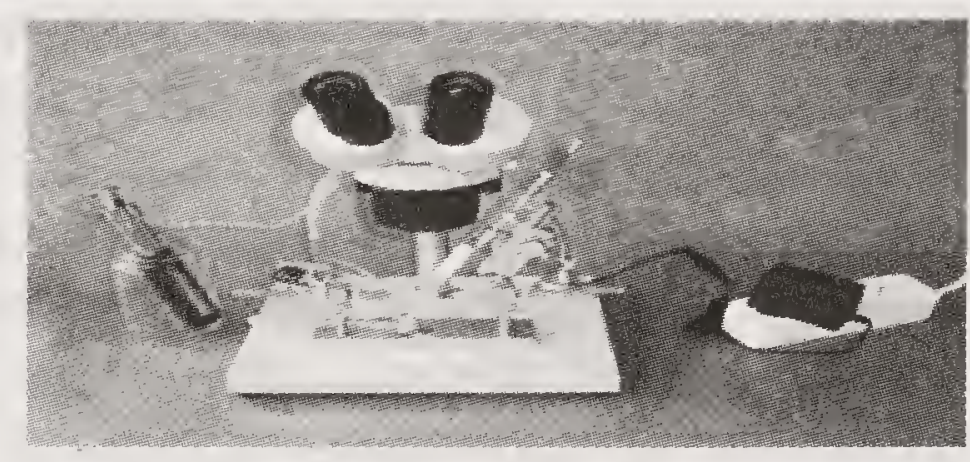

Fig. 7.3 Schley's instrumental insemination device (Cobey et al., 2013).

Table 7.1 List of tools, chemicals and other material required

\begin{tabular}{llll}
\hline S. N. Items required & S. N. & Items required
\end{tabular}

1. Disinfectant (sterilum/alcohol)

2. Chloroform

3. Boar sperm diluents or normal saline

4. Distilled water

5. Towel

6. Cleaning paper

7. $2 \mathrm{ml}$ and $20 \mathrm{ml}$ injection syringes

8. Cleaning tissue

9. Sterilized ear buds

10. Camel hair brush

11. Two petridishes

12. Two $500 \mathrm{ml}$ beakers

13. Autoclave

14. $\mathrm{CO}_{2}$ cartridge/cylinder with regulator
15. Incubator

16. A pair of scissors

17. Forcepe

18. Stereo microacope $(15.20 \mathrm{x})$ with with $80,120 \mathrm{~mm}$ clearance

19. Cold light source.

20. Insemination apparatus

21. Queen marking

22. Queen cage candy

23. Drone cages

24. Drone flight chamber.

25. Mature drone bees ( 15 to 20 days old)

26. Ready to mate queen bees ( 5 to 7 days old)

27. Queen introduction cages.

28. Mating nuclei

The necessary equipment consists of the insemination device, a syringe for the sperm transfer, a stereomicroscope, a cold-light-source and the anesthetizing device to immobilizing the queen bee.

Filling of the syringe: The syringe is sterilized and filled with sterile saline solution. A common physiological saline solution $(0.9 \%$ brine solution, $\mathrm{NaOH})$ can be used. Sterile water can be obtained in a glass ampule from a scientific supply company or a pharmacy. Alternatively, distilled water running through a bacteria filter with a pore size of $0.2 \mathrm{~mm}$ can be used. An antibiotic is also added to prevent contamination/infection.

Attaching the glass tip to the syringe: The blunt end of the glass tip is pushed into the syringe end/sleeve and the tip is attached with the sealing tube squeeze- 
sealing. The functioning of the hydraulic system of the syringe can be easily tested with the movement of control knob.

Stereo microscope: Magnification required for insemination is $15 \times 20 \times$ and a working space of $80-120 \mathrm{~mm}$ below the objective is required. Not all types of microscopes are suitable to use with the insemination instrument. Hence, be sure that the microscope and instrument chosen must be compatible. A cold light source, which does not produce heat, facilitating proper illumination is necessary for insemination operation.

Eversion of drone endophallus: The reproductive organs of the drone bee is used to collect semen, already marked from mature and healthy drones. Before actual collection of semen, the drones are stimulated to evert their bulb of endophallus (penis) inside out so as to expose the semen. Drone eversion is obtained in two steps i.e. partial eversion and finally complete eversion to expose the semen on the bed of thick mucus on the surface bulb of endophallus.

The drone is stimulated by decapitation, which results in partial or full eversion. Alternatively partial eversion is obtained by subjecting the mature drone, caught from drone flight cage, to some chloroform fumes. Further for full eversion, grasp from anterior part of abdomen and slightly press to get semen along with mucus. Semen is light pinkish to cream coloured, appearing mottled or cloudy.

Semen collection: A small air space in the syringe is created by withdrawing some amount of saline using plunger of syringe. This will prevent dilution of semen with saline. The ejaculated drone (fully everted bulb of penis/ endophallus) is brought near the syringe tip under the microscope. After making contact with semen, it is skimmed out form the more viscous mucus layer below. Avoid placing the tip of the
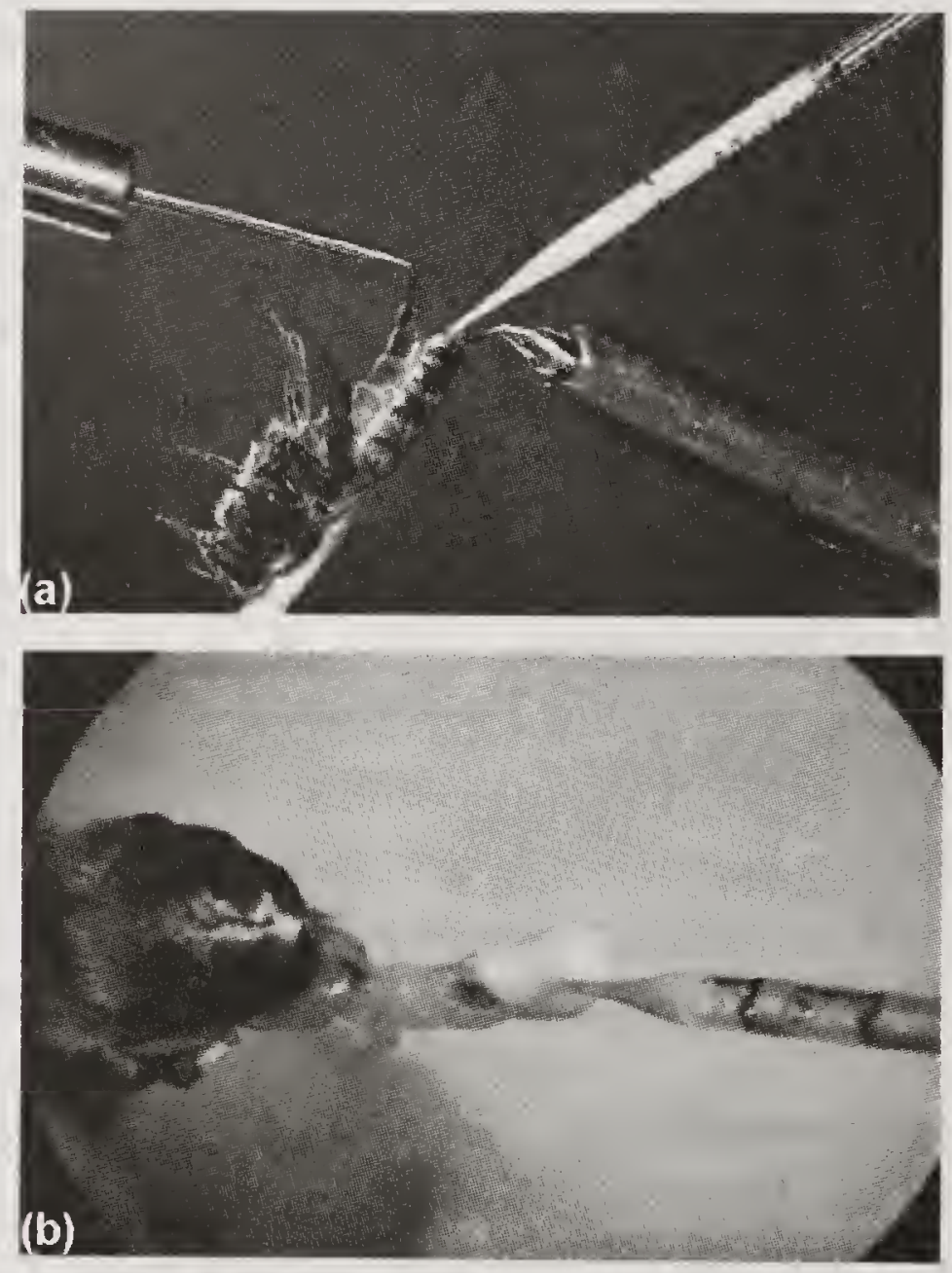

Fig. 7.4 (a) Semen collection from drone; (b) Semen injection in queen (Cobey et al., 2013). syringe deep into the thick mucus layer. Also avoid drying of the semen at the tip by collecting a small amount of saline in the tip of the syringe between drones (Fig. 7.4a).

Repeat this process to collect the quantity of semen needed. Small amount of saline solution is drawn into the syringe every time when you stop semen collection to prevent sealing/clogging up of the tip by dried semen. Expel this saline solution out when you again start semen collection and each queen is required to be given 8 micro liters of semen. (i.e. equivalent to $12.5 \mathrm{~mm}$ length of glass capillary). An experienced person can collect this much semen in just five minutes.

Placing the queen in the holder: Place the queen into the cylindrical backup 
having a small hole on one end. When queen reaches the end of the tube with the small hole, she will backup into the holding tube which is immediately held next to this backup tube. The queen moving backward will protrude its abdomen out of the tapering end of the holding tube. The queen can be helped in this process by light blowing with mouth from the other end. The holding tube with the queen is then put back on the queen holder of the instrument, which is connected to the carbon dioxide line. Flow of $\mathrm{CO}_{2}$ is kept constant at one bubble per sec. The tube is kept in such a manner that the back of the queen is on the right side. The queen is ready for insemination when she becomes motionless.

Anaesthetization: Carbon dioxide through the tube connected with the queen holder is used to keep the queen anesthetized continuously during the insemination. A slow and steady rate of carbon dioxide bubbled through water adjusted at the rate of one bubble per second is generally used to keep the queen quiet during the process. The carbon dioxide treatment is also important to stimulate egg laying. Two treatments are necessary to initiate egg laying, one during the insemination procedure and a second one day before or one day after the insemination. Longer exposures should be avoided as this can shorten life expectancy of the queen bee.

Opening the sting chamber: The reproductive organs of queen bee showing the position of valve fold (Fig. 7.4 b). For injection of semen, the inseminating syringe must pass through the vaginal orifice and vaginal passage beyond the valve fold. As the anesthetized queen in the queen holder becomes quiet, sting chamber of the queen is opened with holding hooks. Ventral hook, by keeping to the left (ventral side of the queens, is first put in the ovipositor to stretch the ventral side (last sternite) of the abdominal tip. The sting hook which is holed is used to thread the sting by keeping it to the right (dorsal) side of the queen bee. When the hooks are properly positioned, the tissue will stretch to form a large triangle. Within the triangle a is ' $v$ ' shaped wrinkled tissue defining the vaginal orifice. Below this is the location of the valve fold, which is not readily visible.

Injecting the semen: The whole process of opening of sting chamber of a queen bee and injection of semen is done under a microscope. The syringe tip having semen is passed just above and slightly right ' $v$ ' shaped wrinkled tissue i.e. the vaginal orifice'. To byepass the value-fold, a slight zigzag motion of the syringe tip-used. This is essential to move the valve-fold for the passage of the semen. If the syringe is properly place, there will be no movement of surrounding tissues when it is inserted further, in the vaginal office.

The semen can now be injected and it should not leak out if the surrounding tissue moves with the syringe tip, you have not bye-passed the valve-fold and the semen would leak out/back up.

Post-insemination care of the queen bee: Inseminated queen bee can be dropped between the combs while it is still anesthetized. But it is better to put it into the queen cage with candy and the queen after insemination becomes active in the incubator. Upon activation, introduce the queen in the queenless colony or nucleus. The tendency of the queen for mating flight persists even after one insemination or one anesthesia with $\mathrm{CO}_{2}$. Therefore, queen must remain confined in the colony until second insemination or anesthesia is completed. Queen guard should not be removed from the entrance until queen starts oviposition. The first 
$24 \mathrm{hr}$ after insemination is a critical period. Caged queens must always be near the brood nest because at lower temperature, transfer of injected spermatozoa to spermatheca is difficult. Hence, newly inseminated queen should be kept at brood nest temperature and be attended by nurse bees to facilitate sperm migration. Sperm migration is influenced by environmental conditions. Therefore, queens should not be subjected to cold or isolation. Queen bee inseminated with less than $5 \mathrm{~mm}$ semen can be maintained under the normal colony conditions. But queen bee inseminated with semen from single drone should be kept in nuclei where a lack of room restricts egg laying and thereby prolongs the life considerably and fertilized queen is maintained in a strong queen bee bank/reservoir colony (Singh and Gatoria, 2003) for over 4 weeks.

\section{Instrumental insemination of Apis mellifera vs. Apis cerana}

Woyke (1973) explored the possibility of instrumental insemination in Apis cerana queens. He found that semen was difficult to be separated from mucous and average semen was only $0.20 \mathrm{~mm}^{3}$ per drone as compared to $1.60 \mathrm{~mm}^{3}$ in Apis mellifera. Concentration and activity of spermatozoa is also lower in Apis cerana (4.655 million $/ \mathrm{mm}^{3}$ ) of that found in A. mellifera (11 million). The penetration ability of Apis cerana spermatozoa into spermatheca is also lower than that of $A$. mellifera queens. Naturally mated Apis cerana queen had lower number of spermatozoa in the spermatheca (the highest number found 2.665 million) than $A$. mellifera queens (average 5.340 million). Nevertheless, the queens of A.cerana must copulate with higher number of drones (15 in one flight or 30 in two) than do $A$. mellifera queens (average 8 matings in one flight). Woyke (1973), further found that artificial insemination of $A$. cerana indica queens with $1 \mathrm{~mm}^{3}$ to $4 \mathrm{~mm}^{3}$ of semen resulted in $4.11 \mathrm{~m}$ to to 11.12 million thousands of spermatozoa in their spermatheca. Queens inseminated with doses higher than $3 \mathrm{~mm}$ of semen produced at the end of the season exclusively worker brood. Two or three inseminations with $3 \mathrm{~mm}^{3}$ of semen each are recommended. For this purpose, 100 to 150 drones should be tried, out of which 40 to 60 may give the required quantity of semen for effective insemination of $A$. cerana queen. Taking Apis

Table 7.2. Number and motility of spermatozoa of four honey bee species stored in the spermatheca

\begin{tabular}{lccc}
\hline $\begin{array}{l}\text { Origin of } \\
\text { spermatozoa }\end{array}$ & Sperm number & $\begin{array}{c}\text { Motility after } \\
3 \text { days }\end{array}$ & $\begin{array}{c}\text { Motility after } \\
4 \text { weeks }\end{array}$ \\
\hline A. mellifera & $0.16+0.05$ & $98.5+3.2 \%$ & $96.9+4.6 \%$ \\
& $\mathrm{n}=21$ & $\mathrm{n}=13$ & $\mathrm{n}=8$ \\
A. cerana & $0.22+0.07$ & $\mathrm{n}=8$ & $93.3+5.4 \%$ \\
& $\mathrm{n}=16$ & $61.2+37.8 \%$ & $\mathrm{n}=8$ \\
A. dorsata & $0.11+0.04$ & $\mathrm{n}=5$ & $26.0+37.2 \%$ \\
& $\mathrm{n}=10$ & $83.4+22.5 \%$ & $\mathrm{n}=5$ \\
A. florea & $0.15+0.06$ & $\mathrm{n}=8$ & $33.9+38.9 \%$ \\
& $\mathrm{n}=16$ & & $\mathrm{n}=8$ \\
\hline
\end{tabular}

(Source: Phiancharoen et al., 2004). 
mellifera as a reference, spermatozoa from 8 drones of Apis cerana, 5 drones of Apis dorsata and 20 drone of Apis florea is equivalent to one drone of Apis millifera. Similarly, motility of spermatozoa stored in Apis mellifera is more followed by Apis cerana, Apis florea and Apis dorsata, respectively. Crosses between the two species Apis mellifera and Apis cerana have also been attempted but could not be successful. The Table 7.2 reveals the number and motility of spermatozoa of four honey bee species (Phiancharoen et al., 2004).

\section{REFERENCES}

Alley, H. 1883. The Beekeeper's Handy Book: Twenty-Two Years'Experience in QueenRearing. Kessinger Publishing. Montana, United States of America

Buchler, R., Andonov, S., Bienefeld, K. Costa, C., Hatjina, F., Kezic, N., Kryger, P. Spivak, M., Uzunov, A. and Wilde. J. 2013. Standard methods for rearing and selection of Apis mellifera queens. Journal of Apicultural Research 52(1).

Cobey, S.W., Tarpy, D.R. and Woyke, J. 2013. Standard methods for instrumental insemination of Apis mellifera queens. Journal of Apicultural Research 52(4): 1-18.

Doolittle, G. M. 1889. Scientific queen rearing. Thomas G. Newman. Chicago. III

Graham J. 1992. The hive and the honey bee. Dadant and Sons printing, Hamilton, Illinois, USA.

Hamdan, K. 2008. Raising Honey Bee Queens. Apeldoorn, The Netherlands.

Hopkins, I. 1886. The Australasian Bee Manual. Chapter XII. $211 \mathrm{pp.}$

Laidlaw, H. H. 1975. Queen rearing. American Bee Journal 115(10): 384-38.

Laidlaw, H. H. 1979. Contemporary Queen Rearing. Hamilton, Illinois, USA: Dadant \& Sons.

Mishra, R. C. 1995, Honey bees and their management in India. ICAR, New Delhi.

Phiancharoen, M., Wongsiri, S., Koeniger, N., Koeniger, G. 2004.Instrumental insemination of Apis mellifera queens with hetero- and conspecific spermatozoa results in different sperm survival. Apidologie 35: 503-11.

Ruttner, F. 1983. Queen rearing: biological basis and technical instruction. Bucharest, Romania: Apimondia Publishing House.

Singh, B. and Gatoria, G.S. 2003. Maintaining queen bee reservoirs/banks. Proc. Internat. Workshop on Conservation and Management and Honey Festival (Apiexpo): 38.

Smith, J. 1949. Better Queens, Judd and Detweiler, U.S. 100 pp.

Woyke, J. 1973. Reproduction and artificial insemination of Apis cerana indica Fabr. Indian Bee Journal 33: 10-20. 


\section{8 \\ Apiculture Equipments}

$\mathrm{B}$ EES are managed in modern hives. The hive design is based on the principle of "bee space". There is space between the frames, between top bars of frames and inner walls and this space allows the free movement of bees. Because of the bee space, the parts are not attached to each other. Hive is composed of bottom board, brood chamber, brood chamber frames, super chamber, super chamber frames, inner cover and top cover (Fig. 8.1). There are different types of hives with different bee space being used for different species and races of bees.

Apis cerana is largely kept in modern movable frame hive but even now, especially in tribal areas, the species is still kept in log and pot hives. Wall hives are also made while constructing houses and sometimes mud receptacles are fixed in the wall. The outer surface of such structures has small entrance hole while a board covers large inner opening. The species has large variations in size and hence the movable frame hives with different bee spaces are used to keep the bee colonies. The type of the hive used also depends upon the build up capacity of the race. Newton, Jeolikot, ISI (A and B) and Langstroth are different hives used for the species. Apis mellifera has always been kept in movable frame hives and only Langstroth hive is in use for the species.

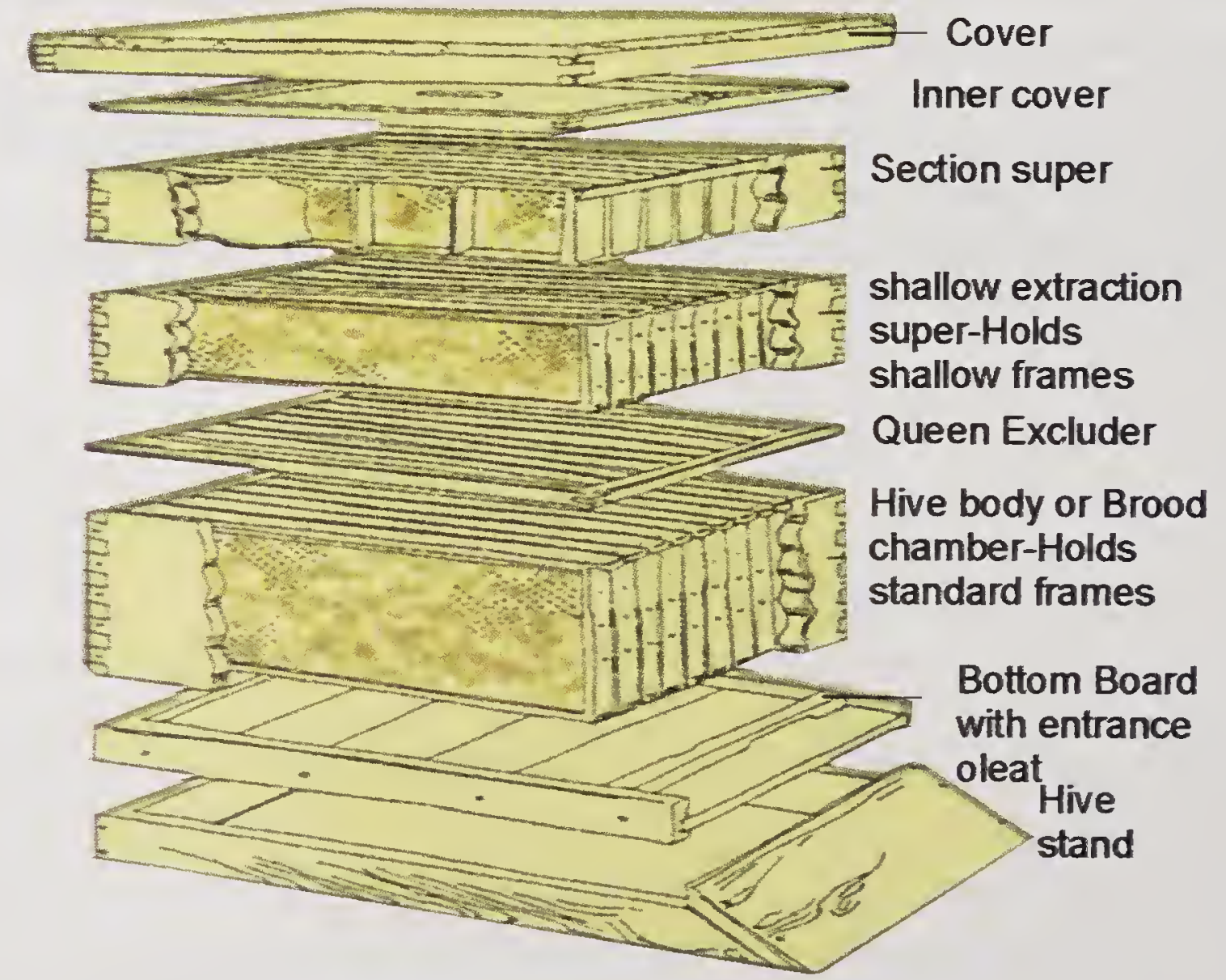

Fig. 8.1 Different parts of bee hive (Langstroth, 1878). 
Traditional hives like bamboo baskets, mud hive, clay pots, hollow logs of wood and clay cavities fixed in the walls of mud houses have been in use for rearing bees in India till the end of nineteenth century. Primitive hives are still in use in some parts of the country. The hive developed on the principle of bee space by L. Langstroth revolutionized the whole concept of beekeeping from 1851 onwards. Langstroth's contribution to the industry was quickly followed by the invention of comb foundation by Johannes Mehring in 1857, honey extractor by Frang von Hruschka in 1885 and many others. Beginning was made to keep bees in movable frame hives in 1880's in India which occurred after the widespread adoption of Langstroth hive in West. The modern movable frame hive consists of a bottom board one or more hive bodies fitted with the frames on which the combs are built and a top cover.

In India, Langstroth hive is in vogue for keeping Apis mellifera colonies in Kashmir. Apis cerana colonies are now kept in ISI hives or Newton hives in other parts of the country. The bee space given for Apis mellifera $(9.525 \mathrm{~m})$ by Langstroth has been modified depending upon the standardization of beehives on the basis of bee space providing the scientific apiculture. Fabricator can follow a standard norms in fabricating different beehives to other area with hives, transport hives and frames. Of course, the use of standard size equipment over large areas is not practicable because the type and size of hive would vary with climate, flora and species and race of honeybee. Small colonies in large hives may get their brood chilled during a sudden cold spell and their surplus combs may get attacked by wax moth. Colony must be able to build up strength to attain super chamber strength. Surplus honey can be obtained only if strength is enough to store in combs of super. Therefore, size of hive should be such that colonies cover the super chamber frames by the onset of main honey flow. Apis mellifera queens are very prolific and lay large number of eggs and hence colony builds up large population but in Apis cerana, the egg laying rate of queen is low and colony strength does not grow comparable to A. mellifera. Within Apis cerana, different races differ greatly in colony strength build up. The buildup of colonies also depends upon the availability of flora in a locality. Enough flora will ensure more populous colonies but in marginal areas the size of the hive frames has been reduced accordingly. Therefore, the size of the hive would differ with all these factors. However, keeping in view, the benefits of stabilization of equipment any unwanted tendency to multiply the number and sizes of frames in unscientific way should be discouraged. Hence for Apis cerana races two type of hives ISI-A and ISIB type being developed.

Table 8.1. Dimensions of movable frame hives

There are many types of movable frame hives being used in different parts of the world. Dimensions of movable frames of some of the

\begin{tabular}{lcc}
\hline Name & $\begin{array}{c}\text { Dimensions } \\
\text { of brood } \\
\text { frame }\left(\mathrm{m}^{2}\right)\end{array}$ & $\begin{array}{c}\text { Super frame } \\
\left(\mathrm{m}^{2}\right)\end{array}$ \\
\hline British standard & $350 \times 212$ & $440 \times 228$ \\
Langstroth & $440 \times 228$ & $440 \times 130$ \\
Dadant & $462 \times 281$ & $462 \times 156$ \\
Dadant & $462 \times 156$ & $462 \times 156$ \\
Villager & $300 \times 175$ & $300 \times 175$ \\
Newton & $206 \times 144$ & $206 \times 62$ \\
Travancore & $300 \times 150$ & $300 \times 100$ \\
\hline
\end{tabular}


important ones are given in Table 8.1. The Langstroth, Indian Standards Institute (ISI) and Newton frame hives are more in use than other types in India. Details for making these types are outlined below. Emphasis should be given for proper specification so that inconvenience and mismanagement can be avoided.

\section{Langstroth design}

The Langstroth design is having ten frame hives and following are the requirements (Fig. 8.2).

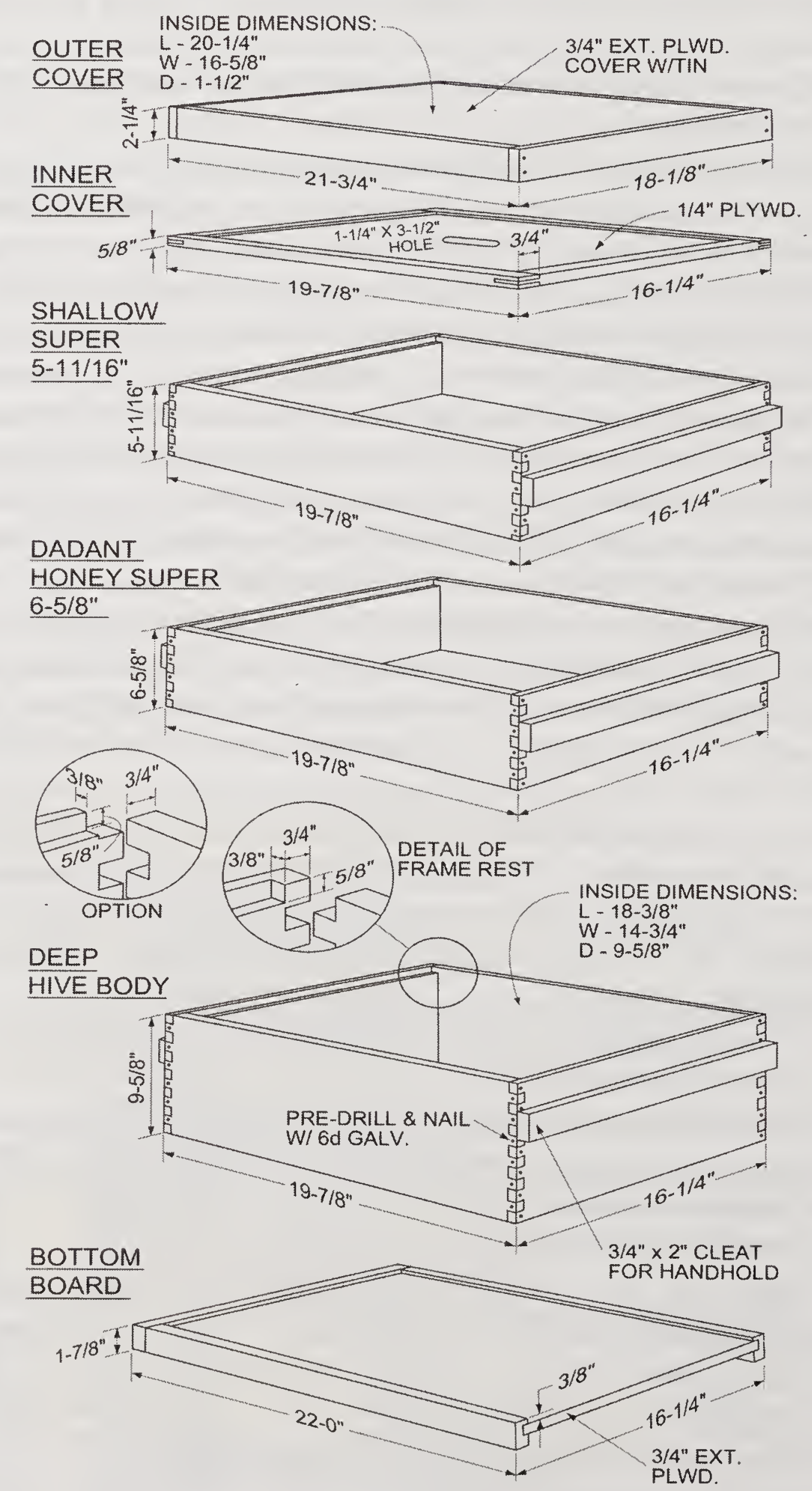

Fig. 8.2 Langstroth bee hive (Langstroth, 1878) 
Stand: Any four legged stand of 25 to $30 \mathrm{~cm}$ height will be usefull but its upper dimension should be as per requirement of different type of hives to support the bottom board adequately. The stand may be made of timber for temporary use and iron for longer durability.

Bottom board: The beehive board can be made either by taking a piece of wood $550 \mathrm{~mm}$ long, $406 \mathrm{~mm}$ broad and $22 \mathrm{~mm}$ thick, or by joining 2 wooden boards tighter, nailing in position with wooden roads. Along each of the longer side a wooden rod is nailed $550 \mathrm{~mm}$ long which is $22 \mathrm{~mm}$ broad and $22 \mathrm{~mm}$ thick and another wooden rod, $363 \mathrm{~mm} \times 22 \mathrm{~mm}$ is nailed at the back. The front is provided with entrance rod which is $363 \mathrm{~mm} \times 22 \mathrm{~mm} \times 22 \mathrm{~mm}$ and this has an entrance $75 \mathrm{~mm}$ long and $22 \mathrm{~mm}$ deep in its middle. Two wooden blocks, to be used for shortening the entrance, when necessary, should also be prepared, each block being $75 \mathrm{~mm} \times 38 \mathrm{~mm} \times 22 \mathrm{~mm}$.

Brood chamber: It is a rectangular box without top and bottom and is made of $22 \mathrm{~mm}$ thick wood. Its length on the outside is $500 \mathrm{~mm}$ and on the inside $456 \mathrm{~mm}$, its breadth on the outside is $406 \mathrm{~mm}$ and on the inside $363 \mathrm{~mm}$ and its height is $238 \mathrm{~mm}$. A rabbet $16 \mathrm{~mm}$ deep and $13 \mathrm{~mm}$ wide is cut along the entire length of its width planks.

Frame: Consists of top bar, two side bars and a bottom bar. Dimensions for self spacing frame are as follows:

Top bar: $475 \mathrm{~mm}$ long, $25 \mathrm{~mm}$ wide and $22 \mathrm{~mm}$ thick. It is cut in to $9 \mathrm{~mm}$ thickness on both sides for a length of $25 \mathrm{~mm}$. It has a groove in the middle of its lower side for fixing the comb foundation sheet.

Side bar: Each is made of $9 \mathrm{~mm}$ thick wood and is $226 \mathrm{~mm}$ long. The upper part of each is $34 \mathrm{~mm}$ wide and lower part $25 \mathrm{~mm}$ wide. Each is cut out from the middle portion at end to accommodate the top and the bottom bars, respectively. There are 4 holes in each side bar for wiring the frame.

Bottom bar: $440 \mathrm{~mm}$ long, $19 \mathrm{~mm}$ wide and $9 \mathrm{~mm}$ thick. The outside measurements of the frame are $440 \mathrm{~mm} \times 228 \mathrm{~mm}$. Two $15 \mathrm{~mm}$ staples should be driven in (to leave only $9 \mathrm{~mm}$ outside) to top bar on its opposite side so that the frames stand $34 \mathrm{~mm}$ apart. One should make all frames either Hoffman or staplespaced type. Tinned wire of 28 gauge should be used in wiring the frame.

Super: The dimensions of the super and the super frames should be the same as those of the brood chamber and the brood chamber frames respectively, super as the case may be. It is $500 \mathrm{~mm}$ long, $406 \mathrm{~mm}$ broad and $9 \mathrm{~mm}$ thick wood. It has $9 \mathrm{~mm}$ thick and $22 \mathrm{~mm}$ wide wooden bar nailed on to each of its four sides.

Inner cover: This is a wooden board to cover the brood chamber or the super as the case may be. It is $500 \mathrm{~mm}$ long, $406 \mathrm{~mm}$ broad and $9 \mathrm{~mm}$ thick wood. It has $9 \mathrm{~mm}$ thick and $22 \mathrm{~mm}$ wide wooden bar nailed on to each of its four sides.

Top cover: It is made up of $9 \mathrm{~mm}$ thick wooden board nailed to a rectangular frame $50 \mathrm{~mm}$ high, all covered over with a metallic sheet so as to make it impervious to rain water. Its inside measurements are $525 \mathrm{~mm} \times 425 \mathrm{~mm}$. It rests loosely over the hive.

\section{ISI $A$ and $B$ type of hive}

Reverend Newton standardized a hive for Apis cerana during 1881-84 (Kapil, 


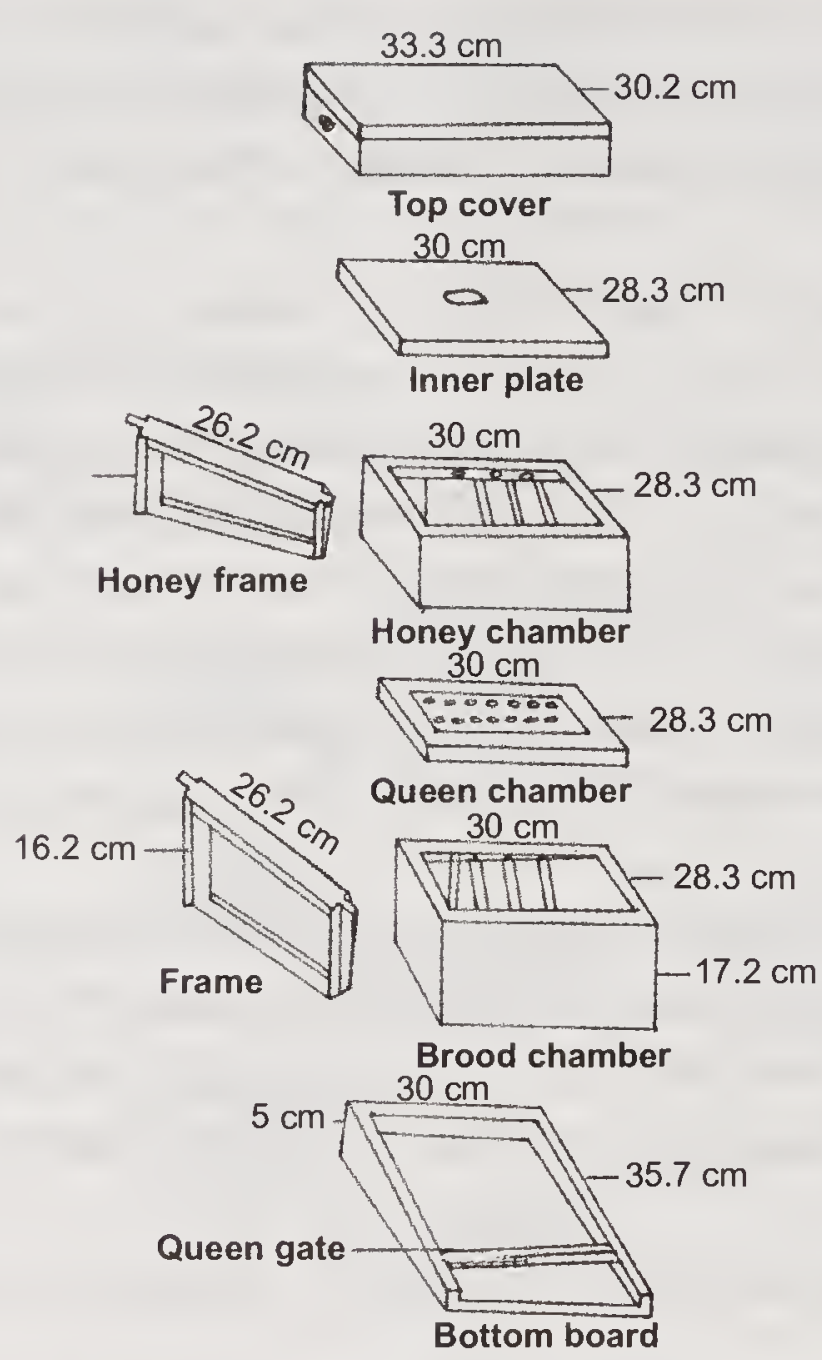

(a)

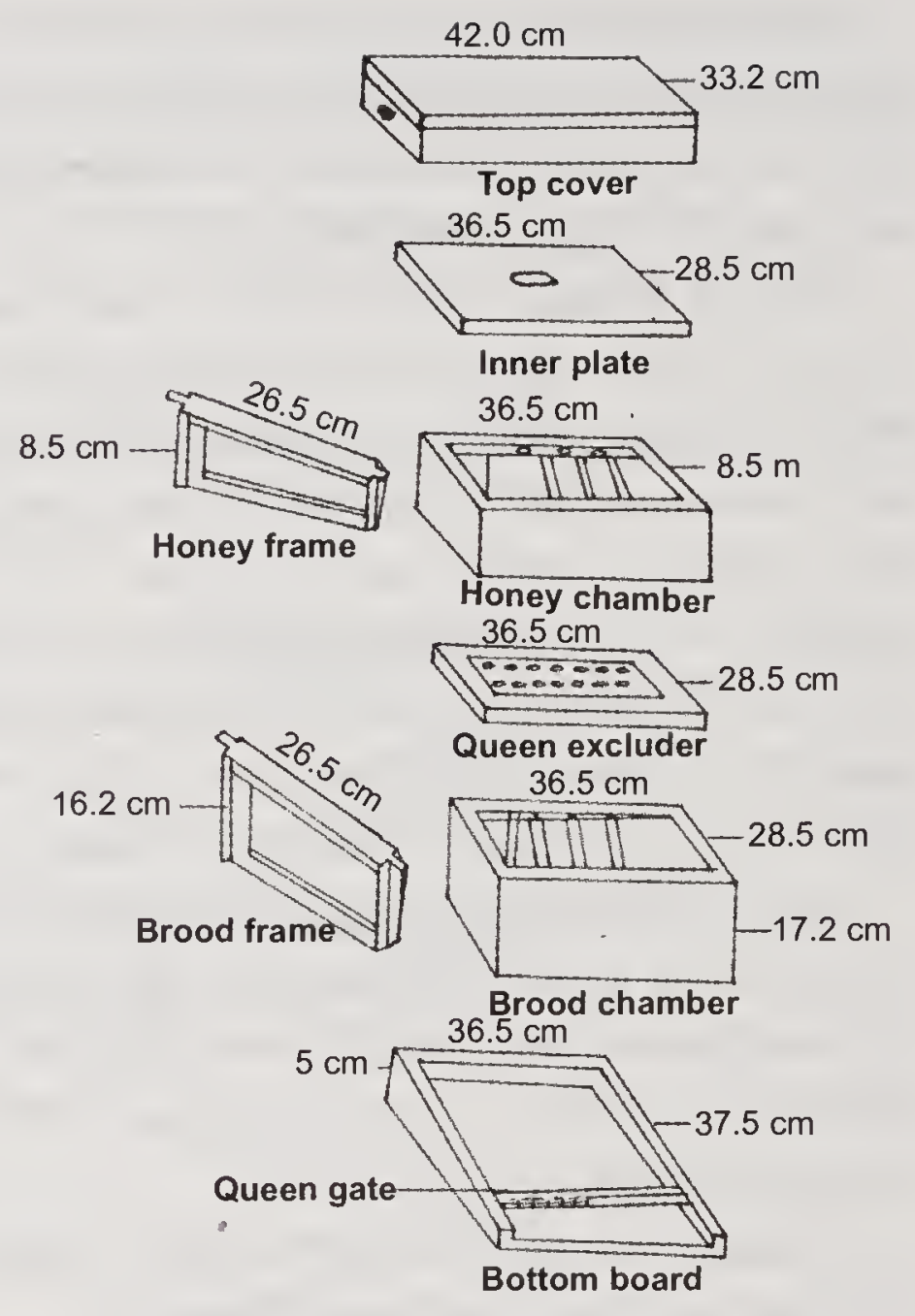

(b)

Fig. 8.3 (a) ISI-A type; (b) ISI-B type

(Abridged from AICRP on honey bees and pollinators, AAU, Jorhat)

1971) which is named after him. The following are the parts of newton hive. Later, on two types of hives viz. ISI-A type having 8 frames and ISI-B Type with 10 frames have been designed for rearing different races of Apis cerana (Fig. 8.3a,b). The ISI- A type is suitable to rear smaller races of Apis cerana, i.e. A. c. himalaya, A. c. indica but ISI-B type is convenient for rearing bigger races such as Apis cerana cerana. The detailed specifications of ISI-A and B type are given in Table 8.2.

Stand: A log of wood of about $10 \mathrm{~cm}$ in diameter and well soaked in solignum is buried deep in the ground. A length of about 20 to $30 \mathrm{~cm}$ is left above ground and a board $40 \times 30 \mathrm{~cm}$ is fixed on its top with long nails and screws. The hive is placed on this platform on the log.

Bottom board: It is a plank slightly wider and $25 \mathrm{~mm}$ longer than the brood chamber with beadings on three sides into which the hive-body fits in tightly. The extension of the front serves as the alighting board.

Brood chamber: It is a box without top and bottom and is made of $22 \mathrm{~mm}$ thick planks with outer dimensions $278 \mathrm{~mm} \times 256 \mathrm{~mm} \times 160 \mathrm{~mm}$ and inner 234 $\mathrm{mm} \times 225 \mathrm{~mm} \times 160 \mathrm{~mm}$. Along the top of the front and rear planks a groove of $6 \mathrm{~mm}$ depth and $9 \mathrm{~mm}$ width is made for resting the frames and a clearance of about $6 \mathrm{~mm}$ is provided between the lower extremity of the frames and the bottom board. The front plank has an opening $88 \mathrm{~mm} \times 9 \mathrm{~mm}$ at its lower side to serve as an entrance.

Brood frame: Self spacing (i) top bar breadth $22 \mathrm{~mm}$, length $250 \mathrm{~mm}$ and 


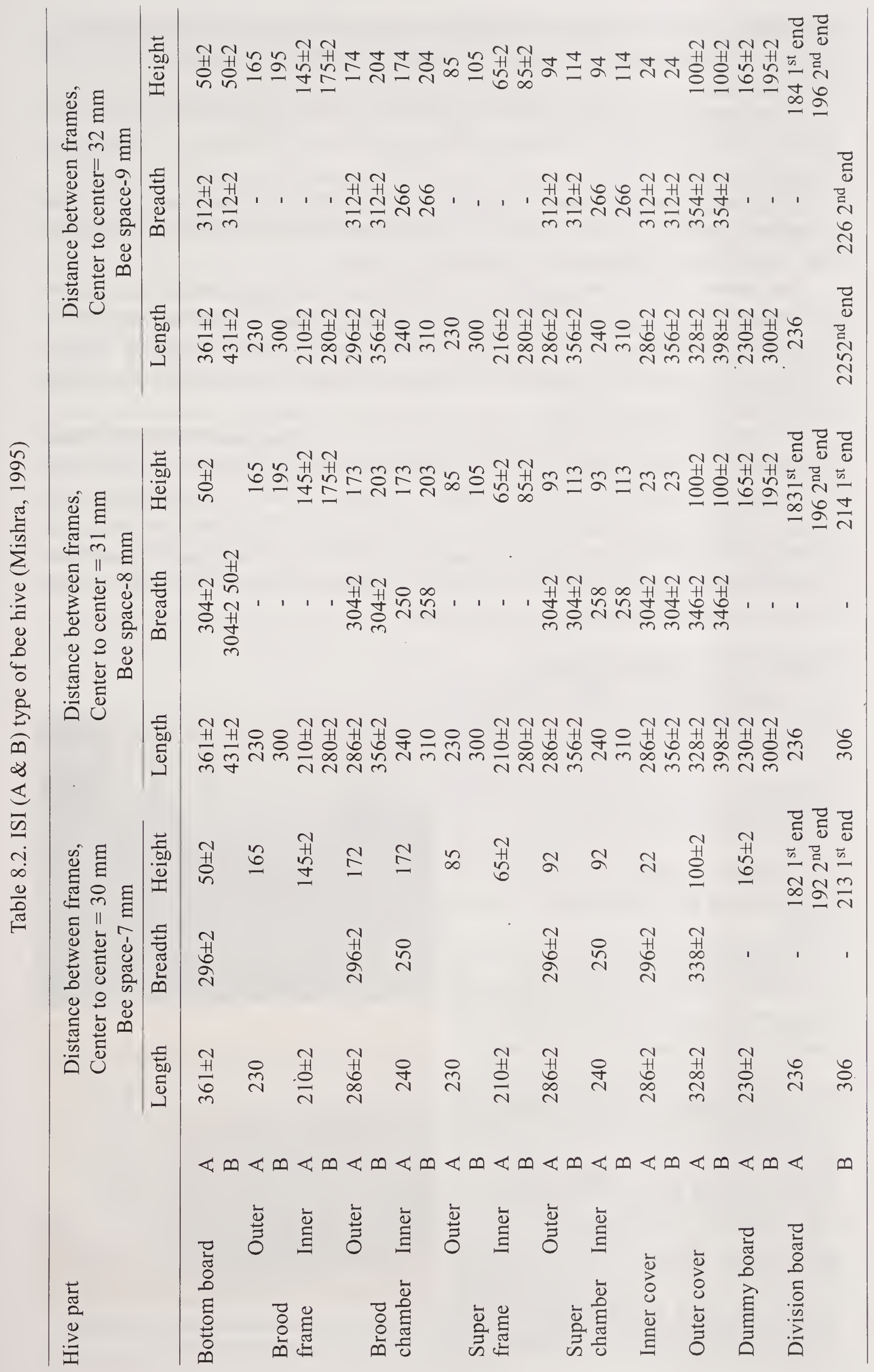


thickness $3 \mathrm{~mm}$, (ii) side bar height $144 \mathrm{~mm}$, width at top $28 \mathrm{~mm}$ and width at bottom $122 \mathrm{~mm}$, (iii) inner length of frame $206 \mathrm{~mm}$, inner height of frame 144 mm.

An extension of $3 \mathrm{~mm}$ is given on either side of the side bar and a clearance of $6 \mathrm{~mm}$ is affected when 2 frames are kept side by side. There are 7 frames in a brood chamber.

Super and super frame: It has the same length and breadth as the brood chamber, but its height is $78 \mathrm{~mm}$. The dimensions of the super frame are those of the brood frame but the internal height is $62 \mathrm{~mm}$.

Top cover: It has sloping planks on either side. An opening of $87 \mathrm{~mm}$ square, fitted with wire gauge is made on the low ceiling plank to provide ventilation. Two holes in the front and rear planks of the top provide the necessary draught. Care should be taken to provide a clearance of about $6 \mathrm{~mm}$ between the ceiling plank and the frames below.

For the fabrication of hives, light, well seasoned, good quality timber should be used. The wood should not have a strong smell. Kail (Pinus excelsa), teak (Tectona grandis) and toon (Toona ciliata) are some of the woods suitable for the purpose. The hives should preferably be painted white or aluminum on the outside to protect the timber from weathering agencies. The hive parts should be accurately cut so that they may be inter-changeable throughout the apiary and as emphasized earlier, in the particular part of the country.

\section{Other beekeeping equipments}

Comb foundation Mill (Fig 8.4a):

It is engraved using advanced casting technique with high precision and deep cell, that will avoid beeswax block while processing wax sheet or act as Embossing Roller. The finished wax foundation sheets is continuous, symmetrical and with sharply defined cells.

Comb foundation sheet (Fig. 8.4b): is a sheet of bee wax embossed on both sides with the bee and beginning of cell wall in which bees build their combs.

In nature, bees build new combs from beeswax produced by them and make parallel combs which are attached to the ceiling of the cavity or box. The combs may be built in the direction of the entrance, at right angles to it or in an oblique fashion. In the movable frame hive it is imperative that straight combs be built in the frames so that when shifted from hive to hive they may
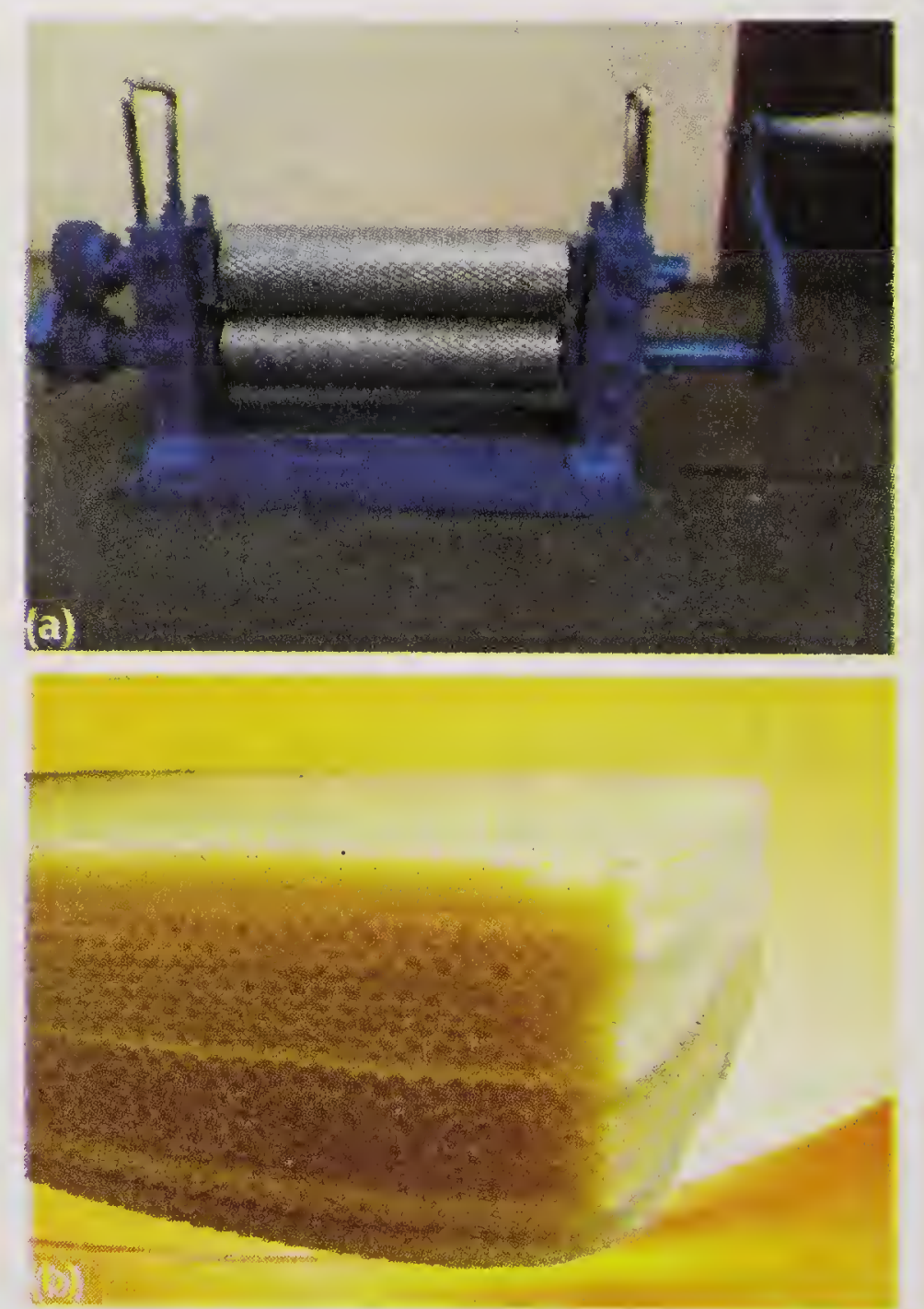

Fig. 8.4 (a) Comb foundation mill; (b) Comb foundation sheet. 
maintain the correct bee space between them. This may be done by fixing sheets of beeswax, on which the bases of worker brood cells are embossed in the frames. They are reinforced by fixing horizontal wires in the frames and embedding the same into comb foundation on a wire embedding board by means of a wireembedder.

As Apis cerana bees build cells of various sizes in combs in different parts of the country and therefore, the use of several types of comb foundation mills are required. Number of cells would vary between 20 to 24/100 mm for Apis cerana in India and for Apis mellifera this number is about 19. Therefore, the size of cells required should be specified while placing an order.

The combs built on comb foundation are strong and sturdy. Brood combs and combs with honey after extraction can be reused. As stated above, the repeated use of such combs helps one to produce more money as the bees do not have to build new combs. Besides, in building combs on comb foundation, bees have to add the cell walls only. Brood comb cells get narrowed down by continuous use and it is wise to destroy them for rendering wax after 3-4 years of use and get new combs raised.

Queen excluder: To obtain pure honey free from extraneous matter it is necessary to separate the brood nest from the surplus honey stores (Fig. 8.10). This is done with the help of queen excluders, which are perforated sheets of zinc or round wires assembled together $3.75 \mathrm{~mm}$ apart for $A$. cerana indica. The workers with their thorax varying from $3.33 \mathrm{~mm}$ to $3.50 \mathrm{~mm}$ can pass through these perforations but not the queens with their thorax varying from $4.40 \mathrm{~mm}$ to 450 $\mathrm{mm}$. For $A$. mellifera, the diameter of the perforation in the sheet or space between the wires is $4.20 \mathrm{~mm}$. Since the queen bee is unable to reach the super, the brood nest is limited to the lower hive body, that is brood chamber.

The wire entrance guard and the drone traps are also based on the principle of the queen excluder. The former restricts the queen inside the hive and the latter after routing the drones into upper chamber traps them in it.

Honey-extracting equipment: The honey extractor is a machine with which honey is extracted in its purest form from the honey comb (Fig. 8.4). The honey comb is whirled in a cage enclosed in an outside contraction. A plain steel knife (Fig. 8.7) or a double jacketed knife heated by steam or electric heated knife with thermostically controlled temperature are used for the purpose.

\section{Equipments for handling bees}

Smoker: It is used to give smoke to the bees for easy handling. It consists of a tin cane provided with a spout for directing smoke from the smouldering material inside it with the help (Fig. 8.6) of fire.

Hive tool: It is a piece of flattened iron with hammered down edges and is used for parting apart the frames in the hive and for scraping bee glue and superfluous pieces of comb from the various parts of the hive.

Bee veil: It is worn over the face for protection against stings. It should be made of black light material such as nylon netting (Fig. 8.5).

Gloves: They may be made of heavy canvas or rubberized cloth and are useful for beginners to develop confidence but handling of frames becomes cumbersome, 


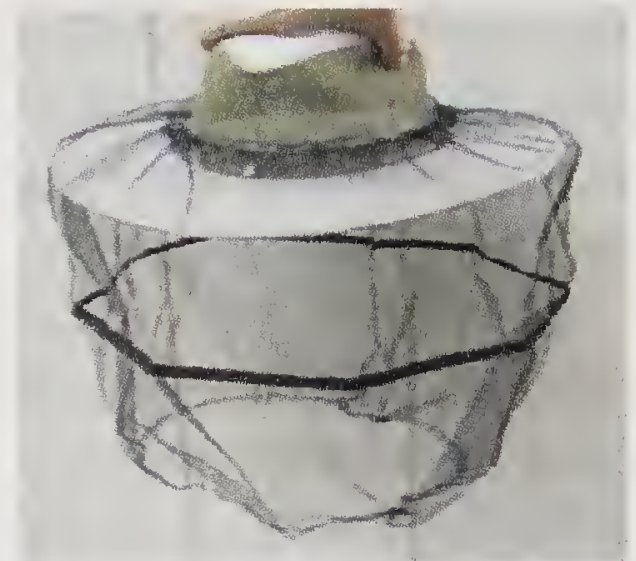

Fig. 8.5. Bee veil

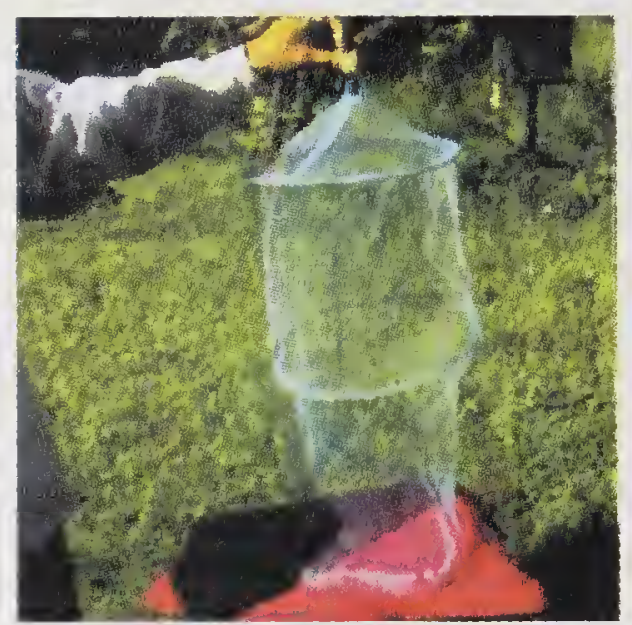

Fig. 8.8. Swarm catcher

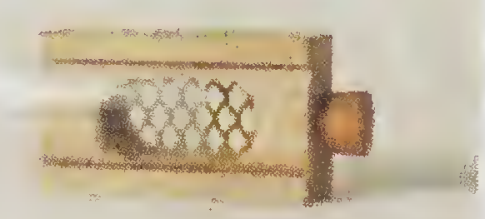

Fig. 8.11. Queen cage

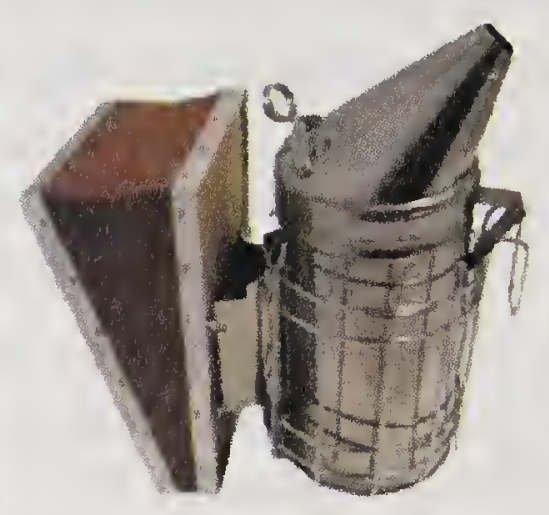

Fig. 8.6. Smoker

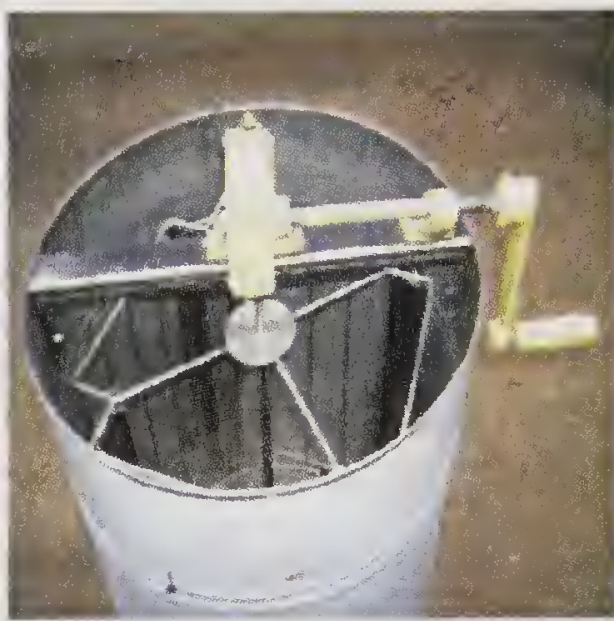

Fig. 8.9. Honey extractor

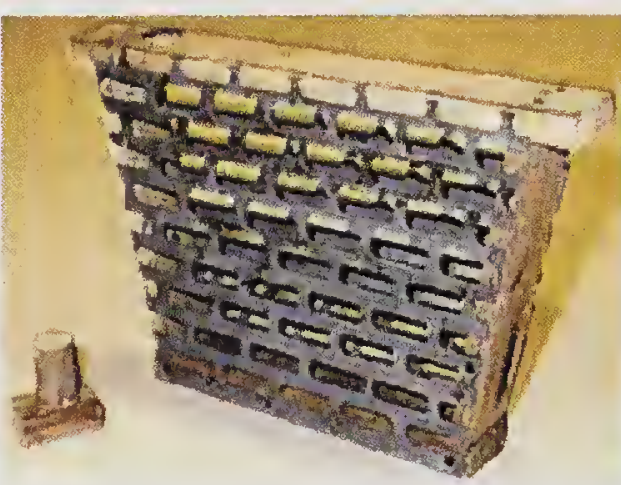

Fig. 8.12. Drone trap

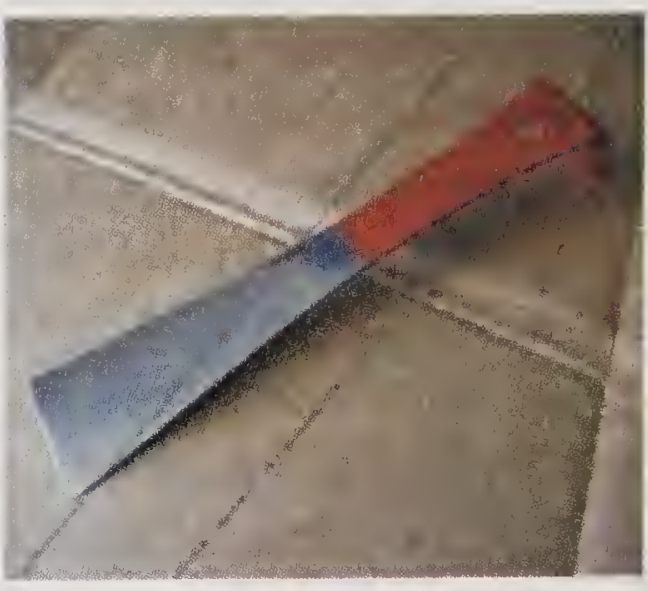

Fig. 8.7. Uncapping knife

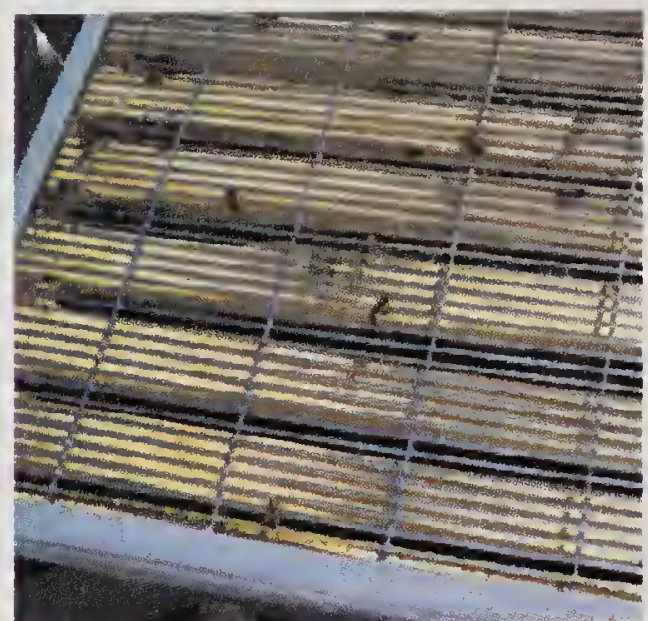

Fig.8.10. Queen excluder

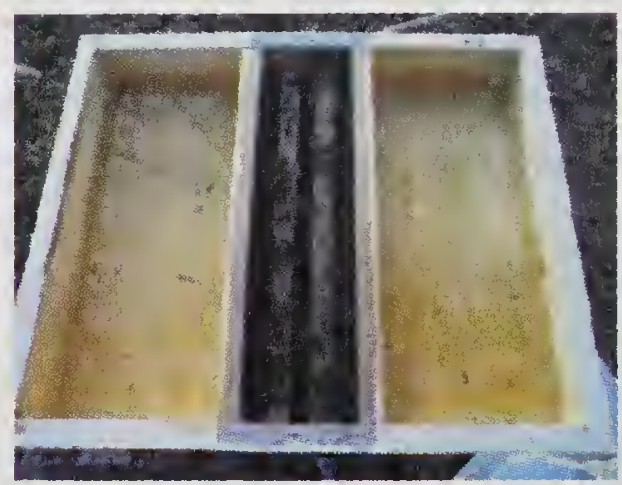

Fig. 8.13. Feeder

Different beekeeping equipments (Abridged from AICRP on Honey bees and Pollinators)

therefore, a good beekeeper will never prefer to use gloves.

Bee brush: A bee brush or a with broom is often employed to brush off bees from honey combs before it is taken away for extraction.

\section{Swarm-catching equipment}

Generally swarms settle on branch of nearby trees. If they cluster on a thin branch, it can be gently cut above the swarm by a scateur and taken to the hive. If the swarm has settled on a thick limb it has to be approached and the swarm collected in a swarm-catching basket by gently directing the bees into it (Fig. 8.8). Sometimes, the bees are shaken into a box which is held on the underside of the limb or caught in a swarm-catching bag from an inaccessible limb. Swarms can be helped in settling down early by sprinkling water into the hovering swarm with the help of a syringe.

\section{Feeders}

Various kinds of feeders for feeding sugar syrup to bees are used by beekeepers. 
The division board feeder, a wooden trough of the regular frame dimensions with shoulders so made that it may hang in the hive just like any other frame and with a wooden strip to serve as a float, is a useful appliance. A lever-lid tin (empty tin) with holes in the lid are also good types of feeders (Fig. 8.13).

\section{Queen cage}

Various types of queen cages are in use. The miller queen introducing cage, the smith introducing cage, the queen mailing cage and the wire gauge cages are some of the tyes often used (Fig. 8.11).

\section{Queen cell protector}

A queen cell which may have to be introduced in a queen right to a queenless colony is often protected in a queen cell protector until its acceptance by the bees.

Dummy or division board: It is a wooden partition which serves as a movable wall and helps to reduce the size of the brood chamber so that bees can keep the hive air-conditioned and well protected from bee-enemies or inclement weather.

\section{Bee escape}

It is a device for allowing the bees to go through a self-closing exit.

Wire guage cone: It has a broad and a narrow end. The broad end is nailed to a board, etc., and the narrow end, which is wide enough to let the bees pass out but not large enough to attract their attention for re-entry, serves as the exit.

Spring bee escape: A pair of delicate strings is so fixed as to allow the bees to push through and make an exit. The springs close the opening by springing back to their original position.

Often a double bee escape is used in boards which are used for clearing honey supers of bees in them. The boards are placed between the honey supers and brood chambers.

\section{Queens and drone traps}

In most equipments supply catalogues, queens and drone traps (Fig. 8.12) are seldom used by professional beekeepers. These are the devices which fit over the hive entrance to catch drones and to prevent a swarm from absconding by confining the queen in the device.

Bhinder et al. (2001) developed an electrically heated knife for uncapping honey combs and reported that it worked on $35 \mathrm{v}$ A.C. and took a load of only 11 watts. The knife is more convenient and simpler and reduced the uncapping time as compared to mild steel (MS) simple uncapping knife. Chuneja et al.(2002) fabricated a portable royal jelly extractor based on Edwards water vacuum pump for royal jelly extraction. Vacuum created in the syringe by the flowing water was used for continuous suction of royal jelly from queen cells. Singh et al. (2004) evaluated five source of the beeswax. Pure beeswax (mix-type) was taken for the preparation of beeswax comb foundation using wooden, plastic and glass planks with varied number of dips. It was reported that the mean time taken for sheet making increased significantly with increase in number of dips. The amount of shaving (on material basis) was maximum with plastic plank and increase in 
number of dips. The plank material did not affect time taken for embossing workercell impressions on wax sheets. The thickness of top, middle and bottom of the plain wax sheet was significantly more with plastic plank. Maximum number of comb foundation per kilogram was recovered through wooden plank followed by glass and plastics planks.

\section{REFERENCES}

Bhinder, J. S., Chhuneja, P. K. and Kumar, G. J. 2001. Development and evaluation of an electrically heated knife for uncapping honey combs. Indian Bee Journal 63(12): 4550.

Chhuneja, P. K., Singh, J. and Gatoria, G. S. 2002. Development and evaluation of portable royal jelly extractor. Indian Bee Journal 64(3-4): 68-70

Kapil, R.P. 1971. A hive for the Indian honeybees, Apiacta 3.

Langstroth, L. L. 1878. The classic Beekeeper's Manual. J B Lippincoot \& Co. Philadelphia. Mishra, R. C. 1995. Honey bees and their management in India. ICAR, New Delhi

Singh, R., Singh, J. and Chhuneja, P. K. 2004. Studies in beeswax comb foundation sheet making. Indian Bee Journal 66 (3-4): 77-83. 


\section{9 \\ Bee Management}

$M$

ANAGEMENT is the key to the success of apiculture. All good beekeeping conditions cannot be utilized properly if the management of an apiary is faulty and ill planned. It is useful to start with few bee colonies and build up the stock. Bees need to be protected in extreme weather conditions during dearth periods and from disease and enemies. Success of a beekeeper depends upon his knowledge of bee behaviour and his aptitude to enjoy working with bees. Following outlines give the broad guidelines for management of honeybee colonies. To start with rearing of honeybees, the knowledge on species, their handling and management and local flora is essential. It is necessary to acquire proper training before starting beekeeping. The following points are to be taken care of to start beekeeping and establishment of apiary.

Pollen and nectar source: Good apiary location is ane with abundance of nectar and pollen producing plants. Commercial beekeepers generally migrate their colonies from one crop field to another and may produce more than one api crop to get pollen and nectar supply throughout the year. Cultivated crops in irrigated conditions and forest flora ensure good beekeeping.

Site and season: Location of an apiary should be proper with the following factors given below.

Good aeration: Site with good air circulation should be selected for apiary. Air with high moisture should be regularly drained away from the apiary. Dampness is bad for bee flight and retards ripening of nectar. Moreover, dampness helps in many viral, bacterial and fungal disease developments. Air drainage is more important in rainy season.

Water: Artificial sources of water should be managed in the apiary if natural sources are not available. Adding some common salt (1\%) makes water more attractive.

Wind breaks: Wind breaks of tree or artificial structures give protection against cold winds, storms and cyclones.

Shade: Bees have greater difficulty in lowering down hive temperature during summer in hot plains of India. Bee colonies definitely need fairly dense shade of trees. Artificial shade can be provided by an open frame structure with trees serving as cover. The structure in north south direction protects the bees in the hottest hour of the day.

Season: The bee rearing season starts with the onset of honey flow i.e. spring having peak brood rearing is known as breeding season. In this, colony tries to build new queen cells and generates new queen in order to replace the old ones. 
Hence, natural propagation of bee colonies is there and the interested rearer can obtain seed/colonies from the beekeeping farms or from nature. The swarming tendency of the colony is also very high and swarm may be collected in this season.

\section{Seasonal management}

Beekeeper's calendar starts with the activity of bee colonies in spring after prolonged cold in temperate climate and during winter in tropical climates. Colony buildup and honey flow period is from October to May in various parts of the India. There is a tendency to expand colonies with increased rate of brood production. Brood rearing starts with the blooming of oilseeds and last upto spring nectar pollen flow. Four major seasons are important in regard to bee management viz. spring, summer, rainy and winter in India. There is no continuous nectar and pollen flow throughout the year in India. However, surplus pollen and nectar flow is there in some period of the year, minor and subsistence food is available during other periods, whereas bees may face dearth period for certain parts of the year. There are different seasons in a year with greatly varying weather conditions and the weather at times may be harsh for bees. A beekeeper must handle his bees in such a manner that the colonies are well prepared for the coming honey flow. This has to be done by helping the bees in successfully abridging the dearth period and by reducing the effect of severe weather conditions. In such cases, the honey flow season and weather conditions vary from locality to locality and the management practices different. However, the underlying principles are the same and the beekeeper will have to adjust to their specific condition. In this regard, hardly any published works are available and management to be followed according to the locality and situation.

\section{Spring management}

With blossom in nature, honey flow season starts during spring. It should be the earliest attempt to examine the colonies on a bright sunny day to assess the condition

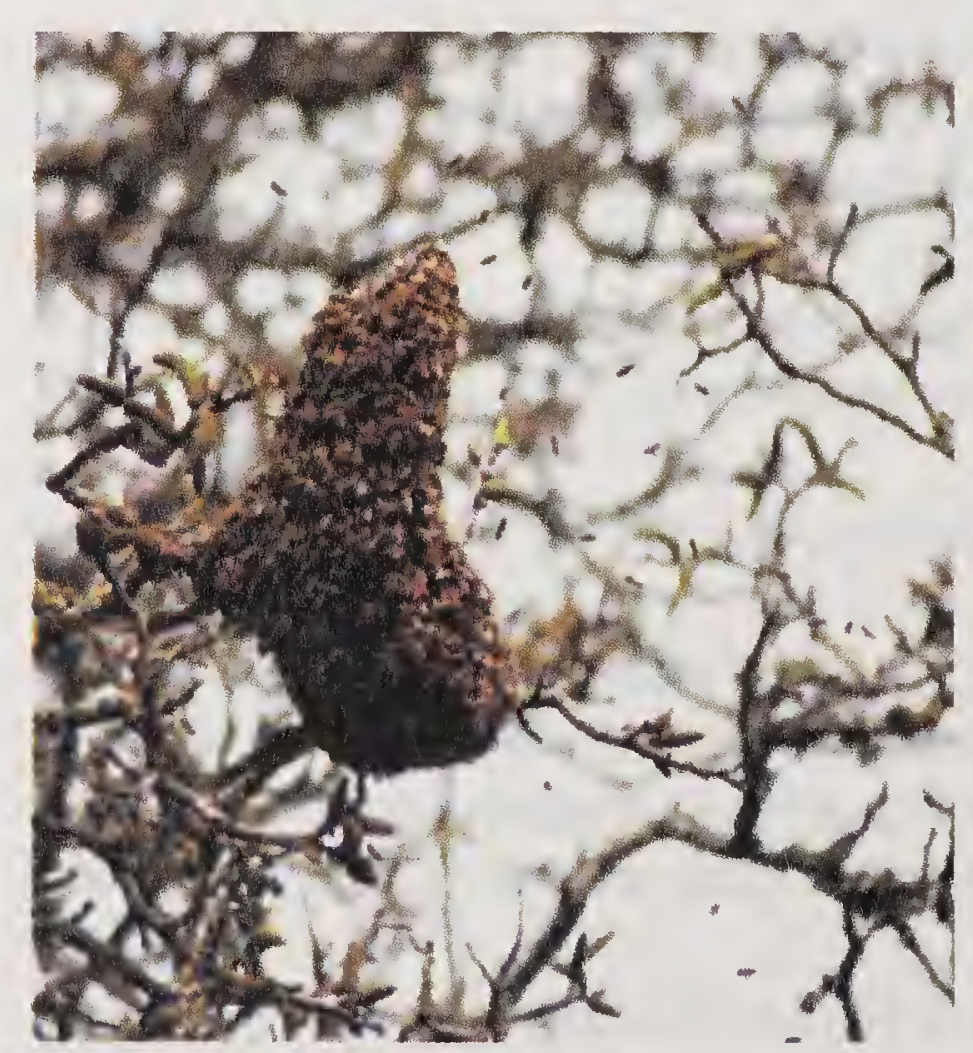

Fig. 9.1 Swarming of Apis mellifera

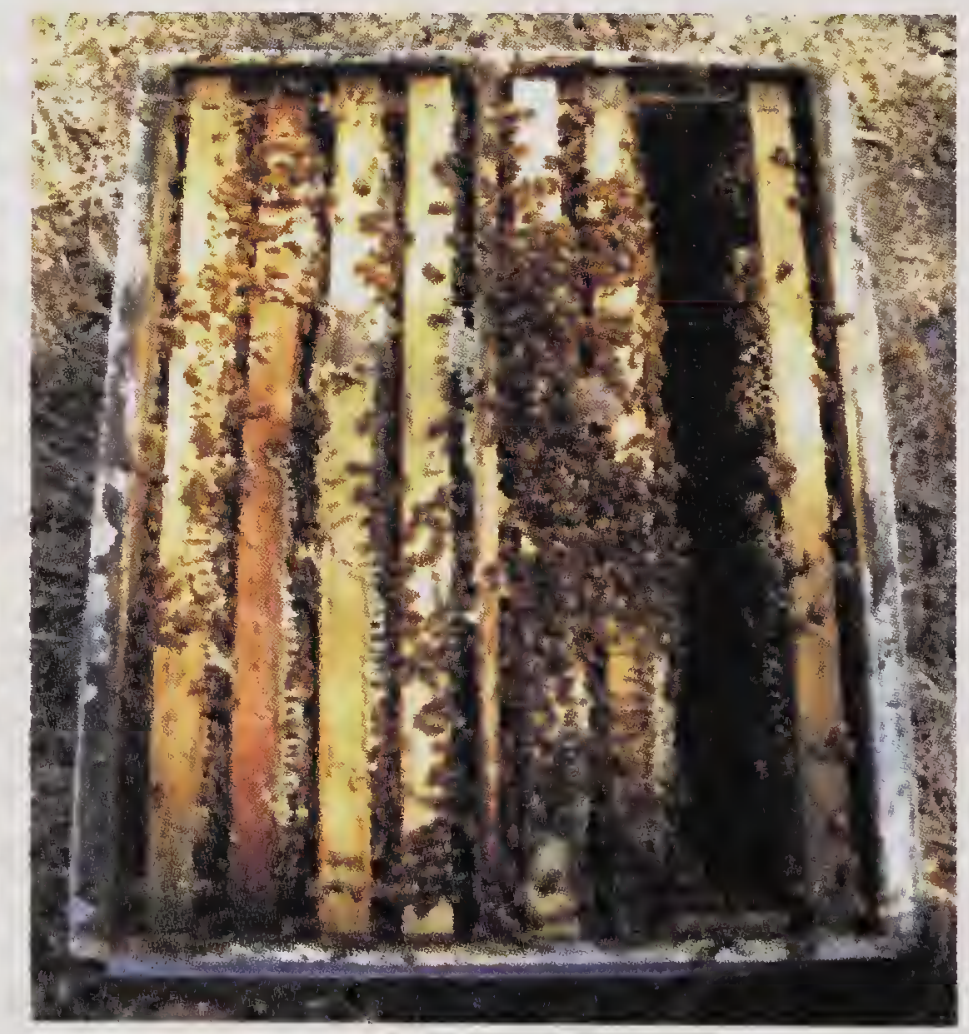

Fig. 9.2 Division process

(Abridged from AICRP on Honey bees and Pollinators, AAU, Jorhat). 
of the colony, working of the queen, amount of brood present and stored pollen and nectar area. During spring, bee colonies go all out to rear brood and invest all resources in increasing their strength. Queen lays more vigorously as is inspired by the worker. As this is a peak breeding season, more and more combs are added and drone bees are produced. There is a tendency for "swarming" (Fig. 9.1).

Swarm prevention: Swarming is the natural instinct of a honeybee species to propagate themselves. Swarming instinct can be exploited to increase the number of colonies.

1. Frequent inspection of colonies during spring.

2. Removal of queen cell regularly in strong colony.

3. Combs with young brood can be removed and given to weak colonies and in place more empty combs can be added.

4. To overcome the swarming, the colonies can be temporarily divided which are reunited just before honey flow.

5. Colonies can be divided if increase in colony number is desired so that swarms are not lost.

\section{Queen rearing}

Queens are required for division of colonies or replacing old exhausted queen. Any bee colony when rendered queenless will raise one or few new queen. But raising queen in mass in a colony is a wise practice since bee colony losses more than a month with respect to egg laying and brood rearing and hence gives a big set back. It is easy to produce queen on mass scale in a queenless or queen right colony by grafting technique. In case of queen right colony, the queen is removed from the queen rearing area by a queen excluder. Wax queen cups of appropriate size are attached to a bar made to fit in a special frame. Larvae of upto $24 \mathrm{hr}$ age put into the cell cups at optimum temperature and humid condition .Some colony can be used both as cell builder and cell finisher colony. Sealed queen cells are removed after 10 days of grafting and kept in queen nursery colonies or given to mating nuclei. The details have been discussed is chapter 7 for queen rearing and multiplication.

Requirement of cell builder colony: The requirements of cell builder Colony are as follows:

(a) Enough honey store or colony should be fed with sugar syrup .

(b) Enough pollen stores, it is useful to provide pollen supplements.

(c) Bees over flowing in the hive after emergence and mating, the queens can be shifted in queen cages.

(d) Ideal queen cage is a soft wooden block $(5 \mathrm{~cm} \times 7.5 \mathrm{~cm})$ with three cavities. Queen with few attended worker bees are put in the cage and are provided candy in a cavity of the cage. The cavities are covered with a wire gauge screen, pinned to the wooden block. For queen introduction about $7.5 \mathrm{~cm}$ long round cage of hardware cloth is ideal.

\section{COLONY DIVISION}

Honey bee colonies which are not very strong and be spared from honey 
production can be divided into 2 or 3 divides each (Fig. 9.2). Each divide is given a new queen. These divides grow in spring and summer and colonies produce surplus honey only during next season. One or two combs with bees and brood can be removed from strong colonies without impairing their production. The bees from two colonies can be united and made into a new colony by giving a queen. In hills, the winter is severe and there is lack of flora, the bees remain confined to their hive for most of the time. The bees have also been facing the problem of maintaining nest temperature. At the onset of spring, the colonies emerge in considerably weak condition. It should be the earliest attempt to examine the colonies on a bright, warm and calm day to assess the condition of the colony, working of the queen, amount of brood present, honey and pollen stores and to clean the bottom board debris accumulated during winter. It is a useful management to give a stimulant feeding to colonies when very few spring flowers have blossomed. The stimulant feeding with sugar and protein supplement (30 to 40\%) will help the colonies to rear more brood and raise greater foraging force to avail spring and summer flow. Thus feeding also raises the morale of the bees. It is an established fact that colonies which receive stimulant feeding produce more honey. The examination of colony should be done carefully and quickly because robbing is easily induced. All manipulations should be stopped once the robbing becomes apparent and reduce all entrances so that colonies are able to guard against the invasion of robbers. During spring, bee colonies go 'all out' to rear brood and invest all resources in increasing their strength. Queen lays more vigorously after winter egg laying rest. More drone combs are added for expanding brood nest. If the queen is working unsatisfactorily, that she is laying sparingly and/or laying drone eggs, effort must be made to replace the queen at the earliest opportunity. It may be pointed out that very weak colonies desert their hives if disturbed unnecessarily and are easily robbed out if they are fed syrup without great care. It is a wise practice to unite them with others and follow the golden rule, "always help first those colonies that need the least help, leaving the weakest to be helped the last". Colonies which are just below average in strength may be helped by giving them each a frame or two of capped brood from strong colonies. Another good practice is to equalize the strength of the colonies to avoid disparity so that all the colonies require the beekeepers attention at about the same time and respond equally to the treatment. During early spring, the weather is uncertain and beekeepers are warned against over expanding the brood nest and dividing it into two or more part by insertion of empty comb or comb foundations because there can be chance of the outlying brood being left unattended by the worker bees. Consequently, the neglected brood gets' chilled' because of treacherous weather that can prevail during early spring. But on the other hand, shortage of frames of stores at this time of the year cripples the colony for the whole season and the colony is not fully prepared to avail good honey flow.

Similar management practices in spring are needed under mid hill and sub mountainous conditions. But in plains of north India, the conditions are different in spring. In most areas extensive Brassica flora is available from October to January. The bees get 3 to $5 \mathrm{hr}$ for foraging during a day and instead of depletion of strength, there is some build up. Good colonies attain yielding strength and 
honey extraction is possible in January. The precautions against extension of brood nest, stimulant feeding etc. can be relaxed. Similarly, bees in southern peninsular India do not face weather problem. Spring is also a swarming season. Swarm prevention and control measures should be taken. Sharma and Kumar (2001) while evaluating the appropriate time for Apis mellifera colony division at Hisar during spring and autumn reported that February/March and November/December are suitable for colony division in Hisar, Haryana.

\section{Honey flow period}

Major honey flow period starts after winter and onset of spring season. Management of the bees is essential during these days. It is true that any amount of negligence during the honey flow will result in the poor management of the colonies ultimately leading to the crucial end of the colonies. To manage the colonies efficiently, the beekeeper should have the fullest knowledge of honey flow trends and the state of the colonies.

The principal function of the beekeeper during honey flow period is to keep the colony strength properly. In other words, he should ensure that the honey gathering instinct is dominant and that the instinct is not checked. Congestion in the hive must be avoided and surplus house bees are drawn to supers. A colony is particularly liable to have this trouble during honey flow because of rapid nectar income, and the beekeeper should do his best to remain ahead of bees providing space for honey storage. It must be remembered that great deal of space is required for the evaporation of honey than for its final storage. Therefore, drone combs should be provided liberally. A second super should be added between the first super and brood chamber and not above the first super. Many times, the queen goes to the super chamber and lays eggs and honey extraction becomes difficult. At last, weeks before honey extraction, a queen excluder should be placed in between brood and super chamber, and queen is confined to brood chamber. The supers can be of full depth or half supers. Handling and various operations are easy with full depth supers because frames can be exchanged between the chambers. But the judgment to use the kind of super depends on the colony strength. Apis mellifera colonies attain sufficient strength before honey flow and full depth supers on Langstroth hives are used in India. In case of ISI hives for A. cerana full or half supers are used. In Jammu and Kashmir Langstroth hive is used even for Indian honey bee. In most southern beekeeping areas, the Newton hive is still in use, where half super is common. Colony should be examined once a week and frames full of honey should be removed to the sides of the super and such frames can be raised from brood to super chamber. The frames which are three-fourth filled with honey or pollen and one -fourth with sealed brood should also be taken out of brood chamber and in its place empty combs or frames with foundation is added. Bees draw comb foundation better and quickly in brood chamber. The frame with comb foundation should be placed next to the brood nest. Often the beekeeper is short of drawn combs and getting more combs raised would lower honey yield. In such cases, the combs which are completely sealed or two thirds capped may be taken out for honey extraction and returned to the supers after honey extraction. Such extraction of uncapped honey should be avoided because 
this unripe honey has higher moisture percentage and is liable to ferment. Honey extraction, after the flow is over, can induce severe condition not within the species but also between the species too. It is a common experience that $A$. dorsata robbing domesticated hive bees become beyond control and loss of colonies is the result. On warm days, bees are noticed to gather in clusters at the entrance. This is a sign of congestion and poor ventilation. This affects the honey gathering instinct. The situation should be remedied promptly by improving ventilation and removing the entrance rod placing or queen gate

\section{Honey harvesting}

During honey flow season, the frame containing honey should be removed for extraction honey can also be extracted during the flow if super frames are ready. The honey should finally be extracted when bees are still bringing the nectar. To remove honey combs, a colony is smoked, the desired combs taken out and bees brushed off with a soft brush or grassy brooms. These combs are placed in bee tight hive bodies, remove to the extraction room and stock one about the other. A real beekeeper would never rob the coloney of its honey stock but takes away surplus only. Depending upon the strength, 5 to $15 \mathrm{~kg}$ of honey should be left with the colony of $A$. mellifera in rainy dearth periods. Apis cerana is a frugal species and colony strength is also less and $5-7 \mathrm{~kg}$ of honey stores may suffice for dearth period.

For extraction of honey, a room with wire-gauged bee-tight doors is necessary. It is better if it has double doors. In case, extraction room is not available then honey can be extracted in the open during night. To uncap the frames either a steam heated double walled uncapping knife or plain uncapping knives with provision for heating them in boiling water should be arranged. Electrically heated uncapping knives with a thermostat are used in big apiaries. A tray with expanded metal screen is also required. If too hot knives are used, lot of wax from the cells would melt into the honey and solidify after sometime into an undesirable layer over it. The uncapped frames should be placed in hive bodies with drip trays underneath them to await their transfer to the extractor. Beginning slowly, the extractor should be worked at about $150-200 \mathrm{rev} / \mathrm{min}$ for about $2-3 \mathrm{~min}$. Then the sides of the frames are reversed and the extractor is again worked. Empty frames are stocked in hive bodies till they are returned to supers in the bee colonies. It is advisable to make arrangement for straining and packing honey in tins promptly to obviate a need for its subsequent heating. Freshly extracted honey is warm and hence, easy to strain. Wax capping is handled for wax extraction. After the job has been done, the place should be swabbed with water and the application cleaned. Hive bodies are washed to remove honey drop. The empty wet combs should be returned to the bees for cleaning and the hive entrance be reduced to avoid robbing.

\section{Summer management}

The spring "honey flow" is followed by a summer dearth period. In most localities, the honey flow is followed by a summer dearth period. With the ceasing of honey flow season, they develop a strong tendency to protect their stores and became nervous and excited. Bees start throwing out drones and are not allowed 
to return because they are now useless in the colony. And becomes unmanaged colonies stop brood rearing in order not to starve in future. There is sudden decline in colony strength due to the death of old and decrepit bees who have put in strenuous work in gathering honey. Bees especially Apis cerana gnaw old and empty combs besides protecting their hives against the enemies and robber bees, the bees have to keep their hive cool and properly ventilated. Summer is rather a testing period for the colony and well compared to the difficult winter season in the west.

In a left alone colony, the bees mostly stay indoors, do little work remain listless and wait for the developing brood to emerage. The queen stops egg laying and if she persists in depositing eggs, they are neglected by the workers and allowed to shrivel. When almost all the brood has emerged and not enough is left, the colony absconds. Only empty combs and sometimes infested with wax moth are left. The deserting bees behave
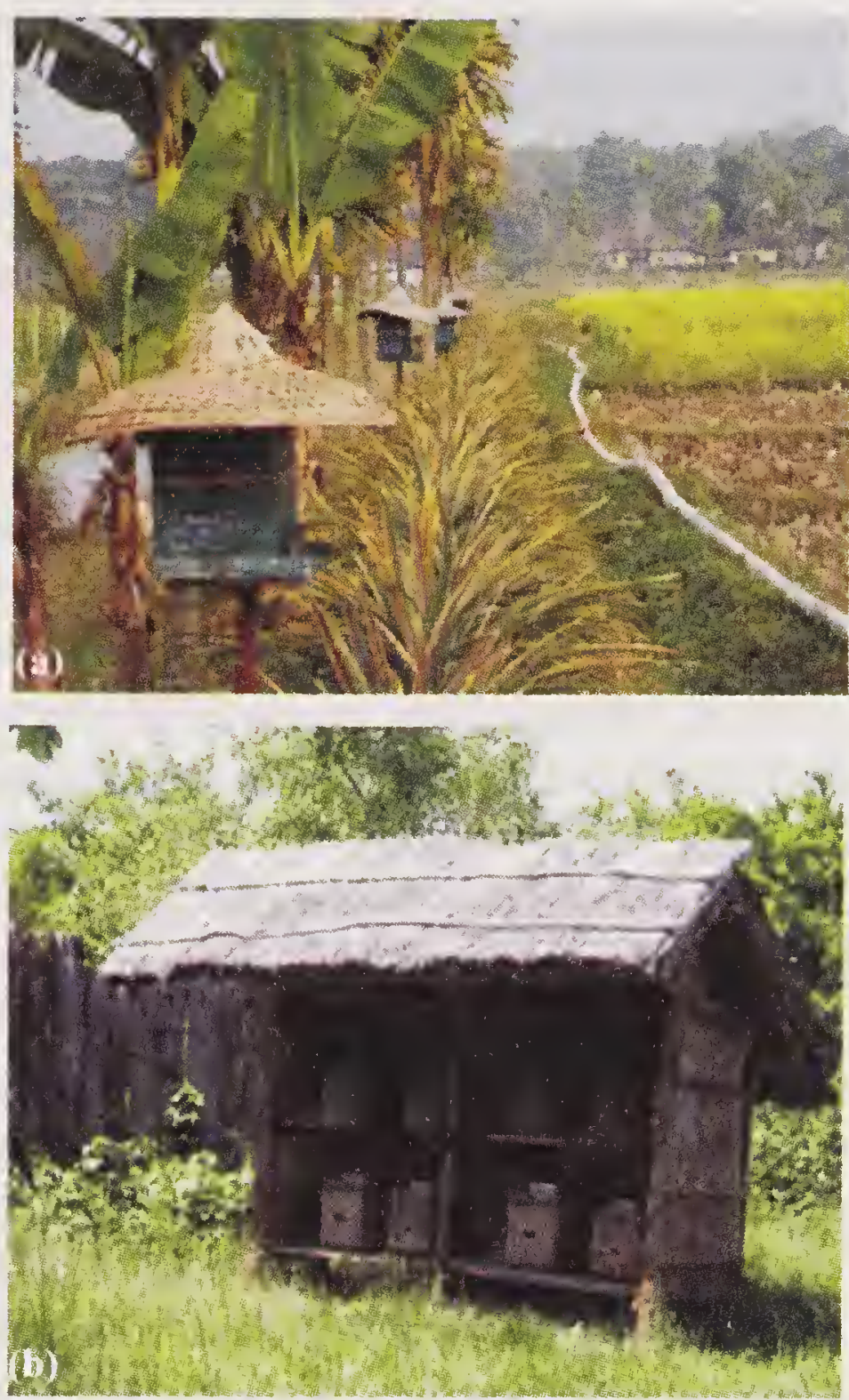

Fig. 9.3 (a) Bee hive under bamboo hat (AAU Jorhat); (b) Bee hive under thatched house adopted in North-east India. almost in a similar fashion as swarming bees rise very high and it is rather difficult to make them settle down. Desertion or absconding is little known in Apis mellifera but the tendency is very strong in Indian honeybee, Apis cerana, Apis mellifera colony would rather die because of starvation or due to the attack of enemies but show little tendency to abscond.

The best thing to do during this period is to avoid broodlessness in colonies and stimulate them to rear brood. The strong colonies with sufficient store would continue to rear some brood during summer. Colonies headed by young prolific queens will continue to lay eggs. Strong colonies are less troubled by enemies and are able to take advantage of subsistence floral sources, the colonies cannot be kept in the open in the sun (Fig. $9.3 \mathrm{a} \&$ b). These should always be shifted to a place with thick shade. Beekeeper can further help bee colonies by placing them under open thatched huts. The hut is of 'L'shape from east to west and west to south. At some place the temperature rise as high as $45^{\circ}-47^{\circ} \mathrm{C}$ and gunny bags, moistened twice at noon and the afternoon, can be spread over top covers .Ventilation of hive is be ensured but holes, cracks and crevices also allow easy passage for enemies. The brood and supper chamber can be raised slightly by putting shavings or splinters of wood in between the space so made should not allow the bees to pass through to avoid robbing. Sufficient honey stores are must in a colony. Beekeepers should have complete information of subsistence flora 
that would be available to the bees and make his judgment about the stores to be allowed at the time of last honey extraction. The brood rearing in summer can also be boosted by feeding pollen substitute or pollen supplement, a continuous supply of which is required during dearth period since these are not stored in cells. Frequent examination should be avoided and the honey bee colonies should be left in their comfort. Kumar et al. (2006) while studying the production of drones in Apis mellifera colonies during non breeding seasons recorded that laying workers required more time to initiate egg-laying after de-queening of the colonies during autumn (30-33 days) than in summer (18-23 days). In the first 4 days of egg-laying, the number of eggs per cell varied from 1-7. Drone emergence from the sealed brood varied from 46.52 to $58.60 \%$ in the test colonies. The development period of drones from egg to adult stage ranged from 23 to 27 and the weight of laying workers averaged $88.3 \mathrm{mg}$ as compared to $72.4 \mathrm{mg}$ of the normal workers.

\section{Constraints in rainy season}

Rainy season follows hot summer months in India. In some areas, bees are confined to hives for long intervals because of continuous rains. Large number of forager bees are lost in sudden storms or downpour reducing the strength of the colonies. High humidity in the hive, coupled with high temperature, creates an unfavourable environment for bees. They become lethargic and listless, and often suffer from different diseases. Pollen in comb cells becomes mouldy and unripe honey may ferment. Bee enemies, on the other hand grow in number and further weaken the colonies. The tendency to rob is accentuated. Good management requires the intensification of the measures usually employed in summer. Locating the apiary in the thick groove of trees where air stagnates and it is often hot and close should be avoided. During rains, candy or dry sugar should be given to the bees if artificial feeding becomes necessary. The feeding of pollen supplements and substitutes is useful.

It is often noticed during the monsoon that a few weak colonies queenless and laying workers appear. In most cases, it is difficult to make such colonies accept new queens. Moreover, there are no drones and new queens cannot be mated. It is advisable to unite them with others. Regular examination and constant vigilance to check robbing is important because severe robbing often leads to queen mortality.

\section{Artificial diet}

Honey is the best food for the bees and a beekeeper should always leave enough stores for them at all times. However, during dearth periods artificial feeding becomes necessary (Fig. 9.4). When honey is not available, the best substitute is sugar syrup made from white crystalline sugar by dissolving 2 parts of sugar and one part of water or 1 part of sugar and one part of water. The use of jaggary, molasses etc. is not recommended as these substances ferment in the cells and also cause dysentery. The sugar syrup can be fed to the bees in small dishes with floating straws. The bees will not dip in sugar and feed while sitting on these straws. The feeding should not be done during the day time which may result in robbing. It should be done in the evening hours. During early spring, the feeding of the bees is done to stimulate them as the season starts. The queen starts laying 
more and more eggs before the flora is available. This type of feeding is called as simulative feeding to prepare the colony to utilize the nectar flow season.

Feeding of sugar is must to survive the colonies during dearth periods, but if the feeding lasts a long time, the functional activity of bees negatively affected and they perform more poorly and their productivity is greatly reduced. Experiments have shown that honey feeding is the best, honey mixed

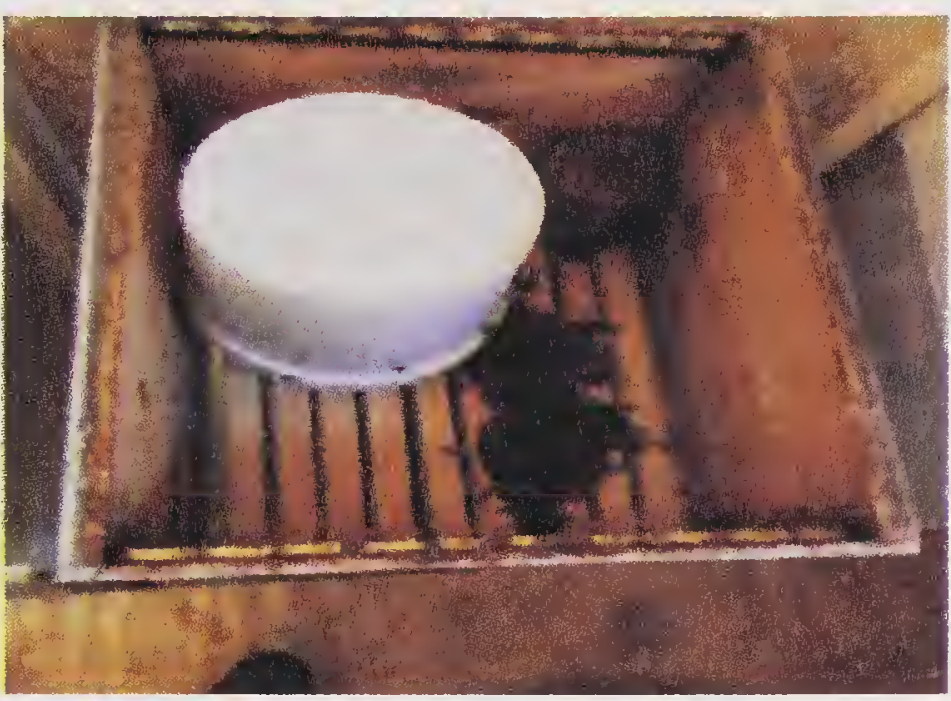

Fig. 9.4. Artificial diet application. with sugar is of secondary importance and sugar alone as the lowest quality food. It is therefore recommended that while extracting the honey, sufficient honey stores be left for bees. It has been found that disturbance in animal nutrition diminishes their enzymatic activity, weakens the defense of organism and brings about various pathological changes. Bodla et al. (2009) in their study on effect of sugar feeding on Apis mellifera colonies build up and storage dearth period recorded that feeding $A$. mellifera colonies with $500 \mathrm{~g}$ sugar syrup (1: 1 sugar: water) during dearth period (June to August) at 1, 2, 3, and 4 weeks intervals proved beneficial. All the colonies fed with sugar survived during dearth period, whereas all those colonies in control (without sugar syrup feeding) could survive till July and dwindled during August.

\section{Pollen feeding}

Pollen is a protein food. Brood rearing is impossible without it. Therefore, there is a natural direct dependence between the arrival of pollen to the nest and the amount of its brood. Pollen like honey must be available in adequate quantities to a wintering colony, otherwise spring dwindling occurs due to insufficient pollen stores. A wintering colony must replace its fall population with young bees and have a large activity brood nest by the time natural pollen is available in late winter or early spring. Whenever there is a pollen shortage, it can be provided in two ways. Singh et al. (2010), while studying on pollen feeding preference in Apis mellifera L. recorded that the mean number of honey bees over the time interval (12 and $24 \mathrm{~h}$ ) attracted to Brassica pollen (33.21 bees/Petri plate) was significantly the highest followed by the mixture of Brassica and Helianthus annuus pollens in the ratio of $1: 1 \mathrm{w} / \mathrm{w}$ ( $28.13 \mathrm{bees} /$ Petri plate) and significantly the lowest ( 19.71 bees/Petri plate) to $H$. annuus pollen. Mean consumption of Brassica pollen continued to be significantly the highest $(50.00 \mathrm{~g})$ six days after its provisioning. The mixture of Brassica pollen and $H$. annuus pollen was consumed in significantly lower quantities (43.58 g) than Brassica pollen alone, but was consumed significantly more than the $H$. annuus pollen alone $(32.75$ $\mathrm{g})$. The ingredients required for formulation of pollen substitute as standardized by Chhuneja et al. (2013) consisted of Brewer's yeast, skimmed milk powder, dehusked parched gram, sugar and distilled water as given below:

Chhuneja and Sandhu (2011), while studying the influence of vitamin 
supplementation of pollen substitutes on palatability, brood mortality, worker brood rearing and bee strength in Apis mellifera colonies revealed that the maximum bee longevity was observed on pollen feeding due to the higher consumption of nutritionally adequate diet followed by the basic diet standardized by them as shown in Table 9.1.
Table 9.1. Pollen feed content (Chhuneja et al., 2013)

\begin{tabular}{lc}
\hline Ingredients & Quantity\% \\
\hline $\begin{array}{l}\text { Brewer's yeast (inactivated } \\
\quad \text { and dried) }\end{array}$ & 41.8 \\
Dehusked parched gram & 4.2 \\
Skimmed milk powder & 4.0 \\
Sugar solution (Sugar: & 50.5 \\
$\quad$ water=13: 12, w/w) & \\
\hline
\end{tabular}

\section{Autumn care}

Proper management of colonies during autumn is the key to successful wintering and obtaining high honey harvest in coming season. Colonies should raise many workers which would go for overwintering. The queens of proceeding spring period build up or of those raised before honey flow season continue to lay eggs for longer duration in areas with severe winter conditions. But queens of previous year slow down and lay only few eggs in autumn. Therefore, age of the queen makes a difference in colony strength that overwinter. It is a useful practice to unite the weaker colonies and not to allow weak colonies to enter winter.

In hilly areas, bees avail rich autumn flow between September and October. The colonies should be handled as is done during a honey flow season. During this period, the colonies may prepare both for swarming and supersedure but the number of queen cells raised are fewer and the queens of the season are poorer as compared to those raised during spring or early summer. Experienced beekeeper will not extract all honey but leaves enough stores for overwintering. In certain areas, bees may not have flora to accumulate sufficient honey stores in autumn. Such colonies have to be fed with sugar syrup if the area has no winter flora or where winters are severe. Artificial diet has to be served in frequent interval under plains conditions, Brassica species start flowering from the month of October and unirrigated early Brassica species may present food to bees even during September. The Brassica flow continues till the beginning of February. Although, the working hours in winter are reduced to 3 to $5 \mathrm{hr} /$ day, collect enough food and there is no need of ensuring large for overwintering. But even under these condition, the bee colonies must rear large brood in autumn to avail winter sources.

Queen stops egg laying in autumn, if there are less or no honey and pollen stores, and this is done to avoid starving in future. Such queens are difficult to induce egg laying even by artificial feeding because even in winter free zones in sub tropical India, the respond to seasonal variations and the bee activity fades away as it happens in areas where they prepare for wintering. Therefore, honey and pollen stores should always be ensured during autumn to keep the queen and the colony active. Such colonies are also to explore and avail every subsistence source. Good beekeeper would always attempt to locate his apiary close to the sources of autumn honey flow. In lower hills and sub mountainous regions as well as plains, the autumn is more or less a dearth period. If the summer is long followed by monsoon then broodlessness persists and absconding may be explicit which is more prominent in Apis cerana but is little known in Apis mellifera. 


\section{Winter management}

Honeybees live in an environment of their own and regulate hive temperature between $32^{\circ}$ and $35^{\circ} \mathrm{C}$. Bees form a cluster when the atmospheric temperature drops below $10^{\circ} \mathrm{C}$. This, roughly spherical cluster becomes tighter as the temperature drops further down. The cluster is composed of inner and outer shell. This serves as insulation and prevents the heat loss. Bees raise the temperature by muscular movement and is possible by the consumption of honey in very cold winter, the bees go out on short flights to defecate. They can retain the faeces in rectum for long period when weather does not allow even short flight, strong colonies overwinter well because large number of bees can produce heat and retain it.

Honeybee colonies can be helped to overwinter by saving their energy in raising nest temperature. Wooden hives do give protection to bees against the vagaries of weather. But care is needed to further protect colonies from frosty winds and high humidity. All cracks, crevices and holes other than entrance should be plugged. The direction of hives should never be facing to north to avoid winds entering into the hives. The colonies find it difficult to regulate the nest temperature when relative humidity is high, that is about $70-75 \%$.the colony should not be located in damp places and under thick grooves of vegetation. Periodic inspection to verify the food stores is essential in winter. Insulation of hives helps to reduce consumption of honey and save energy of bees. Insulation is desirable in localities which have long spells of cold or where there is wide range between day and night temperatures, for purpose of insulation the climatic zone in different beekeeping tracts in the country can and the minimum temperature not falling below $10^{\circ} \mathrm{C}$ at any time of the year. Three cold months namely, December, January and February with the day hours bright and warm and the nights cold with foggy mornings as in north Indian plains. The fluctuations between the maximum and the minimum temperatures during $24 \mathrm{hr}$ may be $5^{\circ}-20^{\circ} \mathrm{C}$ in the open and honey flow from Brassica spp. is available, four cold month from November to February with cold being more intense and a large number of frosty days (lower hilly tracts). Minor honey flow from some Brassica, Prunus and litchi may occur, five cold months from November to March with severe cold snowfalls and cold wind (higher hilly tracts). No floral sources are available during the period.

Because of differences in winter weather, different management practices are needed in different regions. Whereas no insulation will be necessary in region with equitable temperature throughout the year and the minimum temperature not falling below $10^{\circ} \mathrm{C}$ at any time of the year, light insulation will be required in region with three cold months namely, December, January and February with the days generally bright and warm and the nights cold with frosty mornings as in north Indian plains. In this second region, bee colonies start expanding towards the second half of winter. Therefore, light insulation should be so provided that examination and providing extra space should be easy. Strong colonies with bees on 8-10 frames actually need no insulation and can winter well. In this region, good colonies yield surplus honey from Brassica in January or early February. In region the thickness of insulation should be increased, and in region it should be $7-10 \mathrm{~cm}$ on all sides of the hive. The winter packing is given at the end of autumn 
and after the colonies were properly prepared for winter season. Only strong colonies with number of young bees and enough honey and pollen reserves should be overwintered. Weak colonies will not be able to pull through the winter and should be united with others.

\section{Winter hive packing}

During winter, the bees form cluster when the temperature falls below $10^{\circ} \mathrm{C}$. In some parts of India, the temperature goes below $0^{\circ} \mathrm{C}$. In such circumstances, the honeybee colony should be exposed to sunlight; bees tried to regulate the temperature by muscular movement and are possible by the consumption of honey. Strong colonies overwinter well because larger number of bees can produce heat and retain it. Bee colony can be held to overwinter by saving their energy in raising hive temperature. Insulation of hive with doubling the thickness of wooden hives does give protection to bees against chill cold. Insulation is desirable in localities which have long spell of cold or where there is wide range between day and night temperatures. Insulation is not required where equitable temperature throughout the year and minimum temperature not falling below $10^{\circ} \mathrm{C}$ in that case only exposure to sunlight is necessary. The winter packing is given at the end of autumn and colonies have been properly prepared for winter season. During winter in northern India, colonies are generally migrated to the Brassica field. Simulative feeding is a normal practice with the bee keepers. The feeding is provided at least 2-3 weeks before the start of colony build up. This simulative feeding enhances the brood rearing activity and colony build up. Simulative feeding consists of brewers yeast, sugar, gram powder and skimmed-milk@10: 10: 1: 1. Finely chopped dry grass, wood shaving saw dust, dry leaves, chopped rice straw or wheat are the handy packing materials, through thermocal and woolen rugs can also be used. In regions (b) and (c) pacing can be given in the brood chamber, if the colony is weak, by packing the space beyond dummy board (Fig. 52). The packing material is also used between the inner top cover. In case the region (d) thick packing may be needed on all sides of the hive. The packing material is kept in place with string or water proof wrapped over the packing material. Care should be taken that packing material should not be moist since the moisture makes them poor insulators. If the hive are located in a protected place, the packing material can be kept in position around the hive with old pieces of gunny bags. Abrol (2002) in an attempt for utilization of waste materials such as wheat chaff (chopped wheat straw), paddy straw, saw dust, and thermocole sheets as inner packing for outdoor wintering of Apis mellifera colonies in Jammu and Kashmir reported that thermocole in combination with polythene sheets was effective.

\section{REFERENCES}

Abrol, D. P. 2002. Utilization of waste materials for outdoor wintering of Apis mellifera. L. colonies. Biological Research Technology 81(2): 159-61.

Bodla, R., Kumar, Y. and Sharma, S. K. 2009. Effect of sugar feeding on Apis mellifera colonies build up and storage during dearth period. Ann Plt Protec Sci 17: 103-06.

Chhuneja, P.K. and Sandu, G.S. 2011. Influence of vitamin supplementation of pollen substitutes on palatability, brood mortality, worker brood rearing and bee strength in 
Apis mellifera Linn. Colonies. Proceedings Experimental Exchange Workshop on Prospects and Promotion on Apiculture for Augmenting Hive and Crop Productivity, Punjab Agricultural University, Ludhiana, India.

Chhuneja, P.K., Singh, J. and Singh, G. 2013. Field evaluation of PAU pollen substitute. Proceedings of Biennial Meet. AICRP on Honey bees and Pollinators, GBPUAT, Pantnagar.

Kumar, R., Gupta, J.K., Thakur, R.K. and Rana, B.S. 2006. Studies on the production of drones in Apis mellifera L. colonies during nonbreeding seasons under mild-hill conditions of Himachal Pradesh. Pest Management and Economics Zoology 14(1 \&2): 195: 198.

Sharma, S.K. and Kumar, Y. 2001. Appropriate time and strength for Apis mellifera colony division and subsequent build up in Hissar(Haryana). Annual Biology 17(1): 87-90.

Singh, J., Singh, G. and Chhuneja P.K. 2010. A study on pollen feeding preference in Apis mellifera L. Journal of Insect Science 23(4): 403-08. 


\section{0 \\ Bee Diseases and their Management}

$\mathrm{H}$

ONEYBEES in their brood and adult stages are infected by various types of diseases. There has been a continuous effort to evolve effective management practices against those diseases. Prevention and control of diseases have been an essential aspect in apiculture. Honeybees are affected by large number of viral, bacterial, fungal and protozoan organisms. The extent of losses varies from death of some brood or adults to complete annihilation of colonies. Some may tolerate the infection but any extent of severity leads to loss in honey yields. Diagnosis of maladies has been possible by refined methods with the help of sophisticated equipments. But essentially, the need is to detect and diagnose the infection at the initial stages because it is easy to treat the colonies at that stage. Bee diseases are spread from one colony to another or from one apiary to another mainly by robber bees, swarms or migration of colonies. Because of these, quarantine measures within the country or between the countries which have geographical contiguity are not feasible. Restrictions on the movement of bees between the countries which are separated by barriers seem useful and practicable. Spread of diseases is also frequent by manipulative operations in the apiary. Beekeeper may be required to transfer honey and pollen combs from one colony to another. Similarly, weaker colonies may need to be strengthened by transferring brood frames or combs with adult bees. Even uniting of colonies has to be resorted to in certain circumstances. Providing water in a container in apiary is another hazardous practice. All these manipulations lead to spread of diseases and parasites from affected to healthy colonies. Disease spread is even possible through hands; hive tools etc. while examining the colonies. Therefore, beekeeping requires not only the knowledge of basic principles of colony management but beekeeper should be well acquainted with the nature of bee diseases. Early disease detection and prompt application of control measures is very important.

Many diseases which affect honeybees in other countries are not yet serious in India but there are isolated reports of their incidence except for some viral diseases. Any known diseases in the west can be expected to appear in epidemic form in India too and therefore, very brief account of all the diseases and their management practices have been discussed in this chapter. Diagnosis, cause and spread of brood disease have been given in Table 10.1 .

\section{VIRAL DISEASES}

Many viral diseases of honeybees are known but the extent and severity of 
Table 10.1. Diagnosis, cause and spread of brood diseases

\begin{tabular}{|c|c|c|c|c|}
\hline Character & $\begin{array}{l}\text { American } \\
\text { foul brood }\end{array}$ & $\begin{array}{l}\text { European } \\
\text { foul brood }\end{array}$ & Para & $\begin{array}{l}\text { Sac brood } \\
\text { foul brood }\end{array}$ \\
\hline $\begin{array}{l}\text { General } \\
\text { apperance of } \\
\text { brood combs }\end{array}$ & $\begin{array}{l}\text { Brood irregular; } \\
\text { inter-mingling } \\
\text { of capped, open } \\
\text { and punctured } \\
\text { cells; much dead } \\
\text { brood in capped } \\
\text { cells; cells with } \\
\text { punctured cappings } \\
\text { and cells uncapped } \\
\text { by bees }\end{array}$ & $\begin{array}{l}\text { Brood irregular } \\
\text { dead brood } \\
\text { mostly in } \\
\text { open cells }\end{array}$ & $\begin{array}{l}\text { Brood irregular; } \\
\text { most dead } \\
\text { larvae in } \\
\text { open cells; } \\
\text { varying amount } \\
\text { of dead brood } \\
\text { in sealed cells }\end{array}$ & $\begin{array}{l}\text { Brood slightly } \\
\text { irregular; dead } \\
\text { brood mostly } \\
\text { in cells with } \\
\text { punctured } \\
\text { in uncapped } \\
\text { cells. }\end{array}$ \\
\hline $\begin{array}{l}\text { Capping } \\
\text { cover dead } \\
\text { brood }\end{array}$ & $\begin{array}{l}\text { Many punctured } \\
\text { red, sunken and } \\
\text { discoloured }\end{array}$ & $\begin{array}{l}\text { Few capping } \\
\text { sunken, } \\
\text { punctured or } \\
\text { discoloured }\end{array}$ & $\begin{array}{l}\text { Cappings cover } \\
\text { dead brood or } \\
\text { discoloured } \\
\text { coloured, } \\
\text { sunken or thi- } \\
\text { ckened and } \\
\text { sharply } \\
\text { depressed in } \\
\text { the center. }\end{array}$ & $\begin{array}{l}\text { Usually } \\
\text { punctured }\end{array}$ \\
\hline $\begin{array}{l}\text { Proportion } \\
\text { of dead }\end{array}$ & $\begin{array}{l}\text { Varying from } \\
1 \text { to } 75 \% \\
\text { of brood }\end{array}$ & $\begin{array}{l}\text { A few coiled } \\
\text { larvae to most } \\
\text { in open cells } \\
\text { and a few in } \\
\text { capped cells }\end{array}$ & $\begin{array}{l}\text { A few larvae } \\
\text { to practically } \\
\text { all the brood }\end{array}$ & $\begin{array}{l}\text { Small amount } \\
\text { of brood dead }\end{array}$ \\
\hline $\begin{array}{l}\text { Age at the } \\
\text { time of } \\
\text { death }\end{array}$ & $\begin{array}{l}\text { Late larval and } \\
\text { early pupal } \\
\text { stages, rarely } \\
\text { coiled stages }\end{array}$ & $\begin{array}{l}\text { Coiled stage, } \\
\text { occasionally } \\
\text { late larval } \\
\text { stages }\end{array}$ & $\begin{array}{l}\text { Coiled stage, } \\
\text { occasionally } \\
\text { late larval } \\
\text { and early } \\
\text { pupal stages }\end{array}$ & $\begin{array}{l}\text { Late larval } \\
\text { stage; } \\
\text { occasionally } \\
\text { coiled larval } \\
\text { and } \\
\text { pupal stages }\end{array}$ \\
\hline $\begin{array}{l}\text { Position of } \\
\text { dead brood }\end{array}$ & $\begin{array}{l}\text { Fully extended } \\
\text { on floor of cell, } \\
\text { tail turned up on } \\
\text { bottom, head } \\
\text { lying flat, great } \\
\text { irregularity }\end{array}$ & $\begin{array}{l}\text { Coiled on } \\
\text { bottom or } \\
\text { twisted on side, } \\
\text { few larvae } \\
\text { fully extended } \\
\text { on floor of cell; } \\
\text { very regular }\end{array}$ & $\begin{array}{l}\text { Coiled on } \\
\text { bottom, twisted } \\
\text { on side walls } \\
\text { or fully extended } \\
\text { on the floor of } \\
\text { the cell; great } \\
\text { irregularity }\end{array}$ & $\begin{array}{l}\text { Fully extended } \\
\text { on floor; heads } \\
\text { prominently } \\
\text { raised, } \\
\text { great } \\
\text { irregularity }\end{array}$ \\
\hline
\end{tabular}


(Contd. from p. 123)

\begin{tabular}{|c|c|c|c|c|}
\hline Character & $\begin{array}{l}\text { American } \\
\text { foul brood }\end{array}$ & $\begin{array}{l}\text { European } \\
\text { foul brood }\end{array}$ & $\begin{array}{c}\text { Para } \\
\text { foul brood }\end{array}$ & Sac brood \\
\hline $\begin{array}{l}\text { Colour of } \\
\text { dead brood }\end{array}$ & $\begin{array}{l}\text { From dull-white to } \\
\text { dark- brown or } \\
\text { almost black }\end{array}$ & $\begin{array}{l}\text { From dull } \\
\text { white to } \\
\text { yellowish white, } \\
\text { often dark brown }\end{array}$ & $\begin{array}{l}\text { From dull-white } \\
\text { to reddish- } \\
\text { brown }\end{array}$ & $\begin{array}{l}\text { Greyish to } \\
\text { straw coloured } \\
\text { to black, head } \\
\text { end usually } \\
\text { darker }\end{array}$ \\
\hline $\begin{array}{l}\text { Kind of brood } \\
\text { affected }\end{array}$ & $\begin{array}{l}\text { Mostly worker, } \\
\text { occasionally } \\
\text { drone, rarely } \\
\text { queen }\end{array}$ & $\begin{array}{l}\text { Worker, drone } \\
\text { and queen }\end{array}$ & $\begin{array}{l}\text { Worker, } \\
\text { drone and queen }\end{array}$ & $\begin{array}{l}\text { Usually } \\
\text { worker but } \\
\text { sometimes } \\
\text { drone }\end{array}$ \\
\hline $\begin{array}{l}\text { Consistency } \\
\text { of dead brood }\end{array}$ & $\begin{array}{l}\text { At first watery or } \\
\text { slightly viscid, } \\
\text { becoming } \\
\text { ropy; finally } \\
\text { brittle }\end{array}$ & $\begin{array}{l}\text { At first soft and } \\
\text { afterwards } \\
\text { pasty, rarely } \\
\text { viscid and ropy; } \\
\text { scales tough; } \\
\text { rubbery or brittle }\end{array}$ & $\begin{array}{l}\text { At first soft and } \\
\text { in open cells } \\
\text { coming pasty and } \\
\text { brittle in capped } \\
\text { cells, frequently } \\
\text { becoming ropy } \\
\text { finally tough and } \\
\text { leathery }\end{array}$ & $\begin{array}{l}\text { Skin fairly } \\
\text { tough, watery, } \\
\text { contents } \\
\text { watery } \\
\text { and granular, } \\
\text { scales tough } \\
\text { brittle when } \\
\text { completely } \\
\text { dry }\end{array}$ \\
\hline Scales & $\begin{array}{l}\text { Uniformaly ex- } \\
\text { tended on lower } \\
\text { side wall; tail } \\
\text { curved up, dead } \\
\text { pupae with } \\
\text { tongue exteneded } \\
\text { upwards, often } \\
\text { attached to upper } \\
\text { cell wall; difficult } \\
\text { to remove } \\
\text { from cell. }\end{array}$ & $\begin{array}{l}\text { Usually coiled } \\
\text { on bottom of } \\
\text { cells; often } \\
\text { irregurly twisted } \\
\text { some times fully } \\
\text { extended; } \\
\text { tracheae often } \\
\text { clearly visible } \\
\text { tough and } \\
\text { rubbery; easy } \\
\text { to remove } \\
\text { from cell. }\end{array}$ & $\begin{array}{l}\text { Coiled on bottom, } \\
\text { irregurarly } \\
\text { twisted; on side } \\
\text { walls or fully } \\
\text { extended in the } \\
\text { cell; tracheae } \\
\text { some times } \\
\text { visible; easily } \\
\text { removed from } \\
\text { the cell }\end{array}$ & $\begin{array}{l}\text { Uniformly } \\
\text { extended } \\
\text { from lower } \\
\text { side of wall; } \\
\text { head } \\
\text { prominent } \\
\text { raised; out } \\
\text { line wavy; } \\
\text { greyish- brown } \\
\text { to neraly } \\
\text { black; head } \\
\text { darker; easily } \\
\text { remove from } \\
\text { cell. }\end{array}$ \\
\hline Odour & $\begin{array}{l}\text { Distinct odour in } \\
\text { early stages; } \\
\text { gluepot odour in } \\
\text { brown ropy } \\
\text { remains in scales. }\end{array}$ & $\begin{array}{l}\text { No specific } \\
\text { odour, sour, } \\
\text { odour in partly } \\
\text { decayed remains; } \\
\text { odours variable. }\end{array}$ & $\begin{array}{l}\text { Resembles E.F.B. } \\
\text { but more intense. }\end{array}$ & $\begin{array}{l}\text { Absent or } \\
\text { slightly sour }\end{array}$ \\
\hline $\begin{array}{l}\text { Caused } \\
\text { organism } \\
\text { Spread of } \\
\text { disease }\end{array}$ & $\begin{array}{l}\text { Bacillus larvae } \\
\text { Through hive } \\
\text { parts, combs, } \\
\text { honey }\end{array}$ & $\begin{array}{l}\text { Melissococcus } \\
\text { pluton } \\
\text { Drifting } \\
\text { nurse bees }\end{array}$ & $\begin{array}{l}\text { Bacillus paralvei } \\
\text { Drifting, nurse } \\
\text { bees }\end{array}$ & $\begin{array}{l}\text { A filterable } \\
\text { virus Drifting, } \\
\text { nurse bees }\end{array}$ \\
\hline
\end{tabular}


different viruses vary. The bee viruses appear to be species specific. Three viruses, viz. Apis irridescent virus, Thai sac brood virus and Kashmir bee virus, have been reported from India. Out of these three, the first two have devastating effect on Apis cerana in some parts of the country.

\section{Sacbrood diseases}

Sacbrood diseases is caused by a virus named sacbrood virus - SBV. Typically, there are number of uncapped or partially uncapped cells throughout the brood nest. These cells contain discolored larvae, usually grey to black, lying flat on the cell bottom with markedly darkened heads. The disease receives its name from the fact that the infected individual appears sac-like due to an accumulation of fluid between larval and pupal cuticles. The exercise of care, the SBV infected bee can be easily removed intact from the cell with forceps. In puncturing of the sac, the watery contents will run out. In more severe cases, it may be dark, brittle scales on the bottoms of the cells. These scales are easily removed from the cell. Like Chalkbrood, SBV is almost always self-limiting. There are no approved medications for control of SBV. There is a persistent case of SBV, the requeening with a different stock of bees is effective. Rana and Rana (2008) while attempting to detect sacbrood virus in Apis mellifera colonies reported the disease from Kangra valley of Himachal Pradesh.

\section{Thai sac brood virus}

This virus disease was first detected in India in Apis carana from Meghalaya in 1978 (Kshirsagar et al., 1982). The causative virus multiplies in adults which transmit the virus to larvae. Trophallaxis, swarms and drifting are believed to be the reasons of spread of the disease. Exchange of brood combs in between the colonies is the reason of spread within the apiary. Sac brood disease which is closely related virus disease in many other countries, is not considered serious but Thai sac brood took up to $95 \%$ toll of Indian honeybee colonies during early nineties in northern India. The disease occurred with similar severity in south India during 1991-92.

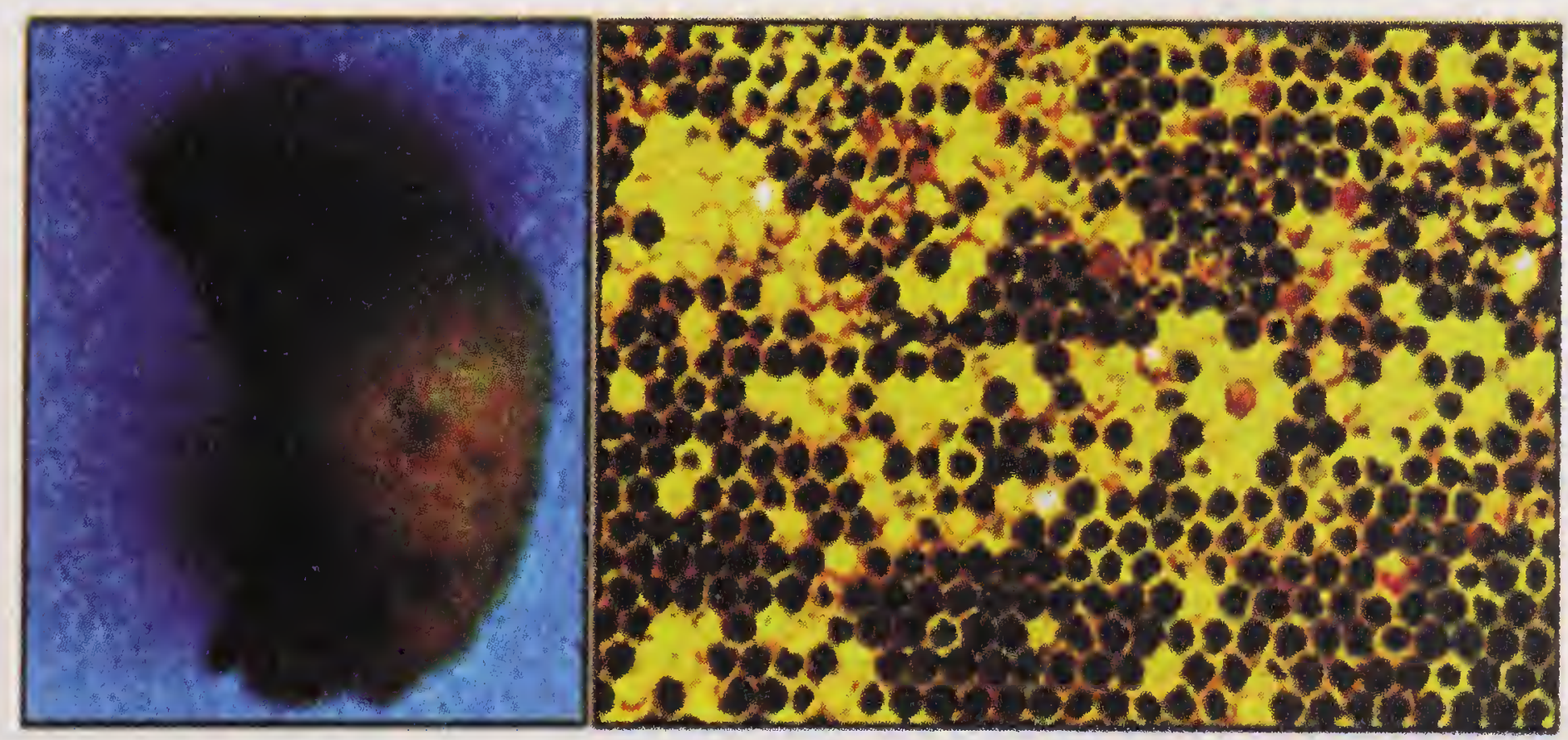

Fig. 10.1. Symptom of Thaisac brood (AAU, Jorhat). 


\section{Symptoms}

(i) Brood die in prepupal but in unsealed stage. (ii) Dead larvae straighten out and lie on their backs, with tip of head capsule turned upwards. (iii) Dead prepupae turn into sac like structure. (iv) affected larvae are yellow or greyish, later darkening to blackish; the change in colour first starts from mouth-parts and head. (v) dead larvae and prepupae dry up in brood cells forming loose scales (Fig. 10.1).
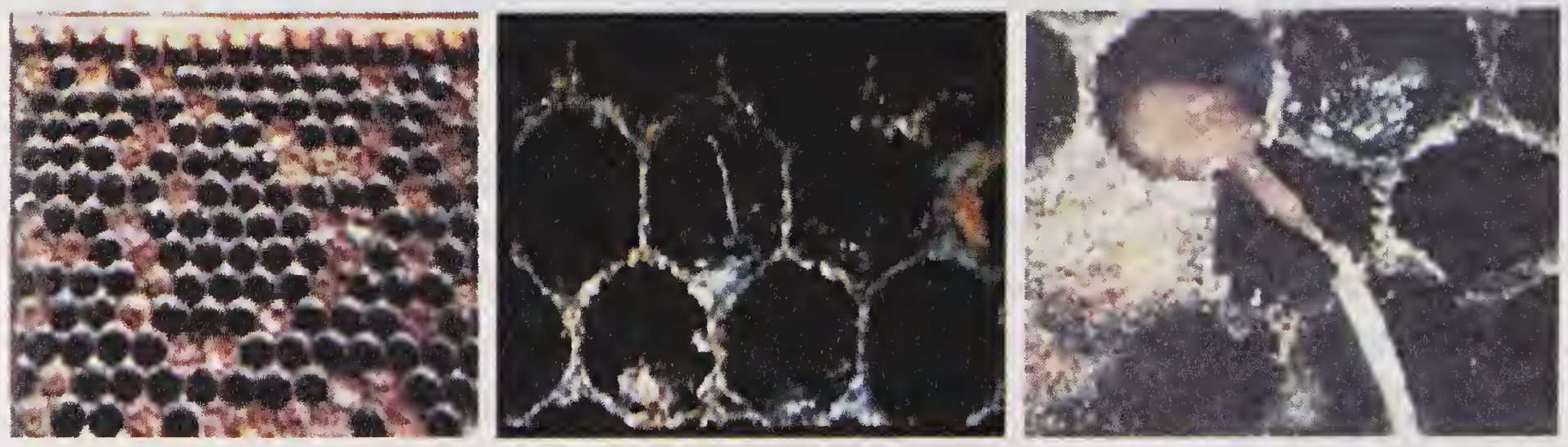

Fig. 10.2. Symptom of American foul brood (Wolfgang, 2008)

Devanesan et al. (2005) studied the incidence of thai sac brood virus on Apis cerana in Kerela, India and reported the visible symptoms as the presence of unsealed cells in brood area with the head of the larvae directed outward like the prow of a boat. Dead larvae lying stretched out on their back, appearing like sacs filled with milky white fluid when lifted up. Dead and lying larvae seen strewn on the floor board, hive entrance or on the floor near the hive.

\section{Management}

No definite preventiveor remedial measures against the disease are available, but keeping the colonies strong, avoiding exchange of hive parts and restricted movement of bees are suggested. Natural selection of tolerant colonies is expected and in endemic areas the surviving colonies can be multiplied with screening for disease tolerance in each generation.

Bai et al. (2007) while evaluating herbal extracts viz., Mimosa pudica, Phyllanthus niruri, Ocimum sanctum, Boerhavia diffusa, Azadiractha indica, Adathoda vasica, Hemidesmus indicus and Curcuma longa in control of thai sac brood disease of Asian honey bees, Apis cerana found that $C$. longa was effective followed by $M$. pudica and $P$. niruri for controlling the disease.

\section{Dequeening and requeening technique}

Creating bloodlessness for some time in the infected colony by dequeening and again requeening through production of new queen cell is proved to be effective (Rahman, 1992). Infected colony is treated with antibiotics like Oxytetracycline $250 \mathrm{mg} @ 1$ tablet/4 litre of sugar syrup so as to give strength to the worker bees. Natural selection of tolerant colonies and multiplication of these colonies in endemic areas. Restricted movement of colonies to disease prone areas and the infected colonies to be isolated to a safe distance from apiary.

\section{Apis iridesecent Virus}

This viral disease was reported from north -western states of India in seventies. 
The virus is specific to $A$. cerana and even in mixed apiaries, the disease does not appear in $A$. mellifera. It forms crystals in tissues where the virus multiplies. The crystals appear bright blue-violet or green when observed under microscope with incident light. This is also revealed even with hand lens, or in sunlight with the naked eye .The virus multiplies in the fat bodies and other tissues of adult bees.

Symptoms: (i) Infected bees form clusters on the inside and later on the outside walls of the hive, hence it is also called as clustering diseases. (ii) Many crawling bees are found on the ground. (iii) Worker bees stop foraging, sit listlessly and even brood rearing is stopped. (iv) Queen stops egg laying and the eggs laid are not attended by nurse bees. (v) Death of the entire colony follows.

\section{Kashmir bee virus}

The virus was first isolated from diseased samples of Apis cerana from Kashmir strains Kashmir bee virus have also been found in Apis mellifera in Australia. All stages of honey bee are vulnerable to the disease. The virus is transmitted by injection or even by contact of body surface and death is fast.

\section{BACTERIAL DISEASES}

\section{American foul brood}

Bacillus larvae is the causative bacterium of the disease. The American foul brood (AFB) disease occurs in temperate and subtropical regions of the world. There is solitary report of the disease incidence in India on Apis millifera since its establishment in the country. Infected brood is invariably found dead after spinning of the cocoon in the sealed cell. The dead prepupae lye straight with head towards the opening of the cells.

Cell capping of infected brood becomes darker in colour, sunken and perforated. A tooth pick inserted into the body of prepupa and drawn out shows ropiness. The putrefying brood turns brown and has fish glue odour. Dead brood dry up into scale which adhere to the cell bottom. Large number of spores are formed and are present in the scale. Hive bees pick-up the spores while cleaning the cells and spread the disease. The spores germinate in the gut of the larvae, the rods penetrate the gut wall and multiplication takes place in the body cavity. The spores are very resistant and they remain infective even under desiccation for 35 years. The disease may subside during some parts of the year and reappear later. There is no seasonal cycle and outbreak appears when the brood is present. Destruction of affected colonies and equipment though suggested, is a costly and cumbersome measure. Fumigation can be resorted for sterilizing the equipment in a fortnight. Ethylene oxide, $1 \mathrm{~g} /$ litre space at $43^{\circ} \mathrm{C}$ for $48 \mathrm{hr}$ is effective for sterilization but forms explosive mixture with air. Many antibiotics have been tested with variable efficacy.

\section{Field and laboratory diagnosis}

Bee hive may show less than normal bee flight with dead bees on the bottom board. The colony may appear weak after opening the hive. Capped brood is uneven with puncture holes in the caps of brood cells (Fig. 10.2). Colonies with 
heavy infection often display irritable behaviour. AFB has a distinct "foul" odour that can help in alerting the beekeeper to the disease problem. With a toothpick, lift punctured cap and remove content of brood cell. The larval remnant may be a light brown mass sunk onto the bottom side of the brood cell. If the mass is ropy when withdrawing the toothpick from the cell, there is a strong indication of American Foulbrood disease (AFB). The larval remains in the cell will dry and harden into a dark brown leathery scale on the bottom side of the brood cell. A single scale contains millions of spores that remain viable for decades. Bees cannot remove scales from cells. AFB scales can be readily detected in the field by holding the brood frame at an angle of approximately 15 degrees. Scales should be easily visible.

AFB is caused by Paenibacillus larvae, a spore-forming bacterium, where a microscope slide can be prepared by dissolving a small part of an AFB scale. Stir the scale with a toothpick in a droplet of water placed on a slide and apply a cover slip. Under 400X magnification, the AFB spores are readily visible. AFB spores are characterized by being very slightly oblong, uniform in size and shape. The spores "jiggle" in a characteristic Brownian movement. Paenibacillus larvae is competitive and does not tolerate growth of other bacteria in the parasitized bee larva. As a result, most microscopic slides will show a predominance of $P$. larvae spores.

\section{Management}

Regular inspections, especially when disease has been reported in the area or after the colony has been placed in crop pollination. Visually the disease can be detected an when AFB has been confirmed, kill the bees and burn all the equipment or shake bees onto foundation and burn all the old equipment. Feed the bees with medicated sugar syrup at two week intervals until foundation has been drawn out. Reduction of the exchange of hive equipment between hives and apiaries and replacement of $20 \%$ of all brood frames each year are good preventive measure. Hygienic management practices, including clean clothing, hive tools, and gloves are necessary. Use of antibiotics when necessary is effective.

\section{European foul brood}

The causal bacterium was earlier placed in the genus Stratococcus but in 1981, Bailey and Collins showed that the bacterium has nucleic acid composition which qualifies to place it under different genus and it was named as Melissococcus pluton. Diseased larvae are killed usually when 4-5 days old. Diseased larvae became flaccid, turn brown and give foul-sour smell. European foul brood disease is present in most of the countries. Infection was once observed in Maharashtra on Apis cerana by Diwan et al. (1972). Bacteria on swallowing with food, multiplies in mid gut and are discharged with faeces. Older larvae are less susceptible to infection. The extent of disease is higher in spring and there is recovery during honey flow. Control of disease is achieved by sterilizing the equipment with ethylene dioxide and treatment with selective antibiotics heal the disease.

Rao (2013) in his attempt for serological detection of Melissosoccus plutonius from Apis mellifera and A. cerana in north west Himalayas of India by using anti 
serum against $M$. plutonius reported the band formation between $M$. plutonius from $A$. mellifera isolate confirmed that European foul brood disease caused in $A$. mellifera was due to $M$. plutonius bacterium.

\section{Field and Laboratory diagnosis}

European Foulbrood (EFB) is much less serious than American foul brood (AFB). EFB shows up when the colonies have been under stress due to other diseases, colonies nearby, poor management and weather. EFB affects bee brood much the same as AFB except that the disease affects open brood, i.e. the larvae are affected before they are capped. Affected cells show discoloured larvae often in twisted positions with visible tracheal tubes (Fig. 10.3). The

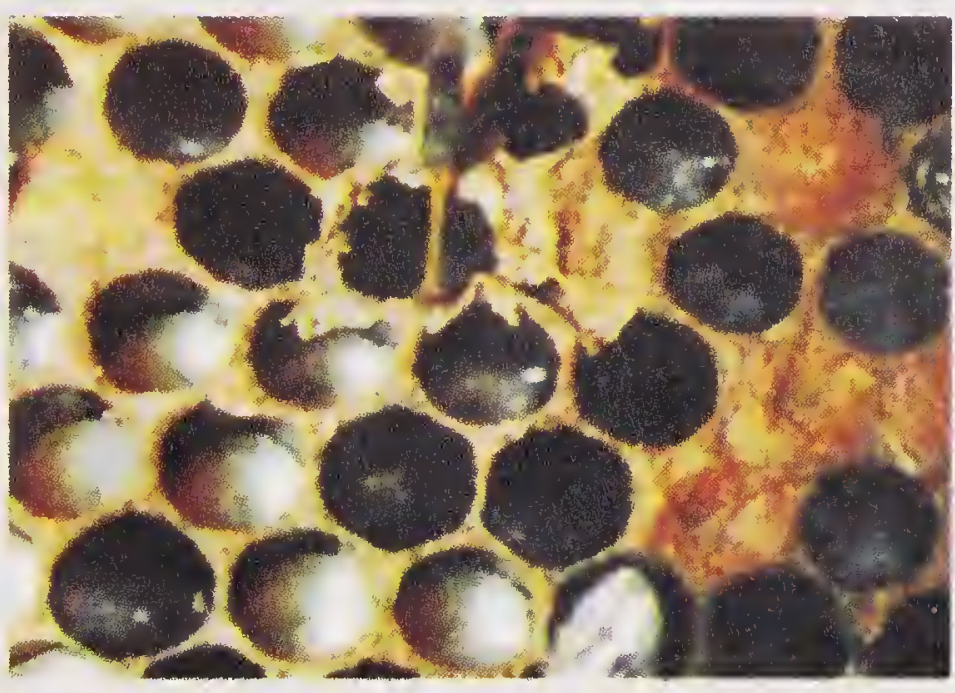

Fig. 10.3. Symptom of European foul brood (Wolfgang, 2006) brood has a "sour" odour, distinctly different from AFB. EFB scales are easily removed from the cell and may be examined in the laboratory.

EFB is caused by Melissococcus pluton, but the secondary invader Bacillus alvei is mostly observed when samples are examined microscopically. Samples are prepared the same way as AFB samples. At $400 \mathrm{X}, B$. alvei is readily visible by its long spindle shaped spores. The spores do not jiggle but float by in the solution. Unlike AFB, EFB microscopic samples generally display a wide variety of microbes.

Management: Inspect brood frames regularly and be familiar with field symptoms, frames with significant numbers of affected cells should be removed. Requeening provides a distinct break in the brood cycle of the colony, allowing the bees to clean up existing disease. It may also provide new bees with better cleaning behaviour, i.e. less susceptible to disease. Hygienic management practices such as cleaning of hive tools, smoker and gloves after inspection of each apiary and replacement of brood frames are effective measures.

Bahman and Rana(2003) studied the control of European foul disease in Apis mellifera with six antibiotics, viz. ciprofloxacin, chlorotetracycline, penicillin, oxytetracycline, cloxasillin and tetracycline which were treated to the infected colonies and oxytetracycline was found to be effective for suppressing the disease. Hence, spraying with antibiotics (oxytetracycline) dissolved in $250 \mathrm{ml}$ of sugar syrup over the colony every 3-4 days interval is effective.

\section{Fungal disease}

Two fungal disease, viz. chalk brood (Ascophera apis) and stone brood (Aspergillus flavus) are known in honeybees. Incidence of both is very minor and there cannot be any problem in well attended apiaries because incidence occurs under cool and damp conditions. The brood which remains unprotected by bees in the outer combs is infected by A. apis. The larvae are reduced to white mummies and dark spots appear when fruiting bodies are formed. In case of $A$. flavus 
infection, the mummies are hard and not spongy. These fungal diseases have not attracted attention and no methods for control have been worked out. Both the diseases are unknown to Indian apiculture.

\section{Chalkbrood disease}

Chalkbrood is caused by a fungus, Ascosphaera apis. The fungus infects larvae three to four days after egg hatch and is most commonly found in worker and drone brood. Before the fungal growth, it may be noticed that an otherwise healthylooking larvae has lost its glistening look. The infected larva is quickly covered by a white, fibrous mycelium, which fills the entire cell. The fungal mass quickly dries to form a hard, shrunken mass called a mummy that is easily removed from cell. The shrunken head often remains visible as a light-brown protrusion. If different strains of the fungus invade a larva, they may form spore cysts, in which case the mummy will take on black and white mottling, or it may become entirely black. Mummies are often seen in large numbers at the entrance of a heavily infected colony. They may also be found in capped cells. There are no approved medications for control of Chalkbrood. Fortunately, it is usually self-limiting; although some areas in the northeast are known to have serious problems with this disease. If you encounter a severe and persistent case of Chalkbrood in an area where the incidence of the disease is low, try requeening the colony to eliminate the condition.

\section{Stone brood disease}

Stone brood is caused by the fungi Aspergillus flavus and Aspergillus fumigatus. Spores of the fungus are present in the soil and are common on moldy hay. It is unlikely that they will germinate on the bee or its environment and is rare. After germination the vegetative growths (hyphae) of the fungus invade the larval tissues and kill them after they have been capped. The fungus then produces fruiting bodies containing many spores to spread the infection. Adult bees will tear down the cappings of the dead larvae to reveal yellow/green (A. flavus) or grey/green ( $A$. fumigatus) mummies. These lie along the length of the cell and often take on the hexagonal pattern. The bees remove the mummies from the hive and they can be seen on the hive floor or outside the hive. The mummies are usually found scattered throughout the brood nest but are unlikely to reach high numbers. The disease is likely to occur in the late spring/early summer as the colony expands and the brood outnumbers the bees.

\section{Protozoan disease}

This is a spore forming protozoan infecting adult bees. Bees become dysenteric with distended and swollen abdomens. Young infected bees take up nursing duties as usual but soon stop rearing brood because food glands are affected and they shift to foraging. Affected bees have disjointed wings and are found crawling in front of the hive. Large number of spores can be observed in the mid gut content of infected bees under microscope. The spores when reach midgut, they germinate and vegetative rods multiply in the epithelium is particularly severe during spring and winter and there is depletion of strength. Combs are contaminated by 
defecation by diseased bees and the spores are picked up by hive bees during cleaning and polishing the cells. The colony management is important to reduce disease incidence. Wintering with more colony strength, with sufficient store and open sunny sites helps overcoming disease incidence. Sterilization of infected equipment and combs is possible by fumigation with acetic acid which are left in stacked airtight hive bodies for one week. Temperature treatment at $49^{\circ} \mathrm{C}$ for 24 hr destroys spores. Fumagillin @10 mg/liter of sugar syrup is best known chemical for the control of the disease but is now not available in the market. Other alternative such as Eltakon -M, a hydroxyquinoline product has been prescribed to control protozoan disease in India (Rahman and Rahman, 1996)

\section{Nosema disease}

Among the disease of adult honeybee, Apis mellifera, Nosema is one of the most serious diseases caused by Nosema apis. It is quite common in the tropics where the weather is warm and humid; the young honeybees are infected due to ingestion of protozoan parasites present in water or in food. Nosema apis spores are large, oval bodied 4-6 $\mu$ by $2-4 \mu \mathrm{m}$ size (Shimanuki and Knox, 1991). The nosema disease was first reported by Rahman and Rahman (1996) in India.

Nosema apis is a microsporidian, a small, unicellular parasite which mainly affects honey bees. It causes nosemosis, also called nosema, which is the most common and widespread of adult honeybee diseases. The dormant stage of $N$. apis is a long-lived spore which is resistant to high temperature and dehydration, and cannot be killed by freezing the contaminated comb. Nosema apis is a singlecelled parasite of the western honeybee, Apis mellifera. The species is of the class Microsporidia, which were previously thought to be protozoans, but are now classified as fungi or fungi-related. Nosema apis has a resistant spore that withstands temperature extremes and dehydration. In 1996, a similar microsporidian parasite of the eastern honeybee, Apis cerana was discovered in Asia, which was named Nosema ceranae. Little is known about the symptoms and the course of the disease. Chinese researchers found $N$. ceranae in spring 2005 in Taiwan for the first time, and it has now been observed on western honey bees. The new pathogen was discovered in 2005 in Spain and was observed to have a notably higher virulence than the western version. The disease caused by $N$. ceranae in western honey bees in Spain is related to heavier disease patterns deviating from the previously typical findings (unusually heavy intestine injuries in the bees, no diarrohea, and preferential affliction of older collecting bees). Bees die far away from the dwellings, as when they leave they are too weak to return. This leads to collapse of the bee colony. Within a few years, a strongly increased propagation of Nosema was observed, and its occurrence was happening all year round due to the higher resistance of $N$. ceranae. A higher reinfection rate of the bee colonies is assumed, since the pathogen survives longer in the external environment.

\section{Transmission}

Newly emerged bees are always free from infection. Spores must be swallowed by a bee for the infection to be initiated. Spores germinate quickly after entering 
the ventriculus, and the epithelial cells of the ventriculus are infected when the vegetative stage is introduced by way of the hollow polar filament. Once inside a cell, the vegetative stage increases in size and multiplies, affecting an apparent concurrent reduction of RNA synthesis in the host cell. In 6 to 10 days, the infected host epithelial cells become filled with new spores. Epithelial cells are normally shed into the ventriculus where they burst - releasing digestive enzymes. When infected cells are shed similarly, they release 30-50 million infective spores when they burst. Rana and Katna (2001) studied the incidence of nosema disease in Apis mellifera and reported as the fungal disease instead of protozoa from Himachal Pradesh as reported earlier.

\section{Effects on the hive}

Nosema spores are spread to other colony members through fecal matter. The disease impairs the digestion of pollen, thereby shortening the life of the bee. A greater proportion of worker bees become infected than drones or queens, probably due to the comb-cleaning activities of young bees in which drones and queens do not participate. Nosema-infected bees do not attend or feed the queen to the same extent as healthy bees, which helps the queen to escape infection. When the queen becomes infected, her ovaries degenerate and her egg-laying capacity are reduced due to atrophy of the oocytes. Queens that become infected by the parasite during the brood-rearing season are superseded by the bees.

The seasonal trend of typical infections exhibits low levels during summer, a small peak in autumn, and a slow rise of infection during winter. It is more common during times of confinement - winter and spring. In the spring, the level of infection increases rapidly as brood-rearing starts and while flight possibilities are still limited. Colonies in northern climates are more seriously affected than colonies in the south because of the increased amount of time bees are confined in the hive. Nosema, if left untreated, can cause queen supersedure, winter kills, reduced honey yields, and dwindling populations.

\section{Diagnosis}

Diagnosis is dependent on microscopic examination of the ventricular (midgut) content and/or fecal matter or on PCR analysis of infected tissue. No specific outward sign of disease may be present, although in dissections, the ventriculus often

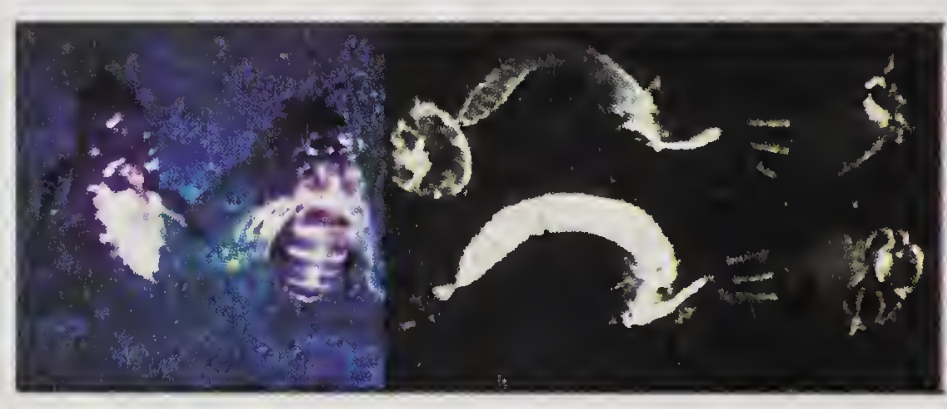

Fig. 10.4. Diagnosis of Nosema disease. appears whitish and swollen in late stages of infection (Fig. 10.4). The disease is easily detected in samples of whole bees macerated in water. The fluid is examined under a light microscope at 250-500 x magnification where the characteristic Nosema spore can be observed. Though the spores of $N$. apis and $N$. ceranae have slight morphological and ultrastructural differences, they cannot be reliably differentiated via light microscopy. PCR analysis or electron microscopy of spores are the only reliable ways to differentiate between the two types of Nosema infection, given genetic variation and variation in the number of sporular polar filament coils between the two species. 


\section{Management}

Treatment with the antibiotic Fumidil B (prepared from Aspergillus fumigatus), the causative agent of stonebrood, inhibits the spores reproducing in the ventriculus, but does not kill the spores. A disinfection of the honeycombs and utensils is recommended to prevent extensive disease outbreak. The spores are sensitive to chemicals such as acetic acid and formaldehyde, and physical radiation: ultrasonic and gamma radiation. Heat treatment in $49^{\circ} \mathrm{C}$ for $24 \mathrm{hr}$ can be used to kill the spores on contaminated equipment.

Nosema ceranae: is a microsporidian, a small, unicellular parasite that mainly affects Apis cerana, the Asiatic honey bee. It may cause nosemosis, also called nosema. The dormant stage of nosema is a long-lived spore which is resistant to temperature extremes and dehydration. Nosema ceranae was first described in 1996 and was identified as a disease of Apis mellifera in 2004 in Taiwan (Huang et al., 2007). Since its emergence in honeybees, Nosema ceranae has now been identified in bumblebee species in South America (Plischuk, et al., 2009), China (Li et al., 2012) and England (Graystock et al., 2013) with infection studies indicating Nosema ceranae has a higher virulence in bumblebees than honeybees (Graystock et al., 2013). Researchers in Spain have analysed samples of Apis mellifera, the European honey bee, mostly sent from colonies suffering unexpected decreases in bee population per hive or lower honey production, as reported by the beekeepers during the last two/three years. During 2006, both France and Germany have detected the disease and recognized the genetic sequence of Nosema ceranae in their respective territories. In the United States, N. ceranae has been detected in honey bees from Nebraska, Wisconsin, Arkansas, New York and South Dakota using PCR of the $16 \mathrm{~S}$ gene. In New York, $N$. ceranae was detected in 49 counties, and of the 1,200 honey bee samples collected, 528 (44\%) were positive for Nosema, from which, PCR analysis of 371 spore positive samples revealed that $96 \%$ were $N$. ceranae, $3 \%$ had both $N$. ceranae and $N$. apis, and $1 \%$ had $N$. apis only. Recently in India also the disease has been detected in Himachal Pradesh of India.

This pathogen has been tentatively linked to colony collapse disorder, a phenomenon reported primarily from the United States, since fall of 2006 . Highly preliminary evidence of $N$. ceranae was reported in a few hives in the Central Valley area of California (USA). Tests of genetic material taken from a "collapsed colony" in Merced County point to a once-rare microbe that previously affected only Asian bees but might have evolved into a strain lethal to those in Europe and the United States. A USDA bee scientist has similarly stated, while the parasite Nosema ceranae may be a factor, it cannot be the sole cause. The fungus has been seen before, sometimes in colonies that were healthy. Field tests on colonies of $N$. ceranae and $N$. apis revealed that have similar life cycles, but they differ in spore morphology. Spores of $N$. ceranae seem to be slightly smaller under the light microscope and the number of polar filament coils is between 20 and 23, rather than the more than 30 often observed in $N$. apis. The disease afflicts adult bees and depopulation occurs with consequent losses in honey production. One does not detect symptoms of diarrohea like in Nosema apis. The most significant difference between the two types is how quickly $N$. ceranae can cause a colony to 
die. Bees can die within 8 days after exposure to $N$. ceranae (Higes et al., 2006). The forager caste seems the most affected, leaving the colony presumably to forage, but never returning. This results in a reduced colony consisting mostly of nurse bees with their queen; a state very similar to that observed in CCD. There is little advice on treatment but it has been suggested that the most effective control of Nosema ceranae is the antibiotic fumagillin as recommended for Nosema apis. The genome of Nosema ceranae was sequenced by scientists in 2009. This should help scientists trace its migration patterns, establish how it became dominant, and help measure the spread of infection by enabling diagnostic tests and treatments to be developed.

Nosema ceranae is apparently released from the suppressive effects of fumagillin at higher concentrations than that of Nosema apis. At fumagillin concentrations that continue to impact honey bee physiology, $N$. ceranae thrives and doubles its spore production. The current application protocol for fumagillin may exacerbate $N$. ceranae infection rather than suppress it. Fumagillin application should be a major cause of $N$. ceranae dominance in this time.

Symptoms: The disease can be diagnosed on the basis of external and internal symptoms (Fig. 10.5 a)

Infected bees have disjoined wings and are found crawling in front of the hive. Affected bees will try to fly and hop around for only short distances The infected bees are found on the bottom board and in front of the hive with abdomen distended and fecal matter on bottom board. The internal symptoms showed the ventriculous soft, swollen with dull grayish white coloration and with obscure constrictions. The microscopic study revealed the presence of Nosema spore both in the
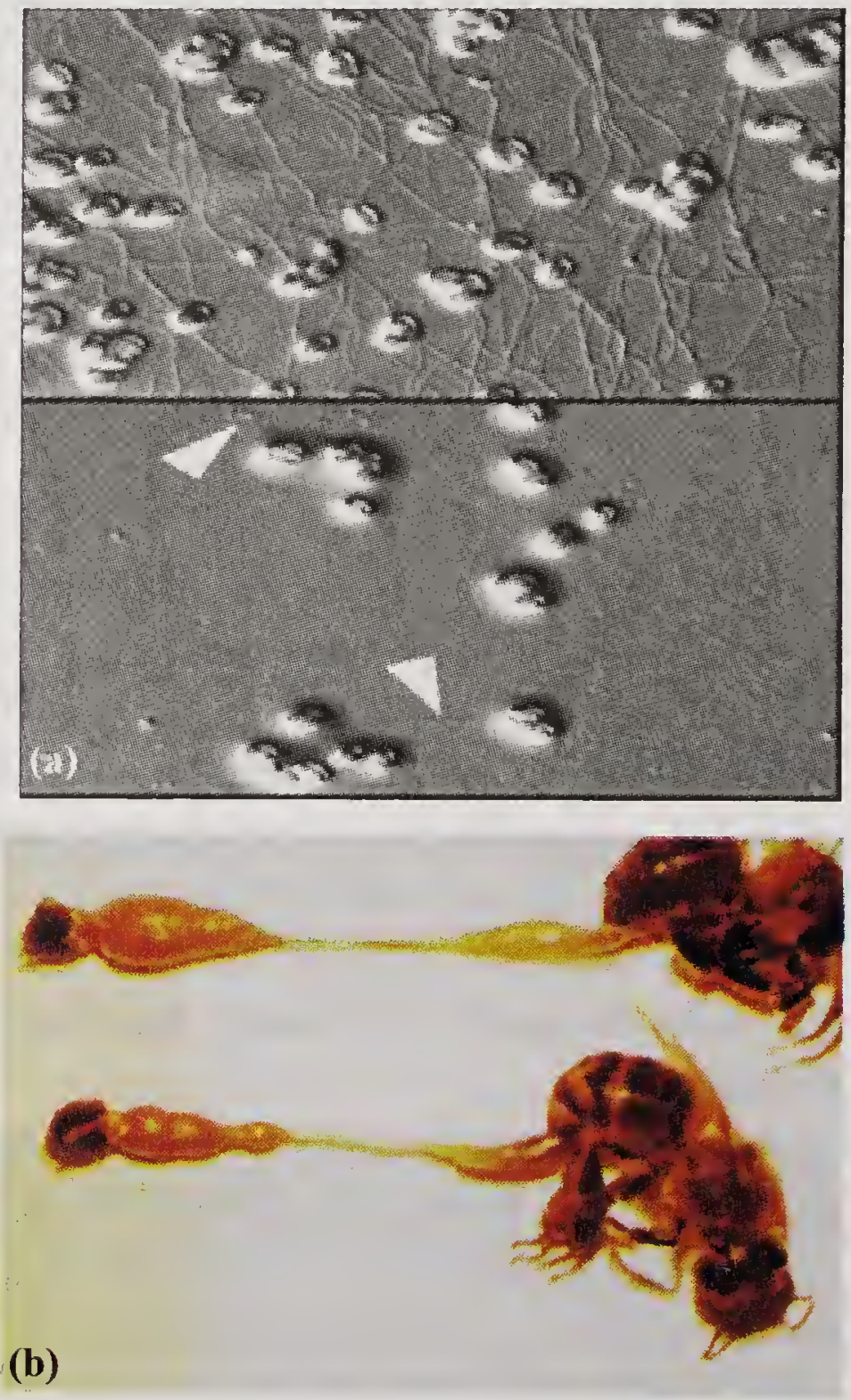

Fig. 10.5 (a) Symptom of Nosema ceranae;

(b) Diagnosis of Nosema ceranae (Sabastian et al., 2010). wet mount of ventriculus and in the faecal matter of the bee (Fig. 10.5 b)

\section{Management}

Nosema disease occurs when colonies are under stress and poorly managed. The condition is often exacerbated when there is moisture build up and poor air circulation in the hive.

The treatment with antibiotic fumagillin, is highly effective. The best natural defense is a strong healthy colony with a prolific queen and sufficient food stores. 
Rapid replacement of adult bees will minimize or eliminate the disease. As the fumagillin is not available in India, an alternative medicine Entakon-M 250, a hydroxyquinoline product @45.5 ppm/liter of sugar syrup is effective against the disease (Rahman and Rahman, 1996) as found effective against $N$. apis.

\section{Chilled brood}

Bee brood may die when sudden cold spells occur in spring. This happens most readily in smaller colonies where the adult bee population is not strong enough to maintain brood temperature. Placement of the frame in the center of the colony will cause the bees to remove and clean all the cells.

\section{Moldy pollen}

Stored pollen in comb is preserved when covered by honey. If the honey is removed and bees not present, the pollen will become moldy. No disease is involved and the frame can be placed back into a strong colony for cleaning and use.

\section{REFERENCES}

Bahman, S. and Rana, B.S. 2002. Incidence of the European foulbrood disease in Apis mellifera L. colonies at Solan, Himachal Pradesh. Pest Management and Ecolgical Zoology 10(1): 87-91

Bai, H., Devanesan, S., Shailaja, K.K. and Ajitha, S. 2007 Potential of herbal extracts in the control of the thai sac brood virus disease of Asian honeybees, Apis cerana indica.F. Proceedings Apimondia International Apicultural Congress, Melbourne Australia.

Devanesan, S., Jacob, A., Premila, K.S. 2005. Incidence of Thai sac brood Virus disease to Asian Honey Bee, Apis cerana indica F. in Kerela, India. Proc $39^{\text {th }}$ Apimond. Int. Apic. Cong, Dublin, Ireland.

Diwan, V. V., Kshirsagar, K. K., Raman, R. A. V., Raghunath, D., Bhambure, V. and Godbole, S. H. 1972. Occurrence of new bacterial disease of Indian honey bee, Apis indica F. Current Science 40: 196-197.

Graystock, P., Yates, K., Evison, S.E.F., Darvill, B., Goulson, D., Hughes, W.O.H. 2013. The Trojan hives: pollinator pathogens, imported and distributed in bumblebee colonies. Journal Applied Ecology 1-9.

Higes, M., Martin-Hernandez, R., and Meana, A., 2006. Nosema ceranae, a new microsporidian parasite in honeybees in Europe. Journal Invertebrale Pathology 92:9395.

Huang, W.F., Jiang, J.H., Chen Y.W. and Wang C.H. 2007. A Nosema ceranae isolate from the honeybee Apis mellifera. Apidologie 38: 30-37.

Kshirsagar, K.K., Saxena, U.C. and Chauhan, R.M. 1982. Occurrence of sacbrood disease in Apis cerana indica F. in Bihar, India. Indian Bee Journal 44 : 8-9.

Li, J., Chen, W., Wu, J., Peng, W., An, J., Schmid-Hempel, P. and Schmid-Hempel, R. 2012. Diversity of Nosema associated with bumble bees (Bombus spp.) from China. International Journal Parasitology 42(1): 49-61.

Plischuk, S., Martín-Hernández, R., Prieto, L., Lucía, M., Botías, C., Meana, A., Abrahamovich, A.H., Lange, C. and Higes, M. 2009 South American native bumble bees (Hymenoptera: Apidae) infected by Nosema ceranae (Microsporidia), an emerging pathogen of honey bees (Apis mellifera). EnvironmentalMicrobiology Reports.1: 131135.

Rahman, A. 1992. Management and control of Thai sac brood disease of Apis cerana indica F. in Assam . Indian Bee Journal 54(1-4): 33-36. 
Rahman, A. and Rahman, S. 1996. Diagnosis and control of nosema disease of Apis mellifera L. in Assam, India. Indian Bee Journal 58(3): 122-24.

Rana, B.S. and Rana R. 2008. Detection of sacbrood virus and the incidence of sacbrood disease in Apis mellifera colonies in the North-Western Himalayas. Journal Apicultural Research \& Bee World 47(1): 58-62.

Rana, B.S. and Katna, S. 2001. Incidence of Nosema disease in Apis mellifera L. of the north India. Insect Environment 17(3): 143-44.

Rao, K.M. 2013. Serological detection of Melissosoccus plutonius from Apis mellifera L. and A. cerana F. brood from north west Himalayas, India Prooceedings of International Conference on Insect Science Bengaluru, India.

Sebastian, G., Kati, H., Nadine, M., Marie-Charlotte, F., Andreas, L. and Elke, G. 2010. Five-Year Cohort Study of Nosema spp. in Germany: Does Climate Shape Virulence and Assertiveness of Nosema ceranae. Applied Environment Microbiology 79(9): 3032: 38.

Shimanuki, H. and Knox, D.A. 1991. Diagnosis of honey bee diseases. USDA, Agriculture Handbook. AH-690. 


\section{1 \\ Bee enemies and their Management}

$\mathrm{H}^{\circ}$ ONEYBEES are subjected for predation or infestation by various enemies such as wasps, wax moth, wax beetles, ants, birds, lizard, cockroach and mites etc.

\section{Wax moths}

There are two different types of wax moth viz. the greater wax-moth, Galleria mellonella L. and lesser wax moth, Achroia grisella F. Between them, the greater wax moth is the most dreaded enemies of hive bees whereas, lesser wax moth is comparatively minor one. While, the details of greater waxmoth is discussed and brief account of comparatively minor pest the lesser wax moth, Achroia grisella $\mathrm{F}$. is also given.

\section{Greater wax moth}

Adult brownish-grey, $10-18 \mathrm{~mm}$ length; wing expanse $25-40 \mathrm{~mm}$; the female is larger than male (Fig. 11.1a). The colour and size of adult vary a great deal in accordance with the food eaten during the larval period; consumption of dark-brown comb containing pollen give rise to darker and bigger adults, The outer margins of the fore wings of the male has a semi-lunar notch, whereas that of the female smooth, egg spherical, smooth, creamy-white 0.4 to $0.5 \mathrm{~mm}$ in size.

Eggs: Hatch in 3 to 5 days at $29^{\circ}$ to $35^{\circ} \mathrm{C}$ but in 30 days at $18^{\circ} \mathrm{C}$.

Caterpillar: Freshly hatched larva is white, full grown larva dirty - grey with brown head. They live in silken tunnels made in mid rib of combs.

Pupa: The young pupa is brownish white and dark brown; 14-16 mm long. The cocoons usually form a mass or
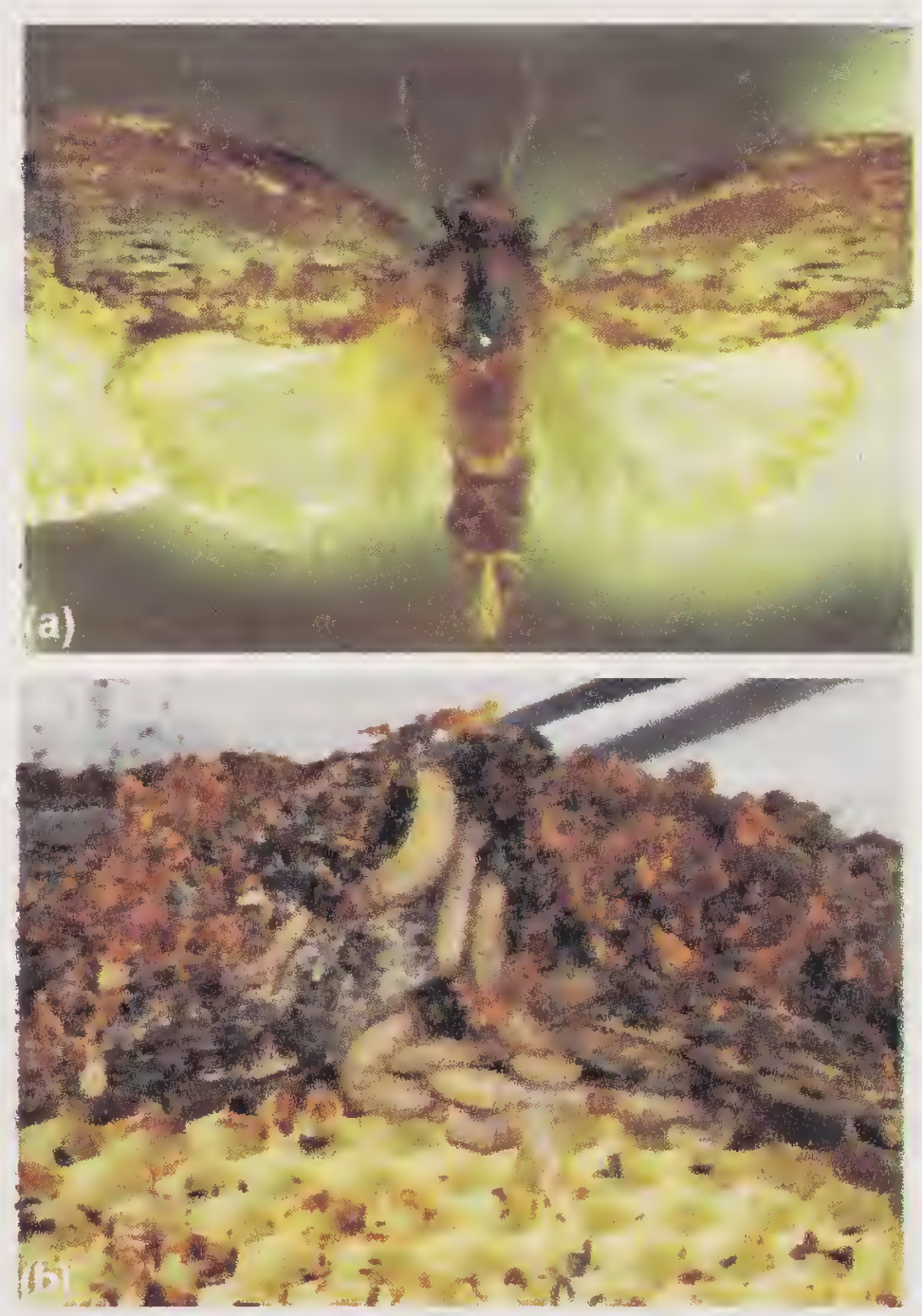

Fig. 11.1 (a) Adult wax moth; (b) Infestation by wax moth larvae. silken fibers strongly webbed together in rows, sometime curved in the wooden parts of hive. 


\section{Life-cycle}

The males and females mate within a day of their emergence and males enter the hive usually at night when the bees are not active but occasionally during day time in case of weak colonies. Female starts egg laying in clusters in one or two days after mating and lays 300-600 eggs in 4-10 days, males live for 3-4 weeks, incubation period of eggs vary with temperature. Eggs hatch in 3-5 days at $29^{\circ}-$ $35^{\circ} \mathrm{C}$ but in 30 days at $18^{\circ} \mathrm{C}$. The eggs cannot stand temperature below $16^{\circ} \mathrm{C}$ and above $35^{\circ} \mathrm{C}$. Young caterpillars are exceedingly active and eat gnawed pieces of comb (Fig. 11.1b). They soon spin silken tunnels in comb or tubular galleries on the bottom board to protect themselves. If the food on the bottom board is not sufficient, they migrate to the combs and moves towards its mid rib. The caterpillars cast off their skin four to six times. The total life cycle may be completed in six weeks to six month. At normal temperature of $29^{\circ}-32^{\circ} \mathrm{C}$ egg may become adult in about 7 weeks.

Seasonal history: There are several overlapping generations of the pest in a year depending on temperature availability and nature of food and conditions of the pest inhabited in hive or stored combs. In localities with comparatively warm winter, all stages of the pest are found within hive throughout the year. In stored combs, the pest hibernates in caterpillar stage (about 70\%) and in pupal stage (about 30\%). The development even in warm localities is considerably slowed down in winter and the pest is active from March to October. Varshneya et al. (2008) recorded the seasonal incidence of wax moth, Galleria mellonella L. in Apis mellifera infesting bee colonies from July and acquired peak in September.

Nature and extent of damage: The caterpillars eat away combs, damage them by making tunnels in mid rib of combs. The first indication of the entry of the larvae in the comb is the presence of small pieces of minute particles of wax outside the holes. Later faint webbing is perceptible over some cells of the comb. When infestation has progressed considerably, silken tunnels with caterpillars wriggling in them are noticed and eventually whole comb is reduced into mass of webbing in which the excreta of caterpillars is enmeshed. In severe cases the brood rearing is stopped in the colony and bees desert their nest.

\section{Management}

Weak colonies are prone to attack by wax moth whereas strong colonies are able to resist. Proper sanitation measures, keeping the beehive without cracks and crevices protect the colony from wax moth attack. Mechanical devices such as cut and burn or burry, the infested portion of comb save the colonies from destruction. While using the old beehive, the bee boxes should be treated with Sulphur smoke and be kept in a stake during lean period. The comb stored is disinfected by Sulphur smouldering at $180 \mathrm{gm}$ per cubic meter of space. Sulphur dusting@2gm/hive over top bar also protects the colony from infestation. Biocontrol practice such as treatment with Bt. formulation var. Karstack@5g/ hive/litre of sugar solution gives effective control. (Rahman and Bharali, 2002). Deka et al. (2010). While studying seasonal incidence and management of wax moth, Galleria mellonella in Apis colonies reported the maximum incidence during July (44.44\%) and minimum in May (13.33\%). Application of Bt. formulation 
var. Kosstock@5g/hive gave the highest control (85\%) of G. mellonella followed by sulphur dusting (70-75\%). Yadav and Chuneja (2012) in an attempt for management of Galleria mellonella under storage conditions reported that the most effective treatment against $G$. mellonella was fumigation of aluminum phosphide followed by combs placed in deep freezer, sulphur fumigation and treatment with neem seed kernel extract (NSKE). Mishra et al. (2009) tested neem oil and Dipel in three concentrations against first to fifth instars larvae of Wax moth, Galleria mellonella. Neem oil (33\%) concentration found to be most effective followed by Dipel (1.5\%) in controlling G. mellonella infesting Apis mellifera.

\section{The lesser wax moth, Achroia grisella}

As its name implies, the lesser wax moth is generally smaller than the greater wax moth, except when the latter is dwarfed owing to poor diet during its larval stage. Adult Achroia grisella are silver-grey in colour, with a distinct yellow head. The insect is quite small, with a slender; normal body lengths of adult female and male are about 13 and $10 \mathrm{~mm}$, respectively. The life-span of the adult female is about seven days, during which she can lay 250 to 300 eggs. Infestation by the lesser wax moth usually occurs in weak honey bee colonies. The larvae prefer to feed on dark comb, with pollen or brood cells. They are often found on the bottom board among the wax debris. As larvae prefer to form small canals between the bottoms of the brood cells the brood is lifted. The bees continue constructing cells, heading upward leading to the typical scratched comb surface.

\section{Management}

The methods employed in controlling Galleria mellonella are equally effective for the control of Achroia grisella.

\section{Predatory wasp}

Several predatory wasps species viz. Vespa magnifica, $V$. cincta, $V$. auraria, $V$. orientalis, V. basalis are found in plains and hills of India (Fig. 11.2 a \& b). They are social insects and make nest in the cavity of trees, walls or hang them down from tree trunk. Vespa magnifica is burrowing type, nesting in the soil. They are predacious by nature and catch the prey from flowers and the bees from hive entrance. Wasps macerate bees and feed their young ones by making paste like materials. Fecundated female overwinter and starts new nests in spring. The females render all the work in the nest and also collect food for herself and the young ones. The worker wasps on emergence help their mothers and take over nursing duties and foraging work. The nest becomes populous during late summer and autumn. The nest population is at its peak during autumn and, at the end of which all castes except fecundated female die out. The female overwinters in cracks and crevices and start nesting in the following spring. Rana et al. (2000) while studying the influence of environmental factors on population dynamics of predatory wasp and their control reported that lower temperature during MarchApril and high rainfall in April to May delayed the wasp attack in the colony. Various devices such as use of wire gauge cage at the hive entrance, trapping and 
killing the wasps in jars containing fermented honey were not found effective but fresh fish bait found to be effective in controlling wasps. Varshneya et al. (2009) investigated the seasonal incidence of predatory wasp infesting Apis mellifera at GBPUAT, Pantnagar and recorded all three species Vespa tropica haematoides, V. orientalis and Polistis hebraeus during july and started declining from November. Maximum activity of predatory wasps were recorded in last fortnight of September to first fortnight of October during the year.

\section{Management}

Beekeepers adopt methods such as bait-trapping, trap at the hive entrance and using protective screens. Locating hornet nests by following flight passes of individual wasps back to their nests and then destroying the nests. In Thailand, this approach has proved to

(a)
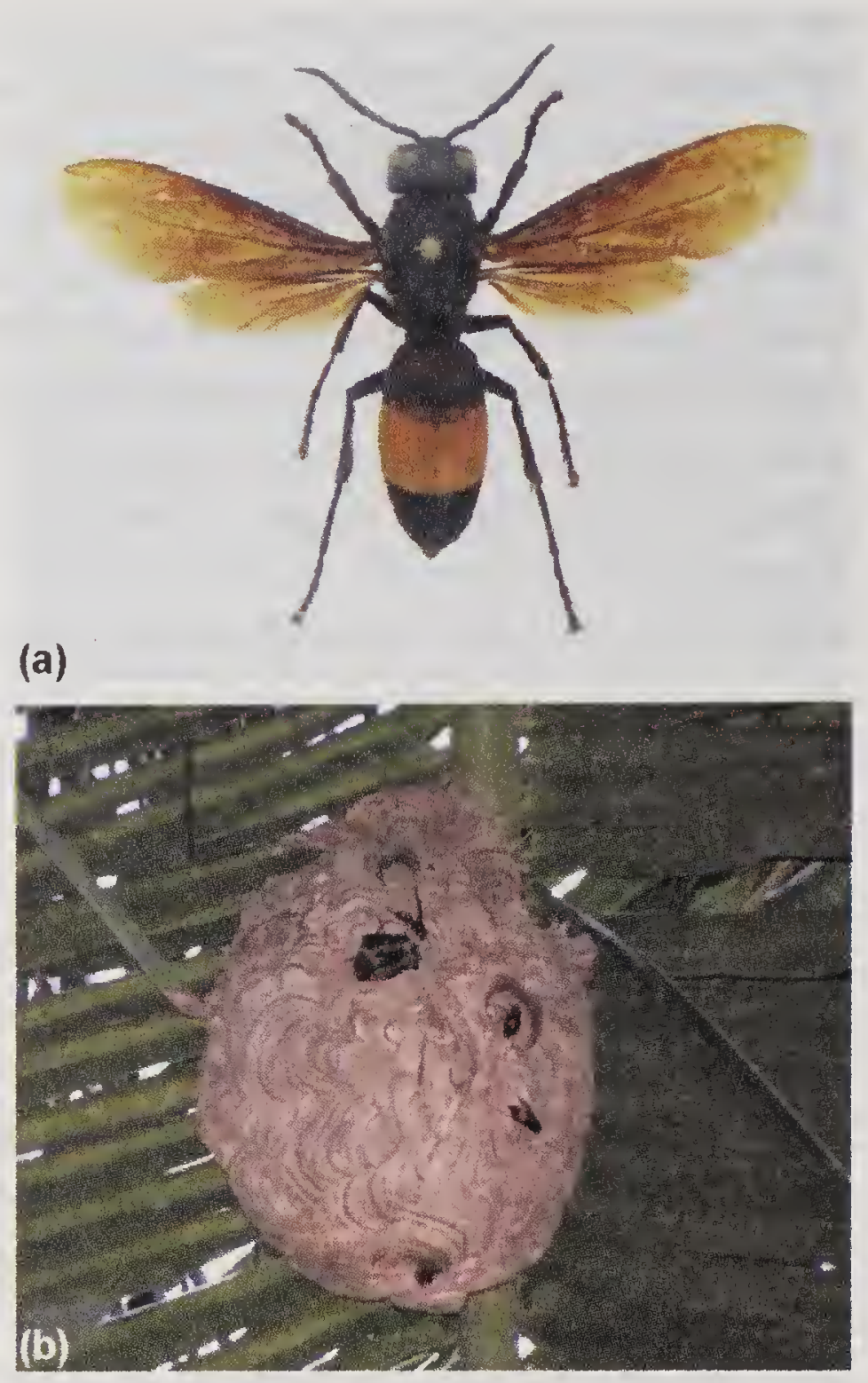

Fig. 11.2 (a) Vespa cincta; (b) Aerial nest of $V$. cincta. be quite effective, largely because the period of most intense hornet attacks is only 2 to 3 months. It has been observed that the real damage inflicted by hornet attacks on honeybee colonies occurs during the rainy season in India. Killing hornets in the early stage of predation has the effect of disrupting the hunting phase and preventing the predation process from reaching the more destructive phases. Mass destruction of the colonies by community approach is thus prevented or, at the least, minimized. As a final, and more general, recommendation for protective action against hornet attacks when the hives cannot be relocated to a safer place. Beekeepers should as a minimum preventive measure narrow the hive entrance. In this way, the final invasion of the hive can generally be avoided. To control these predatory wasps, many method right from flapping to the poison bating have been tested in India. However, none of them proved to be full proof. Killing fecundated females during spring means destroying future wasp colony. However, the flapping practice in the initial in which females being killed partially reduces the intensity of wasp attack. Mechanical exclusion device by covering the hive during summer with nylon net having $1 \mathrm{~cm}$ mesh size in which bees may go out and get in to but prevent the wasp to enter gives effective control (Rahman et al., 2001). In an attempt for management of predatory wasp, Vespa magnifica in the apiary by using physical exclusion device involving protection with $1 \mathrm{~cm}$ mesh size nylon cage recorded that bee predation was reduced in $0.13 / \mathrm{min}$ against $1.44 / \mathrm{min}$ resulting in $96.46 \%$ protection from wasp attack. 


\section{Ants}

Ants are among the most common predators of honey bees in tropical and subtropical India. They are highly social insects and will attack the hives en masse, taking virtually everything in them: dead or alive adult bees, the brood and honey. In addition to this destruction, they can also be a nuisance to beekeepers and may sometimes cause pain from their bites. Apiaries of Apis mellifera under ant attack become aggressive and difficult to manage; weak colonies will sometimes abscond, the indigenous Apis cerana colonies also subject to the frequent ant invasions. Many ant genera and species are reported to cause problems to both traditional beekeeping with $A$. cerana and to modern beekeeping with $A$. mellifera (Fig. 11.3). Among the most frequently recorded species are the weaver ant (Oecophylla smaragdina), the black ant (Monomorium indicum), Monomorium destructor, Oligomyrmex
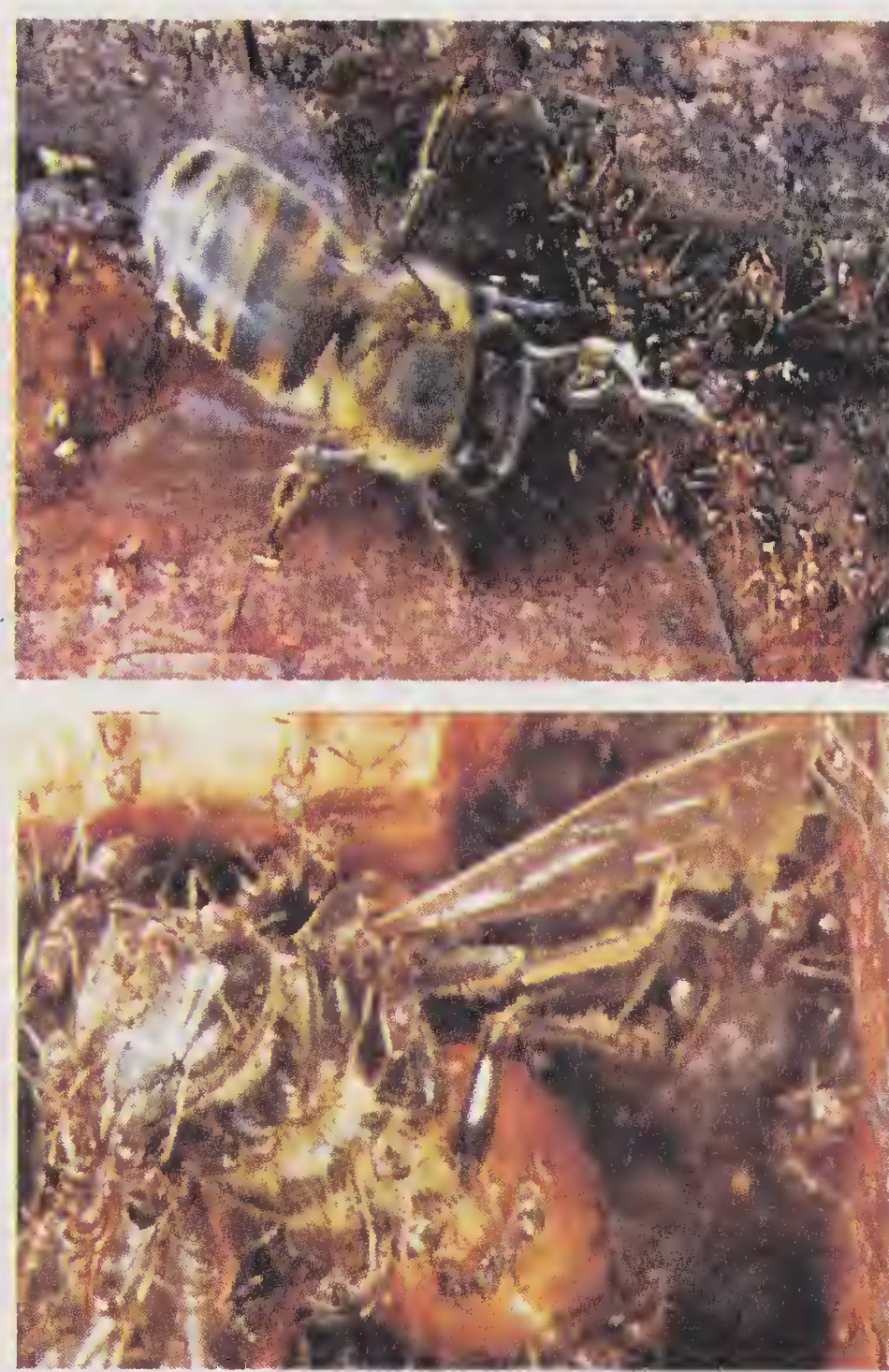

Fig. 11.3. Predatory ants attacking spp., Dorylus spp., the fireants, Solenopsis spp. and Formica spp. Various species of black ants, viz. Camponotus compressus F. Monomorium indicum Morell. and $M$. destructor Ters. intrude bee hive and take away honey and pollen.

\section{Management}

Ants are more troublesome to weak colonies but strong ones usually succeed in keeping them at bay. As black ants live in underground nest, the colonies can be destroyed by fumigation or treatment with furadon granules or sealing them by pouring insecticide solution. Bee colonies can be saved from intrusion of ants by placing the hives on stand with their legs in earthen pots containing water.

General recommendations are to reduce ant nesting sites include eliminating bush and rotten wood from the apiary and cutting the grass. A good general defense against ants in tropical apiaries is to place the hives on stands supported by posts $30-50 \mathrm{~cm}$ height and to coat the posts with used engine oil or grease. Frequent inspection and renewed application of grease are both necessary and a source of soil pollution. A more reliable method is to place the hive-stand posts in tin or plastic containers filled with either water or oil. Regular clean up is required to avoid the formation of bridges of vegetation or earth that can be crossed by ants and liquids need to be replaced frequently.

Beekeepers have found that the most effective method of controlling weaver ants is to search systematically for the ants' nests in the vicinity of the apiaries 
and, when found, to destroy them by burning. Sometimes wrapping the legs of stand with impregnated kerosinised cloth also protect the hive from ants.

\section{Beetle}

There are several different beetles living in honey bee colonies. Few beetle species are harmful and feed on pollen or honey. Small hive beetle is such which harms colonies. Originally, this beetle (Aethina tumida), was only found in Africa, south of the Sahara. It first appeared in the southern United States of America in 1998 and has continued to spread north as far as Canada. Since 2002 , this beetle has been found in parts of Australia and Africa. In India also the beetle has been found to infest bee hives (Fig. 11.4 a \& b).

\section{Management}

The best way to protect against an infestation of the small hive beetle is to keep strong colonies and to remove those that are weak from an apiary. The comb should be removed from weak colony and be kept in freezing temperature so that infestaed comb along with beetles will be killed. Currently, a successful control is made possible using a preparation named 'Checkmate'strip produced by Bayer (as Coumaphos). However, the problem

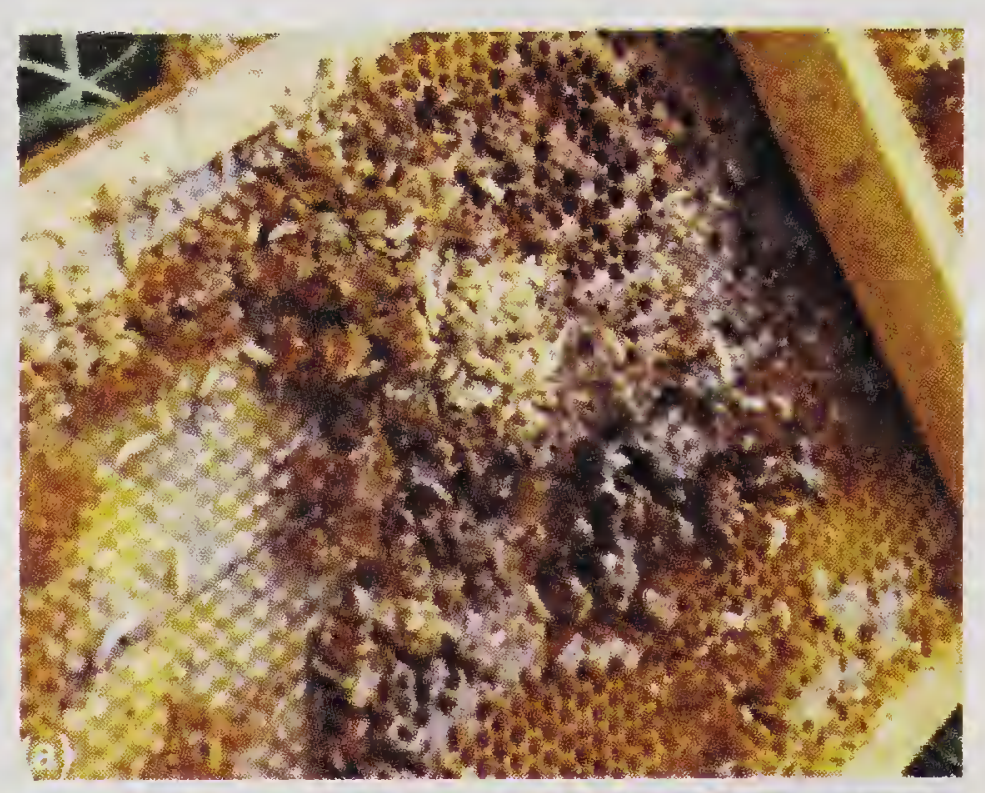
is that this beetle contrary to the varroa

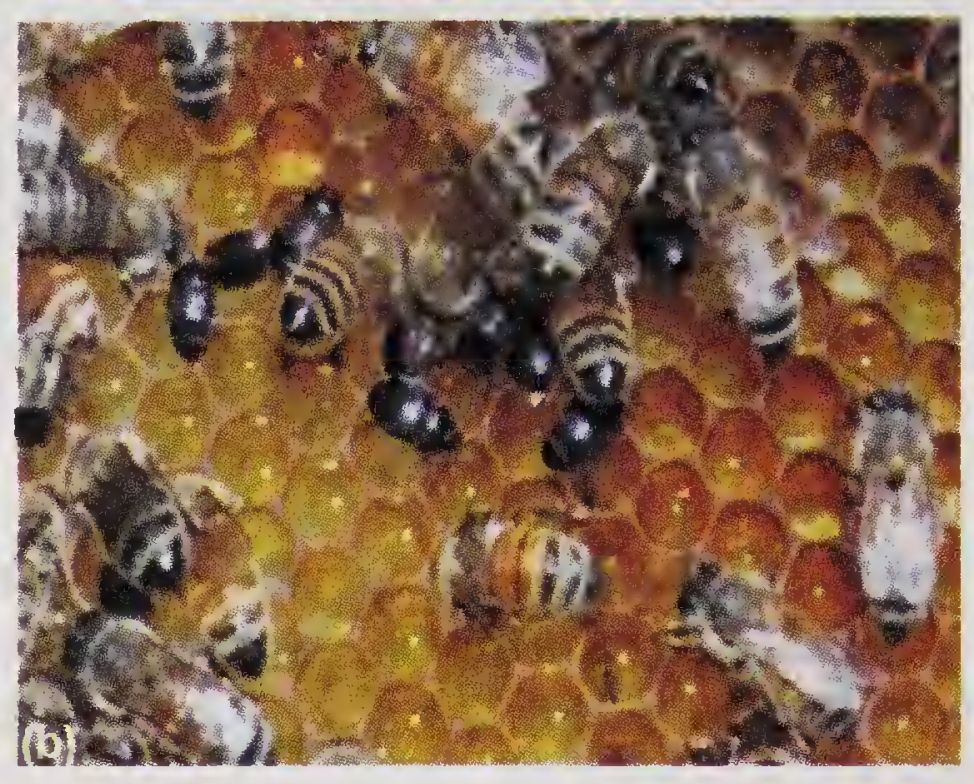

Fig. 11.4 (a) Larval infestation of Small hive beetle in Apis mellifera comb; (b) Infestation of Small hive beetle in Apis mellifera comb. mite can live and multiply outside the bee hive, where it seems to prefer rotting fruits (e.g. apples and bananas) as nesting sites. This is why reinvasion is always possible. The beetle is extremely quick moving and can fly, which contributes to its rapid spread among bee colonies and apiaries. Therefore, clean culture is important to control the pest.

There are caterpillars of several other moths; the Mediterranean flour Moth [Ephestia kuhniella (Zell.)], Fig moth [E.cautella (Walk)], Indian meal moth [Plodia interpunctela (Hbn.)] and dried fruit moth (Vitula spp.) are also noticed in combs, but their damage is occasional and they do not occur widely.

\section{Birds and other enemies}

Birds are important enemies of honey bees as some of them prey upon bees. Once airborne, the bees are virtually defenseless against birds, several species of which can tolerate their bee stinging. The heavy traffic of bees flying in and out 
of the hives of commercial apiaries provides an exceptional opportunity for insectivorous birds, large numbers of which may be attracted by this situation. Birds that have been listed predating on honey bees in India included King Crow [Discrurus maccerocerous (Vielliot) and D. ater (Nerm)]; the bee eater, Merops orientalis (Latham.) and M. supercilosus; Swiftes (Cypselus spp., Apus spp); drongos (Dicurus spp) and woodpeckers (Picus spp.) etc. Damage by birds is more severe during summer and monsoon. They sit on tree or telegraph wires near apiary and pick the bees. As they are beneficial and insectivorous, hence keeping in view of the environmental and ecological balance, no large scale measures against them can be recommended. However, scaring them away from apiaries or migration of colonies to a safer place is advocated. Biocontrol practice such as use of hawk bird which predates on birds would be effective. Use of "Scare crow" or robotic device and bursting the crackers and flying the kites are some of the effective device to drive away the birds from the apiary.

Lizards are minor enemies which can be controlled through timely inspection and proper management of colonies.

\section{Mites}

Honeybees are infested by both ecto and endo-parasitic mites and also some phoretic mites have also been observed in bee hives. In tropical Asia, the success or failure of beekeeping operations with Apis mellifera depends largely on mite control. Several major factors exacerbate bee-mite problems in the continent. First, all known major species of parasitic honeybee mites are currently present in Asia, most being native to the continent. Second, the complete eradication of the mites from an apiary is impossible, because the feral nests of native bees infested by the parasites serve as reservoirs of mite reinfestation of domesticated honey bee colonies. Moreover, some mite species are able to survive, or even thrive, on more than a single species of host bee. Several species of mites have been reported as causing devastation to both $A$. mellifera and $A$. cerana beekeeping operations throughout Asia, though not all mite species found within the hives or in association with the bees are true parasites. Several species of pollen-feeding mites are occasionally found in hives or attached to foragers. These phoretic mites are mostly innocuous to beekeeping. In India also mite problem has been aggravated and warranted effective management practice.

\section{VARROA mite, Varroa destructor Anderson and Trueman}

This mite is a native parasite of Apis cerana throughout Asia. Since, the initiation of beekeeping development projects with A. mellifera in the continent, it was reported as causing damage in both temperate and tropical Asia. The overall effect of Varroa infestation is to weaken the honey bee colonies and thus decrease honey production, often seriously. Occasionally in A. melllfera, and more frequently in $A$. cerana, heavy infestation may cause absconding. Today this parasite is found throughout the world, except for Australia and New Zealand. In temperate Asia, most beekeepers agree that varroa damage is a constraint to the success of beekeeping operations with $A$. mellifera, while in tropical Asia success is limited by the loss of $A$. cerana colonies through absconding, which is far less serious 
and frequent than damage to A. mellifera. Deosi and Chhuneja (2011) studied the biology of Varroa destructor mite in Apis mellifera in Punjab and found that the mite population on adult bees was maximum in March and minimum in SeptemberOctober.

\section{Identification}

Varroa destructor (previously confused with Varroa jacobsonii) is quite large, as compared with other mite species, and can be observed with the unaided eye. The shape of the adult female is distinctive: observed from above, the width of the body is clearly observed to be greater than the length, i.e. about $1.6 \times 1.1 \mathrm{~mm}$. The mite is reddish brown in colour, shiny and the body is dorso- ventrally flattened covered with short hairs or setae (Fig. 11.5a). Adult females of $V$. destructor are found inside brood cells or walking rapidly on comb surfaces (11.5b). Individual mites are often seen clinging tightly to the body of adult bees, mostly on the abdomen, where the segments overlap, between the thorax and the abdomen and at the ventral entry. Adult males, and the immature stages of both sexes (egg, protonymph and deuteronymph), are not commonly seen outside the brood cells. Deosi and Chuneja (2011) studied the biology of
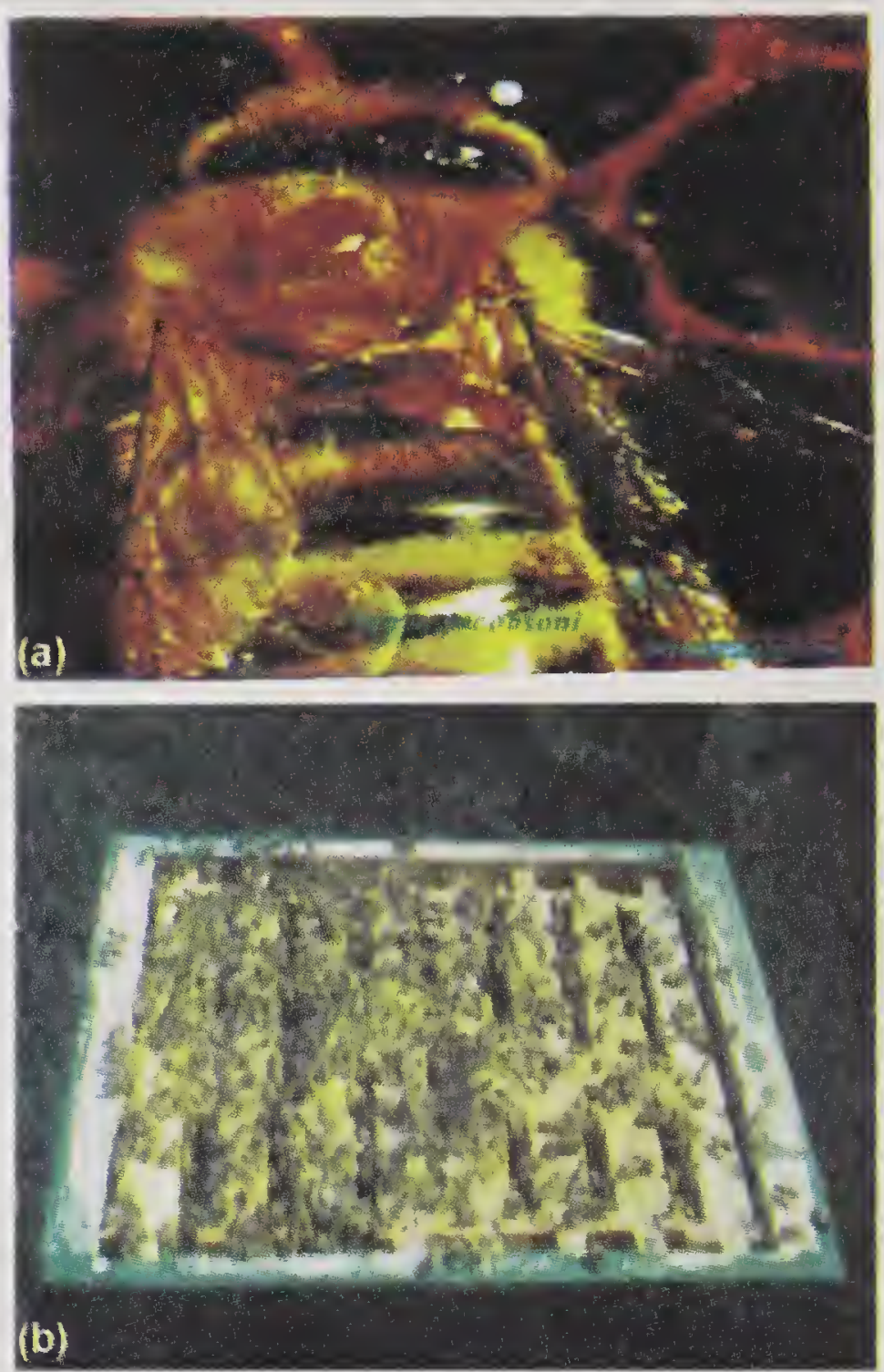

Fig. 11.5 (a) Varroa destructorparasitize Apis mellifera; (b) Solar treatment of $V$. destructor.

Varroa destructor mite in Apis mellifera under Punjab conditions and recorded the mean fecundity of $V$. destructor was $4.63 \pm 0.02$ and $6.78 \pm 0.05$ eggs/female/ reproduction cycle in worker brood and drone brood, respectively.

\section{Nature and extent of damage}

All immature stages of the parasite live inside the brood cells. They can be observed when infested cells are opened and the brood is carefully removed. The immature mites are bright white and the adult females are brown, while male mites are smaller than females and are rarely seen, since they are only found inside brood cells. Varroa causes injuries to honey bees by direct feeding. The adult female pierces the bees' soft intersegmental membrane with their pointed chelicera and sucks the bees' haemolymph ('blood'). The adult bee, however, is only damaged if the infestation is severe. Varroasis occurs, if more than one parasitic female mite infests the brood cell the brood decays or deformations occur including shortened abdomen or deformed wings. If only one mite infests symptoms may not be visible, 
although the bees' life-span is considerably shortened. Moreover, the bees' behaviour may be disturbed, e.g. in orientation or gathering food. Infested bees often have a reduced fat body that hampers the functioning of their glands or increases their susceptibility to pesticides. The semen production of drones may be considerably reduced. Varroasis is a multi-factorial disease and viral diseases that may have caused little damage before infestation by varroa mites often accompany it. Normally, the exoskeleton protects the bees from many virus infections. However, the mite penetrates this natural barrier transferring viruses or stimulating the multiplication of viruses with its saliva. In turn viruses seem to speed the development of varroasis enhancing the parasite's virulence. Moreover, unfavourable climatic conditions or insufficient stocks of pollen and nectar can increase the process of disintegration. Without treatment, the colonies normally die after two to three years, management errors may also cause the collapse of colonies. Colonies destroyed by the varroa mite are often left with only a handful of bees and the queen, the other bees having died during foraging or having drifted to neighbouring colonies, where the mite population can increase before killing these colonies also. In this way mites may cause colonies to die.

\section{Diagnosis}

The presence of adult bees with deformed wings, crawling on comb surfaces or near the hive entrance, usually indicates a late stage of heavy mite infestation. Several other methods may be used to detect mites. The most reliable, perhaps the most time-consuming, is direct sampling by the random opening of brood cells, particularly drone cells. The older the larvae/pupae the easier this procedure becomes. The brood is removed from the cell with a fine forceps and the cell is inspected for the presence of the mites. Between 100 and 200 cells must be opened before an assessment of the level of mite infestation can be made. To inspect adult bees, the bees are captured from the brood combs and placed in jars, into which chloroform, ether or alcohol is introduced on a piece of cotton wool. The bees are intoxicated and the mites crawl on the glass wall. Returning foragers may also be captured by hand at the hive entrance and held up against the sunlight; any mites attached to the bees' abdomens may be observed. Another method is to use specially constructed zinc, plastic or wood trays, built to the size of the bottom board, with a white or light-coloured floor. The trays, equipped with a screen of a mesh less than $2 \mathrm{~mm}$ fixed at about $\mathrm{cm}$ above the tray floor, are placed on the bottom boards of the hives and are inspected one to three days later for the presence of dead mites. The screen prevents the bees from removing the dead parasites from the hive.

\section{Management}

The management of Varroa destructor is one of the most difficult tasks facing apiculturists and beekeepers throughout the world. The mite is a highly successful parasite, whose life history is well synchronized with that of its host. Two principal approaches to its control are currently available: chemical control and hive manipulation techniques, sometimes referred to as bio and chemical control is by far the most popular method of varroa control among Asian beekeepers including India. 


\section{Chemicals}

The organic acids: Formic acid, the ethereal oil thymol and the synthetic pyrethroids, amitraz oxalic acid may still be chosen to treat colonies with brood. Formic acid can kill some of the mites in the sealed brood cells. It is recommended that the formic acid be allowed to evaporate in colonies with sealed brood for at least two to three weeks. In this way, mites emerging from the brood will also be killed. Various applicators have been proved effective for this purpose. A small container equipped with a wick or paper felt is filled with $200 \mathrm{ml}$ of $85 \%$ formic acid to evaporate for at least 14 days. The quantity to evaporate can be regulated by means of the length of the wick or the size of the paper felt. The container is either placed on top of the combs, in an empty upper section or after some combs have been taken out, in the empty space. The external temperature should not be less than $12^{\circ} \mathrm{C}$ and not more than $25^{\circ} \mathrm{C}$. The formic acid should be introduced into the colony only in the late afternoon to avoid damage to bees and brood. In addition, physiological tolerance is improved if the entrance hole is wide open. An easier way to introduce formic acid is to use a sponge or a similarly absorbent material. A solution of $3 \mathrm{ml}$ of $60 \%$ formic acid is applied into the sponge tissue per comb (Langstroh size). The only ether oil that is sufficiently affective against varroa mites is Thymol. Thymol can be applied as a commercially available readymade preparation or in crystal form. For this purpose, $0.5 \mathrm{mg}$ thymol per bee-way are put into a gauze bag and deposited onto the combs for some weeks. In this way mites emerging from the brood will be covered. Thymol $0.25 \mathrm{~g}$ powder dusted in passages of frames is effective and it is also slightly effective when used as an evaporating agent. In India, Tiwari and Mall, 2011 evaluated formic acid 85\% @ $5 \mathrm{ml}$, sulphur dusting@200 mg crystals hive, flumethrin drop $0.5 \mathrm{ml} / \mathrm{hive}$ with two applications and reported that flumetherin was most effective followed by formic acid and thymol, sulphur dusting is least effective. Gulati and Sharma (2009) while evaluating formic acid against Varroa destructor infesting Apis mellifera reported that formic acid $85 \%(5 \mathrm{ml})$ applied by cotton swab method was found to be $71.7 \%$ effective against Varroa destructor. Rana et al. (2010) reported that the treatment with formic acid soaked in sponge pads@50 ml/bee colony placed at bottom board at 10 day interval gave $90 \%$ recovery of mite infestation.Application of oxalic acid@,50 g/hive over the frame gives effective control.

Synthetic chemicals: Synthetic Pyrethroids are contained in Apistan and Bayvarol, which developed for application to bees. The plastic strips are fixed in bee-ways in the brood nest. When the bees come into contact with them they transport the substance to the other bees, thus killing the parasitic mites on the bees. As the strips remain for several weeks in the colony mites emerging from the brood are affected. Synthetic pyrethroids are highly effective, although there is the disadvantage that mites may rapidly develop resistance to them. Therefore, their effectiveness should be controlled regularly. Synthetic pyrethroids are also available in formulations not specifically intended for use on bees. Amitraz; Taktic and Mitac are trade names of products containing amitraz at different concentrations. The recommended dosage for use on honey bee colonies is $1 \mathrm{ml}$ of Amitraz to 1 litre of water, sprayed lightly on bees, the comb surface of brood 
frames and hive alls. The amount of the solution to be sprayed at each application depends on the size of the colony, but is usually within the range of 80 to $250 \mathrm{ml}$. Amitraz: can also be used as a hive fumigant.

Mechanical: The mites can also be trapped in worker-brood frames by using vertical queen-excluders in single- storey hives. The queen is confined between two excluders and allowed to lay eggs in one frame only. Female mites in the colony will be attracted to this brood frame which, when the cells are sealed, is removed from the colony so that the brood cells infested by the parasites can be destroyed. Solar treatment by exposing mite infested colony to the bright sunshine (Fig. 11.6b) is also effective.

\section{ECTOPARASITIC MITE}

Tropilaelaps clarae Delfinado and Bakeris' another serious ectoparasitic mite of honey bee (Fig. 11.6a). The mite is a native parasite of the giant honey bee Apis dorsata, widely distributed throughout tropical Asia, and wherever A. mellifera is kept within the range of distribution of $A$. dorsata, mite infestation of the colonies cannot be avoided. Though its infestation is observed on A. dorsata but it becomes serious on A. mellifera as reported by Atwal and Dhaliwal (1969) in India. Dual parasitism of $A$. mellifera colonies by both parasites sometimes occurs, the population of Tropilaelaps often being greater than that of varroa, as the Tropilaelaps mite can almost completely prevent multiplication of the varroa mite.

\section{Identification}

Tropilaelaps mites are much smaller than varroa mites, although the trained unaided eye can still detect them. The adult female mite is light reddish-brown in colour, with an oval-shaped body about $0.96 \mathrm{~mm}$ in length and $0.55 \mathrm{~mm}$ in width. The mite's entire body is covered with short setae. A red streak running longitudinally on the ventral surface of the adult female, the fusion of her epigynial and anal shields may be perceived through a strong magnifying glass. When the mites are present in a honey bee colony in large numbers, they can be observed walking rapidly on the surface of the comb. They are rarely found on adult bees. In all its immature stages, the mite lives within the brood cells of the bees, feeding on the broods haemolymph. Fertilized adult females enter the cells before they are capped to lay their eggs. The stages of development of the mite are as follows: egg, six-legged larva, protonymph, deutonymph and adults. Adult males of Tropilaelaps spp. do not feed, their chelicerae (the organs originally used for piercing the bees' integument) were modified to transfer sperm as in the varroa mite. The lifecycle of the mite is well synchronized with that of the host bee.

\section{Symptoms and diagnosis}

The damage caused to colonies by Tropilaelaps infestation is similar to that brought about by varroa and the injuries inflicted on individual bees and bee brood are essentially the same. The abdomen of bees surviving mite attacks is 
reduced in size, and they have a shorter life-span than healthy bees. In heavily infested colonies, bees with deformed wings can be observed crawling about the vicinity of the hive entrance and on the comb surfaces, while pieces of dead bee brood evacuated from the hive by the house bees can be observed in front of the entrance. Inspection of hives severely infested by Tropilaelaps reveals an irregular pattern of sealed and unsealed brood as found with all brood diseases (Fig.11.6b). The best means is to open sealed cells gently and inspect them for the presence of the mite. If mites are present, adult females will be observed walking rapidly out of the cells. To obtain a reasonably accurate estimate of the level of infestation, $100-200$ cells should be opened and the brood removed with forceps for close inspection. Hosamani et al., 2005 reported the effect of Tropilaelaps clarae infestation on colony build up in Apis mellifera and significant

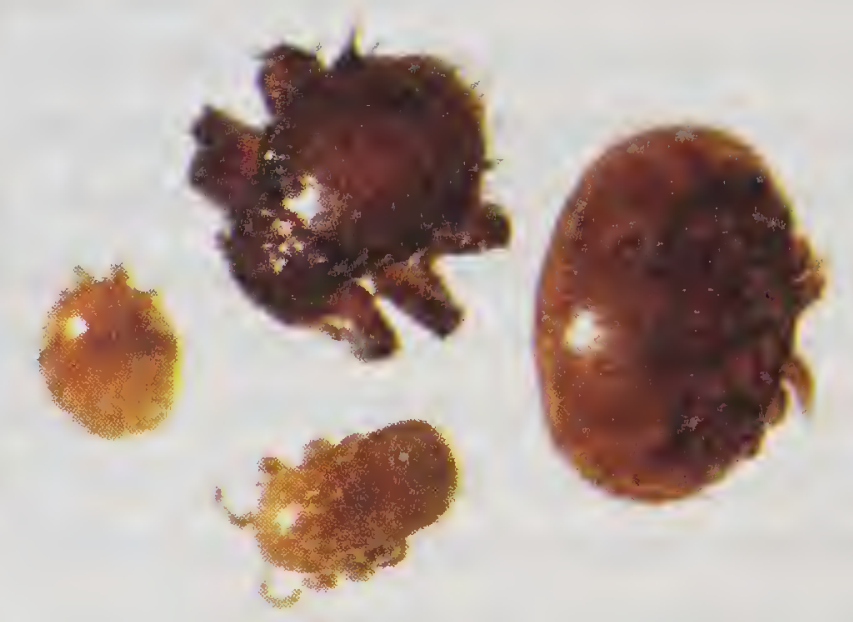

(a)

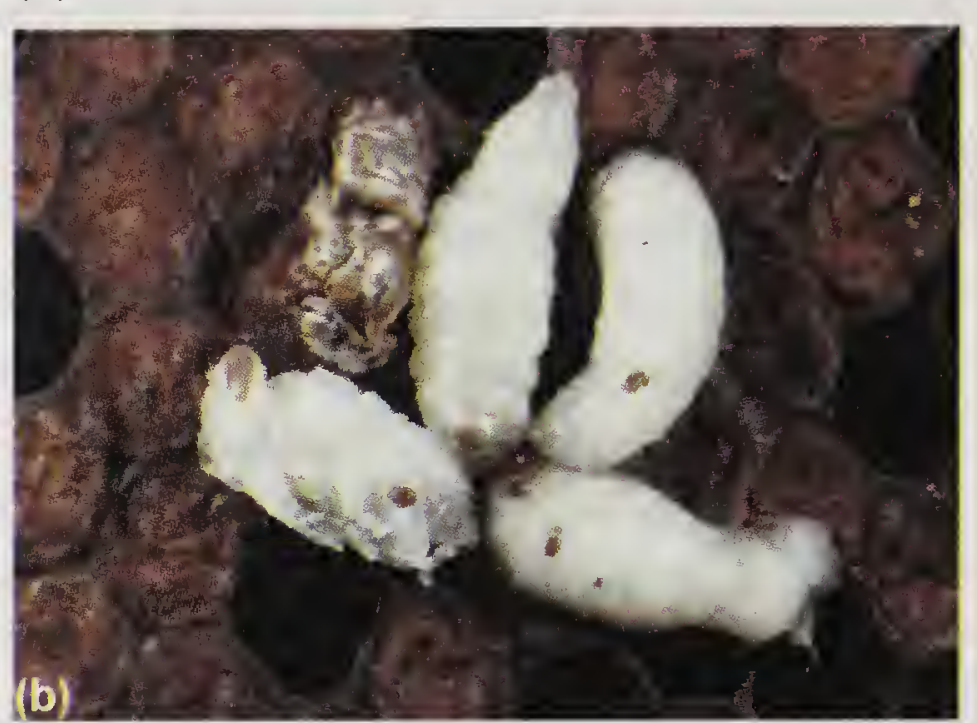

Fig. 11.6 (a) Tropilaelaps clarae nymph and adults; (b) Tropilaelaps clarae parasitize larva, pupa and adult of Apis mellifera

(Anderson et al., 2013) positive correlation between fluctuation in mite incidence and brood area was recorded. Further, they evaluated some botanicals in 2007 against the ectoparasitic mite and found that garlic extract was more effective than the sulphur treatment.

\section{Management}

To manage the Tropilaelaps mite both chemical and cultural method to be adopted.

Chemical control: The chemotherapeutic treatments as use to control of Varroa are also effective in the control of Tropilaelaps. Formic acid can be used successfully in its treatment. However, special attention must be paid in tropical areas regarding its dosage to avoid damage to the bees. The dosage per comb should not exceed $2 \mathrm{ml}$ in a one- storey Langstroth-hive. The formic acid is placed onto a cloth deposited in the rear section of the hive. Formic acid is strongly caustic; therefore, the user should wear acid-proof gloves and protective goggles. Applications of amitraz are very effective either as a liquid spray on the surface of the brood comb and hive walls, or as a hive fumigant, in the same dosages. The treatment requires three to four applications at four-day intervals. The precautions to be taken in treating Tropilaelaps are the same as for Varroa; all chemical treatments must be suspended at least eight weeks before the honey-flow season arrives, and amitraz must not be used in spray form in the presence of large numbers of honey bee eggs and newly-hatched larvae. 
Colony manipulation techniques: Many beekeepers prefer not to use chemicals to control Tropilaelaps, but to manipulate the brood-rearing cycle of their infested colonies in such a way that the mites are deprived of sealed and unsealed brood, their food, for at least three days. During this period, a large proportion of the mite population will starve to death. There are several means of creating this broodless situation in infested colonies. In smaller apiaries, the beekeeper can simply remove the brood-comb frames - both sealed and unsealed - from the infested colonies and put them in new hives. Before the new larvae hatch, the hives manipulated in this way will be short of brood for 2-3 days, time enough to starve most of the mites. The new hives with the removed brood frames are given mated queens, which are caged for 14 days, a period that allows most of the brood to emerge, while no new brood was reared because the queen has been confined. In this process mites are subjected for starvation due to lack of sealed and unsealed brood in the hive.

\section{TRACHEAL MITE, Acarapis woodi (Rennie)}

Acarapis woodi is an endo-parasitic mite of adult bees (Fig. 11.7). It was first reported in Apis mellifera in Europe in 1921. Acarine was subsequently reported from India in 1957 by Singh from Apis cerana colonies. Singh and Adlakha $(1958,1960)$ found that $10 \%$ of colonies in Shimla Hills were infested. It is present in north-western states of India. The mite is present in many parts of the world but absent in temperate and tropical parts of America, Australia and New Zealand. It infests the tracheae of first thoracic spiracle where they suck the haemolymph.

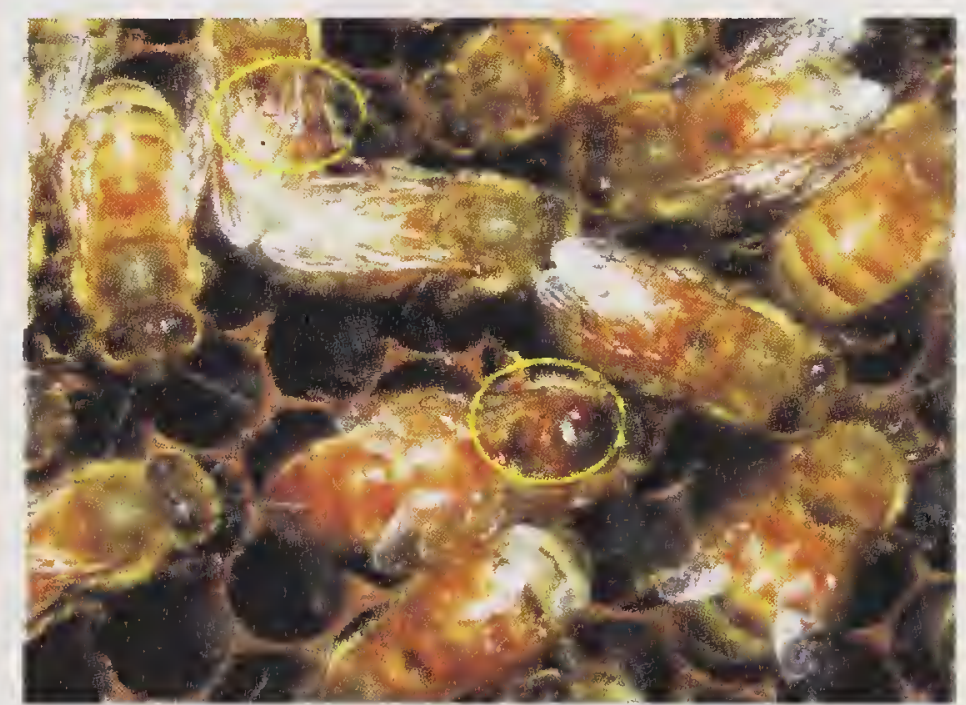

Fig. 11.7. Acarapis woodi infestation on Apis mellifera (Courtesy: Jessica Louque).

\section{Symptoms and diagnosis}

Acarapis woodi infestations are: (1) Bee crawlers are found in front of hive; (2) bees are unable to fly and wings are held disjointed in ' $\mathrm{K}$ ' winged condition; (3) life of infested bees is shortened; (4) mites, if present in large numbers in tracheae, hinder the intake and supply of oxygen to flight muscles; (5) infected bees are short lived; and (6) mite infestation leads to secondary invasion by viruses. To confirm the presence of acrine, the prothoracic collar is removed to expose the largest trachea and observed under microscope. Mites in all developmental stages are observed and tracheae become dark due to punctures made by mites and also because of accumulation of faeces.

Mode of infestation: Acarapis woodi infests the tracheal system of adult bees, queen, workers and drone. Female mites enter the tracheae of young bees. Because of developing of a hair barrier, mites cannot enter after the bees are more than 9 days old. Female lays 5-7 eggs which hatch in 3-4 days and it takes 6-10 days to 
reach adult stage. They mate inside the tracheae and mated females migrate through body hairs to other bees. Mite spread through drifting or by beekeepers when they transfer diseased bees to a healthy colony while uniting them.

\section{Management}

Folbex (cholorobenzilate) fumigation is the tested control method for the endoparasitic mites. In India, Atwal (1971) recommended 5-7 fumigations with Folbex strips at weekly intervals. Adlakha (1976) reported that methyl salicylate and menthol were ineffective. Mixture of nitrobenzene + methy 1 salicylate and petrol was effective but it induced severe, uncontrollable robbing and also damaged the brood. In the event of non-availability of Folbex strips and chorobenzilate, other control measures were also evaluated. Formic acid, $5 \mathrm{ml}$ of $85 \%$, was found effective against the mite and the colonies cleared of infestation in a fortnight. The chemical had no adverse effect on the brood or on the longevity of the adult bees (Sharma et al., 1982). Menthol strips (300 mg/strip) were found to be effective for the control of the mite (Kshirsagar et al., 1980) but Garg and Sharma (1988) achieved partial control of the mite with menthol and they suggested its use as prophylactic measure like methyl salicylate.

Other species of Acrapis, viz. A. vagans, A. externus and A. dorsalis, are ectoparasitic mites but have not been reported in India.

\section{Quarantine measure}

Quarantine is based on the principle that prevention is better than cure with the objective of reducing their risk factor against the introduction of exotic pests and disease and if already present checks its further spread and multiplication. Quarantine can, therefore, be defined as a legal enforcement measures to prevent pests and pathogens from spreading, or prevent them from multiplying further in case they have already found entry and have established in a new restricted area. Though quarantine measures may not guarantee, an everlasting protection against that entry of exotic pests but will certainly check or delay introduction of these unwanted organisms and their subsequent establishment in hitherto clean areas. The legislative measures such as international and national quarantine, and modified campaigns need to be enacted to prevent the entry of new pests and diseases and their further spread. As a consequence, various countries have promulgated bee laws/legislations to avoid the risk of introduction of bee pest diseases and other related problems. Such quarantine legislation and its enactment in India would help preventing many invasive pest and diseases of honey bees.

\section{REFERENCES}

Adlakha, R. L. 1976. Acarine disease of adult honeybees in India. American Bee Journal 116(7): 324-44.

Atwal, A. S. 1971. Acarine disease problem of Indian honey bees, Apis indica F. American Bee Journal 111: 134-36.

Atwal, A. S. and Dhaliwal, G. S. 1969. Robbing between Apis indica F. and Apis mellifera L. American Bee Journal 109: 462-63 
Deka, M. K., Das, P. K. and Majumdar, A. 2010. Seasonal incidence and management of wax moth (Galleria melllonella) in Asom. Pestology. 34(12): 36-36.

Deosi, H. K. and Chhuneja, P. K. 2011. Biology of Varroa destructor Anderson and Trueman in Apis mellifera colonies under Punjab conditions. Proceedings Third Congress Insect Science On Pest Management for Food Security and Environment Health, Punjab Agricultural University, Ludhiana. 278.

Deosi, H. K. and Chhuneja, P. K. 2011. Seasonal abundance of Varroa destructor Anderson and Trueman in Apis mellifera colonies under Punjab conditions. Proceedings Third Congress Insect Science On Pest Management for Food Security and Environment. Health, Punjab Agricultural University, Ludhiana. 277.

Garg, R. and Sharma, O. P. 1988. Efficacy of cholrbenzilate and methol against Tropilaelaps clarae Delfinado and Baker(Laelaptidae: Acarina) in Apis mellifera L. Indian Bee Journal 50(3): 65-66.

Gulati, A. R, and Sharma, S. K. 2009. Effieiency of screen floor and powder sugar against Varroa destructor Anderson and Trueman in Apis mellifera L. colonies. Biopesticidal International 5(2): 118-25.

Hosamani, R. K., Sharma, S. K. and Gulati, R. 2005. Effect of Tropilaelaps clareae Delfinado and Baker (Mesostigmata: Laelapidae) infestation on colony buildup and stores in Apis mellifera L. colonies. Korean Journal Apiculture 10(1): 35-38

Krishnasagar, K. K., Salvi, S. R., Mahindre, D. B. and Chauhan, R. M. 1980. Menthol as an effective acaricidal fumigant. Proceedings $2^{\text {nd }}$ International Conference of Apis Tropical Climates, New Delhi, 254-56.

Mishra, S. N., Padhi, J and Jena, B. C. 2009. Management of greater wax moth, Galleria melllonella $\mathrm{L}$. in honey bee colonies. Journal of Plant Protection and Environment 6(1): 140-42.

Rahman, A., Rahman, S. and Das, P. 2001. Management of predatory wasp, Vespa magnifica L. in the apiary. Indian Bee Journal 63(3\&4): 72-73.

Rana, B. S., Kumar, A. and Gupta, J.K. 2000. Influence of environmental factors on the population of predatory wasps on honeybees and evaluation of methods for controlling the wasps. Indian Bee Journal 62(1-2): 47-54.

Rana, K., Sharma, H. K. and Rana, B. S. 2010. Efficacy of formic acid sponge pad against Varroa destructor infesting Apis mellifera. Indian Journal Entomology 72(3): 209-11.

Sharma, O.P., Garg, R. and Dogra, G. S. 1982. Efficacy of formic acid against Acarapis woodi (Rennie). Indian Bee Journal 45(1): 1-2.

Singh, S. and Adlakha, R. L. 1958. Acarine disease of adult honey bee. Indian Bee Journal 20(6): 64-78.

Singh, S. and Adlakha, R. L.1960. Survey of acarine disease of adult honey bees in Simla hills. Indian Bee Journal 22(1/3): 3-6.

Varshneya, I., Pandey, A. K., Mall, P. and Rathore R. R. S. 2008. Seasonal incidence of wax moth (Galleria melllonella) in European honey bee (Apis mellifera) colony. Journal of Entomology Research 32(1): 1-6.

Varshneya, I., Pandey, A. K, Mall, P. and Rathore, R. R. S. 2009. Sesonal incidence of predatory wasps in Apis mellifera colony having different number of frames. Journal of Entomology Research 33(1): 45-49.

Yadav, S., Singh, J. and Chhuneja, P.K. 2012. Management of Galleria melllonella Linn.(Lepidoptera: Dryralidae)under storage conditions. Proceedings of National Seminar Emerging Pest Problems \& their Bio-rational Management MPUAT, Udaipur: 158-59. 


\section{2 \\ Bee Pasturage}

ECTAR and pollen are the natural food of honeybees. The nectar of the
flowers which bees collect and convert into honey, are the main source of carbohydrates and vitamins. Pollen, the dusty rain in the flowers is the major source of protein and is mixed with honey before it is fed to larvae. Nectar is secreted by nectarines and is usually a reward for the visitors bringing about pollination requirements of the crop. Honey is made by bees from the nectar collected from floral and extra floral nectarines. Sometimes, honeydew is also important source in certain localities, but the well being of bees is greatly dependent on the value of the flora. For the selection of the apiary site it is essential to know the plants which provided nectar or pollen to bees. Data on different aspects can be gathered for couple of years to establish the potentials of an area for beekeeping. Scaled colony provides useful information. Weight of the scaled colony is regularly recorded and the changes in weight are correlated with the flowering plants which are being visited by bees and also the weather conditions. Flowers present nectar and pollen during specific time of the day, therefore, bee activity on the flora should be carefully recorded. Recording the bee activity at different day hours should give useful information. Melissopalynogical studies are essential to ensure as to which plants are availed by bees. Pollen analysis of honey samples taken at different time of the year and comparing with reference slides give the exact information about the floral sources for bees in vicinity.

Bee flora should be studied from different angles to find out the value of bee forage though the total nectar production per flower is important. Some flowers secrete nectar only for one day and few others for short time and still there are flowers like Schefflera wallichiana which continue nectar secretion for about a fortnight. The time for which nectar plant blossoms is another important point determining the value of flora. In some forages the duration between the start and end of flowering is very short, whereas in others like Brassica spp. there is a succession of flowering and it lasts for about a month. Trees present larger number of flowers as compared to bushes, shrubs and crop plants unless the latter are growing in large continuous areas. Concentration of nectar sugar gives an objects measure. Total sugars per flower per day are the sugar value which is normally estimated for such studies. Sugar value is the number of $\mathrm{mg}$ of secreted by one flower over a period of $24 \mathrm{hr}$. however, total quantity of nectar produced and the amount available to or harvested by bees give valuable information. 


\section{Nectar-sugar concentration}

Nectar concentration in most bee foragers varies between $20-50 \%$ but may be as low as $6 \%$ in Bombax ceiba to $15 \%$ in pear as high as $79 \%$ in silver oak (Grevillea robusta). Nectar and sugar concentration (\%) has been worked out for some flora in India. For example, Grevillea robusta had 79\% sugars in the nectar (Deodikar et al., 1957), 23 plants including Tecoma grandiflora had 14\%, peach and pear $70 \%$, Brassica juncea 52\%, Barberis 48\%, some citrus spp. 40-44\%, Sapindus detergens 40\%, Plectranthus 38\%, Cidrella cerata 36\% (Sharma, 1958); Carvia callosa 35\% (Phadke, 1964); Thelepaepale ixiocephala 35-64\% (Phadke, 1965); Impatiens balsamina 16-25\% (Singh and Sharma, 1972), Nephelium litchi 61-78\% (Nair, 1983), Plectranthus 26-54\% (Gupta et al., 1984); Woodfordia floribunda 10-12\% (Mishra et al., 1987), Brassica campestris var. toria 38.5$53.5 \%$ (Kapil and Brar, 1971) and onion 59-75.5\% (Rao and Lazar, 1980). Gupta et al. (1984) there are considerable differences in the amount of nectar sugar production in the flowers of different cultivars of cauliflower and in the attraction of bees to them. Average nectar sugar contents varied from 0.035 to $0.150 \mathrm{mg}$ / flower/24 hr. On the basis of such studies honey potentials per unit area are estimated for cultivated crop/fruit plants. For wild flora the density per unit area is estimated by sampling and honey potentials of the flora in the area are worked out. Honey potentials of forage are only estimates but it serves as a useful guide. Honey potentials of forage are liable to change. This is happening fast in developing agriculture in India where changes in land-use patterns was very frequent. Under extensive agriculture, vast waste lands are cleared for cultivation and this reduced the wild flora. Land may be put to urbanization or industrialization causing reduction in cultivated and wild bee flora. There are introductions and extension of cultivation of new crops like sunflower, safflower and other oilseed crops and this has substantially changed the scenario with regard to beekeeping potentials. There are many agricultural practices which affect the bee flora. Mechanized agriculture reduces the weed plants which may be serving as bee forage. The use of weedicides is another agricultural practice which reduced the weed forage for bees.

The nectar yielding plants contributing to nectar/honey flow are specific to different areas and they have definite micro-regional habitats. Even in rich floral areas continuous succession of nectar yielding plants throughout the year is lacking. In some localities there is single surplus honey flow and in good areas 2 surplus flows may be available. In north-western hills of Himachal Pradesh and Jammu and Kashmir, the lower and mid hills present spring, early summer flow and in areas like Kashmir and parts of Himachal Pradesh, there is rich flow from Plectranthus in autumn. Bees face protracted dearth period in winters and only subsistence flora is rainy season but heavy downpours are hazardous to bees. In North Indian and Gangetic plains, major flora of Brassica is available from September through early February. This builds up and surplus flow is followed by spring and summer surplus honey flow from Eucalyptus, Dalbergia sissoo, and other trees and berseem is availed by bees till May. Hard summers are also no flora availability period but some weeds and crops present subsistence forages in rainy season. In western Ghats and South India, there is medium to major flora 
available from October to May and important sources being jamun, carvi, soap nut, rubber plant, Schefflera etc. but June to September is a dearth period. Therefore, for beekeeping sub-tropics may have an inactive period of 1 or 2 months. In tropics it is dry season or excessive rainfall and in hills it is winters which are troublesome to bees. Surplus flow season may vary from 1 or 2 and rarely 3 in a year. Beekeeper, to maximize his honey crop, should have a thorough knowledge of the floral cycle, onset of major honey flow and dearth periods. The bee colonies should be managed in a way so as to have maximum foraging strength to avail major flow and economical or minimum strength in dearth period. Kumar and Singh (2005) assessed the nectar sugar concentration in linseed flower and recorded $29.43 \%$ nectar during peak hours of flowering. Similarly, Kumar and Singh (2005 and 2008) recorded 24.26\% nectar sugar in niger flower and $31.26 \%$ nectar sugar in safflower. Abrol (2007) estimated nectar sugar concentration of Brassica campestris var. toria which ranged between 36.0 and $38.0 \%$.

\section{Nectar composition}

Nectar is a solution and total solids in nectar are mostly sugars. There are only few exceptions where lipids are present in nectar. Chromatographic studies help to know the sugars in nectar. Monosaccharide's, glucose, fructose and disaccharide, sucrose, are the common sugars in nectar. In general, flowers with tubular corolla secrete sucrose dominant nectar. In open flowers, such as Brassica, only glucose, fructose and sucrose are present. Bee's preference to nectar is also governed by the sugar balance and the nectars with equal amount of glucose, fructose and sucrose are preferred by bees. Minute amounts of other substances such as amino acids, minerals, essential oils, organic acids and other components usually comprise less than $0.03 \%$ of total dry weight. Essential oils impart characteristic aroma to nectar and honey and bees are attracted by this aroma to flower nectar. Solid particles in the form of pollen grains, yeast cells, fungal spores and bacteria can be found in small amounts.

Attempts were made by Indian scientists to gather information on the nectar composition of bee flora. Sucrose, fructose and glucose (28: 1: 1) make up to $60 \%$ of the total solids of Thunbergia grandiflora nectar (Nair et al., 1962). They also detected small amounts of aspartic acid, alanine, glycine, serin and valine by paper chromatography. Moringa pterigosperma Gaertn. Nectar contained $0.90 \%$ of reducing and $11.81 \%$ of non-reducing sugars (Nair and Singh, 1974). Wakhle et al. (1981) analyzed nectars from 4 species; nectar of Carvia callosa contained fructose, glucose, maltose, raffanose and an unidentified sugar; nectar of Thelepaepale ixiocephala had only fructose, glucose and sucrose, whereas nectars of Schefflera roxburghii and Grevillia robusta had only fructose and glucose. Only these 2 sugars were observed by Mishra et al. (1987) in Woodfordia floribunda nectar. Soapnut (Sapindus emerginatus) nectar had 85.5\% sucrose, and 7.25\% each glucose and fructose (Reddi et al., 1980). Sihag and Kapil (1983) analysed the nectars of 44 plants visited by Apis florea and Apis dorsata. Nectar of Tecoma stans and all 11 cruciferous plants, Althea rosea, Prunus persica, $P$. domestica and Petunia alba contained glucose dominated sugars, and sucrose and fructose were in very small fractions. Bahadur et al. (1986) analyzed nector 
of 103 plants from 100 species and revealed that 54 plants had 3 sugars, viz. sucrose (S), glucose (G) and fructose (F). In addition to these, 7 plants had 4 or more sugars, 6 having $\mathrm{S}+\mathrm{G}+\mathrm{F}+2$ unknown sugars. Forty plants had 2 sugars (29: $\mathrm{S}+\mathrm{G} ; 3: \mathrm{S}+\mathrm{F} ; 8: \mathrm{G}+\mathrm{F})$ and 2 had only one each $(1: \mathrm{G} ; 1: \mathrm{S})$. In the nectar these plants, 24 had dominant sugar as sucrose, 7 had $S+G, 2$ had $G$, and one had $G+F$ and there was no plant having either $\mathrm{S}+\mathrm{F}$ or $\mathrm{F}$ dominant sugar. Six plants had balanced $\mathrm{S}+\mathrm{G}+\mathrm{F}$ sugars, 3 plants had $\mathrm{S}+\mathrm{G}$ and there was no plant having $\mathrm{G}+\mathrm{F}$ balanced sugars. In 90 plants amino acid was present, whereas in 15 plants, the amount was double than the remaining ones.

\section{Factors affecting nectar secretion}

Honey flow from the same plant is not the under varying weather, soil and vegetation habitat conditions. The nectar secretion in a plant is the function of specific features of the forage and other external factors. Factors related to a plant species are age of the flowers and the cultivar or varieties. In Woodfordia floribunda Salisb, the flowers continued to secrete nectar for 3 days (Mishra et al., 1987); it was maximum on second day and minimum on first day of flower opening. The difference in nectar secretion have also been found in many plant species and differences with age of the flowers and cultivars was reported in peach (Mishra et al., 1985) and cauliflower (Gupta et al., 1984) in India. Nectar secretion in flowers after opening is expected to be correlated with the degree of receptibility of the stigma. Fertilization in flowers is also known to activate a feedback mechanism to switch-off nectar secretion, after certain period of flower opening there is reduction in amount of nectar sugars. This happens because of reabsorption of nectar. Reabsorption only of nectar sugars takes place and not of water. Therefore, the reabsorption at the end of nectar secretion leads to lowered nectar sugar concentration. The total amount of nectar secretion over a period by a flower is more when it is periodically removed than in case of its non-removal by insects. Besides these, growth regulators have also been found to affect nectar volume and nectar sugars. The effect of GA3 was more pronounced in mustard and cauliflower than with other growth regulators (Mishra and Sharma, 1988).

Sunlight and temperature: Sunlight has a direct bearing on photosynthesis. Photosynthesis produces carbohydrates which are secreted in nectar. Effect of sunlight and consequently of photosynthesis may not be immediate because stored carbohydrates do make good but ultimate effect is there. Temperature has direct relationship with nectar secretion. For every plant species there is a specific threshold temperature at which the nectar secretion is started and it increases when the temperature is optimum. This is the range of temperature at which enzymes responsible for nectar secretion are activated. On the other hand, very high air temperature may result into water stress in plants and the water stress causes more water loss than the uptake. The imbalance results into lowered nectar secretion through reduced sugar transport in the conducting tissues.

Relative humidity: Nectar is hygroscopic in nature and for this reason atomospheric humidity is inversely linked to nectar sugar concentration. After secretion, nectar sugar concentration changes and attains an equilibrium with the moisture in the air. Water is always lost from nectar unless the relative humidity 
is near $100 \%$. High relative humidity causing reduction in sugar concentration can affect the attractiveness of the source to bees. Conversely higher sugar concentration at lower relative humidity can affect the nectar column in the tubular flowers and bees may be unable to reach and imbibe the nectar. Water loss in the plant is also a function of relative humidity as also of air temperature.

Soil: Optimum soil moisture is essential for good plant growth. With soil water as a limiting factor the number of flowers is reduced and nectar secretion is also adversely affected. Balanced nutrient level in soil which supports good plant growth also favours nectar production. Phosphorus $(\mathrm{P})$ and potassium $(\mathrm{K})$ increase nectar production but high level of phosphorus reduces it. A balance between the two elements should be beneficial. Excessive application of nitrogen causes abnormal vegetative growth and comparatively lesser number of flowers are produced. Some of the bee forages were briefly discussed in this chapter.

Bee floral species are specific to different areas and they have definite microregional habitats. Under subtropical climate of India nectar and pollen sources are available for most part of the year but continuous succession throughout the year is lacking in some localities. There is a single surplus honey flow and in good areas two surplus flows may be available. North-west, lower and mid-hills present spring/early-summer flow and autumn flora of plectranthus is also available in hills. Bees face protracted dearth period in winters and only subsistence flora is available in rainy season. Vast agricultural plains of North India and Gangetic plains offer major flora of Brassica from October to early February; the total area under oil seeds crop being 20 million ha in India. This builds up honey flow which is followed by spring and summer surplus honey flow from Eucalyptus, Dalbergia sisso, Litchi, other fruit trees, Mimusops, Pongamia and later Egyptian clover is availed by bees till May; due to introduction and adoption of sunflower crop bee avail pollen upto May/early June. Harsh summers have no floral availability period but some weeds and crop present subsistence forage in rainy season and fall. In eastern and western -ghats and South India, there is medium to major flora available from October to May and the important sources being Syzygium cumini, Terminalia chebula, Carvia spp., Sapindus spp., Heavea brasilliensis, Terminalia indica and Scheifflera spp. Tamil Nadu and Kerala have belts of about 0.36 million ha of rubber, coconut for bees. Rubber leaf exudate is of short durations but is very rich. Cultivated crops like Sesamum, Cajanus cajan, Lathyrus sativus, Helianthus annuus, Zea mays, and Carthamus also serve as important sources. In North East, both wild and cultivated flora are available from late autumn to early summer. Brassica being the major crop in winter followed by spring blossoms. Important bee floras have been worked out for their value as nectar and pollen sources to bees. Quantity of nectar produced and honey potentials of flora were assessed and more studies are underway. This can now serve as a guide for deciding tree plantations by different agencies on the basis of multiple use principle and value as bee forage as one of the use. Most serious problem in Indian beekeeping had been the decreasing honey plants. But recently, Central and state Governments and local organizations under Social forestry programme are trying to extend planted area of bee forages and thus highway plantations have come up to present sufficient forage for bee in many parts of the country. 
Flowers of large number of plant species are visited by honeybees for nectar and pollen but the importance of the source, besides richness of floral rewards, also depends on the density of the species in an area. Though the major sources are not many in any locality yet large number of minor and subsistence sources serve the important purpose of build up for sustaining the bee colonies.

\section{Bee flora}

Certain beeforage groups of plants in India with biochemical composition was described by Singh (1962) and Mishra (1995) and efforts were made to discuss and update the information in this chapter.

\section{Forest and avenue trees}

Eucalyptus spp. These are evergreen trees and are indigenous to Australia. In Australia most species are bushes and shrubs but fortunately in India Eucalyptus spp. attain gigantic size. Different species and even varieties flower during different parts of the year but main bloom is available in spring. Eucalyptus plantations have expanded very fast on road side, canals, even waste lands and thus presenting vast potentials to bees. Honey is light amber coloured and granulation is fairly quick.

Hirad (Terminialia chebula). Hirad is distributed in the Western Ghats and in sub-mountainous regions. The fruits have medicinal value and also a source of dyes and tannins. It ia a major flora in beekeeping areas of Maharashtra (Chaubal and Deodikar, 1965; Deodikar and Thakur, 1953). It flowers in April to June. Hirad honey is composed of $17 \%$ water, $35 \%$ glucose, $40-41 \%$ fructose, sucrose, maltose, melezitose, ash and it also contains calcium, phosphorus, iron, magnesium, sodium, potassium and silicon. Tartaric, citric, malic, succinic acids are also present (Narayana, 1970; Phadke, 1962; Phadke et al., 1970). Honey is light yellow coloured; granulation is slow and has characteristic pungent aroma and tastes akin to fruit tannins. Terminalia arjuna (Rob.) Wight and Arn was widely planted in forests and as avenue plantation. It is also a nectar and pollen source but details of value as bee forage have not been worked out. T. bellerica (Gaertn.) Roxb. has also both nectar and pollen forage but no data on nectar and honey is available.

Karanj Pongamia pinnata (L. Pierre), Karanj grows well in humid tropical area. Pongamia glabra is grown as avenue and shade tree in drier climate. Leaves are used as fodder. It blooms in April-May and both nectar and pollen are availed from karanj. Data on nectar production, honey characteristics and honey potentials are not available but it is considered to be good flora by the beekeepers.

Moulsari (Mimusops elegni L.), Moulsari is evergreen tree with whitish flowers. It has good nectar flow in May-June in Bihar (Naim and Phadke, 1976), Maharashtra (Subramaniam, 1979) and also in Uttar Pradesh. Bees also collect pollen from this flora. No information on nectar and honey from moulsari is available.

Phalsa (Grewia asiatica L.), Phalsa shrub is grown for its fruits. It blooms from April to August and yields nectar to bees. The extent of its cultivation Grewia less. G. oppositifolia Roxb, is a medium-sized tree which is planted for lopping 
its foliage for fodder, for its best fibre for ropes and for timber. It blooms in AprilMay and is a nectar source to bees. These species of Grewia are only minor sources.

Schefflera wallichina Harms. It grows as a strangler or small tree in forests or cardamom estates of Coorg area of Karnataka. Schefflera blooms in April-June and is a rich nectar source. Most honey in Coorg is obtained from this source. Pollen availability to bees is very low.

Shisham (Dalbergia sissoo DC). Shisham's habitat is very varied, from lower hills to dry plains; normally planted on banks of canals or roadside as avenue plant. This is a source of valuable timber especially for furniture. Pale-yellowish flowers are put forth in April. Corolla is tubular but narrow tube has nectar well up to the reach of bees. Wind blows flower from branches and nectar availability is adversely affected. It is a major nectar source for bees in many states especially Himachal Pradesh, Punjab, Haryana and Uttar Pradesh. Shisham honey is dark amber with moisture $18.75 \%$, glucose $34.6 \%$, fructose $39.1 \%$, sucrose $1.04 \%$ and ash $0.18 \%$. honey flavor is strong and not attractive.

Silver oak (Graevillea robusta A.) Silver oak is planted in coffee plantations and also as avenue tree. It profusely flowers and is an important nectar source (Deodikar et al., 1957; Wakhle et al., 1981), and nectar secretion is abundant with $17-79 \%$ nectar concentration. Honey is reddish-black with prominent flavor and it granulates rapidly.

Soapnut (Sapindus spp). Soapnut is an avenue and forest tree; fruits are used as substitute to soap. S. emerginatus Vahl is a species found in Andhra Pradesh, Karnataka, Odisha and Tamil Nadu (Krishnaswamy, 1970). The species flowers in October-December. It gives $20-25 \%$ of total honey yield in some parts of Andhra Pradesh. S. emerginatus nectar has $85.5 \%$ sucrose and $7.25 \%$ glucose and fructose (Reddi et al., 1980).

Toon (Toona ciliate Roem.) Toon grows as timber and avenue tree in lower hills and plains of Northern India especially in moist soil. It is also lopped for fodder but is not to the liking of cattle. Toon is a major nectar source in Himachal Pradesh (Singh, 1948), Kashmir (Saraf, 1972), Punjab (Chaudhary, 1977) and Uttar Pradesh (Kohli, 1958; Ramesh, 1980). It is a minor source of pollen. Large numbers of trees have recently been cut and floral source has declined. Nectar sugar concentration varies from 26 to $72 \%$ in freshly opened to $48 \mathrm{hr}$ old flowers. Average nectar sugar value is $2.38 \mathrm{mg} /$ flower/day and nectar is secreted for 4 days. Honey is light amber in colour with pronounced flavor. Normally its honey is mixed with Dalbergia sissoo honey and is obtained in May.

Whayati [Thelepeale ixiocephala (Benth.) Bremk]. Whayati is a tree of moist forests of Western Ghats of Maharashtra and Karnataka. Whayati flowers after every 8 years. It blooms in November-January and is a major nectar source. Sugar concentration of nectar is $35-46 \%$ (Phadke, 1965). Honey contains $38 \%$ glucose and $39 \%$ fructose; sucrose, maltose, raff nose and melezitose are present. Sodium, potassium, calcium, magnesium, iron, phosphorus and silicon are contained in whayati honey. It is light yellow and granules rapidly but granulation is uniform (Chaubal and Deodikar, 1965).

There are many other avenue and forests trees which are good sources of nectar and pollen but their number is small and at best serve as subsistence sources. 
These trees are bottle brush (Callistemon lanceolatus DC.), pride of India (Lagetstroemia indica L.), Indian laburnum (Cassia spp.), puna (Ehretia acuninata B.), siris (Albizzia spp.), willows (Salyx spp.) and chestnuts (Aesculus spp., Castanea spp.

\section{Fruits}

Jamun (Syzygium cumini Skeels). Jamun is widely planted avenue-cumfruit tree and naturalized as forests in many parts of India. It is a predominant flora of Western Ghats. It is reported to be a major flora in Bihar (Naim and Phadke, 1976), Maharashtra (Chaubal and Deodikar, 1965; Chaubal and Kotmire, 1980; Deodikar and Thakar, 1953), Punjab (Chaudhary, 1977), Tamil Nadu (Chandran and Shah, 1974) and Uttar Pradesh (Kohli, 1958). Its flowers are dirty white and bloom in April-May. The honey flow extends over a period of 2 or 3 weeks. Nectarsugar concentration is very high up to $72 \%$ but may be as low as $9 \%$ (Satyanarayana, 1975), Jamun is also a pollen source. Chemical composition of honey was given by Narayana (1970); Rajebhonsale and Kapandis (1970); Phadke et al. (1970). Fructose is high
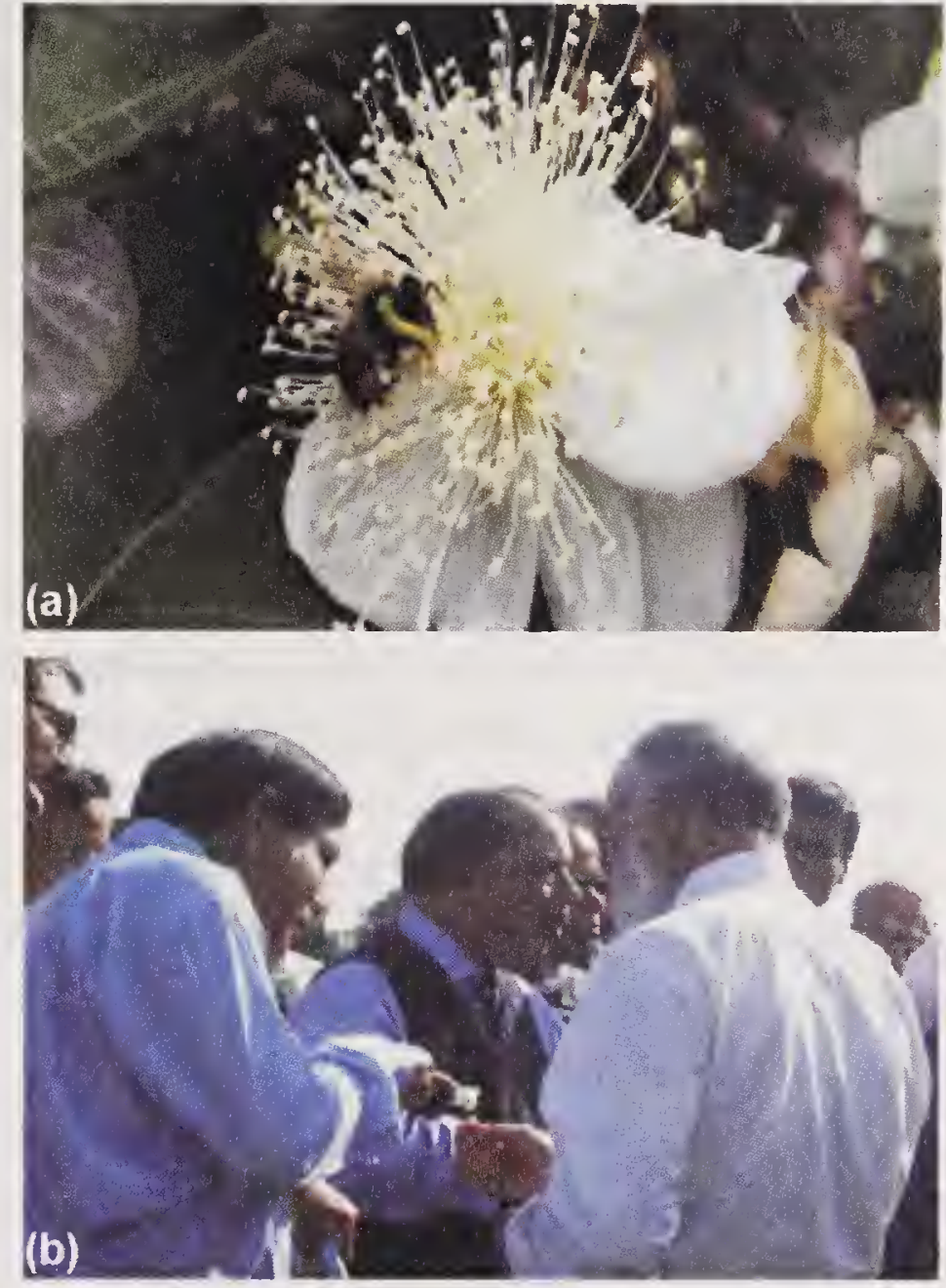

Fig. 12.1 (a) Apis cerana foraging on guava; (b) The author showing self incompatible guava flower to erstwhile Director General, ICAR \& $\mathrm{VC}, \mathrm{AAU}$. $(43.30 \%)$ and glucose is $32.26 \%$, sucrose, maltose, reffinose and melezitose are present in Jamun honey. Protein $(0.656 \%)$, dextrin $(1.55 \%)$, ash $(0.182 \%)$ and riboflavin, ascorbic acid, thiamine and niacin are also present in honey. It is light reddish-brown and has characteristic taste of jamun fruit. The honey does not granulate for years. Guava, a subtropical fruit crop is extensively grown in India having pollen and nectar source (Fig. 12.1 a and b).

Tamarind (Tamarindus indica L). Tamarind is a large evergreen shade tree cultivated in many parts of India for pods which are used in curries. The tree has many other uses like fuel, timber etc. It blooms in April-July and is a good nectar and minor pollen source in South India. Honey is rich golden and has sour flavor.

Banana (Musa spp). Perennial herb, stem formed by leaf petioleś. Flowers are large and monoecious. Musa spp. Flowers throughout the year and is a medium to good source of nectar which has $25-30 \%$ sugar concentration. Banana flowers are also visited by bees for pollen which is in abundance. Banana plantations are common in many states of India.

Cashew (Anacardium occidentale L). Cashew is cultivated in South India. It is ever green tree, flowers pink, small and fragrant. Devadason (1971) has advocated migratory beekeeping to avail cashew flow. It is also a pollen source: values of 


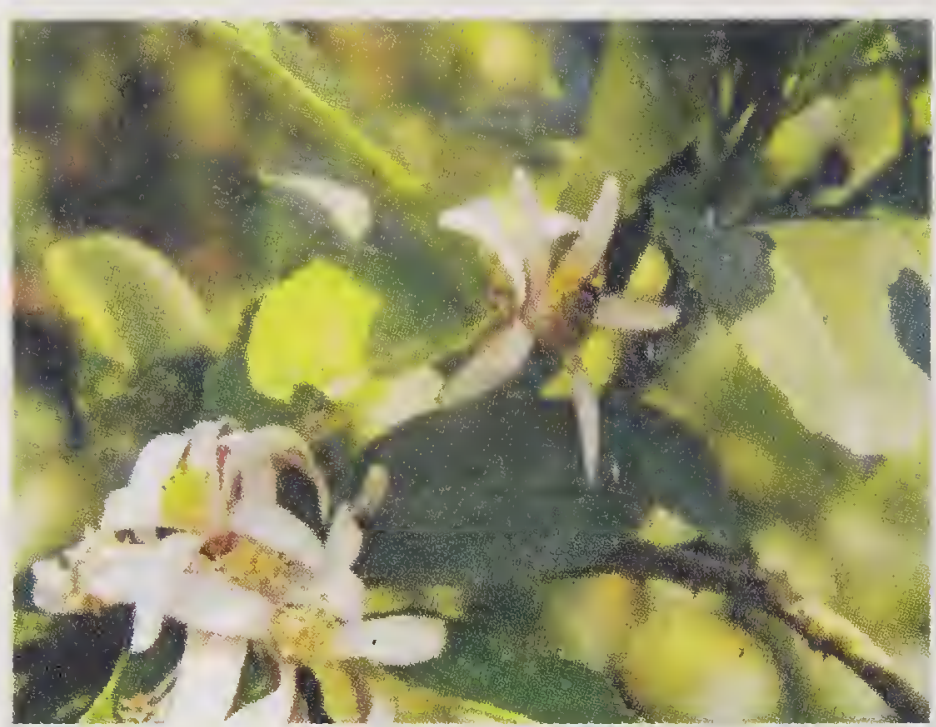

Fig. 12.2 Apis cerana foraging on Asom lemon

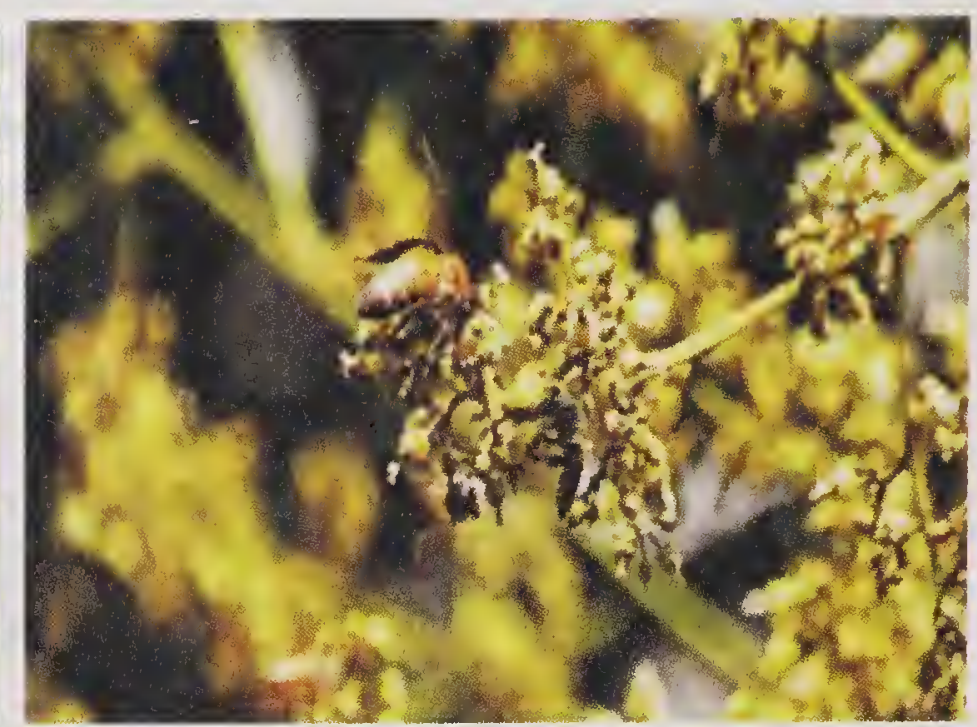

Fig. 12.3 Apis dorsata foraging on litchi

the flora and honey characteristics are not known.

Citrus spp. These are C.aurantifolia (Christm) Swingle, C. grandis (L.) Osbeck; C. limon (L.) Burm; C. paradise Macfad.; C. reticulate Blanco; and C. sinensis (L) Osb. These citrus species flower during February-March. Nectar production and nectar sugar concentration is medium. Citrus spp. also serves as pollen source (Fig. 12.2). Citrus honey has delicate flavor. In India Citrus mostly serves as a build up flora and surplus is not extracted anywhere, though large areas are under citrus and it is widely distributed.

Coconut (Cocos nucifera L.). It is grown in coastal regions. Flowers are small, monoecious, both male and female flowers have nectarines. It blooms in MayJune and bees collect abundant pollen from staminate flowers in spathes.

Jujube (Ziziphus mauritiana Lam). Indian jujube is cultivated in tropical parts of India, advantageously below 600 m.s.1. It tolerates severe heat and is drought resistant. It flowers during July to October and flowering is much protected. The flora gives surplus honey when the colonies are strong but bees get nectar source when there is other flora. Some pollen is also availed and, therefore, it is very useful forage for bees. The jujube honey is yellow-brown with very sweet flavor.

Litchi (Litchi chinesis Sonn.). Litchi has become very popular in submountainous regions for expensive fruits. It blooms in March and is a rich source of nectar to bees (Naim and Phadke, 1976; Chaudhary, 1977; Chaturved, 1969; Nair, 1981). Sugar concentration of nectar is high. Juice from damaged fruits is also availed by bees (Fig. 12.3). Litchi honey is light golden coloured with very pleasing aroma.

Pome and stone fruits, apple, pear, plum, peach, apricot, cherry, almond and their closely allied wild species are included in temperate category. They flower from February to April and bees gather both nectar and pollen. These fruit trees have local importance and have good build up sources before surplus honey flow season. Pear nectar is very low in sugar concentration. Therefore, it is normally avoided in favour of other competing flora. Surplus honey is not gathered from these cultivated fruit trees. But wild cherry Prunus puddum Roxb. flowers in October to November when no other flora is available in and lower hills of Himachal Pradesh. On an average a flower secretes $35 \mu$ nectar for 4 days with $3.47 \mathrm{mg}$ nectar sugar/ flower. Nectar sugar concentration veries from 12 to $18 \%$. 
Chromalographic separation revealed glucose, fructose, sucrose and one unidentified sugar in the ratio of 39.6, 40.7, 12.3 and 7.5 (Reddy and Gupta, 1987). This flora gives mild honey extraction in some localities. Honey is light with medium flavor and granulates slowly.

\section{Plantation fibre and forage crops}

Bramble (Rubus spp.).

It starts flowering from middle of January and continues till mid March in hills. Nectar sugar concentration of $R$. ellipticus is $65-71 \%$. Mean sugar value for the nectar of this species is $2,400 \mu \mathrm{g} /$ flower/24 $\mathrm{hr}$ (Gupta and Thakur, 1987).

Plectranthus rugous Wall.

It is a wild bush in hilly areas of Himachal Pradesh and Kashmir. It flowers profusely in August to October. Plectranthus is a very rich nectar source, though pollen is also collect by bees. Nectar sugar concentration varies from 26 to $54 \%$. Beekeepers migrate their colonies to avail the flora and bring back their colonies to lower hills before winter. Singh and Singh (1971) reported P. rugosus to be the major honey plant of Kashmir but Atwal and Goyal (1974) reported that Apis mellifera did not avail the honey source in autumn. Later Gupta et al., (1984) confirmed the foraging on P. rugosus and surplus honey extraction from mellifera colonies. In good years, an average of $30-40 \mathrm{~kg}$ honey per colony is obtained from this rich flora.

Vitex negundo L.

The shrubs sometimes grow into small tree. It is common in sub-Himalayan tract, also grown as hedge and as an ornamental up to an altitude of $1,500 \mathrm{~m}$. It blooms in April-May (June in hills) and bees visit the flowers mainly for nectar. Nectar sugar value is $690 \mathrm{ug} /$ flower/day with nectar sugar concentration of $32 \%$. Alfalfa, Lucerne (Medicago sativa L.).

Lucerne is a fodder crop cultivated in irrigated areas, especially in North India. It is rated as medium source of nectar (Chaubal and Kotmire, 1980). It flowers in August-September. Nectar sugar concentration has been reported to vary from 14 to $60 \%$ by different workers in different countries. Honey potentials are very high in seed crop. Lucerne honey contains $22-35 \%$ glucose, $34-41 \%$ fructose, $2-7 \%$ sucrose and other sugars are maltose, isomaltose, trehalose, gentiobiose, raffinose, melezitose and turanose. Whitish to light-amber colored honey granulates rapidly but granulation is fine. No data on the value of this flora is available from India. Rubber (Hevea brasiliensis Muell.).

Rubber plant is deciduous tree with male and female flowers on the same inflorescence. Nectar is available to bees only from the extra-floral nectarines at the base of young buds. The nectar flow is there for about 2 weeks when leaves are young. Rubber is a major flora in Kerala where large plantations are grown (Devadason, 1971-1972). Honey potential is estimated to be $3 \mathrm{~kg} /$ tree (Mathew, 1975). Rubber honey is clear straw coloured.

Coffee (Coffea arabica, C. robusta.)

Extensive coffee plantations in Karnataka and Tamil Nadu provide intensive nectar flow but flowering lasts for about a week only. It flowers in FebruaryMarch and nectar secretion mainly depends on soil moisture which is greatly 


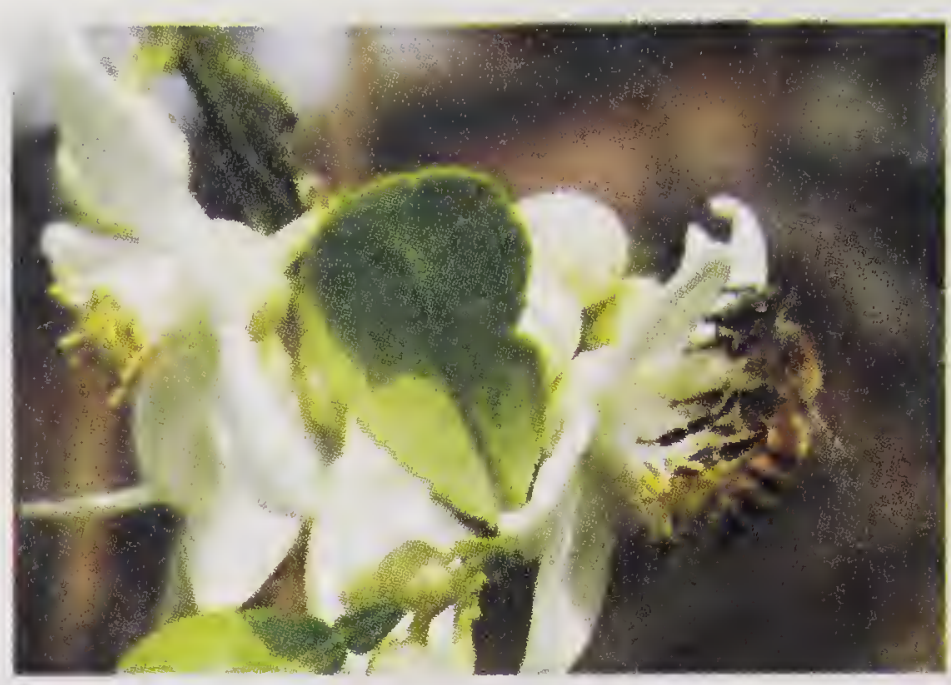

Fig. 12.4. Apis dorsata pollination in coffee.

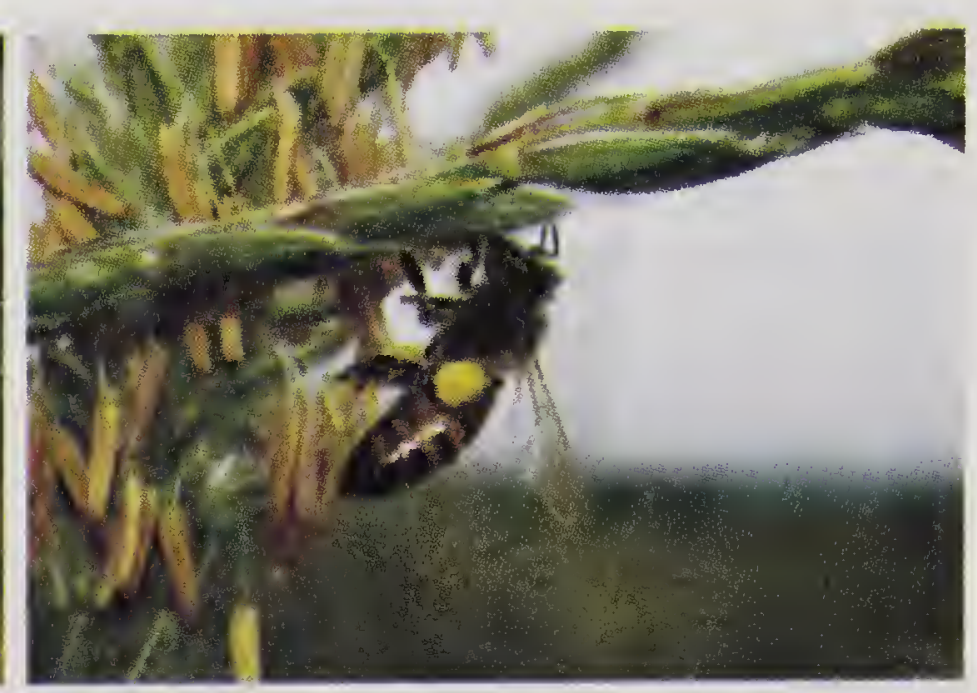

Fig. 12.5. Apis dorsata pollination in maize.

reduced by drought. Sugar concentration various from 30 to $40 \%$. Pollen grains are heavy and stick, and bees do collect some pollen (Fig. 12.4), though not a major source.

\section{Cotton (Gossypium spp.)}

Several species of cotton are grown all over India. They are sown at different times of the year and put forth blossom over a period of about 4 months in each locality. Most species are visited by bees for pollen and little nectar is available in the extrafloral nectarines. Cotton bloom is not visited by bees in case some other flora is available in the locality.

Egyptian clover (Trifolium alexandrinum $\mathrm{L}$.)

Egyptian clover is a popular fodder crop. After taking 4 or 5 cuttings the crop is allowed in the field as seed crop. Some flowering appear in between the cuttings but seed crop serves as a major source of surplus honey (Naim and Phadke, 1976; Atwal et al., 1970). It blooms in April-May and late varieties even extend up to mid June. Nectar sugar concentration is medium. Egyptian clover honey has low water content and contains about $71 \%$ of reducing sugars. Sodium, calcium, potassium, magnesium, iron, copper, manganese, and phosphorus are present in honey. Its granulation is slow. In North Indian plains an average of $15-20 \mathrm{~kg}$ honey is obtained per Apis mellifera colony from Egyptian clover. White clover (Trifolium pretense L.) is flora in hills.

Maize (Zea mays L.)

Maize is mainly grown for fodder in summer and autumn but in some areas this also serves as human food. Oil from maize is considered better than animal fats for cooking. The crop produces large tassels which produce abundant dry pollen (Fig. 12.5). Dehiscense takes place in the morning and the pollen falls down or blown off in about $2 \mathrm{hr}$. Maize pollen is poor in nutrition but is a valuable source since it flowers when hardly any other flora is available. It is considered to be medium source of pollen.

\section{Oilseeds and pulses}

Cruciferous oilseeds Brassica spp. is important source of edible oil in India, especially whole of North India. These oil seed crops are grown in extensive areas. They start flowering from October and continue till mid-February. The depleted colonies in rainy season and autumn dearth period build up quickly on early unirrigated crops. The colonies are ready to avail the main flow from 
December to February. Surplus honey is obtained in January-February. Bee also collects enough pollen (Fig. 12.6). Brassica honey is yellowish-white and granulates very quickly. Sometimes the stored honey granulates in combs itself which cannot be extracted but has to be left for own consumption of the colony. Honey also has some pungent flavor and the degree depends on the variety and species. Abrol (2007) estimated nectar-sugar concentration of Brassica campestris var. toria which range between 36.0 and $38.0 \%$

Niger: It, (Guizotia abyssinica Cass) is cultivated oilseed crop. Niger blooms in September-October. It is a major source of nectar in Maharashtra (Chaubal and Kotmire, 1980), and now its cultivation is extending fast. Nectar sugar concentration is medium and honey yield is moderate. It is also a minor source of pollen.

Sesamum: Sesamum (Sesamum indicum L) is an oilseed crop and seeds are also eaten raw or drink made from seeds. Oilseed cake is a good fodder too. The crop flowers in May- June in summer and August-September in kharif. White with slight purple shade flowers have nectaries and extrafloral nectaries on the base of flowers (Fig. 12.8). Sesamum is an important nectar source in areas where crop is grown. It is also a major source of pollen. Sugar concentration is medium $(38 \%)$. Honey is light coloured, clear and granulates slowly.

Sunflower: Sunflower (Helianthus annuus L.) was only an ornamental but recently it has become popular as an oilseed crop in warm climates. More than one crop in a year can be raised. It does not tolerate damp soils and high rainfall.

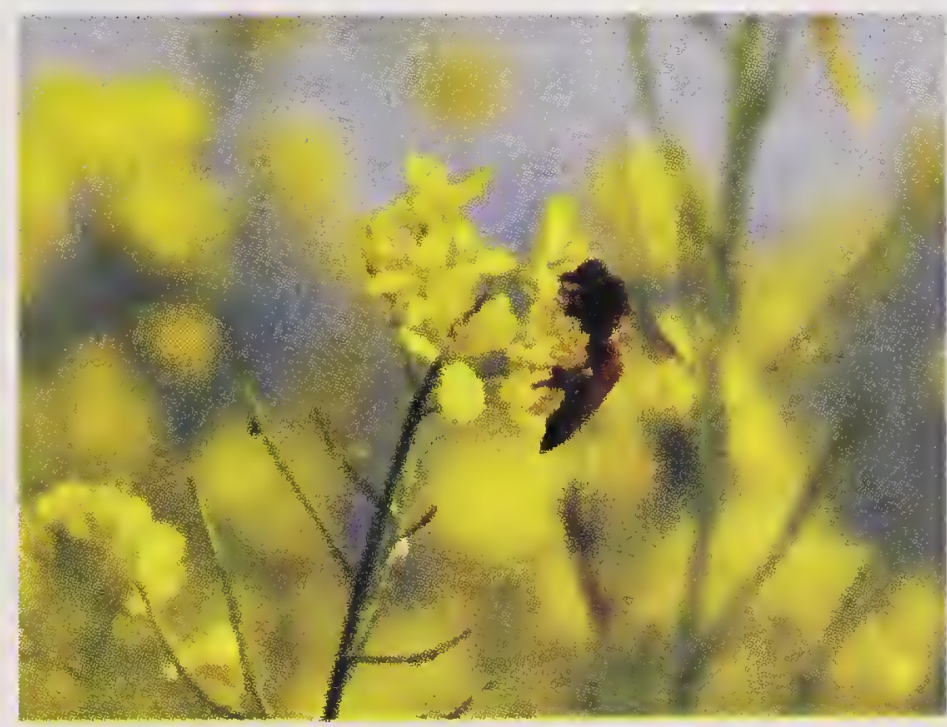

Fig. 12.6. Pollen rich rape seedflower.

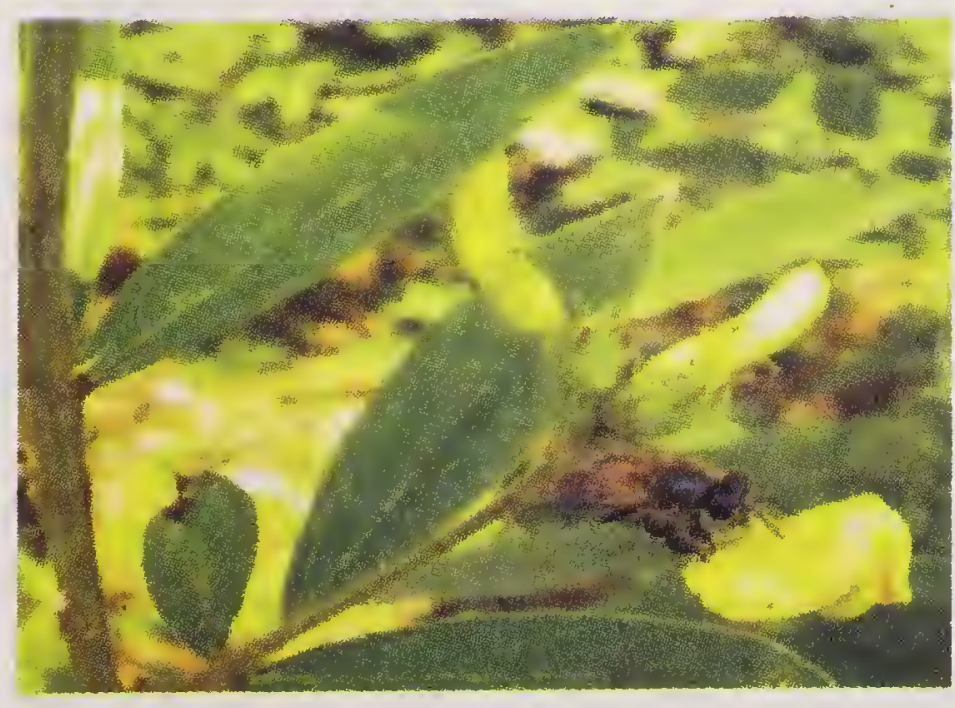

Fig. 12.8. Apis cerana foraging on sesamum.

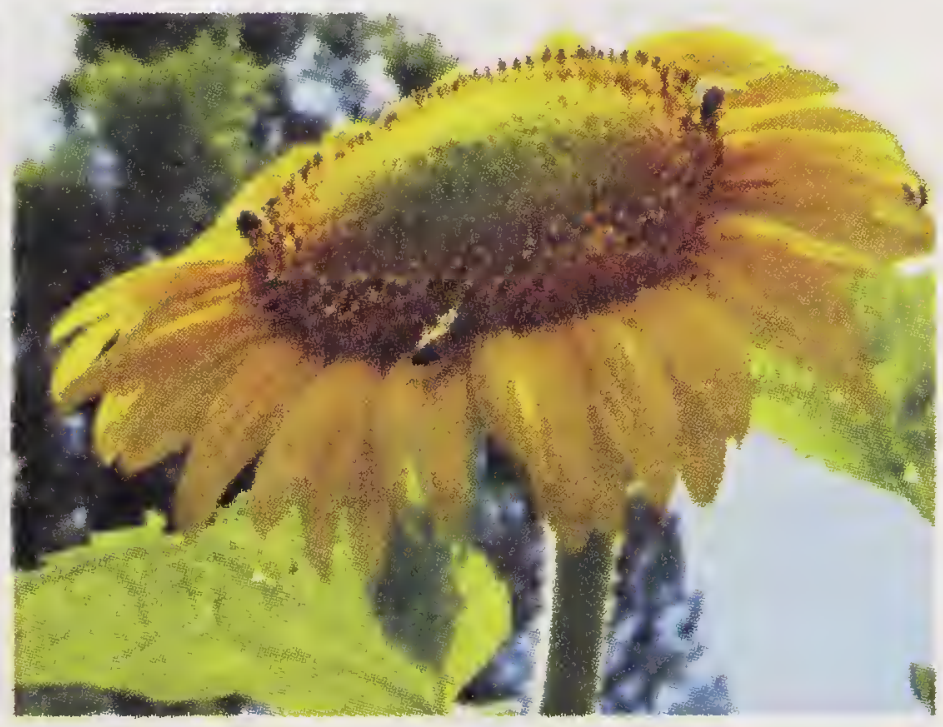

Fig. 12.7. Pollen rich sunflower.

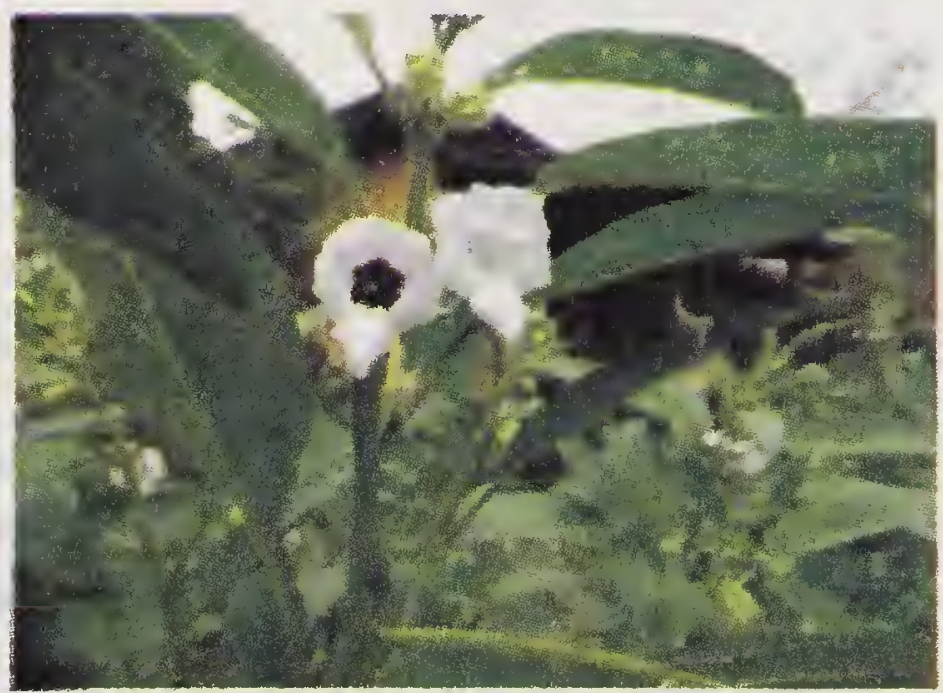

Fig. 12.9. Apis cerana föraging on pigeon pea. 
Nectar sugar concentrations is $33-60 \%$ varying with cultivars. Sunflower is a minor to medium source of nectar but major source of pollen (Fig. 12.7). The honey contains $31-42 \%$ glucose, $34-41 \%$ fructose and $0-7 \%$ sucrose. Honey is yellow or golden and since it contains high amount of glucose, the granulation is rapid.

Safflower: Safflower (Carthamus tenctorious) is rich in pollen and nectar. Singh (2007) recorded 31.26\% nectar sugar in safflower.

Linseed: Linseed (Linum usitalissimum) is rich in pollen and nectar sugar concentration in linseed flower was recorded to be $29.43 \%$ (Kumar and Singh, 2005).

Pigeon pea: Pigeon pea (Cajanus cajan) is rich in pollen (Fig. 12.9).

\section{Vegetables}

Generally, vegetables are minor source of pollen and nectar because their small plots are scattered over large areas. Many vegetables are grown for their leaves, stems, corns, etc. and seed production is there in small areas. However, there are some crops like umbelliferous crops and cucurbits which serve the cause of bees and are important. Cruciferous vegetables are grown extensively all over India but are not allowed to put forth blossoms except in seed crops. They yield both nectar and pollen from December to March.

Carrot (Dacuus carota L.); coriander (Coriandrum sativum L.) and fennel (Foeniculum vulgare L.) Their flowers are favourably visited by bees more for nectar but also obtain pollen in the absence of better sources. They flower from February to May. Because of small plots these serve as only minor flora.

More than a dozen species of cucurbits are grown in patches throughout India and they bloom almost throughout the year except in winter where the winters are severe. Flowering period spreads over a long time but the cucurbit field does not provide enough flowers for bees. They supply both nectar and pollen but only few crops are profitably visited by bees. Moreover, the pollen grains are large sized and not availed by bees. However, bumble bees and some solitary bees do visit and pollinate cucurbit crops.

Onion (Allium cepa L.) Ordinarily it is not allowed to flower but large fields

Table 12.1 Bee pasturage

\begin{tabular}{|c|c|c|}
\hline Family/scientific name of bee & Bee pasturage & Period \\
\hline \multicolumn{3}{|l|}{ Acanthaceae } \\
\hline Adhatoda vasica & Nectar & March-May \\
\hline Barleria buxifolia & Pollen-Nectar & October-January \\
\hline Barleria prattensis & Pollen-Nectar & September-October \\
\hline Barleria cristata & Pollen-Nectar & September-October \\
\hline \multicolumn{3}{|l|}{ Amaranthaceae } \\
\hline Amaranthus gracilis & Pollen & February-March \\
\hline Amaranthus spinosus & Pollen & September-October \\
\hline Celosia argentea & Pollen-Nectar & August-September \\
\hline Amaranthus viridis & Pollen-Nectar & Round the year \\
\hline
\end{tabular}


(Contd. from p. 164)

Family/scientific name of bee

Anacardiaceae

Mangifera indica

Spondias mangifera

Anacardium occidentale

Lannea coromadelica

Annonaceae

\section{Annona reticulata}

Apiceae

Coriandrum sativum

Apocynaceae

Carissa spinarum

Carissa carandas

Grewia microios

Nerium indicum

Alstonia scholanis

Arecaceae

Areca catechu

Cocos nucifera

Phoenix sylvestris

Asteraceae

Aster sp.

Bidens biternata

Chrysanthemun indicum

Cosmos caudatus

Dahlia variabilis

Dicoma tomentosa

Guizotia abyssinica

Zinnia elegans

Balsamnaceae

Impatiens glandulifera

Bignoniaceae

\section{Delonix regia}

Jacaranda acutifolia

Bombaceae

\section{Salmalia malabarica}

Bombax ceiba

Brassicaceae

Brassica sp.

Cactaceae

Opuntia spp.

Caesalpinaceae

Bauhinia variegata

Cassia fistula

Cannaceae

Canna indica
Nectar

Nectar

Nectar

Pollen

Nectar

Pollen-Nectar

Nectar

Pollen-Nectar

Nectar

Nectar

Pollen

Pollen-Nectar

Pollen

Pollen-Nectar

Pollen-Nectar

Pollen-Nectar

Pollen-Nectar

Pollen

Pollen-Nectar

Pollen-Nectar

Pollen-Nectar

Pollen-Nectar

Pollen-Nectar

Pollen-Nectar

Pollen-Nectar

Nectar

Pollen-Nectar

Nectar

Nectar

Pollen-Nectar

Pollen-Nectar

Pollen-Nectar
Period

March-April

June-July

April-July

April- June

April-May

September-December

April-May

Mar-Apr

April-May

April-May

October

June-December.

January-December

December-February

January-December

July-February.

January-December

November-December.

January-December

June-January

Sep-Nov

Jul-Jan

July-September

March-May

March-May

February-March

February-March

Oct-November

May-July

March-April

May-June

March-April 
(Contd. from p. 165)

\begin{tabular}{|c|c|c|}
\hline Family/scientific name of bee & Bee pasturage & Period \\
\hline \multicolumn{3}{|l|}{ Capparidaceae } \\
\hline Capparis sepiaria & Pollen & March-May \\
\hline Capparis zeylanica & Pollen & February-March \\
\hline \multicolumn{3}{|l|}{ Caricaceae } \\
\hline Carica papaya & Pollen-Nectar & Whole year \\
\hline Terminalia chebula & Combretaceae & Nectar, June-July \\
\hline \multicolumn{3}{|l|}{ Casuarinaceae } \\
\hline Casuarina equisetifolia & Pollen & February-July \\
\hline \multicolumn{3}{|l|}{ Combretaceae } \\
\hline Terminallia bellerica & Nectar & June-July \\
\hline Terminallia chebula & Nectar & June-July \\
\hline Terminallia arjuna & Nectar & May-June \\
\hline \multicolumn{3}{|l|}{ Commelinaceae } \\
\hline Commelina benghalensis & Pollen & August- September \\
\hline \multicolumn{3}{|l|}{ Compositae } \\
\hline Dahlia spp. & Pollen-Nectar & January-February \\
\hline Chrysanthemum spp. & Pollen & November-February \\
\hline Guizotia abyssinica & Pollen-Nectar & July-October \\
\hline Helianthus annus & Pollen & April-May \\
\hline Ageratum conyzoides & Pollen & August-November \\
\hline Carthamus tinctorius & Pollen-Nectar & January-February \\
\hline Coreopsis grandiflora & Pollen-Nectar & July-September \\
\hline Cosmos sulphureus & Pollen-Nectar & April-May \\
\hline Tagetes erecta & Pollen-Nectar & January- March \\
\hline Cersium sp. & Pollen-Nectar & July-August \\
\hline Helianthus sp. & Pollen-Nectar & April-June \\
\hline Calendula officinalis & Pollen-Nectar & July-August \\
\hline \multicolumn{3}{|l|}{ Convolvulaceae } \\
\hline Ipomoea palmata & Pollen-Nectar & July-August \\
\hline \multicolumn{3}{|l|}{ Cordiaceae } \\
\hline Cordia dichotoma & Pollen-Nectar & March-April \\
\hline \multicolumn{3}{|l|}{ Cruciferae } \\
\hline Brassica campestris & Pollen & December-January \\
\hline Brassica campestris & Var. toria & Octber-November \\
\hline Brassica juncea & Pollen & December-January \\
\hline Brassica olercea & Pollen-Nectar & March-April \\
\hline Raphanus sativus & Pollen-Nectar & November-December \\
\hline Brassica rapa & Pollen-Nectar & February-March \\
\hline \multicolumn{3}{|l|}{ Cucurbitaceae } \\
\hline Cucurbita maxima & Pollen-Nectar & May-June \\
\hline Benincosa hispida & Pollen-Nectar & June-August \\
\hline Trichosanthes anguina & Pollen-Nectar & July-August \\
\hline Lagenaria vulgaris & Pollen-Nectar & April-July \\
\hline Cucunis sativus & Pollen-Nectar & March-June \\
\hline Cucurbita maxima & Pollen-Nectar & May-June \\
\hline
\end{tabular}


(Contd. from p. 166)

\begin{tabular}{|c|c|c|}
\hline Family/scientific name of bee & Bee pasturage & Period \\
\hline Luffa acutangula & Pollen-Nectar & March-April \\
\hline Cucumis melo & Pollen-Nectar & April-May \\
\hline Citeullus nulgaris & Pollen-Nectar & June-July \\
\hline Luffa cylindrica & Pollen & April-May \\
\hline Luffa spp. & Pollen-Nectar & June-September \\
\hline Cirullus lanatus & Nectar-Pollen & April-June \\
\hline \multicolumn{3}{|l|}{ Chenopodiaceae } \\
\hline Spinacia oleracea & Pollen-Nectar & November-December \\
\hline Chenopodium ambrosiodes & Pollen-Nectar & January-December \\
\hline Chenopodium murale & Pollen-Nectar & March-June \\
\hline \multicolumn{3}{|l|}{ Dipterocaepaceae } \\
\hline Shorea robusta & Pollen & April \\
\hline \multicolumn{3}{|l|}{ Dilleniaceae } \\
\hline Dillenia indica & Pollen-Nectar & June-July \\
\hline \multicolumn{3}{|l|}{ Ebenaceae } \\
\hline Diospyros melanoxylon & Pollen-Nectar & Mar-May \\
\hline Diospyros Montana & Pollen-Nectar & January-December \\
\hline \multicolumn{3}{|l|}{ Euphorbiaceae } \\
\hline Mallotus albus & Pollen-Nectar & September \\
\hline Eupatorium odoratum & Pollen & October-March \\
\hline Euphorbia pulcherrima & Nectar-Pollen & December-January \\
\hline Phyllanthus emblica & Nectar-pollen & July-August \\
\hline Riccinus communis & Nectar-pollen & August- Septemer \\
\hline \multicolumn{3}{|l|}{ Fabaceae } \\
\hline Acacia auriculiformis & Nectar-pollen & March-May \\
\hline Acacia leucophloea & Nectar-pollen & August-November \\
\hline Acacia nilotica & Nectar-pollen & July-October \\
\hline Acacia polyacantha & Nectar-pollen & June-September \\
\hline Albizia amara & Nectar-pollen & February-April \\
\hline Albezia chinensis & Nectar-pollen & March-May \\
\hline Albezia lebbeck & Nectar-pollen & March-May \\
\hline Arachis hypogaea & Pollen & September-November \\
\hline Bauhinia purpurea & Pollen & October-May \\
\hline Bauhinia racemosa & Pollen & February- July \\
\hline Cajanus cajan & Nectar & December-March \\
\hline Cassia mimoisoides & Pollen & July-October \\
\hline Cassia Montana & Pollen & February-July \\
\hline Cassia italica & Pollen & May-September \\
\hline Cassia occidentalis & Pollen & March-June \\
\hline Casia tora & Pollen & September-November \\
\hline Caesalpinia pulcherrima & Pollen & March-May \\
\hline Dalbergia sissoo & Pollen & February-April \\
\hline Delonix regia & Nectar-pollen & March-May \\
\hline Erythrina indica & Pollen & February-April \\
\hline Medicago sativa & Nectar-pollen & September-November \\
\hline
\end{tabular}


(Contd. from p. 167)

\begin{tabular}{|c|c|c|}
\hline Family/scientific name of bee & Bee pasturage & Period \\
\hline Millettia peguvensis & Nectar-pollen & January- March \\
\hline Peltaphorum pterocarpum & Nectar-pollen & January- June \\
\hline \multicolumn{3}{|l|}{ Fagaceae } \\
\hline Castanea indica & Pollen-Nectar & May-June \\
\hline Phaseolus vulgaris & Pollen-Nectar & July-September \\
\hline \multicolumn{3}{|l|}{ Flacourtiaceae } \\
\hline Flacourtia jangomas & Nectar & May-June \\
\hline \multicolumn{3}{|l|}{ Gramineae } \\
\hline Zea mays & Pollen & April-August \\
\hline Digitaria sanguinalis & Pollen, & May-July \\
\hline Elusine indica & Pollen & May-July \\
\hline Sorghum vulgare & Pollen & July- August \\
\hline Pennisetum typhoides & Pollen & June-July \\
\hline \multicolumn{3}{|l|}{ Guttiferae } \\
\hline Mesua ferrea & Pollen-Nectar & April-May \\
\hline \multicolumn{3}{|l|}{ Iridaceae } \\
\hline Gladious sp & Pollen-Nectar & May-June \\
\hline \multicolumn{3}{|l|}{ Labiateae } \\
\hline Ocinum sanctum & Pollen-Nectar & August-September \\
\hline Leucas linifolia & Pollen & January-August \\
\hline Leonurus sibiricus & Pollen-Nectar & April-September \\
\hline Plectranthus rugosus & Pollen-Nectar & August-October \\
\hline \multicolumn{3}{|l|}{ Lauraceae } \\
\hline Cinnamomum macrocarpum & Pollen-Nectar & January-July \\
\hline \multicolumn{3}{|l|}{ Leguminosae } \\
\hline Tamarindus indica & Nectar & April-May \\
\hline Pongamia pinnata & Pollen-Nectar & April-May \\
\hline Cajanus cajan & Pollen-Nectar & July-Aug/Dec-Jan \\
\hline Cicer arielunn & Pollen-Nectar & July-Aug/Dec-Jan \\
\hline Pisum sativum & Pollen & November-December \\
\hline Delonix regia & Pollen & May-July \\
\hline Cassia fistula & Pollen-Nectar & April-June \\
\hline Albizia lucida & Pollen-Nectar & June-July \\
\hline Dalbergia sisso & Pollen-Nectar & April-May \\
\hline Glycine $\max$ & Pollen-Nectar & August-September \\
\hline Vigna Mungo & Pollen-Nectar & March-April\&Dec-Jan \\
\hline Vigna radiata & Pollen-Nectar & December-January \\
\hline Cassia sophera & Nectar & March-April \\
\hline Albizia lebbeck & Pollen-Nectar & April-June \\
\hline Dolichos lablab & Pollen-Nectar & October-November \\
\hline Acacia modesta & Pollen & Mwrch-April. \\
\hline Lathyrus odoratus & Nectar-Pollen & January-April \\
\hline Medicago sativa & Pollen-Nectar & March-May \\
\hline Phaseolus mungo & Nectar & August-September \\
\hline Trifolium alexandrinum & Pollen-Nectar & March-May \\
\hline
\end{tabular}


(Contd. from p. 168)

\begin{tabular}{|c|c|c|}
\hline Family/scientific name of bee & Bee pasturage & Period \\
\hline Trigonella foenumgraecum & Nectar & March-April \\
\hline Vigna unguiculata & Nectar-Pollen & May-September \\
\hline Vigna mungo & Nectar & August-Pollen \\
\hline Robinia pseudoacacia & Nectar & May-June \\
\hline \multicolumn{3}{|l|}{ Linaceae } \\
\hline Linun usitatissimum & Pollen & January-February \\
\hline \multicolumn{3}{|l|}{ Liliaceae } \\
\hline Allium cepa & Pollen-Nectar & December-Januäry \\
\hline Allium sativum & Pollen-Nectar & May-June \\
\hline Asparagus officinalis & Pollen-Nectar & May-November \\
\hline Yucca sativa & Pollen-Nectar & May-June \\
\hline \multicolumn{3}{|l|}{ Logaiaceae } \\
\hline Buddleja asiastica & Nectar-Pollen & March-April \\
\hline \multicolumn{3}{|l|}{ Lythraceae } \\
\hline Lagirstroemic indica & Pollen-Nectar & April-May \\
\hline \multicolumn{3}{|l|}{ Maguotiaceae } \\
\hline Michelia champaca & Pollen-Nectar & April-May \\
\hline \multicolumn{3}{|l|}{ Maliaceae } \\
\hline \multicolumn{3}{|l|}{ Magnoliaceae } \\
\hline Magnolia grandiflora & Pollen & August- September \\
\hline \multicolumn{3}{|l|}{ Malvaceae } \\
\hline Hibiscus mutabilis & Pollen-Nectar & February-March \\
\hline Gossypium spp. & Pollen & July-August \\
\hline Abutilon indicum & Pollen-Nectar & January-February \\
\hline Abelmoschus esculentus & Pollen-Nectar & Feb-March/Oct.-Nov \\
\hline Althea officinalis & Pollen-Nectar & April-July \\
\hline Malva sylvestris & Nectar-Pollen & February-March \\
\hline Gossypium hirsutum & Nectar-Pollen & August- October \\
\hline \multicolumn{3}{|l|}{ Masingaceae } \\
\hline Moringa oleifera & Pollen-Nectar & February-March \\
\hline \multicolumn{3}{|l|}{ Meliaceae } \\
\hline Cedrela ciliata & Nectar & May-June \\
\hline Azadirachta indica & Nectar & April-May \\
\hline Melia azedarach & Nectar & March-April \\
\hline Murraya koenigii & Pollen & December-April \\
\hline \multicolumn{3}{|l|}{ Mimosae } \\
\hline Acacia indica & Pollen & July-August \\
\hline Acacia catechu & Pollen & May-July \\
\hline Acacia arabica & Pollne-Nectar & December-April \\
\hline \multicolumn{3}{|l|}{ Moraceae } \\
\hline Artocarpus heterophyllus & Pollen-Nectar & January-February \\
\hline Ficus glomerata & Nectar & January-February \\
\hline Morus alba & Pollen & February-March \\
\hline \multicolumn{3}{|l|}{ Moringaceae } \\
\hline Moringa oleifera & Pollen-Nectar & March-April \\
\hline
\end{tabular}


(Contd. from p. 169)

\begin{tabular}{|c|c|c|}
\hline Family/scientific name of bee & Bee pasturage & Period \\
\hline \multicolumn{3}{|l|}{ Musaceae } \\
\hline Musa paradisiaca & Pollen-Nectar & September- October \\
\hline \multicolumn{3}{|l|}{ Mystaceae } \\
\hline Syzygium jambolanum & Pollen-Nectar & April-May \\
\hline Psidium guajava & Pollen-Nectar & March-April \\
\hline Syzygium cumini & Pollen-Nectar & May-June \\
\hline Callistemon lanceolatus & Pollen-Nectar & March-April \\
\hline Callistemon linearis & Pollen-Nectar & March-April \\
\hline Eucalyptus spp. & Pollen-Nectar & December-January \\
\hline Aegle marmelos & Pollen-Nectar & April-May \\
\hline Syzygium jambos & Pollen & February-March \\
\hline \multicolumn{3}{|l|}{ Nyctaginaceae } \\
\hline Boerhavia repens & Pollen & July-August \\
\hline Bougainvillea spp. & Pollen & April-May \\
\hline \multicolumn{3}{|l|}{ Nymphaceae } \\
\hline Nymphea spp. & Pollen & May-July \\
\hline Nymphaca lotus & Pollen-Nectar & August-September \\
\hline \multicolumn{3}{|l|}{ Oleaceae } \\
\hline Olea europacea & Pollen-Nectar & June-July \\
\hline \multicolumn{3}{|l|}{ Oxalidaceae } \\
\hline Averrhoa carambola & Pollen & September-October \\
\hline Oxalis repens & Nectar & March-April \\
\hline \multicolumn{3}{|l|}{ Palmae } \\
\hline Areca catechu & Pollen-Nectar & July-August \\
\hline Cocos nucifera & Pollen-Nectar & May-June \\
\hline Phoenix sylvestris & Pollen-Nectar & April-May \\
\hline Borassus flabellifer & Nectar & April-May \\
\hline Caryota urens & Pollen-Nectar & September \\
\hline \multicolumn{3}{|l|}{ Paparveraceae } \\
\hline Papaver shoeas & Pollen & February-March \\
\hline $\begin{array}{l}\text { Papaver somniferum } \\
\text { Argemone mexicana }\end{array}$ & Pollen & February-March \\
\hline \multicolumn{3}{|l|}{ Pedaliaceae } \\
\hline Sesamum indicum & Pollen-Nectar & December-January \\
\hline \multicolumn{3}{|l|}{ Poaceae } \\
\hline Cynodon dactylon & Pollen & August-October \\
\hline Zea mays & Pollen & January-December \\
\hline \multicolumn{3}{|l|}{ Polygonaceae } \\
\hline Fagophyrum esculentum & Pollen-Nectar & February-March \\
\hline Antigonum leptopus & Pollen-Nectar & June-November \\
\hline \multicolumn{3}{|l|}{ Polemoniaceae } \\
\hline Phlox drummondii & Nectar & January-February \\
\hline \multicolumn{3}{|l|}{ Portulacaceae } \\
\hline Portulaca grandiflora & Pollen & July-August \\
\hline
\end{tabular}


(Contd. from p. 170)

Family/scientific name of bee Bee pasturage Period

Punicaceae

Punica granatum

Ranunculaceae

Delphinium denudatum

Rananculus bulbosus

Rhamnaceae

Zizyphus mauritiana

Zizyphus oenoplia

Zizyphus jujubea

Rosaceae

Eriobotrya japonica

Fragaria sp.

Prunus persica

P. communis

P. salicina

Pyrus malus

P. pashia

Rosa moschata

Rubus ellipticus

Rosa sp.

Rubiaceae

Mitragyna parvifolia

Hamelia patens

Anthocephalus indicus

Borretria sp.

Coffea arabica

Rutaceae

Citrus limettioides

C. aurantium

C. reticulate

C. grandis

C. aurantifolia

C. sinensis

C. medica

Aegle marmelos

Sapotaceae

Achras sapota

Mimusops elengi

Madhucam indica

Salicaceae

Salix acutifolia

Sapindaceae

Litchi chinensis

Sapindus detergens

Bacdaurea sapida
Pollen

Pollen

Pollen

Pollen-Nectar

Pollen-Nectar

Pollen-Nectar

Pollen-Nectar

Pollen-Nectar

Pollen-Nectar

Pollen-Nectar

Pollen-Nectar

Pollen-Nectar

Pollen-Nectar

Pollen-Nectar

Pollen-Nectar

Pollen-Nectar

Pollen

Pollen

Pollen

Pollen-Nectar

Pollen-Nectar

Pollen-Nectar

Pollen-Nectar

Pollen-Nectar

Pollen-Nectar

Pollen-Nectar

Pollen-Nectar

Pollen-Nectar

Pollen

Nectar

Pollen-Nectar

Pollen-Nectar

Pollen

Pollen-Nectar

Pollen- Nectar

Nectar
March

Mach-April

February-March

June-September

December-January

August-September

January- February

March-April

January-February

February-March

March-April

January- February

March.

march-April

March-April

January-December

January-August

July-November

May-June

Aug-January

March-April

April-May

April- May

May-June

May-June

May-June

April-May

March-April

April-May

March-April

August-October

February-March

February-March

February-March

April- May

February-March 
(Contd. from p. 171)

\begin{tabular}{|c|c|c|}
\hline Family/scientific name of bee & Bee pasturage & Period \\
\hline Sapindus mukorossi & Nectar & March-April \\
\hline \multicolumn{3}{|l|}{ Scrophulariaceae } \\
\hline Antirrhinum majus & Pollen-Nectar & March-April \\
\hline \multicolumn{3}{|l|}{ Simaroubaceae } \\
\hline Ailanthus excelsa & Pollen-Nectar & January-March \\
\hline \multicolumn{3}{|l|}{ Solanaceae } \\
\hline Solanum melongena & Pollen-Nectar & June-September \\
\hline Solanum tuberosum & Pollen-Nectar & June-September \\
\hline Capsicum frutescens & Pollen & July-August \\
\hline Datura stramonium & Pollen & April-September \\
\hline Lycopersicon esculentum & Pollen & May-September \\
\hline Nicotiana plumbagnifocia & Pollen & February-March \\
\hline \multicolumn{3}{|l|}{ Styaceae } \\
\hline Symplocos spicata & Pollen-Nectar & June-July \\
\hline \multicolumn{3}{|l|}{ Tiliaceae } \\
\hline Grewia spp. & Pollen-Nectar & September \\
\hline Corchorus aestuans & Pollen & November-December \\
\hline Corchorus trilocularis & Pollen & August-December \\
\hline \multicolumn{3}{|l|}{ Umbelliferae } \\
\hline Daucus carrota & Pollen-Nectar & February-March \\
\hline Copriandrum sativnum & Pollen-Nectar & February-March \\
\hline Foeniculum vulgare & Pollen-Nectar & April-May \\
\hline \multirow[t]{2}{*}{ Apium graveolens } & Pollen & March-April \\
\hline & Pollen-Nectar & March-April \\
\hline \multicolumn{3}{|l|}{ Urticaceae } \\
\hline Canabis sativa & Pollen & July-August \\
\hline \multicolumn{3}{|l|}{ Verbenaceae } \\
\hline Clerodendrum inerme & Pollen-Nectar & March-April \\
\hline Clerodendrum viscosum & Pollen-Nectar & January- March \\
\hline \multicolumn{3}{|l|}{ Violaceae } \\
\hline Viola odorata & Nectar & Narch-April \\
\hline \multicolumn{3}{|l|}{ Vitaceae } \\
\hline Vitis vinifera & Pollen-Nectar & March-April \\
\hline Vitex negundo & Pollen-Nectar & May-August \\
\hline Lantana camara & Pollen-Nectar & March- September \\
\hline Tectona grandis & Pollen-Nectar & May-June \\
\hline \multicolumn{3}{|l|}{ Zingeberaceae } \\
\hline Ellettaria cardamomum & Nectar & July-November \\
\hline \multicolumn{3}{|l|}{ Zygophyllaceae } \\
\hline Tribulus terrestris & Pollen-Nectar & May- June \\
\hline
\end{tabular}

(Adopted from AICRP on Honey bees and Pollinators)

left for seed production have the blossoms in May-June. Flowers produce lot of concentrated nectar. It is an insect pollinated crop and bees also collect sticky pollen. 


\section{Ornamentals}

There are many ornamentals which are visited by bees for nectar or pollen. But the number of ornamental plants in a locality is too few and as such are of little significance as bee forage. However, these may flower when no other sources are available and prove useful to bees.

A list of some bee forage plants along with their scientific name, family, period of flowering, pollen and nectar source has been included.

\section{REFERENCES}

Abrol, D. P. 2007. Foraging behaviour of Apis mellifera and Apis cerana F. as determined by the energetic of nectar production in different cultivars of Brassica campestris var. toria. Journal of Apicultural Science 51(2): 19-23

Atwal. A. S,. Bains. S. S. and Singh, B. 1970. Bee flora for four species of Apis at Ludhiana. Indian Journal of Entomology 32(4) . 330-34.

Atwal. A. S. and Goyal, N. P. 1974. Apis mellifera turns indifferent to shain (Plectranthlus rugosus). Everyday Science 19(2) : 25-26.

Bahadur, B., Chaturvedi, A. and Swami. N.R. 1986. Nectar types in Indian plants. Proceedings of the Indian Academy of Science (Plt. Sci.) 96(1): 41-48.

Bhadur, B., Chaturvedi, A. and Swami, N. R. 1986. Nectar types in Indian Plants. Proceedings Plant Science 96: 41-48.

Chandran, K. and Shah, F. A. 1974. Beekeeping in Kodai hills (Tamil Nadu). Indian Bee Journal 36 (1-4) : 1-8.

Chaturvedi, P. L. 1969. A tip for migratory beekeepers of Kumao region. Indian Bee Journal 31: 48-51.

Chaubal, P. O. and Deodikar, G. B. 1965. Morphological characterisation of pollen grains of some major honey yielding plants of the Western Ghats (India). Indian Bee Journal 27(1): 1-28.

Chaubal, P. O. and Kotmire, S. Y. 1980. Floral calendar of bees forage plants of Sagarmal Indian Bee Journal 42(3): 65-68.

Chaudhary, R. K. 1977. Bee forage in Punjab plains (India). Pathankot and adjacent viliages. Indian Bee Journal 39(1-4): 5-20.

Deodikar, G. B., Thakur, C. V. and Phadke, R.P. 1957. High nectar concentration in floral nectariies of silver oak, Grevillea robusta. Indian Bee Journal 19(7-8): 84: 85.

Deodikar, I. B. and Thakar, C. V. 1953. A pollen study of major honey yielding plants of Mahabaleshwar hills. Poona village industries committee, 8 pp.

Devadason, A. 1971. Migratory beekeeping in Kerala. Indian Bee Journal 33(3-4): 35-38.

Devadason, A. 1972. Rubber plantation and beekeeping. Indian Bee Journal 34(1-2): 3839.

Gupta, J. K., Kumar, J. and Mishra, R. C. 1984. Nectar sugar production and honeybee foraging activity in different cultivars of cauliflower, Brassica oleracea var. botrytis. Indian Bee Journal 47: 21-22.

Gupta, J. K. and Thakur, R.K. 1987. Nectar sugar production and flower visitors of the bramble, Rubus elliplicus Smith (Rosaceae) at Solan, India. Apidologie. 18 : 223-30.

Gupta, J. K., Kumar, J. and Mishra, R. C. 1984. Nectar sugar production and honeybee foraging activity in different cultivars of cauliflower, Brassica oleracea var. botrytis. Ind. Bee J. 47: 21-22.

Gupta, J. K., Kumar, J. and Mishra, R. C. 1984. Nectar sugar production and honey bee foraging activity in different cultivars of cauliflower, Brassica oleracea var. botrytis. Indian Bee Journal 47: 21-22.

Gupta, J. K., Mishra, R. C. and Kumar, J. 1984. Plectranthus as forage for Apis cerana 
indica F., and Apis mellifera L Apidologie15(1) : 75-82.

Kapil, R. P. and Brar, H. S. 1971. Foraging behaviour of Apis florea Fab. in relation to Brassica campestris var. toria. Proc. $23^{\text {rd }}$ Congr. Apic., Moscow: 335-39.

Kohli, N. 1958/59. Bee flora of Northern India. Indian Bee Journal 20: 113-18,

Krishnaswamy, S.V. 1970. Soapnut trees: a nectar source. Indian Bee Journal 32(3-4) : 83.

Kumar, N. and Singh, R. 2005. Relative abundance of honeybees and nectar sugar concentration in linseed flower (Linum usitatissimum). Environmental \& Economics 23(2): 374-80.

Kumar, N. and Singh, R. 2005. Relative abundance of honeybees and nectar sugar concentration in niger flower (Guizotia abyssinica). Annals of Plant Soil Research 7(2): 149-53.

Kumar, N. and Singh, R. 2008. Relative abundance of honeybee foragers visiting safflower (Carthamus tinctorius L.) and nectar sugar concentration in bloom. Pest management and Economic Zoology 16(2): 135-41.

Mathew, T. 1975. The rubber tree as a source of honey in Kerala, India. Glean. Bee cult. 103(6): 190.

Mishra, R. C. and Sharma, S. K. 1989. Growth regulators effect nectar pollen production and insect foraging in Brassica seed crop. Current Science 57: 1297-99.

Mishra, R. C., Gupta, J. K. and Kumar, J. 1987. Nectar secretion, amount and type of nectar sugars, insect foraging in Woodfordia floribunda. Apidologie. 18(2): 173-78.

Mishra, R.C. Gupta, J. K. and Kumar, J. 1985. Nectar sugar production in different cultivars of peach. Prunus persica L. Indian Bee Journal 47: 37-38.

Mishra, R. C., Gupta, J. K. and Kumar, J. 1987. Nectar secretion, amount and type of nectar sugars, insect foraging in brassica seed crop. Current Science 57: 1297-99.

Mishra, R. C. 1995. Honey bees and their management in India. ICAR, New Delhi.

Naim, N. and Phadke, R. P. 1976. Bee flora and seasonal activity of Apis cerana indica at Pusa (Bihar). Indian Bee Journal 38(1-4): 13 -19

Nair, A. G. R., Nararanjan, S. and Subramanian, S. S. 1962. Chemical compositon of nectar in Thunbergia grandiflora. Current Science 33(13): 401.

Nair, K. S. 1983. Evaluation of importance of litchi as a nectar source. Indian Bee Journal 45(4): 108-09.

Nair, P. K. K and Singh, K. N. 1974. A study of two honey plants, Antigonun leptopus Hook and Moringa pterigosperma Gaertn. Indian Journal of Horticultural 31(4): 375 79.

Nair. K. S. 1981. Beekeepers of Muzaffarpur (Bihar). Indian Bee Journal 43: 97-100.

Nairn, M. and Phadke, K.G. 1976. Bee flora and seasonal activity of Apis cerana indica at Pusa (Bihar). Indian Bee Journal 38(1-4): 13-19.

Narayana, N. 1970. Studies on Indian honey bees waxes, Poona, India. Proceeders of Research Institution: 13.

Phadke, R.P. 1964. Nectar concentration in Carvia callosa Bremk. Indian Bee Journal 26(20): 22-25.

Phadke, R. P., Nair, K. S. and Namdekar, K. U. 1970. Studies on Indian honeys. IV. Minor constituents. Indian Bee Journal 32(112) : 28-35.

Rahman, A. 1990. Bee forage plants of Jorhat (Assam, India). Indian Bee Journal 52(14): 47-50

Rajebhonsale, M. R. and Kapadnis, D. G. 1970. Viscosity of honey under different ambient conditions. Indian Bee Journal 32(3-4) : 58-61.

Ramesh, B. 1980. A visit to the cultivated forest area of Peepalpada, U.P. Indian Bee Journal 43(3). 86.

Rao, G. M. and Lazar, M. 1980. Studies on the behaviour and pollination on onion (Allium 
cepa L.) Proc. $2^{\text {nd }}$ Int. Conf. Apic Trop. Climates, New Delhi. 580-89.

Reddi, C. S. Reddi, E. U. B. and Reddi, N. S. 1980. Floral rewards and honeybee visitation rates in soapnut tree. Proc. $2^{\text {nd }}$ Int. Conf Apic. Trop. Climates, New Delhi 1980: 60002.

Reddy, M. C. M. and Gupta J. K. 1987. Wild cherry, Prunus puddum Roxb., A honey plant. Social Forestry for Rural Development (ed. P.K. Khosla and R.K. Kohli), I.S.T.S: 207-14.

Saraf, S. K. 1972. Bee flora in Kashmir. Indian Bee Journal 34(112) : 1-10.

Satyanarayana, I. 1975. Sugar concentration in nectar from Syzygium cuminis Skeels. Indian Bee Journal 37(14) : 21.24.

Sharma, P. L. 1958. Sugar concentration of nectar of some Punjab honey plants. Indian Bee Journal 20(7): 81-91.

Sihag, R. C. and Kapil. R. P. 1983. Foraging strategies of honeybees as determined by quality and quantity of nectar. Proc. $5^{\text {th }}$ International Symposium Pollen, Versailles: 51-59.

Singh, G. and Singb G. 1971. Plectranthus rugosus Wall; the major honey plant of Kashmir Valley. Indian Bee Journal 33(3-4): 58-59.

Singh, O. S. and Sharma, V. K. 1972. Nature of sugar secretion in the nectarines of balsam (Impatiens balsamina L.) Indian Bee Journal 34(1/2): 32-33.

Singh, R. C. and Kapil, R. P. 1983. Foraging strategies of honeybees as determined by quality and quantity of nectar. Proc. $5^{\text {th }}$ International Symposium Pollen, Versailles. 51-59.

Singh, S. 1962. Beekeeping in India. ICAR, New Delhi.

Singh, S. 1948. Some important boney plants of the Punjab (India). Rep. Iowa State Apiar.: 34-42.

Subramaniam, K. 1979. The role of Forest Department in developing beekeeping in Western Ghat areas of Maharashtra. Indian Bee Journal 41(3-4): 91-93.

Wakhle, D.M., Nair, K.S. and Ramesh,-B. 1981. Sugar composition in nectars of certain plants. Indian Bee Journal 43(1): 6-8. 


\title{
13 \\ Bee Pollination
}

\begin{abstract}
$P_{i}$ LANTS reproduce asexually or sexually. For sexual reproduction, pollination is required and pollination is the transfer of pollen from anther to the stigma of flowering plant. There are two major types of pollination self and cross pollination. In self pollination, there is transfer of pollen from anther to stigma of the same plant or another plant with similar genetic makeup. The flowers may be perfect that have both male and female parts in the same flower or imperfect that produce only pollen or embryo sacs. In some cases, the flowers may appear to be perfect but have one sterile sex. Imperfect flowers can be present on the same plant or one plant may have only pollen or only embryo sacs that is, imperfect flowers of two sexes are borne on separate plants. In this process, no external agents are required. Cross pollination is the transfer of pollen from the anther to the stigma of another plant with different genetic make up. Cross pollination is always brought about by some external agents. Such agents are insects, winds, water and gravity. Insects pollinated crops are known as entomophilous and bees are dominant in entomophily ecosystem. Bees are considered as effective pollinators of many of our cultivated or wild crop plants. In this process, there is mutual benefit of enhancing crop production through pollination and honey reward to the beekeepers.
\end{abstract}

\section{Pollination and fertilization}

There are two different types of pollination such as self pollination and cross pollination which are discussed below. The Fig 13.1 is a floral diagram showing different parts of flower.

Self-pollination: Transfer of pollen from anther to stigma of the same plant or to another plant with similar genetic make up. Two plants from a single clone or plants a completely 'homozygous' variety have identical genetic constitution. A completely homozygous plant is one whose sex cells have identical sets of parental chromosomes when they undergo meiosis, the daughter nuclei are indentical and in each plants, offsprings are genetically similar if self pollination takes place.

Auto-self pollination: It is self pollination where no external agent is involved. In the transfer of pollen. This is usually brought about by growth and movement of flower parts. Auto self pollination can occur within the same flower or betwwen adjacent flower on the same plant (geitongamy) or on ifferent plants (xenogamy).

Indirect self pollination: Self pollination affected by some external agent is called indirect self pollination. This type of pollination may again be autogamy or allogamy. 
Inheritable characteristics both the parent through egg and sperm cells combined in the developing embryo. No new genetic elements are incorporated in the offspring if the parents are the same .but due to independent segregation during the reduction, there can be

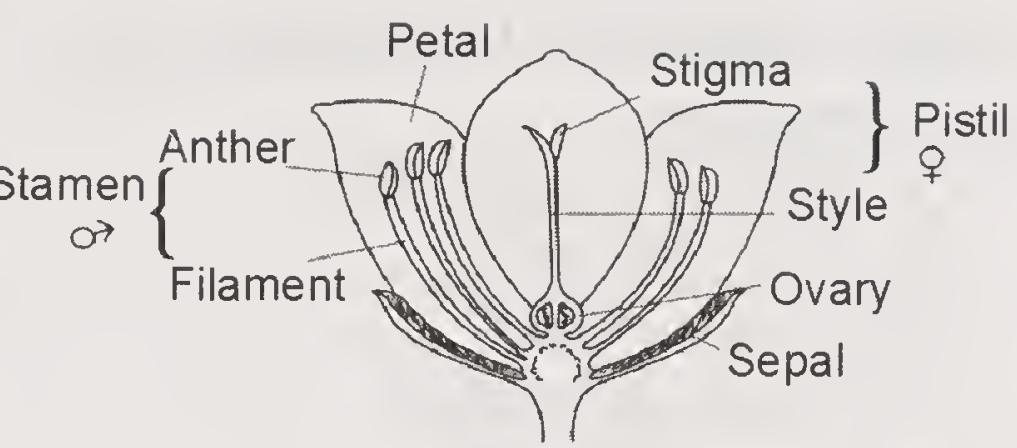

Fig. 13.1. Floral diagram. recombination in different pattern and resulting offsprings from self fertilization may differ from their parent.

Cross pollination: Cross pollination is the transfer of pollen from the anther of one plant to the stigma of another with different genetic make up. Cross pollination is always brought about by some external agents, the pollen transfer can be between two plants of a single variety (intra-varietal cross pollination) or between separate species or genera (interspecific or intergeneric cross pollination).

Pollen, when transferred to stigma, germinates and grows as a pollen tube through the style to the embryo sac. It discharges two sperm nuclei in the embryo sac; one unites with egg cell and accomplished fertilization and the other unites with the polar bodies to form the endosperm nucleus. From the latter develops the seed endosperm and it dies out early in the development of young seedling.

Fertilization is also generally essential for the development of the fruit around the seeds, though parthenocarpic development does take place in some instance where ovary enlarges in a fruit without stimulation. Developing seeds in the ovary are understood to provide stimulus for fruit development in adjacent area. Inadequate pollination in plants with more than one ovule results in lopsided development of fruits.

Cross pollination on the other hand can lead to complete pollination and fertilization. It also induces hybrid vigor where the plants are more vigorous than the parents in terms of size, quality, maturity, susceptibility to diseases, etc. Cross pollination increases the range of variations in the population and unfavourable recessive hereditary features remain ineffective. The plants propagated asexually can survive for a long time but continuous asexual reproduction result in fixed genetic structure. Such plants are incapable of adjusting to change. Many species which are self pollinated will perish some plant species are completely dependent on cross pollination for reproduction.

\section{Pollinating agents}

The process of pollination requires pollinators as agents that carry or move the pollen grains from the anther to the receptive part of the stigma. Faegri and Van der Piji (1966), in their classic book on pollination ecology, defined two major types of pollen dispersal: Biotic pollination in which the pollen dispersal agent is an animal and abiotic pollination where pollen is dispersed by an inanimate physical agent, such as wind or water. The various flower traits that attract different pollinators are known as pollination syndromes. Methods of pollination, with common pollinators or plants, are: 
Biotic pollination (Armstrong, 1979)

Invertebrates

- Beetles : Cantharophily

- Flies : Myophily

- Hymenopterans

- Wasps : Sphecophily

- Bees : Melittophily

- Ants : Myrmecophily

- Lepidopterans

- Butterflies : Psychophily

- Moths : Phalaenophily

\section{Vertebrates}

- Birds : Ornithophily

- Mammals : Therophily

- Marsupials : Metatherophily

- Placentals : Eutherophily

- Bats : Chiropterophily

- Rodents : Sminthophily

Abiotic pollination (Ackerman, 1999)

- Self- pollination : Autogamy + cleistogamy

- Wind- pollination : Anemophily

- Water-pollination : Hyphydrophily

- Gravity pollination

In this chapter, pollination by domesticated honeybees has been exclusively discussed.

\section{Honeybee pollination}

Honeybees (Apis spp.) are the most valuable pollinators of economic crops. The bee population can be utilized and colonies can be managed to achieve the optimum pollination. Honeybees possess some qualities which are in common with other bees. They have bodies covered with branches hairs. Both adults and immature stages depend on nectar and pollen for food and they are not injurious to plants with no public health menace. True honeybees store nectar and pollen for colony requirement and, therefore, are superior pollinators as compared to wild bees and other insect species which forage only for their own requirement. Honeybees also need to be active in winter and this makes them to visit more flowers than the species which hibernate during winter. Honeybees can warm up and are capable of foraging at lower temperature. The body size and proboscis length of honeybees suits them to forage many varied types of flowers than other insect pollinators. The host range of bees is very wide and thus can serve as pollinator of many types of crops. Honeybees are highly evolved social insects. Their foraging behaviour patterns are highly favourable to qualify them as the most efficient pollinators of crops.

Foraging behaviour of honeybees: Honeybees have highly organized field 
activities. Knowledge of the behaviour pattern can help the beekeepers to exploit bees for better pollination services and honey production.

Bees fly in the vicinity of the hive in search of food sources and these are the worker bees which have completed their phase of hive duties. This scouting is irrespective of communication by foragers. After discovering a source, the workers gather a good load of nectar and/or pollen, return to the hive and communicate the information to field bees in the hive. The field bees then decide upon the suitability of alternate sources searched out by the scout bees. Activities of field bees are greatly influenced by environmental factors. Foraging is reduced at lower temperatures and water foraging increased above $34^{\circ} \mathrm{C}$. Rainfall also adversely affects foraging activities. Bees avoid foraging when the wind is high. Depending upon the availability and access. The bee foragers collect nectar or pollen. Nectar gatherers are not always exclusive but may also collect pollen along with nectar. The nectar gatherers though spend more time foraging on a flower but they may reach the nectarines by side working and may not come in contact with reproductive parts of the flowers. Even top workers can specialize to collect nectar through the reproductive column without effecting pollination. Nectar gatherers, pollen gatherers work on the flowers more thoroughly and are established to be the better pollinators. Even pollen collectors take some nectar and many a times there is overlapping of rewards collection. The proportions of these reward collectors are believed to depend upon the needs of the colony, though availability of rewards is important.

Communication and memory: Bees on the combs perceive the odour of floral rewards brought in by fellow foragers or scouts. Coupled with odour perception they also communicate the direction and distance of source by performing signal dances. Because of this efficient communication, the bees cater on all potential sources within a radius of 2-3 km. They keep on changing to new sources with changes in availability and preferences. The information is rapidly spread in the hive. The richer sources are informed through more lively and vigorous dance and by more number of returning individuals. As a result better sources have more abundant bees than poor and distant sources. This competition is an important aspect of successful pollination. Bees have memory and they continue to visit the source as long as they don't find a better one. They also restrict their successive visits to restricted area. This behavivour varies with crop and cultivars of crop. The knowledge of this behavior is essential for hybrid seed production. Nectar and pollen rewards are available during particular hours of the day and bees memorize to visit the source during those hours. They shift to other sources during other times of the day. Breeding bees with preferences for specific crop has been possible in case of alfalfa and other crops.

Flight range and foraging rate: Honeybees can have extreme foraging range up to 7-10 km but economic foraging range is up to $2 \mathrm{~km}$ for Apis mellifera and 1 $\mathrm{km}$ for Apis cerana. Within these ranges, the richness of source is more important than distance from the hive but young foragers forage close to the hive. Energy balances in nectar collection are more favourable with decrease in distance. Nectar sources are easily located by bees and more visits are made by them resulting in better pollination of the crop. Benefit is further achieved in pollination by more 
number of trips made by each forager per day.

Number of flowers visited per unit time depends upon the abundance of pollen and nectar per flower. The foraging rate is also affected by environmental condition, that is, at lower temperatures bees may need time to raise their thoracic temperature in between the time spent to collect nectar or pollen from each of new flowers. To collect a load, a bee may visit few (25) to many (400) flowers. Bees often return to the hive incidental pollen collection in which case to the load is not full.

There are many mechanisms in plants which favour cross pollination and cross fertization. Imperfect flower, dioecious plants and dichogamy where anthers mature before stigma or stigma matures before anther are the conditions which favour cross pollination. Placement of reproductive parts is sometimes against self pollination in some crop varieties, the pollen of same variety is incapable of fertilization the ovary and pollen from other pollinizer variety should be transferred. Another condition may exist, where foreign pollen grow faster as a pollen tube fertilizes the egg and favours cross fertilization in perfect and clestogamous flower. The self pollination is favoured in self pollinated plants the anthers and stigma mature at the same time. In these plants, the male and female parts readily come in contact and selfing is affected.

Pollination requirements by bees vary with crop to crop. Although qualitative information on pollination has been available from early period but quantitative approach is of recent one. Free (1972) attempted to provide comprehensive data on the effect of insect pollination in several crops. Ample information has been generated in temperate regions but the study of pollination ecology and its requirements in India of different crops has recently been taken up. More than $50 \%$ of existing sexually propagated plants are dependent upon insects for adequate pollination. The importance of cross pollination was recognized long before its biological significance was understood. The concept of cross pollination was made clear by N.Grew in 1682 stating that pollen must reach the stigma before seeds develop and it was realized in 1760's that bees and other insects could transfer pollen. Thomas Andrew Wright (1799) showed the value of cross pollination and finally it was Charles Darwin (1859) who proved and popularized the importance of pollination in the maintenance of vigor and perpetuation of the plant species. Honeybees play pivotal role in increasing the yield of many economic crops through pollination. A brief account is given in this chapter on effect of bee pollination of different group of crops. Migratory beekeeping or managed pollination would help in greater extent for increasing the crop yield.

\section{Management of honeybees for pollination}

Due to their morphological characters, social behavior and management practice followed by our farmers, honeybees have become the most important and only managed pollinators of the crops. The uncertainty of populations and the difficulty in maintaining and using solitary bees, bumblebees and the other pollinators places all the onus of planned pollination on honeybees alone. The following points are most important to consider a colony for foraging and getting desired pollination outputs.

1. Foraging strength of colonies: In order to get maximum honey and 
pollination benefits from a colony, it must be full-sized and populous not a growing one - as the brood bee ratio diminishes in it, so that a greater proportion of bees is available for foraging. Methenson (1991) suggested that a colony used for pollination sould contain at least 7 frames with $60 \%$ brood (at least $25 \%$ in egg or larval stage) in the brood chamber, a young prolific queen, at least 12 frames covered with bees, sufficient empty combs for expansion and enough honey and pollen stores to sustain it. Separate colony strength standards were also recommended for field colony and orchard colony by Roubik (1995)

2. Pollination requirement and concentration of colonies: The number of colonies needed per hectare of crop will depend on local conditions including the number of honeybees and other pollinators already present, the size of the crop and the presence of competing crops of the same and different species like weed species. In Southwestern Haryana, the population of natural pollinators especially the solitary bees is so high that it suffices to great extent the pollination requirement of mustard crop. There is a difference in the number of colonies that could be profitably maintained for honey and the numbers necessary for pollination in the crop. In general, 3-5 colonies/ hectare placed equidistant from each other within the crop are recommended. This number of colonies can be handled easily.

3. Foraging efficiency of colonies and their distance from the crop: Honey bees are capable of foraging considerable distance from their hives but their efficiency is indirectly proportional to the distance covered. Generally, foraging range is $2.5 \mathrm{~km}$ for Apis mellifera, $1.5 \mathrm{~km}$ for Apis cerana, $3 \mathrm{~km}$ for A. dorsata and $1 \mathrm{~km}$ for $A$. florea. Apis mellifera have been observed to forage up to $11.3 \mathrm{~km}$ but foragers were concentrated within $0.6 \mathrm{~km}$ of their hives. The yields of the crops are more when the colonies are kept up to a distance of $0.5 \mathrm{~km}$ and decrease to almost half at a distance of $1.0 \mathrm{~km}$ and these impacts are even greater in poor season. The number of foraging bees on the crop diminishes with increase in the distance from the hive. In general, placing the hive within $0.5 \mathrm{~km}$ radius increase the crop pollination. Requirement of nest mates to the nearby sites is also greater as the information is more easily communicated. Colonies placed near crops collect more pollen and nectar, spend less time collecting load of pollen and nectar, the number of flights increase for both types with proximity to the floral source.

4. Moving colonies to crops: It is advisable to take as short migration as possible because of risks involved in long distance migration which result in killing of brood and low foraging efficiency. The settling and arrangement of colonies after migration is very important. Formal arrangement with identical hives should be avoided as it may result in drifting of foragers especially during their first flight which may result in weakening of some colonies and strengthening of others, lowering the mean foraging potential, honey production and pollination efficiency. The colonies should be arranged irregularly in different directions and spacing. They should be put near landmarks and windbreaks and different coloured boards may be placed about the entrance. 
5. Time for moving colonies on crops: The factor of food stores of a colony plays important role in determining the species as the species that did before moving them. But the predominance of one species at the new site results in changing their foraging behaviour. Therefore, colonies should be moved to the crop needing pollination only when it is sufficiently flowering. The colonies should be moved to a target crop when bloom is between $5-10 \%$ to influence the number of foragers that are turn around on it. Care must be taken to avoid the blooming of too many flowers as an important part of the crop may fail to be pollinated. It is practical to move a few colonies to the crop at the beginning of flowering and the rest when more flowers have bloomed.

\section{Pollination research in India}

Oil-seed crops: Honeybees are major pollinators of mustard crop. Insect foragers on mustard and rape seed were recorded by Bisht et al. (1980) and Sihag (1986). Proportions of Apis spp. visitors to mustard bloom were given by Naim and Phadke (1976) and observed that Apis cerana had high degree of fidelity. Bisht et al. (1980) found that flower of rape seed visited by Apis spp. had higher pod set, more number of seeds per pod and weight of seeds was also higher in comparison to those where no pollinators visited. Experiments on crop yields carried out in open and caged plots revealed that in self -incompatible crops: mean pod (siliqua) length, number of seeds set per pod, weight of seed per plant and weight of seeds per hectare were significantly greater in open plots. Singh et al. (1983) on their studies on the effect of bee pollination on the yield of rapeseed observed that yield from bee pollinated plot was significantly higher than that of the plot having without pollinators. Ahmed and Rahman (2002) proved that there was significant yield increase in Brssica campestris by managed Apis cerana pollination having $127.27 \%$ increase with 5 Apis cerana colonies (Fig. 13.2b) per hectare.

Sunflower (Helianthus annuus) is an important oil seed crops popularly grown in tropics. The flower contains 31-42\% glucose, 34-41\% fructose and nectar, sugar concentration is $33-60 \%$ varying with cultivars. Previously hand dusting was practiced for pollination but introducing bee colonies to sunflower fields increased seed setting by $27 \%$ and much higher seed yields and weights from plots with Apis cerana colonies than from plots without bees were reported by Deodikar et al. (1976). The seed yield in bee, open and hand pollinated plots was 203.2, 188.6 and $131.0 \%$ higher over the self pollinated plots. The increased in seed yield in open pollinated plots was mainly due to pollination by honey bees. Bee pollinated plots also exhibited a uniform seed setting resulting in an early harvest of the crop. Sharma and Singh (2000) studied the pollination efficiency of Apis dorsata and Apis mellifera on sunflower and recorded the abundance of $A$. dorsata $(7.09$ bees/head/ $5 \mathrm{~min}$ ) while $A$. mellifera was 6.05 bees and the pollination index of $A$. dorsata was higher $(162,247)$ as compared to $A$. mellifera $(124,066)$. Singh et al. (2001) reported that open pollination with natural honey bee population resulted not only in higher hybrid seed yield $(81.6 \%)$ of sunflower but also better its quality than the hybrid seed obtained by other mode of pollination such as hand pollination $(66.8 \%)$. 
Mishra and Rahman (2013) reported that manged pollination by Apis cerana@5 colony/ha gave the optimum yield of $7.61 \mathrm{~g} / \mathrm{ha}$ which is $48.63 \%$ higher than without bee and $25.71 \%$ over open pollinaton. The oil content also increased in the honey bee mediated pollination. Patnaik et. al (2004) in their investigation on effect of bee pollination on the yield of sesamum conducted at OUAT, Bhubaneshwar reported that honeybee pollination (Apis cerana and A. mellifera) gave $15.5 \%$ higher yield as compared to caged plots

Niger (Guizotia abyssinica) is coming up as an important oil seed crop. The pollination work by Bhambure (1958) revealed that the number of bees increased the seed yield under screen cages. Rahman and Rahman (1993) in his studies on role of honey bee, $A$. cerana in pollination and seed set of niger reported that there was $120.21 \%$ increase of seed yield in bee pollinated

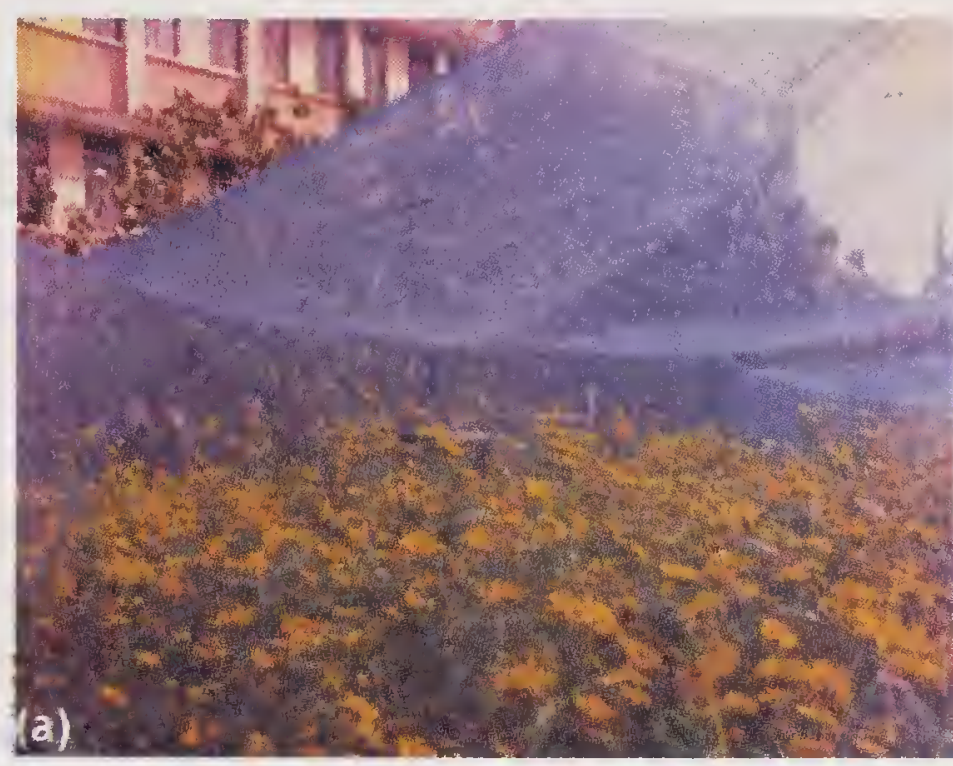

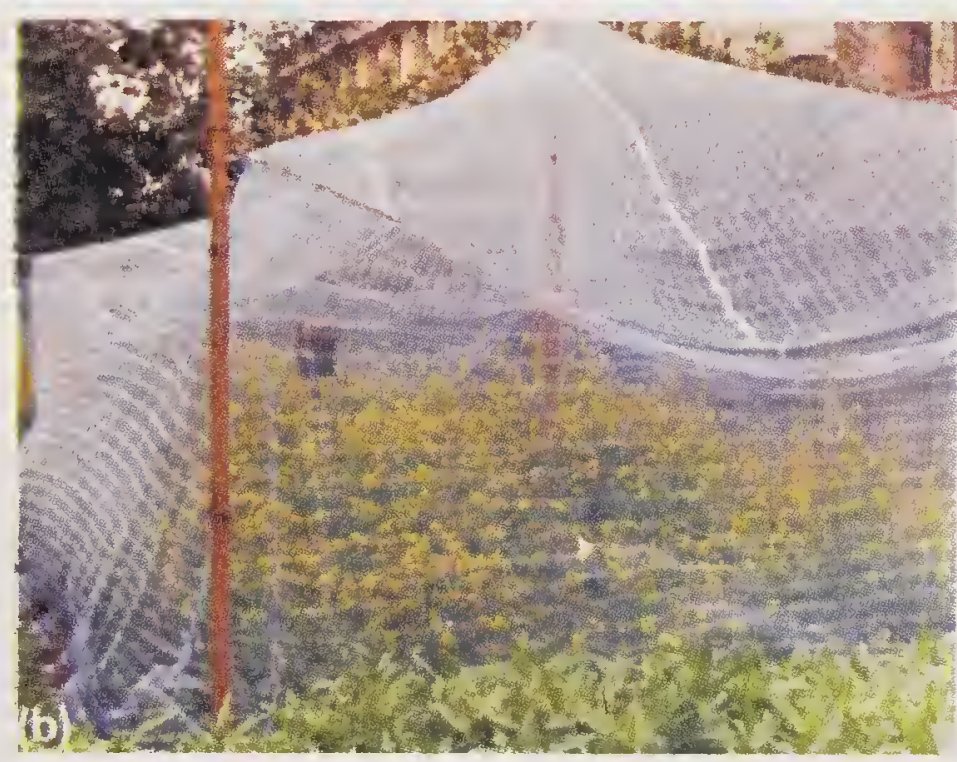

Fig. 13.2 (a) Honeybee pollination experiment on Niger; (b) Honeybee pollination experiment on rapeseed. plots and 5 A.cerana colonies/ha were recommended (Fig. 13.2a).

Panda et al. (1988) established the role of honeybees in increase of yield and oil content of mustard, seasmum, niger and sunflower.

Singh et al. (2004) studied the effect of bee pollination (Apis mellifera, A. dorsata, and A. florea) on yield of Brassica campestris var. toria and reported that the mean number of siliqua/plant, number of seeds/siliqua, 1,000 seed weight and seed yield were $88.3,5.11,3.13,3117.52$ and 11.74 , respectively, in open pollinated having natural population of bees over self pollination. Singh and Chaudary (2005) investigated the effect of honeybee pollination on yield of mustard, Brassica juncea and recorded that Apis mellifera dominated (63.97\%) over other insect pollinators. Kumar et al. (2012) while comparing the Apis mellifera visits on Brassica juncea and $B$. napus recorded that number of seeds per pod (4.14) and seed weight (77.47 mg) were the highest in B. napus flowers having 5 visits of $A$. mellifera whereas number of seeds per pod (3.97) and seed weight per pod (130.14 mg) in $B$. juncea flowers in the same number of visit.

\section{Fruit and nuts}

Most of fruits and nut crops are pollinated by bees. apple, pear, plum, peach, apricot, cherry, almond and their closely allied wild species are included in pome and stone fruit category. They flower from February to April and bees gather both nectar and pollen. Generally two bee colonies (Apis mellifera) per hectare are 
recommended for apple but "Delicious" cultivars prefer side working by bees and thus require more than two colonies per hectare for effective pollination. Pear (Pyrus spp.) is similar to apple in pollination requirement. Most varieties of peach (Prunus spp.) are self fertile but peach flowers are profusely visited by Apis spp. and fruit set is higher in managed pollination. Honeybees are main pollinators of plum (Prunus spp.) and greatly contributed in fruit set. Sharma et al. (2000) revealed that Apis cerana was more active than Apis mellifera in apple bloom. The placement of bee colonies in apple and pear orchard has a significant effect on fruit set and yield of these fruit crops. Apis cerana is more reliable pollinator of apple crop particularly under adverse climatic condition. Sharma et al. (2012) while studying impact of honey bee pollination on apple in Uttarakhand reported that the fruit setting was significantly higher in orchard having bee colonies (Apis cerana) over dependent on natural pollination.

Litchi is a popular fruit plants in sub Himalayan region and is known for its expensive fruit. It blooms in FebruaryMarch and is a rich source of nectar to bees (Naim and Phadke, 1976). Wind pollination does occur but fruit set is higher by insect pollination and little or no fruit set is obtained under selfing. Honeybees, stingless bees comprise more than $90 \%$ of the flower visitors. Mahanta and Rahman (1997) reported that 5 standard Apis cerana colonies give optimum yield of litchi with $123.97 \%$ increase in yield against caged condition (Fig. 13.3a). Kumar et al. (2002) recorded the per cent increase in yield of litchi due to bee pollination was 324.10 over self pollination (S.P) and that of $234.4 \%$ increase in open over self pollination; moreover physiological characters also found to be superior in bee pollination treatment.

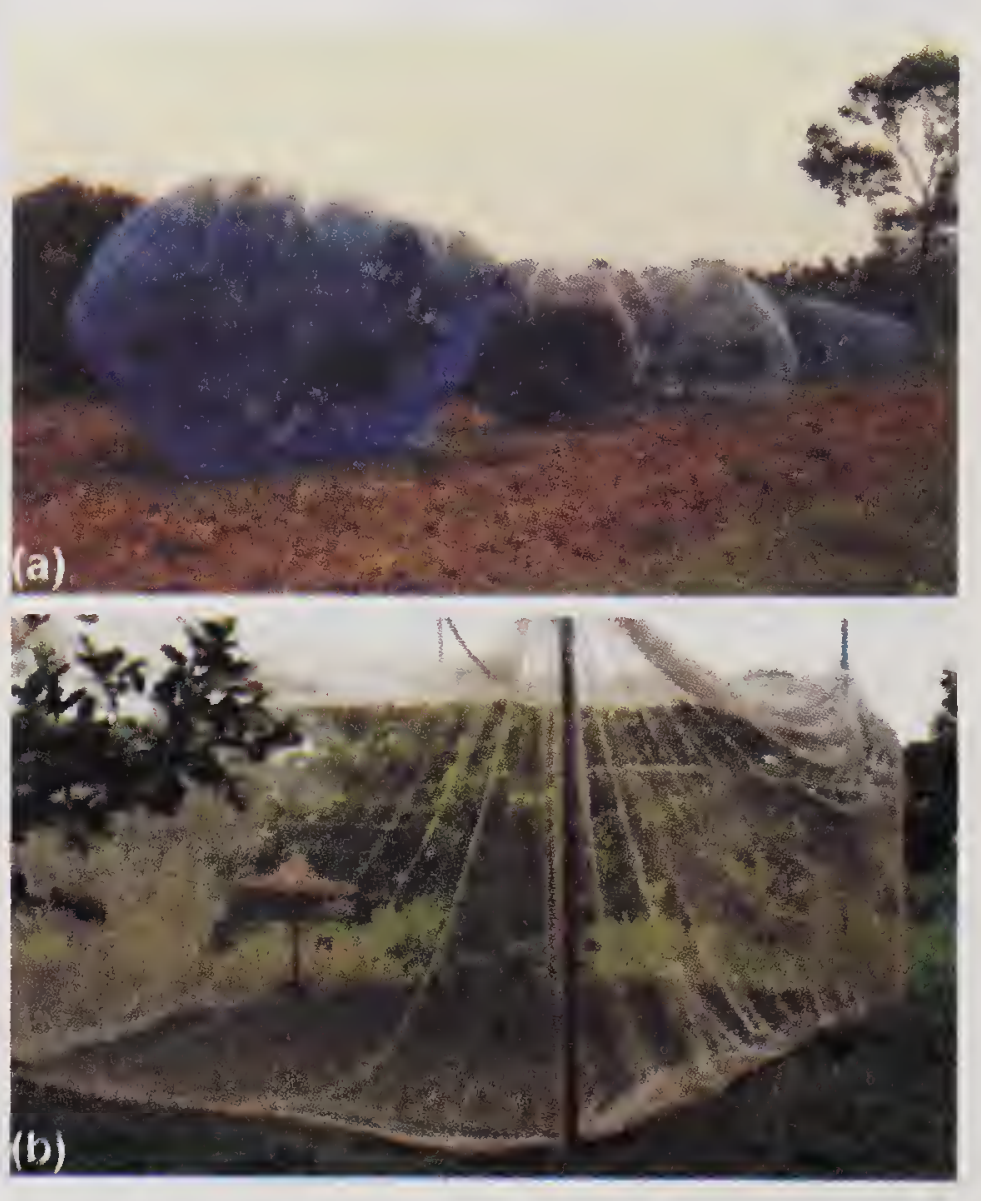

Fig. 13.3 (a) Honeybee pollination experiment on litchi; (b) Pollination experiment on guava. Kumar and Singh (2008) reported that per cent fruit set of litchi was the highest in Apis mellifera pollination over self pollination, the yield was maximum (112.34 $\mathrm{q} / \mathrm{ha}$ ) in bee pollination over self pollination (27.27 q/ha). Rai and Srivastav (2012) determined the impact of bee pollination on yield of litchi and recorded the yield per tree was significantly higher in cage tree (with Apis mellifera boxes) as compared to open tree. The fruit size ( $3.42 \mathrm{~cm}$ length, $3.02 \mathrm{~cm}$ width), fruit weight $(21.5 \mathrm{~g})$ and TSS $(21.9 \mathrm{~g})$ were found to be higher in caged trees (A. mellifera) over open trees.

Citrus species and varieties greatly vary in their pollination needs. There can be parthenocarpic fruit development on selfing but in some there is self sterility. Sweet lime, mandarin oranges are generally benefited from cross pollination. Bee pollination requirement for Asom lemon (Citrus limon) was studied by 
Rahman et al. (2005) and reported that 4 Apis cerana colonies require for optimum yield and $52.2 \%$ yield increase was recorded. Tanuja et al. (2012) in a study on effect of insect pollination (bees) on fruit set of citrus recorded that the bagging had significant effect on fruit setting as the per cent fruit setting was higher (8.4$12 \%$ ) in bagged trees over unbagged.

Jujube (Ziziphus spp.) flowers are foraged by many insects. All Apis spp. more particularly Apis dorsata, Apis florea are major visitors of the fruit plant. Mango (Mangifera indica) bloom is visited by bees. It is reported that honeydew secretions in mango flower attract bees for its nectar. Cashew, cardamom and rubber exudates are foraged by honeybees. Guava is subtropical fruit crop grown in India and is exclusively required for bee pollination and 5 Apis cerana colonies required for optimum yield.

\section{Vegetable crops}

Flowers of many vegetable crops are rich source of pollen and nectar to bees. Most of the vegetable crops are meant for table purpose and are not allowed to flower. But in almost all the cases the propagation is by seed and insect pollination is important for seed production. Cole crops are cross pollinated to the extent of 90-95\%. Apis cerana is the major insect pollinator of cauliflower seed crop. Open pollination significantly increased seed set, seed weight and yield over exclusion of insect pollinators (Gupta and Sharma, 1996) Apis mellifera and A. cerana are the main visitors of carrot and coriander inflorescence. In intensive bee pollination under caged condition increased seed set by $59-70 \%$ and seed yield by 59.9 73.6\% (Jhajj et al., 1996). All the Apis spp. are foragers of radish. Brar et al. (2010) recorded the seed yield increase of radish was $84.5 \%$ in bee pollinated over pollination exclusion (22.49\%).

Brinjal (Solanum melongena), tomato (Lycopersicum esculatum) and pepper rarely require bee pollination. However, bee visitors in okra improve the quality and yield of the crop (Mishra et al., 1987). Honeybees are most important foragers of onion flowers and benefits derived from Apis cerana pollination was threefold (Kumar et al., 1989). Sharma et al. (2001) while studying the pollination efficiency of Apis dorsata, Apis florea reported the pollination index of 12, 082 for A. dorsata and 4,298 for $A$. florea.

Cucurbits are mostly monoecious with male and female flowers are separated on the same plant. Xylocopa, Bombus along with honeybees are primary pollinators and cross pollination is must for fruit production. Rana et al. (2006) studied the effect of pollination for seed productivity of cucumber and reported that significant fruit set was found in bee pollination with seed weight over open pollination. Islam and Deka (2009) recorded the maximum fruitset of cucumber was with 5 Apis cerana colonies/ha (18.35\%) and obtained 74.10 t/ha yield over without bee pollination $(23.8 \mathrm{t} / \mathrm{ha})$.

\section{Pulses}

Few information are available in the pollination needs of pulses. Most pulse crops are considered to be self pollinated but bees do visit the flowers of different pulse crops. Pigeon pea, although a self pollinated crop but cross pollination has 
shown significant yield increase of the crop (Brar et al., 1992). Chalicodoma lanata was identified as specialist pollinator of pigeon pea which enhances significant yield. Rajkhowa and Deka (2013) reported that Apis cerana is the effective pollinator of pigeon pea and 5 colony/ha gave the optimum yield of $11.32 \mathrm{q} /$ ha against $4.72 \mathrm{q} / \mathrm{ha}$ without bee.

\section{Forage crops}

Major forage crops berseem (Trifolium alexandrium), alfalfa (Medicago sativa) are foraged by both honeybees and solitary bees. Berseem is an important surplus honey source in North western plains and alfalfa is grown in drier parts of tropical India, Bee visits greatly enhance seed set and yield of the crops. Sharma and Singh (2003) worked out the pollination efficiency of 3 Apis species, viz. Apis mellifera, A. dorsata and A. florea and expressed in index as A. dorsata $(53,219)$ as the highest and the lowest was $(7,030)$ in case of $A$. florea on Egyptian clover, Trifolium alexandrium.

\section{Fiber crops}

Cotton (Gossypium spp.) is the most widely grown fiber crop in India. Plants caged with bees gave $17.19 \%$ more seed cotton over plants caged without insects. Bolls per plant and weight of seed cotton (lint) and seed per boll were also increased both in Asiatic and American cotton (Jhajj, 1996). Honeybees are not very effective as pollinators of sunhemp (Crotolaria juncea) but wild bees are found to be effective. Information on pollination of jute (Corchrous spp.) crop is not available in India.

Table 13.1 Pollination management in different crops

\begin{tabular}{lllcl}
\hline Crop & \multicolumn{1}{c}{$\begin{array}{c}\text { Blooming period } \\
\text { of the crop }\end{array}$} & $\begin{array}{c}\text { Apis } \\
\text { mellifera } \\
\text { colony } \\
\text { requirement } \\
\text { /ha }\end{array}$ & $\begin{array}{c}\text { Apis } \\
\text { cerana } \\
\text { colony } \\
\text { requirement } \\
\text { /ha }\end{array}$ & $\begin{array}{c}\text { Time of } \\
\text { placement of } \\
\text { colonies }\end{array}$ \\
\hline Fruit crops & Mid-February to mid-March & $5-8$ & $10-12$ & $5-10 \%$ bloom \\
Almond & April (7-10) days & $5-8$ & $10-12$ & $5 \%$ bloom \\
Apple & Mid-February (2-3 weeks) & $2-3$ & $4-6$ & $5-10 \%$ bloom \\
Apricot & April-May & $5-8$ & $10-12$ & $10-15 \%$ bloom \\
Avocado & February (7-10) days & $2-3$ & $4-6$ & $5 \%$ bloom \\
Cherry & March-April & $8-3$ & $4-5$ & $5-10 \%$ bloom \\
Citrus & March-April & $2-3$ & $16-20$ & $5-10 \%$ bloom \\
Kiwifruit & February-March & $2-3$ & $4-6$ & $5-10 \%$ bloom \\
Litchi & February-March & $1-2$ & $2-3$ & $5-10 \%$ bloom \\
Mango & February-March (3-4 weeks) & $2-3$ & $4-6$ & $5-10 \%$ bloom \\
Peach & March-April (2 weeks) & $2-3$ & $4-6$ & $5 \%$ bloom \\
Persimmon & February (1-2 weeks) & $>15$ & 25 & $5-10 \%$ bloom \\
Plum & February to April (2 months) & $>15$ & & \\
Strawberry & & & & \\
\hline
\end{tabular}


(Contd. from p. 187)

\begin{tabular}{|c|c|c|c|c|}
\hline Crop & $\begin{array}{l}\text { Blooming period } \\
\text { of the crop }\end{array}$ & $\begin{array}{c}\text { Apis } \\
\text { mellifera } \\
\text { colony } \\
\text { requirement } \\
\text { /ha }\end{array}$ & $\begin{array}{c}\text { Apis } \\
\text { cerana } \\
\text { colony } \\
\text { requirement } \\
\text { /ha }\end{array}$ & $\begin{array}{l}\text { Time of } \\
\text { placement of } \\
\text { colonies }\end{array}$ \\
\hline \multicolumn{5}{|l|}{ Vegetable crops } \\
\hline Cabbage & February-March & 5 & $8-10$ & $10-15 \%$ bloom \\
\hline Carrot & March-April & $5-8$ & $10-12$ & $10-15 \%$ bloom \\
\hline Cauliflower & March-April & 5 & $8-10$ & $10-15 \%$ bloom \\
\hline Cucumber & June-September & $\begin{array}{c}2 \text { for } \\
\text { monoecious } \\
8 \text { for } \\
\text { dioecious }\end{array}$ & $\begin{array}{l}\text { 4-5 for } \\
\text { monoecious } \\
12-16 \text { for } \\
\text { dioecious }\end{array}$ & \\
\hline $\begin{array}{l}\text { Cucurbits } \\
\text { (pumpkin, }\end{array}$ & June-September & $5-8$ & $10-12$ & $10-15 \%$ bloom \\
\hline \multicolumn{5}{|l|}{ Squash gourd) } \\
\hline Okra & June-September & $1-2$ & $2-3$ & $10-15 \%$ bloom \\
\hline Onion & April & $5-8$ & $10-12$ & $5-10 \%$ bloom \\
\hline Radish & March-April & $2-3$ & $4-6$ & $10-15 \%$ bloom \\
\hline Turnip & February-March & $2-3$ & $4-6$ & $5-10 \%$ bloom \\
\hline \multicolumn{5}{|l|}{ Oilseed crops } \\
\hline $\begin{array}{l}\text { Mustard } \\
\text { and rapeseed }\end{array}$ & December-January & $3-5$ & $5-6$ & $10 \%$ bloom \\
\hline \multicolumn{5}{|l|}{ February- } \\
\hline \multicolumn{5}{|l|}{ March } \\
\hline Niger & February-March & $3-5$ & $6-8$ & $10-15 \%$ bloom \\
\hline Safflower & March-April & 5 & $4-6$ & $10-15 \%$ bloom \\
\hline Sesamum & April-May & $2-3$ & $5-6$ & $10-15 \%$ bloom \\
\hline \multicolumn{5}{|l|}{ Spice crops } \\
\hline Cardamom & March-April & $2-3^{*}$ & $4-6$ & $10-15 \%$ bloom \\
\hline Chilli & July- September & $2-3^{*}$ & $4-6$ & $10-15 \%$ bloom \\
\hline $\begin{array}{l}\text { Coriander } \\
\text { Pulses }\end{array}$ & February-April & $2-3 *$ & $4-6$ & $5-10 \%$ bloom \\
\hline Pigeonpea & Novebmer-December & $2-3$ & $5-6$ & $10-15 \%$ bloom \\
\hline
\end{tabular}

(Source- Pratap, 1999).

Cereal crops: Cereal crops are generally self pollinated but maize, rye, bajra and buckwheat are reported to be foraged by bees for their nectar reward. Apis cerana pollination on buckwheat increased the yield of the crop by $121.87 \%$ as reported by Rahman et al., 2000.

Pollination management in different crops in India and elsewhere was given in Table 13.

\section{POLLINATION OF GENETICALLY MODIFIED (GM) CROPS}

Genetically modified crops (GM crops, or Biotech crops) are plants in which the DNA has been modified using genetic engineering techniques. In most cases, 
the aim to introduce a new trait to the plant which does not occur naturally in the species. Genetically modified, "transgenic" plants (GM plants) carry genetic information derived from other organism (microbes, plants or animals), or have been modified by genetic engineering to provide them with new properties. Genetically modified (GM) plants manifest new traits via the production (expression) of novel proteins encoded by inserted transgenes (DNA). Many insect resistant crops carry genetic information originally derived from the soil bacterium Bacillus thuringiensis. The gene enables the bacteria or the GM plant to produce a protein with insecticidal activity. Therefore, the crop plant can protect itself against insect pests. There are numerous variants of the gene, encoding different proteins active in a highly specific manner against defined groups of insects. For example, cotton modified to contain a Bt (Bacillus thuringiensis) gene and expressing Bt insecticidal protein in its leaves and buds will be protected from insect attack. Both the transgene DNA and the novel protein in such plants could be considered "GM material". CryB is one of these proteins with activity against boll blosoms.

Bees and plants are interdependent to each other for their survival and perpetuation. Bees collect pollen and nectar from plants as food for their colonies. They may also collect honeydew (plant sap that has been ingested and then excreted by sucking insects such as aphids) for food and plant resin to make propolis with which to seal up cracks in the hive. With GM plants, there is a possibility that transgene DNA and or novel proteins may be present in the plant parts and secretions collected by bees.

Since, bees are primary agents for pollination of several crops travelling considerable distances and potentially causing crossing of GM and non-GM crops. A hive may contain up to 50,000 bees and individual bees may visit up to 100 flowers on each trip. Hive products intended for human consumption and derived from the plant parts collected by bees including honey (from nectar or honeydew, and containing traces of pollen), pollen and propolis. Honey can be contaminated by GM pollen, leading to potential economic losses for beekeepers. Evidently, there is a need to analyse whether Cry B protein have negative effects on honeybees. Other products, such as pure royal jelly, bee venom and beeswax, are secrations from the bees themselves and would not be expected to contain any plant matter.

Honey contains pollen grains from plants that bees have visited, and can therefore bee contaminated by GM pollen. It is not known what effect honey containing GM pollen could have on people consuming it. For example, the novel proteins produced by GM crops can also be present in their pollen are already causes for people who are allergic to honeybee and this has been linked to pollen in the honey. Genetic engineering is imprecise and unpredictable. Genes are inserted from organism which have never been eaten as food, and so new proteins are introduced into the human and animal food chains. There is concern that these could cause allergic reactions or other health effects.

They are between 20,000 and 80,000 pollen grains in $10 \mathrm{~g}$ of honey. This means that honey containing GM pollen could pose a potential health risk. Researchers who studied this problem concluded that, if GM pollen contained novel toxins or proteins it "could cause problems, not only to man who consumes honey as a 
food, but also to bee populations which rely on pollen as the sole source of protein".

It was found that bees can pass proteins from nectar unchanged into honey. If GM crops produce novel proteins or toxins in the nectar as well, this may further threaten the safety of honey produced from GM crops. GM plants may also contain genes which provide resistance to commonly used antibiotics such as ampicillin. There is concern that these could be passed on to the bacteria that live in humans and animals. DNA from pollen has been found to be able to survive in honey for seven weeks. It may be that this could be a route for such gene transfer. Inspite of the risks, there was almost no safety testing of GM pollen, either for humans or bees. Even the food safety tests of GM crops have been limited to short-term tests on animals. In India, non edible GM crops like Bt cotton has extensively been grown and $70 \%$ almost $12 \mathrm{~m}$ hectare crop area being saturated by this crop, but the edible G.M crops yet to be adopted. Hence, a proper biosafety measure alongwith food safety of GM Crops is necessary to ascertain the welfare of the health.

\section{Effect of GM plants on bee health}

Although, not directly related to the presence of GM material in bee products, there may be impacts of GM plants on bee health that could affect on the bees ability to produce honey, pollen and propolis. There is a growing body of published research on the impacts of GM plants and novel proteins on bee health. This research has recently been reviewed (Pham-Delegue et al., 2002). These reviews

Table 13.2. Effects of novel proteins and GM plants on bees

\begin{tabular}{|c|c|c|}
\hline $\begin{array}{l}\text { Novel protein } \\
\text { or GM plant }\end{array}$ & Type of experiment & Results \\
\hline \multirow{4}{*}{$\begin{array}{l}\text { Bt toxins } \\
\text { (Lepidopteran active) }\end{array}$} & Larval survival & Non toxic \\
\hline & $\begin{array}{l}\text { Adult survival } \\
\text { (in lab \& in colony) }\end{array}$ & Non toxic \\
\hline & Adult food consumption & Non effect \\
\hline & $\begin{array}{l}\text { Adult flight activity } \\
\text { (protein fed to colony) }\end{array}$ & Non effect \\
\hline \multirow{3}{*}{$\begin{array}{l}\text { Bt toxins } \\
\text { (coleopteran active) }\end{array}$} & Larval survival & Nontoxic \\
\hline & $\begin{array}{l}\text { Larval survival, pupal } \\
\text { weight protein fed }\end{array}$ & No effects \\
\hline & To colony) & \\
\hline \multirow{5}{*}{$\begin{array}{l}\text { Bt-corn } \\
\text { (Lepidopteran active) } \\
\text { Serine protease } \\
\text { Inhibitors }\end{array}$} & $\begin{array}{l}\text { Larval development, } \\
\text { adult survival, foraging }\end{array}$ & No effects \\
\hline & frequency (in field) & High concentrations \\
\hline & $\begin{array}{l}\text { Adult survival } \\
\text { (in lab and in colony) }\end{array}$ & $\begin{array}{l}\text { Reduce survival by a few } \\
\text { day; lowconcentration have } \\
\text { no effcect }\end{array}$ \\
\hline & Adult digestive proteases & Inhabition of some proteases \\
\hline & $\begin{array}{l}\text { Adult flight activity } \\
\text { (Protein fed to colony) }\end{array}$ & $\begin{array}{l}\text { Flight activity begins a few days } \\
\text { earlier (when fed a high } \\
\text { Concentration) }\end{array}$ \\
\hline
\end{tabular}


(Contd. from p. 189)

\begin{tabular}{|c|c|c|}
\hline $\begin{array}{l}\text { Novel protein } \\
\text { or GM plant }\end{array}$ & Type of experiment & Results \\
\hline & $\begin{array}{l}\text { Olfactory learning } \\
\text { response }\end{array}$ & $\begin{array}{l}\text { One inhibitor offered in sugar } \\
\text { reward reduced ability to learn; } \\
\text { Others did no } \\
\text { Larval survival } \\
\text { High concentration reduce } \\
\text { survival }\end{array}$ \\
\hline $\begin{array}{l}\text { Cysteine protease } \\
\text { inhibitors }\end{array}$ & Adult survival & No effect \\
\hline $\begin{array}{l}\text { Cysteine protease } \\
\text { Inhibitor-expressing } \\
\text { Oilseed rapeseed }\end{array}$ & Foraging behaviour & No effect \\
\hline Chitinase & $\begin{array}{l}\text { Adult survival } \\
\text { Olfactory learning response } \\
\text { Foraging behaviour } \\
\text { (suger feeder } \\
\text { With chitinase added) }\end{array}$ & $\begin{array}{l}\text { No effect } \\
\text { No effect } \\
\text { No effect }\end{array}$ \\
\hline $\begin{array}{l}\text { Chitinase-expressing } \\
\text { oilseed rapeseed }\end{array}$ & Foraging behaviour & No effect \\
\hline a- 1,3 glucanase & $\begin{array}{l}\text { Adult survival } \\
\text { Olfactory learning response } \\
\text { Foraging behaviour } \\
\text { (sugar feeder With a-1, } 3 \\
\text { glucanase added) }\end{array}$ & $\begin{array}{l}\text { No effect } \\
\text { No effect } \\
\text { No effect }\end{array}$ \\
\hline $\begin{array}{l}\text { Biotin-binding protein } \\
\text { (avidin)2 }\end{array}$ & $\begin{array}{l}\text { Adult survival } \\
\text { Adult food consumption } \\
\text { Larval development } \\
\text { and survival }\end{array}$ & $\begin{array}{l}\text { No effect } \\
\text { No effect } \\
\text { No effect }\end{array}$ \\
\hline $\begin{array}{l}\text { Herbicide (glufosinate) } \\
\text { resistance oilseed rape } \\
\text { (pat gene) }\end{array}$ & $\begin{array}{l}\text { Larval and adult survival, } \\
\text { foraging behaviour } \\
\text { (in colony) }\end{array}$ & No effect \\
\hline
\end{tabular}

Source: Malone, 2002.

are summarized below in Table 13.2 GM plants may have direct or indirect effects on bees. Direct effects are those that arise when a bee ingests a novel protein expressed by a GM plant. Indirect effects may arise if the process of introducing the transgene into the plant result in inadvertent changes to plant phenotype affecting its attractiveness or nutritive value to bees.

\section{REFERENCES}

Ackerman, J. D. 1999. Abiotic pollen and pollination ecological function and evolutionary perspective. Plant Systematics and Evolution. 222: 167-185.

Ahmed, B. and Rahman, A. 2002. Population dynamics of insect foragers and their effect on seed yield of rapeseed (Brassica campestris L. var. toria). Indian Bee Journal 64(385): 1-5.

Armstrong, J. A. 1979. Biotic pollination mechanisms in the Australian flora - a review, 
New Zealand J. Bot 17(4): 467-508.

Bhagawati, S. and Rahman, A. 2013. Effect of honey bee, Apis cerana F.(Hymenoptera; Apidae) pollination of Sesamum, Sesamum indicum L. Thesis submitted to Assam Agricultural University. Jorhat

Bhambbure, C. S. 1958. Effect of honeybee activity on niger seed production. Indian Bee Journal 20(12): 189-91.

Bisht, D. S., Naim, M. and Mehrotra, K. N. 1980. Studies on the role of honeybees in rapeseed production. Proc. $2^{\text {nd }}$ int. Conf. Apic. Trop. Climate, NewDelhi: 491-96.

Bisht, D. S., Naism, M. and Mehrotra, K. N. 1980. Studies on the role of honeybees in rapeseed production. Proc. $2^{\text {nd }}$ Int. Conf. Apic. Trop. Climates, New Delhi: 491-96.

Brar, H. S., Gatoria, G. S. and Jhajj, H. S. 1992. Field toxicity of insecticides recommended on American cotton, Gossypium hirsutum L., to honeybees, Apis mellifera L. Indian Journal Ecology 19(2): 183-86

Brar, P. K., Gatoria G. S. and Chhuneja P. K. 2010. Requirement of Apis mellifera Linn. Colonies for maximizing seed yield of radish, Raphanus sativus Linn. J. Inst. Sci.23(4): 366-74.

Darwin, C. 1859. Origin of species. John Murry Albemarle street, London

Deodikar, G. B., Seethalaxmi, V. S. and Suryanarayana, M. C. 1976 .Floral biology of sunflower with special reference to honey bees. Journal of Palynology 12: 115-25.

Faegri, K., and L. Van der Pij1. 1971. The Principles of Pollination Biology. Pergamon Press, New York. 281 pp.

Free, G. B. and Williams, I. H. 1972. The transport of pollen on the body hairs of honeybees (Apis mellifera L.) and bumblebees (Bombus spp.). Journal of Apiculture Research 9: 609-15.

Grew, N.1682. Anatomy of plants. Rawlins, London.

Islam, N. and Deka, M. K. 2009. Role of Apis cerana (Hymenoptera: Apidae)on fruit set and yield of cucumber. Geobios.36: 161-64.

Jhajj, M. S., Gatoria, G. S. and Bakhetia, D. R. C. 1996. Three decades of bee keeping research in the Punjab. Nat. Agric. Tech. Conf. Ludhiana (Punjab). 23-27 pp.

Knight, T. A. 1799. An account of some experiments on the fecundation of vegetables. Royal Soc. London, Phil. Trans., Plt. 195-204. pp.

Kumar S., Chhuneja, P. K. and Singh, J. 2012. Seed setting in Brassica napus L. and Brassica juncea L. viz. Apis mellifera L. visitation frequency. Proc. Int. Conf. Ent. Punjabi University, Patiala: 120.

Kumar, J., Mishra, R. C. and Gupta, J. K., 1989. Effect of honeybee pollination on onion (Allium cepa L.) seed production. Indian Bee Journal 51: 3-5.

Kumar, N. and Singh R. 2008. Effect of Bee Pollination in Litchi chinensis(cv. Shahi.) Nat. Sem. Production, Processing, Marketing and Export of Litchi. NCR for Litchi, Muzaffarpur.

Kumar, S. Singh, B. and Kumar, N. 2002. Insect visitors and pollination effect of Apis mellifera L. on yield of litchi (Litchi chinensis Sonn.). $6^{\text {th }}$ Int. Conf. \& World Apiexpo. Bengaluru, India.

Mahanta, M. and Rahman, A. 1997. Studies on pollination of litchi (Litchi chinensis Sonn.) by honey bees, Apis cerana F. Indian Bee Journal 59(2): 74-75.

Malone, L. A. 2002. Literature review on genetically modified plants and bee products. Hort. Res. Mt. Albert, Auckland, New Zealand.

Matheson, A. 1994. Forage for bees in an agricultural landscape. Cardiff : Int. Bee Res. Assoc., U.K.

Mishra, R. C., Kumar, J. and Gupta, J. K. 1987. Effect of modes of pollination on fruit characteristics of okra, Abelmoscus esculentus. L. Moench. Proc. Ind. Natn. Sci. Acad. 53 (2): 157-60. 
Naim, M. and Phadke, K. G. 1976. Bee flora and seasonal activity of Apis cerana indica at Pusa (Bihar). Indian Bee Journal 38(1-4) : 13-19.

Panda P., Sontakke, B. K., Sarangi P. K., 1988 - Preliminary studies on the effect of bee (Apis cerana indica Fab .) pollination on yield of sesamum and niger. Indian Bee Journal 50: 63-64.

Partap, U. 1999. Pollination management of mountain crops through beekeeping- Trainers' Research book. International centre for Integrated Mountain Development (ICIMD), $130 \mathrm{pp}$.

Patnaik, H. P., Mohapatra, L. N. and Das, B. 2004. Effect of bee pollination on yield of sesame under protected conditions. Indian Bee Journal 66(3-4): 84-91.

Rahman, A. and Rahman, S. 2000. Effect of honey bee (Apis cerana indica) pollination on seedset and yield of buckwheat (Fagopyrum esculentum). Indian Journal of Agricultural Science 70(3): 168-9

Rahman, S. and Rahman, A. 1993. Comparative pollen gathering activity of Apis cerana indica F. and Apis mellifera L. under Jorhat conditions of Assam (India). Indian Bee Journal 55(3-4): 42-46.

Rai, V. and Srivastav, P. 2012. Studies on the impact of bee pollination on yield and quality of litchi (Litchi chinensis Sonn.) Prog. Hort. 44(2): 262-64.

Rajkhowa, D. and Deka, M. K. 2013. Insect foragers and foraging behaviour of honey bee, Apis cerana on pigeon pea. Ind. J. Ent. 75(3): 232-35.

Rana, R. S, Rana, B. S. and Joshi, A. K. 2006. Pollinator fauna in Cucumis sativus L. and their effect on seed productivity in Solan District of Himachal Pradesh. Proc. Natn. Sem. Sustainable Beekeeping Dev. and Honey Festival. RAU Pusa, Bihar: 36.

Roubik, D. W. 1995. Pollination of Cultivated Plants in the Tropics, Food and Agriculture Organization of the United Nations, Bulletin 118, Rome, Italy.

Sharma, S. K. and Singh, J. R. 2000. Efficiency of two Apis spp. pollinating sunflower (Helianthus annus L.). Ann. Ent. 18(1): 15-17.

Sharma, H. K., Gupta J. K. and Thakur J. R. 2000. Pollination studies on apple and pear. $7^{\text {th }}$ Int. Conf. Trop. Bees: Mangn and Diversity \& $5^{\text {th }}$ Asian Apic. Asso. Conf. 265-70.

Sharma, H. K, Paratap, U.'Brist, K., Tewari, P. and Phartyal. 2012. Impact of honeybee pollination in enhancing the apple production in Nainital district of Uttarakhand. $A d v$. Polln. Res.30: 99-102.

Sharma, S. K. and Singh, J. R. 2003. Pollination efficiency of Apis spp. on Egyptian clover, Trifolium alexandrium L. Forage Res., 28(4): 218-19.

Sharma, S. K., Singh, J. R. and Kaushik, H. D. 2001. Efficiency of two wild honeybee (Apis spp.) as pollinators of onion (Allium cepa L.) Haryana. J. Hort. Sci. 30(1\&2): 134-35.

Sigha, R. C. 1986. Insect pollination increases seed production in cruciferous and umbellferous crops. Journal of apiculture Research 25(2): 121-26.

Singh, B., Kumar, M., Sharma, A. K. and Yadav. L. P. 2004. Effect of bee pollination on yield attributes and seed yield of toria (Brassica campestris var. toria). Environ \& Ecol. 22(3): 571-73.

Singh, G., Kashap, R. K., Khan, M. S. and Sharma, S. K. 2001. Effect of different modes of pollination on seed production and quality parameters in hybrid sunflower LSH3. Seed Science and Technology 29(3): 567-74.

Singh, R. and Chaudhary, D. K. 2005. Effect of honey bee pollination on yield and quality of Mustard, Brassica juncea L. Int. Beekeeping Cong. Bengaluru, India: 36.

Singh, R. C. and Kapil, R. P. 1983. Foraging strategies of honeybees as determined by quality and quantity of nectar. Proc. $5^{\text {th }}$ Int. Symp. Pollen, Versailles. 51-59.

Tanuja, P, Poonam, S., Khan, M. S. and Srivastav, R. M. 2012. Abundance of insect pollinators in citrus crop and their impact on fruit setting under tarai agroclimatic condition. J. Ent. Res. 36(3): 211-13. 


\section{4 \\ Toxicity to Honey Bees}

$\mathrm{M}_{\mathrm{r}}^{\mathrm{s}+\mathrm{s}_{2}}$

ODERN agriculture has come a long way from subsistence to the exploited phase and recently entered into integrated phase. The pest problems have been aggravated by the advancement in agricultural technology. Although the agricultural production system has entered in the integrated phase but the use of pesticide in the system has unabatedly been continuing. Most farmers apply large amount of pesticides at regular interval and indiscriminate use of pesticides causes adverse effect in agro-ecosystem. Honeybees are susceptible to many groups of pesticides used in pest control programmes. Pesticidal poisoning is recently overshadowing all other problems in apiculture. Farmers in India mostly small holders use manual sprayer/duster for treating small crop area. This results into a continuous exposure of honeybee to pesticidal poisoning. Moreover, visible integrated approach is lacking between the beekeepers and farmers of India. Selective use of insecticide is one of the requisite for integrated pest management. In this context, evaluations of selectivity of insecticides which are effective against target pest but less toxic to pollinators are essential. Toxicity is an inherent property of a chemical to cause adverse biological effect at adequate dosage. In recent years, many insecticides have been screened for their efficiency target pest and their toxicity to the honeybees. Mortality of bees is high when most toxic chemicals are applied during blooming period of the crops. It is not possible to quantify the loss in terms of food production or to assess the financial value of bees killed. Therefore, a cost benefit ratio to be worked out between the gains in crop production due to bee pollination and economics of pest control. Our primary aim should be to assess how crop pest can be kept under control without harming the insect pollinators. Such effort is possible under sound and programmatic approach of Integrated Pest Management System.

The climate of India mostly ranges between tropical to subtropical and the climate favours the outbreak of many crop pests. The pest problems further intensified due to irrigation, intensive agriculture, introduction of crops and crop varieties and disturbing the indigenous and primitive cropping patterns have contributed in increasing the pest problem of crops. Reduction in uncultivated land, canals and bunds destroy nesting and hibernating places of wild pollination and succession of nectar and pollen yielding flowers round the year is declined. Weedicides are used to control the weeds, and hence lead to starvation of pollinating insects. The advanced agricultural technology has helped to destroy the agriculture cycle through indirect effect. There is also a prominent negative direct factor, i.e. the insect pollinators are killed by pesticidal usage in crop protection. There is 
increasing use of pesticides for the control of rodents, mites, insects, nematodes and fungal and bacterial diseases of crop plants. The loss by bee kill is direct, i.e., loss of honey production and indirect inadequate pollination of crops resulting in reduced productivity.

Although, there is an integrated approach in pest management, most farmers apply large quantities of pesticides at regular intervals and in most cases the pesticides are non-selective coupled with untimely application. Unfortunately, honeybees are susceptible to many pesticides used in pest control programmes. This problem is recently overshadowing all other problems in agriculture. Farmers in India have small holdings and hand sprayers/dusters are commonly used for treating small area each day. These results into a continuous threat of chemical poisoning to bees. Moreover, there is no co-ordination between the beekeepers and the farmers by any Government decree and therefore, measures to save bees cannot be taken. Large number of bee mortalities found in front of the hives or in the fields by insecticidal poisoning. It is not possible to quantify the loss in terms of food production or to assess the financial value of the bees killed. Even more important is the loss in future crop yields because a beekeeper whose bees are killed gives up beekeeping and others too are discouraged to take up beekeeping. Therefore, a balance sheet between the gains in crop yields by control of pests and losses due to decreased pollinator activity and honey production by bee mortality should be worked out. While controlling pests, the scientists and farmers are looking on to one aspect of the economic considerations in insecticidal applications. Our primary aim should be, to assess how crop can be kept under control without killing insect pollinators and to ensure optimum pollination by these insects. Widespread destruction of beneficial insects (including pollinators) often occurs as a consequence of irresponsible and improper use of pesticides. It should be accepted that some loss is inevitable in certain circumstances and that a realistic aim should be an acceptable low level of loss rather than complete protection of bees. In short, the following constraints are important:

(i) Use of inappropriate pesticides, ill timed, wrong methods of application wrong formulations and unnecessary high doses

(ii) Over reliance on chemical methods of pest management

(iii) Absence of certain essential instructions and legislation for using pesticides

As toxicity is the inherent property of a chemical to cause adverse biological effect at adequate dosage but on the other hand hazard is the possibility of producing an adverse effect to organism in specific circumstances, which is discussed below:

\section{Pesticidal hazards to bees}

Many of the Indian crop plants need cross-pollination and about one-third of the cropped area is under entomophilous crops. These crops are infested by pests even during flowering and their depredations warrant the application of control measures. The pesticidal control of the pests of crops which also serve as bee forage pose serious danger and eliminates large population of insect pollinators. Some points on the use of insecticides for pest control vis-à-vis insect pollination in some of the important crops are included here as discussed by Mishra (1995) 
Fibre crops: Among fibre crops, cotton is most sensitive crop for bees. As many as 15-20 insecticidal applications at shorter and regular intervals are recommended for the control of various cotton pests. The flowering continues for about 2 months and during this period insecticides are regularly applied for the control of many pests like bollworms, aphids, bugs etc. Foraging bees are killed by these sprays. New generation of bees develop in 3 weeks. Insecticidal applications at shorter intervals than this kill more adult bees than can be replaced and ultimately the colonies die. But co-ordinated application of insecticides can minimize bee kill. (1) Flowering in cotton continues for about 2 months but flowers that set fruit appear within 3-4 weeks. Therefore, use of insecticides during this period should be reduced so that bees can be moved to the crop. (2) Nectar in flowers and extra floral nectaries is exhausted by mid day and very few bees are foraging in the afternoon when insecticides can be applied with reduced hazards to bees. (3) Air spraying has picked up for cotton. In such a situation the colonies should be located away from the flight path of the plane.

Oilseed and vegetable crops: These are attacked by aphids, caterpillars and bugs during flowering and pod formation stage. These crops include oilseeds Brassica, seed crops of cauliflower, cabbage, radish, turnip, carrot, fennel and coriander. In these crops too, the flowering is greatly extended, lasting for about 1-1.5/2 months. These crops need insecticidal applications during flowering periods. But all these crops are also enthusiastically foraged by bees which are very useful pollinators of these crops. There are extensive pesticidal poisoning to bees on these crops. There are no specific recommendations to safeguard bees and only general guidelines to reduce bee mortality can be followed. Singh et al. (1974) sprayed endosulphan on mustard to control aphids at 08:00, 09:00, 16:30 or 17:30 hrs and found that Apis spp. foraged between 10:30 and 15:30 hrs without any effect on foraging intensity and no bees were killed.

Sunflower: Its cultivation is gaining importance in India. Bees contribute much in increased crop production by pollination services but bee mortality has been reported by insecticidal sprays for the control of aphids and caterpillars. In India, endosulfan was found to be less toxic to honeybees than Fenthion, Carbaryl or Parathion and seed set and yield were not affected since bee activity was not reduced in endosulphan sprayed plots (Ramakrishna et al., 1947; Bhattacharya et al., 1982). Bees mostly forage in the forenoon and there is limited activity till early afternoon. Therefore, evening or late in the afternoon is appropriate time for chemical control operations.

Sesame: It is often self-pollinated but natural cross-pollination also occurs. Honeybees are very active on the flowers of sesame. The crop at flowering stage suffers from the attack of aphids, brown leafhopper, sucking bugs, whiteflies and caterpillars. Chemical application at blossoming would cause hazards to bees also.

Forage crops: Like lucern and clovers, these are rich bee forages. Under semiarid tropics, the legume flowers usually close in the afternoon and it allows time for safe application of pesticides afterwards against caterpillar pests.

Pulses: Like soybean, Cajanus and others are self-pollinated crops but yield increases by bee pollination have been observed. Considerable mortality of 
honeybees from insecticide poisoning is reported in some countries but lack of knowledge in India is due to non-monitoring of hazards.

Cucurbits: These require the control of fruit flies, pumpkin beetle and aphids when in flowering. Cover sprays of insecticides are given against these pests. Honey bees visit the flowers of melon and other cucurbits. Steps to minimize bee kill from these sprays are required.

Plantation crops: In this case, self-pollination is normal but honeybees and other insects visit the flowers for nectar, affecting some cross pollination. Aphids, whiteflies, thrips and caterpillars are the pests which may warrant insecticidal application during flowering which consequently would lead to bee hazards. Flowering period in coffee is short and insecticidal applications can be avoided during coffee flowering. Coffee may be attacked by bugs, leaf miner and thrips during flowering. In case of outbreak during flowering, the crop should be treated when bees are not active and less persistent insecticides be used.

Pome and stone fruits: Apple, peach, plum, apricot and almond are attacked by caterpillars at blooming time. Insecticidal use has been suggested by economic entomologists against thrips, though economic losses by thrips have not been ascertained. The recommendations are made in ignorance of insecticidal bee hazards. Therefore, caution is important so that the huge benefits from bee pollination are not reduced.

Other fruit crops: Insecticides can be applied for pest control at flowering time in citrus. litchi, olive, grapes, coconut and cocoa. Care should be taken because they are also visited by bees for floral rewards.

\section{Symptoms and effects of pesticidal poisoning}

Bees come in contact with pesticidal deposits while foraging on treated crops or weeds where the chemicals are deposited by drifting. The nectar and pollen can also be contaminated with pesticides and there can be stomach toxicity to bees and also to brood when fed on contaminated pollen (Fig. $14.1 \mathrm{a}, \mathrm{b} \& \mathrm{c}$ ). Some pesticides may even cause hazards by fumigant action. After gaining entry into body, different pesticides have different modes of action. Atkins et al. (1981) has given the detail of specific symptoms caused by poisoning of different groups of pesticides but general symptoms of pesticide poisoning are:

1. Appearance of large number of dead bees in front of the hive. Bees also die in the field and in between the field and the hive.

2. Bees become paralytic, lose the power of orientation; legs, wings and digestive tract stop functioning and poisoned bees show uncoordinated movements.

3. Abdomen becomes distended.

4. Bees are irritated and become aggressive; they sting heavily and guard bees are confused.

5. Regurgitation of gut contents can occur.

6. Brood chilling can occur due to reduced adult bee population.

7. Contaminated pollen can be collected by bees and stored as bee bread. This pollen fed to brood results into dead brood inside the colonies; young emerging bees are also killed. 

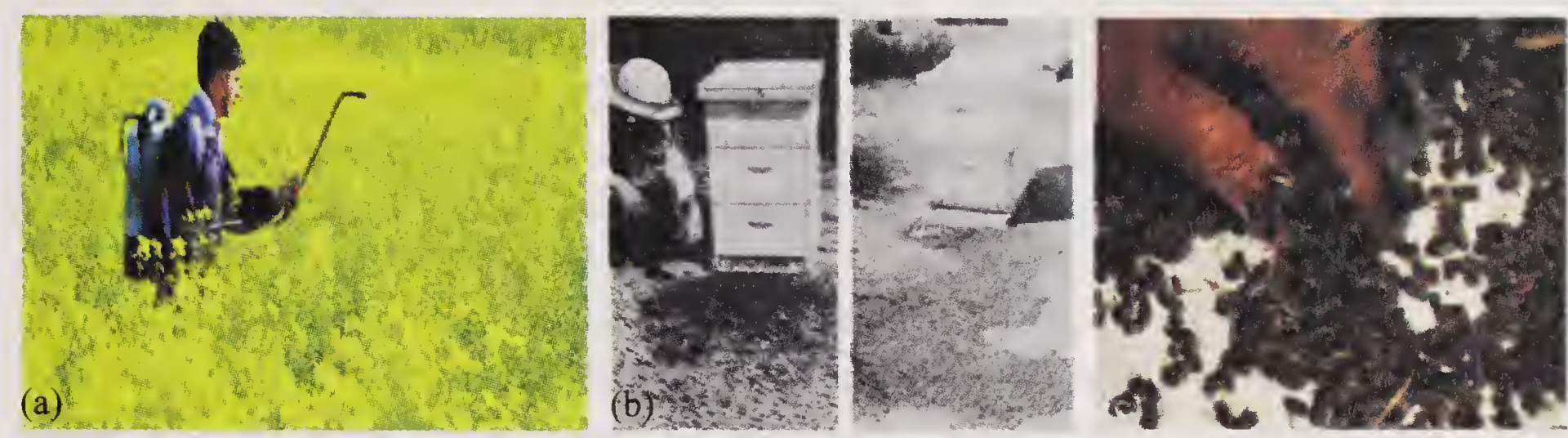

Fig. 14.1 (a) Application of pesticides; (b) Honeybee mortality; (c) Honeybee mortality due to pesticides.

8. Sometimes the queen is also affected. Queen may stop laying eggs or lays eggs in irregular pattern, there may be brood in only some of the cells of the brood area, as in case of colonies suffering from foul brood disease. In colonies which survive, queen may be superseded. Sometimes queenlessness may develop.

9. Longevity of adult bees is reduced due to sub-lethal doses of pesticides.

\section{Pesticides and their relative toxicity to bees}

Some remarkable studies have been conducted on relative toxicity of pesticides to Apis mellifera and A. cerana. Atkins et al. (1973) have categorized the pesticides on the basis of their relative toxicity. Exhaustive reviews and summary of the results of their laboratory and field studies with large number of pesticides are very illuminating and serve as an important reference. As per their categorization, the pesticides in use in India are listed in tables ahead. The list is very important in choosing the appropriate pesticide, particularly when alternate choices for a pest control are available. Some insecticides have been screened in laboratory in India for their toxicity to bees. First study in this field was carried out by Cherian and Mahadevan (1946) with DDT and gammexane against Apis cerana indica. Hameed et al. (1973) allowed the worker bees of Apis mellifera to forage on cut flowers of mustard to which systemic and contact insecticides had been sprayed. On the basis of safety index, Formothion, Vamidothion, Dimethoate and Phosalone were considered to be relatively safer to bees. Contact toxicity to Apis cerana to insecticide applied as sprays was compared with Menazon by Kapil and Lamba (1974). Taking the $\mathrm{LC}_{50}$ for Menazon as 100, the comparative values for Endosulphan, Eormothion, Methyl demeton, Endrin, Dieldrin, Malathion, Parathion, Phosphamidon, Lindane, Phorate and Mevinphos were 1.17, 1.18, 14.00, $15.70,17.79,22.25,26.01,28.45,36.99,57.96$ and 64.24, respectively. Singh et al. (1974) tested 15 insecticides and reported that Menazon and Endosulphan were least toxic and were considered nontoxic to Apis cerana at their recommended doses. According to Thakur et al. (1981) Fenitrothion and Fenthion were highly toxic as compared to Endosulfan, Trichlorfon and Hinosan were moderately toxic as determined by residue film method. Comparative toxicity of organophosphates, chlorinated hydrocarbons and carbamates was worked out by Bai and Reddy (1977). Attri and Sharma (1969) and Mishra and Verma (1982) also assessed the contact and oral toxicities of some insecticides. Toxicity of several organophosphates to Apis cerana was determined in the laboratory using topical 
application method (Qadri et al., 1982). Determination of the kinetic parameters of the reactions by the authors showed that differences in anticholinestrase activity were due mainly to differences in affinity rather than to different chemical structure of the compounds. Cholinestrase inhibition by insecticides in Indian honeybee was studied by Dale and Mehrotra (1976). Bai and Reddy (1977) reported that signs of poisoning in Apis cerana indica were first observable when acetylcholinestrase inhibition exceeded $35 \%$ and death occurred at $96 \%$ or more inhibition. Reddy (1979) reported the inhibition of magnesium activated adenosine triphosphate as the criterion to determine the degree of organochlorine insecticide poisoning to Apis cerna indica. Digestive amylase and protease of Apis cerana indica were inhibited to the same level by the insecticide poisoning from different groups of insecticides (Reddy, 1979). Studies on the level of ions of amino acids in the haemolymph of worker bees of Apis cerana indica treated topically showed pronounced stimulatory effect with organophosphates, a relatively strong inhibitory action with chlorinated hydrocarbons and an intermediary effect with carbamate pesticides (Reddy, 1983). Sharma et al. (2000) while evaluating some insecticides viz.Carbary150wP@200g, alfamethrin10 EC@200 ml, endosulfan35 EC@ 2,000 ml,Cypermethrin25 EC@2,000 ml and deltamethrin2.8 EC@500 ml and monochrotophos36wsC@1,500 ml/hectare against Apis mellifera worker in cotton reported that endosulfan caused least mortality $(26.67 \%)$ followed by carbaryl (91.67\%) and rest are highly toxic to bees. Abrol and Andotora (2003) reported that endosulfan and carbaryl were the least toxic, while choropyriphos, quinolphos and malathion were moderately toxic and dimethoate was found to be highly toxic against Apis mellifera. Kumar and Rahman (2012) while evaluating neonicotinoids, viz. imidacloprid and thiocloprid against and their toxicity to Apis cerana reported that imidaclorprid is highly toxic to bees followed by thiocloprid moderately toxic to honey bees. Metcalf and Luckman (1994) while formulating pest management rating of widely used insecticides categorized the pesticides on the basis of toxicity as given below:

\section{Table 14.1 Pesticides most toxic to bees}

For minimal hazard to honeybees, these pesticides should not be applied on blooming crops or weeds. Their residual toxicity is usually high even after $10 \mathrm{hrs}$.

\begin{tabular}{ll}
\hline Acephate & Formothion \\
Aldicarb G & Gamma BHC \\
Aldrin & Heptachlor \\
Aminocarb (1kg/ha or more) & Isobenzene \\
Azinphos-ethyl 1 & Lead arsenate \\
Azinphos-methyl 1 & Malathion D \\
Bendiocarb & Malathion ULV $(0.5 \mathrm{~kg} / \mathrm{ha}$ or more) \\
Calcium arsenate & Methamidophos \\
Carbaryl ULV (over 0.5kg/ha) & Methidathion \\
Carbaryl D, WP, XLR & Methiocarb \\
Carbofuran F & Methomyl D \\
\end{tabular}


(Contd. from p. 198)

\begin{tabular}{ll} 
Carbophenthion D & Mevinphos \\
Carbosulfan & Monocrotophos \\
Chlorpyrifos & Parathion \\
Cypermethrin (over $0.025 \mathrm{~kg} / \mathrm{ha}$ ) & Parathion-methyl \\
Deltamethrin & Permethrin \\
Diazinon & Phenthoate \\
Dicapthon & Phosmet \\
Dichlorvos & Phosphamidon \\
Dicrotophos & Phoxim \\
Dieldrin & Pirimiphos-ethyl \\
Dimethoate & Pirimiphos-methyl \\
Dinoseb & Propoxure \\
DNOC (more than $0.4 \%$ dilution) & Quinalphos \\
EPN & Resmethrin \\
Fenitrothion & Tetrachlorvinphos (at higher rates) \\
Fensulfothion & Thionazin \\
Fenthion & Triazophos \\
Fenvalerate & Vamidothion \\
& Flucythrinate \\
\hline
\end{tabular}

Table 14.2. Pesticides very toxic to bees

For minimal hazard to honeybees, these pesticides should be applied only during late evening. Their residual toxicity is usually low within $8 \mathrm{hr}$.

\begin{tabular}{ll}
\hline Carbaryl $(1.5 \mathrm{~kg} / \mathrm{ha}$ or less & Oxamyl $(1 \mathrm{~kg} / \mathrm{ha}$ or more $)$ \\
Endosulphan $(\mathrm{more}$ than $0.5 \mathrm{~kg} / \mathrm{ha})$ & Phorate EC \\
Fenvalerate $(0.1 \mathrm{~kg} /$ ha or less $)$ & Profenophos \\
Imidacloprid $17.8 \% \mathrm{SL}$ & Thiocloprid $21.7 \% \mathrm{SC}$ \\
Malathion EC & Thiometon \\
Naled EC & \\
\hline
\end{tabular}

Table 14.3. Pesticides less toxic to bees

For minimal hazards to honeybees, these pesticides should be applied only during late evening or night. Their residual toxicity is usually low within $3 \mathrm{hr}$.

\begin{tabular}{ll}
\hline Aminocarb ULV & Fenchlorphos \\
\hline Carbaryl ULV $(0.5 \mathrm{~kg} / \mathrm{ha}$ or less $)$ & Fenthion G, MA \\
Carbophenothion (not D) & Formetanate \\
Chlordane & Heptachlor G \\
Chlorfenvinphos & Leptophos \\
Chlorpyrifos & Malathion \\
Chlorpyrifos ULV & Menazon \\
Cypermethrin $(0.025 \mathrm{~kg} / \mathrm{ha}$ or less $)$ & Methomyl \\
DDT & Methoxychlor
\end{tabular}


(Contd. from p. 199)

Demeton

Demeton-S-methyl

Deltamethrin $11 \mathrm{SC}$

Dichlorfenthion

Dichlorvos MA (0.05 kg/ha or less)

Dieldrin $G$

Dimetilan

Dinobuton

Dioxathion

Disulfan EC

DNOC (less than $0.4 \%$ dilution)

Endosulfan $(0.05 \mathrm{~kg} / \mathrm{ha}$ or less)

Endrin

Ethiofencarb

Enthion
Oil sprays (superior type)

Oxamyl $(0.5 \mathrm{~kg} / \mathrm{ha}$ or less $)$

Oxydemeton-methyl

Phorate G

Phosalone

Pirimicarb

Propoxur MA

Rotenone D

Temephos

TEPP

Tetrachlorvinphos (at lower rates)

Toxaphene

Table 14.4. Pesticides least toxic to bees

These pesticides can be applied at any time with reasonable safety to honeybees. Their toxicity is usually low with direct application.

Allethrin

Amitraj

Azocycloting

Bacillus thuringiensis

Botanicals

Bromoprophylate

Carbary $1 \mathrm{G}$

Carbofuran $\mathrm{G}$

Chlorfentezin

Chlorbenside

Chlordimeform

Chlorfenethol

Chlorfenson

Chlorfensulphide

Chlorobenzilate

Choloroprophylate

Cryolite

Cyhexatin

Dicofol

Diflubenzuron

Dinocap

Disulfoton $G$

Fensulfothion $\mathrm{G}$
Fenbutating oxide

Fenoxycarb

Fenson

Fluvalinate

Hydroprene

Isofenphos

Lime sulphur

Malathion G

Mancozeb

Mirex G

Nicotine sulphate

Permethrin

Propargite

Propoxur G

Pyrethrum

Rotenone EC

Ryania

Schradan

Baits

Sulphur

Tetradifon

Thiocyclam

Table (15-18) Partly adopted from Atkins et al. (1973), Metcalf and Luckman (1994). 
Mortality of bees due to field application of pesticides serve as valuable information but such studies and assessments are difficult to be made. Only limited surveys on effect of honeybee losses was conducted in Western countries. Some useful information can be found in the review of Anderson and Atkins (1968). Laboratory studies have been interpreted to obtain useful information to predict the expected hazards of pesticides to honeybees in field application (Atkins et al., 1973). $\mathrm{LD}_{50}$ values with slope (probity) and field, test data on residues to bees can be used to predict the degree of toxicity or hazards to honeybees in the field when pesticide is applied as an early morning spray. In most instances the $\mathrm{LD}_{50}$ ( $\mathrm{g} / \mathrm{bee}$ ) can be converted into equivalent number of $\mathrm{kg}$ of chemicals per ha when applied to aerial portion of plants. Generally speaking, a pesticide with a slope value of 4 probits or higher can be made safer to honeybees by only slightly lowering dosage. On the other hand, by increasing the dosage only slightly the pesticide becomes much more hazardous. This valuable information can be used to manipulate the field hazards to bees. Honey bee mortality predictor has been developed by Atkins et al. (1981) with laboratory data on bee toxicity.

\section{Reduction of pesticidal poisoning to bees}

Almost all the pesticides/insecticides in use for the management of insect pests are also hazardous to bees but most pesticides used for the management of bee diseases and non-insect pests are not hazardous. This subjects the bees to extensive hazards of chemical poisoning. But certain points can be kept in mind for reducing these hazards. A golden rule for the safety of bees and other insect pollinators is not to apply pesticides unless the pest damage is at threshold level. Gain from the control of pest should outweight the losses to beekeepers and losses due to insufficient pollination. Application of pesticide should be avoided when the crop is in bloom. In most cases, it can be possible to control the pest before the start of flowering and next treatment can be postponed till the end of flowering period but in some crops the flowering period is staggered and pesticidal treatments may become essential.

Location of bees: Bee colonies, should not be located in and around the field where insecticides are to be applied. It is always possible to move bees to safer location. Chemical treatments in the vicinity of apiary are also equally dangerous. The farmers can also help reducing bee kills but in India there is no such coordination. In many countries there is legislation safeguarding bees, though enough safeguard may not be achieved.

Pesticide formulation: Dust formulations are more hazardous to bees than sprays, as these contaminate atmosphere and can be carried to neighbouring localities/fields. Wettable and dispersable powders have longer residual effect than emulsions. Bees are less likely to come in contact with emulsions because these are absorbed in surface tissues or for systemic translocation. Moreover small droplet sprays are safer than coarse droplet sprays. Granular formulations applied in soils are the safest for bees but micro-encapsulated granules applied to crops can be collected by bees as they are within the size range of the pollen grains. These encapsulated granules are stored in the hive, where they may be eaten by adult bees and fed to brood for many instances of high bee mortality are more 
dangerous to colonies and should be avoided.

Selection of pesticides: In general, organic pesticides are less toxic to bees than inorganic ones. Organic insecticides also have shorter residues. For the control of any pest, the entomologists and farmers have alternate choices. Therefore, pesticide chosen for application should be comparatively safer to bees with shorter residual period.

Timing and method of application. It is most dangerous to apply insecticides when the bees are actively foraging. They come in direct contact with insecticidal applications. Flower rewards are presented by a crop during specific day hours. In most cases the insecticidal applications can be given beyond these day hours and when the bee activity is least. It is also possible to treat crops before or after bee activity. For example bees in winter start foraging late by about 1,000 hr and stop foraging before 1,600 hr. By treating Brassica and other winter vegetable seed crops before the bee activity starts or after the bees stop working can be a useful practice to reduce bee hazards. Ground applications are more hazardous when small areas are treated everyday. Aircraft sprays, when the bees are foraging, hit larger number of foraging bees than by ground spray applications.

Dosage of pesticide. Sometimes pesticides per unit area are recommended for pest control giving the lowest and highest ranges of quantity. But this makes a lot of difference in bee hazards. The recommendation for pest control should be specific, quantity and dosage should be lowest that gives good pest control. Slight changes cause greater difference in bee kills in the fields.

Local beekeepers should be cautioned before applying pesticides. The bee colonies can be moved to other localities or bees can be kept confined inside the hive during treatments. While confining bees, due attention should be paid to some important points. While confining the bees, proper space should be available. Congestion and overcrowding can lead to bee mortality. Ventilation must be provided at the top and/or sides of the hive and not only through the entrance because this may be blocked by dead bees. Ventilating screen should have as large a mesh as possible. Bee hives in which the bees are confined should be provided with shade. Shade can usually be provided by the use of local material. Covering the hives with wet clothes/gunny bags can be of great benefit because evaporation of the water helps to reduce the rise in colony temperature. If pesticides are applied by aircraft, it is important to cover whole of the hive; otherwise it may be sufficient to wrap a wet cloth on the flight entrance. This greatly reduces flight activity or bees but it does not prevent flight entirely. During warmer months, it becomes essential to provide water inside the hives. This water is taken by the bees and spread out in the hive, where it evaporates and thus reduces the high temperature. The confinement must of course continue as long as the pesticide near the hive retains unexpectable toxicity and its duration can satisfactorily be reduced, only if the pesticides applied do not have long residual life. In case there are no stores in the hive then pollen supplement/substitute, sugar syrup may also be provided.

When the damage to bees and also to brood is due to pesiticidal contaminated pollen being carried back to the hive, two actions by the beekeepers may be helpful, i.e. prevention of pollen being stored in the hive and provision of a safe pollen 
supply inside the hive. Provision of pollen cakes in the hive during this period greatly reduces the collection of toxic pollen. Cakes of pure pollen are more effective than pollen supplement or pollen substitutes.

Bee repellents. Safety of the pollinators against pesticides can be ensured by providing them a functional protection through the use of repellents. Basic idea of using repellents is to mix such chemicals with poisonous pesticides which would repel bees for sometime and reduce bee losses. Pesticidal treatment and residues remain hazardous to bees for few hours and keeping bees away during this period is helpful. More chemicals have been screened by Atkins et al. (1973). Pyrethroids have been found to give some repellency. Oily materials increase the absorption of pesticides and less hazardous residues are left by such adjuvants. Plastic and latex-resin additives make insecticidal sprays safer for bees.

Some work has also been done in India. Lantana oil (from leaves) was shown to have repellent activity against honeybees (Apis mellifera) by Attri and Singh (1978). Gupta and Kapil (1983) tested the response of workers of Apis florea to 16 compounds ( 14 ketones +2 essential oils), in semi-field conditions each with a concentration of $5 \mathrm{~g} /$ litre. Maximum repellency was obtained with 0 -amino acetophenon and ethyl benzyl keton, while minimum was with Mentha piperata oil. Gupta and Mohla (1986) also found a structure-activity relationship of straight chain ketones and an increase in repellency with an increase in the number of carbon atoms was a general trend. They also reported that linalool, terpineol and $\mathrm{D}(+)$ carvone could show a repellent effect for a maximum of $2 \mathrm{hr}$. Kumar et al. (1986) studied the oils of Citronella, Lantana, Eucalyptus, Chenopodium and Trachyspermum for their gustatory repellency and toxicity and found that Citronella oil was most repellent with least toxicity in Apis cerana. Ketones are good repellents but their cost is prohibitive for field use. Effective and economical repellents are needed to be searched to fulfill the noble aim of saving bees. Rahman and Rothonga (1999) while evaluating some of the insecticides against mustard aphid, Lipaphis erysimi and their toxicity to Apis cerana found that deltamrthrin was most effective followed by cypermethrin and fenvalerate in controlling pest, L. erysimi and deltamethrin was also found to be least toxic to A. cerana. Sharma et al. (2000) evaluated relative field toxicity of different insecticides to Apis mellifera foraging on green gram and revealed that oxydemeton-methyl, malathion and phosphamidon were toxic up to $48 \mathrm{hr}$ whereas, formothion and dimethoate were toxic upto $72 \mathrm{hr}$ after spray.Rahman and Saikia, (2005), reported that the maximum reduction of Lipaphis erysimi population was obtained by the treatment of Econeem ( $0.1 \%$ ) followed by Achorus calamus (3.5\%), Nicotina tobacum $(3 \%)$, Melia azadarch (3\%) and Polygonum hydropiper (3.5\%). Gulati et al. (2004) while analyzing the residues in honey sample reported that residues of lindane was maximum $(0.002-0.090 \mu \mathrm{g} / \mathrm{g})$ followed by profenophos $(0.012-0.023 \mu \mathrm{g} / \mathrm{g})$. Mall and Ram (2010) evaluated some biorational insecticides on Apis mellifera foragers and found that endosulfan and dimethoate $39 \mathrm{EC}$ were safer as compared to imidaclorpid $200 \mathrm{SL}$, quinolphose $25 \mathrm{EC}$ and phosphamiden $100 \mathrm{EC}$. Mohapattra and Patnaik (2009) tested five insecticides viz. Cartap hydrochloride, dimethoate, thidicarb, fenvalerate and endosulfan and results revealed that among the insecticides dimethoate, fenvalerate and endosulfan did not exibit repellency at 
1, 3 and 7 days after spraying but considerable mortality was recorded on treated flowers by those insecticides. Sharma and Abrol (2005) studied the contact toxicity of some insecticides to Apis mellifera and A. cerana and arranged the order of toxicity of insecticides after $8 \mathrm{hr}$. of treatment was malathion $>$ fenvalerate $>$ deltamethrin. Abrol and Kumar (2009) observed the effect of pesticides on foraging activity of Apis species and reported the toxicity of insecticides in decreasing order of efficacy as malathion $>$ carbaryl $>$ metasysto $>$ chloropyriphos $>$ neem oil $>$ endosulfan $>B$. thuringinesis. Of all the insecticides, metasystox was found to be most toxic to all honeybee species and $B$. thuringinesis was least toxic

\section{Care of the poisoned colonies}

Colony loses foragers by poisoning. The availability of pollen and nectar is adversely affected in the hive. In such cases, pollen and sugar syrup should be supplied. If the treatment remains residual for long time then the bee colonies should be moved to safer places. Sometimes, poisoned pollen is stored in combs and this causes adult bee and brood death even after the treatments are over. This badly affects the development of bee colonies. In such cases, the combs with poisoned pollen can be soaked in water for few hours and washed by slight shaking. The strength of poisoned colonies is reduced and uniting of weak colonies should be preferred. One or two combs of bees can be added to the weak colonies for quick recovery.

\section{Plant toxicity to bees}

There are evidences of pollen or nectar of some plants being poisonous to bees. Poisonous substances in nectar or pollen have been identified in few cases. Plant poisoning is difficult to differentiate from pesticidal poisoning. Field bees may die in front of hive entrance. Some plant poisoning render field bees black and shiny from loss of hair. Brood can also be killed and dead brood do not have brown or black colour as produced in foul brood diseases larvae in all stages may die. Egg laying by queens can be affected and superseded. Following plants have been found to be poisonous to bees; Buckeye, Aesculus californica; Black night shade, Solanum nigrum; Death camas, Zygadenus venenosus; Dodder, Cuscuta spp.; Leather wood, Cyrilla racemiflora; Locoweeds, Astragalus spp.; Mountain laurel, Kalmia latifolia; Seaside arrowgrass, Triglochin meritima; Whorled milkweed, Asclepias subverticillata; Western false hellebore, Veratrum californicum and Rhododendrons, Rhododendron spp.

Cases of poisonous pollen have been reported in India. Curved abdomen, outstretched wings with loss of sting power, inability to hold on with the legs of bees foraging in Euphorbia geniculata were observed by Deodikar et al. (1958). Deodikar also reported the presence of pollen grains of poisonous nature in honey sample from Western Ghats. The plants were: Clematis gouriana, C. wightiana, Datura arborea, Euphorbia geniculata, Lasiosiphon criocephalus and Lobelia nicotianaefolia. Nectar of tea, Camellia thea, was found toxic to honeybees and colony gathering nectar of this plant suffered larval mortality (Sharma et al., 1986). 


\section{REFERENCES}

Abrol, D. P. and Kumar, A. 2009. Foraging activity of Apis species on strawberry blossoms as influenced by pesticides. Pak. Ent.31(1): 57-65.

Anderson, L. D. and Atkins, E. L. 1968, Pesticide usage in relation to beekeeping, Ann. Rev. Ent. 13: 213-38.

Atkins, E. L., Greywood, E. A. and Macdonald, R. L. 1973. Toxicity of pesticides and other agricultural chemicals to honeybees: Univ. Calif. Div. Agri. Sci. 2287.

Atkins, E. L., Kellum, D. and Atkins, K. W. 1981. Reducing pesticide hazards to honeybees; Mortality production techniques and integrated management strategies. Division of Agricultural Sciences, Univ. of Calif. 2883.22 pp.

Attri, B. S. and Sharma, P. L. 1969. Toxicity of some new insecticides to the Indian honeybee. Apis indica, Pesticides 3(6): 27-29.

Attri, B. S. and Singh, R. P. 1978. A note on the biological activity of the oil of Lantana camera L. Ind. J. Ent. 39(4): 384-85

Bai, A. R. K. and Reddy, C. C. 1977. Laboratory toxicity of some insecticides to Apis cerana indica.Journal of Apiculture Research 16(3): 161-62.

Bhattacharya, P., Samuel, R. C., Ghosh, M. R., Dasgupta, S. K. and Roy, A. 1982. Sunflower seed yield as influenced by pollination and insect pests. Proc. 10th Int. Sunflower Conf. Sulfers Paradise: 132-34.

Cherian, M. C. and Mahadevan, V. 1946. Preliminary trials With DDT and Gammexane against the Indian bee. Apis indica. Indian Bee Journal 8(9/10): 128-30.

Dale. D. and Mehrotra, K. N. 1976. Studies on the inhibition of honeybee cholinestrase by carbamates. Entomon.1(1): 39-42.

Deodikar. C. B., Thakar, C. V., Shah, P. N., Salvi, S. R., and Chitale, P. S. 1958. Foraging of honeybees on fungal rust spores (Cercospora oleae) on Olea dioica. Bee World 39(5): 120-21.

Gulati, R. Kumari, B. and Sharma, S. K. 2004. Field and residual toxicity of some insecticids to honeybee (Apis mellifera L.) and residues of common insecticides from apiary honey. Korean Journal of Apiculture 19(1): 51-56.

Gupta, M. and Mohla, R. S. 1986. Aliphatic straight chain ketones as potential bee repellents. Chem. Ind. 5: 327-28.

Gupta, M. and Kapil, R. P. 1983. Olfactory response of Apis florea F. to some repellents in semi field conditions. Proc. 5th Int. Symp. Polln., Versailles, pp. 65-78.

Hameed. S. F., Adlakha, R. L. and Gianzo, S. P. 1973. Relative toxicity of some insecticides to the workers of Apis mellifera. Madras Agriculture Journal 60(7): 552-56

Kapil. R. P. and Lamba, D. P. S. 1974. Toxicity of some important insecticides to Apis cerana Fab. Ind. J. Ent. 36(1): 6-10.

Kumar, M. P. and Rahman, A. 2012. Efficacy of some insecticides against mustard aphid, Lipaphis erysimi (Kalt.) and their toxicity to honeybee, Apis cerana. F. M.sc. Thesis submitted to Assam Agricultural University, Jorhat, India.

Kumar. J., Patial. S. K. and Mishra, R.C. 1986. Evaluation of some essential oils as repellents to Indian honeybee, Apis cerana indica F.1. Gustatory repellency and toxicity. Journal of Apiculture Research 25(4): 256-59.

Mall, P. and Ram, S. 2010. Evaluation of preference and safeness of some biorational insecticides on foraging of Italian bee, Apis mellifera L. Ann. Ent. 28(1): 69-73.

Metcalf, R. L. and Luckman, W. H. 1994. Introduction to insect pest Management (Edt.) John Wiley and Sons, New York. 577 pp.

Mishra, R. C. 1995. Honey bees and their management in India, ICAR, New Delhi. 168 pp.

Mishra. R. C. and Verma, A. K. 1982. Relative toxicity of some insecticides to A. cerana 
indica workers. Indian Bee Journal 44(3): 69-71.

Mohapatra, L. N. and Patnaik, H. P. 2009. Studies on relative safety of some insecticides to the Indian hive bee, Apis cerana indica F. in mustard. J. Plt. Protc. Environ. 6(1): 30-32.

Qadri, S. S. H., Sultana, H. and Anjum, F. 1982. Selective toxicity of organophosphorus and carbamate pesticides to honeybees and freshwater fish. Int. Pest Conf. 24(5) : 12426.

Rahman, A. and Rothanga, J. 1999. Bioefficacy of certain insecticides against Mustard aphid, Liphaphis erysimi (Kalt) and their toxicity to honeybee, Apis cerana indica $\mathrm{F}$. Environment and Agriculture Ecology Society. Nepal, Katmandu: 366-370.

Rahman, A. and Saikia, K. R. 2005. Efficacy of plant products against mustard aphid (Liphaphis erysimi) and their toxicity to honeybees (Apis cerana) Ind. J Agric. Sci.75(3): 175-177.

Ramakrishna, C. C., Rajmohan, N. and Subramaniam, T. R. 1974. Effect of insecticidal sprays on the pollinators of sunflower. Madras Agriculture Journal 61(6): 175-77.

Reddy, C. C. 1983. Effects of pesticides on the level of ions and amino acids in the haemolymph of worker Apis cerana indica Fab. Indian Bee Journal 45(5) : 105-07

Reddy, C. C. 1979. Effect of insecticides on the activities of digestive amylase and protease of honeybee, Apis cerana. Indian Bee Journal 41(3/4): 19-23.

Sharma, D. and Abrol, D. P. 2005. Contact toxicity of some insecticides to honeybee, Apis mellifera L. and Apis cerana F. J. Asia-Pacific Ent. 8(1): 113-115.

Sharma, S. K., Khan, M. S. and Kumar, Y. 2000. Relative field toxicity of different insecticides to Apis mellifera L. workers foraging on green gram, Vigna radiata (L.) Wilezek flowers. Korean J. Apic. 16(1): 45-48.

Sharma, O. P., Raj. D. and Garg. R. 1986. Toxicity of nectar of tea (Camellia thea L.) to honeybees. J. apic. Res. 25(2): 106-08.

Singh, M. T., Sharma, P. L. and Dhaliwal, H. S. 1974. Toxicity of insecticides to honeybee workers, Apis cerana indica. Pesticides 8(12): 28-29.

Thakur, A. K., Kashyap, N. P. and Dogra, G. S. 1981. Relative toxicity of some pesticides against Italian bees. Apis mellifera. Indian Bee Journal 43(4): 101-03. 


\section{5 \\ Migratory Apiculture}

$\mathrm{M}$

IGRATION of honeybee colonies is necessary to get the nectar and pollen

reward from the flower sources by the worker bees. Such migratory practice is being done on rape-seed and mustard and other oil seed crops during winter. Again in the spring, the colonies are migrated from oil seed crops to fruit crops such as apple, litchi, mango, guava, lemon, citrus etc. This practice profusely helps both beekeepers who obtains honey from the colonies and the farmer also benefits through effective pollination. In fact, this is mutual benefit farm activities.

There are frequent cases when a nectar plant which was focused of one's hope to get surplus honey-stores, fails suddenly or its blooming coincides with very hot weather or very rainy weather when conditions are not conductive for bee's flight activity. Some of the localities provide nectar flow for one season followed by dearth period during the other. Therefore, it becomes necessary to transport colonies to areas where sufficient nectar, pollen providing flowering plants are available. Such transportation of bees from one honey source to another is called migration. Migratory beekeeping is a tremendous apicultural achievement. It permits gathering nectar where its quantities are the largest; consequently, one can get rid of "windows without honey flow" and to some extent become independent of the environment. Migratory beekeeping is a very old technique in apiculture. Colonies are transported not only to the sources of the main honey flow, but also to such nectar plants which are of secondary importance but help intensify young-bee rearing for the main honey flow, or provide for the beesbetter preparation for winter. If the conditions are favourable one can gather surplus honey. It was found that migratory beekeeping can bring three or four honey yields per year. If a beekeeper has migrated colonies to a honey harvesting area at once, he has definitely appreciated the great advantages of this technique over the stationery ones. After that they will become a travelling beekeeper and will never miss the chance to gather honey flows somewhere nearby. Unfortunately, too many beekeepers do not travel with their bees. Some of them find it difficult to prepare their bees for transportation or regard the transportations very dangerous for their bees and are afraid they may perish enroute; others are too busy with their full time jobs to spare time for such migration. Only full time beekeepers who have very few number of colonies and cannot afford to migrate individually; they must follow cooperative migratory beekeeping. They can pool up their colonies and one of the trained beekeeper can look after the colonies at the migration site on wage basis. With migratory beekeeping, one can get an additional 30 or $40 \mathrm{~kg}$ of honey/hive. Migratory beekeeping has not only increases the 
production of honey per hive but also enhances the chances of success in the division of colonies to a great extent. Migratory beekeeping can very safely be classified as an economic proposition, because of the fact that total expenditure incurred on the whole migratory operations are much less than the profit received from it. Migratory beekeeping not only helps increased honey production, surplus honey stores for winter and build up of the colonies but also prevents the loss of colonies. Experience shows that more than $60 \%$ of the colonies suffer mortality due to floral dearth coupled with attack of wasps or birds and other predators in stationery colonies. Further more, weak colonies are more susceptible to wasp attack, bee diseases and abscond. Strong colonies on the other hand can very effectively defend against the wasp attack and have less tendency to abscond. Furthermore, at migration sites there are no difficulties in protecting the bees in the forest or field, if the migrating beekeepers cooperate and take turn guarding the bees. With this kind of organized bee migration and a cooperative association no matter how small it may be the beekeepers can have effective, adventure some and highly advantageous beekeeping. Migratory beekeeping is one of the best forms of active recreation. It is particularly practiced when the plant blooms. If two sites with equally good sources of nectar are available, the site with higher soil fertility should be selected. The plants growing on peat bogs, does not secrete much nectar while those on freshly burned areas secrete high yields of nectar. It is not desirable to locate one's apiaries close to large bodies of water or near the roadsides, especially when the sources are situated on the opposite side of the river, road. One will inevitably lose many of his flying bees if these factors are neglected. The amount of precipitation within the period of nectar plant vegetation should also be taken into account. Rain is another most important factor if rains are normal, nectar secretion will be more. It is highly desirable that next to the source of the main honey flow, or at least nearby, there are plants providing secondary nectar flows. In case the main nectar plant is not strong enough or its secretion lasts not the whole day or few hours, the bees will be able to work on nectar plants of secondary importance. The qualities of the local nectar bearing flora and the expected honey flow are a most important factor determining the outcome of the final output of the entire apicultural season.

When a beekeeper decides to migrate his bee hives to cultivated fields, he must get the permission of the farm management to accommodate his hives on their land and official grounds. It must be negotiated pre-hand that no fields near the apiary will be sprayed with insecticides or only safer insecticides will be used when bees are not foraging. It is necessary to make a survey of the area where colonies are intended to be taken. A site suitable for an apiary is selected and all arrangements to locate colonies on site after transport are completed. Migration of colonies is done during the night time, when bees rest within the hives. All the colonies are inspected a day or two before migration. Sugar feeding is given where necessary.

If the beekeeper wants to shift his bees to forest, he must address the local forest authorities. The latter will also allocate the places for accommodating the apiaries. Such places are usually fixed in the forest skirt, near or among the nectarbearing areas. The plot chosen should be dry, well heated by the sun; its vegetation 
should protect the hive against the sunshine during the hot day hours. Over crowdedness of colonies in an area should be avoided. It is better to divide colonies into small groups depending upon the source. It has been found that the temporary division of apiaries into smaller units is a most successful technique for utilizing honey yielding areas to their utmost.

\section{Migration of beehives}

The migration of beehives is integral part of migratory apiculture. Movement of beehives can be made with the help of transport and before transportation of colonies, beekeeper should plan systematically. The distance to which the colonies are migrated must be kept in mind. If they are to move more than $2-3 \mathrm{~km}$ away from the apiary, then there is no problem as this distance lies outside their short range. But if they are to be moved less than $3 \mathrm{~km}$ away from the apiary, one cannot move them all of a sudden. They should be either moved a meter daily in the evening towards the side he wants to establish them or if the same is not possible they should be first shifted to a place which is at a distance of about 2 or $3 \mathrm{~km}$ or more than this from both the places i.e. from the place where the colony is being shifted and where it is intended to be established. After keeping the bees for about a week to such a new site, they can be brought to the desired site without any hesitation. On reaching a new place, they become accustomed to the new site. If the bees are to be moved to a considerable distance, they should be moved at least $3-5 \mathrm{~km}$ beyond their flight range. The bees should be moved when all the field bees have returned to their hive, either later in the evening or early in the morning. It should be ascertained that all the cracks or openings between the hive parts are closed by filled them with paper, rags, or similar materials so that the bees will not find their ways out during transit. The bottom board and hive parts be fastened securely. Hive staples are made to secure hive parts tightly so that they may not shift position when raising and handling the colonies. In hot weather, the hives should be provided with a top moving screen to provide a clustering surface and air for the bees. When colonies are loaded on trucks or other vehicles each layer or hive should be separated by wood strips to provide a space between for free movement of air. Properly prepared colonies can be moved in the hottest weather. The truck should be kept moving, if stops are necessary it should not be parked in the sun. It is always advisable to transport colonies during night. After, all the colonies were unloaded at the new location, the entrances can be opened and screens removed. On a bright hot day, it is better to spray the bees with water to prevent flight and drifting.

During winter the cold weather when bees are not flying, or after they have ceased flight for the day, colonies can be moved without any specific preparation as the bees make little attempt to come out of the their hives while the truck is in motion. If the weather is fine for flight, the colonies may be left on the truck until morning before unloading. Sometimes, if colonies are to be moved immediately at a short notice when the bees are working in the field, one can shift the colonies leaving one colony full or combs in the apiary so that bees returning from the field trips can be collected in this hive. It is preferable to reach the destination while it is still dark outside. Bees remain in their rest and come out of the hive to 


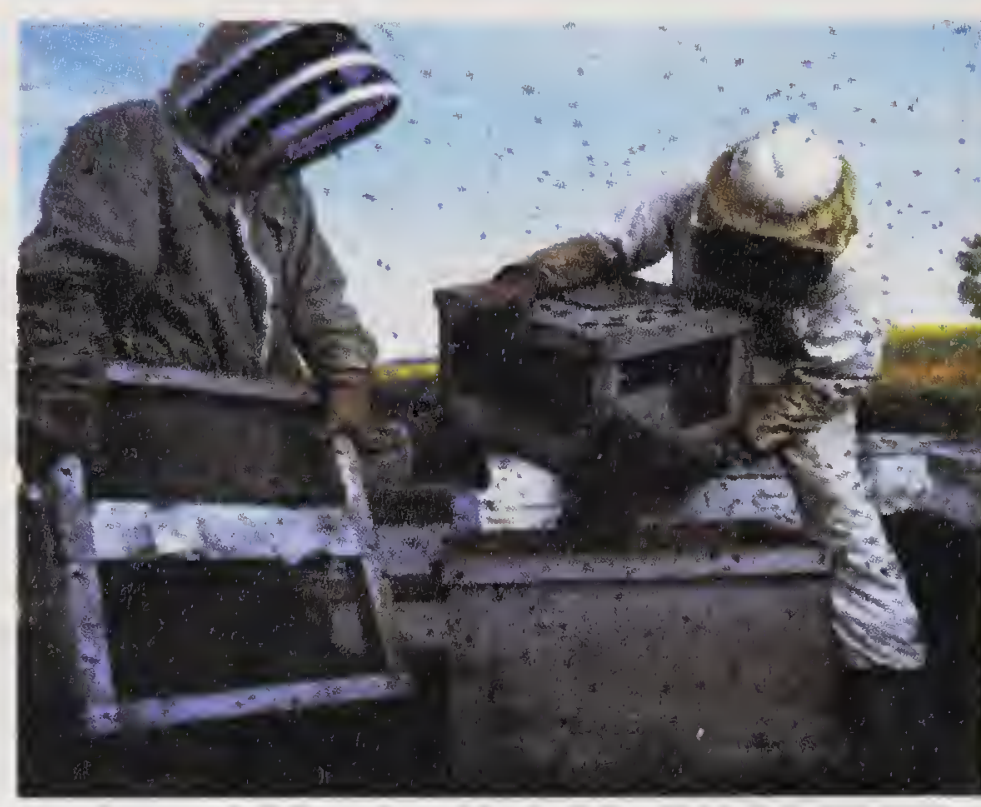

Fig. 15.1. Migratory preparation of honey bee colonies.

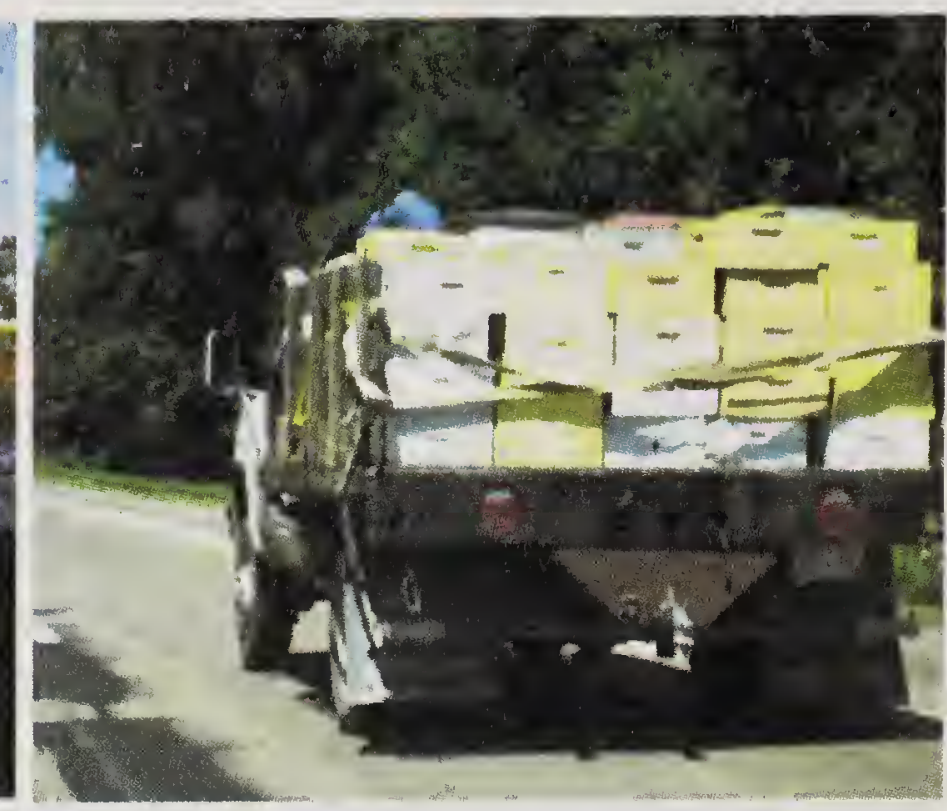

Fig. 15.2. Transportation of honeybee colonies.

resume their usual activities in the following morning. On reaching the migratory site, the hives are distributed and kept in their selected spots. The entrance gate is kept open, removing the wire screen. They are left in that position for a day or two. After about a day of migration, when the bees have got their acquaintance with the new location, the inspection work can be done after removing the screen covers and when the inspection work is over, the hives should be closed with their original cover. The broken combs should be replaced and all the bottom boards cleaned. Colonies are given sugar feeding to encourage foraging for pollen. After the colonies resume normal working activity, necessary management is taken up for the purpose for which the migration is undertaken.

\section{Different types of migration}

The migrations could be short distance ones when undertaken between different parts of the local forests, or between forests and adjacent farms when there is short duration floral dearth. Monsoon in the tropical and subtropical regions and winter in the temperate region along the Himalayas constitute the long periods of floral dearth, when it is worthwhile to migrate the colonies to areas where bee flora is available (Suryanarayana and Rao, 1998).

\section{Migration: needs and considerations}

Because of temporal and spatial distribution of different bee plants, the availability of surplus flora or honey flow for bees varies in time and space. In any specific beekeeping area, only one or two honey flows are available and when honey flow ceases at particular site, the beekeepers move their apiaries to some other site within or outside their state, where honey flow from some other plant species can be available to the bees. The type of movement of honeybee colonies, several times a year from one region to the other, for getting multiple honey crops and increasing colony yields is referred to as 'migratory beekeeping' and is a common practice with many beekeepers (Mishra and Shrama, 1998). The need, types, some routes and useful consideration for migratory beekeeping, its prospects, problems and possible solutions are discussed below. A beekeeper may need to move his honeybee colonies to long distance for various reasons such as 
to abridge the floral dearth periods, to exploit different bee floral sources/honey flows, to rent out his colonies for pollination of the crops/orchard plants or to establish a new apiary at some new location. The migratory beekeeping in earnest is, however, an important component of commercial beekeeping undertaken not only to augment honey production but also to increase the colony strength either for exploiting the ensuring better honey flow to its maximum or to have an ease in the colony multiplication well in advance of some good ensuing honey flow.

While preparing the honeybee colonies for migration and practically migrating them, the beekeepers needed to consider a number of factors discussed in this chapter. Abrol (2010) discussed some of the useful factors for effective migration.

Season: Migration of honeybees during winter is not a great problem. Exposure to cold simply has the effect of causing bees to consume more honey stores, produce heat and cluster together on the brood nest as they do in the winter. In cold weather, the bee colonies should be taken care of simply by closing their hive entrances with wire screen ensuring required ventilation especially if there is some warmth in the air. If the colonies are strong, full screened inner (migration) covers be nailed over the bee frames. In cold and rainy weather, the hives should be covered with a tarpaulin when being moved.

During summer or monsoon season, colonies should be migrated during night when it is cooler and all the bees are in the hives. The bees clustering outside can be made to drive inside the hive by giving a few puffs of cool smoke or light sprinkling of water over them. Enough ventilation must, however, be ensured by exchanging the inner wooden cover with full screened one. A small piece of screen nailed on or thrusted into the entrance to keep the bees inside the hive will also facilitate the ventilation roots. It is also wise to sprinkle a little water at the hive entrances and travelling screens at intervals if it is long distance migration but do not over do it, because if the hive becomes wet, inside temperature will rise instead of falling. It is worth emphasizing that it is not be cold but heat that injures bees while confined their hives for migration. Infact, very little harm ever results from chilling of the packed colonies while moving the bees. So the golden rule in moving bees is to provide ample ventilation, plenty of inner space and to keep them cool. Making short time halts and temporary siting of the apiaries enroute on some suitable bee flora for a day or so is also advisable when long distances and several journey days, especially in summer season, are involved. It may not only lessen the problem of food dearth in the colony but will also avoid arousing of the absconding instinct among the bees due to unnatural/unfavorable conditions. For colony migration in summer or monsoon season, the bottom board of the hives can also be modified for providing extra ventilation. The bottom board can be divided into two parts by nailing a lengthwise bar inside its centre. One half is provided with a regular entrance for bees. Whereas the other half can be covered with a full wire screen to prevent the bees from landing on its floor. The portion of the entrance rod in front of this screened half is cut and totally removed so that only the air can pass freely though that screened half but bees cannot escape.

Distance of migration site: Very long distance migrations of colonies during winter seasons at a stretch is possible provided the bees have sufficient food reserves. During cold weather, bees consume excessive food stores to produce 
heat and cluster together over the brood nest. During such weather, the hive entrance can simply be closed and bee carted. But if some warmth is expected in some region enroute, the entrance should always be closed with screen/perforated zinc sheet and hive body (bee frames) be covered with full sized travelling screen. Bees are killed very often by overheating and lack of aeration but very seldom by getting chilled. During long distance colony migrations in hot weather, as already discussed above, the populous colonies may be divided to create more room for the expansion of the cluster. Alternatively, these colonies are shifted with supers in position to allow plenty of room for expansion of the cluster. The hive body and supers and course be stapled properly to avoid their sipping en route.

During summer, it is worthwhile to have one or two halts/journey breaks for short temporary siting of the apiary for a day or two at some suitable place having some bee flora by easing the confined bees. Moving the colonies continually for more than $48 \mathrm{hr}$ often leads to their brood mortality and such colonies produce poor results particularly when migrated for pollination.

Number of hives: If the number of hives to be migrated is small, it will not be economical to migrate as per colony carriage/transport charged will be much higher than when the beekeeper has full vehicle-load. Hence, full vehicle-load (number) of colonies be migrated to make it more economical. However, in case the number of colonies is small, and migration at all has to be done, make it a full truck-load by joining with fellow beekeepers who also intend to take up migration to the same or nearby areas.

To accommodate more colonies in the vehicle, and for quick dissipation of heat, the top and inner covers of the packed colonies are removed and replaced with travelling screens. Before stacking the other row over the lower row of the colonies to be migrated, rectangular wooden bars on near the anterior edge and another near the posterior edge of the travelling screen be placed. Same may be repeated for stacking the subsequent (upper) rows of colonies in the vehicle. This will prevent chocking of ventilation through travelling screens. Alternatively, some built in provision must be there so that bottom boards of the upper row of stacked bee hives do not jam the travelling screens of the lower row of the stacked bee hives. The left over spaces towards the end of the rows of stacked colonies may be jammed by inserting the removed top and inner covers.

Colony strength: Migratory beekeeping means a good deal of movements of honeybee colonies and this is a job that seems to frighten the beginners. Bees get excited in confinement which in populous colonies leads to increased production of heat in the packed colony and suffocation of bees until there is sufficient room expansion of the cluster and plenty of aeration. If weather is very hot and the colony is populous but the hives is not spacious enough to allow expansion of the cluster, bees may very quickly smother and get suffocated even when the bee frames are covered with full wired travelling screen. For safety, the heat must be dissipated sufficiently and rapidly to keep the temperature of the interior of the hive low enough for the bees to be comfortable. As the temperature rises high enough, the bees get upset and crowded all over the travelling screen, thereby preventing the heat from escaping. This may result in the rise of inside hive temperature higher than the melting point of beeswax, the combs might melt, the 
bees immediately discharge the gorged honey and in a matter of seconds they start dying leaving sticky mass of half-animate bedraggled. Hence, populous colonies may be shifted with an empty super, filled with drawn combs or empty frames, in position to allow plenty combs may be added for the expansion of the cluster in the hives before migration. If empty combs are not available, empty wooden frames alone or with well fixed comb foundation sheet can be added in between brood/bee frames to ease congestion and facilitate ventilation.

Preparing and packing the colonies for migration: Extraction of surplus honey to be made few days prior to the migration. All cracks and crevices in the hive should be sealed or closed. Excessively broken hive parts should be replaced with new ones. The hive body, bottom board and inner cover should be fastened together by stapling/nailing. Always use two staples on each side of the juncture and slant the staples in opposite directions to prevent the hive parts from shifting/ slipping. An alternative to the hive staples is to use metal or nylon travelling (migration) belts around the hive. It is however, not wise to use rubber belts as being elastic in nature, the rubber belts cannot withstand slipping of hive parts. Sometimes, some beekeepers move bees at night with their entrances open and covering the whole vehicle with nylon netting so that bees are not confined to the hives any way. In such case, the bees cluster outside the hive and make unloading at destination very difficult. If unloading is done during day time, the bees will get confused and are lost. Moreover, because of some reason or the other, the vehicle need to be stopped enroute, the leaking bees may get lost and can also pose serious problems to the passerby. Therefore, it is better to make the colonies be full proof but sufficiently ventilated before the same are loaded for migration.

Type of the vehicle: Generally, the colonies should be migrated by using shockproof vehicle (vehicles with effective shockers), such as trucks, mini trucks four wheelers (tempo). However, sometimes, for short distance migration, beekeepers use their own tractor-trailers. While migrating the honeybee colonies in vehicles such as trucks, the jerking movements will be forward and backward hence, the length side of the hives should be kept parallel to the body of the vehicle (i.e. length of the hive should be perpendicular to the axle of the vehicle). While loading the colonies in a tractor-trailer where the jerking movements are sideways, the bee hives should be loaded with their length side parallel to the vehicle or the axle of the vehicle. Such type of loading will avoid striking of the bee frames enroute with each other, thereby avoiding the bee mortality due to crushing during migration. It is best to have running engine of the vehicle running during the loading and unloading process. The vibrations caused by the engine have an effect on the bees which causes them to move up and away from the hive entrance. This makes it less likely for the bees to fly out of the hives during loading and unloading. For extra precaution, cover the sides of the vehicle with wire mesh and the entire load of beehives from the above with some type of nylon netting. Some extra provisions on the sides of the vehicles near its floor may also be built in to ventilate the bottom most beehives of the stacks loaded in to vehicle. If a short duration stop is necessary on the way, it is recommended that engine be left running unless it is for a long period of time. It is better to place the hives in the new location late in the evening or at night so as to reduce the tendency of 
some of the foragers to fly away from the hive and get lost in search of food before they have learnt the new location of the hive. After unloading, wait a few minutes to remove the entrance screens. New site location can be reinforced by placing wooden board against the hive entrance. This will tend to confuse the forgers and encourage them to take orientation fights and learn the new location. Facing hives towards the walkway or areas of human activity should be avoided.

Time of the day: If the whole of the apiary is to be shifted, it is better to move the bees in the evening or at night (when all the bees are inside the hive and temperature is low) or during inclement or cold weather when the bees have not gone out for foraging. However, if a part of each colony (nucleus) is to be shifted, it can be done even during day times as the field bees will return to the parent hive left behind and will not be lost. As already discussed above, the colonies at the new site should be opened preferably in the late evening so that bees leave with prior orientation fights the following day and are not lost in an endeavor to forage.

Migration time in relation to floral phenology: Colonies should not be taken to crop needing pollination until it is in good bloom and can be considered the predominant species in the locality. It was reported that delay in shifting colonies to the crop until flowering period has begun, invariably increases pollination particularly when the crop has short flowering period and is less attractive to bees than the crops in the area. The same is true for honey production. In either circumstance, few colonies should be released in the crop before successive days of flowering. However, it should be pointed out that if a great proportion of flowers of crop are open before colonies are taken to it, an important part of crop may fail to be pollinated as the receptivity to fertilize the flowers or many species diminishes. A flower produces/releases most of its nectar and pollen at a time characteristic to its species. Some plant species produce nectar in morning hours and release pollen grains in afternoon or vice versa. For example in case of Pyrus and Malus (apple), most of pollen is released in the afternoon. In musk melon, pollen is released in early morning. If the colonies are to be shifted to these floral sources, they should be brought at the time when majority of the pollen is being released. If the colonies are shifted and brought at the time when the crop in question does not shed pollen, bees will approach the flowers of other crops that are releasing pollen during that time and the bees will then get conditioned to that crop which we do not intend to pollinate. Under these situations, hive entrances of the colonies should remain closed with wire mesh for the first day after transportation and should be opened at a time when the crop intended to be pollinated, releases the pollen. Following this type of practice, we can increase both the nectar collection and the pollination efficiency of the honey bees.

Placement of the migrated stock: The migrated honey bee colonies should be placed away from the passage/walkways where human or domestic animals' movements are expected. If there is no choice but to site along passages, the hive entrances be kept in the opposite direction to the passages. If migration is for pollination purpose, the bee colonies be placed within the crop and should be evenly distributed over the area to harvest maximum pollination benefits and should not be crowded at one place. Even for honey production, care should be 
taken that the site is amply away from any other migrated bee-yard so that overcrowding could be avoided.

The colonies should not be opened immediately after placement. Time should be given to the bees to calm down otherwise they should be aggressive and resort to stinging. Entrances of the colonies should preferably be opened late in the evening to avoid the loss of foragers in the field that are taking off to the crop for food immediately without any orientation flights. The drifting behavior which is extensive when identical hives are arranged in regular fashion is particularly undesirable because it results in undue weakening of some colonies while strengthening of others. This results in less nectar collection by the weaker colonies and lowers the average foraging potential for pollination. The drifting can be reduced by arranging hives, irregularly, placing them with their entrances in different directions, spacing them apart, putting them near the land marks and putting different coloured boards above hive entrance. The first two measures are particularly effective and whenever possible they should be applied when migrated particularly for crop pollination. New site/location can be reinforced by placing slanting wooden planks against the hive entrance. This will tend to confuse the foragers and encourage them to orientation flight and learn then new hive location.

Increasing attractiveness of the crop: When honey bee colonies are migrated for pollination purposes, many attempts need to be made to direct bees to a certain crop by simulative feeding with a little sugar syrup containing the scent of target crop intended to be visited by the bees. The technique implies to immerse and/or crush the flowers of the crop in sugar syrup for some hours, then strain/sieve the flowers and feed the sugar to the colony (Kumar et al., 1998). Often fresh flowers of the crop are also provided for bees to stand on while lapping/licking the syrup. Bees, that take syrup communicate odour of target crop to other bees in the hive which then leave the hive to visit the communicated food source. Spraying the crops with 'bees cues' (bee lures) and use of reflected UV light on the crops reported to increase the crops' attractiveness to the bees.

Conditioning of the colonies: For pollination purposes, the pollen gatherers are more useful than nectar gathering bees if the purpose is the increased pollination of the crop on which the colonies are intended to be migrated. Therefore, it is beneficial to increase number of pollen gathers for higher efficiency in pollination. Since, the proportion of foragers that collect pollen increases with the amount of brood in the colonies, the colonies for pollination should contain plenty of brood. Simulative sugar feeding is useful for increasing colony's brood rearing and thus enhances its pollen foraging potential. Colonies can be induced to pollen collection by removing some of their pollen stores and giving them extra combs of young larval brood to be reared. Restriction on incoming pollen to the colonies with pollen traps is also helpful in increasing pollen foraging.

Anticipated profits: From the beekeepers point of view, one must be able to have good honey crop and the colony growth as well on the migrated crop, not only to offset the expenditure incurred on migration but also to have sufficient monetary and physical benefits. Good colony growth would help the beekeeper in selling the bees or would ensure him its division or he would better exploit the ensuing honey flow elsewhere owing to colonies' increased strength. Thus, to 
achieve above benefits, the beekeepers must be conversant with the climatic conditions of the area, bee flora and all the more its relative utility to the bees. The beekeepers must be aware of the honey production potential of the bee flora on per unit area basis, honey collection potential of the honey bee colonies and the expected level to which his colonies would develop (Gatoria et al., 1994; Chand et al., 1995; Chhuneja et al., 2001). The migration should be undertaken only when estimates ensure the required profits/benefits.

\section{Migratory routes in India}

The floral sources and blooming period are the prime indicators for migratory apiculture. Thomas et al. (2001) discussed some of the effective migratory routes in India. Rao and Rao (2011) while migratory management of Apis mellifera in India mentioned that Apis mellifera beekeeping is mainly dependent on cultivated and agricultural crops. Over 24 million ha were under oilseed crops like ground nut, sunflower, safflower and mustards. Except ground nut other oilseed crops are useful to honey bees. Among other commonly cultivated plant species useful to honeybees are coconut, areca nut, red oil palm, date palm, cocao, mango, custard apple, jujube, cinnamon, clove, cashew, coffee, lemon, orange, plum, pear, peach, cherry, jamun, fodder legumes, coriander, fennel, fenugreek, onion and other spice and condiment crops. Avenue plantations that contribute to honey production include eucalyptus, karanj, tamarind, gulmohr, copper pod and soap nut. Hedges and fence plants like the Indian privet, duranta, mulberry, Justicia and Jatropha, do also add to the bee forage value of farms and orchards. Many pulse and oilseed crops are good sources of bee forage. Among the plantation or commercial crops, coffee, orange and other citrus fruits, apple and other pomaceous fruit species, cardamom and rubber tree are important from beekeeping point of view. Rubber tree is the single-most largest sources of nectar in India. Rubber plantations are found in southwestern and northeastern parts of India, where tropical humid climate prevails. Kerala, Tamil Nadu, Karnataka, Tripura and Asom have large areas under rubber plantation. The nectaries on young leaves of rubber trees secrete nectar profusely in the refoliation stage, before the tree blooms. In 1990-91 this source alone provided over 6,200 tonnes of honey. Next in importance is the litchi tree. The entire north India from West Bengal to Jammu has large areas under litchi orchards that constitute an excellent source of nectar during March to May. Beekeepers of the Punjab shift their bee colonies near roads, railway tracts, canal banks etc. for availing eucalyptus honey flow during February-March. There after some beekeepers who migrate the apiaries to Pathankot and Dehradun areas for litchi honey flow during April; to Hoshiarpur, Jalandhar, and Amritsar, Ludhiana and Bathinda during April-June on sunflower; to Brassica campestris var. toria growing belt in and around Amritshar, Taran-taran, Rajpura and Patiala areas during October-November; to Rajasthan (Ganganagar, Sanghria, Padampupr, Bhartpur, Karanpur, Alwar etc.) and Haryana (Hissar, Karnal and Rewari) and Uttar Pradesh on B.campestris var. sarson and B. juncea during DecemberFebruary. Few beekeepers utilize khair flow during June to August at Bhilaspur, Haldwani, Amb, Nalgarh, Hamirpur etc. and some migrate to areas rich in Fagopyrum sp. or to the hills of Himachal Pradesh for Plectranthus. Afterwards, 
they bring back the colonies to the Parent State. During July- August colonies withstand the dearth period due to the migration, otherwise artificial diet is essential. Colony development and breeding is done during mustard blooming. Half of the mustard flow and other blooms are utilized for honey extraction. Beekeeper reports an average 50 to $60 \mathrm{~kg}$ honey productions per hive and 1: 1 colony multiplication during these migrations. Generally colonies ranging 100 to 200 are migrated in single truck and cover a distance of 300 to $500 \mathrm{~km}$. In Bihar, which is a dominant honey producing state, commercial beekeepers adopt migratory beekeeping mainly for litchi and karanj honeys. The colonies are migrated from various pockets of the state to Muzzaffarpur and East Champaran during March-April for litchi nectar. After litchi nectar, few beekeepers migrate colonies to Jharkhand till end of May to avail the karanj. Generally beekeepers migrate back to their apiary after litchi flow or karanj. Some beekeepers extend the period up to November for survival and build up of the colonies on brassica, coriander, moringa, and maize at Jharkhand area. In the southern states of Kerala and Tamil Nadu, intensive migration is practiced to rubber plantations from January to April, since it is the only dominant source in this region. It is estimated that 4 lakh hectares of rubber plantations are available for exploitation of honey with the potential for honey production thus is about 80,000 tonnes. Rubber is considered as the third major source of honey next to rape seed/mustard and sunflower in India. Beekeepers from Kerala and Tamil Nadu migrate their colonies mainly to Quilon, Kottayam, Changanacherry, Trichur, Palghat, and Kozhikode, Cannannoore districts for rubber honey flow. As the period of nectar secretion of rubber varies from region to region, accordingly beekeepers exploit the rubber flow by shifting the colonies from one region to other. Few beekeepers migrate to tamarind flow from May to June in Tamil Nadu. Colonies are also migrated to high ranges of Devikulum, Peerimedu, Idukki districts etc. to cardamom estates for buildup of the colonies. The colonies can also be migrated to cashew, coffee, and eucalyptus common in the region. The vast coconut belt and groundnut flora sustains the colonies during the rest of the period. In West Bengal, large number of colonies is migrated to Sunderban mangrove forests for organic honey production. In Kashmir, the colonies are migrated to Isodon rugosus, saffron, Crochus sativus for major flows. Local migration is also practised in India within 50 to $80 \mathrm{~km}$ radius for the survival, strengthening and breeding of the colonies. Of late, migratory practices is being done in north east particularly in Asom, colonies are migrated from rapeseed-mustard to rubber, litchi, citrus and durun bon, (Leucus linifolia) and Sesamum both for pollen and nectar.

\section{REFERENCES}

Abrol, D. P. 2010. Beekeeping: a comprehensive guide to bees and beekeeping. Scientific Publication. India: 896 pp.

Chand, H., Singh, R. and Yazdani, S. S. 1995. Migratory beekeeping with Apis mellifera - a profitable business in Bihar. Indian Bee Journal 57: 147-148

Chhuneja, P. K., Aulakh, R.K. and Singh, J. 2001. Migratory beekeeping in India: its prospects and problems. Indian Bee Journal 63 (1-2): 23-34 
Gatoria, G. S., Jhajj, H. S. and Rataul, H. S. 1994. History of introduction of Apis mellifera L. and development of beekeeping in Punjab (India). Indian Bee Journal 5(1-2): 8-15.

Kumar, J., Mishra, R. C. and Thakur, S. S. 1998. Use of honey bees for increasing agricultural yields. 187-211 pp. In Mishra, R. C. (Edt.), Perspective in Indian Apiculture, Agro Botanica, Bikaner (India), 412pp.

Mishra, R. C. and Sharma, S. K. 1998. Technology for management of Apis mellifera in India, 131-147 pp. In Mishra, R. C. (Edt.), Perspective in Indian Apiculture, Agro Botanica, Bikaner (India), 412pp.

Rao, S. K. and Rao L. K. 2004. Management of bee floral resources to increase honey through migration. Bee keeping with Apis mellifera in India. Beekeeping Times: 1-6.

Suryanarayan, M. C. and Rao, K. S. 1998. Apis cerana F. for Indian apiculture and its management technology. 66-108 pp. In Mishra, R.C. (Edt.), Perspective in Indian Apiculture, Agro Botanica, Bikaner (India), 412pp.

Thomas, D., Pal, N., Chawla, S. S. and Rao, K. S. 2001. Bee flora and migratory routes in India. Proc. $37^{\text {th }}$ Int. Apic. Cong. Durban, South Africa. 


\title{
16 \\ Bee Hive Products
}

\begin{abstract}
AICULTURE in India was mainly meant for production of honey. However, - with the progress in research and development in apiculture, the other valuable beehive products such as beeswax, royal jelly, bee venom, pollen and propolis have been known to the apiculturist. Commercialization of these products is a new boon to beekeeping industry. The production and uses of hive products are discussed here.
\end{abstract}

\section{Honey}

Honey is a sweet, viscous liquid produced by honeybees mainly from nectar of plants. Bees also collect sweet exudates deposited by insects as 'honey dew' and it is like flower nectar. Some plants also have nectaries other than on flowers. These nectaries also secrete sweet liquids and bees do avail this extra floral nectar. Besides nectars, bees can collect any sweet material like fruit juices, cane juice etc. Depending upon the source of sweet liquid and also the plant species in case of floral and extra floral nectar, the quality of honey varies (Fig. 16.1). On this basis, the honey can be classified as floral honey or honeydew honey. Though mono floral honeys are not common, yet honeys can be categorized on the basis of floral source such as litchi honey, berseem honey, eucalyptus honey, Brassica honey etc. It is also customary to name the honeys on the basis of colour. Honey is extracted and prepared for market by different methods. The honey from Apis dorsata combs is squeezed and it is ought to contain more pollen grains and even the juices of some brood and the honey is normally called squeezed honey. The honey from combs of hive species is extracted with the help of honey extractors, so it is

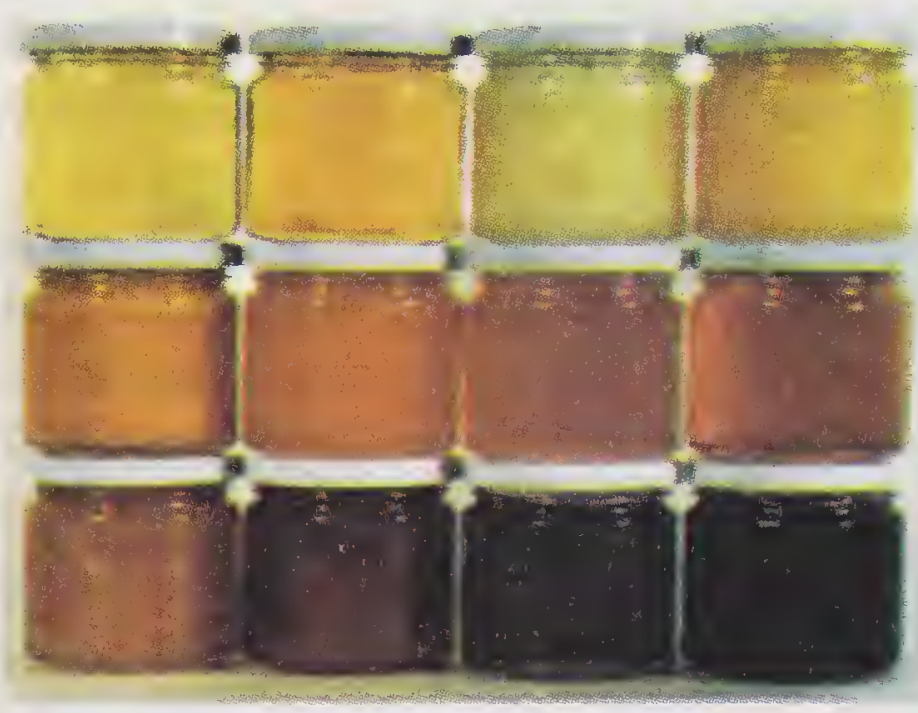

Fig. 16.1. Different types of honey. extracted honey. These honeys may remain in liquid form or may crystallize, and, hence, can be presented to consumers as liquid honey or granulated honey. There are some other preparations for marketing honey which are not common in India. Small combs can be made to be raised and sealed honey in these combs is marketed as such as comb honey. Small pieces of combs are suspended in liquid honey packing and the preparation is marketed as chunk honey. 
Composition of honey: Chemical composition of honey is very complex. Honey mainly contains sugars but acids, minerals, vitamins, enzymes and antibiotic substances are also present in small amounts. The solids in honeys vary with the floral source.

Honeybees, after putting through the ripening process, seal honey in comb cells when the moisture content is about $20 \%$. The honey in north Indian hot plains have lesser moisture content as compared to honey from Western and Eastern Ghats, North east and areas with very humid climates. In these areas, the moisture level in honey can be up to $23 \%$ and honeys are thinner in consistency. The moisture contents may even change after extraction during storage because honey is hygroscopic and absorbs moisture (Table 16.1). Honey contains many types of sugars but it chiefly consists of 2 reducing sugars, dextrose and levulose (fructose). The 2 sugars account for about $70 \%$ of total solids. Sucrose in honey varies between 0 and $5 \%$. A reducing disaccharide maltose is also present in higher amount that is $3-16 \%$. This disaccharide may not be present initially, but the quantity increases with storage and this probably happens by conversion of other sugars by the action of enzymes and acids. Precise analytical methods have also shown the presence of many other lesser common sugars such as isomaltose, trehalose, genitiobiose, maltulose, panose, turanose etc. These complex sugars account for $1-2 \%$ only.

Mineral complex of honey is very wide consisting of potassium, calcium, phosphorus, sodium, magnesium, manganese, copper, sulphur, silica, silicon and iron and all these account for up to $1 \%$ of solids in honey. Different vitamins are present in honey and these are: thiamine (B1), riboflavin (B2), nicotinic acid, vitamin $\mathrm{K}$, folic acid, biotin, pyridoxine, pantothenic acid, ascorbic acid and carotene. There is loss of vitamins during storage. The losses in thiamine, riboflavin, niacin and ascorbic acid in different unifloral honey is given below (Kalimi and Sohonic, 1965).

Physical properties of honey. Besides chemical composition, the physical properties are used to lay down standards for honey. These characteristics also give an inkling of purity of honey. Honey is hygroscopic, which means it absorbs

Table 16.1 Average values of multifloral honey from 4 zones of India (Phadke, 1967)

\begin{tabular}{lccccc}
\hline Items & $\begin{array}{c}\text { East zone } \\
\text { (Asom } \\
\text { W.B. Bihar) }\end{array}$ & $\begin{array}{c}\text { West zone } \\
\text { Karnataka) }\end{array}$ & $\begin{array}{c}\text { North zone } \\
\text { (Pb., U.P } \\
\text { and J\&K) }\end{array}$ & $\begin{array}{c}\text { South zone } \\
\text { (Kerala, } \\
\text { Madras) }\end{array}$ & $\begin{array}{c}\text { All India } \\
\text { (Av.) }\end{array}$ \\
\hline Specific gravity & 1.392 & 1.392 & 1.397 & 1.40 & 1.399 \\
Direct polarization & -20.6 & -10.9 & & 3.27 & -2.20 \\
Total diss. solids (\%) & 76.81 & 76.87 & 77.50 & 78.19 & 77.57 \\
Reducing suger (\%) & 68.91 & 69.97 & 72.78 & 72.88 & 70.24 \\
Non-reducing sugers (\%) & 3.19 & 3.97 & 2.01 & 1.99 & 3.27 \\
Levulose (\%) & 36.01 & 36.72 & 38.04 & 38.77 & 33.39 \\
Dextrose (\%) & 32.31 & 36.72 & 35.03 & 34.07 & 33.39 \\
L/D ratio & 1.136 & 1.120 & 1.084 & 1.137 & 1.097 \\
\hline
\end{tabular}

(WB, West Bengal; M.S, Maharashtra; Pb, Punjab; UP, Uttar Pradesh; J\&K, Jammu \& Kashmir). 
moisture from air. In areas with high humidity, the honey if not stored properly, tends to draw water from moist air. This happens in surface layer of honey which increases in moisture content. The hygroscopicity depends upon the sugar composition and moisture in honey. Moisture in honey is in equilibrium to particular relative humidity level. For instance $21-23 \%$ moisture in honey is in equilibrium with $66 \%$ relative humidity. The moisture content of honey can be lowered if exposed to air with lower relative humidity. On the contrary, the honey can be saved from absorbing moisture and rendering it liable to fermentation by proper storage of honey in very humid areas. Therefore, the hygroscopicity has practical application to the beekeeper. Honey is a viscous liquid and the viscosity determines the flowability. Yadav et al. (2004), studied the physiochemical characteristics of honey from four species of honey bees in north India and reported that moisture content ranged between 16.22 to $18.87 \%$ and total reducing sugar from 63.62 to $68.1 \%$. The mineral contents of the honey were high in honey samples from Apis dorsata (0.33) compared to those of other honey bee species $(0.20-0.24 \%)$. Fiehe's test was negative for all the samples.

Gairola et al. (2013) investigated the physicochemical properties of Apis cerana indica $\mathrm{F}$. honey obtained from Uttarakhand and reported that the honey composed of moisture ranged from 19-25\%. Fructose percentage ranged from $37.27-40.51$, whereas values for glucose were $35.12-38.04 \%$. The study indicated that the honey samples had good quality and will be important for the commercialization of regional honey.

Average values of multifloral honey from 4 zones of India is given in Table 19 (Phadke, 1967). Measurement of viscosity can be used to determine moisture content. Heating reduces the viscosity thus the heat treatment is given to handle honey. But in addition, the viscosity is also dependent on the protein contents which in turn is dependent on the source of nectar. Honey with higher protein contents tend to be more viscous. Specific gravity and refractive index are other important properties. Ratio of weight of honey to the weight of same volume of water is the specific gravity of honey. Pure honey should have the specific gravity of about 1.35 to 1.44 . There are different methods of measuring specific gravity but it is customary to specify the temperature. Similarly, refractive index of honey is the ratio of the velocity of light in honey to that in air. By using refractometers the moisture in honey can be determined. The measurement of these two properties gives quick readings for moisture content.

Honey has specific aroma and flavour. This aroma is imparted by nectar of flowers which is an important physical property for judging honey. Honey has also an ability to acquire foreign odours, so an improper storage containers can impart some metallic flavours. Purity standards have been laid for both apiary and squeezed honey by Indian Standard Institution (1969).

Fermentation of honey. Honey containing higher moisture content can ferment. This more often happens in case the honey crystallizes and the crystallization is not uniform. The honey granulation starts from the bottom and the dextrose crystallizes forming solids at the bottom. The upper layer of honey becomes dilute with lower sugar concentration. There are many species of osmophilic yeasts in honey and these sugar tolerant yeasts are responsible for honey fermentation. Fermentation 
of honey is very common at the temperature between $11^{\circ}$ and $21^{\circ} \mathrm{C}$ and the tendency to ferment is reduced at lower and higher temperatures. Fermentation of honey leads to the formation of alcohol and carbon dioxide. The alcohol may further be converted into acetic acid and water, the chain will continue and the whole of honey in the container is fermented. Fermented honey is sour in taste because the acidity is as high as 1.5-3.1 milli equivalents. Heating honey to $64^{\circ} \mathrm{C}$ for about $30 \mathrm{~min}$. destroys yeasts in honey and thus the fermentation is prevented. There are no chances of honey fermentation if it granulates uniformly and quickly.

Crystallization or granulation of honey: Granulation of honey is the greatest problem for Indian beekeeper. The granulation is considered to be an indication of impurity or adultration in honey and granulated honey is not acceptable to the consumers. Granulated honey is also difficult to handle. Some honeys granulate soon after extraction but some do crystallize even when in combs and this was observed to happen in Brassica honey when combs remain partly uncovered by bees. This makes honey extraction impossible and such combs are good only for feeding colonies in dearth period. The consumers do not understand that honey is a super-saturated sugar solution. The major sugars in honey are fructose and dextrose. Dextrose has the tendency to crystallize and because of this, the honey has a natural property to granulate. Fructose is more soluble in water than glucose, therefore, moisture content of honey also contributes to the granulation of honey.

Fructose: glucose ratio gives an indication of rapidness with which the honey granulates. The honey which has higher ratio of L/D will granulate slowly. Carvia callosa (Wall) Brenek honey contains 38.29\% levulose and 28.17\% dextrose, giving L/D ratio of 1.43 which never granulates. In case of Strobilanthes ixiocephalus honey the ratio is 1.038 and the honey granulates quickly. But this ratio cannot give correct indication of granulating property because in Syzygium cumini (jamun) honey ratio is 1.10 but the honey does not crystallize. Therefore, it is not only the $\mathrm{L} / \mathrm{D}$ ratio which is important but there seem to be other factors effecting crystallization. Recently, dextrose (D) is to moisture ratio (W) has been considered to give more accurate indication of granulation. Honey with higher $\mathrm{D} / \mathrm{W}$ ratio is expected to granulate rapidly but this also does not hold good in all the cases and again the exception is jamun honey. But the two criteria are enough for generalization.

Any foreign particles like pollen grains, dust particles and pieces of wax serve as nuclei for granulation and even air bubbles serve the same purpose. The granulation starts around these nuclei. Honey may granulate uniformly and rapidly. In such cases the granules are fine and there are little chances of fermentation of honey. But some honeys granulate slowly in which case the crystals fuse into bigger lumps leading to coarse granulation. The bottom layers in the container granulate, whereas the top honey layer is still in liquid form. The top liquid layer becomes dilute and fermentation occurs.

Heating of honey destroys yeasts in honey and all dextrose granules are dissolved, therefore, granulation is delayed. The crystallization is also reduced at low temperature between $0^{\circ}-5^{\circ} \mathrm{C}$. The optimum temperature for crystallization is about $14^{\circ} \mathrm{C}$. This property gives an important clue to beekeepers regarding storage temperature of honey. 


\section{Antioxidant properties of honey}

Antioxidants are substances which protect the body from damage caused by free radicals. Free radicals are vary reactive chemicals which react with and change other molecules next to them. Maurya et al. (2014) studied, the antioxidative properties of honey from different flora and reported that honey serve as a good source of natural antioxidant and hence, it is free radical scavengers that either reduce the formation of or neutralize free radicals. Honey is a healthy foodstuff for human health and nutrition. The composition and source of honey greatly indicates about its biochemical properties. The study highlighted on the antioxidant/ radical scavenging capacity of various honey of different flora and geographical origin using spectrophotometric tests: Folin-Ciocalteu assay for phenol content, ferric reducing antioxidants assay(FRAP assay) for total antioxidant activity, 1, 1-diphenyl-2-picrylhydrazyl (DPPH) assay for antiradical activity and florimetric method namely, oxygen reactive antioxidant capacity (ORAC) for the antilipoperooxidant activity. The phenolic and other compounds in honey are responsible for free radical scanvenging and antioxidant activity that produce beneficial effects in human health

Processing of honey: Honey in comb cells has desirable flavor and aroma, and has no foreign particles except pollen grains. During extraction and handling for marketing the quality of honey may be deteriorated by the beekeeper himself. During extraction, bits of comb wax are incorporated in honey. The honey is extracted with the help of extractors and it is drawn in thin film from the comb cells, thus some aroma is lost. During extraction some air-borne dust particles may also be added to honey. Faulty storage conditions such as inappropriate containers, high storage temperatures, etc. would further deteriorate the quality of honey. Raw honey is always loved by the consumers but beekeeper wants to

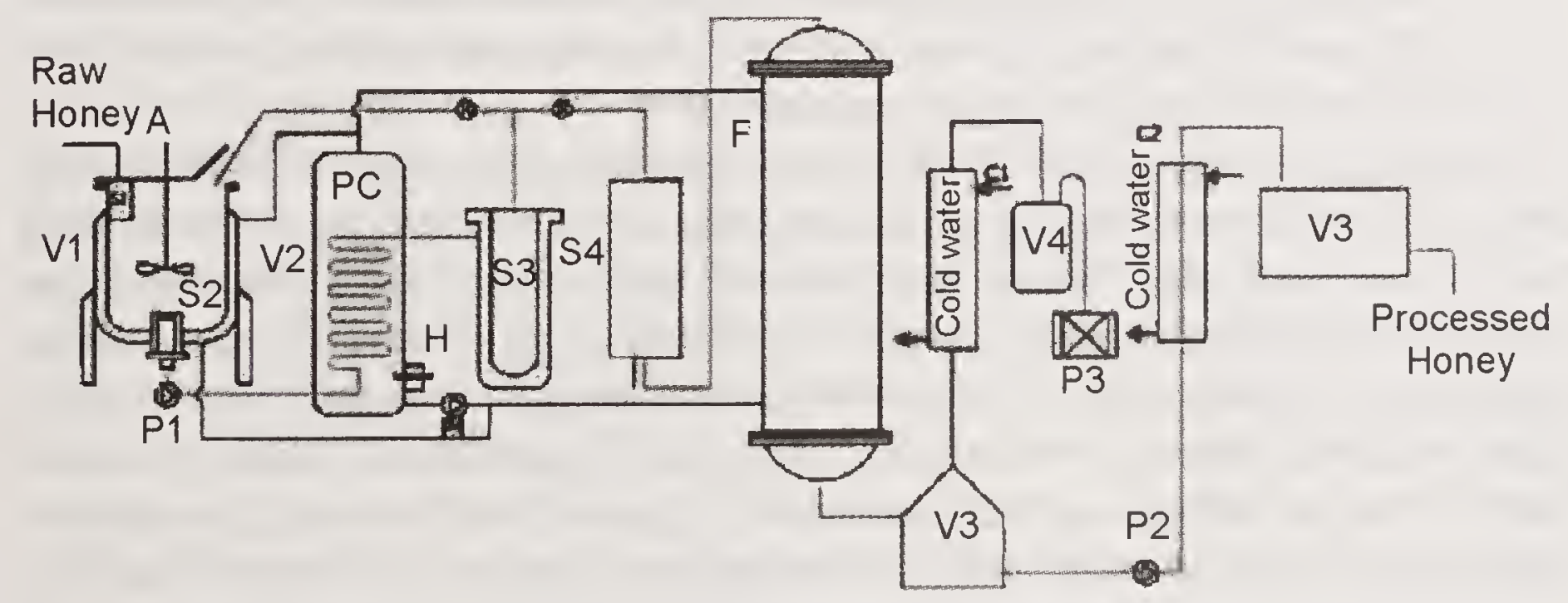

Fig. 16.2. Honey Processing Plant (Courtesy: R.D \& Company, India)

Details of Fig. 16.2 Honey Processing Plant:

(Yellow line- Honey flow line; Green line- water flow line; Blue line- Vacuum line; PC: Process Coil; F: Falling Film Evaporator;C1: Vapor Condenser; C2: Honey Cooler;V1: Primary Heating Vessel Jacketed with fins; V2: Hot Water Generator; V3: Vapor Separator;V4: Condensate Receiver ;V5: Settling Tank; A : Homogenizer; H: Electric Heaters;P1: SS Gear Pump for Raw Honey; P2;SS Gear Pump for Processed Honey; P3: Vacuum Pump (Oil Ring Type);P4: Hot Water Circulating Pump; Honey Filtration: -S1: Trough Screen SS 304 - 60 mesh S2: Online Screen SS $304-100$ mesh S3: Online Primary Filter, Polypropylene Bag 10 micron S4: On Line Secondary Filter, Resin Bonded Cartridge 5 micron). 
put the honey in the market in a best way. But it should be remembered that 'least processing is good processing' (Fig.16.2).

Honey from different sources vary in physical characteristics and chemical composition. The processing, therefore, depends upon the composition of honey. Some honeys as discussed earlier tend to granulate quickly, whereas others do not or do granulate but slowly. Any attempt to keep the granulating honey in liquid form will be a bad practice, since this will be against the natural properties and such honey tends back to the granulated form. But consumers require the honey that does not ferment and in India crystallized honey is also considered to be impure by most ill-informed consumers. Honey is attempted to be kept in liquid form in India at the cost of losing the valuable aroma.

Heating is the only treatment given for processing honey. But heat treatment if not carefully given can lead to adverse effects. Heat affects honey in many ways which are discussed below:

1. Hydroxymethyl furfural is produced by degradation of honey sugars. This change also takes place during long storage at comparable higher temperatures but heating is the common reason.

2. Honey enzymes are destroyed by heating.

3. Heating reduces the viscosity, which facilitates handling. To achieve this objective the appropriate temperature to move honey is between $38^{\circ}-43^{\circ} \mathrm{C}$.

4. The treatment is usefully employed to destroy yeasts in honey. This honey if not again contaminated will not ferment. The honey can be made yeast free by heating at $71.1^{\circ} \mathrm{C}$ for $0.4 \mathrm{~min}$ of $65.5^{\circ} \mathrm{C}$ for $2.8 \mathrm{~min}$ or $60.0^{\circ} \mathrm{C}$ for 22 min. Honey needs time to raise its temperature and this time is taken into account for its pasteurization.

5. Honey contains some crystal nuclei of dextrose. These nuclei, when very small may not be apparently visible but they are the cause of crystallization of honey. The heating destroys the crystal nuclei and thus the granulation is delayed, though it cannot be avoided.

Honey is first warmed to $38^{\circ}-43^{\circ} \mathrm{C}$ and this will allow easy flow. This warm honey is then taken to holding tank at about the same temperature. In the holding tank the wax and other foreign particles rise to the surface from where they are removed. The holding tank is provided with paddle type agitator. The paddles are rotated at the speed of $10 \mathrm{rev} / \mathrm{min}$ while it is submerged in honey. The agitation helps in homogenization and blending of honey. The agitator is rotated at a slow speed so that air bubbles are not incorporated in honey. Next in line are the strainers which are provided in series with decreasing mesh sizes and minimum should be around $80 \mathrm{mesh} / \mathrm{inch}$. These strainers remove all particles. Any wax particles not removed through straining will give hazy appearance to honey because high temperature $\left(66^{\circ}-70^{\circ} \mathrm{C}\right)$ for pasteurizing will also melt the wax. The strained honey is then passed through a tank to raise the honey temperature to $63^{\circ}-65^{\circ} \mathrm{C}$ for $5-7$ min to destroy the yeast. This is achieved by flash heating, that is heating honey in thin layers; it is required because of poor conductivity. The honey so heated is quickly cooled to avoid deterioration of quality. Small scale beekeepers cannot afford to have elaborate processing arrangements; for them warming and straining of honey is only applicable method. 


\section{Storage}

Storage containers for liquid or crystallized honey should be made either of glass or stainless steel or coated with food grade plastic, paint or beeswax. Nothing should be allowed to impart any odour to the honey. Particularly if used containers are recycled, care must be taken that they are absolutely clean and have not the slightest residual odour. Honey readily absorbs odours of all kinds and these can, for example, be readily absorbed by a beeswax coating and then passed into the honey. Containers previously used for toxic chemicals, oils or petroleum products should never be used for storing any bee products, even after coating with paint, plastic or beeswax. Openings in wholesale containers have to be big enough to facilitate removal even of crystallized honey. To keep moisture out, lids have to be airtight and all products should be kept away from heat and (preferably) light. Also, most products containing honey should be protected from excessive moisture by special packaging; baked products in moisture proof clear plastic bags, caramels in separate plastic or waxed paper wraps and single portions of liquid or pulverized product in laminated foil envelopes made of aluminum foil covered with plastic and paper envelopes. Storage rooms should have a temperature near $20^{\circ} \mathrm{C}$ and a relative humidity of less than $65 \%$. Storage of honey at more than $25^{\circ} \mathrm{C}$ causes increasing quality loss with time, due to progressive chemical and enzymatic changes. Honey is considered a stable product, in the sense that it is not spoiled by the bacteria and fungi normally responsible for food spoilage. Products containing honey however, are preferred targets for such organisms and therefore demand pasteurization (stabilization with heat) or chemical preservatives (according to product requirements) plus adequate storage and protection from recontamination after production. Proper storage and packaging together with quick marketing and consumption will reduce or eliminate the need for preservatives. Fermentation remains the major threat to unprocessed honey, whether it is liquid or crystallized. Therefore storage conditions have to prevent fermentation through either low temperature storage or by preventing further absorption of moisture. Even honeys which are not susceptible to deterioration by yeasts however, can be subject to other progressive alterations due to chemical and enzymatic action. These changes include organoleptic characteristics such as colour, taste and aroma, together with a loss of biologically active substances (inactivation of enzymatic and antimicrobial activity). Substantial changes may also occur in the sugar composition with an increase of disaccharides and other complex sugars and a corresponding decrease in simple sugars. Other transformations of the initial composition include an increase of acidity and Hydroxymethyl furfuraldehyde (HMF) content. These changes occur in all honeys, but at different rates according to their initial composition (more moisture and a lower $\mathrm{pH}$ result in faster changes) and storage temperatures (higher temperatures also lead to faster change). The same changes take place even faster during (and after) the heat treatments of various processing technologies. Though damaged honey does not become dangerous to human health, it nevertheless loses some of its nutritional and organoleptic values. Therefore in almost all countries, legal limits are set for the degree of "ageing" (or deterioration) of honey for food use. Heat and sunlight (mostly the ultra violet (UV) spectrum) can destroy the quality 
of honey both in brief high exposure or in low level exposure over a long period of time. Some decay is unavoidable, but it should be kept to a minimum. UV radiation destroys glucoseoxidase and thus most of the antibacterial activity. The half-life of diastase in honey at different storage temperatures. Since it is difficult to give a precise preservation limit for honey, due to the large variability of different factors, HMF and diastase are used as indicators of damaging treatment received by a honey during either processing or storage. Decreasing half-life, i.e. faster disappearance of diastase, can therefore be equated with increasing damage to honey. However, initial diastase contents vary in different honeys and have to be known for the fresh untreated material. HMF is used more frequently as an indicator since, its value is close to zero in very fresh honeys (other than a few tropical honeys) and its level increases with time and exposure to heat. EC regulations state a minimum of 8 diastase units for honey. Thus a honey initially containing 16 units can no longer be sold as food grade honey if stored for 4 years at $20^{\circ} \mathrm{C}$, 18 months at $25^{\circ} \mathrm{C}, 7$ months at $30^{\circ} \mathrm{C}, 4$ months at $32^{\circ} \mathrm{C}$ etc. In view of normal production to consumption periods, a storage temperature of $20^{\circ} \mathrm{C}$ is considered an economical compromise. In warm climates, it is important to protect storage vessels from overheating and possibly cool them by special shading or ventilation. Processing, moving and selling honey have to be as fast as possible. Care also needs to be taken that the honey is not damaged by overheating during trucking (particularly during parking in direct sunlight) or while waiting for reloading in harbours or railroad yards.

\section{Other beehive products}

In addition to honey, there are several other beehive products, such as bee wax, royal jelly, bee venom, propolis and pollens which are having commercial importance.

\section{Bee wax}

Bee wax is a natural wax produced in the bee hive of honey bees of the genus Apis. It is mainly esters of fatty acids and various long-chain alcohols (Fig. 16.3). Worker bees secrete wax in the abdominal sternites IV-VII when they are 14-18 days old. This is secreted as liquid but solidifies when exposed to air and scales are formed. These scales are removed by hive bees and used for comb building. Wax scales when secreted are white in colour but the colour to wax is imparted by the pigments of pollen. Beeswax is a complex substance (Phadke et al., 1971). Complex esters of monoatomic alcohols and fatty acids form 70.4 to

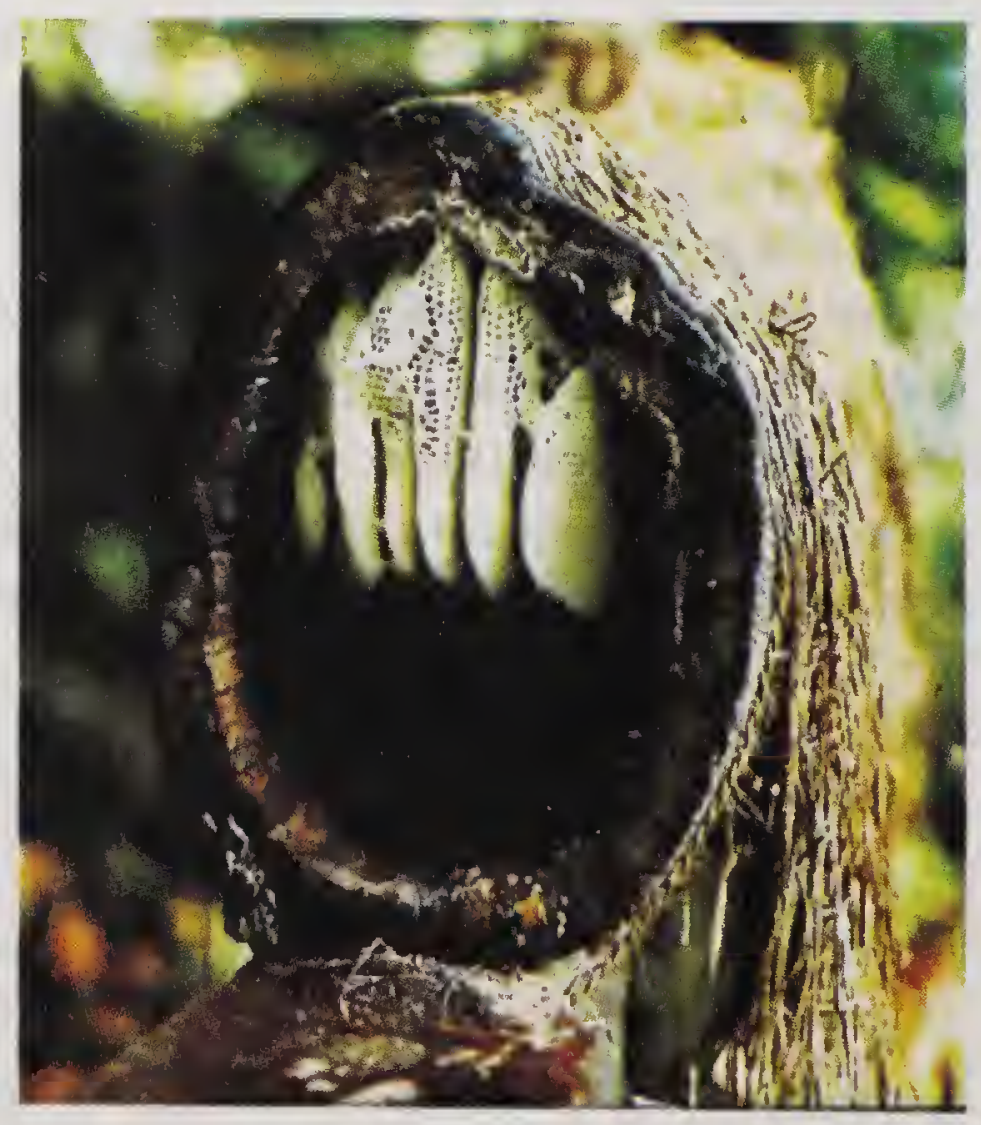

Fig. 16.3 Natural bee wax in comb (Krell, 1996). 
$74.7 \%$ of wax; other components are, free acids 13.5 to $15.0 \%$ and saturated hydrocarbons 12.5 to $15.5 \%$. It is rich in vitamin A and $100 \mathrm{~g}$ contain $4096 \mathrm{I} . \mathrm{U}$. Specific gravity of beeswax is 0.95 and melting point is $65^{\circ} \mathrm{C}$. There are slight variations in properties of waxes of different species (Phadke and Phadke, 1975) as shown in Table 16.2.

Collection and processing: Beeswax is obtained from the cappings collected during honey extraction. Some combs are damaged during honey extraction and wax is also obtained from old combs which become unfit for use. Best grade wax is obtained from cappings and the recovery per cent is also higher. In India, major proportion of wax comes from the combs of Apis dorsata.

There are different methods of collecting wax. More commonly in frame hive beekeeping, wax is rendered from the cappings removed during honey extraction. This produces a very high quality, light coloured wax (Fig. 16.4). Light coloured broken combs provide the next quality of wax, whereas old black brood combs yield the smallest proportion and lowest quality of wax. The combs or washed cappings can be boiled in water tanks. It is strained through a muslin cloth or strainer, the water and molten wax passes through. The wax block is obtained after it solidifies at the top of water. The combs and cappings can be filled in a thick cloth sack. The filled sack is submerged in hot water tank where the water temperature is above melting point of wax. The water is heated to bring it to

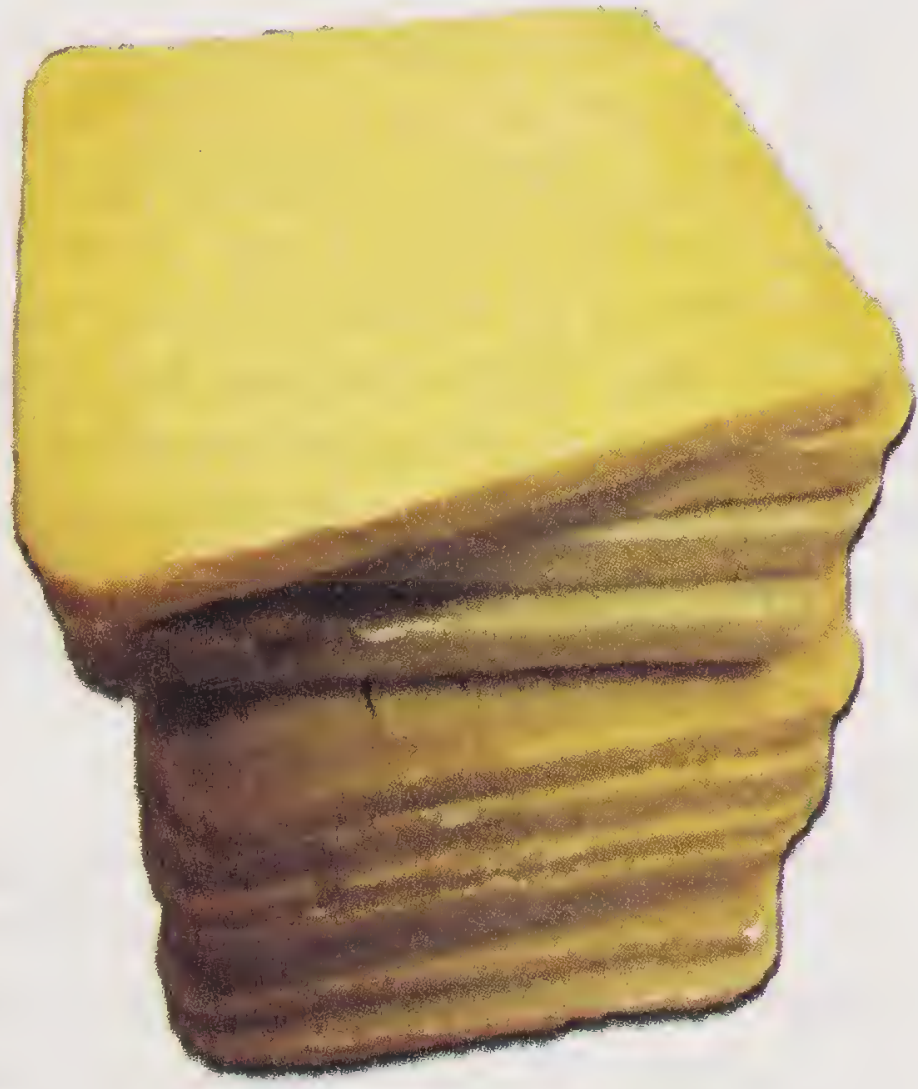

Fig. 16.4 Processed bee wax. boiling. The wax after melting is strained out of the sack and solidifies as top layer on cooling of water in the tank.

Hot wax press is used for efficient and large scale rendering. Raw material is placed in sieve and the material is pressed from both sides with water or steel heated plates. The raw material can even be filled in sacks for rendering. The wax melts with hot plate and it drips from the sides.

Solar wax extractor is also common in use and is particularly effective in hot tropical/subtropical climates. Solar extractor is a box with double glass cover and in between the two cover is air space. The covers are snuggly fitted in the top of the box. On inside bottom, there is metallic wax melting pan which slants to a container. The inside of the box is painted white while from the outside it is painted black. The melting tank/pan is fitted with a strainer at the outlet to strain off the sludge. The wax drops to the other container placed at the outlet of the melting pan. The solar wax extractor does not recover more than $50 \%$ of the wax but is convenient and cheap for rendering wax. Singh et al. (2001) while standardizing the extraction and purification of beeswax mentioned the purification of beeswax by melting the 
Table 16.2 Physico chemical characteristics of Indian bees wax (Phadke and Phadke, 1975)

\begin{tabular}{lccc}
\hline Characteristics & A. cerana & A. dorsata & A. florea \\
\hline Melting point $\left({ }^{\circ} \mathrm{C}\right)$ & 65.82 & 60.67 & 63.03 \\
Saponification value & 98.36 & 98.95 & 91.94 \\
Acid value & 8.21 & 8.04 & 6.77 \\
Ester value & 90.19 & 92.55 & 85.17 \\
Iodine value & 7.82 & 5.39 & 10.28 \\
Viscosity (centipoises) & & & \\
$70^{\circ} \mathrm{F}$ & 11.85 & 10.22 & 12.67 \\
$80^{\circ} \mathrm{F}$ & 8.78 & 7.20 & 6.93 \\
$90^{\circ} \mathrm{F}$ & 6.55 & 5.32 & 6.86 \\
Refractive index & & & \\
$80^{\circ} \mathrm{F}$ & 1.44429 & 1.44363 & 1.44501 \\
$90^{\circ} \mathrm{F}$ & 1.43981 & 1.43922 & 1.43983 \\
\hline
\end{tabular}

crude beeswax by using water-wax mix and indirect heating technique. Molten beeswax then filtered through sack, wire and cloth filters and found that pure beeswax recovery was maximum from burr comb $(39.46 \%)$ followed by brace combs $(36.27 \%)$, old comb $(28.78 \%)$, honey cell capping $(18.87 \%$ and extracted honey $(0.86 \%)$. The melting of bees wax with water-wax mix was more efficient $(10.94 \%)$ as compared to indirect heating $(5.525 \%)$.

\section{Composition of beeswax}

Pure bee wax from Apis mellifera consists of at least 284 different compounds. Not all have been completely identified but over 111 are volatile (Tulloch, 1980). At least 48 compounds were found to contribute to the aroma of beeswax (Ferber and Nursten, 1977). Quantitatively, the major compounds are saturated and unsaturated monoesters, diesters, saturated and unsaturated hydrocarbons, free acids and hydroxy polyesters. The Table 16.3 shows the proportion of compounds as presented by Tulloch (1980). There are 21 major compounds, each making up more than $1 \%$ of the pure unfractionated wax. Together they account for $56 \%$ of the wax. The other $44 \%$ of diverse minor compounds probably account for beeswax's characteristic plasticity and low melting point (Tulloch, 1980). The ratio of ester values to acids, a character used by the various pharmacologists to describe pure beeswax is changed significantly by prolonged or excessive heating. At $100^{\circ} \mathrm{C}$ for $24 \mathrm{hr}$ the ratio of ester to acid is changed beyond the limits set for pure beeswax.

Table 16.3. Composition of bee wax (Tulloch, 1980)

\begin{tabular}{|c|c|c|c|c|c|c|c|c|c|c|c|}
\hline $\begin{array}{l}\text { Wax } \\
\text { content } \\
\text { type }\end{array}$ & $\begin{array}{l}\text { Hydro- } \\
\text { carbons }\end{array}$ & $\begin{array}{c}\text { Monoe- } \\
\text { sters }\end{array}$ & $\begin{array}{l}\text { Dies- } \\
\text { ters }\end{array}$ & $\begin{array}{c}\text { Tries- } \\
\text { ters }\end{array}$ & $\begin{array}{l}\text { Hydroxy } \\
\text { monoe- } \\
\text { sters }\end{array}$ & $\begin{array}{c}\text { Hydroxy } \\
\text { polye- } \\
\text { sters }\end{array}$ & $\begin{array}{l}\text { Acid } \\
\text { esters }\end{array}$ & $\begin{array}{c}\text { Acid } \\
\text { polye- } \\
\text { sters }\end{array}$ & $\begin{array}{l}\text { Free } \\
\text { fatty } \\
\text { acids }\end{array}$ & $\begin{array}{l}\text { Free } \\
\text { fatty } \\
\text { alcohols }\end{array}$ & $\begin{array}{l}\text { Uniden- } \\
\text { tified }\end{array}$ \\
\hline $\begin{array}{l}\text { Perce- } \\
\text { ntage }\end{array}$ & $14 \%$ & $35 \%$ & $14 \%$ & $3 \%$ & $4 \%$ & $8 \%$ & $1 \%$ & $2 \%$ & $12 \%$ & $1 \%$ & $6 \%$ \\
\hline
\end{tabular}


Use of wax: Beeswax is mainly consumed by candle industry and bee industry for preparing comb foundation sheets. Wax is also an important constituent of cosmetics like cold creams, lipsticks and rouges because it adheres better to skin. Pharmaceutical and perfume industries are also major users of wax. It is also used in ointments, capsules, pill coatings and deodorants. Wax is used for preparing shoe polish, furniture etc. because it acts as water proofing. Its minor use is made in adhesives, chewing gums and inks etc.

\section{Bee venom}

Sting of worker bee is attached to a poison sac where venom is stored. Newly emerged bee is unable to sting because she cannot insert the sting which is not fully chitinized. Moreover, there is very little venom stored in the venom sac. A bee, when two weeks old has maximum venom in her poison sac and there is no more addition to this quantity. Composition of bee venom is complex and is composed of many active substances such as histamine, apamine, acithinase, hydrochloric acid, formic acid, orthophosphoric and, sulphur, calcium, copper and magnesium sulphate (Table 16.4).

Production. Commercial method of obtaining bee venom is by the use of electric shock (Fig. 16.5). Thin copper wires are stretched about one centimeter apart on a wooden frame which is alternatively charged. This wired frame is inserted

Table 16.4 Composition of bee venom (Dotimas and Hider, 1987)

\begin{tabular}{llc}
\hline Class of molecules & Component & \% of dry venom \\
\hline Enzymes & Phospholipase A2 & $10-12$ \\
& Hyaluronidase & $1-3$ \\
& Acid Phosphomonoesterase & \\
& Lysophospholipase & \\
Other proteins and & $\alpha$-glucosidase & 50 \\
peptides & Melittin & $1-3$ \\
& Pamine & $1-2$ \\
& Mast Cell Degranulating Peptide & $0.5-2.0$ \\
& (MCD) & $1-2$ \\
& Secapin & 0.1 \\
& Procamine & $13-15$ \\
& Adolapin & \\
& Protease inhibitor & \\
Physiologically active & Tertiapinc & \\
amines & Small peptides (with less than 5 & $0.5-2.0$ \\
Histamine & amino acids) & $0.2-1.0$ \\
Amino acids & Histamine & $0.1-0.5$ \\
Sugars & Dopamine & 0.5 \\
Phospholipids & Noradrenaline & 1 \\
Volatile compounds & $\tau$-aminobutyric acid & 2 \\
& $\alpha$-amino acids & 5 \\
& Glucose \& fructose & $4-8$ \\
\hline & &
\end{tabular}




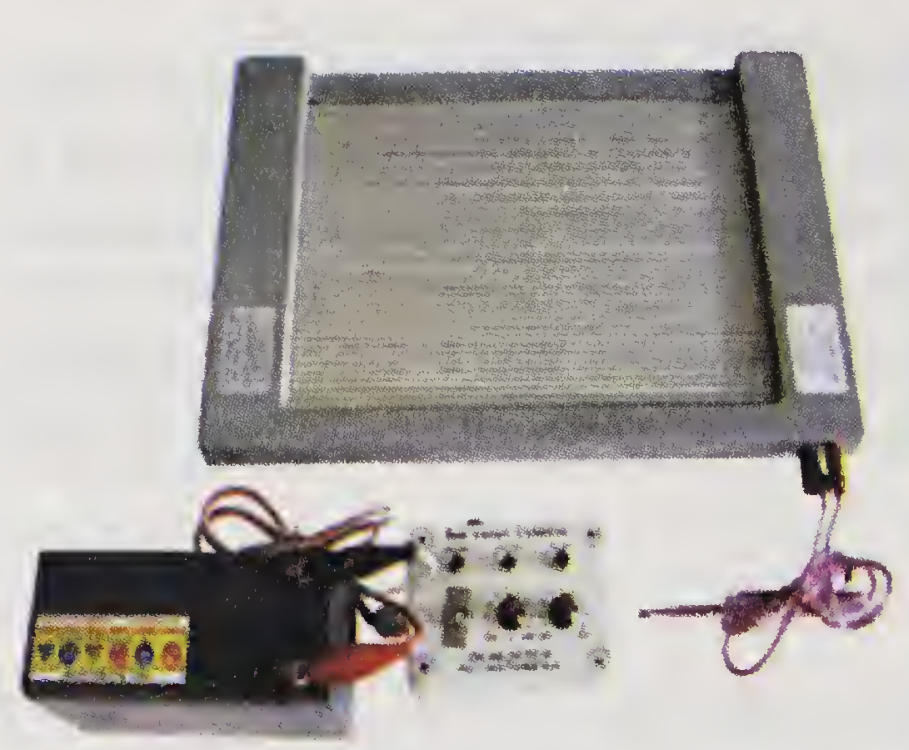

Fig. 16.5 Bee venom extractor.

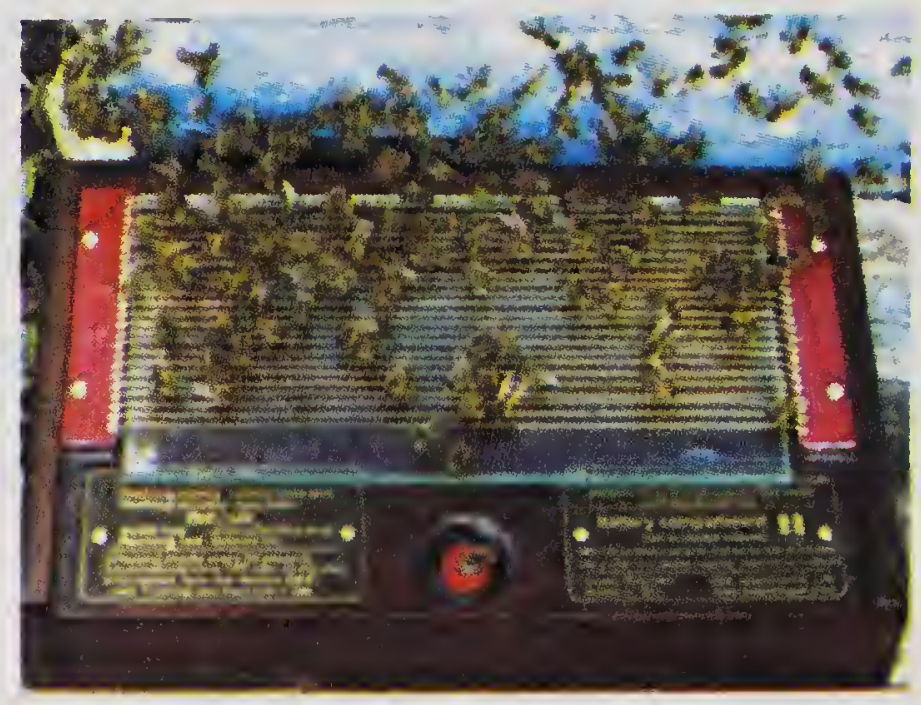

Fig. 16.6 Venom extraction process.

(Adopted from AICRP on Honey bees and Pollinators).

between the bottom board and the brood chamber. An electric current is passed through the wires at 12 volts. The bees get shock when come in contact with any two conducting wires (Fig. 16.6). Such bees get irritated and release venom by inserting the sting into a thin nylon cloth below the copper wires. Venom is deposited on a glass plate placed below the nylon sheet. The venom on drying is scrapped from the glass plate. One mellifera colony yields almost $50 \mathrm{mg}$ of venom. Bees which release the venom do survive but the colony gets greatly irritated. It takes about 5 min to harvest a colony.

Another crude method is to place bees in wide mouth glass jar which is then covered with filter paper. Some ether is poured on the filter paper, the vapours of which irritate bees and they deposit venom on the walls of glass jar.

Bee venom has been reported to be useful for curing many diseases and disorders. Rheumatism cannot be cured by any other system of medicine but majority of patients can be cured by bee venom. It has stimulating effect on heart muscles and decreases cholesterol level and also lowers blood pressure. Bee venom has also given positive results in curing neurosis, endoarteriosis, endoarthritis and neuralgia.

Some people may show allergic reactions to bee venom and bee sting causes general indisposition, vomiting and diarrhea but with time many become immune. Protein antigens of bee cause hypersensitivity. Antihistamine creams or injections and adrenaline are used as anti-allergents. Honey and ethyl alcohol plus ascorbic acid $(100 \mathrm{~g}+1 \mathrm{~g})$ in one litre of water is given to allergic person after every $2-3 \mathrm{hr}$ and this mixture is good anti-allergent. These are only first aid measures, however, doctor should be consulted. Devanesan et al. (2003) reported that bee venom is a bitter, hydrolytic blend of proteins with basic $\mathrm{pH}$ and the major constituents are peptides like melittin (40-50\%), apamin (3\%) and mast cell granulating peptides $(2 \%)$. They recorded the venom secretion by bees of different caste and age groups as two weeks bees has maximum venom in her poison sac and mature bee has 100-150 $\mu \mathrm{gm}$ venom and a young queen about $700 \mathrm{mg}$. Rana et al. (2011) collected bee venom from Apis mellifera by using full Langstroth size Helix make bee venom extractor. On an average $8.7 \pm 1.02 \mathrm{mg}$ and $25.82 \pm 4.18 \mathrm{mg}$ of dry venom was collected from colonies having 5.0-5.5 and 6.0-6.5 combs strength at 18-22 
volts for 5 min operations which was found to be conducive to the bee colonies against 26 to 30 volts for $30 \mathrm{~min}$ irritated the colonies.

\section{Royal jelly}

Royal jelly is secreted by glands of nurse bees of the age of 6-12 days when the glands are fully active. It is very nutritious food and is fed to the young worker larvae and the queen larva and adult. Royal jelly is milky or light pale in colour (Fig. 16.7). It is composed of proteins $15-18 \%$, lipids $2-6 \%$, carbohydrates 9 $18 \%$ and ash $0.7-1.2 \%$. It contains $65-70 \%$ moisture. The proteins are mainly amino acids which are alanine, arginine, aspartic acid, gultonic acid, glycine, isoleucine, lysine, methionine, phentl alanine. Tryptophane, tyrosine and serine. Eight essential amino acids for human beings are present in royal jelly. Carbohydrates in royal jelly are glucose, fructose, melibiose, trehalose, maltose and sucrose (Table 16.4). It also contains vitamin A, B and C. Iron, copper, phosphorus, silicon and sulphur are present in royal jelly. Royal jelly contains some other chemical constituents which are responsible for queen determination and full knowledge of the chemical composition is lacking.

Royal jelly is very nutritious food for human beings as it increases vigour and vitality. It can be taken alone or in mixture with honey. It is not commercially produced in India. Royal jelly production efficiency of Indian bees is not studied but in case of Apis mellifera about $200 \mathrm{mg}$ of royal jelly is obtained from a queen cell. For royal jelly production the technique used for mass queen rearing by Doolittle methods is practicable. The queen cell is trimmed to the level of the royal jelly and after two or three days of grafting, larvae is gently removed with forceps and the royal jelly is removed with royal jelly spoon (Fig. 16.8 and 16.9). This is stored in refrigerated conditions. Rana et al. (2000) attempted to extract royal jelly from Apis mellifera in Himachal apradesh and reported that royal jelly production increase with different strength of bee colonies. The amount was 259.33 $\mathrm{mg} / \mathrm{cup}$ in 5 frame colonies after $72 \mathrm{hr}$ grafting which was significantly more in 10,15 and 20 frame colonies having $332.60,372.17$ and $380.6 \mathrm{mg} / \mathrm{cup}$.

Gill and Chhuneja (2011) evaluated the technique for royal jelly production from Apis mellifera having 6 factors viz. bee strength/crowdiness, queenlessness of colonies, priming status of queen cell cups, number of grafts, materials of queen cell cups and different feed materials and out of them queen right cell builder colonies feed vitamins $\mathrm{B}_{6}$ supplemented pollen substitute provided 90

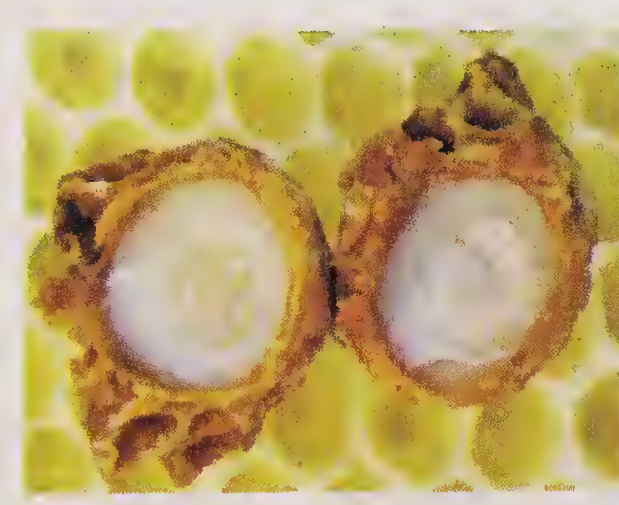

Fig. 16.7 Queen Cell with royal jelly.

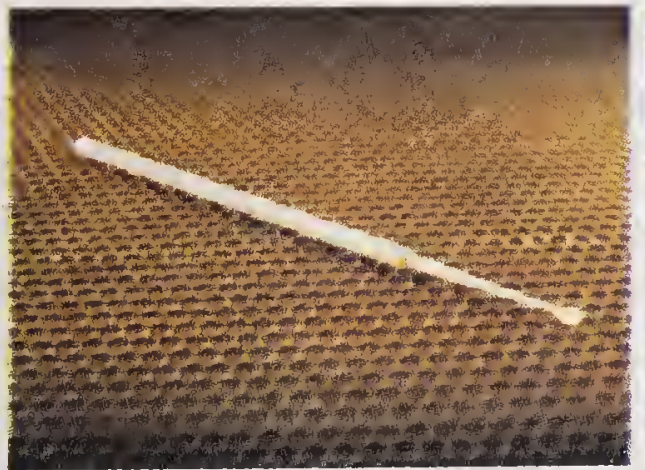

Fig. 16.8 Royal jelly collecting spoon.

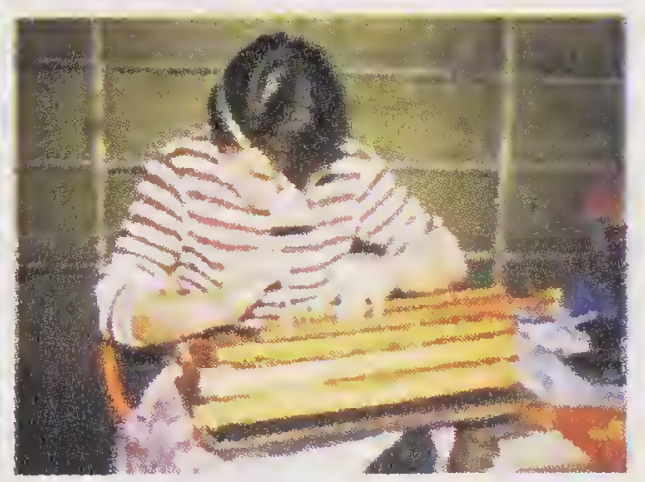

Fig. 16.9 Royal jelly collection.

(Courtesy: Waugsberg, 2008) 
Table 16.5 Composition of royal jelly (Lercker et al., 1984)

\begin{tabular}{lcc}
\hline & \multicolumn{1}{c}{ Minimum } & Maximum \\
\hline Water & $57 \%$ & $70 \%$ \\
Proteins & $17 \%$ of dry weight & $45 \%$ of dry weight \\
Sugars & $18 \%$ of dry weight & $52 \%$ of dry weight \\
Lipids & $3.5 \%$ of dry weight & $19 \%$ of dry weight \\
Minerals & $2 \%$ of dry weight & $3 \%$ of dry weight \\
\hline
\end{tabular}

grafts in primed PVC cell cups resulted maximum royal jelly production of 5.69 $\mathrm{g} / 72 \mathrm{hr} /$ cycle day.

\section{Propolis}

Propolis is a mixture of various amounts of beeswax and resins collected by the honeybee from plants, particularly from flowers and leaf buds. Since, it is difficult to observe bees on their foraging trips, the exact sources of the resins are usually not known. Bees have been observed scraping the protective resins of flower and leaf buds with their mandibles and then carrying them to the hive like pollen pellets on

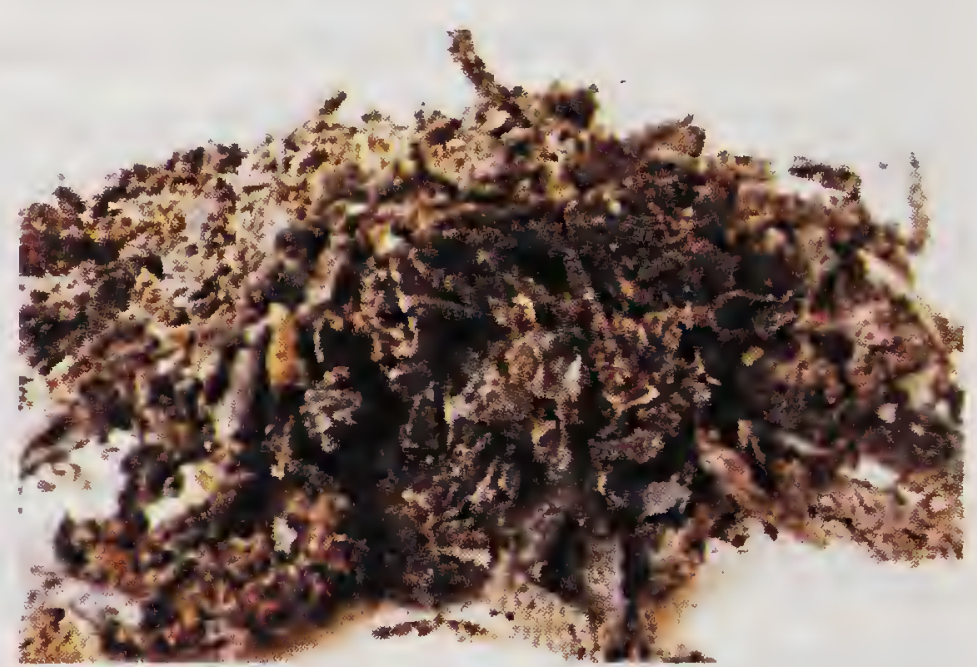

Fig. 16.11 Pollen grains. their hind legs. It can be assumed that in the process of collecting and modelling the resins, they are mixed with some saliva and other secretions of the bees as well as with wax.

Propolis is gathered by bees from resinous exudates of trees. In the bee colony propolis is used by bees for sticking frames, sealing cracks and crevices but it makes handling of frames difficult and is also a contaminant of comb wax. Propolis is mainly composed of resins and balsams $55 \%$, ethanol and scented oils $10 \%$ and pollen 5\%. Many flavonic components have also been identified.

Propolis is obtained by scrapping it from the frames (Fig. 16.10). It has quality of healing wounds effectively and common use in preparing ointments for treating cuts; wounds and abscesses in cattle. Mixed with Vaseline, it smoothens burns. Propolis is used more commonly in wood preservatives or varnishes than may be suggested by the single, frequently cited reference to Stradivarius (Jolly, 1978)

\section{Pollen}

Pollen is frequently called the "only perfectly complete food". High performance athletes are quoted as

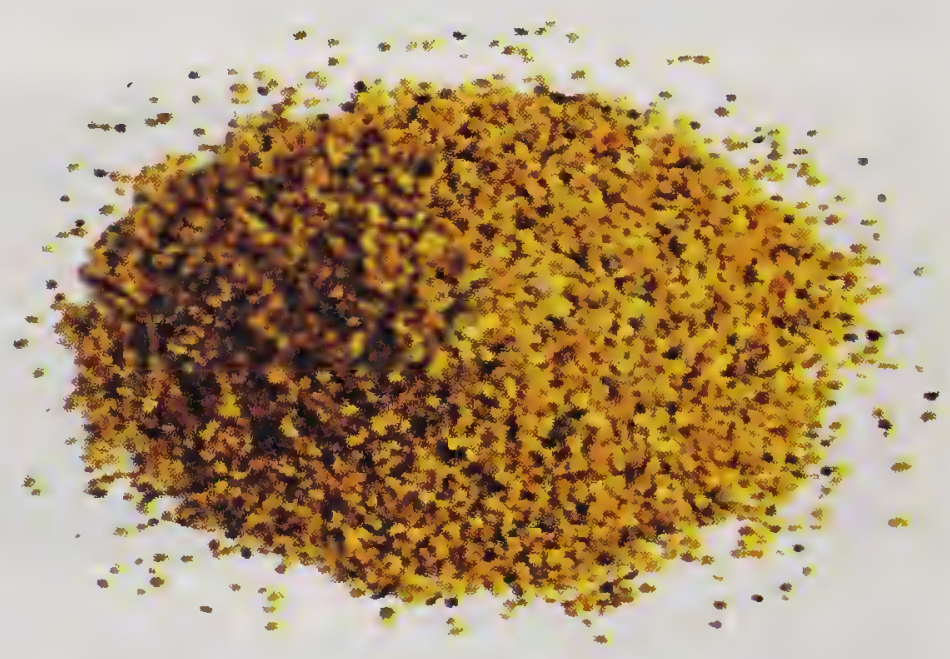

Fig. 16.10. Propolis. Courtesy: (Lesster, 2008). 
eating pollen, suggesting their performance is due to this "miracle food", just as the "busy bee" represents a role model for an active and productive member of society. Using suggestive names, labels and descriptions in marketing of various products containing pollen sometimes reach almost fraudulent dimensions, creating false hopes and expectations in people, often connected with high prices of the product. Such practices are untruthful, unethical and should be avoided. Pollen collected by pollen trap from ingoing pollen foragers is a rich protein source for human diet (Fig. 16.11). Ojha and Gupta (2000) reported the pollen from honey bee colonies of Himachal Pradesh and peak collection was found during April (424.5 g/colony) and was minimum in June (37.63 g/colony). The main pollen flow period is February to May in the year.

Pollen is used as medicine, food, beebread and cosmetic industry.

\section{REFERENCES}

Devanesan, S., Shailaja, K. K. and Premila, K. S. 2003. Apitheraphy Scientific India 6(11): 25-26.

Dotimas, E. M., Hider, R. C. 1987. Honeybee venom. Bee World. 68 (2): 51-70.

Gairola, A., Tiwari, P. and Tiwari, J. K. 2013. Physicochemical properties of Apis ceranaindica F. Honey from Uttarkashi district of Uttarakhand, india. Journal of Biotic Science 2(1), 20-25.

Gill, A. K. and Chhuneja, P. K. 2011. Standardization of techniques for royal jelly production from Apis mellifera. Linn. Colonies during non-breeding seasons under Punjab conditions. Experience Exch. Workshop on Prospects and Promotion of Apiculture for Augmentation Hive and Crop Productivity. Punjab Agricultural University, Ludhiana, India. 168-74 pp.

Jolly, V. G. 1978. Propolis varnish for violins. Bee World. 59 (4): 158-61.

Kalimi, M. Y. and Sohonie, K. 1965. Mahabaleshwar honey.III. Vitamin contents (ascorbic acid, thiamine, riboflovin and niacin) and effect of storage on these vitamins. Journal Nutrition and Dietetics. 2(1): 9-11.

Krell, R. 1996. Value-added products from beekeeping, FAO agricultural services Bulletin No. 124, Food and Agriculture Organization, Rome.

Lercker, G., Capella, P., Conte, L. S., Ruini, F. and Giordani, G. 1982 Components of royal jelly: II. The lipid fraction, hydrocarbons and sterols. Journal of Apicultural Research 21(3): 178-84.

Lesster, L. 2008. Bringing ecology and society together, Redefining apiculture in Uganda and Rawanda, East West Innovation Ltd., Uganda.

Maurya, S., Kushwaha, A. K., Singh, S. and Singh, G. 2014. An overview on antioxidant potential of honey from different flora and geographical origins. Ind. J. Natl. Products. and Res.5(1): 9-19.

Nair, K. S. 1980. Physicochemical characteristics of rubber honey in India. Proc. 2nd International Conf. Apic. Trop. Climates, New Delhi: 676-84 pp.

Ojha, K. N. and Gupta, J. K. 2000. Seasonal variations in the amount of pollen trapped from honey bee colonies in Solan area of Himachal Pradesh, India. $7^{\text {th }}$ IBHA Conf. \& $5^{\text {th }}$ Asian Apic. Assocn. Conference: 22.

Phadke, R.P. 1962. Physico-chemical composition of major unifloral honeys from Mahabaleshwar (Western Ghats). Indian Bee Journal 24(7-9): 56-65.

Phadke, R. P. 1967. Studies on Indian honeys. 1. Approximate composition and physicchemical characteristics of Indian multifloral apiary honeys from Apis indica bees. Indian Bee Journal 29: 14-26. 
Phadke, R. P., Nair, K. S. and Namdekar, K. U. 1971. Indian bee waxes. II. The nature of their chemical constituents. Indian Bee Journal 33(1-2): 3-5.

Phadke, R. P. and Phadke, R. S. 1975. Physiochemical characteristics of waxes from Indian honeybees. II. Viscosity and refractive index. Indian Bee Journal 37(1-4): 15-18.

Rana, B. S., Katna, S., Sharma, H. K. and Rana, K. 2011. Studies on bee venom collection from Apis mellifera L. in Himachal Pradesh, India. Advance Applied Research 3(2): 194-96.

Rana, V. K., Goyal, N. P. and Gupta, J. K. 2000. Studies on royal jelly production in Himachal Pradesh. Prog. Res. \& Dev., Asian bees and beekeeping (Eds. Matsuka, M., Verma, L. R. Wongsiri, S, Shresta, K. K. and Pratap, U.). Oxford \&IBHP publishing Co., New Delhi.

Singh, R., Singh, J. and Chhuneja, P. K. 2001. Extraction and purification of beeswax. Indian Bee Journal 63(1-2): 17-22.

Tulloch, A. P. 1980. Beeswax - composition and analysis. Bee World, 61(2): 47-62.

Yadav, S. P., Goyal, N. P., Nath., A. and Gupta, J. K. 2004. Physicochemical characters of honey from four species of honeybees in North India. Pest Managment and Ecology Zoology 12: 213-15. 


\section{Value Added Beehive Products}

$\mathrm{H}^{\circ}$

ONEY BEES in India are primarily known for production of honey and wax. Other valuable beehive products such as pollen, royal jelly, bee venom and propolis are less known neither commercially produced nor used. The best known primary products of honeybee are honey and wax, but pollen, propolis, royal jelly, venom, larvae are also marketable primary bee products. In some cases the traditional and early technological uses of primary bee products have been replaced by other because of better availability, lower cost and easier processing. But in regard to food or health products, there are no synthetic substances which can substitute for the wide variety of characteristics of primary bee products. Only when it comes to highly specialized application and conditions the synthetics sometimes out perform these unique and versatile products. In that sense, all products containing one or several of primary bee products are value added products.

Traditionally, honey is considered the major apiculture product. Wax has played a considerable role in international market but propolis is less known products. However, with increasing knowledge on apiculture and an awareness of the beneficial aspects of many bee products. The use and demand for other products is increasing. The inclusion of natural bee products in cosmetics, medicines and foods has improved consumer appeal. While such appeal is not always based on scientific evidence, further studies confirmed at least some of the traditionally claimed benefits of primary bee products. Krell (1996) and Abrol (2010) mentioned the various value added products from beekeeping.

\section{Honey}

Honey is utilized in products such as, medicine, foods like- marmalade and jams, in Icecreams, whole dried fruits and nuts preserved in honey.

\section{Medicinal value of honey}

Honey has been in use as medicine from time in memorial and is ingredient of folk medicine such as Ayurveda, Siddha, Unani and other indigenous system of medicine. Its super saturated nature does not allow growth of bacteria and other microbes. It is thus antimicrobial and antiseptic, at the same time its nutritive properly helps in healing of wounds and burns in a natural way. These and other properties of honey contribute to its utility as medicine. Consumption of honey for medicinal purposes is the highest in the pharmaceutical industry and in 
Ayurvedic and Unani medicine. Honey has been used as carrier of ingredients of those two pharmaceutical industries.

\section{Food value of honey}

In ancient India, honey has been a component of "panchamiritra". It was valued for its nutritive value, giving energy, health, strength and vigour. It was considered as the food of the gods that made men immortal. After the discovery of the grasses that gave sweet juice, followed by the invention of sugar, the important of honey as food began to decline. Beekeeping was already a closely guarded secret, and the craft was not pursued seriously because of the difficulties in producing honey and the comparative ease with which sugar could be produced. Forest honey was thin and fermented. Because of its association with immortal gods, honey remained mainly as an essential food in religious ceremonies at the time of birth, marriage and death, as well as an item offered to the gods during worship. Social and cultural customs in all religious groups include use of honey. Use of honey as food continues, however, because of its natural flavor, taste and its preservative properties. Honey has been used directly in cooking and as an ingredient of other regular food items such as baked products.

Honey is now consumed for table and other household purposes. It is used in pickles, jams, jellies, marmalades and preservatives because of its keeping quality. In cooking honey is used as a sweetner and flavouring agent in the preparation of pancackes, pastries, pies and puddings. Other major households use of honey as food is in bakery, diary products including yogurts and processed foods and confectionery.

Institutional consumption of honey as food is also significant. Hotel, health club and restaurants serve honey on the table, as bread spread, in salads or in their special food and drinks preparations. Major ayurvedic companies sell 350 to 400 tonnes of forest honey in this market under band names like Baidyanathe, Charak, Dabur, Phondaghat, Ramtrith and Zandu. Over $55 \%$ of the production went in the unorganized rural sectors for household consumption.

\section{Industrial importance of honey}

Almost $10-12 \%$ of total production of honey is used in industry. This is largely due to the fact that honey is costly and therefore adds significantly to the cost of production. In several ends uses honey, constitutes one of the ingredients and undergoes physical and chemical changes as a result the end product does not have the flavor or taste of honey. Naturally, use of honey in the industry is more for its medicinal properties, than for its nutritional value. Forest honey is usually preferred in the industries because of its low costs.

\section{As food and ancillary products}

Use of honey in mass production and fast-food industry has recently been increasing. Some products that use honey are processed food like cereals, readyto-eat mixes, health food and baby foods and dairy products like yogurts, milk, sweetmeats, creams, fudges and ice creams. Health food producing companies 
and ice cream producing factories like Kwality and Vadilal increased their sales by advertising the use of honey in their products.

\section{As confectionery}

During the past decade or so, use has been made of honey in confectionery like sweets, candies, toffees, éclairs and chocolates. Raolgaon sweets, Nutrine confectioney products are the major consumers for confectioney that accounts for about 100 tonnes of honey.

\section{In bakery}

Small quantities of honey are also being used in bakery products like special types of breads, biscuits, cakes and cookies. Britannia biscuit company is using honey in its popular brands of cookies and biscuits (Fig. 17.1). The hygroscopic nature of honey keeps bread soft, while improving its keeping qualities.

\section{Honey as preservatives}

This emerging industry has good potential to use honey both as a preservatives and as a flavouring medium (Fig. 17.2). The fruit products industry that includes manufacture of jams, jellies, canned fruits, syrups, squashes, sauces and ketchups is just beginning to use honey in its products. The Muzaffarnager Industrial Honey Produces Co-operative Society (MIHPCO. Ltd.) in Uttar Pradesh has been successfully marketing fruit and vegetables products developed by it with honey as an important ingredients.

\section{Use in pharmaceuticals}

Much of the honey used in industry is for manufacture of medicines like cough droops, losenzes or syrup, tonics and other medicinal formulations (Fig. 17.3). Pharmaceuticals companies like Cynamid, proctor and gambles, roussel and warner, Hindustan

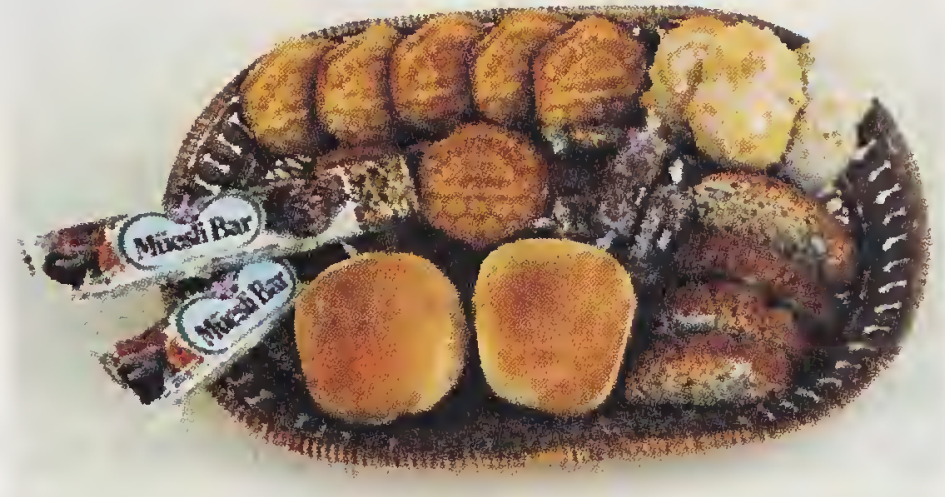

Fig. 17.1 Honey biscuits (Courtesy: Krell, 1996).

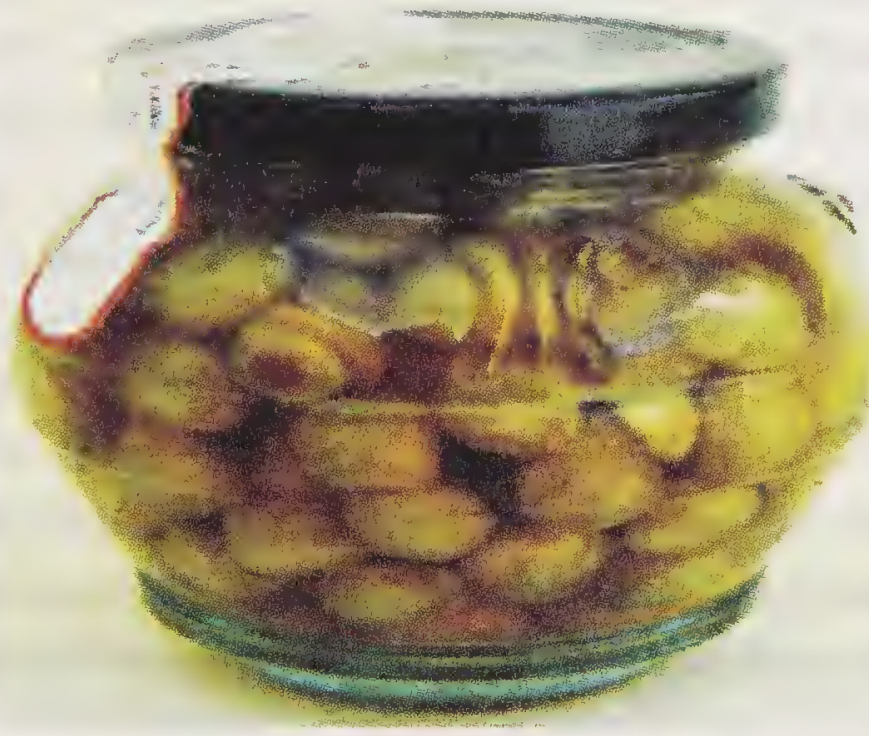

Fig. 17.2 Honey as preservative (Courtesy: Krell, 1996).

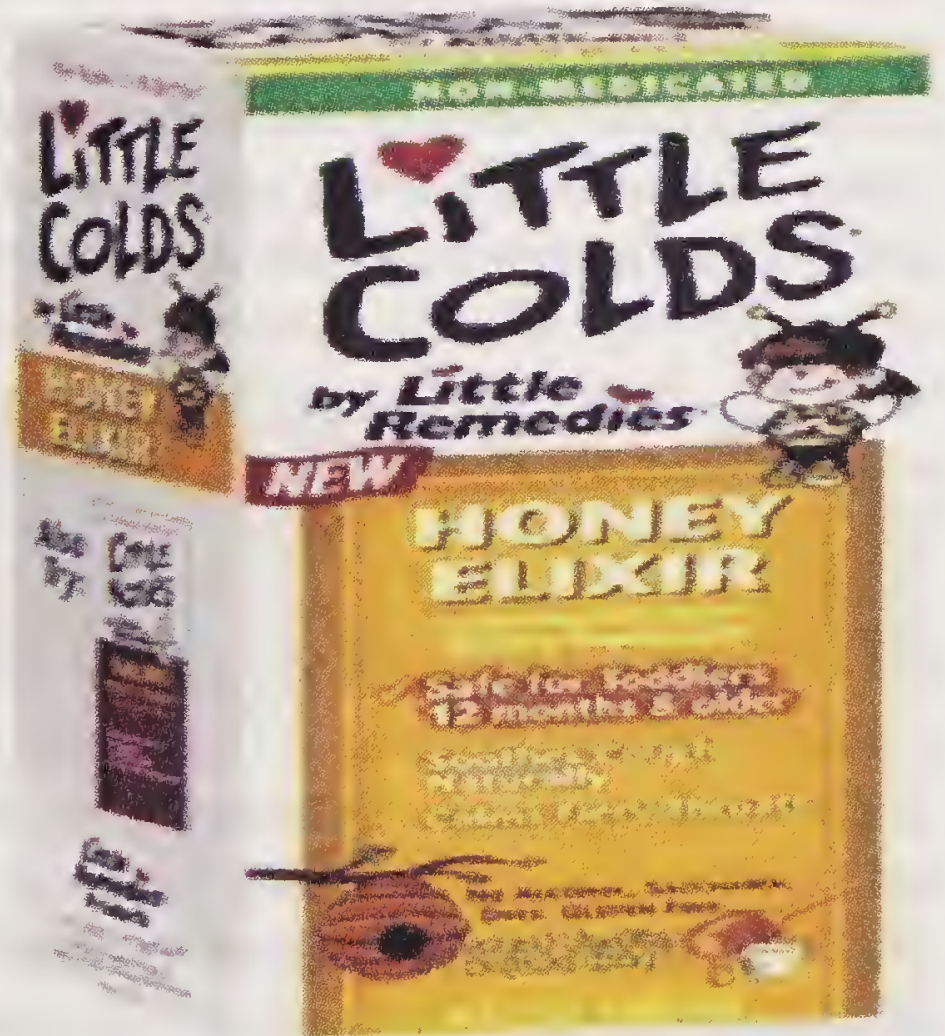

Fig. 17.3 Honey cough syrup. 
consumed about 183 tonnes of honey in 1985-86. Interestingly, forest honey contributed to only $22 \%$ of the honey used in this industry. Dental creams and antiseptic eye lotions are newly developed products of this industry using honey.

\section{In cosmetics}

Honey has a mild action on skin, but at the same time protects it from infection and nourishes it. Because of these properties it is in use in facials, shampoos and other cosmetics. Consumption in this sector was negligible. With the recent perceptible shift towards herbal preparation honey is increasingly used for manufacture of

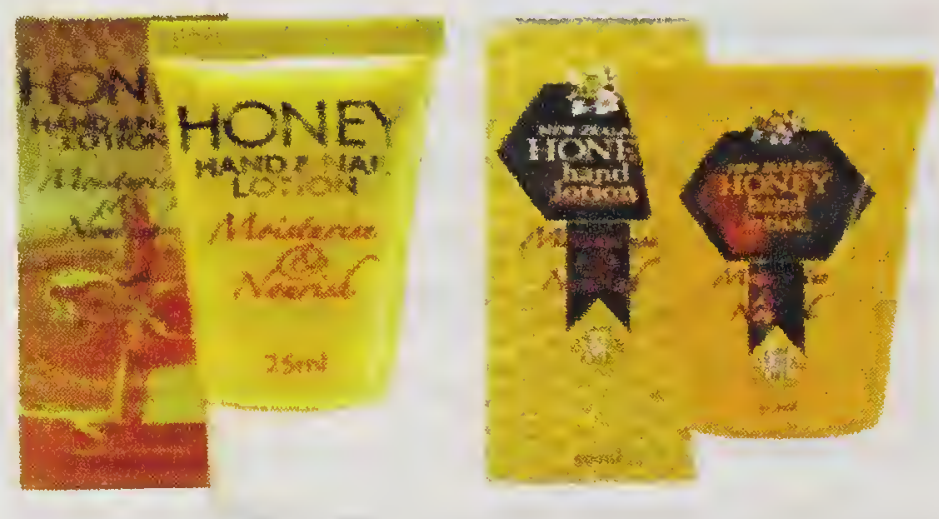

Fig. 17.4 Honey lotion skin-care and hair-care products as a natural therapeutic and medicinal ingredient (Fig. 17.4): Jiwadaya Netraprabha Karyalaya, Bombay uses 10-15 tonnes of honey for preparation of the commonly used mascara for eye-care. Honey is also used in special herbal soaps and cosmetics powders and packs. The MIHPCo. Ltd. in Uttar Pradesh and a few herbal products firms in Mumbai introduced some cosmetic items that have honey.

\section{Other industrial uses}

Significant quantities of forest honey are used in incense sticks manufacture, perfumery, tobacco curing and cigarette manufacture. The Golden Tobacco Co. and other cigar and cigarette manufacturers use 5 to 10 tonnes of honey. The Ambika chemical works, Eluru, Andhra Pradesh uses over 10 tonnes of honey in the manufacture of their famous perfume and incense sticks that are even exported.

\section{Beeswax}

Though in many cases beeswax can be replaced with cheaper, synthetic waxes, its very special characteristics, medicinal benefits, plasticity and aroma ensure its continuing use. Many of these characteristics cannot be achieved with artificial waxes. The trend for more natural products in cosmetics may also increase its use. Presently, there is a scarcity of beeswax in industrialized countries, at least seasonally. Bee wax are used in bee keeping, for candle making (Fig. 17.5), in cosmetics, food processing, industrial technologies and in textiles, varnishes \& polishes (Fig. 17.6), printing and in medicines for coating of drugs and pills etc. (Fig. 17.7).

Worker bees secrete wax in their abdominal sternites IV-VII, when they are 2 to 3 weeks old. Wax is secreted in the form of liquid but solidifies when exposed to air and scales are formed. These scales are removed by hive bees and used for comb building. Bee wax is used commercially to make fine candles, cosmetics and pharmaceuticals including bone wax, in polishing materials as a component of modeling waxes and in a variety of other products. It is commonly used during the assembly of pool tables to fill the screw holes and seams between the slates. Bee wax candles are preferred in most Eastern Orthodox churches because they 


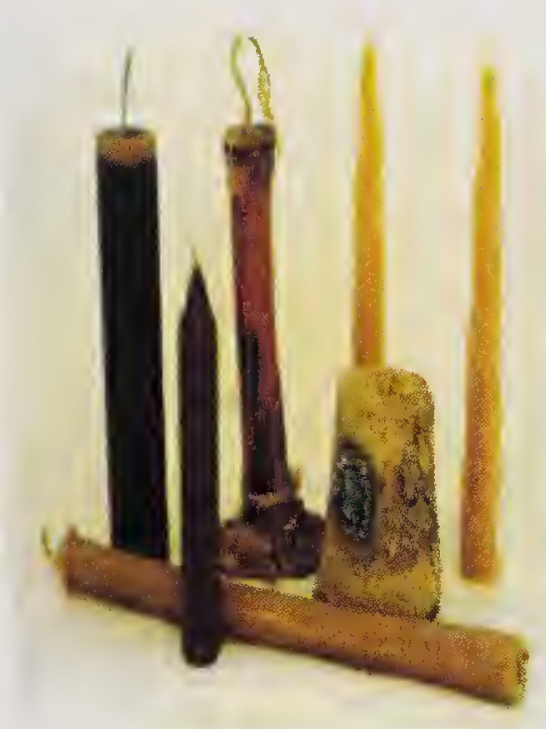

Fig. 17.5 Bee wax candle.

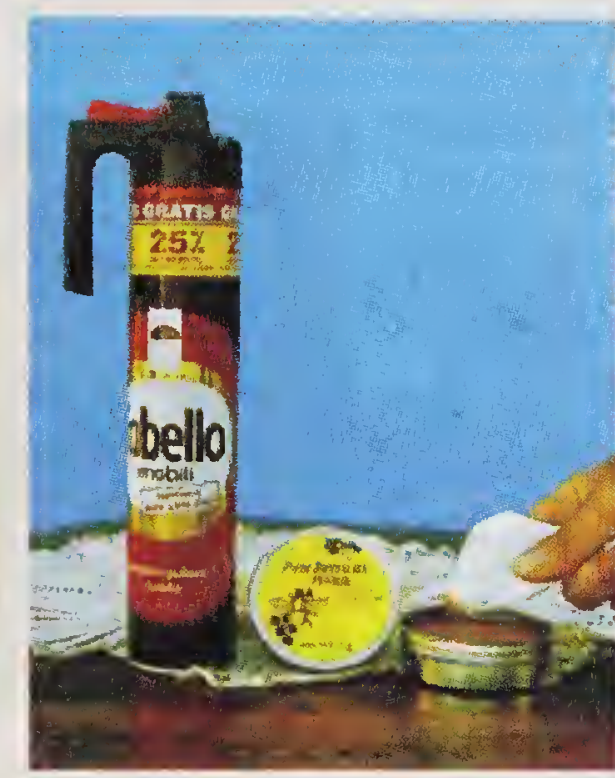

Fig. 17.6 Bee wax polish.

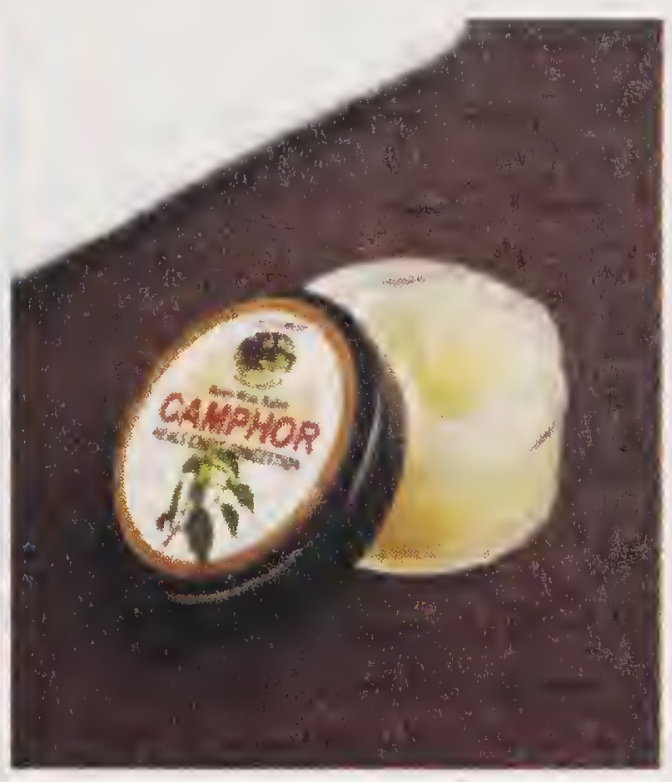

Fig. 17.7 Bee wax balm.

(Courtesy: Krell, 1996)

burn cleanly, with little or no wax dripping down the sides and little visible smoke. It is also used as a coating for cheese, to protect the food as it ages. While some cheese makers have replaced it with plastic, many still use bee wax in order to avoid unpleasant odour that results from plastic. Singh et al. (2001) in an attempt to purify the beeswax maximum recovery was made from burr combs $(39.46 \%)$ followed by brace combs $(36.27 \%)$, old combs $(28.78 \%)$, honey cell cappings $(18.87 \%)$ and extracted honey $(0.86 \%)$.

\section{Bee venom}

Apitoxin, or honey bee venom, is a bitter colourless liquid; its active portion a mixture of proteins, which causes local inflammation and acts as an anticoagulant (Czarnetzki et al., 1990). A honeybee can inject $0.1 \mathrm{mg}$ of venom via its stinger. It may have similarities to sea nettletoxin. Devanesan et al. (2003) reported that bee venom is a bitter, hydrolytic blend of proteins with basic $\mathrm{pH}$ and the major constituents are peptides like melittin (40-50\%), apamin (3\%) and mast cell granulating peptides $(2 \%)$. Bee venom is used in medical purpose for treating arthritis and other rheumatoid inflammation. Several patients suffering from phlebitis and thrombophlebitis noticed an increase in their skin temperature with change in the blood circulation. In chronic inflammatory nerve affections the results were also very good with ceasing of pains and a partial recuperation of movement. When combined with oral therapy such as vitamin therapy good analgesic effects were obtained in cortisone-dependent patients suffering from rheumatoid polyarthritis. The bee venom is applied for 4-5 days, followed by 2-3 days break. Treatment is then

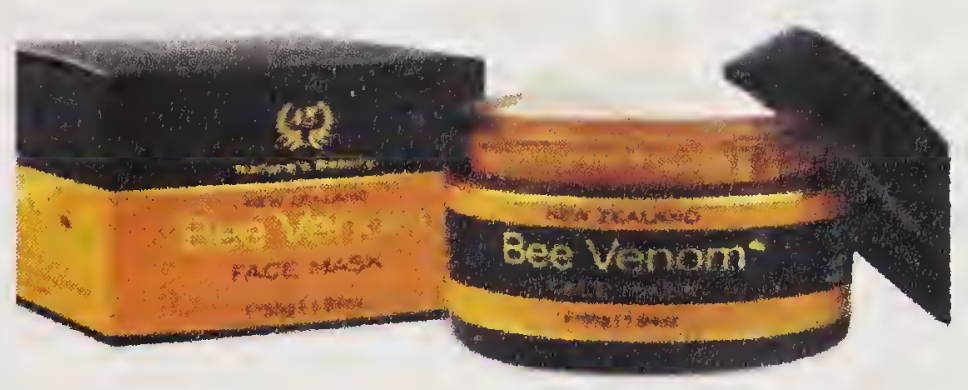

Fig. 17.8 Bee venom face mask recommended again. Using this no adverse effects was reported. Applying venom topically provide a long lasting effect and offer significant benefits in arthritic and rheumatic conditions (Fig. 17.8). The application of bee venom as apitherapy has been included in next chapter. 


\section{Royal Jelly}

Royal jelly is used as dietary supplements, ingredient in medicines, in food and in cosmetics etc. (Fig. 17.9). Royal jelly is a hypopharyngeal secretion of bees that aids in the development of immature or young bees. It is secreted by the head of young workers and used to feed the young until they develop to the desired rank. If a queen is desired, the progeny will receive only royal jelly as its food

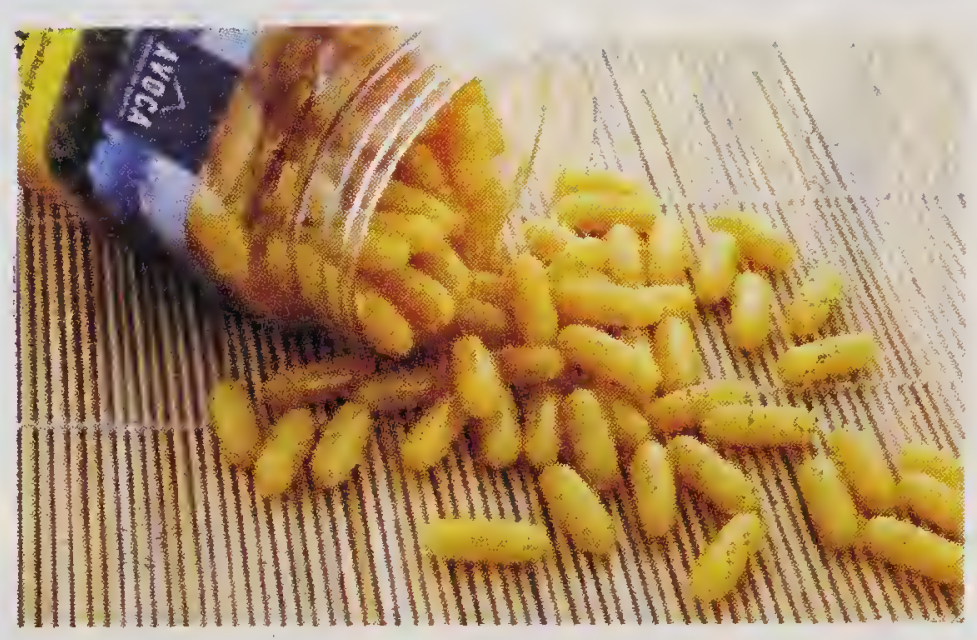

Fig. 17.9. Royal jelly capsules (Courtesy: Krell, 1996). source, in order that she will become sexually mature and have the jelly developed ovaries needed to lay more eggs for the hive. Propolis is marked by health food stores as a traditional medicine and for it claimed beneficial effect on human health. Depending upon its precise combination it may show powerful local antibiotic and antifungal properties. Also, it is generally efficient in treating skin burns. Claims have been made for its use in treating allergy, it stimulates immune system but some warn that it should not be taken if the user is likely to have severe allergic reaction to bees.

\section{Pollen}

Pollens are used as medicine, foods, beebread, in cosmetics, for pollination and for pollution monitoring etc. Bees collect pollen in the basket and carry it back to the hives. In the hive, pollen is used as a protein source necessary during brood-rearing. In certain environment excess pollen can be collected from hive. It is often eaten as a healthy supplementary.

\section{Propolis}

Propolis are used in medicines, in cosmetics, food technology and as traditionally in wound healing etc. Propolis is a mixture of various amounts of beeswax and resins collected by the honeybee from plants, particularly from flowers and leaf buds. Since, it is difficult to observe bees on their foraging trips the exact sources of the resins are usually not known. Bees have been observed scraping the protective resins of flower and leaf buds with their mandibles and then carrying them to the hive like pollen pellets on their hind legs. It can be assumed that in the process of collecting and modelling the resins, they are mixed with some saliva and other secretions of the bees as well as with wax.

Gladys (2014) while studying the influence of value addition in bee farming products concluded that advanced value addition increases income and in return enhances food security, health/housing and education levels of bee farmer families. The study recommended that farmers be trained on the importance of value addition and how to identify hive products and their uses. Berem et al. (2010) listed the beehive products along with the cosmetic functions as given in Table 17.1. 
Table 17.1 Cosmetic functions of five primary bee products

\begin{tabular}{ll}
\hline Product & Cosmetic function \\
\hline Honey & $\begin{array}{l}\text { Sweetener, emollient, moisturizer, humectant, tonic, refresher, } \\
\text { anti-irritant, skin softener, epithelial reconstitution and soothing } \\
\text { agent }\end{array}$ \\
Exax & $\begin{array}{l}\text { Excipient, protectant, film formant, water repellent, sebum } \\
\text { restorant, depilatory, anti-irritant and emollient }\end{array}$ \\
Propolis & $\begin{array}{l}\text { Anti-dandruff and anti-wrinkle agent, hair conditioner, deodorant, } \\
\text { purifier, tonic, disinfectant, antioxidant, preservative and UV } \\
\text { screen }\end{array}$ \\
Pollen and royal jelly & $\begin{array}{l}\text { Anti-wrinkle, anti-stretchmarks, elastifier, nutrifier, firmer, } \\
\text { revitalizer, hair conditioner, tonic and sebum equalizer, tanning } \\
\text { aid (pollen only) }\end{array}$ \\
\hline
\end{tabular}

Source: Berem et al. (2010).

\section{REFERENCES}

Abrol, D. P. 2010. Beekeeping, A comprehensive guide to bees and beekeeping. Scientific Publication, India. $896 \mathrm{pp}$.

Berem, R. M., Obare, G. A. and Owuor, G. 2010. Is Value Addition in Honey a Panacea for Poverty Reduction in the ASAL in Africa? Empirical Evidence from Baringo District, Kenya. $3^{r d} A A A E \& A E A S A$ Conf. Cape Town, South Africa.

Czarnetzki, B. M., Thiele, T. and Rosenbach, T. 1990. Evidence for leukotrienes in animal venoms". The Journal allergy and clinical immunology.85 (2): 505-509.

Devanesan, S., Shailaja, K. K and Premila, K. S. 2003. Apitheraphy. Sci. Ind. 6(11): 2526.

Gladys, O.O. 2014. Influence of value addition in bee - farming products on the livelihood of bee - farmers in Kakamega Central Sub - Country, Keneya. Master's Degree research project submitted to The University of Nairobi, Keneya.

Krell, R. 1996. Value-added products from beekeeping. FAO Agricultural Services Bulletin No. 124. FAO, Rome.

Singh, R. Singh, J. and Chhuneja, P. K. 2001. Extraction and purification of beeswax. Indian Bee Journal 63(1\&2): 17-22. 


\section{8 \\ Commercialization of Apiculture}

$\mathrm{T}$

HE concept of Apiculture has undergone change from honey to pollination and ancillary industry mode. The benefits derived from apiculture are manifolds as discussed by Breadbear (2009) such as pollination service; honey production, beeswax, bee venom, royal jelly, propolis and other products: Apiculture is feasible even for people with minimal resources: Land ownership is not essential; different sectors and trades benefit from a strong apiculture industry; it encourages ecological awareness and promotes organic farming; encouraging apiculture means the maintenance of biodiversity.

The ancillary industry is known as unit which produces parts, components, sub assemblies and tooling for supply against known or anticipated demand from large manufacturing unit to make complete product. There is an ample scope for establishing apiculture industry in the form small scale or agro based industry in rural and periurban areas of the country. Such industries have been discussed below:

\section{Fabrication and packaging}

Bee hive fabrication: Few small scale industries have come up for fabricating the different type bee hives, viz. ISI A type, B type for Apis cerana species and Langthroth hive for Apis mllifera. There is scope for initiating such industry in all the districts of the country and will provide opportunity for self employment and a kind of service provider (Fig. 18.1). The supportive price differs for different type of bee hive and hive tools and may vary from region to region in India on the basis of raw materials available. For example apart from wooden hive, bamboo hive has been designed in north east India, the price of which is almost half the price of wooden hive.
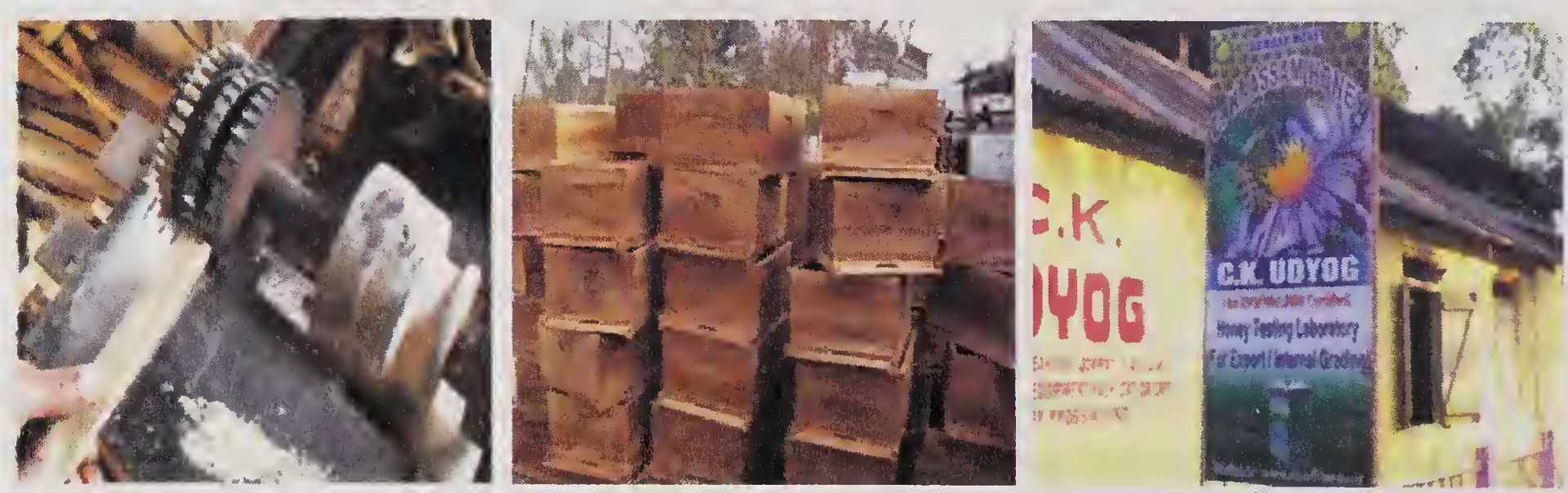

Fig. 18.1 Bee hive fabricating unit. 
Fabrication of uncapping machinery: Any company skilled in the production of stainless equipment for the food industry would be capable of manufacturing the machinery required to uncap combs and extract honey. Both mechanical and power driven honey extractor based on centrifugal principle may be fabricated.

Packers' equipment: Bottle and bottling equipment are required by packers. In addition, drum manufacturers provide the special galvanized drum, made with side stainless that is not generally available from other sources for producers and packers. A gradual change to plastic drums is taking place with intermediate bulk containers of pallet size being used which hold more honey than do the traditional drums.

Transport and handling equipment: All commercial beekeepers must purchase trucks and utilities for transporting and servicing hives. Many also own front end loaders for loading hives on pallets and loading drums or use other forms of mechanism.

Quality assurance: Beekeepers and packers are increasingly introducing quality assured aspects and equipments for handling honey as a food product for human consumption. Again, this is not necessarily a specialized activity unique to the industry, but represents an additional demands for existing services.

\section{Extraction and processing}

Honey is the prime output of commercial beekeepers and is produced by bees from plant nectar. The major producers are China, Russia, Mexico, Argentina, Canada, Brazil, Australia and India. The major exporters are China, Mexico and Argentina, but the highest colony yields are recorded in Australia and Canada which have a favourable environment as well as highly developed colony management. The increased consumption over the last few years can be attributed to the general increase in living standards and a higher interest in natural and health products. In general, light colored honeys bring the highest price and dark ones are most frequently used for industrial production. Mild flavoured honeys are preferred, but characteristically flavoured honeys bring remunerative prices in some countries. Large honey packers usually prefer honeys with a low tendency to crystallize. Some unifloral honey such as Hungarian Black Locust honey brings twice the price of regular, multifloral honey. Expansion of markets with honey containing products should be considered on a national level or for across-the-border trade. Consumer education and of course, spending
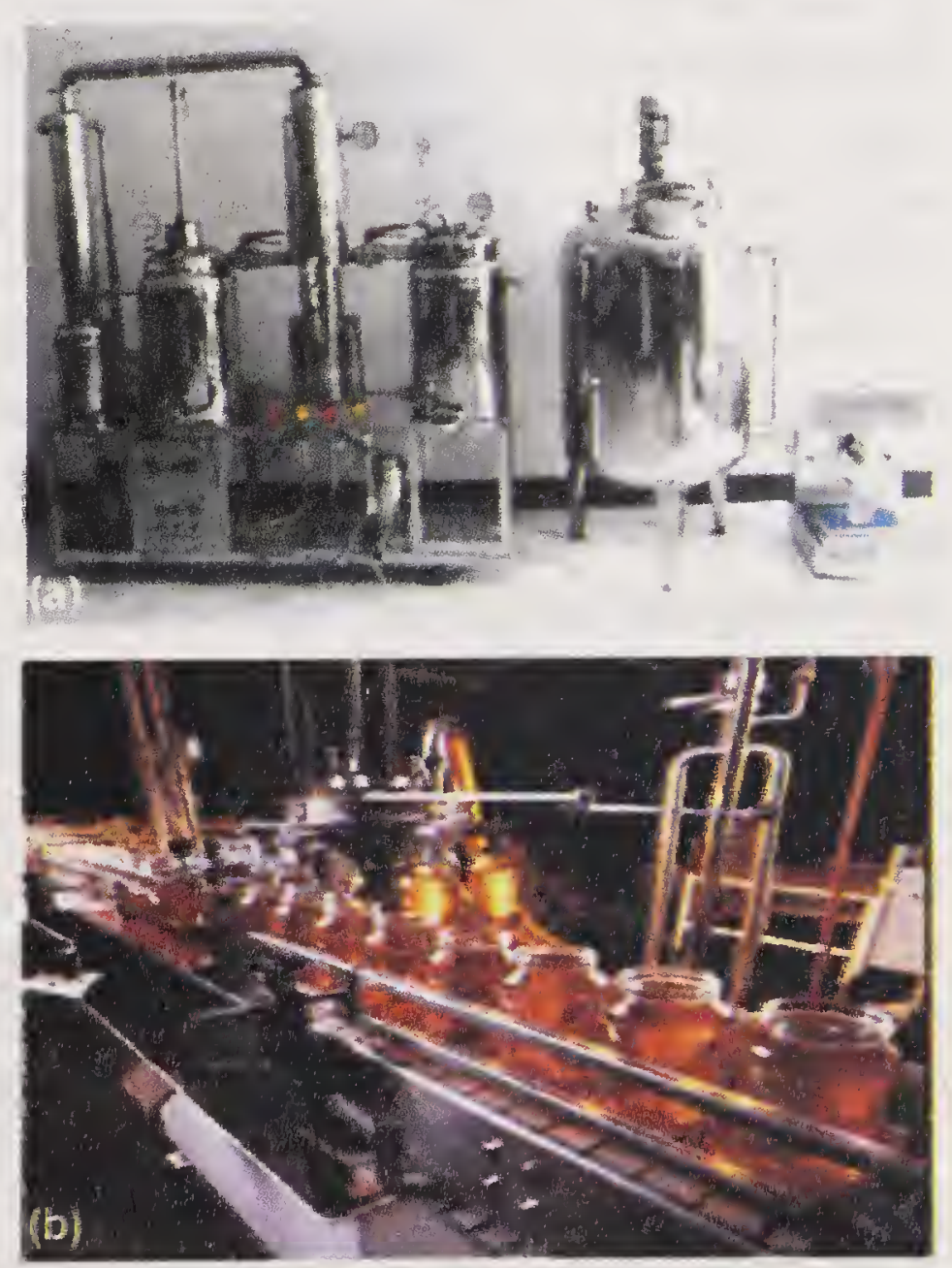

Fig. 18.2 (a) Honey processing plant; (b) Honey packaging plant (courtesy Krell, 1996). 
power will probably be the most important factors influence the possibility of expanding local markets or for increased product diversity. The majority of the production of honey takes plays in developing countries, while the developed countries are the largest consumers. India occupies eighth position and exported $25,780.74$ MT of natural honey to the world for the worth of ₹ 356.28 crore during the year of 2012-13 (Agrawal, 2014). Major Export destinations (201213) are United States, Saudi Arabia, United Arab Emirates, Yemen Republic and Morocco. The examples given in this chapter might serve as ideas for possible modification and adaptation to individual circumstances (Fig.18.2a and b).

The majority of production of honey takes place in developing countries. India, due to its bio-diversity produces approx. 65,000 MT per year (Kejriwal, 2012).

\section{Bees wax for ancillary industry}

Beeswax is a substance secreted by the worker bees. It is recovered by beekeepers primarily from honey comb cappings and also from cell combs and wax pieces. Beeswax is used in certain pharmaceutical and cosmetic preparation as a base for polishes and some ointments for candles and for comb foundation for beekeeping. It has the highest melting point of natural waxes and can be sold in either the raw or refined form. Commercial bees wax is generally refined for sale by a manufacturer of apiary product. The cosmetic and pharmaceutical industries have no complete substitute for beeswax. At least, small quantities will always be needed to maintain quality and specific characteristics. Like honey prices, prices for bees wax may vary considerably from place to place. Markets and prices for products made from beeswax vary widely from country to country. In these industries, beeswax forms only a minuscule part both of the manufacturing process and of the final product. It is used in candle making, skin creams, grafting was for horticulture, polishes and varnishes, paste furniture polish, liquid furniture polish, spray police, floor polish, shoe polish, cream type. Cravons, leather preserves, waterproofing textiles and paper, paint, wood preservative, swarm lure, veterinary wound cream, adhesive lotions etc.

Royal jelly: A milky white smooth jelly secreted by nurse bees, used to feed developing queen larvae and young worker bee larvae. The production of royal jelly is a very specialized procedure, and floral conditions must be ideal before production can be considered. Royal jelly is used as tablets or mixed into creams and shampoos. Royal jelly can be sold in its fresh state, unprocessed except for being frozen or cooled, mixed with other products or freeze-dried for further use in other preparations. The fresh production and sale can be handled by enterprises of all sizes since no special technology is required. In its unprocessed form it can also be included directly in many food and dietary supplements as well as medicinelike products or cosmetics. For larger industrial scale use, royal jelly is preferred in its freeze-dried form, because of easier handling and storing. Freeze-dried royal jelly can be included in the same products as the fresh form.

\section{As dietary supplement}

Royal jelly belongs to a group of products generically described as dietary supplements. These are products which are consumed neither for their caloric 
content nor for pleasure, but to supplement the normal diet with substances in which it might be lacking.

\section{As ingredient in food products}

A mixture of royal jelly in honey is probably the most common way in which royal jelly is used as a food ingredient. Among the advantages of this products are that no special technology is required and the honey puts any visible changes in the royal jelly. The final product is pleasant tasting and it provides the beneficial effects of both products.

\section{As ingredient in medicine}

In medicine like formulations royal jelly is generally included for its stimulatory effects. However, it is also used to solve specific health problems. A variety of formulations are available, often containing ingredients otherwise used to alleviate particulars afflictions or as medicine.

\section{As ingredient in cosmetics}

Except honey, probably the largest use of royal jelly is in cosmetics. Royal jelly is included in many dermatological preparations, but mostly in those used for skin refreshing and skin regeneration or rejuvenation. It is also used in creams or ointments for healing burns and other wounds.

\section{Bee venom- Therapeutic use}

Bee venom is collected by stimulating bees with mild electric shock. The venom is processed and used in the preparation of pharmaceutical materials. It can be used to detect hypersensitivity or allergic reaction to bee stings. Bee venom is a highly specialized product with only very few buyers. The market volume is relatively small too, although there are no comprehensive surveys. The main venom producer is the USA which has produced only about $3 \mathrm{~kg}$ of dry venom during the last 30 years but there is a large producer in Brazil and more or less significant amounts are produced in many other countries.

\section{Apitherapy}

Therapeutic use of bee venom is known as Apitherapy. Honey bee venom is toxic aqueous solution of non-volatile proteinaceous material and volatile organic compounds. When injected in human body through bee sting, it causes pain, redness and local swelling. For this reason, the bee sting is considered to be dreaded. The fact, however is that the sting coupled with venom is primarily an organ of defense from honey-robbing animals, including mammals, other vertebrates and insects etc. Therefore, bees usually depict their stinging behavior mostly in the proximity of their hive or nest and not while on their foraging trips. The venom of bees is stored in the poison sac present at the base of sting. The amount of poison contained in the venom sac is about 3-4 $\mu$ l and part of it is passed on to the body of the enemy. The quantity of poison may be lethal to small animals and invertebrates, however, in humans, deaths are vary rare until and unless a person is hypersensitive and therefore, humans usually do not suffer complications even after being stung 
by $10-20$ bees. Beekeepers, owing to being usually exposed to stinging get immunized for bee poison. Because of this fact, bee venom has found therapeutic application for the relief of arthritic and rheumatic pains etc. and such application of bee venom and bee products for cure of human diseases are now getting popularized as Apitherapy. Hence, bee venom is attracting the attention of many scientists, medical personnel and general public for detailed studies with the view to finding out its usefulness against human diseases and also to solve out various biochemical and pharmacological problems.

Venom is produced by venom glands which begin to function soon after the emergence of new adult bee, venom being detected after three days with maximum production being reached after 2 to 3 weeks. Older bees have a diminished capability for regenerating venom, degeneration of the venom glands becoming evident in the later part of adult life. In general, the venom quantity of worker bees appear to be highest during the summer months when there is peak activity in the hive and relatively young bees are serving as hive guards. The quantity of venom present in a worker bee was estimated

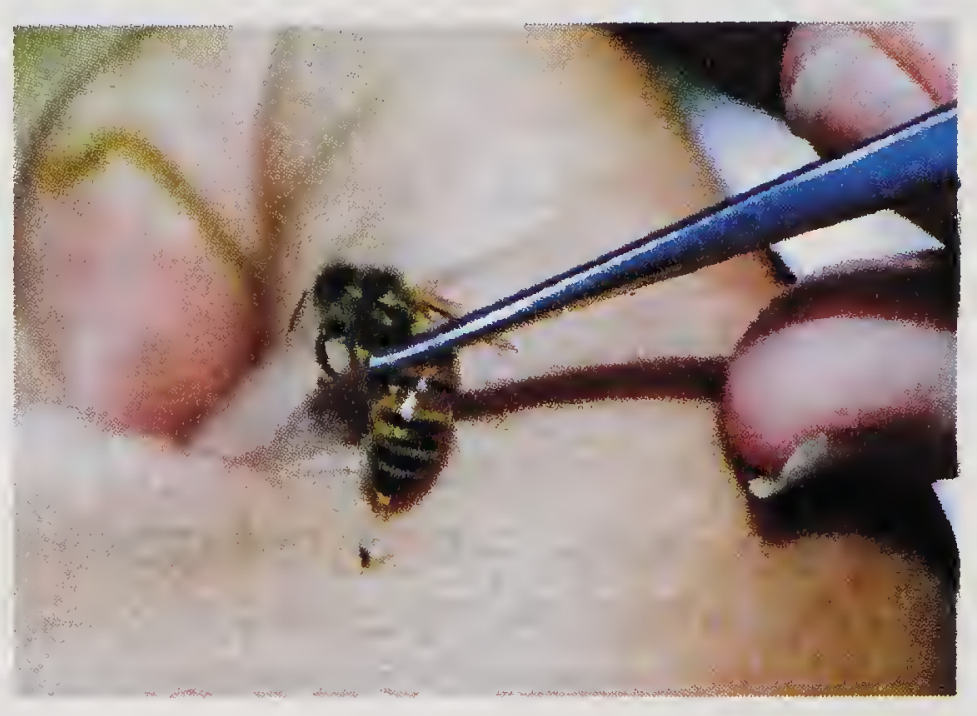

Fig. 18.3. Application of bee venom (courtesy Krell, 1996). to be between 3-4 $\mu 1$. It is difficult to obtain the venom a single individual and typically $0.5-1.0 \mu 1$ venom can be obtained.

Early work on venom isolation was achieved using one of two techniques: dissection of the whole stinging apparatus of application of pressure to the abdomen, which results in the appearance of a venom droplet at the end of the sting. However, for larger quantities of venom an electrical milking method has been developed, in which venom is obtained by administrating electric shock to bees. In this method applied voltage, frequency and current are regulated within certain limits. The colour of venom collected by this device is brownish yellow and may be contaminated with nectar, pollen, faeces or honey. This whole dried bees venom is the most widely used for research and in preparations such as creams, lotions and ointments. Now-a-day bee venom collected devices have improved. With the invention of integrated circuits in the devices, it is possible to control several parameters such as frequency, voltage, current, waveforms and time intervals. Another important improvement is the speeding up of venom collecting process by using 1-40 collector frames at the same time with on controlling device. Bee venom collected by this device using the space-age material can be classified as pure whole derived venom. It is white in colour and free from contamination. Presently, microprocessor controlled bee venom collector device is being developed. Essentially no processing is done on the product collected. Most commonly, all venom collected is pooled, dried and sold in crystalline form. Honey bee venom is a colorless liquid that becomes a white crystalline powder after drying. Atleast, 3 different forms of venom are available; pure whole dried, 
whole dried and freeze dried. Pure whole dried venom is free from contamination. Whole dried venom may also contain pollen, faeces, dust, nectar or honey. Freeze drying removes moisture in a vacuum while the venom is frozen, allowing the maximum preservation of venom proteins. The levels of enzyme phospholipase $\mathrm{A}_{2}$ and hyaluronidase should fall within a specific range.

Bee venom is made up of different components, viz. protein (hyaluroxidase and phospholipase $\mathrm{A}_{2}$ ), peptides (melittin, secapin, $\mathrm{MCD}$ peptide, tertiapin, apamin and procamin), physiologically active amines (histamine, dopamine, noradrenaline and gamma aminobutyric acid), sugars (glucose and fructose), phospholipids, $\alpha$ amino acids and volatile compounds. Among the different components of bee venom, melittin constitutes about $50 \%$ of total components followed by phospholipase $\mathrm{A}_{2}(10-12 \%)$. Hyaluronidase helps in penetration of other components. It is not directly toxic, it merely aids in the delivery of toxins to the cells. Phospholipase $\mathrm{A}_{2}$ is also not directly toxic; it is one of the most important allergens in the bee venom. Thus, it is a source of aggravations of hypersensitivity. Melittin helps in lysis of cells which may lead to the leakage of harmful compounds eg. Lysis of thromocytes, releasing serotonin and mast cells which will release histamine. Histamine causes local pain and increases capillary permeability whereas 5-hydroxytryptamine or serotonin is the major pain producing component of bee venom. The other components of bee venom have multifarious uses.

\section{Propolis}

A byproduct of the bee hive. It originates as a gum secretion gathered by bees from a variety of plants and can vary in colour depending on the plant species of origin. Propolis has remarkable therapeutic qualities, and is much sought after in some countries for the treatment of a range of human ailments and for cosmetic purposes. It is used by honey bees as an antiseptic to furnish the interior of honey comb cells used by the hive to rear young brood, to seal crackers in the hive from the winter chill, and for general hive cleanliness purposes.

\section{Pollen}

Pollen can also be harvested by beekeepers at a rate of around 7-10 kgs/hive/ year. Pollen is used by bee colonies as a source of protein, but harvesting pollen by the beekeeper requires detailed knowledge of resources, hive management, species, flowering variations and timing, and hive response to different honey and pollens. Pollen is collected via specialized traps fitted to the hives and must be processed rapidly after collection to avoid excessive moisture absorption and fermentation. Many beekeepers harvest pollen to feed back to their hives during periods of natural pollen deficiency. Most of the buyers and large scale sellers of pollen are also honey traders. At least in industrialized countries and those with increasing numbers of health conscious consumers, pollen consumption is likely to increase further. On the other hand, there seems to be a wide market for reasonable priced, encapsulated pollen and tablets.

\section{Paid pollination services}

Some beekeepers receive payment for placing hives in close proximity to 
flowering crops, according to contractual arrangements with farmers. In Himachal Pradesh, India this practice has already been started and is likely to be followed in other states as the awareness about pollination benefits is realize by the farming community.

Evidently, to ensure the countries self-sufficiency in foodstuff to receive foreign currency from excess production, the stabilization of rural population by complementary activities of both a financially rewarding and environmental friendly nature and there is no doubt that apiculture fits perfectly within this framework and hence efforts are required to popularize and increase beekeeping still an enormous potentiality to be tapped.

\section{Production and shipment of package bee}

The production of queen bees and of entire colonies of bees is the main diversification available to beekeepers. The queen bee industry is dependent on the existence of a profitable honey industry and on an export market to buy queens at a period when little or no sales. Package bees and nucleus colonies are other forms of live bee production, and are sold both within the country and overseas. In India, where great potential of beekeeping exists, marketing for live bees has enormous potentiality.

\section{REFERENCES}

Agrawal, T. J. 2014. Beekeeping industry in India: Future Potential. International Journal of Research in Applied Natural and Social Science 2(7): 133-140.

Breadbear, N. 2009. Bees and their role in forest livelihood, Food and Agricultural Organization of United Nations, Rome. 194 pp.

Kejriwal, P. 2012. An overlook on the Indian honey Industry. Kejriwal Bee Care India (P) Ltd.

Krell, R. 1996. Value-added products from beekeeping. FAO Agricultural Services Bulletin No. 124. Rome. 


\section{9 \\ Perspective in Apiculture}

$\mathrm{H}_{\mathrm{r}}^{\mathrm{o}}$

ONEYBEES and apiculture contribute marginally to livelihoods of Indian

people. Honey, and other products obtained from bees have long been known by human society. The honey bee culture varies from region-to-region and beekeepers operate under varying conditions and with widely differing resources available to them in India. The different areas and resources required in apiculture are Natural Resources, i.e. bees; plants and other natural resources: Human resources: existing apicultural skills, value addition to different types of bee products, apitheraphy, skills in packaging and marketing of hive products; Physical resources: infrastructure, tools, equipment and transport, and financial resources.

\section{Livelihood from apiculture}

Livelihood is the means of securing basic necessities for living. Livelihood strategies are different in different situation. These strategies are the combination of people's activities and the choices they make in order to achieve their livelihood goals. These depend on the opportunities and access of individuals, households andcommunities have to exploit different levels and combinations of assets, are probably the major influence on people's choice of livelihood strategy. Apiculture is a useful means for adopting as livelihood because of its uses and creates a range of different capital assets. Successful apiculture can be achieved by utilizing five categories of resources viz. natural (floral resource, bee colonies), social resources (family or group involvement), human resources (human skill, knowledge of marketing intelligence), physical resources (Infrastructure, equipments etc.) and financial resources (funds, access to credit or grants). There is a great prospect for developing agrobased industry on apiculture in India. Bee hive, smoker, honey extractor, bee veil, swarm catcher etc. can be fabricated in rural agrobased industry in India. For this purpose, indigenous timber and bamboo materials are to utilized for fabricating different types of bee hive. Recently, bamboo hives being designed and fabricated for rearing Apis cerana, an indigenous species. Unemployed educated youth from rural background can properly be trained for taking up this venture. Such venture can be explored in each potential zone of India. The fabricating unit for beehive, honey processing and packaging unit, bee wax extraction unit, bee venom extraction for Apitherapy may be taken up in both rural and periurban areas. Other products are: honey production, wax production, multiplication of queen and colony production and package bees etc have potentiality in India. 


\section{Honeybees and biodiversity}

Without bees, there would be no flowering plants, and without flowering plants there would be no bees (Breadbear, 2009). Without bees biodiversity would not be sustainable. Biodiversity is measured as the number of different plant and animal species found in a certain unit area. Biodiversity is the highest in tropical forest areas but lowest in the temperate. High biodiversity is related to the high age of the ecosystem and a stable environment. A stable environment creates the possibility of development of specialization and use of narrow ecological niches. The explanation of the high biodiversity in tropical forests can be as the species' efforts to avoid attack by diseases and pests. Both can be much more serious in a tropical forest biome with a constant supply of water in hot and humid climate. The specialist pollinator must have access to food all the year round. Many of the smaller vegetations bloom all the year round or nearly so, but the larger plants have blooming seasons. Some flower every year, others are biennial, where all trees from the same species bloom at the same period and maybe even at the same hours. If the specialized bees lose their stable resources by deforestation, they will not be there when the bigger trees require their pollination service.

\section{Honeybees as ecosystem service provider}

Pollinators strongly influence ecological relationships, ecosystem conservation and stability, genetic variation in the plant community, floral diversity, specialization and evolution. Bees play an important, but little recognized role in most terrestrial ecosystems where there is green vegetation cover for at least 3 to 4 months each year. In tropical forests, mangrove, and in temperate deciduous forests, many species of plants and animals would not survive if bees were missing. This is because the production of seeds, nuts, berries and fruits are highly dependent on insect pollination, and among the pollinating insects, bees are the major pollinators. In rain forests, especially in high mountain forests where it is too cold for most bees, other pollinators like bats and birds play a greater role in plant pollination. In farmed areas, bees are needed for the pollination of many cultivated crops, and for maintaining biodiversity in 'islands' of non-cultivated areas. The main role of bees in the different ecosystems is their pollination work. Other animal species are connected with bees: either because they eat the brood or honey, pollen or wax, because they are parasitic to the bees, or simply because they live within the bee nest

Honey bees belong to the order Hymenoptera under sub-order Apocrita that includes the wasps, ants and bees. Bees are similar to the group of wasp. Probably the most important activity of bees, in terms of benefits to humans, is their pollination of natural vegetation, something that is rarely observed by nonspecialists and is almost never appreciated. The products of honey bees, i.e. wax and honey plus small quantities of royal jelly are of obvious benefit, but are of trivial value compared to the profoundly important role of honeybees as pollinators. Most of the tree species of tropical forests are insect-pollinated, and that usually means bee-pollinated. A major study of tropical forest pollination was summarized by Frankie et al. (1993) Jones and Little (1983), Roubik (1989), and Bawa 1990). In temperate climates, most forest trees (pines, oaks etc.) are 
wind-pollinated, but many kinds of bushes, small trees, and herbaceous plants, including many wild flowers, are bee-pollinated. Desertic and xeric shrub areas are extremely rich in bee-pollinated plants whose preservation and reproduction may be essential in preventing erosion and other problems, and in providing food and cover for wildlife. Conservation of many habitats thus depends upon preservation of bee populations, for if the bees disappear, reproduction of major elements of the flora may be severely limited. Closer to our immediate needs, many cultivated plants are also bee-pollinated, or they are horticultural varieties of bee-pollinated plants. Maintenance of the wild bee-pollinated populations is thus important for the genetic diversity needed to improve the cultivated strains. Garden Flowers, most fruits and vegetables, many fiber crops like flax and cotton, and major forage crops such as alfalfa and clover are bee-pollinated. Some plants require bee pollination to produce fruits. Others, commonly bee-pollinated, can self-pollinate if no bees arrive; but inbreeding depression is a frequent result. Thus crops produced by bee-pollinated are usually better than non bee-pollinated crops, i.e. the numbers of seeds or sizes of fruits are enhanced by pollination. Scientists have determined that the worldwide economic value of the pollination service provided by insect pollinators, bees mainly is $\bullet 153$ billion in 2005 for the main crops that feed the world. This figure amounted to $9.5 \%$ of the total value of the world agricultural food production.

The honeybee and the fruits of its toils have been familiar to mankind since prehistoric time. It is one of the few insects that are directly beneficial to man. One comes across a number of folk-lores praising the honeybee's diligence, usefulness and sacrifice. These winged creatures and the honey they produce find mention in many religious epics. Figures and carvings of the honeybee, its combs and hives are found in tombs, coffins, crowns, maces of kings and coins of ancient and modern empires. Many religious customs mention high value of honey and beeswax and enjoin their followers to use these two commodities in various rites performed during festivals and on many occasions in the life of an individual. Honey is also prized as food and medicine and the uses of beeswax are many and varied.

Gatoria et al. (1994) narrated the success story of Apis mellifera and development of beekeeping in Punjab. After much failure, Dr A.S. Atwal distinguished entomologist of Punjab Agricultural University with his associates renewed their effort during sixties to introduce $A$. mellifera in the country first at Nagrota of Kangra Valley in Himachal Pradesh and with the success it was extended to Punjab plains during seventies and later on to North West India including Jammu and Kashmir. Mishra (1995) highlighted the bees and their economic importance in India. Honey bees make nests with wax secreted from their bodies, resins, mud, sand and fibers or from secretions of sting gland and silk produced by adult which are of economic value. There was a comparison between Apis mellifera and Apis cerana where in A. mellifera was found to be superior both in honey yield and foraging. Apiculture with $A$. mellifera in India has given pride place in the honey export map of the world.

Verma and Attri (2008) in their indigenous beekeeping for sustainable development mentioned the indigenous technique of harvesting honey and bee 


\begin{tabular}{|c|c|c|c|}
\hline Top Exporters & 2009 Value & & Share \\
\hline China & $\$ 284,064,882$ & & $11.8 \%$ \\
\hline Germany & $\$ 212,519,898$ & & $8.9 \%$ \\
\hline Mexico & $\$ 164,486,793$ & & $6.9 \%$ \\
\hline Brazil & $\$ 134,944,059$ & & $5.6 \%$ \\
\hline New Zealand & $\$ 117,387,647$ & & $4.9 \%$ \\
\hline Spain & $\$ 116,734,881$ & & $4.9 \%$ \\
\hline Hungary & $\$ 114,880,765$ & & $4.8 \%$ \\
\hline India & $\$ 87,560,291$ & & $3.7 \%$ \\
\hline Canada & $\$ 81,491,036$ & & $3.4 \%$ \\
\hline \multirow[t]{2}{*}{ Vietnam } & $\$ 74,327,554$ & & $3.1 \%$ \\
\hline & $\begin{array}{l}m \\
m \\
m \\
m \\
m \\
m\end{array}$ & $\begin{array}{l}\text { China } \\
\text { Germany } \\
\text { Mexico } \\
\text { Brazil } \\
\text { New Zealanc } \\
\text { Spain } \\
\text { Hungary } \\
\text { India } \\
\text { Canada } \\
\text { Vietnam }\end{array}$ & \\
\hline
\end{tabular}

Fig. 19.1 Global honey export country (Agrawal, 2014).

wax from honeybees using various indigenous type of hive and other equipments in Himachal Pradesh of India. In their study, it was revealed the potential and success in apiculture development is dependent on quality and quantity of bees and bee flora available and the technology used. In their assessment 53.94\% adopted the indigenous technology on apiculture in the state. Abrol (2010) gave an account of history and importance of beekeeping in his book, "Beekeeping: A comprehensive guide on bees and beekeeping". India occupies eighth position in the honey export map of the world as reported by Agrawal (2014) as shown in Fig. 19.1.

\section{REFERENCES}

Abrol, D. P. 2010. Beekeeping-A comprehensive guide to bees and beekeeping. Scientific Publishers, Jodhpur.

Agrawal, T. J. 2014. Beekeeping industry in India: Future Potential. International Journal of Applied, Natural \& Social Science 2(7): 133-140.

Bawa K. S. 1990. Plant pollinator interactions in tropical rain forests. Annu. Rev. Ecol. Syst. 21: 399-422.

Breadbear, N. 2009. Bees and their Role in Forest Livelihood, Food and Agriculture Organization United Nations, Rome.194 pp.

Charles, M. 1995 . Health and the HoneyBee. Queen City Publications, 112 pp.

Frankie, G. W., Newstrom, L. E., Vinson, S. B. and Barthell, J. F. 1993. Nesting habitat preferences of selected Centris bee species in Costa Rican dry forest. Biotropica; 25: 322-33.

Gatoria, G. S., Jhajj, H. S. and Ratual, H. S. 1994. History of introduction of Apis mellifera L. and development of beekeeping in Punjab (India). Indian Bee Journal 5(1-2): 8-15 
Little C. E. and Jones R. J. 1983. Handbook of Experimental Pollination Biology, (edt). New York, Van Nostrand-Reinhold. 361-72 pp.

Mishra R.C. 1995. Honeybees and Their Management in India. ICAR New Delhi. 168pp Pastala.V. and Krishnamoorthy, S. 2012. Honey Bees-Farmers best friends. LEISA India. 14 (1).

Roubik D. W. 1989. Ecology and Natural History of Tropical bees. New York: Cambridge University Press.

Verma, S. and Attri, P. K. 2008. Indigenous beekeeping for sustainable development in Himachal Himalaya. Indian Journal Traditional Knowledge 7(2): 221-25. 


\section{Glossary}

Abdomen Metasoma or third region of the body of the bee that encloses the honey stomach, stomach, intestines, sting and the reproductive organs.

Absconding swarm An entire colony of bees that abandons the hive because of biotic and a biotic stress.

Acarapis woodi A mite, called the Tracheal mite, which infests the bees breathing or tracheal system; sometimes called Acarine disease, this refers to bees that are heavily infested with the Tracheal mite.

Acidity The state of being acid or sour; the acids in honey, called organic acids, including gluconic acid, formed by the enzyme glucose to produce the acid and hydrogen peroxide.

Adulterated honey Any product labeled "Honey" or "Pure Honey" that contains ingredients other than honey but does not show these on the label. (Suspected mislabeling should be reported to the Food and Drug Administration).

Afterswarm Swarms which leave a colony with a virgin queen, after the first swarm has departed in the same season; followed warms are also referred to as secondary or tertiary swarms.

Africanized Bee A term used indiscriminately to describe the African honey bee Apis mellifera scutellata (A.m. adansonii) or its hybrids; an African bee released in Brazil and known for its volatile, its aggressive behaviour may cause concern to the nonbeekeeping public.

Alarm odour A chemical (iso-pentylacetate) substance released near the worker bee's sting which, alerts other bees to danger; also called alarm pheromone.

Alighting board A small projection of bottom board at the entrance of the hive.

Allergic reaction A systemic or general reaction to some compound, such as bee venom, characterized by itching all over (hives), breathing difficulty, sneezing or loss of consciousness.

American foulbrood A brood disease of honey bee caused by the spore-forming bacterium, Bacillus larvae and characterized by a ropy of gummy condition of affected larvae.

Anaphylactic shock Constrictions of muscles surrounding the bronchial tubes of a human, caused by hypersensitivity to venom and resulting in sudden death unless immediate medical care is received.

Anther Derived the Greek anthros (flower), referring to the pollen - bearing portion on top of the stamen or male part of a flower.

Antenna ( $\mathrm{pl}$ - ae) One of two long segmented sensory filaments located on the head of the bee, which enable bees to small and tests.

Apiary (pl-ies) The location and total number of hives (and other equipment) at one site; also called bee yard.

Apiculture The science and culture of raising honey bees.

Apis mellifera A native European bee that is kept for its honey and wax in most parts of the world, has developed into several races differing in size, colour, disposition, 
and productivity, and has escaped to the wild wherever suitable conditions prevail; subspecies include: A.m. ligustica (Italian), the most common domesticated bee; A.m. caucasia (Caucasian); A.m. carnica (Carnio-lan) A.m. mellifera (German black); and A.m. scutellata/A.m. adonsonii/A.m. intermissa (African).

Automatic uncapper Automated device that removes the capping from honey combs, usually by moving heated knives, metal teeth, or fails.

Bacillus larvae The bacterium that causes American foulbrood.

Balling Refers to the action of worker bees surrounding a queen who is unacceptable, they are trying to kill her by pulling her legs, wings, and by stinging and suffocation; the bees from a small cluster or ball around this queen.

Basket extractor A honey extractor that spins out one side of the frame at a time.

Bee blower A gas or electrically driven blower used to blow bees from supers full of honey.

Bee-bread Pollen collected by bees and stored in wax cells, preserved with honey.

Bee brush Soft brush or whisk (or handful of grass) used to remove bees from frames.

Bee cellar An underground room used for storing bee hives during long cold winters; difficult to use as constant temperature and humidity must be maintained to ensure colony survival.

Bee diseases Diseases affecting brood and adult honey bees, not all of which are infectious (such as dysentery); important diseases are American and European foulbrood, highly infectious larval diseases.

Bee escape A device constructed to permit bees to pass one way, but prevents their return; used to clear bees from supers or other uses.

Bee Go A chemical, such as benzaldehyde, repellent to bees and used with a fume board to clear bees from honey supers.

Beehive A box or receptacle with movable frames, used for housing a colony of bees.

Bee metamorphosis The three stages through which a bee passes before reaching maturity: egg, larva, and pupa.

Bee space A space, big enough to permit free passage for a bee but too small to encourage comb building, and too large to include propolizing activities; measures $9.5 \mathrm{~mm}$.

Bee suit A pair of suits, usually white, made for beekeepers to protect them from stings and keep their clothes clean; some come equipped with zip-on veils.

Bee tree A tree with one or more hollows occupied by a colony of bees.

Bee veil A cloth or wire netting for protecting the beekeeper's head and neck from stings.

Bee venom Poisonous substance secreted by honeybees, used chiefly in defense and communicated by stinging.

Beeswax A substance that is secreted by bees by special glands on the underside of the abdomen, deposited as thin scales, and used after mastication and mixture with the secretion of the salivary glands for constructing the honeycomb.

Beeway super The shallowest or secretion super used with wooden section boxes to make comb honey; has a built - in beeway or bee space.

Benzaldehyde A colourless nontoxic liquid aldhehyde $\mathrm{C}_{6} \mathrm{H}_{5} \mathrm{CHO}$ that has an odor like that of biter almond oil, that occurs in many essential oils (as bitter almond oil and peach-kernel oil) and is usually made from toluene; used to drive bees out of honey supers.

Black scale Refers to the appearance of a dried down larva or pupa which died of a foulbrood disease.

Bottling tank A plastic or stainless steel tank holding 5 or more gallons of honey and equipped with a honey gate to fill honey jars.

Bottom board The floor of a bee hive.

Brace comb A bit of comb built between two combs to fasten them together, between a 
comb and adjacent wood, or between two wooden parts such as top bars.

Brood Immature stages of bees not yet emerged from their cells; the stages are egg, larvae, pupae.

Brood chamber The part of the hive in which the brood is reared; may include one or more hive bodies and the combs within.

Brood diseases Diseases that affect only the immature stages of bees, such as American, European foulbrood or suckboard.

Brood nest The part of the hive interior in which brood is reared; usually the two bottom supers.

Buckfast hybrid A strain of bees developed by Brother Adam at Buckfast Abbey in England, bred for disease resistance, disinclination to swarm, hardiness, comb building and good temper.

Burr comb Small pieces of comb made as connecting links between combs or between a frame and the hive itself; also called brace comb.

Cage shipping Also called a package, a screened box filled with 1 to $2 \mathrm{~kg}$ of bees, with or without a queen, and supplied with a feeder can; used to start a new colony, or to boost a weak one.

Candy plug A fountain type candy placed in one end of a queen cage to delay her release.

Capped brood Immature bees whose cells have been sealed over with a brown wax cover by other worker bees; inside, the non-feeding larvae are isolated and can spin cocoons prior pupating.

Capping melter Melter used to liquefy the wax from cappings as they are removed from honey combs.

Cappings The thin wax covering over honey; once slice of the extracting frames they are referred to as cappings and are a source of premium beeswax.

Capping scratcher A frock-like device used to remove wax cappings covering honey, so it can be extracted.

Carbohydrate A food (organic compound) composed of carbon, hydrogen, and oxygen with the hydrogen: oxygen ratio frequently $2: 1$, as in water.

Carnelian bees A greyish race of honey bee, Apis mellifera carnica named for Carniola, Austria but originating in the Balkan region; while they are gentle and do not propolize, they tend to swarm more than other races.

Castes The three types of bees that comprise the adult population of a honey bee colony: eg. workers, drones, and queen.

Caucasian bees A black race honey bee Apis mellifera caucasica, originating in the Caucasus Mountains; gentle but less propolizing tendency.

Cell The hexagonal compartment of a honey comb.

Cell bar A wooden strip on which queen cups are placed for rearing queen bees.

Cell cup Base of an artificial queen cell, made of beeswax or plastic and used for rearing queen bees.

Chalkbrood A disease affecting bee larvae, caused by a fungus Ascosphaera apis, larvae eventually turn into hard, chalky white "mummies".

Chilled brood Immature bees that have died from exposure to cold; commonly caused by mismanagement.

Chimmey effect The tendency for bees to fill only the center frames of honey supers; happenes when bees are given too much room too fast.

Chromosome A brand of nuclear bodies (from the nucleus) containing genes; responsible for the differentiation and activity of a cell, and undergoing characteristics division stages such as mitosis.

Chunk honey Honey in the comb, but not in sections, frequently cut and packed into jars then filled with liquid honey. 
Clarifying Removing visible foreign material from honey or wax to increase its purity.

Cluster A large group of bees hanging together, one upon another.

Cocoon A thin silk covering secreted by larval honey bees in their cells in preparation for pupation.

Colony The aggregate of worker bees, drones, queen, and developing brood living together as a family unit in a hive or other dwelling.

Comb The wax portion of a colony in which eggs are laid, honey and pollen are stored.

Comb, drown Wax foundation with the cell walls drawn out by the bees, completing the comb.

Comb foundation A commercially made structure consisting of thin sheets of beeswax with the cells bases of worker cells embossed on both sides in the same manner as they are produced naturally by honey bees.

Comb honey Honey in the wax combs, usually produced and sold as a separate unit, such as a wooden section 4-1/2" square, or a plastic round ring.

Conical escape A cone-shaped bee escape, which permits bees, a one-way exit; used in a special escape board to free honey supers of bees.

Creamed honey Honey that has been pasteurized and undergone controlled granulation to produce a finely textured candied or crystallized honey which spreads easily at room temperature.

Crimp- wired foundation Comb foundation into which crimp wire is embebbed vertically during foundation manufacture.

Cross-pollination The transfer of pollen from the anther of one flower to the stigma of another flower of the same species.

Crystallize As in granulate.

Cut-comb honey Comb honey cut into various sizes, the edges drained, and the pieces wraped or packed individually.

Dearth A period of time when there is no available forage for bees, due to weather conditions (rain, drought) or time of year.

Decoy hive A hive placed to attract stray swarms.

Demaree The method of swarm control that separates the queen from most of the brood within the same hive.

Dequeen To remove a queen from a colony.

Dextrose Also known as glucose, it is a simple sugar (or monosaccharide) and is one of the two main sugars found in honey; forms most of the solid phase in granulated honey.

Diastase A starch digesting enzyme in honey adversely affected by heat; used in some countries to test quality of heating history or stored honey.

Disease resistance The ability of an organism to resist a particular disease; primarily due to genetic immunity or avoidance behaviour.

Dividing Separating colony to form two or more units.

Division See split.

Division board feeder A wooden or plastic compartment which is hung in a hive like a frame and contains sugar syrup to feed bees.

Double screen A wooden frame, $1 / 2$ to $3 / 4$ to inch thick, with two layers of wire screen to separate two colonies within the same hive, one above the other. An entrance is cut on the upper side and placed to the rear of the hive for the upper colony.

Double story Referring to a beehive comprised of two deep supers, one for brood and one for honey.

Drawn combs Combs with cells built out by honeybees from a sheet of foundation. 
Drifting The movements of bees that have lost their location and enter other hives; common when hives are placed in long straight rows where returning foragers from the center hives tend to drift to the row ends.

Drone The male honeybee which comes from an unfertilized egg (haploid) laid by a queen or les commonly, a laying worker.

Drone brood or drone comb Brood, which matures into drones, reared in cells larger than worker brood.

Drone congregating area (DCA) A specific area to which drones fly waiting for virgin queens to pass by; it is not known how or when they are formed, but drones return to the same year after year.

Drone layers A drone laying queen or laying workers.

Drone laying queen A queen that can lay only unfertilized eggs, due to age, improper or no mating, disease or injury.

Drumming Pounding on the sides of a hive to make the bees ascend into another hive placed over it.

Dwindling The rapid dying off of old bees in the spring; sometimes called spring dwindling or disappearing disease.

Dysentery An abnormal condition of adult bees characterized by severe diarrohea and usually caused by starvation, low-quality food, moist surroundings, or Nosema infection.

Eggs The first phase in the bee life cycle, unusually laid by the queen, is the cylindrical egg $1 / 16$ in $(1.6 \mathrm{~mm})$ long; it is enclosed with a flexible shell or chorion.

Electric embedder A device allowing rapid em bedding of wires in foundation with electrically produced heat.

Entrance reducer A notched wooden strip used to regulate the size of the bottom entrance.

Escape board A board having one or more bee escapes in it; used to remove bees from supers.

European foulbrood An infectious brood disease of honey bees caused by Streptococcus pluton.

Extracted honey Honey removed from combs by means of a centrifugal force; the combs remain intact.

Feeders Various types of appliances for feeding bees artificially.

Fermenting honey Honey which contains more water (greater than $20 \%$ ) in which a chemical breakdown of the sugars takes place producing carbon dioxide and alcohol; caused by naturaly-occuring osmophylic yeasts of the genus Saccharomeyces.

Fertile queen A queen, inseminated instrumentally or mated with a drone, which can lay fertilized eggs.

Fertilized Usually refers to eggs laid by a queen bee, That are fertilized with sperm stored in the queen's spermatheca.

Festooning The activity of young bees, engorged with honey, hanging on to each other and secreting beeswax.

Field bees Worker bees which are usually 21 or more days old and work outside to collect nectar, pollen, water and propolis; also called foragers.

Flight path Usually refers to the direction of bees flight leaving their colony; if obstructed, may cause bees to become aggravated.

Follower board A thin board used in place of a frame usually when there fewer than the normal number of frames in a hive.

Food chamber A hive body filed with honey for winter stores.

Forage Natural food source of bees (nectar and pollen) from wild and cultivated plants.

Foreign matter In honey, unusually high amounts of wax, bee bodies, pollen grains, or other objectionable debris. 
Foundation, wax Thin sheets of beeswax embossed or stamped with the base of a worker (or rarely drone) cells on which bees will construct a complete comb (called drawn comb); also referred to as comb foundation, it comes wired or unwired.

Foundation, wired Comb foundation which includes evenly-spaced vertical wires for added support; used in brood or extracting frames.

Frame Four pieces of wood forming a rectangle, designed to hold honey comb, consisting of a top bar, two end bars, and a bottom bar (one or two pieces); usually spaced a bee-space apart in the super.

Fructose See levulose.

Fume board A devise used to hold a set amount of a volatile chemical (a bee repellent like bee go) to drive bees from supers.

Fumagillin Bicycohexyl-ammonium fumafilin, whose trade name is fumadil-b (abbot labes), is a whitish soluble antibiotic power discovered in 1952; it is mixed with sugar syrup and fed to bees to control Nosema disease.

Fumidil-b The 'trade name for fumagilin, an antibiotic used in the prevention and suppression of Nosema disease.

Fume board A rectangular frame, the size of a super, covered with an absorbent material such as burlap, on which is placed a chemical repellent to drive the bees out of supers for honey removal.

Gloves Leather, cloth or rubber gloves worn while inspecting bees.

Glucose See dextrose.

Gluconic acid See acidity.

Grafting Removing a worker larva from its cell and placing it in an artificial queen cup in order to have it reared into a queen.

Grafting tool A needle or probe used for transferring larvae in grafting of queen cells.

Granulate The process by which honey, a super-saturated solution (more solids than liquid) will become solid or crystallize; speed of granulation depends on the kinds of sugars in the honey.

Guard bees Worker bees about three weeks old, which have their maximum amount of alarm pheromone and venom; they challenge all incoming bees and other intruders.

Gum A hollow long beehive, sometimes called a long-gum (Appalachia), made by cutting out that portion of a tree containing bees and moving it to the apiary; since it contains no moveable frames, it is therefore not permissible.

Hive A man made home for bees including a bottom board, hive bodies, frames enclosing honey combs, and covers.

Hive body A wooden box containing frames.

Hive stand A structure serving as a base support for a beehive; it helps in extending the life of the bottom board by keeping it off damp group.

Hive staples Large c-shaped metal nails, hammered into the wooden hive parts to secure bottom to supers, and supers to super before moving a colony.

Hive tool A flat metal device with a curved scraping surface at one end and a flat blade at the other; used to open hives, landing and scrape frames.

Honey A sweet viscid material produced by bees from the nectar of flowers, composed largely of a mixture of dextrose and levulose dissolved in water; contains small amounts of sucrose, mineral matter, vitamins, proteins, and enzymes.

Honeydew An excreted material from insects in the order Homoptera which feed on plant sap; since it contains almost $90 \%$ sugar, it is collected by bees and stored as honeydew honey.

Honey bee The common name of honey yielder bees, a highly social insects, belong to order Hymenoptera.

Honey colour Measured by a grader, honey coloures are classified between water white 
to white, to amber to dark amber.

Honey extractor A machine which removes honey from the cells of comb by centrifugal force.

Honey flow A time when enough nectar-bearing plants are blooming such that bees can store a surplus of honey.

Honey gate A faucet used for removing honey from tanks and other storage receptacles.

Honey house A building used for activities such as honey extractions, packaging and storage.

Honey plants Plants flower which (or other parts) yields enough nectar to produce a surplus of honey.

Honey pump A pump used to transfer honey from a pump or extractor to a holding tank or strainer.

Honey sac Also called honey stomach, an enlargement at the posterior (back) end of a bees' esophagus but laying in the front part of the abdomen, capable of expanding when full of liquid such as nectar or water.

Honey stomach The forgot in the abdomen of the honey bee used for carrying nectar, honey, or water.

Honey sump A clarifying tank between the extractor and honey pump for removing the coarser particles of comb introduced during extraction.

Honey supers Refers to hive bodies used for honey production.

Hornets and wasp Social insects belonging to the family Vespidae. Which make aerial as well as underground next and is he chief enemy of honeybees.

Hypersensitive A condition in which reactions to any environmental stimulus to life. Threatening, such as honey bee venom.

Imperfect Not fully formed, such as a worker, considered an imperfect female.

Increase To add to the number of colonies, usually by dividing those on hand. see split.

Infertile Incapable of producing a fertilized egg. As a laying worker.

Inhibine Antibacterial effect of honey caused by an accumulation of hydrogen peroxide, a result of the chemistry of honey.

Injections, desensitizing A series of injections given to persons with allergies (such as bee venom) so they might build up an immunity.

Inner cover An insulating cover fitting on top of the super but underneath the outer cover, with an oblong hole in the center.

Insecticide Any chemical that kills insects.

Instrumental insemination The introduction of drone spermatozoa into the genital organs of a virgin queen by means of instrumentation.

Invertase An enzyme in honey, which splits the sucrose molecule (a disaccharide) into its two components dextrose and levulose (monosaccharide).

Isomerase An enzyme used to convert glucose in can syrup into fructose, which is a sweeter sugar called isomerose, is now used as a bee feed.

Italian bees A common race of bees, Apis mellifera ligustica, with brown and yellow bands, from Italy; usually gentle and productive.

Langstroth, L. L A Philadelphia native and minister (1810-95), he lived for a time in ohio where he continued his studies and writing of bees, recognized the importance of the bee space, resulting in the development of the movable-frame hive.

Larva, capped (pl-ae) The second developmental stage of a bee, ready to pupate or spin its cocoon (about the 10th day from the egg).

Laying workers Worker bees which lay eggs in a colony hopelessly queenless; such eggs are infertile, since the workers cannot mate, and therefore become drones.

Leg baskets Also called pollen baskets, a flattened depression surrounded by curved spines located on the outside of the tibiae of the bees hind legs and adapted for carrying 
flower pollen or other dusts.

Levulose Also called fructose (fruit sugar), a monosaccharide commonly found in honey that is slow to granulate (such as mustard honey); chemical formula is like glucose, but has it's carbonyl group in a different place.

Mandibles The jaws of an insect; used by bees to form the honey comb and scrape pollen, in fighting and picking up hive debris.

Maternal From the mother's side of family.

Mating flight The flight taken by a virgin queen while she mates in the air with several drones.

Mead Honey wine

Midnight hybrid A combination of the Caucasian and carniolan races.

Migratory beekeeping The moving of colonies of bees from one locality to another during a single season to take advantage of two or more honey flows.

Moisture content In honey, the percentage of water should be no more than 18.6; any percentage higher than that will allow honey to ferment.

Movable frames A frame constructed to such a way to preserve the bee space, so they can be easily removed; when in place, it remains unattached to its surroundings.

Moving board A framed screen that fits over the top as a hive cover; used to move bees in hot weather to provide sufficient ventilation to keep bees from suffocating.

Natural honey Mechanically unprocessed honey.

Nectar A liquid rich in sugars, manufactured by plants and secreted by nectar glands in or near flowers; the raw material for honey.

Nectary glands Special nectar secreting glands usually found in flowers, whose function is to attract pollinating insects, such as honey bees for the purpose of cross pollination, by offering a carbohydrate-rich food.

Nectar guide Color marks on flowers believed to direct insects to nectar sources.

Nectaries The organs of plants which secrete nectar, located within the flower (floral nectaries) or on other portions of the plant (extrafloral nectaries).

Newspaper method A technique to join together two strange colonies by providing a temporary newspaper barrier.

Nosema disease An adult bee disease caused by a one-celled spore-forming organism wosema apis; it infects the mid gut of bees.

Nuclei, nucleus A small colony of bees often used for queen rearing.

Nurse bees Young bees, three to seven days old, which feed and take care of developing brood.

Observation hive A hive made largely of glass or clear plastic to permit observation of bees at work.

Osmotic pressure The minimum pressure that must be applied to a solution to prevent it from gaining water when it is separated from pure water by a permeable membrane; in honey, its ability to absorb water from the air of other microscopic organism, about 2,000 milli mols $/ \mathrm{kg}$.

Outer cover The last cover that fits over a hive to protect it from rain; the two most common kinds are telescoping and migratory covers.

Ovary The egg producing part of a plant or animal.

Ovule An immature female germ cell, which develops into a seed.

Oxytetracycline An antibiotic sold under the trade name terramycin; used to control American and European foulbrood diseases.

Package See shipping cage.

Package bees Quantity of adult bees ( 1 to $2 \mathrm{~kg}$ ), with or without a queen, contained in a screened shipping cage.

Paralysis A viral disease of adult bees which affects the legs or wings normally. 
Parthenogenesis The development of young from unfertilized eggs laid by virgin females (queen or worker); in bees such eggs develop into drones.

PBD (Paradichlorobenzene) A white crystalline substance whose vapors are heavier than air and are used to fumigate wax moths in stored hive bodies.

Piping A series of sounds made by a queen, frequently before she emerges from her cell.

Play flights Short flights taken in front and in the vicinity of the hive by young bees to acquaint them with hive location; sometimes mistaken for robbing or swarming preparations.

Poison sac Large oval sac containing venom and attached to the anterior (front) part of the sting; stores venom produced by the poison gland, and its primary ingredients are peptide and mellitin.

Pollen The dust-like male reproductive cells (gametophytes) of flowers, formed in the anthers, and important as a protein source for bees; pollen is essential for bees to rear brood.

Pollen basket See leg basket.

Pollen cakes or pollen pellets The cakes of pollen packed in the leg baskets of bees and transported back to the colony.

Pollen substitute A food material which is used to substitute wholly for pollen in the bees diet; usually contains all or part of soy flour, brewers' yeast, powdered sugar, or other ingredients.

Pollen supplement A mixture of pollen and pollen substitutes used to stimulate brood rearing in periods of pollen shortage.

Pollen trap A device for collecting the pollen pellets from the hind legs of worker bees; usually forces the bees to squeeze through a screen mesh, which scrapes off the pellets.

Pollen tube A slender thread - like growth, containing sperm cells, which penetrates the female tissue (stigma) of a flower until it eventually reaches the ovary; there the sperm cells unit with the ovule.

Pollination The transfer of pollen from the anthers to the stigma of flowers.

Pollinator The agent that transfers pollen from an anther to a stigma.

Pollinizer The plant source of pollen used for pollination.

Prime swarm The first swarm to leave the parent colony, usually with the old queen.

Proboscis The mouthparts of the bee that form the sucking tube or tongue.

Propolis Plant resins collected and modified by bees; used to fill in small spaces inside the hive.

Protein Naturally occurring complex organic substances, such as pollen; composed of amino acids, the building blocks of protein.

Pupa The third stage in the development of the bee during which it is inactive and sealed in its cocoon; the organs of the sealed in its cocoon.

Queen A fully developed mated female bees responsible for reproduction.

Queen cage A special cage in which queens are shipped and/or introduced to a colony, usually with 5 or 6 young workers called attendants, and a candy plug.

Queen cell A special elongated cell resembling a peanut shell in which the queen is reared; usually over an inch in length, it hangs vertically from the comb.

Queen clipping Removing a portion of one or both front wings of a queen to prevent her from flying.

Queen Cup A cup-shaped cell hanging vertically from the comb, but containing no egg, also made artificially of wax or plastic to raise queens.

Queen Excluder A device made of wire, wood or zinc (or any combination thereof) having openings of 163 to. 164 inch, which permits workers to pass but excludes queens and drones; used to confine the queen to a specific part of the hive, usually the 
brood nest.

Queenright A colony that contains a laying queen.

Queen substance Pheromone material secreted from glands in the queen bee and Transmitted throughout the colony by workers to alert other workers of the queen's presence.

Races of bees The four most common races of Apis are mellifera, cerana, dorsata and florea; other newly discovered races are currently under investigation.

Radial extractor A centrifugal force machine to throw out honey but leave the combs intact; the frames are placed like spokes of a wheel, top bars towards the wall, to take advantage of the upward slope of the cells.

Raw honey See natural honey.

Requeen To introduce a new queen to a queenless hive.

Rendering wax The process of melting combs and capping and removing refuse from the wax.

Reversing The act of exchanging places of different hive bodies of the same colony; usually for the purpose of nest expansion, the super full of brood and the queen is placed below an empty super to allow the queen extra laying space.

Robbing The act of bees stealing honey/nectar from the other colonies; also applied to bees cleaning out wet supers or cappings left uncovered by beekeepers.

Ropy characteristic A diagnostic test for American foulbrood in which the decayed larvae form an elastic rope when drawn out with a toothpick.

Royal jelly A highly nutritious, milky white glandular secretion of young (nurse) bees; used to feed the queen and young larvae.

Sacbrood A brood disease of bees caused by a filterable virus which interferes with the moulting process; the dead larva resembles in sac of fluid.

Scout bees Worker bees searching for a new source of pollen, nectar, propolis, water, or a new home for a swarm of bees.

Screened ventilated board A framed screen used to cover the top of a hive being moved in hot weather.

Sealed brood See "capped brood".

Self-pollination The act of a single flower, or flower from the same plant, pollinating itself.

Self-spacing frames Frames constructed so that they are a bee space apart when pushed together in a hive body.

Self-sterile The inability of a flower, such as a fruit tree, to be fertilized within its own variety; it is only fertilized by pollen from another variety.

Settling tank A large capacity container used to settle extracted honey; air bubbles and debris will float to the top, clarifying the honey.

Skep Beehive without movable frames, usually made of twisted straw in the form of a basket.

Smoker A metal container with attached bellows which burns organic fuels to generate smoke; used to control aggressive behavior of bees during colony inspections.

Solar wax melter or extractor A glass-covered insulated box used to melt wax from combs and cappings using the heat of the sun.

Sperm cells The male reproductive cells (gametes) which fertilize eggs; also called spermatozoa.

Spermatheca - A small sac connected with the oviduct; of the queen bee in, which is stored, the spermatozoa received in mating with drones.

Split To divide a colony for the purpose of increasing the number of hives.

Spur embedder A device used for mechanically embedding wires into foundation by employing hand pressure. 
Starline Hybrid An Italian bee hybrid known for vigour and honey production.

Stigma Receptive portion of the female part of a flower to which pollen adheres.

Sting An organ belonging exclusively to female insects developed for egg laying mechanism, used to defend the colony; modified into a piercing shaft through which venom is injected.

Sting sac See poison sac.

Straining screen A metal or plastic screen through which honey is filtered; also serves as a base for other, finer screening material.

Streptococcus pluton Bacterium that causes European foulbrood.

Sucrose Principal hexase sugar found in nectar.

Sugar syrup Feed for bees, containing sucrose or table (cane) sugar and hot water in various ratios.

Super A receptable in which bees store honey; usually placed over or above the brood nest; so called honey chamber.

Supering The act of placing honey supers on a colony in expectation of a honey flow.

Supersedure Rearing a new queen to replace the old queen in the same hive, shortly after the daughter queen begins to lay eggs, the mother queen disappears.

Surplus honey Any extra honey removed by the beekeeper, over and above what the bees require for their own use, such as winter food stores.

Swarm A collection of bees, containing at least one queen that split apart from the mother colony to establish a new one; a natural method of propagation of honey bees.

Swarm cell Queen cells usually found on the bottom of the combs before swarrning.

Swarming The natural instinct of propagation of the honey bee colony.

Swarming season The time of year, usually mid-summer, when swarms usually issue.

Terramycin An antibiotic used to prevent American and European foulbrood. See oxyteracycline.

Tested queen A queen whose progeny shows she mated with a drone of her own race and has other qualities which would make her a good colony mother.

Thin super foundation A comb foundation used for comb honey or chunk honey production which is thinner than that used brood rearing.

Thorax Mesosoma the central region of an insect to which the wings and legs are attached.

Top bar The top part of a frame.

Transferring The process of changing bees and combs from common boxes to movable frame hives.

Travel stains The darkened appearance on the surface of honey comb caused by bees walking over its surface.

Uncapping knife A knife used to shave off the cappings of sealed honey prior to extraction; hot water, steam or electricity can heat the knives.

Uncapping tank Container over which frames of honey are uncapped; usually strains out the honey which is then collected.

Unfertilized An ovum or egg, which has not been fertilized by sperm.

Uniting Combining two or more colonies to form a larger colony.

Varroa jacobsoni (V.destructor) An ecto-parasitic mite of honeybees.

Veil A protective netting that covers the face and neck; allows ventilation, easy movement and good vision.

Venom allergy A condition in which a person, when stung, may experience a variety of symptoms ranging from a mild rash or itchiness to ansphylactic shock.

Venom hypersensitivity A condition in which a person, if strong, is likely to experience a aphylactic shock.

Virgin queen An unmated queen bee.

Warming cabinet An insulated box or room heated to liquefy honey. 
Wasp A close relative of honey bees, usually in the family Vespidae; they are carnivorous, some species preying on bees.

Wax See beeswax.

Wax glands The 8 glands located on the last 4 visible, ventral abdominal segments (IVVII) of young worker bees; they secrete beeswax droplets.

Wax moths Usually refers to the wax moth, Galleria mellonella whose larvae bore through and destroy honeycomb as they eat out its impurities.

Wax scale A drop of liquid beeswax that hardens into a scale upon contact with air; in this form it is shaped into comb.

Wax tube fastener A metal tube for applying a fine stream of melted wax to secure a sheet of foundation to an un-grooved frame.

Wind pollinated Plants whose flowers produce light pollen (and usually no nectar) which is released into the air to fall by chance on a receptive stigma; examples include the grasses (corn, oats) and conifers (pines).

Windbreaks Specially constructed or naturally occurring barriers to reduce he force of the (winter) winds on a beehive.

Winter cluster A tight ball of bees within the hive to generate heat; forms when outside temperature falls below 57 degrees $\mathrm{F}$.

Winter hardiness The ability of some strains of honeybees to survive long winters by frugal use of stored honey.

Wire, frame Thin wire used to reinforce foundation destined for the brood nest or honey extractor.

Wire cone escape A one-way cone formed by window screen mesh used to direct bees from a house or tree into a temporary hive.

Worker bees Infertile female bee whose reproductive organs are only partially developed, responsible for carrying out all the routine of the colony.

Worker comb Comb measuring about five cells to the inch, in which workers are reared and honey and pollen are stored. 


\section{Subject Index}

A Handbook on Beekeeping in India 5

A. andreniformis 15

A. cerana 12,197

A. dorsata 63

A. florea 63

A. mellifera $6,12,63$

Abiotic pollination 178

Acarapis woodi 149

Achroia grisella 137

Activities of the field bees 57

Adult wax moth 137

Aesculus 159

Alarm pheromone 69

Albizzia 159

Alfalfa 161

Alley method 88

Allium cepa 164

American Bee Journal 3

American foul brood 127

Anacardium occidentale 159

Anaesthetization 95

Anticipated profits 215

Antioxidant properties of honey 223

Ants 141

Apiculture Equipments 98

Apis

and reniformis 16

cerana $8,16,40,44,96,99,159$

dorsata 5, 14, 69, 219, 227

foraging on litchi 160

pollination in

coffee 162

maize 162

foraging on Asom lemon 160

indica $18,49,51,63$

florea 5, 40, 97

iridesecent Virus 126

mellifera 5, 17, 19, 44, 53, 58, $96,97,113,120,179,184$, 197,203

Apitherapy 245
Artificial

diet 116

queen bee insemination 91

As

dietary supplement 244

food and ancillary products 236

ingredient in cosmetics 245

in food products 245

in medicine 245

Asclepias sub. erticillata 204

Ascophera apis 129

Aspergillus flavus 129

Atkins 197

Attaching the glass tip 93

Auto -self pollination 176

Autumn care 118

Bacillus thuringiensis 188

Bacterial diseases 127

Banana 159

Bee

Behaviour 52

brush 106

dance on 67

Diseases and their Management 122

enemies and their Management 137

escape 107

flora 157

hive 103

keeping equipments 104

fabrication 242

Products 219

under bamboo hat 115

Management 109

Pasturage 152

Pollination 176

veil 105

venom 229, 239

- Therapeutic use 245

wax 226, 238

for ancillary industry 244

Beetle 142 
Behavior of bees in collecting 60

Biological basis of queen rearing 85

Biometrical study in India 50

Biotic pollination 178

Birds and other enemies 142

Bottom

bar 101

board 101, 102

Bramble 161

Brassica 153

campestris var. toria 163,216

juncea 153, 216

spp. 152

Breeder colony 87

Breeding 78

methods 80

Brood chamber 101, 102

frame 102

pheromone 69

C.aurantifolia 160

Cajanus 195

cajan 156, 164

Callistemon lanceolatus 159

Camponotus compressus 141

Care of the poisoned colonies 204

Carrot 164

Carthamus 156 tenctorious 164

Carvia callosa 153

Cashew 159

Cassia spp 159

Caterpillar 137

Cell builder or finisher colony 87

Cereal crops 187

Chalicodoma lanata 186

Chalkbrood disease 130

Chemicals 146

Chenopodium 203

Chilled brood 135

\section{Cidrella 153}

Citronella 203

Citrus 160

Coconut 160

Cocos nucifera L 160

Coffea arabica 161

Coffee 161

Collection and processing 227

Colony division 111

organization and caste system 52

strength 212
Comb

building 55

foundation Mill 104

Commercialization of Apiculture 242

Communication and memory 179 in bees 65

Composition of bee venom 229 beeswax 228 honey 220

Conditioning of the colonies 215

Conditions for queen cell construction 86

Constraints in rainy season 116

coriander 164

Coriandrum sativum 164

Cosmetic functions of five primary bee products 241

Cotton 162

Crops 187

Cross pollination 177

Crystallization 222

Cucurbits 196

Dacuus carota 164

Dalbergia sissoo 158

Darmee method of swarm prevention 88

Deposition of the egg 46

Dequeening and requeening technique 126

Development of hive designs 3 the larval and pupal stages 48

Developmental Biology 43

Diagnosis

cause and spread of brood diseases 123

of Nosema disease 132

Different

caste of honeybee in comb 53

migration 210

types of honey 219

Dimensions of movable frame hives 99

Distance of migration site 211

Diversity of honey bees 12

Doolittle or Grafting method 89

Dosage of pesticide 202

Drone 53, 75

Ectoparasitic mite 147

Effect of

GM Plants on bee health 189

novel proteins and GM plants on bees 189

pesticidal poisoning 196 
Effects on the hive 132

Eggs 137

Ehretia acuninata 159

Emergency impulse 86

Encyclopadia Britannica 2

Endocrine organs 40

Equipments for handling bees 105

Eucalyptus 157, 203

European foul brood 128

Eversion of drone endophallus 94

Evolution and Diversity 10

External morphology 25

Extraction and processing 243

Fabrication

and packaging 242

of uncapping machinery 243

Factors affecting nectar secretion 155

Fagopyrum 216

Family, sub-family and genus of Apoidea 13

Feeders 106

fennel 164

Fermentation of honey 221

Fiber crops 186

Filling of the syringe 93

Flight range 76 and foraging rate 179

Floral diagram 177 fidelity 58

Foeniculum vulgare 164

Food value of honey 236

Forage crops 186, 195

Foraging

behaviour 58

distance 181

efficiency of colonies and their distance 181

of honeybees 178

strength of colonies 180

Forest and avenue trees 157

Formica spp. 141

Frame 101

Fruits 159

and nuts 183

Fungal disease 129

\section{Galleria mellonella 137}

Gatherer bee 55

General development of the egg 46

Genetics and Breeding 73

Germplasm storage 81

Glands 39
Glossary 254

Gloves 105

GM 187

Good aeration 109

Gossypium spp. 162

Graevillea robusta A 158

granulation of honey 222

Greater wax moth 137

Grewia asiatica 157

Guard bee 55

Guarding and defense 55

Guizotia abyssinica 163

Hairs 61

Heavea brasilliensis 156

Helianthus annuus 156, 163, 182

Hirad 157

Historia annimalium 1

History and Development 1

History in India 4

Hive tool 105

Honey 219, 235

as preservatives 237

extracting equipment 105

flow period 113

harvesting 114

Processing Plant 223, 243

Honey bee

and biodiversity 250

as ecosystem service provider 250

pollination 178

Hopkin method 89

Hybrid breeding 80

Important attributes for selection of breeder quee 86

Impulse for natural increase 86

replacement of aged queen bee 86

In bakery 237

In cosmetics 238

Increasing attractiveness of the crop 215

Indian Bee Journal 5

Indirect self-pollination 176

Industrial importance of honey 236

Injecting the semen 95

Inner cover 101

Insemination 91

technique 93

Instrumental insemination 96

Internal morphology 33

Invertebrates 178

ISI A and B type of hive 101 
Jamun 159

Johnston's organ 40

Jujube 160

Karljenter Queen cell cup kit method 89

Kashmir bee virus 127

Lagetstroemia indica 159

Langstroth design 100

Lantana 203

Larval activities 53

Lathyrus sativus 156

Life-cycle 138

Line-breeding 80

Litchi 160

Litchi chinesis 160

Livelihood from apiculture 249

Lucerne 161

Maize 162

male reproductive organs 38

Management 128

of honeybees for pollination 180

Mating behavior 76

Measuring superior breeding stock 79

Medicago sativa L 161

Medicinal value of honey 235

Melissosoccus plutonius 128

Mellisselogia- The Female Monarchy 2

Mentha piperata 203

Mesosomal appendages 29

Metasoma 29

Methods for commercial queen rearing 87

Migration of beehives 209

: needs and considerations 210

time in relation to floral phenology 214

Migratory

Apiculture 207

routes in India 216

Miller method 88

Mimusops elegni 157

Mites 143

Moldy pollen 135

Monomorium indicum 141

Morphology and Physiology 25

Morphometrics of Indian honey bee 31

motility of spermatozoa 96

Mouth parts 61

Moving colonies to crops 181

multifloral honey from 4 zones of India 220

Musa spp. 159
Nasanov pheromone 69

National Commission on Agriculture 6

Nectar 62 composition 154

Nephelium litchi 153

Nervous system 35

Nosema

ceranae 133

disease 131

Number of

eggs laid by a queen 45

hives 212

trips per day 59

Nurse bee 55

Nursing 54

Oecophylla smaragdina 141

Oenocytes 40

Oilseed crops 182

and pulses 162

vegetable crops 195

Oligomyrmex 141

Onion 164

Opening the sting chamber 95

Ornamentals 164

Other

beehive products 226

fruit crops 196

industrial uses 238

Packers' equipment 243

Paid pollination services 247

Perspective in Apiculture 249

Pesticidal hazards to bees 194

Pesticides and

their relative toxicity to bees 197

formulation 201

least toxic to bees 200

less toxic to bees 199

most toxic to bees 198

very toxic to bees 199

Pheromone for navigation 68

Phylogeny and classification 19

Physiology 33

Pigeon pea 164

Placement of the migrated stock 214

Placing the queen in the holder 94

Plant toxicity to bees 204

Plantation

crops 196 
fibre and forage crops 161

Plectranthus 153

rugous 161

Pollen 61, 232, 240, 247

and nectar source 109

feeding 117

load 62

Pollinating

agents 177

and fertilization 176

of genetically modified 187

requirement and concentration of colon 181

research in India 182

Pome and stone fruits 196

Pongamia pinnata 157

Post-insemination care of the queen bee 95

Predatory wasp 139

Preparing and packing the colonies for migration 213

Processing of honey 223

Production and shipment of package bee 248

Propolis 60, 232, 240, 247

Protozoan disease 130

Prunus puddum 160

Pulses 185, 195

Pupa 137

Quality assurance 243

Quarantine measure 150

Queen 52

cage 107

cell builders 90

protector 107

starter colony 87

excluder 105

pheromone 68

rearing 87,111

and Multiplication 84

methods 87

Queenlessness 86

Queens 75

and drone traps 107

Races of Apis mellifera 20

Reduction of pesticidal poisoning to bees 201

Relative humidity 155

Reproduction 74

Requirements 93
Rock bees 14

Round dance 66

Royal jelly 231, 240, 244

Rubber 161

Rubus spp. 161

Sacbrood diseases 125

Safflower 164

Salyx 159

Sapindus 158

detergens 153

spp. 156

Schefflera wallichiana 152,158

Scolopophorous organs 40

Season 109, 211

Seasonal management 110

Selection

methods for the desired stocks 79

of breeding stock 85

mother stock 84

pesticides 202

Self-pollination 176

Semen collection 94

Sesame 195

Sesamum 156, 163

indicum L. 163

Sex determination 77

Shade 109

Shisham 158

Sickle dance 66

Side bar 101

Silver oak 158

Site and season 109

Smith method 88

Smoker 105

Soapnut 158

Soil 156

soybean 195

Special organs 39

Spheciformes 10

Spring management 110

Stand 101, 102

Stereo microscope 94

Stock improvement 78

Stone brood disease 130

Storage 225

Stratococcus 128

Summer management 114

Sunflower 163, 195

Sunlight and temperature 155

Super 101

and super frame 104 
Supersedure impulse 86

Swarm

-catching equipment 106

prevention 111

Swarming impulse 86 instinct 56

Syzygium cumini 156, 159

Tamarind 159

Tamarindus indica 159

Tecoma grandiflora 153

Terminalia chebula indica 156, 157

Thai sac brood virus 125

The antennae 26

Bees of the World 3

circulatory system 35

digestive system 33

dorsal scent gland 30

egg 45

excretory system 34

female reproductive organs 37

Feminine Monarchie 2

larva 47

lesser wax moth, Achroia grisella 139

mesosoma 28

mouth parts 27

nervous system 34

pupa 48

reproductive system 37

respiratory system 36

speed of flight 60

sting 30

wax glands 30

Thelepeale ixiocephala 158

Time for moving colonies on crops 182 of the day 214

sequence of instars and moults in the worker 49
Timing and method of application 202

Toon 158

Toona ciliate 158

Top

bar 101

cover 101,104

Toxicity to Honey Bees 193

Tracheal mite 149

Trachyspermum 203

Transmission 131

Transplanting queen cells 91

Transport and handling equipment 243

Tropilaelaps 148 clarae 147

Type of the vehicle 213

Use in pharmaceuticals 237

Value Added Beehive Products 235

Varroa 143 destructor $143,145,146$

Vegetables 164 crops 185

Vertebrates 178

Viral diseases 122

Vitex negundo 161

Wag-tail dance 66

Water 60, 109

Wax moths 137

Western honeybee 19

Wind breaks 109

Winter hive packing 120

Winter management 119

Worker 53

Zea mays 156

Ziziphus mauritiana 160 




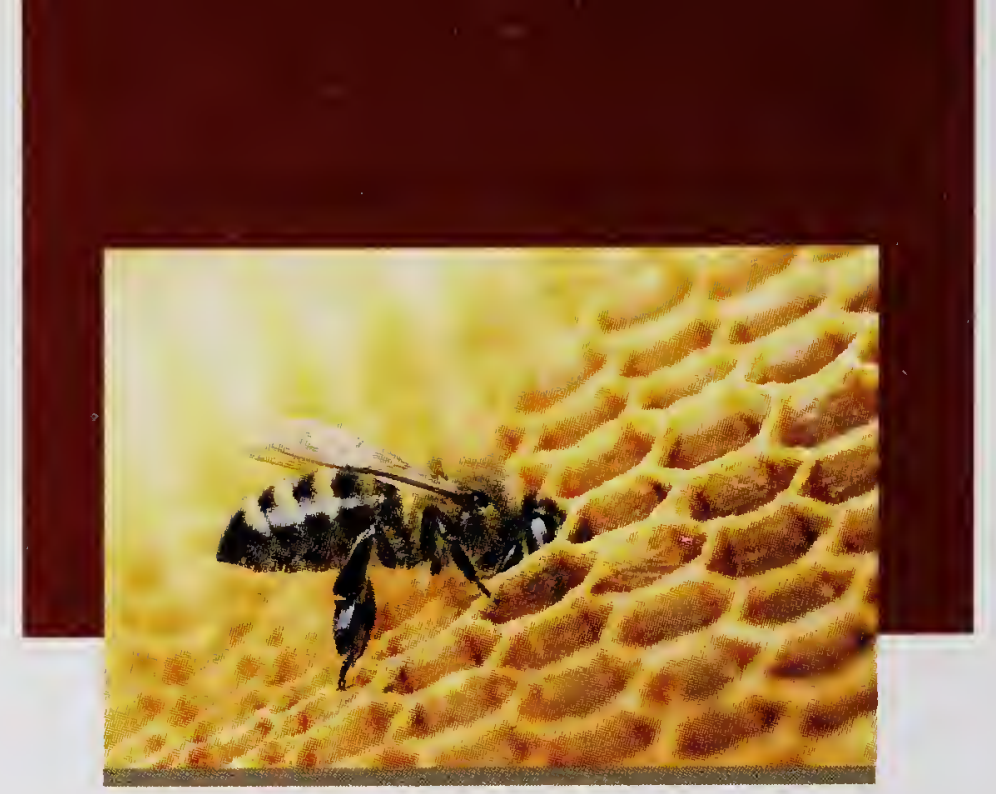

\section{APICULTURE IN INDIA}

Apiculture is the science and culture of honey bees and their management. Most of the people are attracted to fascinating world of honeybees for their wonderful behaviour and contribution to mankind in the form of hive products and crop production. The ICAR established Beekeeping Research Station in Punjab and Coimbatore in Tamil Nadu 1951. From 1980 onwards, ICAR formulated an All India Coordinated Project on Honeybee Research and Training. Since then the beekeeping has got the momentum for its scientific venture as well as for developmental activities. The research and developmental activities of honeybees have broadened its field to apiculture, which includes crop productivity through pollination, toils of honey bees, i.e. honey and other bee-hive products such as beeswax, royal jelly, bee venom etc.

Apiculture taken up as rural livelihood is an additional source of income for farm-families. It is non-land based and requires low investments can be taken up by small-, marginal- and landless-farmers and educated unemployed youth. It can thus serve as an additional income generating activity and provide round-the-year employment in the activities of managing hives, migrating honey bee colonies in different crop fields, harnessing honey and other bee-hive products. In the present day, organic farming concept, bees are considered as an input for crop production. Many developments in apiculture have taken place both in national as well as world scene in recent years and some knowledge has been accumulated with reference to Indian conditions. The 'Apiculture in India' deals with both basics and applied aspects of apiculture and designed to address the needs of beekeepers, entrepreneurs, students, academicians and others related to this field. Some of the new areas that are included are value-added products from apiculture and commercialization of apiculture. 